\title{
ROUTLEDGE
HANDBOOKS
善
}

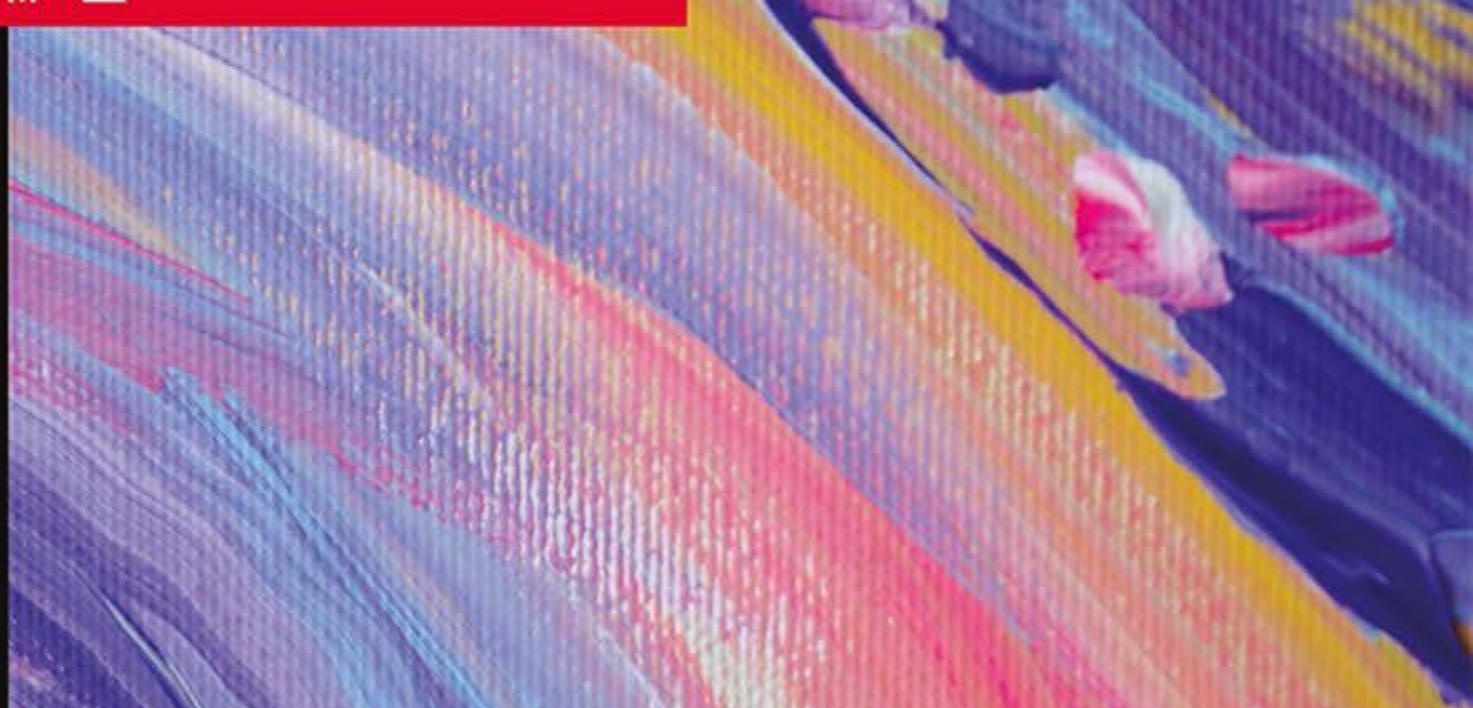

The Routledge Handbook of Translation and Education

Edited by Sara Laviosa and Maria González-Davies 


\section{The Routledge Handbook of Translation and Education}

The Routledge Handbook of Translation and Education will present the state of the art of the place and role of translation in educational contexts worldwide. It lays a sound foundation for the future interdisciplinary cooperation between Translation Studies and Educational Linguistics.

By adopting a transdisciplinary perspective, the handbook will bring together the various fields of scholarly enquiry and practice that make a valuable contribution to enlarging the notion of translation and diversifying its uses in education. Each contribution provides an overview of the historical background to a given educational setting. Focusing on current research approaches and empirical findings, this volume outlines the development of pedagogical approaches, methods, assessment, and curriculum design. The handbook also examines examples of pedagogies that integrate translation in the curriculum, the teaching method's approach, design, and procedure as well as assessment.

Based on a multilingual and applied-oriented approach, the handbook is essential reading for postgraduate students, researchers, and advanced undergraduate students of Translation Studies, and educationalists and educators in the 21 st century post-global era.

Sara Laviosa. Associate Professor in English Language and Translation at Università degli Studi di Bari 'Aldo Moro' (Italy). She is author of Corpus-based Translation Studies (2002), Translation and Language Education (2014) and Linking Wor(l)ds (2018). She is founder and editor of the journal Translation and Translanguaging in Multilingual Contexts.

Maria González-Davies. Freelance translator and Associate Professor in the Department of Foreign Languages and Education, University Ramon Llull (Barcelona, Spain). She has authored Multiple Voices in the Translation Classroom (2004), co-authored Medical Translation Step by Step with Vicent Montalt, and is co-editor of the journal The Interpreter and Translator Trainer. 


\title{
Routledge Handbooks in Translation and Interpreting Studies
}

\begin{abstract}
Routledge Handbooks in Translation and Interpreting Studies provide comprehensive overviews of the key topics in translation and interpreting studies. All entries for the handbooks are specially commissioned and written by leading scholars in the field. Clear, accessible, and carefully edited, Routledge Handbooks in Translation and Interpreting Studies are the ideal resource for both advanced undergraduates and postgraduate students.
\end{abstract}

THE ROUTLEDGE HANDBOOK OF LITERARY TRANSLATION

Edited by Kelly Washbourne and Ben Van Wyke

THE ROUTLEDGE HANDBOOK OF TRANSLATION AND POLITICS

Edited by Fruela Fernández and Jonathan Evans

THE ROUTLEDGE HANDBOOK OF TRANSLATION AND CULTURE

Edited by Sue-Ann Harding and Ovidi Carbonell Cortés

THE ROUTLEDGE HANDBOOK OF TRANSLATION STUDIES AND

LINGUISTICS

Edited by Kirsten Malmkjaer

THE ROUTLEDGE HANDBOOK OF TRANSLATION AND PRAGMATICS

Edited by Rebecca Tipton and Louisa Desilla

THE ROUTLEDGE HANDBOOK OF TRANSLATION AND TECHNOLOGY

Edited by Minako O'Hagan

THE ROUTLEDGE HANDBOOK OF TRANSLATION AND EDUCATION

Edited by Sara Laviosa and Maria González-Davies

For a full list of titles in this series, please visit www.routledge.com/Routledge-Hand books-in-Translation-and-Interpreting-Studies/book-series/RHTI. 


\section{The Routledge Handbook of Translation and Education}

Edited by

Sara Laviosa and Maria González-Davies 
First published 2020

by Routledge

2 Park Square, Milton Park, Abingdon, Oxon OX14 4RN

and by Routledge

52 Vanderbilt Avenue, New York, NY 10017

Routledge is an imprint of the Taylor \& Francis Group, an informa business

(C) 2020 selection and editorial matter, Sara Laviosa and Maria González-Davies; individual chapters, the contributors

The right of Sara Laviosa and Maria González-Davies to be identified as the authors of the editorial material, and of the authors for their individual chapters, has been asserted in accordance with sections 77 and 78 of the Copyright, Designs and Patents Act 1988.

With the exception of Chapters 4, 25 and 26, no part of this book may be reprinted or reproduced or utilised in any form or by any electronic, mechanical, or other means, now known or hereafter invented, including photocopying and recording, or in any information storage or retrieval system, without permission in writing from the publishers.

Chapters 4, 25 and 26 of this book are available for free in PDF format as Open Access from the individual product page at www.routledge.com. It has been made available under a Creative Commons Attribution-Non Commercial-No Derivatives 4.0 license.

Trademark notice: Product or corporate names may be trademarks or registered trademarks, and are used only for identification and explanation without intent to infringe.

British Library Cataloguing-in-Publication Data

A catalogue record for this book is available from the British Library

Library of Congress Cataloging-in-Publication Data

A catalog record for this book has been requested

ISBN: 978-0-815-36843-4 (hbk)

ISBN: 978-0-367-85485-0 (ebk)

Typeset in Times New Roman

by Apex CoVantage, LLC 


\section{Contents}

List of contributors

viii

Acknowledgements

xiv

Introduction: a transdisciplinary perspective on translation and education

Sara Laviosa and Maria González-Davies

\section{PART I}

Theoretical foundations

1 Bilingualism and multilingualism

Katie A. Bernstein and Laura Hamman-Ortiz

2 Educational theory: from Dewey to Vygotsky

Konrad Klimkowski

3 Education for intercultural citizenship

Michael Byram, Melina Porto and Leticia Yulita

\section{PART II}

\section{Early childhood and primary education}

4 Preschool education

Cristina Corcoll López and Jane Mitchell-Smith

5 Primary bilingual classrooms: translations and translanguaging

Ofelia García, Gladys Y. Aponte, and Khanh Le

6 Pedagogical affordances of translation in bilingual education Esa Hartmann and Christine Hélot

7 Translators in schools: valuing pupils' linguistic skills 
PART III

Secondary school education

8 Content-based instruction

Sara Laviosa

9 English as a medium of instruction

BethAnne Paulsrud and Jeanette Toth

10 Bilingual education

Anna M. Beres

PART IV

Higher education

11 Modern languages

Michael Huffmaster and Claire Kramsch

12 Translation and multilingual/creative writing Margarida Vale de Gato

13 Audiovisual translation: subtitling and revoicing Alejandro Bolaños-García-Escribano and Jorge Díaz-Cintas

Ludmila Stern and Xin Liu

15 Community translation in New Zealand

Ineke Crezee, Jo Anna Burn and Wei Teng

16 Translation and technology

Sharon O'Brien and Silvia Rodríguez Vázquez

17 Computer-assisted L2 learning and translation (CAL2T)

Vanessa Enríquez Raído, Frank Austermühl and

Marina Sánchez Torrón

PART V

Special education

18 Heritage language education: A global view

Jenna Cushing-Leubner 
19 Gifted education programmes Eva Reid

20 Sign languages

Ingela Holmström and Krister Schönström

21 Sign bilingual education of foreign languages

Edit H. Kontra

22 Sign language interpreting

Christopher Stone and Jeremy L. Brunson

\section{PART VI}

Teacher education

383

23 Translation teacher training 385 Gary Massey

24 Interpreting teacher training David B. Sawyer

25 Teacher agency in plurilingual learning contexts Olga Esteve

26 Developing mediation competence through translation 434 Maria González-Davies

Index 


\section{Contributors}

Gladys Y. Aponte is a doctoral student in urban education at The Graduate Centre, CUNY. Prior to pursuing a doctoral degree, Gladys was a dual language bilingual teacher in New York City public schools. As a fieldwork advisor and CUNY-NYSIEB Research Assistant, Gladys collaborates with educators to plan and implement translanguaging pedagogies.

Sarah Ardizzone is a literary translator from the French. Co-founder of Translators in Schools, she curates programmes including Translation Nation and the Big Translate. Sarah is a Royal Literary Fund Fellow, judge of the Harvill Secker Young Translators' Prize and co-chair of English PEN's Writers in Translation committee.

Frank Austermühl is Professor of Modern Languages with a chair in translation studies at Aston University in Birmingham (UK). Frank has an MA in Translation Studies and a PDD in Applied Linguistics and Translation Studies from the University of Heidelberg. He has taught at the Universities of Auckland, Heidelberg, and Mainz.

Anna M. Beres has a PhD from Bangor University (UK). Her thesis dealt with the neurobiological bases of bilingual education and translanguaging as a potential teaching and learning strategy in Welsh-English bilinguals. After graduation, she returned to her native Poland where she works as a lecturer and researcher at the Jagiellonian University in Krakow as well as a lecturer at the University of Social Sciences and Humanities in Warsaw. Her research interests are language, bilingualism, and neurodevelopmental disorders such as Autism. She conducts research using a variety of techniques, including EEG and fMRI.

Katie A. Bernstein is Assistant Professor in Mary Lou Fulton Teachers College at Arizona State University. She studies the language and literacy learning of multilingual children and the contexts in which their learning takes place - from the immediate context of peer interactions, to classroom contexts shaped by teachers' beliefs and preparation, to broader political and ideological contexts.

Alejandro Bolaños-García-Escribano is a teaching fellow at University College London, where he teaches translation at the Centre for Translation Studies (CenTraS) and the Department of Spanish, Portuguese and Latin American Studies. His current research examines the pedagogical potential of cloud-based subtitling platforms for the teaching of audiovisual translation. He also works as a freelance translator and subtitler. 
Jeremy L. Brunson is the American Sign Language-English interpreter for the Trial Courts of Arizona in Maricopa County. He is also an applied sociologist. His scholarly interests fall into the sociology of interpreting, sociology of work and the professions, social theory, and institutional ethnography.

Jo Anna Burn is a senior lecturer at Auckland University of Technology, New Zealand. She trained as a lawyer in the UK and has a strong interest in social justice and equity. Her research interests include legal language and interpreting, peer- and self-review strategies for interpreters, and community translation.

Michael Byram studied languages at Cambridge University, wrote a $\mathrm{PhD}$ in Danish literature, and then taught French and German in a comprehensive school. At Durham University since 1980, now Professor Emeritus, he is currently involved in the Council of Europe's work on the 'Reference Framework of Competences for Democratic Culture'.

Cristina Corcoll López is a lecturer and researcher at the Faculty of Psychology, Education and Sports Sciences Blanquerna (Universitat Ramon Llull). Her current research focuses on the implementation of the plurilingual approach in the classroom and the teaching of additional languages to young learners.

Ineke Crezee is Associate Professor of translation and interpreting at Auckland University of Technology, New Zealand. She trained as a linguist, interpreter, translator, and registered nurse and has published extensively on interpreter education, particularly in the health setting. She is co-editor of two international journals: Translation and Interpreting (University of Western Sydney, Australia) and the International Journal of Interpreter Education (Conference of Interpreter Trainers, USA).

Jenna Cushing-Leubner (Assistant Professor Second Language Education, University of Wisconsin-Whitewater) prepares world language, bilingual/bicultural, and ESL teachers and designs/coordinates a certificate in heritage language education. Her research and scholarship focus on critical approaches to bilingual/multilingual education, heritage language education, and critical whiteness studies connected to teacher education.

Jorge Díaz-Cintas is Professor of Translation Studies at University College London, where he founded the Centre for Translation Studies (CenTraS). He has published widely in audiovisual translation, is the Chief Editor of the series New Trends in Translation Studies and a member of the European Union expert group LIND (Language Industry). His extensive research and teaching experience have won him international recognition and several prizes, including the Jan Ivarsson (2014) and the Xènia Martínez (2015) awards.

Vanessa Enríquez Raído is Associate Professor in Translation at the University of Auckland, where she teaches a range of courses in translation. Her fields of expertise are translator education, translation technologies, and process research. More recently, she has developed a strong interest in community interpreting and translation for language learning.

Olga Esteve was a senior tenured lecturer in the Department of Translation and Language Science of the Universitat Pompeu Fabra (Barcelona) from 1998 to 2017. She currently works 
as an educational consultant to public schools and specializes in transformative teacher education. Her research interests include sociocultural theory, teacher professional development, and concept-based instruction.

Ofelia García is Professor Emerita in the PhD programmes in Urban Education and Latin American, Iberian, and Latino Cultures at The Graduate Center of The City University of New York. García has published widely in the areas of bilingualism and bilingual education, the education of emergent bilinguals, sociology of language, and language policy.

Maria González-Davies is a freelance translator and associate professor in the Department of Foreign Languages and Education at the Universitat Ramon Llull (Barcelona, Spain). Her current research focuses on translator training and the role of natural plurilingual and pluricultural practices in language teaching and learning.

Laura Hamman-Ortiz is a post-doctoral research associate in the School of Education at the University of Colorado-Boulder. Her research explores the relationship between language and education in $\mathrm{K}-12$ contexts with a focus on the (trans)languaging and (bi/multi)literacy practices of emergent bilingual students, particularly those learning in two-way bilingual classrooms.

Esa Christine Hartmann (PhD) is Associate Professor of German and Bilingual Education (French-German) at the University of Strasbourg (France), and associated member of the research group Multilingualism, Translation, Creation of the ITEM/ CNRS (France), as well as member of the research group European Multilingualism (GEPE) of the research unit LiLPa of the University of Strasbourg (France). Her research interests include bilingual and multilingual education, multilingual writing, translation studies, genetic criticism, and stylistics.

Christine Hélot is Emeritus Professor of English at the University of Strasbourg, France. As a sociolinguist, her research focused on language in education policies in France and in Europe, bi-multilingual education, intercultural education, language awareness, early childhood education, and children's literature and multiliteracy. In 1988 she obtained her PhD from Trinity College (Dublin, Ireland) for a thesis on bilingualism in the family and in 2005 she was awarded an Habilitation (University of Strasbourg) for her research on bi/plurilingualism at school. Dr Hélot was a lecturer at the University of Ireland before returning to France and since then has been a guest professor in Spain, Germany, and the US She has published widely in French and English, for example Children's Literature in Multilingual Classrooms, (2014 with R. Sneddon \& N. Daly IOE Press/Trentham Books). Her research on critical language awareness was the subject of a documentary film entitled Raconte-moi ta langue/Tell me how you talk: www.youtube.com/watch? $=\mathrm{v}=\mathrm{gP} 500 \mathrm{fk} 34 \mathrm{jk}$.

Sam Holmes is a teacher, researcher, and teacher trainer specializing in English as an Additional Language. He is a member of the Hub for Education and Linguistic Diversity at King's College London and trains translators to deliver workshops to children with Translators in Schools. Sam is co-founder and CEO of Causeway Education.

Ingela Holmström is an assistant professor at the Department of Linguistics, Stockholm University. Her research is directed towards communication issues in interaction between deaf, hard-of-hearing, and hearing people. She has a special interest in bilingualism and conducts research on teaching Swedish Sign Language as a second language. 
Michael Huffmaster, Associate Professor of German at the University of Puerto Rico, Mayagüez, works at the intersection of language and literature. In literary linguistics, he focuses on speech act theory, metaphor theory, and translation. In language education, he investigates how adult foreign language and literature study fosters critical and creative thinking.

Konrad Klimkowski is a translator, interpreter, academic teacher, and researcher in the field of translator/interpreter education. He is an associate professor at The John Paul II Catholic University of Lublin, Poland. His main research areas include social constructivist translator/interpreter curriculum, communicative aspects of educational practices, learning as co-emergence of knowledge and entrepreneurial skills in translator/interpreter education.

Edit H. Kontra is Associate Professor in the Department of English Language and Literature at János Selye University, Komarno, Slovakia. Her recent research has focused on individual differences and learners with special educational needs. She has been involved in investigating the foreign language learning situation of Deaf and hard-of-hearing Hungarians since 2006.

Claire Kramsch is Emerita Professor of German and Professor of the Graduate School of Education at the University of California, Berkeley, where she taught undergraduate and graduate courses in Second Language Acquisition and Applied Linguistics. She has published widely on the relationship of language, culture, and multilingualism in foreign language learning and teaching. She is currently writing a book on Language as Symbolic Power for Cambridge University Press.

Sara Laviosa holds a BAHons. in Psychology, an MA in TESOL, and a PhD in Translation Studies. She is Associate Professor in English Language and Translation, Università degli Studi di Bari 'Aldo Moro' (Italy). She has authored Corpus-based Translation Studies (2002), Translation and Language Education (2014) and Linking Wor(l)ds (2018). She is the Founder and Editor of the journal Translation and Translanguaging in Multilingual Contexts.

Khanh Le is a PhD student in Urban Education at the Graduate Center, CUNY. He is also an adjunct instructor at the City College of New York and a Research Assistant at CUNYNYSIEB. His scholarship, and his Critical Participatory Action Research, focus on disrupting oppressive language ideologies, especially with regard to Southeast Asian American youth.

Xin (Lucy) Liu is a lecturer in the School of Foreign Languages at Dalian University of Technology, China. She holds a $\mathrm{PhD}$ in Humanities and Languages from UNSW Sydney. Her research interests include interpreting studies (especially legal interpreting), pragmatics, and interpreter training.

Gary Massey is Director of the Institute of Translation and Interpreting at Zurich University of Applied Sciences, Switzerland, and past head of its MA and BA programmes in Applied Linguistics, Applied Languages and Translation. His research interests include translator competence and education, trainer training, translation processes, and translation quality.

Jane Mitchell-Smith is a primary school head teacher and is currently undertaking research at the Faculty of Psychology, Education and Sports Sciences Blanquerna (Universitat Ramon Llull). Her current research focuses on the factors affecting language acquisition in young plurilingual learners. 
Sharon O'Brien is Associate Professor in Translation Studies in the School of Applied Language and Intercultural Studies at Dublin City University, Ireland. Her research interests are in translation technology and translator-computer interaction, usability, cognition, and translation in disaster settings.

BethAnne Paulsrud, PhD, is a senior lecturer of English at Dalarna University in Falun, Sweden. Her research focuses on translanguaging and multilingualism, especially in relation to educational practice and policy, teacher education, language ideologies, English-medium instruction, and family language policy.

Melina Porto is a researcher at the National Research Council (CONICET) in Argentina, professor at Universidad Nacional de La Plata and Honorary Research Fellow at the University of East Anglia, UK. Her research addresses the intercultural dimension of English language teaching with a particular focus on intercultural citizenship education.

Eva Reid is an associate professor of English Language Didactics at the Constantine the Philosopher University in Nitra, Slovakia. She specializes in intercultural aspects in English language education, teaching English to gifted children and teaching English pronunciation. She has published numerous papers in the mentioned areas, from which the most significant are a monograph, Intercultural aspects in Teaching English at Primary Schools, published by Peter Lang, and four sets of English language textbooks for primary school children.

Silvia Rodríguez Vázquez is a research and teaching fellow at the Department of Translation Technology (TIM) of the Faculty of Translation and Interpreting, University of Geneva, Switzerland. Her research interests include web accessibility and localization, controlled languages, and the usability and accessibility of translation technologies.

Marina Sánchez Torrón is a Senior Natural Language Analyst at Unbabel and former honorary post-doctoral researcher at the University of Auckland School of Cultures, Languages and Linguistics. She has over 15 years of experience as a translator and her research interests revolve around the use of machine translation by professional translators.

David B. Sawyer has trained conference interpreters in three graduate programmes and codesigned the curriculum for the University of Maryland. He coordinated interpreter training for the US Department of State, where he also interpreted for over a decade. He holds graduate degrees and a doctorate from the University of Mainz, Germany.

Krister Schönström is an associate professor at the Department of Linguistics, Stockholm University. His primary research interests include several aspects within the topics of deaf bilingualism, including questions related to sign bilingualism, acquisition of written languages and sign languages in the deaf, and second language acquisition of sign languages.

Ludmila Stern is Professor of Interpreting at UNSW Sydney. She is the founder of the UNSW Master of Interpreting and Translation. Her research covers interpreting in domestic and international courts and her current projects include "From the Nuremberg Trials to the International Criminal Court. Interpreting in War Crimes Prosecutions and Communication between judicial officers and court interpreters: Implications for access to justice" (ARC Linkage 
grant). Her historical research examines Western intellectuals' involvement with the Stalinist USSR in the interwar period.

Christopher Stone is a senior lecturer in interpreting and Deaf studies at the University of Wolverhampton and is the current MA Interpreting course leader. His current research focuses on multimodal interaction in interpreter-mediated interactions and broadcast interpreting, Deaf interpreters, and interpreting history.

Wei Teng is a lecturer in Chinese and translation at the University of Canterbury, New Zealand. He gained accreditation as a Chinese $<>$ English interpreter in Australia. He is close to submitting his doctoral thesis, which explores a set of ready-to-use criteria to assess the quality of community translation in the health context.

Jeanette Toth, $\mathrm{PhD}$, is a senior lecturer in the Department of Language Education at Stockholm University in Stockholm, Sweden. Her research interests include language ideologies in educational policy and practice as related to English-medium instruction, multilingualism, translanguaging, and Swedish as a second language.

Margarida Vale de Gato translates, writes, teaches, and researches. She is an assistant professor in the areas of translation and US literature at ULisboa, and she co-coordinates the American Studies Group of ULICES. Her most recent academic publications include a chapter for the The Oxford Handbook of Edgar Allan Poe, "Poe and Modern(ist) Poetry", and an article in META on her translation of Lolita, both in 2018. Part of her research has targeted collaborative pedagogy in translation, with the project PEnPAL in Translation (www.penpalintranslation. com), of which she was PI from 2012 to 2016.

Leticia Yulita, $\mathrm{PhD}$, is a senior lecturer in intercultural communication and Spanish at the School of Politics, Philosophy, Language and Communication Studies, University of East Anglia, UK, where she holds a University Teaching Fellowship. Leticia is also a senior fellow of the Higher Education Academy. Her pedagogical research focuses on language learning, intercultural citizenship education, and critical pedagogy. 


\section{Acknowledgements}

The editors would like to thank the Routledge team, particularly Louisa Semlyen and Eleni Steck for their support throughout the editing process. We are most grateful to all the contributors and reviewers who believe, like us, in the value of opening a fruitful dialogue among language and translation teachers, teacher trainers, researchers, and translators who are actively involved in a variety of educational contexts worldwide. A special word of thanks goes to Richard D.G. Braithwaite for revising Chapter 8 before submitting it to the publishers. We are grateful to New Zealand Police for granting permission to reproduce in Chapter 15 the URL address to access the Guide to Crime Prevention Booklet available in English, Arabic, Chinese, and Hindi. We are also grateful to the Chief Executive of Age Concern New Zealand for giving permission to reproduce in Chapter 15 the URL address to access the pamphlet intended to inform the public about the need for an enduring power of attorney. 


\title{
Introduction
}

\section{A transdisciplinary perspective on translation and education}

\author{
Sara Laviosa and Maria González-Davies
}

Applied translation studies and educational linguistics are being influenced by what has been named the 'multilingual turn' in applied linguistics. This orientation foregrounds "multilingualism, rather than monolingualism, as the new norm of applied linguistic and sociolinguistic analysis" (May 2014, p. 1). The multilingual turn is engendered by concerns raised in globalization, cosmopolitanism, and migration studies (cf. Bielsa 2016; Inghilleri 2017) and emphasizes the highly complex processes inherent in languages in contact as they unfold within an individual's psychological and historical spaces, and among speakers of different languages when they engage in intercultural communication in their everyday social, academic, and professional lives. The paradigm shift in favour of multilingualism entails a re-evaluation of reflexivity in language and intercultural education (cf. Byrd Clark and Dervin 2014). It also entails a rethinking of the transmissionist model of learning in terms of mutual exchange of knowledge between teacher and students and among students themselves. In this sense, all the contributions to the volume highlight how learners are active participants in the development of what is taught, as envisaged by the American educational philosopher John Dewey (1938) and implemented in collaborative learning, which is inspired by Vygotskyan sociocultural theory (Vygotsky 1978).

The multilingual turn is increasingly endorsed and promoted by such political forces as the Council of Europe. The CEFR Companion Volume with New Descriptors (Council of Europe 2018), in particular, underscores the importance of mediation in honing plurilingual and pluricultural competence, which is considered from various perspectives: "as a sociological or historical fact, as a personal characteristic or ambition, as an educational philosophy or approach, or - fundamentally - as the sociopolitical aim of preserving linguistic diversity" (p. 28). Crosslinguistic, social, cultural, and professional mediation are at the core of different types of translanguaging activities, namely relaying specific information, processing text, explaining data across languages and cultures in speech and writing, note-taking, expressing personal responses to creative texts, and translating a written text in speech and writing (p. 104). In a similar vein, the new Australian Curriculum for languages adopts an intercultural orientation and includes translation and interpreting as forms of intercultural mediation. These forms of mediation involve the analysis and understanding of language and culture as resources for interpreting and shaping meaning in intercultural exchange (ACARA 2014, in Scarino 2016, p. 480). 
In unison with the multilingual paradigm are the recommendations made in the Ad Hoc Report on Foreign Languages issued by the Modern Language Association of North America (MLA 2007). This programmatic document states that the goal of languages education in the 21 st century is to develop translingual and transcultural competence. In contrast to seeking to replicate the competence of an educated native speaker, "[t]he idea of translingual and transcultural competence places value on the ability to operate between languages", and entails the capacity to reflect on the world and on ourselves through the lens of another language and culture (MLA 2007). The report also recommends the development of programmes in translation and interpretation because " $[\mathrm{t}]$ here is a great unmet demand for translators and interpreters, and translation is an ideal context for developing translingual and transcultural abilities as an organizing principle of the language curriculum" (MLA 2007). Against this backdrop, the aim of the handbook is twofold: to present the state of the art of the place and role of translation and its manifold manifestations in educational contexts worldwide, and to lay a sound foundation for the future interdisciplinary cooperation between translation studies and educational linguistics.

The handbook deals with a transdisciplinary subject area that focuses on the study of translation and education within a multilingual perspective. It is a burgeoning area of investigation which is attracting the interest of translation studies scholars and educationalists worldwide. The volume is addressed mainly to teacher trainers, teacher trainees, and researchers in translation studies and educational linguistics. It also addresses students embarking on MA courses or doctoral studies in this field, final year undergraduate students on degree courses in education, linguistics, applied linguistics, modern languages, communication studies, and crosscurricular studies (e.g. mediation and intercultural studies); students on second degrees or on short specialized courses for business people and other professions that require translation and/or basic interpreting skills and intercultural competence (e.g. journalism and localization); translation purchasers and agencies; administrators setting up new educational programmes; and any readers interested in translation and education.

As regards the structure of the book, the chapters in Part I provide the theoretical foundations for opening up a fruitful dialogue between translation studies scholars and educationalists. The chapters in Part II, III, IV, V, and VI examine the form and function of translation and interpreting in relation to the ways and contexts in which the purpose and process of learning are conceptualized in a particular pedagogical context. For 'purpose' we mean the kinds of knowledge and abilities that constitute the learning objectives. For 'process' we mean the procedures adopted to achieve these goals. These chapters cover educational contexts from early childhood and primary education (Part II), to secondary and higher education (Parts III and IV), special education (Part V), and, finally, teacher education (Part VI). After a brief introduction, each contribution provides an overview of the historical background to a given educational setting and outlines the development of pedagogical approaches, methods, assessment, and curriculum design. Next, it focuses on current research approaches and empirical findings. It then examines one or two examples of pedagogies that integrate translation in the curriculum, the teaching method's approach, design, and procedure as well as assessment, depending on each individual case. In the last two sections the authors make general recommendations for practice and point to future directions, aiming to bring about beneficial changes in teaching approaches, methods, testing or curriculum design. The terminology is explained within each chapter. Each contributor has been asked to define the key terms at the beginning of their chapter in order to ensure both situatedness and clarity. Since the approach is transdisciplinary, various concepts of translation will emerge from the different educational contexts in which it is employed. 
In this Introduction we outline the content of each contribution, highlighting commonalities and differences as well as propose avenues for future collaborative research inspired by the running themes that link together the papers selected for the handbook and are germane to both translation studies and educational linguistics. This transdisciplinary and transcultural perspective becomes self-evident as the chapters are written by a selection of contributors who come from different backgrounds and have been brought together for the first time in this volume.

The volume opens with a section dedicated to setting the theoretical background to the issues dealt with in the book. In Part I, Katie A. Bernstein and Laura Hamman-Ortiz present an overview of bi/multilingualism, focusing on historical and present perspectives, including the transdisciplinary "turns" of the past several decades divided into three central areas of scholarship - psychological, linguistic, and anthropological and sociolinguistic. They then outline bi/multilingual approaches to education and review key outcomes and current debates in bi/multilingual education. Finally, they discuss the role of translation in bi/multilingual learning, both as a practice in which many bi/multilingual children engage at home and as a useful pedagogical tool in the bi/multilingual classroom. Related to this chapter, Konrad Klimkowski follows with an overview and analysis of Educational Theory focusing around the pragmatic view of learning as a process, largely facilitated in social constructivist (Vygotsky) and democratic settings (Dewey). The author claims that these two early 20th-century conceptions are in many ways pertinent to contemporary language and translation classrooms. To illustrate this point from a pragmatic angle, a section presenting two classroom activities is provided. Another objective is to claim that interpreting educational conceptions requires the interpreter's readiness to accept more than one interpretative path since the effort to interpret educational thought that is over a hundred years old calls for re-interpretation rather than for seeking interpretative equivalence. The last chapter in Part I, written by Michael Byram, Melina Porto, and Leticia Yulita, addresses the concept of intercultural citizenship by bringing together theory of the intercultural speaker in foreign language education and theory of citizenship education, in particular the notion that the latter should lead to critical thinking about societal issues and 'action in the community' to engage in collective political action for the promotion of human rights. This framework of concepts and theories is illustrated with examples from a project involving language learners in universities in England and Argentina.

Part II presents how translation and interpreting are embedded in early childhood and primary education contexts. Cristina Corcoll López and Jane Mitchell-Smith start this section by introducing an approach based on a 'Pedagogy of Diversity', which entails the introduction to the plurilingual and pluricultural paradigm in a way that is coherent and respectful with the young learners' needs and abilities. This approach suggests that practitioners should create opportunities for young learners to experience linguistic and cultural diversity in their settings which, in turn, will lead to awareness of otherness, concept exploration, and form a basis for future learning. Several strategies that range from language and culture sensitizing to more specific didactic classroom-based approaches are discussed and exemplified. Ofelia García, Gladys Y. Aponte, and Khanh Le examine the use of translation in primary classrooms and distinguish translation from the concept of translanguaging. To draw a distinction between the two concepts, the authors present examples of teachers in translanguaging primary classrooms who use translation differently from teachers who use translation just to promote the children's intercultural communication with language that is 'appropriate' for the other group. Instead, teachers in translanguaging primary classrooms are not looking for ways of saying things in the language of the other, but in the children's own language and through the children's own experiences and lives. In the same educational contexts, Esa Hartmann and Christine Hélot 
present a research project at the Graduate School of Education of the University of Strasbourg with 25 bilingual teachers completing their first year of teaching practice in bilingual preschools and primary classrooms. Analysis of the teachers' discourses shows the extent to which the one language one teacher policy and the resulting separation of languages in bilingual education in Alsace exert a considerable influence on the ideological representation of translation and its possible pedagogical implementation. However, the analysis of the multilingual reading project demonstrates that translingual activities foster integrated and translingual learning, as well as the development of biliteracy and metalinguistic awareness. In the final chapter in this section, Sarah Ardizzone and Sam Holmes talk about establishing collaborative networks between professional translators and schools to boost students' linguistic skills. Their goal is to adopt a sociolinguistic framework for developing a critical approach to creative multilingual translation projects and programmes in primary schools. By way of example, they report on two translation projects aimed at primary age pupils - Translation Nation and The Big Translate - the aim of which is twofold: affirming pupils' sense of legitimacy and belonging in the classroom and enhancing pupils' existing linguistic skills.

Part III of this volume deals with how translation and education come into contact in secondary education contexts. First, Sara Laviosa traces the evolution of the principles underpinning Content-Based Instruction (CBI), also named Content and Language Integrated Learning (CLIL) in Europe. Next, she surveys the main research styles and findings of empirical studies that have explored the bilingual procedures used by secondary and high school teachers in educational settings that adopt a content-based language teaching approach and focuses on a case study undertaken during the teaching of a CLIL biology module in Italy. The author finally draws some conclusions on the functions fulfilled by different forms of translation and translanguaging in the CBI and the CLIL classroom. In a similar vein, BethAnne Paulsrud and Jeanette Toth explore the role of translation and translanguaging in the context of English as a medium of instruction (EMI) in secondary schools. Studies have found that students lacking sufficient proficiency in the instructional language may struggle with content. Hence, in order to promote the learning of content as well as languages, these programmes require approaches that can involve translanguaging and translation practices, such as bilingual students providing support for their classmates by translating the teacher's statements, thereby connecting content knowledge in the L1 with content knowledge in other languages, thus also offering the potential to challenge language hierarchies. Finally, Anna M. Beres follows the evolution of bilingual education practices to date, focusing on how bilingual education was seen as desirable for hundreds of years, up until the 15th century, when the changing socioeconomic perspective and the development of the printing press prompted the drive to make uniform the language used and make education homogenous. In the 20th century the overarching aim remained to educate all children with the hope of them mastering the 'target' language of the school and then facilitating essentially monolingual education. Other programmes, which aimed at gaining proficiency in both languages, kept them strictly separate, dedicating private lessons, teachers, or even days of the week to one language or the other.

In Part IV, issues related to higher education are examined. Michael Huffmaster and Claire Kramsch acknowledge that globalization and increasing multilingualism are contributing to a reassessment of the role of translation in language learning and teaching. In this context translation is intended broadly not only as a text-centred activity involving the process of relaying the meaning of a text written in one language into a text written in another language, as well as the product of such a process, but also as an integral part of bilingual exchanges between the teacher and their students to facilitate comprehension of abstract vocabulary or unfamiliar concepts. With this definition of translation in mind, the authors illustrate their 
translation-oriented pedagogic approach adopted in a module for elementary learners of German who were introduced to the concepts of overt versus covert translation and were assigned the task of producing two different translations of Paul Celan's "Todesfuge", a canonical poem of 20th-century world literature. From language learning to multilingual writing, Margarida Vale de Gato points out that the turn to creativity in translation studies, underlying translator's subjectivity, voice, and style, has given a new impetus to literary translation in language and writing curricula. She then discusses the rationale of her proposed model for collaborative literary translation education that adopts a socio-constructivist approach and aims to integrate creative writing in the teaching of literary translation, thus creating a continuum between translating, writing the self, and self-translation.

Still in higher education, Alejandro Bolaños-García-Escribano and Jorge Díaz-Cintas focus instead on the pedagogic specificities and challenges that characterize audiovisual translation (AVT), with particular emphasis on subtitling and revoicing. They explore, with illustrative examples from current practices, the potential benefits that teaching paradigms such as socio-constructivism and situated learning can bring about in the AVT classroom. Based on the premise that worldwide mass migration and asylum seeking is creating a need for interpreter training in new settings and in a broad range of languages, Ludmila Stern and Xin Liu assess the state of the art in conference and community interpreter education as regards teaching methodology, assessment, and curriculum design, and discuss the current shift from the traditional natural interpreter and apprenticeship approach to a more evidence-based training approach. More specifically, Ineke Crezee, Jo Anna Burn, and Wei Teng discuss some of the features of community translation (CT) in New Zealand and propose ways in which pragmatic equivalence may be assessed. Second, they present a comparative analysis of two English to Chinese translations to assess in what ways they may help or hinder social inclusion. Third, they discuss student translators' reflections on pragmatic equivalence. And finally, they introduce a non-language-specific pedagogical approach which encourages translation students to incorporate proofreader comments on pragmatic, sociocultural, and language issues so that student translators develop a connection between translation practice and social inclusion. Given the extent to which the translation profession is more and more technologized, Sharon O'Brien and Silvia Rodríguez Vázquez stress the importance of embedding translation technology in the translator training curriculum, and discuss the challenges this poses for curriculum designers, given the fast pace at which technology is continually developing. The teaching methods they analyze are framed within the social constructivist approach and the procedures are based on collaborative learning experiences. The objective of these methods is to hone the ability to critically use and evaluate computer-aided translation (CAT) tools on the basis of suitable translator competence models. At the end of Part IV, Vanessa Enríquez Raído, Frank Austermühl, and Marina Sánchez Torrón explore ways in which the use of technology such as computer corpora and machine translation (MT) can serve as an educational bridge in the training of both L2 translators and L2 learners in an increasingly multilingual and digital world. To this end, they propose to introduce the term computer-assisted L2 learning and translation (CAL2T). Their aim is twofold: re-conceptualizing L2 translation as a core skill in contemporary translator training, and re-evaluating the pedagogical potential of L2 translation to further foster linguistic and intercultural mediation skills in other learning contexts involving the use of a second, or additional, language.

Part V deals with the role of translation in special education. The first chapter in this section, written by Jenna Cushing-Leubner, highlights social, historical, and political factors that shape concepts, approaches to research, and pedagogic approaches to heritage language education. Due to the overrepresentation of Spanish heritage language education in the already 
US-centric literature, Spanish is used as a case example of how these elements come to bear on the complexities of heritage language education research and teaching methods. The chapter closes with the wide range of future directions for heritage language education that might push the field towards more intentional and socio-politically conscious teacher education and identity turns in language acquisition. This is followed by a chapter on gifted education by Eva Reid where the author first introduces different understandings of the concept of giftedness in different cultures and then examines the role of translation in the teaching of modern languages for gifted children. As regards deaf education, Ingela Holmström and Krister Schönström deal with translation as a language teaching practice in sign bilingual education settings, where written language is often considered to be the pupils' second language because they often learn to read and write later in childhood. The focus of this chapter is on translation between sign language(s) and written language(s) as a pedagogical approach in sign languagebased education concerning syllabus design, classroom practice, and assessment. In the next chapter, Edit H. Kontra discusses the most salient issues in sign bilingual education with special attention to implementing a bilingual-bimodal approach in the teaching and learning of foreign languages. In order to help the reader appreciate the complexity of teaching and learning a foreign language in such contexts, this chapter starts with a brief overview of general issues in deaf education, and a detailed discussion of deaf bilingual education. The last part of the chapter looks into the problems encountered when a sign language interpreter is used, and the question of incorporating the foreign sign language in the teaching-learning process. In the last chapter in this section, Christopher Stone and Jeremy L. Brunson examine the different aspects of the role played by a special brand of sign language interpreters in deaf education, i.e. those who work specifically for primary and secondary school pupils. They are referred to as educational interpreters. The authors suggest that, since interpreting has always been seen as a social event, research into educational interpreting must examine larger social processes as well as the everyday of interpreters so as to unearth the various social relations in which the educational interpreter is embedded.

To bring our voyage to a close, Part VI shifts the spotlight from student to teacher education. Here, after drawing together selected approaches and research findings, and presenting results from a previously unpublished survey, Gary Massey considers some of the key pedagogic approaches and models applied in teacher training and suggests that a viable, systematic approach to translation teacher training can be most effectively achieved at organizational level within a coherent organizational learning framework. This chapter ends by proposing a framework based on emergentist and organizational learning models operationalized by appropriate institutional incentives and structures. In the following chapter, David B. Sawyer moves to teacher training for conference interpreting in the spoken languages. He begins with the development of conference interpreting training since the mid-20th century, describing the roles of educational institutions, employer organizations, and professional associations and the emergence of dedicated teaching training programmes. He then addresses approaches to researching interpreting teacher training and presents key conclusions for interpreter education. He ends with an analysis of select contributions to the literature on interpreter education and AIIC's quality criteria for programmes revealing areas of knowledge and skills expected of effective interpreting teachers. A key element in teacher education is teacher agency, which is take in hand by Olga Esteve. The author explores how embracing a plurilingual language teaching perspective involves deeply reconceptualizing current, mostly monolingual, classroom practices. This chapter outlines the benefits of adopting teacher agency-driven formative interventions to promote teachers' professional development efficiently. Through this kind of intervention, teachers' own beliefs about language and the way they teach it are challenged 
by confronting them with a new perspective. This confrontation should help them see language learning and teaching through a new lens that should enable them to reframe their current monolingual classroom practices and engage in plurilingual ones. The last chapter has been written by Maria González-Davies, who first briefly outlines how ideas regarding the integration of previously known languages in foreign language learning have evolved from the grammar-translation method and the communicative approach to an informed Integrated Plurilingual Approach (IPA). She then explores how the students' linguistic repertoire can be integrated in the language learning process and finally focuses on translation as a key skill and a strategy for advancing mediation competence and respecting identity issues.

Some divergences notwithstanding, such as the different epistemologies of translation and translanguaging highlighted by García et al., on the whole trends are converging as is evidenced by the fact that educationalists have begun to quote representative scholars in translation studies and vice versa. Another converging trend concerns common pedagogic techniques such as the one advocated by Garcia et al. and those adopted by Ardizzone and Holmes, or González-Davies. Also, the growing interest in teacher and student agency in situated community practices following socio-constructivist and situated learning premises is evidenced in all the chapters. Translation is used across all educational levels and is regarded as an indispensable tool to smooth, enable and advance social contacts adopting a mediation role.

By adopting a transdisciplinary perspective, such as the one expounded and embraced by the authors of this handbook, we intend to bring together the various fields of scholarly enquiry and pedagogic practice that have been shown to make a valuable contribution to enlarging the notion of translation and diversifying its uses in education. The long-term goal is to extend the boundaries of translation studies and forge close interdisciplinary relationships with neighbouring disciplines that value translation in a broad array of educational contexts. Based on a multilingual and applied-oriented approach, the handbook is principally aimed at educationalists and educators in the 21 st-century post-global era. We would be pleased to hear from readers who may wish to share their thoughts on any of the topics addressed in this volume with a view to exchanging and enriching our mutual knowledge and expertise in this burgeoning field of trans- and interdisciplinary research and practice. Once we have closed the chapters, we think that the original idea of opening a trans- and interdisciplinary dialogue in both directions is bearing fruit. Or at least we would like to think it is.

\section{References}

Bielsa, E. (2016) Cosmopolitanism and Translation: Investigations into the Experience of the Foreign. London: Routledge.

Byrd Clark, J.S. and Dervin, F. (eds) (2014) Reflexivity in Language and Intercultural Education: Rethinking Multilingualism and Interculturality. London: Routledge.

Council of Europe. (2018) Common European Framework of Reference for Languages: Learning, Teaching, Assessment. Companion Volume with New Descriptors [online]. Strasbourg: Council of Europe Publishing. Available from: https://rm.coe.int/cefr-companion-volume-with-new-descriptors -2018/1680787989 [Accessed 19 May 2019].

Dewey, J. (1938) Experience and Education. New York: Macmillan Publishing Company.

Inghilleri, M. (2017) Translation and Migration. London: Routledge.

May, S. (2014) Introducing the 'multilingual turn', in May, S. (ed) The Multilingual Turn: Implications for SLA, TESOL and Bilingual Education. London: Routledge. pp. 1-6.

MLA Ad Hoc Committee on Foreign Languages. (2007) Foreign Languages and Higher Education: New Structures for a Changed World. Available from: www.mla.org/Resources/ Research/Surveys-Reports-and-Other-Documents/Teaching-Enrollments-and-Programs/ 
Foreign-Languages-and-Higher-Education-New-Structures-for-a-Changed-World [Accessed 19 May 2019].

Scarino, A. (2016) Reconceptualising translation as intercultural mediation: A renewed place in language learning. Perspectives: Studies in Translatology. 24(3), pp. 470-485.

Vygotsky, L.S. (1978) Mind in Society: The Development of Higher Psychological Processes. Cambridge, MA: Harvard University Press. 
Part I

Theoretical foundations 
$\because$ Taylor \& Francis

http://taylorandfrancis.com 


\title{
Bilingualism and multilingualism
}

\author{
Katie A. Bernstein and Laura Hamman-Ortiz
}

\section{Introduction}

$\mathrm{Bi} /$ multilingualism is the phenomenon of using more than one language. While some researchers treat bi/multilingualism as something marked and remarkable, in reality, much of the world is bi/multilingual. In the European Union, for example, $54 \%$ of people report being able to hold a conversation in at least one other language (European Commission 2015). Researchers estimate that the same is true for over half of the world (Grosjean 2010).

People become bi/multilingual in a variety of contexts - homes, schools, jobs, communities - and on a variety of timelines - some from birth (simultaneous bilinguals), others in childhood, as adolescents, or as adults (sequential bilinguals). People also become bi/multilingual to varying degrees, as needed for their context(s) of use. Despite the folk definition of bilingualism as the union of two perfect monolinguals, multilingual people often have different kinds of expertise in each of their languages. They often use their languages for different purposes, sometimes one at a time and sometimes in combination, as they encounter others with linguistic repertoires that overlap with parts of theirs (Rymes 2014).

As Valdés (n.d.) points out, the utility of categorizing bi/multilinguals by when, where, or how they learned and use their languages really depends on the question a researcher is asking. For our purposes here, bi/multilinguals are "those who use two or more languages (or dialects) in their everyday lives" (Grosjean 2010, p. 4), regardless of where, when, and how they learned and use those languages.

In addition to examining bi/multilingualism from an individual perspective, it is also possible to examine the ways in which societies are bi/multilingual. From a societal perspective, researchers have studied the functions of societal languages, their statuses (both official and unofficial), their relationships to groups of speakers, and their relationships to power. In this chapter, we primarily focus on individual bi/multilingualism, but address some of the research on societal bi/multilingualism as well. We begin with an overview of historical perspectives on bi/multilingualism, then turn to current issues in research, followed by approaches to bi/multilingual education. We conclude with new directions in the study of $\mathrm{bi} /$ multilingualism. 


\section{Historical perspectives}

$\mathrm{Bi} /$ multilingualism has existed in some form or another in every human society since the earliest civilizations (Baker and Wright 2017). The study of bi/multilingualism, however, emerged as a formal area of inquiry in tandem with the construction of the monolingual nation state in 19th-20th-century Europe (Baker and Lewis 2015; Gramling 2016). At that time, linguistic heterogeneity was perceived to be an impediment to the aims of the nation. National languages were framed as markers of unity, and their use was encouraged, incentivized, and in some cases, mandated (Irvine and Gal 2000; Gal 2006). Colonization spread these language ideologies throughout the world and, in spite of the multilingual reality of most human societies, normalized monolingualism for the national subject (Flores 2013). Ironically, this "invention" of monolingualism (Gramling 2016) and of the "native" speaker enabled the framing of bi/ multilingualism as marked and therefore worthy of study.

These perspectives have had a lasting impact on how bi/multilingualism is understood, contributing to a tradition of language research that views language as separate from speakers and from contexts of use. Ferdinand de Saussure (1916), often called the father of modern linguistics, distinguished between language use (parole) and the linguistic system (langue), declaring parole too unruly for study and, instead, sought to identify stable patterns and structures of langue. Based on his work, structuralist theories dominated linguistics for the next half century. For instance, Chomsky (1965), another foundational figure in the field of linguistics, framed language as a system of abstract structures in the mind of "an ideal speaker-listener, in a completely homogeneous speech community" (p. 3). Within this framework, bilingualism could not be seen as anything but the mastery of two (or more) separate systems.

In the last few decades, however, the study of bi/multilingualism has embraced a series of transdisciplinary turns. The social turn (Block 2003) and the practice turn (Schatzki 2001) marked shifts in the field toward understanding language as inseparable from specific speakers, situated contexts, and relations of power (Bakhtin 1981; Heller 2007). The multilingual turn (May 2013) marked a move away from studying multilingualism from a monolingual perspective, instead viewing the use of multiple languages as authentic bi/multilingual practice. Most recently, the trans- turn (Hawkins and Mori 2018) has meant a "softening of boundaries between languages" (Cenoz and Gorter 2013, p. 594) and even the more radical "disinventing" of languages (Makoni and Pennycook 2007). This conceptual shift has facilitated the theorizing of the fluid language practices of bi/multilinguals as translanguaging (García 2009; Wei 2018), translingual practice (Canagarajah 2013), polylingual languaging (Jørgensen 2008), and metrolingualism (Otsuji and Pennycook 2010). Common across these terms is an acknowledgement of the hybrid and dynamic ways that bi/multilingual individuals leverage their linguistic repertoires to communicate across multiple communities (García and Li Wei 2014). Thus, while many policies and ideologies around the globe continue to promote monoglossic framings of language - at times even weaponizing monolingualism as part of nativist rhetoric - for those who study language, there has been a shift in how bi/multilingualism is understood.

\section{Research approaches and key findings}

Research on bi/multilingualism is vast and increasingly interdisciplinary. While recognizing the overlap among approaches, we frame our review around three broad areas of scholarship: psychological approaches, linguistic approaches, and anthropological and sociolinguistic approaches. 


\section{Insights from psychology: bilingualism and the mind}

Psychological and psycholinguistic approaches to studying bilingualism focus primarily on the relationship between bilingualism and cognition. Early scholarship (1900-1950) linked bilingualism to "language handicap" or "mental confusion" and cautioned against exposing young children to more than one language (Yoshioka 1929; Smith 1931, 1939). Other research during this era drew correlations between bilingualism and low intelligence (Goodenough 1926; see Hakuta 1986 for a review). Much of this early research, however, suffered from serious methodological issues. For instance, Goodenough (1926) used English-language IQ tests as the central measure of intelligence and compared the scores of recently arrived immigrants and monolingual US citizens, while ignoring the immigrants' English proficiency or the test's reliance on US cultural knowledge (e.g. "Why should a married man have his life insured?" [Alpha Test 3, Question 13, in Hakuta 1986]).

Much research today focuses instead on the cognitive benefits of bilingualism (Baker and Wright 2017). Peal and Lambert's (1962) study of 110 middle-class, bilingual and monolingual Canadian elementary students, for example, found that bilingual students demonstrated more abstract thinking, better mental flexibility, and higher verbal IQ scores. While the study had methodological weaknesses (e.g. small sample size, focus on middle-class students, ignoring some home and environmental factors), it marked a turning point in cognitive studies of bilingualism. Recent meta-analyses highlight many cognitive benefits that are now associated with bilingualism, such as increases in working memory and metalinguistic awareness and improved attention and executive control (Bialystok 2005, 2009; Adesope et al. 2010). Other research has found that bilinguals demonstrate more divergent or creative thinking (Ricciardelli 1992; Leikin 2013; Kharkhurin 2015) and are more adept at solving complex problems in mathematics and science (Kessler and Quinn 1982; McLeay 2003).

When contemporary scholarship has identified a monolingual advantage, it is often the result of monolingual measurement. For example, bilingual children have been found to have a smaller vocabulary in a given (single) language when compared to that of their monolingual peers, and bilingual adults perform worse than monolinguals on tasks involving rapid lexical retrieval, or naming as many words as possible within a given time frame and category (Bialystok 2009). However, it is important to note that these differences are often statistically significant rather than clinically significant - meaning they do not create noticeable practical effects - and that these studies assess in only one language, which does not account for vocabulary knowledge distributed across languages (Umbel et al. 1992; Pearson 1998).

In addition to questions of assessment, research on cognitive differences between monolinguals and bilinguals must also account for factors such as socio-economic status, which affects performance on vocabulary assessments for both monolinguals and bilinguals (Umbel et al. 1992). Moreover, speakers' degree of bilingualism can affect outcomes (Thomas-Sunesson et al. 2018) and make it difficult to assign speakers to categorical groups, like "bilingual" and "monolingual" (Luk and Bialystok 2013).

\section{Insights from linguistics: the language practices of bi/multilingual individuals}

Research from linguistics and related fields (e.g. second language acquisition, applied linguistics, educational linguistics) primarily explores the language features, practices, and learning of bi/multilingual individuals. While early scholarship drew from structuralist understandings of bi/multilingualism - considering languages as isolated objects of study - in the 1970s, 
scholars interested in bi/multilingualism began to focus on the social and pragmatic functions of language. One area of scholarship that emerged during this time explored code-switching, or the alternation of two or more languages within the same utterance (intrasentential codeswitching) or between utterances (intersentential code-switching; see MacSwan 2013 for a comprehensive review). Some scholars have examined the formal and informal functions of code-switching, such as Blom and Gumperz's (1972) study of dialects in a Norwegian fishing village. Others have sought to identify structural boundaries of code-switched speech. For example, Timm (1975) identified constraints on Spanish-English code-switching, distinguishing sentences that bilinguals considered well-formed (e.g. The students habian visto la pelicula italiana) from those considered ill-formed (e.g. *The student had visto la pelicula italiana). The substantive body of scholarship that followed (e.g. Poplack 1980; MyersScotton 1993; MacSwan 2000) convincingly demonstrated that code-switching, like other linguistic behaviour, is rule-governed. As contemporary linguistic scholarship has shifted toward poststructuralist understandings of language, researchers have begun to explore the flexible ways that bi/multilingual individuals use language beyond code-switching (Baker and Wright 2017). In particular, translanguaging - the "multiple discursive practices in which bilinguals engage in order to make sense of their bilingual worlds" (García 2009, p. 45) - has become a popular construct for research on bi/multilingualism. Research on translanguaging tends to focus on two central arguments: (1) translanguaging is an authentic communicative practice for bi/multilinguals (see the TLANG project, https://tlang.org.uk/) and (2) translanguaging has pedagogical affordances that can be leveraged to support student learning (e.g. Creese and Blackledge 2010; Palmer et al. 2014; Gort and Sembiante 2015).

Linguistic perspectives have also examined the relationship between language and identity. Bonny Norton is credited with bringing identity to the forefront of second language acquisition research, revealing the multiple sociological factors that shape a learner's investment in acquiring a new language (Norton Pierce 1995; Norton 2013). Others have explored the intimate relationship between language and identity in relation to group membership (Bucholtz and Hall 2004). Le Page and Tabouret-Keller (1985), for example, found that individuals adopt linguistic behaviour to resemble the group(s) they want to identify with or to differentiate themselves from the group(s) from which they wish to be distinguished. While much of early identity scholarship has focused on second language learners, research has also illustrated how bi/multilinguals' identities are tied to dynamic language practices, often in hybrid and complex ways (Anzaldúa 1987; Pavlenko and Blackledge 2004). This work highlights the need for continued research on how bi/multilinguals experience their diverse linguistic worlds.

\section{Insights from sociology and anthropology: bi/multilingual societies and communities}

Anthropological and sociological approaches to bi/multilingualism consider the relationship between language, social contexts, and social groups. They have been influential in a wide range of disciplines, including education, political science, policy studies, social psychology, sociolinguistics, and geography. One line of this research explores how languages and language varieties are used and perceived in multilingual contexts. For example, Ferguson (1959) developed the concept of diglossia to describe societal differentiation between varieties of language, such as in Switzerland where Swiss German is used primarily in the home and Hochdeutsch is used in education and professional settings. Fishman (1964) also investigated diglossia and went so far as to argue that "socially patterned bilingualism can exist as a stabilized phenomenon only if there is functional differentiation between two languages" (Fishman 
et al. 1971, p. 560). More recently, the notion of diglossia has been critiqued for naturalizing linguistic hierarchies and ignoring relations of power that perpetuate these dynamics (Woolard and Schieffelin 1994; Romaine 2006).

Researchers using sociological and anthropological perspectives have also studied language ideologies, or beliefs and attitudes toward language, language practices, and speakers of particular languages (Silverstein 1979; Gal 1989; Woolard and Schieffelin 1994; Kroskrity 2004). This work has shown how language ideologies intertwine with power and power relations between groups, such as the ways that ideologies about language (what counts as "slang"; who gets called "articulate") are always bound up with ideologies about race (Alim et al. 2016; Rosa and Flores 2017). Language ideologies also intersect with language policy, shaping how policies around bi/multilingualism are created and enacted, for whom and toward what end (Ovando 2003; Shohamy 2006).

Anthropological and sociolinguistic approaches have also been used to explore language displacement, a phenomenon that occurs when populations transition from using one language to another. These shifts, frequently connected to unequal relations of power, can result in language endangerment (De Korne and Leonard 2017). In North America, Siberia, and Latin America, for example, colonization of these places and of the people living in them resulted in endangerment of many indigenous languages and the dominance of English, Russian, and Spanish (García 2009). Scholarship on language maintenance and revitalization has aimed at preserving and growing endangered languages through documentation, description, and teaching (e.g. Nettle and Romaine 2000; Hinton and Hale 2001; King 2001; Hinton 2003.) Critical scholars have argued, however, that the notion of "revitalization" of dormant languages is inadequate, focusing solely on language and ignoring the social conditions and relations of power that led to linguistic endangerment in the first place (De Korne and Leonard 2017). Instead, this work might be viewed as reclamation, or "effort by a community to claim its right to speak a language and to set associated goals in response to community needs and perspectives" (Leonard 2012, p. 359, italics ours), and include a focus on shifting power, rather than just language use.

Finally, a substantive body of anthropological scholarship seeks to document the dynamicity of lived bilingualism within particular communities. For example, Zentella's (1997) longitudinal work in a bilingual Puerto Rican community in New York found that children's code-switching was "more than a convenient way to handle linguistic gaps" (p. 99). Instead, code-switching or Spanglish (as she termed it) was part of the active and creative way that the bilingual children communicated to negotiate meaning, establish social identities, and reaffirm community membership. Similarly, Sayer (2013) identified TexMex, which draws on elements of both Spanish and English, as the authentic way that bilingual teachers and children in San Antonio, Texas communicate. He showed how TexMex could be leveraged to support content and language learning and to legitimize students' linguistic identities. As a whole, anthropological and sociological research on bi/multilingualism has provided insights into how languages are used and viewed within a given community.

\section{Pedagogic approaches and methods}

\section{What is a bi/multilingual approach to education?}

Not all approaches to teaching language are multilingual. In fact, many approaches to language teaching are explicitly monolingual, asking teachers and students to engage in collective make-believe that they are all monolingual speakers of the target language (Cummins 2008; 
Cook 2010; Kramsch and Zhang Lihua 2017). Bi/multilingual approaches instead meet two criteria: first, two or more languages are used for instruction, by both teachers and students; and second, these languages are used to teach not just language but also content (Anderson and Boyer 1970).

\section{Types of bi/multilingual programmes: weak bilingual programmes}

Within bi/multilingual approaches, however, there can be a range of aims. Some bilingual programmes, especially those serving linguistically minoritized children, are ultimately focused on assimilation into the dominant language (DL) of the society in which those children live (Skutnabb-Kangas and McCarty 2008). These programmes, known as transitional bilingual education (TBE) or early exit bilingual programmes, use instruction in the home language as a temporary crutch to support the transition to the DL (Wright and Baker 2017; García and Kleifgen 2018). In TBE programmes for US Spanish speakers, for instance, students begin kindergarten with substantive support in Spanish. This support gradually tapers off, with students using only English by third grade. In China, similar programmes can be found for speakers of ethnic languages, who have a legal right to mother tongue education, but with the ultimate goal of assimilating to the national language, Putonghua (Mandarin), by the end of elementary school (Postiglione et al. 2007; Gao and Wang 2017).

Although weak bilingual programmes are ultimately aimed at subtractive bilingualism (Lambert 1974), or acquisition of the DL at the expense of the home language (SkutnabbKangas and McCarty 2008), these programmes still provide benefits. Students in TBE programmes, for example, are able to begin learning grade-level content in their first language while they work to gain proficiency in their new language. In places where TBE programmes are not an option, such as in the US state of Arizona, language minoritized students may spend years in isolated classrooms focusing on English acquisition without engaging with academic content. For older students, this programme design may mean that they never catch up on content learning or on credits required to graduate (Lillie et al. 2010). In 2017, for instance, the graduation rate for English learners in Arizona was 18\%, while for non-English learners it was $75 \%$ (Jung 2017).

\section{Types of bi/multilingual programmes: strong bilingual programmes}

Like weak bilingual programmes, strong bilingual programmes, or late exit bilingual programmes, teach content in students' home languages while supporting target language acquisition. The aim of these programmes, however, is additive bilingualism, or the development of proficiency in the home and societal languages. Strong bilingual programmes provide continued support for both languages across the duration of the programme, often 5-6 years. There are several types of strong bilingual programmes, including one-way immersion, developmental/heritage programmes, and two-way immersion, which are primarily differentiated by the populations they serve.

One-way immersion programmes are for students who speak the societal DL. These students learn content through both the DL and a second language, with the aims of bilingualism and biliteracy by the end of elementary school (Skutnabb-Kangas and McCarty 2008). An early model of one-way immersion education began in Quebec in the 1950s. Englishspeaking children were taught predominantly in French, with English reintroduced into the curriculum gradually across elementary school (Lambert and Tucker 1972; Genesee 1995). In the US, programmes in which English-speaking children learn content through both a 
non-dominant language, such as Spanish or Mandarin, and English are one-way immersion programmes.

Developmental bilingual or heritage language programmes take a similar approach but serve students from non-DL backgrounds. These models of bilingual education are often termed maintenance programmes, as students are taught in their home language as well as the DL, with the aim that they will maintain and strengthen both languages (May 2017). In Ethiopia, for example, non-DL students' home languages are used for all eight years of primary schooling (Heugh et al. 2012; Bunyi and Schroeder 2017). The national language, Amharic, is introduced in grade three and English is taught as an additional, foreign language before becoming a medium of instruction in secondary school. The result is students who are strongly bi/multilingual. Similar programmes have been used for the revival of indigenous languages in the US through programmes that immerse native students in the heritage language of their community or tribe (McIvor and McCarty 2017). For instance, Navajo immersion programmes like Tséhootsooí Diné Bi'ólta' in Fort Defiance, Arizona and Puente de Hózhǫ in Flagstaff, Arizona have been successful in re-introducing Navajo to young speakers (Johnson and Legatz 2006).

A final type of strong bi/multilingual education, two-way immersion (TWI), brings together students proficient in the societal DL and students proficient in another language, like Spanish (as well as students bilingual in both). Students receive instruction in both languages and learn together and from each other, with the goals of biliteracy, bilingualism, and sociocultural competence for all (Howard et al. 2018). TWI programmes may balance the two languages throughout the school day (50/50 models) or may start as immersion in the non-DL and gradually increase the percentage of instruction in the DL throughout elementary school $(90 / 10$ or $80 / 20$ models). TWI programmes are increasingly common in the US but can be found around the world. In Basque-speaking areas of Spain, for instance, Basque-Spanish TWI schools have contributed to developing a new generation of Basque speakers (Gorter and Cenoz 2011).

\section{Other types of bi/multilingual programmes}

CLIL and the European Schools movement are bi/multilingual approaches that do not fit neatly into the preceding categories. CLIL, or Content and Language Integrated Learning, refers to any programme in which a language is used to teach content at the same time that the language is being acquired. Because this is true of all bi/multilingual approaches and because CLIL does not specify whether the languages used are indigenous, heritage, regional, national, or foreign, it is difficult to situate CLIL within - or differentiate it from - the approaches outlined so far (Cenoz et al. 2014). CLIL's strongest distinction may be that the term itself is commonly associated with Europe. Another model that overlaps with those discussed so far is the European Schools Movement. In European Schools, students learn through their first language while being introduced to a second language in early grades. In upper elementary grades, they begin to learn content in the second language while being introduced to a third language. The major distinction between this approach and other bi/multilingual approaches is that languages are taught as subjects before being used to teach content (Baker and Wright 2017).

\section{Outcomes and issues in bi/multilingual programmes}

In the US, one of the most noteworthy outcomes of strong bilingual programmes is high achievement for linguistically minoritized students. In addition to maintaining their heritage language - or, in the case of indigenous language education, acquiring it - linguistically 
minoritized students in strong bilingual programmes consistently outperform their peers in monolingual (societal language) programmes on a range of outcomes - including writing skills, maths achievement, graduation rates, and standardized test scores - and also develop pride in their culture and heritage (Holm and Holm 1995; August and Shanahan 2006; Johnson and Legatz 2006; Howard and Sugarman 2007; Lindholm-Leary and Block 2010; McField and McField 2014). A recent four-year study in the Portland Public Schools (Steele et al. 2017) found that of 1,600 students randomly chosen by lottery for two-way immersion or Englishonly, English learners who participated in the bilingual programmes were significantly more likely to be classified as English-proficient by sixth grade than English learners in English-only classrooms. Perhaps most convincing is Collier and Thomas's (2017) 32-year longitudinal study of English learners in 36 school districts across 16 US states, which compared outcomes for English learners in strong bilingual, weak bilingual, and English-only programmes. Their research found that, after five to six years, English-only programmes did little to close the academic achievement gap between non-DL and DL speakers, weak programmes closed about half of the gap, and strong bilingual programmes succeeded in closing the gap completely.

There have been some critiques of even strong bilingual programmes, however. Scholars have asked who benefits when speakers of a DL and non-DL are brought together in a two-way dual language programme. In the US, bilingual education was originally a response to calls for equal educational access for linguistically (and racially) minoritized populations (Flores 2017; Gándara and Escamilla 2017). Many TWI programmes, however, are framed around providing all students, including English-speaking children, with a linguistic edge in a globalizing world (Flores and García 2017; Valdez et al. 2016). This has led scholars to worry that new programmes will fail to meet the needs of language minoritized students, thereby perpetuating inequities (Lu and Catalano 2015; Valdez et al. 2016; Cervantes-Soon et al. 2017). Others point out that when programmes frame language as a neutral tool, separate from culture and available to all, heritage speakers risk losing any advantage their bilingualism may have once conferred (Valdés 1997; Flores 2017). Finally, some scholars worry that, in schools where students from dominant social groups participate in TWI, linguistically minoritized speakers of the non-DL become commodities themselves, serving as language models for DL students (Valdés 1997; Cervantes-Soon 2014).

Thus, while the interest of DL-speaking families has been helpful in successfully establishing and restoring bi/multilingual programmes, particularly in the US (Kelly 2018; Katznelson and Bernstein 2017), any bi-/multilingual programmes that bring together speakers of DL and non-DL must attend to power relations between languages, students, and families. Palmer et al. (2019) propose that programmes should support the development of not just bilingualism, biliteracy, and biculturalism, but also critical consciousness, or the ability "to reflectively discern the differences in power and privilege rooted in social relationships that structure inequalities and shape the material conditions of our lives" in addition to "recognizing one's role in these dynamics" (p. 3).

Another critique of bi/multilingual education, spanning all programme types, is the separation of languages. Traditionally, bi/multilingual programmes allocate language use by time (Spanish in the morning, say, and English in the afternoon), subject area (maths and science in Spanish; social studies in English), or teacher. Yet, scholars argue that language separation is rooted in a view of bilingualism as double monolingualism (Heller 2007) and does not reflect the ways that bilingual speakers actually use language (Palmer et al. 2014; Flores and Baetens Beardsmore 2015; Sánchez et al. 2018). They point out that when programmes ignore or negatively sanction multilingual children's translanguaging (García 2009), it may limit their possibility of holding a bilingual identity, instead reifying identities such as "English speaker" 
or "Spanish speaker" (Lee et al. 2008; Martínez et al. 2015; de Jong 2016). At the same time, other researchers have found that when schools do not protect time and space for the non-DL, students often default to the DL and may not achieve high levels of proficiency in the partner language (Potowski 2004; Fitts 2006; Ballinger et al. 2017; Cenoz and Gorter 2017). Additionally, in classrooms where teachers do permit flexible language practices, these practices may be imbalanced, with students translanguaging most during non-DL time and rarely during DL time (Palmer 2008; Hamman 2018). Hamman (2018) proposes that one solution may be the creation of critical translanguaging spaces, in which teachers design spaces for and model translingual practices but also attend to power dynamics between languages and speakers and maintain some focused learning spaces for the non-DL.

\section{Translation in bi/multilingual approaches}

Another promising approach to intentionally bridging languages, applicable to all bi/multilingual programme types, is translation. Translation is often something that bilingual children already engage in outside of school, helping family members who may not speak the DL to carry out everyday tasks like reading mail, making appointments, and speaking with professionals such as doctors and teachers (Dorner et al. 2007). This informal translation work, or what McQuillan and Tse (1995) call "language brokering", supports family members' access to English-only institutional resources, such as medical care, housing, community events, and school information (Orellana 2009), and has also been shown to support children's own academic success, such as higher scores on standardized reading tests (Dorner et al. 2007). Additionally, these language brokering skills can be leveraged to help students with other academic skills (Orellana et al. 2003). In one example, Martínez et al. (2008) asked bilingual middle school students in Los Angeles to reflect on and re-enact the ways that they translate outside of school to help others. Students analyzed the translation scenes for ways that translator varied not only the code (English/Spanish), but elements like grammar, vocabulary, and structure. Students were then able to apply the same idea of shifting voice to writing for different audiences.

Translation itself can also serve as a useful pedagogical tool in the classroom. Researchers have found that translation tasks support students' growth in and fluid use of all of their linguistic resources (Cummins et al. 2005), encourage new language learners to maintain a first language identity as they begin to construct a new bilingual identity (Cook 2010), and direct learners' attention to form, meaning, and aesthetics across languages (Witte et al. 2009; Laviosa 2014). Kultti and Pramling's (2017) research in a bilingual Finnish-English school showed that translation can support attention to form even in very young children. As six- and seven-year-olds collaborated with their teachers to orally translate a song, they engaged in a range of high-level linguistic and metalinguistic practices such as "rephrasing, attending to meaning, attending to sound ... differentiating an expression into its constituent parts, and distinguishing between sound and sense" (p. 723).

High school teacher Carol McCarthy has proposed a similar approach for older students. In her "Poetry in Translation" unit (www.poets.org/poetsorg/lesson/poetry-translation), she invites her multilingual students to translate published poems from their home languages into English and to compare these with professional translations for differences in how language is used and the meaning it conveys. Students also research poets' lives and the cultural, social, and political context in which the poems were written. Finally, students write and translate their own poems. Similarly, the "Poetry Inside Out" programme (www.catranslation.org/ education/), created by the Centre for the Art of Translation in San Francisco, uses translation 
of poetry to draw students' attention to relationships between form and meaning. As the program's creators describe, "The translation of poetry by its nature offers multiple possibilities: since there is no single 'correct' rendering of a poem, students must defend their language choices, which inevitably require a deep immersion into a literary work". In her study of Poetry Inside Out's implementation, Park (2015) found that English learners in a US high school developed metalinguistic awareness and engaged in collaboration to construct meaning. Additionally, translation required them to attend to not just semantics and syntax, but also the ways that language is both cultural and political.

Another promising translation activity is children's collaborative writing and translation of their own stories. Dworin's (2006) study described how bilingual fourth graders collected family stories (mostly in Spanish), wrote them down, revised them with peer assistance, and then collaboratively translated them. In his analysis of this process, he found that translation "a sophisticated process that demands that young writers use all that they know about oral and written language" (p. 511) - supported metalinguistic awareness, the ability to write for multiple audiences, and literacy development in both languages. Cummins (2017) proposed similar work using bilingual identity texts, or multilingual and multimodal books in which students represent themselves and their lives using their full linguistic repertoires. He described how three seventh-grade students in the US discussed ideas for their book using their first language, Urdu, then wrote the book using English, and finally translated it back to Urdu, all while engaging in deep discussions about how best to translate certain expressions. In addition to supporting metalinguistic awareness, the activity affirmed students' multilingual identities and enabled them to share their work with multiple audiences - monolingual English-speaking classmates, Urdu-speaking parents. Research on identity texts has been carried out around the globe (including in Canada, the US, Greece, Italy, China, Spain, and Mexico) with similarly positive findings (see Cummins and Early [2011] for case studies).

Martínez (2017), however, provides a useful caution about translation pedagogies. He reminds us that framing translation only as a tool to help monolingual audiences (for instance, by allowing both Spanish and English speakers to read students' work) erases bi- and multilingual audiences. As he put it in his work with bilingual youth in California (p. 86):

By only imagining two sets of monolingual audiences, we fail to prepare bilingual Chicanx and Latinx students to engage with audiences that look and sound like them, like their siblings, like their friends and neighbors. . [which] signal[s] to students that people like them, their siblings, and their friends and neighbors are not worth preparing to communicate with - that they are not a group of people that matters.

When using translation pedagogies, teachers and researchers should be careful not to contribute to the reification of monolingual identities or the centring of monolingual audiences.

\section{Conclusions and future directions}

The past decades have witnessed a multilingual turn, and more recently, a translingual turn, in both teaching and research. Scholars across sub-disciplines and approaches - linguistic, anthropological, psychological, sociological, educational - have critiqued the presumption of monolingualism as the natural, unmarked human condition. Recent scholarship has also made clear that multilingualism cannot be studied without considering its intersection and interaction with other social phenomena. While beyond the scope of this chapter, emerging research in areas such as race (Alim et al. 2016; Rosa and Flores 2017), space (Canagarajah 2018), 
disability (Hernández-Saca et al. 2018), aging (Bialystok and Sullivan 2017), and multiple modalities (Hawkins 2018) points to a future of bi-/multilingual research and teaching that is both intersectional and interdisciplinary.

\section{Further reading}

Baker, C. and Wright, W. (2017) Foundations of Bilingual Education and Bilingualism. 6th ed. Bristol, UK: Multilingual Matters.

This book provides an introduction to bi/multilingualism and bilingual education. The authors helpfully begin with definitions, then draw on research from across disciplines and paradigms to explore key issues, which range from policy and politics to programmes and assessment to learners with disabilities.

García, O. (2009) Bilingual Education in the 21st Century: A Global Perspective. West Sussex, UK: Wiley-Blackwell.

In this seminal text, Garcia engages with a range of topics related to bilingual education and introduces the notion of translanguaging. She outlines different bilingual education models, policies, and pedagogies, with attention to sociopolitical concerns and the nature of contemporary bilingualism and bilingual education around the globe.

García, O., Lin, A. and May, S. (eds) (2017) Bilingual and Multilingual Education. Encyclopedia of Language and Education. 3rd ed. Cham, Switzerland: Springer International Publishing.

This volume, part of the Encyclopedia of Language and Education, provides key concepts and research findings in bilingual and multilingual education, before presenting case studies from around the globe, organized by region - Asia and the Middle East, Africa and the Pacific, the Americas, and Europe. Each chapter focuses on one country, providing both an overview of bi/multilingual education in that country as well as raising issues relevant to bi/multilingual education writ large.

Shin, S.J. (2018) Bilingualism in Schools and Society: Language, Identity, and Policy. 2nd ed. New York: Routledge.

This text provides an accessible introduction to social, political, and educational issues in bilingualism, including bilingual identity, code-switching, and language shift. Shin addresses bilingualism within multilingual societies and families, debunks common myths about bilingualism, and considers some of the major policies, pedagogies, and programme models for bilingual students. The text is primarily focused on US contexts, but also leverages research and examples from around the world.

\section{Related topics}

bi/multilingual education, translation pedagogies, multilingual turn

\section{References}

Adesope, O. O., Lavin, T., Thompson, T. and Ungerleider, C. (2010) A systematic review and meta-analysis of the cognitive correlates of bilingualism. Review of Educational Research. 80(2), pp. 207-245. https://doi.org/10.3102/0034654310368803

Alim, H.S., Rickford, J. and Ball, A. (eds) (2016) Raciolinguistics: How Language Shapes Our Ideas About Race. New York: Oxford University Press.

Anderson, T. and Boyer, M. (1970) Bilingual Schooling in the US. Austin, TX: Southwest Educational Development Lab.

Anzaldúa, G. (1987) Borderlands/La Frontera: The New Mestiza. San Francisco: Aunt Lute Books.

August, D. and Shanahan, T. (2006) Developing Literacy in Second Language Learners. Report of the National Literacy Panel on Minority-Language Children and Youth. Mahwah, NJ: Lawrence Erlbaum. 
Baker, C. and Lewis, G. (2015) A synthesis of research on bilingual and multilingual education, in Wright, W., Boun, S. and García, O. (eds) The Handbook of Bilingual and Multilingual Education. Malden, MA: John Wiley and Sons. pp. 109-126.

Baker, C. and Wright, W. (2017) Foundations of Bilingual Education and Bilingualism. 6th ed. Bristol: Multilingual Matters.

Bakhtin, M. (1981) The Dialogic Imagination. Austin, TX: University of Texas Press.

Ballinger, S., Lyster, R., Sterzuk, A. and Genesee, F. (2017) Context-appropriate crosslinguistic pedagogy. Journal of Immersion and Content-Based Language Education. 5(1), pp. 30-57.

Bialystok, E. (2005) Consequences of bilingualism for cognitive development, in Kroll, J.F. and de Groot, A.M.B. (eds) Handbook of Bilingualism: Psycholinguistic Approaches. New York: Oxford University Press. pp. 417-432.

Bialystok, E. (2009) Bilingualism: The good, the bad, and the indifferent. Bilingualism: Language and Cognition. 12(1), pp. 3-11. doi: 10.1017/S1366728908003477.

Bialystok, E. and Sullivan, M.D. (2017) Growing Old with Two Languages: Effects of Bilingualism on Cognitive Aging. Amsterdam and Philadelphia: John Benjamins.

Block, D. (2003) The Social Turn in Second Language Acquisition. Washington, DC: Georgetown University Press.

Blom, J.P. and Gumperz, J.J. (1972) Social meaning and structure: Code-switching in Norway, in Gumperz, J. and Hymes, D. (eds) Directions in Sociolinguistics. New York: Holt, Reinhart, Winston.

Bucholtz, M. and Hall, K. (2004) Language and identity, in Duranti, A. (ed) A Companion to Linguistic Anthropology. Oxford: Blackwell. pp. 369-394.

Bunyi, G. and Schroeder, L. (2017) Bilingual education in sub-Saharan Africa: Policies and practice, in García, O., Lin, A. and May, S. (eds) Bilingual and Multilingual Education. Encyclopedia of Language and Education. 3rd ed. Cham, Switzerland: Springer. pp. 311-328.

Canagarajah, S. (2013) Translingual Practice: Global Englishes and Cosmopolitan Relations. New York: Routledge.

Canagarajah, S. (2018) Translingual practice as spatial repertoires: Expanding the paradigm beyond structuralist orientations. Applied Linguistics. 39(1), pp. 31-54. doi: 10.1093/applin/amx041.

Cenoz, J., Genesee, F. and Gorter, D. (2014) Critical analysis of CLIL: Taking stock and looking forward. Applied Linguistics. 35(3), pp. 243-262. doi: 10.1093/applin/amt011.

Cenoz, J. and Gorter, D. (2013) Toward plurilingual approach in English language teaching: Softening the boundaries between languages. TESOL Quarterly. 47(3), pp. 591-599.

Cenoz, J. and Gorter, D. (2017) Minority languages and sustainable translanguaging: Threat or opportunity? Journal of Multilingual and Multicultural Development. 38(10), pp. 901-912. doi: 10.1080/01434632.2017.1284855.

Cervantes-Soon, C.G. (2014) A critical look at dual language immersion in the New Latin@ Diaspora. Bilingual Research Journal. 37(1), pp. 64-82.

Cervantes-Soon, C.G., Dorner, L., Palmer, D., Heiman, D., Schwerdtfeger, R. and Choi, J. (2017) Combating inequalities in two-way language immersion programs: Toward critical consciousness in bilingual education spaces. Review of Research in Education. 41(1), pp. 403-427. doi: 10.3102/0091732X17690120.

Chomsky, N. (1965) Aspects of the Theory of Syntax. Cambridge: MIT Press.

Collier, V.P. and Thomas, W.P. (2017) Validating the power of bilingual schooling: Thirty-two years of large-scale, longitudinal research. Annual Review of Applied Linguistics. 37, pp. 203-217. doi: 10.1017/S0267190517000034.

Cook, G. (2010) Translation in Language Teaching: An Argument for Reassessment. Oxford: Oxford University Press.

Creese, A. and Blackledge, A. (2010) Translanguaging in the bilingual classroom: A pedagogy for learning and teaching? The Modern Language Journal. 94(1), pp. 103-115.

Cummins, J. (2008) Teaching for transfer: Challenging the two solitudes assumption in bilingual education, in Hornberger, N. (ed) Encyclopedia of Language and Education. Boston: Springer. pp. $1528-1538$. 
Cummins, J. (2017) Teaching for transfer in multilingual school contexts, in García, O., Lin, A. and May, S. (eds) Bilingual and Multilingual Education. Encyclopedia of Language and Education. 3rd ed. Cham, Switzerland: Springer. pp. 103-116.

Cummins, J., Bismilla, V., Chow, P., Giampapa, F., Cohen, S., Leoni, L., Sandhu, P. and Sastri, P. (2005) Affirming identity in multilingual classrooms. Educational Leadership. 63(1), pp. 38-43.

Cummins, J. and Early, M. (eds) (2011) Identity Texts: The Collaborative Creation of Power in Multilingual Schools. Stoke-on-Trent, UK: Trentham Books.

De Korne, H. and Leonard, W.Y. (2017) Reclaiming languages: Contesting and decolonising 'language endangerment' from the ground up, in Leonard, W.Y. and De Korne, H. (eds) Language Documentation and Description, vol 14. London: EL Publishing. pp. 5-14.

de Jong, E.J. (2016) Two-way immersion for the next generation: Models, policies, and principles. International Multilingual Research Journal. 10(1), pp. 1931-3152. doi: 10.1080/19313152.2016.1118667.

de Saussure, F. (1916) Course in General Linguistics. New York: McGraw-Hill.

Dorner, L.M., Orellana, M.F. and Li-Grining, C.P. (2007) “I helped my mom," and it helped me: Translating the skills of language brokers into improved standardized test scores. American Journal of Education. 113(3), pp. 451-478. doi: 10.1086/512740.

Dworin, J.E. (2006) The family stories project: Using funds of knowledge for writing. The Reading Teacher. 59(6), pp. 510-520.

European Commission. (2015) Europeans and Their Languages (Special Eurobarometer No. 386). Brussels, Belgium. Available from: http://ec.europa.eu/commfrontoffice/publicopinion/archives/ebs/ ebs_386_en.pdf [Accessed 18 May 2019].

Ferguson, C.A. (1959) Diglossia. WORD. 15(2), pp. 325-340. doi: 10.1080/00437956.1959.11659702

Fishman, J.A. (1964) Language maintenance and language shift as a field of inquiry. Linguistics. 9, pp. $32-70$.

Fishman, J.A., Cooper, R.L. and Newman, R.M. (1971) Bilingualism in the Barrio. Bloomington: Indiana University Press.

Fitts, S. (2006) Reconstructing the status quo: Linguistic interaction in a dual-language school. Bilingual Research Journal. 30(2), pp. 337-365.

Flores, N. (2013) Silencing the subaltern: Nation-state/colonial governmentality and bilingual education in the United States. Critical Inquiry in Language Studies. 10(4), pp. 263-287. doi: 10.1080/15427587.2013.846210.

Flores, N. (2017) From language-as-resource to language-as-struggle: Resisting the Coke-ification of bilingual education, in Flubacher, M-C. and Del Percio, A. (eds) Language, Education and Neoliberalism: Critical Studies in Sociolinguistics. Clevedon, England: Multilingual Matters. pp. 62-81.

Flores, N. and Baetens Beardsmore, H. (2015) Programs and structures in bilingual and multilingual education, in Wright, W.E., Boun, S. and García, O. (eds) The Handbook of Bilingual and Multilingual Education. Malden, MA: Wiley-Blackwell. pp. 205-222.

Flores, N. and García, O. (2017) A critical review of bilingual education in the United States: From basements and pride to boutiques and profit. Annual Review of Applied Linguistics. 37, pp. 14-29.

Gal, S. (1989) Language and political economy. Annual Review of Anthropology. 18, pp. 345-367.

Gal, S. (2006) Contradictions of standard language in Europe: Implications for the study of practices and publics. Social Anthropology. 14(2), pp. 163-181.

Gándara, P. and Escamilla, K. (2017) Bilingual education in the United States, in García, O., Lin, A. and May, S. (eds) Bilingual and Multilingual Education. Cham, Switzerland: Springer International. pp. $1-14$.

Gao, X.A. and Wang, W. (2017) Bilingual education in the People's Republic of China, in García, O., Lin, A. and May, S. (eds) Bilingual and Multilingual Education. Encyclopedia of Language and Education. 3rd ed. Cham, Switzerland: Springer. pp. 219-232.

García, O. (2009) Bilingual Education in the 21st Century: A Global Perspective. Malden, MA: John Wiley and Sons.

García, O. and Kleifgen, J.A. (2018) Educating Emergent Bilinguals: Policies, Programs, and Practices for English Language Learners. 2nd ed. New York: Teachers College Press. 
García, O. and Wei, L. (2014) Translanguaging: Language, Bilingualism and Education. New York: Palgrave Macmillan.

Genesee, F. (1995) The Canadian second language immersion program, in García, O. and Baker, C. (eds) Policy and Practice in Bilingual Education: A Reader Extending the Foundations. Clevedon, England: Multilingual Matters. pp. 118-133.

Goodenough, F.L. (1926) Racial differences in the intelligence of school children. Journal of Experimental Psychology. 9(5), pp. 388-397.

Gort, M. and Sembiante, S.F. (2015) Navigating hybridized language learning spaces through translanguaging pedagogy: Dual language preschool teachers' languaging practices in support of emergent bilingual children's performance of academic discourse. International Multilingual Research Journal. 9(1), pp. 7-25. doi: 10.1080/19313152.2014.981775.

Gorter, D. and Cenoz, J. (2011) Multilingual education for European minority languages: The Basque Country and Friesland. International Review of Education/Internationale Zeitschrift Für Erziehungswissenschaft. 57(5/6), pp. 651-666. doi: 10.1007/s11159-011-9248-2.

Gramling, D. (2016) The Invention of Monolingualism. New York: Bloomsbury Academic.

Grosjean, F. (2010) Bilingual: Life and Reality. Cambridge, MA: Harvard University Press.

Hakuta, K. (1986) The Mirror of Language: The Debate on Bilingualism. New York: Basic Books.

Hamman, L. (2018) Translanguaging and positioning in two-way dual language classrooms: A case for criticality. Language and Education. 32(1), pp. 21-42. doi: 10.1080/09500782.2017.1384006.

Hawkins, M.R. (2018) Transmodalities and transnational encounters: Fostering critical cosmopolitan relations. Applied Linguistics. 39(1), pp. 55-77. doi: 10.1093/applin/amx048.

Hawkins, M.R. and Mori, J. (2018) Considering "trans-" perspectives in language theories and practices. Applied Linguistics. 39(1), pp. 1-8. doi: 10.1093/applin/amx056.

Heller, M. (2007) Linguistic Minorities and Modernity: A Sociolinguistic Ethnography. 2nd ed. London: Continuum.

Hernández-Saca, D.I., Gutmann Kahn, L. and Cannon, M.A. (2018) Intersectionality dis/ability research: How dis/ability research in education engages intersectionality to uncover the multidimensional construction of dis/abled experiences. Review of Research in Education. 42(1), pp. 286-311. doi: $10.3102 / 0091732 X 18762439$.

Heugh, K.A., Benson, C., Yohannes, M.A.G. and Bogale, B. (2012) Implications for multilingual education: Student achievement in different models of education in Ethiopia, in Skutnabb-Kangas, T. and Heugh, K.A. (eds) Multilingual Education and Sustainable Diversity Work: From Periphery to Center. New York: Routledge. pp. 239-262.

Hinton, L. (2003). Language revitalization. Annual Review of Applied Linguistics. 23, pp. 44-57. https:// doi.org/10.1017/S0267190503000187.

Hinton, L. and Hale, K. (2001) The Green Book of Language Revitalization in Practice. San Diego: Academic.

Holm, A. and Holm, W. (1995) Navajo language education: Retrospect and prospects. Bilingual Research Journal. 19(1), pp. 141-167. doi: 10.1080/15235882.1995.10668595.

Howard, E.R. and Sugarman, J. (2007) Realizing the Vision of Two-Way Immersion: Fostering Effective Programs and Classrooms. Washington, DC; McHenry, IL: Center for Applied Linguistics and Delta Systems.

Howard, E.R., Lindholm-Leary, K.J., Rogers, D., Medina, N.O.J., Kennedy, B., Sugarman, J. and Christian, D. (2018) Guiding Principles for Dual Language Education. 3rd ed. Washington, DC: Center for Applied Linguistics.

Irvine, J.T. and Gal, S. (2000) Language ideology and linguistic differentiation. In P. Kroskrity (ed) Regimes of Language: Ideologies, Polities, and Identities. Santa Fe: School of American Research Press, pp. 35-84.

Johnson, F.T. and Legatz, J. (2006) Tséhootsooí Diné Bi'ólta'. Journal of American Indian Education. 45(2), pp. 26-33.

Jørgensen, J.N. (2008) Polylingual languaging around and among children and adolescents. International Journal of Multilingualism. 5(3), 161-176. https://doi.org/10.1080/14790710802387562. 
Jung, C. (2017, February 27) Arizona ELL student graduation rate lags far behind national average. KJZZ. Available from: https://kjzz.org/content/440381/arizona-ell-student-graduation-rate-lags-farbehind-national-average [Accessed 18 May 2019].

Katznelson, N. and Bernstein, K.A. (2017) Rebranding bilingualism: The shifting discourses of language education policy in California's 2016 election. Linguistics and Education. 40, pp. 11-26. doi: 10.1016/j.linged.2017.05.002.

Kelly, L.B. (2018) Interest convergence and hegemony in dual language. Language Policy. 17(1), pp. 1-21.

Kessler, C. and Quinn, M.E. (1982) Cognitive development in bilingual environments, in Hartford, B., Valdman, A. and Foster, C.R. (eds) Issues in International Bilingual Education: The Role of the Vernacular. Boston, MA: Springer.

Kharkhurin, A.V. (2015) Bilingualism and creativity: An educational perspective, in Wright, W.E., Boun, S. and García, O. (eds) Handbook of Bilingual and Multilingual Education. Malden: WileyBlackwell. pp. 38-55.

King, K. (2001) Language Revitalization Processes and Prospects: Quichua in the Ecuadorian Andes. Clevedon: Multilingual Matters.

Kramsch, C. and Zhang, L. (2017) The Multilingual Instructor: What Foreign Language Teachers Say About Their Experience and Why It Matters. Oxford: Oxford University Press.

Kroskrity, P.V. (2004) Language ideologies, in Duranti, A. (ed) A Companion to Linguistic Anthropology. Oxford, UK: Blackwell. pp. 496-517.

Kultti, A. and Pramling, N. (2017) Translation activities in bilingual early childhood education: Children's perspectives and teachers' scaffolding. Multilingua. 36(6), pp. 703-725. doi: 10.1515/ multi-2016-0041.

Lambert, W.E. (1974) Culture and language as factors in learning and education, in Aboud, F.E. and Mead, R.D. (eds) Cultural Factors in Learning and Education. Bellingham, WA: Fifth Western Washington Symposium on Learning.

Lambert, W.E. and Tucker, G.R. (1972) Bilingual Education of Children: The St. Lambert Experiment. Rowley, MA: Newbury House Publishers, Inc.

Laviosa, S. (2014) Translation and Language Education: Pedagogic Approaches Explored. London: Routledge.

Le Page, R. and Tabouret-Keller, A. (1985) Acts of Identity: Creole-Based Approaches to Language and Ethnicity. Cambridge: Cambridge University Press.

Lee, J.S., Hill-Bonnet, L. and Gillispie, J. (2008) Learning in two languages: Interactional spaces for becoming bilingual speakers. International Journal of Bilingual Education and Bilingualism. 11(1), pp. 75-94. doi: 10.2167/beb412.0.

Leikin, M. (2013) The effect of bilingualism on creativity: Developmental and educational perspectives. International Journal of Bilingualism. 17(4), pp. 431-447. https://doi.org/10.1177/1367006912438300

Leonard, Wesley Y. (2012) Framing language reclamation programmes for everybody's empowerment. Gender and Language. 6(2), pp. 339-367.

Lillie, K.E., Markos, A., Estrella, A., Nguyen, T., Peer, K., Perez, K., Trifiro, A., Arias, M.B. and Wiley, T.G. (2010) Policy in Practice: The Implementation of Structured English Immersion in Arizona. Available from: https://escholarship.org/uc/item/8742n78n [Accessed 18 May 2019].

Lindholm-Leary, K. and Block, N. (2010) Achievement in predominantly low SES/Hispanic dual language schools. International Journal of Bilingual Education and Bilingualism. 13(1), pp. 43-60. doi: $10.1080 / 13670050902777546$

Lu, J. and Catalano, T. (2015) Let them learn English. International Journal of Language Studies. 9(2), pp. $1-26$.

Luk, G. and Bialystok, E. (2013) Bilingualism is not a categorical variable: Interaction between language proficiency and usage. Journal of Cognitive Psychology. 25(5), pp. 605-621. doi: 10.1080/20445911.2013.795574.

MacSwan, F. (2013) Code-switching and grammatical theory, in Bhatia, T.K. and Ritchie, W. (eds) The Handbook of Bilingualism and Multilingualism. 2nd ed. West Sussex, UK: Blackwell. pp. 323-350. 
MacSwan, J. (2000) The architecture of the bilingual language faculty: Evidence from codeswitching. Bilingualism: Language and Cognition. 3(1), pp. 37-54.

Makoni, S. and Pennycook, A. (2007) Disinventing and Reconstituting Languages. Clevedon, UK: Multilingual Matters.

Martínez, R.A. (2017) Dual language education and the erasure of Chicanx, Latinx, and indigenous Mexican children: A call to re-imagine (and imagine beyond) bilingualism. Texas Education Review. 5(1), pp. 81-92.

Martínez, R.A., Hikida, M. and Durán, L. (2015) Unpacking ideologies of linguistic purism: How dual language teachers make sense of everyday translanguaging. International Multilingual Research Journal. 9(1), pp. 26-42. doi: 10.1080/19313152.2014.977712.

Martínez, R.A., Orellana, M.F., Pacheco, M. and Carbone, P. (2008) Found in translation: Connecting translating experiences to academic writing. Language Arts. 85(6), pp. 421-431.

May, S. (2013) The Multilingual Turn: Implications for SLA, TESOL and Bilingual Education. New York: Routledge.

May, S. (2017) Bilingual education: What the research tells us, in García, O., Lin, A. and May, S. (eds) Bilingual and Multilingual Education. Encyclopedia of Language and Education. 3rd ed. Cham, Switzerland: Springer. pp. 81-100.

McField, G. and McField, D. (2014) The consistent outcome of bilingual education programs: A metaanalysis of meta-analyses, in McField, G. (ed) The Miseducation of English Learners. Charlotte, NC: Information Age Publishing. pp. 267-299.

McIvor, O. and McCarty, T.L. (2017) Indigenous bilingual and revitalization-immersion education in Canada and the USA, in García, O., Lin, A. and May, S. (eds) Bilingual and Multilingual Education. Encyclopedia of Language and Education. 3rd ed. Cham, Switzerland: Springer. pp. 421-438.

McLeay, H. (2003) The relationship between bilingualism and the performance of spatial tasks. International Journal of Bilingual Education and Bilingualism. 6(6), pp. 423-438. doi: 10.1080/13670050308667795.

McQuillan, J. and Tse, L. (1995) Child language brokering in linguistic minority communities: Effects on cultural interaction, cognition, and literacy. Language and Education. 9(3), pp. 195-215. doi: $10.1080 / 09500789509541413$.

Myers-Scotton, C. (1993) Dueling Languages: Grammatical Structure in Codeswitching. Oxford: Clarendon Press.

Nettle, D. and Romaine, S. (2000) Vanishing Voices: The Extinction of the World's Languages. New York: Oxford University Press.

Norton, B. (2013) Identity and Language Learning: Extending the Conversation. Clevedon, UK: Multilingual Matters.

Norton Pierce, B. (1995) Social identity, investment, and language learning. TESOL Quarterly. 29(1), pp. 9-31.

Orellana, M.F. (2009) Translating Childhoods: Immigrant Youth, Language, and Culture. New Brunswick, NJ: Rutgers University Press.

Orellana, M.F., Dorner, L. and Pulido, L. (2003) Accessing assets: Immigrant youth's work as family translators or para-phrasers. Social Problems. 50(4), pp. 505-524. doi: 10.1525/sp.2003.50.4.505.

Otsuji, E. and Pennycook, A. (2010) Metrolingualism: Fixity, fluidity and language in flux. International Journal of Multilingualism. 7(3), pp. 240-254.

Ovando, C.J. (2003) Bilingual education in the United States: Historical development and current issues. Bilingual Research Journal. 27(1), pp. 1-24. doi: 10.1080/15235882.2003.10162589.

Palmer, D.K. (2008) Building and destroying students' "academic identities": The power of discourse in a two-way immersion classroom. International Journal of Qualitative Studies in Education. 21(6), pp. 647-667. doi: 10.1080/09518390701470537.

Palmer, D.K., Cervantes-Soon, C., Dorner, L. and Heiman, D. (2019) Bilingualism, biliteracy, biculturalism, and critical consciousness for all: Proposing a fourth fundamental goal for two-way dual language education. Theory into Practice. 0, pp. 1-13. doi: 10.1080/00405841.2019.1569376. 
Palmer, D.K., Martínez, R.A., Mateus, S.G. and Henderson, K. (2014) Reframing the debate on language separation: Toward a vision for translanguaging pedagogies in the dual language classroom. The Modern Language Journal. 98(3), pp. 757-772. doi: 10.1111/modl.12121.

Park, J. (2015) Learning in/through collaborative poetry translation: Documenting the impact of poetry inside out with high school-aged English language learners. Journal of Language and Literacy Education. 11(2), pp. 134-149.

Pavlenko, A. and Blackledge, A. (2004) Introduction: New theoretical approaches to the study of negotiation of identities in multilingual contexts, in Pavlenko, A. and Blackledge, A. (eds) Negotiation of Identities in Multilingual Contexts. Clevedon, UK: Multilingual Matters. pp. 1-33.

Peal, E. and Lambert, W.E. (1962) The Relation of Bilingualism to Intelligence. Washington, DC: American Psychological Association.

Pearson, B.Z. (1998) Assessing lexical development in bilingual babies and toddlers. International Journal of Bilingualism. 2(3), pp. 347-372. doi: 10.1177/136700699800200305.

Poplack, S. (1980) “Sometimes I'll start a sentence in Spanish y termino en espanol”: Toward a typology of code-switching. Linguistics. 18(7-8), pp. 581-618.

Postiglione, G., Jiao, B. and Manlaji, M. (2007) Language in Tibetan education, in Feng, A. (ed) Bilingual Education in China: Practices, Policies and Concepts. Clevedon, England: Multilingual Matters. pp. 49-74.

Potowski, K. (2004) Student Spanish use and investment in a dual immersion classroom: Implications for second language acquisition and heritage language maintenance. The Modern Language Journal. 88(1), pp. 75-101. https://doi.org/10.1111/j.0026-7902.2004.00219.x.

Ricciardelli, L.A. (1992) Creativity and bilingualism. Journal of Creative Behavior. 26(4), pp. 242-254.

Romaine, S. (2006) Global English: From island tongue to world language, in van Kemenade, A. and Los, B. (eds) Handbook of the History of English. Oxford: Blackwell. pp. 589-608.

Rosa, J. and Flores, N. (2017) Unsettling race and language: Toward a raciolinguistic perspective. Language in Society. 46(5), pp. 621-647. doi: 10.1017/S0047404517000562.

Rymes, B. (2014) Communicating Beyond Language: Everyday Encounters with Diversity. New York, NY: Routledge.

Sánchez, M.T., García, O. and Solorza, C. (2018) Reframing language allocation policy in dual language bilingual education. Bilingual Research Journal. 41(1), pp. 37-51. doi: 10.1080/15235882. 2017.1405098.

Sayer, P. (2013) Translanguaging, TexMex, and bilingual pedagogy: Emergent bilinguals learning through the vernacular. TESOL Quarterly. 47(1), pp. 63-88. doi: 10.1002/tesq.53.

Schatzki, T. (2001) Introduction: Practice theory, in Schatzki, T., Knorr-Cetina, K. and von Savigny, E. (eds) The Practice Turn in Contemporary Theory. London: Routledge. pp. 1-14.

Shohamy, E. (2006) Language Policy: Hidden Agendas and New Approaches. London and New York: Routledge.

Silverstein, M. (1979) Language structure and linguistic ideology, in Clyne, P., Hanks, W. and Hofbauer, C. (eds) The Elements. Chicago: Chicago Linguistic Society. pp. 193-248.

Skutnabb-Kangas, T. and McCarty, T.L. (2008) Key concepts in bilingual education: Ideological, historical, epistemological, and empirical foundations, in Hornberger, N.H. (ed) Encyclopedia of Language and Education. Boston: Springer. pp. 1466-1482. doi: 10.1007/978-0-387-30424-3_112.

Smith, M.E. (1931) A study of five bilingual children from the same family. Child Development. 2, pp. 184-187.

Smith, M.E. (1939) Some light on the problem of bilingualism as found from a study of the progress in mastery of English among pre-school children of non-American ancestry in Hawaii. Genetic Psychology Monographs. 21, pp. 119-294.

Steele, J.L., Slater, R.O., Zamarro, G., Miller, T., Li, J., Burkhauser, S. and Bacon, M. (2017) Effects of dual-language immersion programs on student achievement: evidence from lottery data. American Educational Research Journal. 54(1 suppl), pp. 282S-306S. https://doi.org/10.3102/0002831216634463. 
Thomas-Sunesson, D., Hakuta, K. and Bialystok, E. (2018) Degree of bilingualism modifies executive control in Hispanic children in the USA. International Journal of Bilingual Education and Bilingualism. 21(2), pp. 197-206. doi: 10.1080/13670050.2016.1148114.

Timm, L.A. (1975) Spanish-English code-switching. El porqué and how-not-to. Romance Philology. 28, pp. 473-482.

Umbel, V.M., Pearson, B.Z., Fernández, M.C. and Oller, D.K. (1992) Measuring bilingual children's receptive vocabularies. Child Development. 63(4), pp. 1012-1020.

Valdés, G. (n.d.) Multilingualism. Available from: www.linguisticsociety.org/resource/multilingualism [Accessed 18 May 2019].

Valdés, G. (1997) Dual-language immersion programs: A cautionary note concerning the education of language-minority students. Harvard Educational Review. 67(3), pp. 391-430.

Valdez, V.E., Freire, J.A. and Delavan, M.G. (2016) The gentrification of dual language education. The Urban Review. 48(4), pp. 601-627. doi: 10.1007/s11256-016-0370-0.

Wei, L. (2018) Translanguaging as a practical theory of language. Applied Linguistics. 39(1), pp. 9-30.

Witte, A., Harden, T. and Harden, A.R. de O. (eds) (2009) Translation in Second Language Learning and Teaching. New York: Peter Lang.

Woolard, K.A. and Schieffelin, B.B. (1994) Language ideology. Annual Review of Anthropology. 23(1), pp. 55-82. doi: 10.1146/annurev.an.23.100194.000415.

Wright, W.E. and Baker, C. (2017) Key concepts in bilingual education, in García, O., Lin, A. and May, S. (eds) Bilingual and Multilingual Education. Encyclopedia of Language and Education. 3rd ed. Cham, Switzerland: Springer. pp. 65-80.

Yoshioka, J.G. (1929) A study of bilingualism. Journal of Genetic Psychology. 36, pp. 473-479.

Zentella, A.C. (1997) Growing Up Bilingual: Puerto Rican Children in New York. Oxford: Blackwell. 


\section{Educational theory From Dewey to Vygotsky}

Konrad Klimkowski

\section{Introduction}

This chapter is an outline of pedagogical ideas drawn by two prominent theorists of education, John Dewey and Lev S. Vygotsky. When discussing the latter, I also refer to Jean Piaget. Even though the influence that the three figures had on education theory is enormous and indisputable, it is my conscious choice in this chapter to refer to Piaget only as auxiliary, serving a better illustration of Vygotsky's views. This is not to imply any kind of inferiority in Piaget's thought.

Dewey and Vygotsky are considered influential for 20th- and the 21st-century education since the educational problems they underscored at the turn of the 20th century are - in many ways - topical in the classrooms of today. Despite geographic, social, and political distance, both thinkers found themselves in a position to react to the then-classical way of understanding knowledge, learning, and development, and to change pedagogy so that it takes into account the dynamism of social change and cultural embeddedness. The complexity of thought displayed by both scholars is impressive and overwhelming. In as short a contribution as this one, I can focus only on few concepts that are associated with the two theorists. Such an approach must be considered an inevitable oversimplification of what Dewey and Vygotsky thought and wrote. The choice of these concepts is dictated by their relevance to the main line of argument in this chapter, and I hope that the reader finds this chapter inspiring to take on her own studies of these two prominent figures of education theory.

This chapter has a few objectives to accomplish. Primarily, it is to show that there is no educational approach without - overt or covert - philosophy behind it. If this is so, being a reflexive teacher means being aware (to the extent possible) of one's own epistemological options, methodological preferences, and the cultural embeddedness of everyday educational choices. Another objective is to attract the reader to the claim that thinking about contemporary teaching practices in one, dogmatic way is both unjustified and impractical. The multiplicity of ideas about education and development created by Dewey and Vygotsky gives ample evidence in favour of the claim that pedagogy does not have to - or in fact cannot - subscribe to only one epistemological or methodological outlook. Therefore, another objective posed here is to inspire the reader's reflection on what she finds acceptable and attractive or unacceptable and problematic in this chapter when considered in her own educational contexts. 
The chapter begins with an outline of John Dewey's and Lev Vygotsky's educational thought. It focuses around three key concepts of Dewey's educational philosophy: pragmatism with its vision of learning as a process, democracy, and embodied mind. The subsection devoted to Lev Vygotsky is arranged to discuss the notions of social constructivism, internalization, and Zone of Proximal Development. The second section shows how the main concepts advocated by Dewey and Vygotsky have been represented and further developed in recent educational theories and approaches - with main emphasis on translator and interpreter education. The next section moves us from the predominant theoretical orientation of the chapter towards a demonstration of how the concepts discussed can influence educational practices, and how to make them work for us as learners and teachers. I present two activities for a multilingual classroom to show how Dewey's and Vygotsky's legacy can find practical application. The fourth section draws conclusions and is also intended as inspiration and elementary guidance for readers who wish to explore the subject matter of the chapter. It is followed by a list of suggested publications and topics for further research.

\section{Historical perspectives}

\section{John Dewey's views of learning}

\section{Pragmatism}

John Dewey needs to be seen as a philosopher rather than an education theorist alone. This claim is not intended to undermine the importance of his educational thought, but to show its complex relationship with the other domains of his reflection (metaphysics, logic, epistemology, ethics, and aesthetics). Pragmatism (in its American strand) is one of the philosophical concepts Dewey is related to - along with William James, George Herbert Mead, and Charles Sanders Pierce. Epistemologically speaking, pragmatism is a position under which knowledge is an experiential phenomenon - it results from human experience. Theorizing comes as reflection upon experiencing, not the other way around. Educationally speaking, action (doing things) is a starting point in learning - rather than memorizing rules and developing principles. The principles come if action has proved them meaningful to the learner through experience.

I can now hypothetically hear a teacher colleague asking me: but how can I imagine expecting a student to act without giving him/her an introductory (a priori) instruction, which they must understand (conceptualize) and remember (ability to repeat or divide action into stages)? The question is more than practically valid, and it must be noted that curriculum (educational content) plays a crucial role in Dewey's view of an effective learning environment (cf. Kliebard 2006; Page 2006). Yet the point he makes is that, irrespective of the environment, learning as such starts with a learner who has a problem to solve: a question she faces, a choice she has to make, an alternative she has to find. This experienced problem is an "indeterminate situation" of the learner to which she responds by inquiry, i.e. "controlled or directed transformation of an indeterminate situation into the one that is so determinate in its constituents distinctions and relations as to convert the elements of the original situation into a unified whole" (Dewey [1938] 1986, p. 108). Thus, in other words, the point made by Dewey is that learning is solving a problem that a learner has defined for herself as significant (meaningful to her system of values, needs and objectives, cf. Rogers 1951) and hence challenging. Thus, the main task of the teacher is not to instruct on performance, but to attract learners to learning by delineating significant problems together with the learners and empowering them to pursue problem-solving trajectories. 


\section{Learning as a process}

Dewey views inquiry as taking place in cycles. Thus, he departs from a linear, simplistic "action-reaction" view of educational intervention (cf. Dewey 1896). If inquiry is cyclic, its outcomes are unlikely to be definitive or exhaustive: solving one problem (or failing to solve it) leads to another problem that becomes a new motive for learning. This view emphasizes the role of experience in initiating learning and pinpoints the ultimately intrinsic nature of the factors motivating learning and growth - with no disregard to their social aspects. The cyclic approach to learning implies that knowledge is a process rather than an end product of learning. What we attain through learning is not the ultimate "truth", but "warranted assertions" (Dewey [1938] 1986, p. 15). Thus, learning gives potential, yet not necessarily finite solutions to our problems. These solutions are "parts of an enterprise that is continually renewed" (Dewey [1938] 1986, p. 16).

\section{Learning as democratic}

Dewey's theory of learning is instrumentalist (learning is necessarily purposeful) and ameliorative (learning is never a mere exploration of reality but is always meant to improve the existing situation): "We use our past experiences to construct new and better ones in the future. The very fact of experience thus includes the process by which it directs itself in its own betterment" (Dewey [1920] 1982, p. 134).

The concepts of learning as instrumental and ameliorative are in close link with the idea of democracy as promoted by Dewey. His concept of democracy is much wider than the common, sociopolitical understanding of the term. As observed by Westbrook, for Dewey democracy was a moral ideal to which he devoted all his life (Westbrook 2010, p. 18):

Dewey was the most important advocate of participatory, deliberative democracy: that is, of the belief that democracy as an ethical ideal calls upon men and women to build communities in which the necessary opportunities and resources are available for every individual to realize his or her particular capacities and powers through participation in political, social, and cultural life.

Therefore, democracy provides a space where processes of individual and social growth can take place in the most effective and most egalitarian of ways (Westbrook 2010, p. 18):

[e]very human being, independent of the quantity or range of his personal endowment, has the right to equal opportunity with every other person for development of whatever gifts he has ... the task of democracy is forever that of creation of a freer and more humane experience in which all share and to which all contribute.

\section{Learning as embodied}

There is yet another fundamental aspect of Dewey's philosophical and educational thought that also explains his fascination with democracy as an environment for self-realization, participation, and growth. Dewey was an ardent critic of the Cartesian divide between the mind of the learner and the world that her mind explores (cf. Damasio 1994). He referred to this epistemological stand as "intellectualism". An "intellectualist" learner is "a spectatorial 'knower' detached from the rest of nature" (Westbrook 2010, p. 15). For the intellectualist view of 
learning "object and subject, mind and matter . . . are separate and independent" (Dewey [1925] 1981, p. 20). As diagnosed by Dewey, the intellectualist epistemology "has upon its hands the problem of how it is possible to know at all; how an outer world can affect an inner mind" (Dewey [1925] 1981, p. 20). Instead, Dewey decides to see the learning mind as embodied. As observed by Johnson (2010, p. 130):

Dewey attempts to explain "mind" and all its operations and activities non-dualistically, as grounded in bodily operations of living human creatures, who are themselves the result of prior evolutionary history and who have typically passed through a crucial sequence of developmental stages that have shaped their cognitive capacities and their identity.

The attempt to avoid the body versus mind dualism is also signalled by Dewey's use of the notion body-mind (Dewey [1925] 1981, p. 217):

\begin{abstract}
Body-mind simply designates what actually takes place when a living body is implicated in situations of discourse, communication, and participation. In the hyphenated phrase body-mind, "body" designates the continued and conserved, the registered and cumulative operation of factors continuous with the rest of nature, inanimate as well as animate; while "mind" designates the characters and consequences which are differential, indicative of features which emerge when "body" is engaged in a wider, more complex and interdependent situation.
\end{abstract}

Johnson (2010, p. 130) underlines Dewey's appeal for us to abandon our perspective of thinking, as "disembodied, transcendent activity and instead see it only as one of several very remarkable processes of embodied experience". This embodied view of thinking implies a related view of inquiry (learning), since " $t]$ he experiential prompt for human thinking is our human need for inquiry to help us resolve problematic situations" (Johnson 2010, p. 130).

\title{
Lev S. Vygotsky's view of learning
}

\section{Interpretative controversies}

Even though according to the critics John Dewey's thought is often self-contradictory or illexpressed, its general outline - particularly in the field of education - is relatively easy to construe. The researchers of Lev Vygotsky's legacy point out that the way in which he worked and in which his works were published makes comprehending his oeuvre a venturesome enterprise. Commenting on this state of affairs, Daniels et al. (2007, p. 2) observe:

A close reading of Vygotsky's work shows how his ideas developed and were transformed over a very brief period of time. It is difficult to reconcile some of the writing from the early 1920 s with that which was produced during the last 2 years of his life. These rapid changes, coupled with the fact that his work was not published in chronological order, make synthetic summaries of his work difficult.

To make the picture even more complex, researchers admit that understanding Vygotsky nowadays is thwarted by a confusion caused by diverse interpretations of his thought. This is why researchers often ask: "So who was the 'real' Vygotsky?" (Daniels et al. 2007, p. 9). In this chapter, only two opposing cases are considered: one concerns the question whether Vygotsky 
should be interpreted as a behaviourist or as a constructivist. The other opposition found in the literature of the field is between Piaget interpreted as a (radical) constructivist and Vygotsky read as a social constructivist. Bruner (1984, p. 96, as quoted in van der Veer 2007a, pp. 3-4) accused Piaget of picturing "the learning child as a solitary being divorced from the social surroundings and institutions". Vygotsky, on the other hand, is often interpreted as a social constructivist, owing to his major pedagogic assumption that "in order to understand the inner mental processes of human beings, we must look at human beings in their sociocultural context" (van der Veer 2007b, p. 21).

\section{Vygotsky: a behaviourist or a constructivist?}

In her research on Vygotsky, DeVries (2000) admits having difficulty solving paradoxes in his writings. On the one hand, Vygotsky consistently repeated his belief in a possibility to explain human behaviour exhaustively by means of the stimulus-response analysis, and he expressed his overt support for Thorndike's behaviourist stance (DeVries 2000, pp. 2-3). On the other hand, DeVries (2000) pinpoints those fragments in his writings that testify to Vygotsky's constructivist viewpoint (Vygotsky [1930] 1981, p. 169, as quoted by DeVries 2000, p. 4):

[a]ny new form of cultural experience does not simply come from outside, independently of the state of the organism at a given point of development. The fact is that the organism that is mastering external influences masters a number of forms of behavior or assimilates these forms depending on its level of mental development. . . these external materials are reprocessed and assimilated in the organism.

What DeVries interprets as a constructivist stance in Vygotsky's pedagogy may well be understood as a form of behaviourism: one in which the process of "assimilation" is a mere marker of how the organism adapts to stimuli. At least from the current perspective, under which constructivist education is extensively reliant on such notions as learner's autonomy (e.g. Grow 1991), empowerment (e.g. Kiraly 2000), autopoietic, co-emergent learning (e.g. Kiraly 2013, 2016), self-regulation (e.g. Moser-Mercer 2008) or heutagogy (e.g. Hase and Kenyon 2000), Vygotsky's notion of assimilation does not seem truly constructivist. My intention here is not to decisively solve the dilemma expressed in the title of this section. Instead, I intend to illustrate the point that, as observed by DeVries (2000), reading Vygotsky can pose an interpretative challenge.

\section{Is internalization a constructivist notion?}

Assimilation, as briefly discussed earlier, relates to its kin notion of internalization - one of the key concepts associated with Vygotsky. Internalization is a fundamental assumption in Vygotsky's theory of development. It is a vital part of his general pedagogic position stating that sociocultural context is an indispensable condition for the development of the human brain (Vygotsky 1931, p. 106, quoted after Bakhurst 2007, pp. 53-54):

[E]very function in the cultural development of the child appears on the stage twice, in two planes, first, the social, then the psychological, first between people as an intermental category, then within the child as an intramental category. This pertains equally to voluntary attention, to logical memory, to the formation of concepts, and to the development of will. 
Vygotsky maintains that there are two stages in the cultural development of the child. The first stage is social (intermental), whereas the individual (intramental) stage comes in the wake of the former. Internalization is what happens between the two stages. As explained by Bakhurst, "the child first grasps external mediational means - for example, the practice of tying a knot in a handkerchief as a reminder - and then she 'internalizes' such techniques, coming to deploy mnemonic devices in thought" (Bakhurst 2007, p. 54). If this fragment is to be read from the contemporary constructivist angle, it reveals more of a transmissionist than a constructivist approach to development: learning starts on an extrinsic, social impulse and the role provisioned for the learner is to internalize, assimilate, memorize, adapt, and act as socially expected. However, Bakhurst adds that "[i]nternalization, Vygotsky explains, is not a matter of merely transplanting a social activity onto an inner plane, for the internalized practice is transfigured in the act of internalization" (Bakhurst 2007, p. 54). This comment changes the picture considerably. The notion of "transfiguration" as part of internalization opens a possibility to interpret internalization as a socially conditioned construction of knowledge by an individual brain functioning in its environment. Under this reading, internalization is or at least can be a constructivist notion. The rationale for this section is not to drive the reader to the one or the other interpretation, but to show that, even if conditionally, Vygotsky's notion of internalization can be interpreted in terms of socially influenced, collaborative construction and negotiation of senses. This interpretative option is advocated by the prevalent number of contemporary specialists in Vygotsky (cf. Daniels et al. 2007; van der Veer 2007b; Tobias and Duffy 2009).

\section{Zone of proximal development (ZPD)}

If sociocultural context is directly responsible for how the learner develops, pedagogic intervention needs to shape this context to achieve expected developmental outcomes. According to Vygotsky, a role of the teacher is to determine a "zone" within which the development of a learner can be empowered by appropriate actions on the part of the teacher or more advanced learners. In other words, it is a (physical, cognitive, affective, social, interactive, communicative etc.) space where learner and teacher interact. It is also where "[T] he teacher can gauge intellectual development of the learner and provide the appropriate support to advance the learner's thinking" (Jordan et al. 2008, p. 60). Under the interpretation provided previously, ZPD definitely counts as a constructivist notion. Irrespective of these interpretative dilemmas, the concept of ZPD has inspired the rise of such constructivist ideas as scaffolding, peer collaboration or learner apprenticeship (cf. van der Veer 2007a, particularly Chapter 6).

\section{Vygotsky and Piaget}

Another field of interpretative controversies over Lev Vygotsky's legacy concerns how his thought is positioned against the educational views of Jean Piaget - a prominent figure of the 20th-century theory of learning. Most researchers seek to reconcile the two theorists (and their followers), pointing out that it is viable to read their proposals as by and large parallel, despite noticeable disparities (cf. DeVries 2000; Daniels et al. 2007; van der Veer 2007a, 2007b). Thus, Bruner's (1984) radical criticism of Piaget as being an isolationist constructivist (see earlier section) in contrast to the social constructivist Vygotsky is an exceptional stance. Commenting upon this latter purported opposition, van der Veer (2007a, p. 3) comments:

In the 1960s and 1970s, Vygotsky's ideas may have gained increasing popularity because of a growing dissatisfaction with existing ideas. In its extreme form, behaviorism was now seen by 
many to be inadequate and cognitive psychology returned to the study of the mental processes that underlie behavior. Piaget was increasingly (and undeservedly) viewed as a theorist who pictured the learning child as a solitary being divorced from the social surroundings and institutions (Bruner 1984, p. 96) not unlike Robinson Crusoe on his island. Critical psychologists were looking for an approach that took account of the social or societal origin of human behavior.

DeVries (2000, pp. 5-9) lists three main points of convergence in her interpretation of the pedagogies of Vygotsky and Piaget:

1 Social factors play a central role in child development (2000, p. 5)

2 Internalization is not a process of copying material from the environment but is a transformative process $(2000$, p. 7$)$

3 What develops is the individual (2000, p. 9)

In point 1, DeVries (2000) argues that the researchers who posit Vygotsky's and Piaget's views in opposition tend to ignore the distinction between Piaget's writing as an epistemologist and his views as a psychologist or theorist of education: "When he spoke as an epistemologist, Piaget focused on the development of ideas. When he spoke (less frequently) as a child psychologist, Piaget emphasized the central role of social factors in the construction of knowledge" (DeVries 2000, p. 6). Following this fragment, DeVries quotes from both early and later works by Piaget, where he overtly highlighted that the growth of an individual is determined by its social context (2000, pp. 6-7).

In point 2, DeVries argues that both Vygotsky and Piaget hold the constructivist - not transmissionist - view of internalization. With Piaget, the interpretative controversy is hardly there, since his proposal is a "constructivist theory of the transformative interiorizing mechanisms of intellectual development" (2000, p. 7), whereas in the case of Vygotsky, DeVries takes a stance identical to the one elucidated earlier (internalization as 'transfigurative' cf. Bakhurst 2007).

And finally, in point 3, DeVries (2000) argues that both Vygotsky and Piaget respected the agency of the learner:

While Vygotskians criticize Piaget for having a theory of individual development, Vygotsky certainly saw the higher mental functions of the individual as the goal of development. The discussion of internalization above presents the individual child as the site of intrapsychological activity.

(DeVries 2000, p. 9)

Choosing a reconciliatory approach to Vygotsky and Piaget along the lines developed by DeVries (2000) does not mean ignoring the real and evident differences between the theories. DeVries' (2000) catalogue of these is in fact longer than that of similarities, including nature of the stimulus, nature of knowledge, nature of self-regulation or nature of novelty in intellectual development. The argument in this section is not to prove that Vygotsky's and Piaget's are identical theories. Comparing and contrasting the two enhances our comprehension of the complex classroom reality, and hence equips us with more theoretical and practical options.

\section{Research approaches and key findings}

\section{Dewey's influence on modern education theories}

Studying the literature of the subject, one can conclude that Dewey has an equal number of admirers and opponents. Admirers approve of his vision of education as action-driven, 
participatory, egalitarian, and ecological. For Dewey, the key purpose of educational activity was "to liberate students' interests and energies so that their innate social curiosity is nurtured into a communicative democratic faith" (Fesmire 2015, p. 174). Page (2006, p. 53) presents Dewey's critique of the practices of the American school system of the time, e.g. pressing into students indiscriminate bits and pieces of information without integrating them within the realm of their personal experience. This is an instructionist approach under which knowledge (curriculum) is a ready-made repository "to be collected" rather than being an open-ended resource for shaping the future. Instructionism separates the curriculum content from its social roots by ignoring the social and cultural embeddedness of the content (Page 2006, p. 53). According to Fesmire (2015), Dewey repeatedly voiced his criticism against Thorndike's idea of education as "a technique for matching individuals to existing social and economic roles" (Lagemann 1989, as quoted in Fesmire 2015, p. 176).

Yet, as noted by Jackson (1990), Dewey's influence on pedagogical thought and practice is not as "widespread and enduring" (1990, p. x) as his admirers would like it to be. Fesmire (2015) observes that in the mid-1940s, Dewey's educational proposals met with accusations of promoting " 'a most reactionary philosophy' that had led . . to way-ward and undisciplined youth" (2015, p. 177). Other critics accuse Deweyan pedagogy of being anti-intellectual, or conceptually inconsistent and hence difficult to interpret (e.g. Edwards 2007). For some scholars, it can function as a conceptual framework to situate certain kind of pedagogical reflection, but it fails in providing ready-made or at least empirically proven educational instructions (see references in Biesta 1995). Other commentators find this latter open-ended framework a virtue (Biesta 1995, p. 105, emphasis as in the original):

My claim is that pragmatic pedagogy should primarily be understood as a framework which enables us to envisage education from a specific perspective. Within this framework we can pose specific questions and find suggestions for specific answers. Pragmatic pedagogy is a critical and constructive tool and not a recipe for educational praxis.

Irrespective of the extent to which Dewey's thought indeed affects contemporary pedagogies, there are ideas present in modern approaches to the translation and multilanguage classrooms that can be easily traced to Dewey. Space limits allow me to only briefly signal the ones I find aligned with the objectives of this chapter.

\section{Learning as embodied and emergent}

As observed by Jung (2010, p. 156), Dewey's notion of embodied cognition corresponds directly to contemporary concepts of autopoiesis and emergent learning, as originally prosed in research by Maturana and Varela (1980), and represented in translator pedagogic thought by Kiraly $(2013,2016)$ and a growing number of researchers in the field (e.g. Kiraly and Hofmann 2016; Massey and Brändli 2016; Massey in this volume). Discussing these proposals in detail falls outside the scope of this chapter. Yet, it is perhaps worth signalling that Kiraly's notion of co-emergent learning relies on a concept of cyclicity that is closely parallel to its version presented by Dewey.

\section{Learning as ecological}

Close interrelations between the learner and the environment in which she lives and functions are part of Deweyan programme of avoiding dualism between the learner's mind and what is 
to be learned. The environment in which the learner learns is an inseparable part of the learning process. Deweyan notion of democracy as a learning environment can be regarded as pertinent to the contemporary concept of ecological education (cf. Laviosa 2014). As noted previously, under Dewey's view, democracy provides space for learning through deliberate participation. Sharing this space and using it for collaborative negotiating of senses (cf. Klimkowski 2015) constitutes an ideal in Dewey's educational thought.

\section{Learning as self-corrective}

As already mentioned, Dewey's view of learning (inquiry) is cyclic. When a learner experiences a problematic situation, she initiates inquiry to solve the problem. Yet, the results of a single inquiry loop are very unlikely to be exhaustive and definite. Hence, the learner may soon be in a need to pursue another inquiry loop. Thus, inquiry starts with a realization, experience, perception or feeling that is problematic, and it often has a self-corrective function (cf. Putnam 2010). A similar view can be found in a contemporary conception of self-regulated learning. Belonging originally to the field of performance psychology, self-regulation is adopted to interpreter training by e.g. Arumí Ribas and Esteve (2006), Moser-Mercer (2008), Monacelli (2009) or Fan (2012) and to translator education by e.g. Fernández Sánchez (2008), Washbourne (2014) or recently by Pitkäsalo and Ketola (2018). In a nutshell, self-regulation is a mechanism that empowers a learner to interpret performance difficulties in terms of tasks that can be employed to overcome these difficulties. Analogically to Dewey's view, self-regulation is cyclic and continuous.

The self-corrective view of inquiry can also help contemporary learners and teachers embrace the educational potential of mistakes and errors. Comprehending learning as necessarily self-corrective can help develop a framework for information exchange, necessary to build the optimal level of understanding "what happened" and what to do next about it. It can also help overcome a tendency to interpret learners' mistakes and weak performance predominantly in penal terms, which reduces the information exchange between the learner and her environment to purely behavioural level (negative amplification). In other words, to be selfcorrective, classroom assessment needs to shift from the narrative frame of "action - reward/ punishment" to the "decision-action-consequences" one. This step is possible if assessment is construed as a communicative practice intrinsic to the classroom interaction; instead of being expected to follow a learning cycle (cf. Klimkowski in press).

\section{Vygotsky's influence on modern education theories}

Vygotsky's insight into the developmental and educational processes gave rise to a wide variety of concepts that are recognized in contemporary educational discourse - in particular in its constructivist variety. Three of them are discussed in the following as the most relevant for this chapter.

\section{Knowledge as constructed, not transmitted}

Vygotsky is regularly pointed out as a pioneer of social constructivism as an epistemological and educational stance (cf. e.g. Tobias and Duffy 2009, p. 3). The reason for that lies both in his socially dependent view of learning and the notion of internalization in its transfigurative/transformative reading. Social constructivism was adopted as an epistemology and a didactic approach that contrasted with the so-called transmissionist model of education. 
While the former accents the active participation of learners in constructing their knowledge through social negotiation of senses, the latter is based on the central role of "method" and the teacher expected to transmit objective, ready-to-absorb knowledge packages to the students. The transmissionist approach to translator education was criticized already in the mid-1990s (cf. e.g. Pagano 1994; Klaudy 1996; Nord 1996), and the first researcher to introduce a social constructivist outlook into the translation classroom was Kiraly (2000), followed by contributions like González Davies (2004) or Varney (2009). In my personal view, constructivism currently seems a major - if not predominant - epistemological outlook in the field of translator didactics, even though it takes different forms and undergoes modifications (e.g. Kiraly 2000, 2013, 2016; Laviosa 2014). It also goes without saying that a social constructivist outlook is preferable for multilingual education projects.

\section{Zone of proximal development}

This potent idea of Vygotsky has a lot to offer to modern classroom theory and practice. Apart from its basic meanings and functions - as discussed previously - ZPD can be regarded as a guideline for teachers. Facing the always-present question "are my students ready for the next step?", teachers aware of ZPD can plan to build an effective scaffolding. Yet, for a scaffolding to be effective, it must be co-constructed by students and teachers. In this sense ZPD can also denote shared space where the roles of the classroom protagonists are negotiated in accordance with the objectives of the educational contract. Thus, moving from the original version of Vygotsky's instrument of measuring development, we can reach an interpretation of ZPD as a space for cyclic, participatory negotiation of norms, concepts, and actions. ZPD seems particularly well-suited to the context of translator and multilingual education, allowing reconfigurations of content and methodology to match the concrete needs of the concrete learners - in contrast to the objectivist, method-driven, post-positivist models of mass education.

\section{Collaborative classrooms}

Perhaps the most direct inspiration drawn from Vygotsky (even though promoted by other education theorists as well) is an extensive trust in collaborative classroom methodologies, followed by situated (simulated or real-life) projects or case studies, challenges, and tasks. In translator education, projects have become an element of a pedagogical credo, predominantly thanks to their potential in bringing practical translator training closer to the reality of the service market (cf. Kiraly 2016). Project-based classrooms are also praised for their merits in developing students' transference skills that can be used in a vast number of professional contexts, including but not limited to a language specialist career (cf. González-Davies and Kiraly 2006; Klimkowski 2015; Pitkäsalo and Ketola 2018).

\section{Pedagogic approaches and methods}

The main objective of this section is to present the ideas developed by Dewey and Vygotsky as implementable in a contemporary classroom. Following are two examples of collaborative activities that use translation in its pedagogic variant, with its main function as a mode of multilingual communication. 


\section{Subtitling short media materials}

Subtitling is a potent tool in multilingual education that can be used both individually and collaboratively. With a handful of open-source subtitling applications available, subtitling can be part of classroom and out-of-classroom activities. The activity as briefly presented here consists in students' producing subtitles to a media material selected by the teacher or the students. Effective performance necessarily involves dealing with technical, inter-semiotic, intercultural, textual, contrastive, and language learning challenges. In my own educational practice, I tend to select materials which have a social, ecological role to play, e.g. a short publicity media material for a students' association at our university, or a short movie for a social campaign addressing a problem of a growing group of teenagers in Eastern Poland who fail to find pathways to either education or employment. This activity can be planned as in-class (subtitling is a regular classroom activity), out-of-class (subtitling is done out-of-class and presented in-class) or blended (e.g. the translation brief is discussed in-class, but the actual subtitling is an out-of-class assignment), which depends on the length of the media material, the purpose of the activity, number of the students and languages involved. Table 2.1 sums up the advantages of the project and shows in what way they can be seen an embodiment of the Deweyan or Vygotskyan educational influences.

\section{Code-switching activity}

This activity utilizes interpreting (code-switching) as a language learning method in a multilingual context. The multilingual students in a classroom are divided into two teams. The teams need to work in acoustic separation, ideally in two rooms. From among the team members, two communicators are appointed - one per team. The communicators are responsible for the mutual exchange of information (conversation) in the learned language. After each

Table 2.1 A subtitling activity: Dewey's and Vygotsky's ideas applied to modern multilingual classrooms

\begin{tabular}{|c|c|c|c|}
\hline & Advantages & Relationship to Dewey & Relationship to Vygotsky \\
\hline 1 & $\begin{array}{l}\text { Students produce materials that } \\
\text { are not only publishable, but } \\
\text { factually published }\end{array}$ & $\begin{array}{l}\text { pragmatism; learning- } \\
\text { by-doing }\end{array}$ & $\begin{array}{l}\text { education to improve } \\
\text { social functioning }\end{array}$ \\
\hline 2 & $\begin{array}{l}\text { Students engage in socially } \\
\text { or culturally significant } \\
\text { communicative action }\end{array}$ & participatory democracy & $\begin{array}{l}\text { focus the choice of } \\
\text { content for learning and } \\
\text { development (ZPD) }\end{array}$ \\
\hline 3 & $\begin{array}{l}\text { Engaging in significant } \\
\text { communication, students learn } \\
\text { languages as embedded in } \\
\text { their functional contexts }\end{array}$ & $\begin{array}{l}\text { learning as } \\
\text { communicative } \\
\text { practice }\end{array}$ & $\begin{array}{l}\text { language is a key } \\
\text { educational and social } \\
\text { tool }\end{array}$ \\
\hline 4 & $\begin{array}{l}\text { Students can self-regulate their } \\
\text { learning by selecting materials } \\
\text { for subtitling, negotiating with } \\
\text { the group how the task is to } \\
\text { be performed or opting for the } \\
\text { particular solutions }\end{array}$ & participatory democracy & $\begin{array}{l}\text { collaborative problem } \\
\text { solving }\end{array}$ \\
\hline
\end{tabular}


phase of information exchange, the communicators contact their respective teams and interpret the message into the language(s) of the team. The teams have their exchanges as based on the scenario prepared by the teacher - yet, the scenarios are more like an initial trigger for an exchange that can proceed in a direction that emerges in the course of action.

To prepare a scenario for this activity, the teacher can do as follows:

Table 2.2 A code-switching activity scenario

\begin{tabular}{|c|c|c|}
\hline & Actions & Example \\
\hline 1 & selecting the main narrative & $\begin{array}{l}\text { Professor } \mathrm{X} \text { is to visit university } \mathrm{Y} \text {. The conversation } \\
\text { concerns determining the details of the visit. }\end{array}$ \\
\hline 2 & $\begin{array}{l}\text { selecting negotiating criteria for } \\
\text { Teams A and B }\end{array}$ & $\begin{array}{l}\text { Team A is responsible for negotiating manageable } \\
\text { conditions for X's visit to } Y \text { (e.g. dates, hotels, flights, } \\
\text { lectures). Team B is to secure feasible terms on the part } \\
\text { of university Y. }\end{array}$ \\
\hline 3 & choosing the communicators & $\begin{array}{l}\text { This exemplary scenario can develop as information } \\
\text { exchange, but it is likely to involve negotiating as well. } \\
\text { This fact needs to be signalled to the teams as it can } \\
\text { influence the choice of communicators - for language } \\
\text { and (multi)cultural reasons. }\end{array}$ \\
\hline 4 & $\begin{array}{l}\text { informing the teams about the } \\
\text { negotiating criteria and asking } \\
\text { them to develop a communication } \\
\text { strategy. Some of the criteria are to } \\
\text { be signalled to both teams, others } \\
\text { are disclosed and further outlined } \\
\text { by each team separately }\end{array}$ & $\begin{array}{l}\text { Team A decides the boundary criteria for the visit (e.g. } \\
\text { 10th-13th October is the only option because. .., } \\
\text { one lecture a day maximum, a talk with the university } \\
\text { official. . .). The list must include non-negotiable and } \\
\text { negotiable items. } \\
\text { Team B develops a similar list (separately). }\end{array}$ \\
\hline 5. & $\begin{array}{l}\text { post-activity feedback session (this } \\
\text { activity hardly makes sense without } \\
\text { this part!) }\end{array}$ & $\begin{array}{l}\text { The teacher asks questions to reflect upon what } \\
\text { happened, e.g. } \\
1 \text { What factors helped in negotiating? } \\
2 \text { What was the problem? } \\
3 \text { How reliable was the work of communicators and why? }\end{array}$ \\
\hline
\end{tabular}

As in the case of the previous activity, Table 2.3 sums up the advantages of the activity and pinpoints links to Dewey and Vygotsky.

\section{Conclusions and future directions}

Theories of learning and education like the ones developed over a century ago by Dewey and Vygotsky are important contributions to how we think about and arrange learning environments today, including the translation and the multilingual classrooms. A point I intend to make in this chapter is that these theories give me a choice. As observed in the main text, Dewey and Vygotsky do not offer ready-made educational recipes. Their theories make sense as frameworks of thought that can help form my own teaching practices. Knowing the options (rather than answers), I can choose how to define my relations to this or that group of students, and how I can arrange (scaffold) the space we share. A lot of my teacher colleagues are likely to react that they prefer relying on their own intuition and experience, and that theories give them nothing they 
Table 2.3 Code-switching activity: Dewey' and Vygotsky's ideas applied to contemporary multilingual classrooms

\begin{tabular}{|c|c|c|c|}
\hline & Advantage & Relationship to Dewey & Relationship to Vygotsky \\
\hline 1 & $\begin{array}{l}\text { Students actively negotiate messages } \\
\text { that are meaningful to their } \\
\text { pedagogical, social, cultural, and } \\
\text { professional contexts. The messages } \\
\text { are used in coordinating human } \\
\text { actions. }\end{array}$ & $\begin{array}{l}\text { pragmatism; } \\
\text { learning-by-doing }\end{array}$ & $\begin{array}{l}\text { social coordination } \\
\text { of activity through } \\
\text { communication }\end{array}$ \\
\hline 2 & $\begin{array}{l}\text { Engaging in significant communication, } \\
\text { students learn languages as } \\
\text { embedded in their functional contexts }\end{array}$ & $\begin{array}{l}\text { learning as } \\
\text { communicative } \\
\text { practice }\end{array}$ & $\begin{array}{l}\text { language is a key } \\
\text { educational tool }\end{array}$ \\
\hline 3 & $\begin{array}{l}\text { Students can self-regulate their learning } \\
\text { by choosing negotiating strategies } \\
\text { and goals and reflecting upon their } \\
\text { effectiveness or flaws }\end{array}$ & learning as self-corrective & $\begin{array}{l}\text { collaborative problem } \\
\text { solving (ZPD) }\end{array}$ \\
\hline
\end{tabular}

can use in the classroom. Opinions like these exhibit a need for teacher education initiatives (e.g. developing teacher's identity and attitudes, communication skills for negotiating rather than instructing) to complement teacher training courses (preparing for profession) - at least in the learning environment I am part of. Intuition and experience are indisputable assets of a teacher, but they work best when reflected upon. A decision to ignore theories is a decision to ignore tools of reflecting on my overt and covert actions in the classroom. Equally detrimental is a stance where - consciously or not - I dogmatically pursue only one theoretical approach, expecting the classroom reality to match mine. The interpretative controversies concerning Dewey and particularly Vygotsky presented in the chapter are meant to discourage the reader from a dogmatic pathway of theory use. The predominantly theoretical discussion in this chapter is completed with a practical coda. The activities presented at the end of the chapter are to show that teaching experience and learning theories can be an effective match.

Despite the fact that Deweyan and Vygotskian thought is over a century old it inspires educational debate and is likely to remain a point of reference for education theorists and practitioners for many years ahead. Whether approached with enthusiasm or with criticism, the legacy of both thinkers cannot and should not be ignored. They asked questions that are highly unlikely to find definitive or exhaustive answers in either theory or practice of learning. Hence the development of educational studies consists in finding new ways of redefining the basic dilemmas of education pinpointed by Dewey and Vygotsky - among others. More importantly, conceptions developed by Dewey and Vygotsky can be practically helpful to contemporary learners and teachers in their everyday educational interaction. Trying to face the challenges both authors posed can lead to more effective and satisfying learning processes and environments.

\section{Further reading}

González-Davies, M. and Enríquez Raído, V. (eds) (2017) Situated Learning in Translator and Interpreter Training: Bridging Research and Good Practice. London and New York: Routledge.

This publication discusses a context-dependent approach to translator and interpreter training under which learners are exposed to real-life and/or highly simulated work environments and tasks, both 
inside and outside the classroom. This approach is often referred to as situated learning and the main reason for its classroom application is to empower learners to think and act like translation professionals when learning to be professionals. This is a collective volume of contributions on how translator and interpreter skill development is influenced by different learning environments, levels of study, fields of specialization, the role of information, and communication and translation/interpreting technologies, as well as optimal pedagogical procedures. The volume will be particularly useful for both novice and seasoned reflexive teachers of translation and interpreting (T\&I) that seek to promote translators' and/or interpreters' professional competence.

Jordan, A., Carlile, O. and Stack, A. (2008) Approaches to Learning. A Guide for Teachers. Maidenhead and New York: Open University Press, McGraw-Hill.

A collective guidebook offering a survey of the most prominent learning and teaching theories, their backgrounds and corollaries. A must for novice teachers who would like to understand the complex and often contradictory theoretical conceptions of contemporary classrooms. The book offers the teacher as facilitator an insight into theories of education, access to others' experience, mind-tools for recognizing and evaluating issues in one's own teaching practice, terminology helping to explore and manipulate ideas in a reflexive manner and explain one's positions and practices to peers.

Laviosa, S. (2014) Translation and Language Education: Pedagogic Approaches Explored. London and New York: Routledge.

The book is a proposal for a translation-based pedagogy grounded in theory and applied in real educational contexts. The main perspective taken by the author is the convergence between language and translation embraced by ecologically oriented educationalists and the holistic approach to translating culture. The result is a proposal for a holistic pedagogy that harmonizes the teaching of language and translation in the same learning environment. The book also includes a historical outline of how the role of pedagogic translation was changing from the time of the grammar-translation method until contemporary ecological approaches to foreign language education. The theoretical investigations are complemented by three case studies illustrating how the author's proposal can be put to educational practice.

Mingers, J. (1991) The cognitive theories of Maturana and Varela. Systems Practice. 4(4), pp. 319-338. This paper is a valuable read for those interested in the basic notions in Maturana's and Varela's research into the nature of living systems and their cognitive and self-reproducing (autopoietic) capacities. It offers a straightforward exposition and comments on a complex set of ideas developed by Maturana and Varela. It also discusses the main implications of their major claims for education theory and practice.

Tennant, M. (2006) Psychology and Adult Learning. 3rd ed. London and New York: Routledge. A basic guidebook to theories of psychology that underlie major past and contemporary approaches to learning. A highly recommendable essential reading for any reflexive teacher. The topics dealt with include theories of the self, self-directed and transformative learning, the formation of identities, development of intelligence, and group dynamics.

\section{Related topics}

community-based learning programmes, education for intercultural citizenship, content-based second language instruction, language practices for emergent bilingual youth

\section{References}

Arumí Ribas, M. and Esteve, O. (2006) Using instruments aimed at self-regulation in the consecutive interpreting classroom: Two case studies. Electronic Journal of Foreign Language Teaching. 3(2), pp. 158-189. 
Bakhurst, D. (2007) Vygotsky's demons, in Daniels, H., Cole, M. and Wertsch, J.V. (eds) The Cambridge Companion to Vygotsky. Cambridge: Cambridge University Press. pp. 50-76.

Biesta, G. (1995) Pragmatism as a pedagogy of communicative action, in Garrison, J. (ed) The New Scholarship on Dewey. Dordrecht: Springer Science+Business Media. pp. 105-122.

Bruner, J.S. (1984) Vygotsky's zone of proximal development: The hidden agenda, in Rogoff, B. and Wertsch, J.V. (eds) Children's Learning in the 'Zone of Proximal Development'. San Francisco, CA: Jossey Bass. pp. 93-97.

Damasio, A. (1994) Descartes 'Error: Emotion, Reason, and the Human Brain. New York: G. P. Putnam's Sons.

Daniels, H., Cole, M. and Wertsch, J.W. (eds) (2007) The Cambridge Companion to Vygotsky. Cambridge: Cambridge University Press.

DeVries, R. (2000) Vygotsky, Piaget, and education: A reciprocal assimilation of theories and educational practices. New Ideas in Psychology. 18(2-3), pp. 187-213.

Dewey, J. (1896) The reflex arc concept in psychology. Psychological Review. 3, pp. 257-370.

Dewey, J. ([1920] 1982) Reconstruction in philosophy, in Boydston, J.A. (ed) The Collected Works of John Dewey, 1882-1953. The Middle Works. Vol. 12. Carbondale: Southern Illinois University Press.

Dewey, J. ([1925] 1981) Experience and nature, in Boydston, J.A. (ed) The Collected Works of John Dewey, 1882-1953. The Later Works. Vol. 1. Carbondale: Southern Illinois University Press.

Dewey, J. ([1938] 1986) Logic. The theory of inquiry, in Boydston, J.A. (ed) The Collected Works of John Dewey, 1882-1953. The Later Works. Vol. 12. Carbondale: Southern Illinois University Press.

Edwards, A. (2007) An interesting resemblance: Vygotsky, mead, and American pragmatism, in Daniels, H., Cole, M. and Wertsch, J.W. (eds) The Cambridge Companion to Vygotsky. Cambridge: Cambridge University Press. pp. 77-100.

Fan, D. (2012) The Development of Expertise in Interpreting Through Self-Regulated Learning for Trainee Interpreters [online]. $\mathrm{PhD}$ thesis, University of Newcastle upon Tyne, Newcastle upon Tyne. Available from: https://theses.ncl.ac.uk/jspui/bitstream/10443/1741/1/Fan\%2012\%20\%2812mnth\%29.pdf [Accessed 20 September 2018].

Fernández Sánchez, F. (2008) An example of a collaborative translation project incorporating mediation instruments as a means of encouraging self-regulation, in Garant, M. and Walker, L. (eds) Current Trends in Translation Teaching and Learning. Vol. II. Helsinki: University of Helsinki. pp. 121-151.

Fesmire, S. (2015) Dewey. London and New York: Routledge.

González-Davies, M. (2004) Multiple Voices in the Translation Classroom: Activities, Tasks and Projects. Amsterdam and Philadelphia: John Benjamins.

González-Davies, M. and Enríquez Raído, V. (eds) (2017) Situated Learning in Translator and Interpreter Training: Bridging Research and Good Practice. London and New York: Routledge.

González-Davies, M. and Kiraly, D.C. (2006) Translation pedagogy, in Brown, K. (ed) Encyclopedia of Language and Linguistics. Oxford: Elsevier. pp. 81-85.

Grow, G.O. (1991) Teaching learners to be self-directed. Adult Education Quarterly. 41(3), pp. 125-149.

Hase, S. and Kenyon, C. (2000) From Andragogy to Heutagogy. Ulti-BASE In-Site [online]. Available from: http://pandora.nla.gov.au/nph-wb/20010220130000/http://ultibase.rmit.edu.au/New/newdec00 .html [Accessed 20 September 2018].

Jackson, P.W. (1990) Introduction, in Dewey, J. (ed) The School and Society. The Child and the Curriculum. An Expanded Edition with a New Introduction by Philip W. Jackson. Chicago and London: The University of Chicago Press. pp. ix-xli.

Johnson, M. (2010) Cognitive science and Dewey's theory of mind, thought, and language, in Cochran, M. (ed) The Cambridge Companion to Dewey. Cambridge and New York: Cambridge University Press. pp. 123-144.

Jordan, A., Carlile, O. and Stack, A. (2008) Approaches to Learning. A Guide for Teachers. Maidenhead and New York: Open University Press, McGraw-Hill.

Jung, M. (2010) John Dewey and action, in Cochran, M. (ed) The Cambridge Companion to Dewey. Cambridge and New York: Cambridge University Press. pp. 145-165. 
Kiraly, D.C. (2000) A Social Constructivist Approach to Translator Education. Empowerment from Theory to Practice. Manchester: St. Jerome Publishing.

Kiraly, D.C. (2013) Towards a view of translator competence as an emergent phenomenon: Thinking outside the box(es) in translator education, in Kiraly, D.C., Hansen-Schirra, S. and Maksymski, K. (eds) New Prospects and Perspectives for Educating Language Mediators. Tübingen: Gunter Narr. pp. 197-223.

Kiraly, D.C. (2016) Authentic project work and pedagogical epistemologies: A question of competing or complementary worldviews? in Kiraly, D.C. (ed) Towards Authentic Experiential Learning in Translator Education. Mainz: Mainz University Press. pp. 53-66.

Kiraly, D.C. and Hofmann, S. (2016) Towards a postpositivist curriculum development model for translator education, in Kiraly, D.C. (ed) Towards Authentic Experiential Learning in Translator Education. Mainz: Mainz University Press. pp. 67-88.

Klaudy, K. (1996) Quality assessment in school translation and in professional translation, in Dollerup, C. and Appel, V. (eds) Teaching Translation and Interpreting 3: New Horizons. Amsterdam and Philadelphia: John Benjamins. pp. 198-204.

Kliebard, H.M. (2006) Dewey's reconstruction of the curriculum: From occupations to disciplined knowledge, in Hansen, D.T. (ed) John Dewey and Our Educational Prospect: A Critical Engagement with Dewey's 'Democracy and Education'. Albany: State University of New York. pp. 113-127.

Klimkowski, K. (2015) Towards a Shared Curriculum in Translator and Interpreter Education. Wrocław: Wydawnictwo Wyższej Szkoły Filologicznej we Wrocławiu.

Klimkowski, K. (in press) Assessment as a communicative activity in the translation classroom. IntraLinea. Special Issue.

Lagemann, E.C. (1989) The plural worlds of educational research. History of Education Quarterly. 29(2), pp. 184-214.

Laviosa, S. (2014) Translation and Language Education: Pedagogic Approaches Explored. London and New York: Routledge.

Massey, G. and Brändli, B. (2016) Collaborative feedback flows and how we can learn from them: Investigating a synergetic learning experience in translator education, in Kiraly, D.C. (ed) Towards Authentic Experiential Learning in Translator Education. Mainz: Mainz University Press. pp. 177-200.

Maturana, H.R. and Varela, F.G. (1980) Autopoiesis and Cognition: The Realization of the Living. Dordrecht: Reidel.

Mingers, J. (1991) The cognitive theories of Maturana and Varela. Systems Practice. 4(4), pp. 319-338.

Monacelli, C. (2009) Self-Preservation in Simultaneous Interpreting. Surviving the Role. Amsterdam: John Benjamins.

Moser-Mercer, B. (2008) Skill acquisition in interpreting: A human performance perspective. The Interpreter and Translator Trainer. 2(1), pp. 1-28.

Nord, C. (1996) Wer nimmt denn mal den ersten Satz? Uberlegungen zu neuen Arbeitsformen im Ubersetzungsunterricht, in Lauer, A., Gerzymish-Arbogast, H., Haller, J. and Steiner, E. (eds) Translationwissenschaft im Umbruch. Festschrift für Wolfram Wilss. Tubingen: Gunter Narr Verlag. pp. 313-327.

Pagano, A. (1994) Decentering translation in the classroom. Perspectives: Studies in Translatology. 2, pp. 213-219.

Page, R.N. (2006) Curriculum matters, in Hansen, D.T. (ed) John Dewey and Our Educational Prospect: A Critical Engagement with Dewey's 'Democracy and Education'. Albany: State University of New York. pp. 39-65.

Pitkäsalo, E. and Ketola, A. (2018) Collaborative translation in a virtual classroom: Proposal for a course design. Transletters. 1, pp. 93-119.

Putnam, R.A. (2010) Dewey's epistemology, in Cochran, M. (ed) The Cambridge Companion to Dewey. Cambridge and New York: Cambridge University Press. pp. 34-54.

Rogers, C.R. (1951) Client-Centered Therapy. Its Current Practice, Implications and Theory. London: Constable.

Tennant, M. (2006) Psychology and Adult Learning. 3rd ed. London and New York: Routledge. 
Tobias, S. and Duffy, T.M. (2009) Constructivist Instruction: Success or Failure? New York and London: Routledge.

van der Veer, R. (2007a) Lev Vygotsky. London and New York: Bloomsbury Academic.

van der Veer, R. (2007b) Vygotsky in context: 1900-1935, in Daniels, H., Cole, M. and Wertsch, J.V. (eds) The Cambridge Companion to Vygotsky. Cambridge: Cambridge University Press. pp. 21-49.

Varney, J. (2009) From hermeneutics to the translation classroom: A social constructivist approach to effective learning. Translation and Interpreting. 1(1), pp. 27-43.

Vygotsky, L.S. ([1930] 1981) The genesis of higher mental functions, in Wertsch, J.V. (ed) The Concept of Activity in Soviet Psychology. New York: Sharpe. pp. 147-188.

Vygotsky, L.S. (1931) History of the development of the higher mental functions, in The Collected Works of L. S. Vygotsky. Vol. 4. New York: Plenum Press. pp. 1-251.

Washbourne, K. (2014) Beyond error marking: Written corrective feedback for a dialogic pedagogy in translator training. The Interpreter and Translator Trainer. 8(2), pp. 240-256.

Westbrook, R. (2010) The making of a democratic philosopher: The intellectual development of John Dewey, in Cochran, M. (ed) The Cambridge Companion to Dewey. Cambridge and New York: Cambridge University Press. pp. 13-33. 


\title{
Education for intercultural citizenship
}

\author{
Michael Byram, Melina Porto and Leticia Yulita
}

\section{Introduction}

The concept of intercultural citizenship draws on foreign language education and citizenship education, combining an international perspective from the former with an action orientation from the latter. The purpose is to improve both disciplines so that learners acquire competences to act in their own communities, competences which are enriched by acquiring new concepts and ways of seeing associated with another language and context, and a new identification with an international perspective on local issues and how they can be addressed.

This means that learners have to translate and understand concepts they meet in another language and context in order to reflect on their significance for their own context and how they might take action on local issues. In some cases it also means that learners interact with partners in another country and have to act as interpreters and mediators of concepts in their own language and context to help their partners understand the relevance for their context.

The theory of intercultural citizenship has been implemented in practice in a number of projects which usually take place in foreign language classrooms. The practice has been realized by bringing together learners from different countries and continents through the internet. Learners and teachers choose a topic of common interest, a topic which will lead to activities in their respective communities, and in some cases to changes and improvements in the lives of people in those communities. References to these projects and practices are included in the remainder of this chapter, after an overview of the history and theory of intercultural citizenship.

\section{Historical perspectives}

The evolution of the theory of intercultural citizenship took place in several stages over more than a decade but it can be summarized as a move from the concept of 'intercultural speaker' to an 'intercultural citizen'. The phrase intercultural speaker was coined by Byram and Zarate (1996) in a working paper for the Council of Europe. Byram and Zarate defined four competences: savoir être, the abandoning of ethnocentric attitudes and perceptions; savoir apprendre, the capacity to interpret cultural phenomena which reveals unknown meanings; savoirs, 
knowledge of the cultural references which structure knowledge of another culture; and savoir faire, the ability to combine the three previous competences or savoirs in specific situations of interaction using the target language. In 1997, Byram published a monograph, Teaching and Assessing Intercultural Communicative Competence that built on but also substantially modified this work.

In the first paper, Byram and Zarate (1996) coined the phrases intercultural competence and intercultural speaker. In the monograph (Byram 1997), the latter was further refined to become 'intercultural communicative competence'. 'Intercultural competence' is needed whenever there is interaction of people of different social groups with different cultures using the same language. However, whenever such interaction involves at least one partner using a foreign language, then the term 'intercultural communicative competence' is used.

The phrase intercultural speaker was a deliberate attempt to emphasize that the competence needed in such interactions is not the same as the cultural competence of a member of a social group, whether small or large, i.e. the competence they have acquired through socialization into the group. Intercultural competence is composed of different skills, knowledge, and attitudes, namely the ones which are necessary for overcoming incomprehension and inappropriate attitudes in communication and action among people of different social groups.

In foreign language teaching, the social groups and social identities which are usually the focus of attention are national, i.e. the group or groups which are perceived as the 'native speakers' of the language being taught and learned. Although this is under revision in some kinds of language teaching, and the very term 'native speaker' is challenged (see Houghton et al. 2018), learners are usually expected to model themselves on the linguistic competence of native speakers. It has also often been at least tacitly expected that learners will model their cultural competence on that of native speakers, learning to act culturally as much as possible like native speakers. The introduction of the phrases 'intercultural speaker' and 'intercultural communicative competence' implied that, whatever might be decided about linguistic competence, the imitation of native speakers' cultural competence should not be the purpose of language teaching. Learners need an intercultural competence which enables them to interact with people of other languages and language groups, not a competence which implies that they identify with native speakers in such groups.

In 2006, the book Education for Intercultural Citizenship: Concepts and Comparisons was published by a group of scholars at the University of Durham (Alred et al. 2006) who had brought together experts from foreign language education and citizenship education. This book defined the axioms of education for intercultural citizenship and included chapters about education systems in different countries and how and to what extent there were already curriculum theory and practice which could be described as education for intercultural citizenship.

Two years later, Byram (2008) published a monograph in which he examined in detail the similarities and differences between the objectives of citizenship education as presented by Himmelmann (2001) and the objectives of teaching intercultural communicative competence in foreign language education. This became the basis for later pedagogical projects, one of which is described in the following section.

\section{Research approaches and key findings}

Research on intercultural citizenship is both conceptual and empirical. The historical evolution of conceptual work has been presented in the previous section. Here we explain in more detail the concepts and theory in a systematic overview before describing the outcomes of empirical curriculum research and development. 


\section{Mediation and intercultural (communicative) competence}

Although in foreign language education, the focus is usually on communication with and interactions among people of different languages - in the same country or in two or more countries - people of the same language may find themselves in a situation where the social identities which are salient lead them to potential misunderstandings. For example, two people may identify each other as having the same profession and be able to communicate and act together as professionals, where their professional identity is salient. Yet when they move to a different situation where the salient identities differ - e.g. each sees the other as from a different ethnic group or social class - then they draw upon different beliefs, knowledge, and behaviours and fall into partial or even complete misunderstanding. In this second situation, they need intercultural competence (IC) which enables them to take the perspective of the other, seek ways of enquiring about and understanding the other's preconceptions, and find a common ground on which they can create successful communication.

When, in either situation, at least one of the people involved is using a foreign language the language of their partner or a lingua franca foreign to both of them - then they need intercultural communicative competence (ICC) i.e. a combination of linguistic and intercultural competences. This is described at length in Byram (1997) and summarized in Byram (2008). This model of ICC has been influential (Spitzberg and Changnon 2009) and also criticized (e.g. Belz 2007; Risager 2007; Kramsch 2009).

In some circumstances, two people may need the help of a third, or a 'mediator', someone who has the IC or ICC which the other two lack. In the original work on IC, Zarate et al. (2004) put more emphasis on this function of IC than did Byram (1997). In the meantime, work at the Council of Europe has promoted the concept of 'mediation' in two documents, the second of which is particularly relevant here. The first document (Coste and Cavalli 2015) uses the concept of mediation to analyze the processes of education in general. The second document is a Companion Volume (Council of Europe 2018a) to the Common European Framework of Reference for Languages (CEFR) (Council of Europe 2001) and contains a revised and more complex concept of mediation than was found in the CEFR itself. In the Companion Volume (Council of Europe 2018a, p. 103), it is stated that:

In mediation, the user/learner acts as a social agent who creates bridges and helps to construct or convey meaning, sometimes within the same language, sometimes from one language to another (cross-linguistic mediation). The focus is on the role of language in processes like creating the space and conditions for communicating and/or learning, collaborating to construct new meaning, encouraging others to construct or understand new meaning, and passing on new information in an appropriate form. The context can be social, pedagogic, cultural, linguistic or professional.

Where 'cross-linguistic mediation' takes place, the linguistic competences of the mediator are more obvious and the distinction between 'intercultural competence' (IC) and 'intercultural communicative competence' (ICC) becomes evident. For language teachers this is an extension of the existing concept of 'communicative competence', where there is emphasis on the ability to use a language not only with correct grammar but also in socially appropriate ways (Savignon 2013).

\section{Comparing foreign language education and citizenship education}

In the model of ICC presented in Byram (1997), the crucial development from the work of Byram and Zarate (1996) and the CEFR (2001) was the inclusion of the fifth savoir, the 
concept of 'critical cultural awareness' or 'savoir s'engager'. This was influenced by theory of 'politische Bildung' which is usually translated as 'political education', but this is a translation which misses some of the connotations of Bildung as a process of drawing out the human potential of learners (Løvlie and Standish 2002). At approximately the same time, theoretical work in Germany on 'politische Bildung' was beginning to use the term 'Demokratielernen' (Himmelmann 2006) where the emphasis on learning to be and act in a democracy was more evident in the label.

A comparison of the competences described in models of ICC with models of the competences needed to be and act as a democratic citizen, reveals much overlap but also some differences. Byram (2008) presents a 'Framework of Education for Intercultural Citizenship' which integrates appropriate parts of Himmelmann's (2001) approach to setting objectives for citizenship education/learning for democracy with the approach in Byram (1997) to setting objectives for language teaching for ICC. Byram (2008) suggests that there are limitations to both approaches which can be remedied by a combination of ideas from both. The objectives of citizenship education and learning to act democratically include the notion that learners should become active in their world, not only in the future - a learning for later life - but also at the time that they are learners in a classroom. On the other hand, the world where learners should act is assumed to be their community, whether their local community or their national community. There is no reference to communities beyond the national.

In foreign language teaching, in contrast, the attention of learners is directed to the world beyond their national community, especially to countries where the language they are learning is spoken. Yet in the concept of critical cultural awareness in Byram's (1997) model of ICC, there is no suggestion that criticality should lead to action in the learners' world or community/ies. Combining the two approaches to setting objectives for teaching, which develop the competences of an 'intercultural citizen' is, therefore, the purpose of the analysis and the heart of the framework which is presented in Byram (2008). It was argued there that 'transnational communities' should be created in foreign language teaching and that these become the basis of political action/action in the world.

These principles of intercultural citizenship education were further developed in the collection of articles, already referred to, which deal with policy and practice in several countries. Axioms and characteristics of education for intercultural citizenship were stated in Alred et al. (2006, pp. 233-234). They are reproduced in Table 3.1.

Criteria of 'criticality' were added to this list for projects which would implement a theory of intercultural citizenship. 'Criticality' criteria were taken from Barnett (1997) who identifies three domains of educational experience:

- $\quad$ propositions, ideas and theories - i.e. what learners learn about the world (in formal education what they learn in their 'subjects').

- the internal world, that is oneself, a form of critical thought that is demonstrated in critical self-reflection - i.e. what learners think about themselves as individuals.

- the external world, a form of critical thought that is demonstrated in critical action - i.e. what learners $d o$ as a result of their thinking and learning.

He also identifies four levels or degrees of criticality which are increasingly complex:

- critical skills: at this first level the emphasis is on skills, on learning how to be critical (and 'critical' of course does not mean being negative or attacking something/somebody - it means evaluating positive and negative). 
There are two purposes for this statement of 'axioms and characteristics' of education for intercultural citizenship. They act first as an approach to planning of education for intercultural citizenship in whatever form deemed desirable, and second as criteria for evaluating the degree of intercultural citizenship education already present in existing education systems.

The axioms define what being intercultural entails and the characteristics are what might be expected in education in any form which helps people to think about their experience and to determine how they should respond to it.

\section{Axioms}

- intercultural experience takes place when people from different social groups with different cultures (values, beliefs, and behaviours) meet

- 'being intercultural' involves analysis and reflection about intercultural experience, and acting on that reflection

- intercultural democratic experience takes place when people of different social groups and cultures engage in democratic social and political activity - not avoiding values and judgements

- intercultural citizenship education involves:

- causing/facilitating intercultural citizenship experience, and analysis and reflection on it (and on the possibility of further social and/or political activity, where 'political' is taken in broad sense to mean activity which involves working with others to achieve an agreed end);

- creating learning/change in the individual: cognitive, attitudinal, behavioural change; change in self-perception/spirituality; change in relationships with Others i.e. people of different social groups; change which is based on the particular but is related to the universal.

\section{Characteristics of education for intercultural citizenship}

- a comparative (juxtaposition) orientation in activities of teaching and learning e.g. juxtaposition of political processes (in the classroom, school, country) and a critical perspective which questions assumptions through the process of juxtaposition;

- emphasis on becoming conscious of working with Others (of a different group and culture) through (a) processes of comparison/juxtaposition and (b) communication in a language ( $L 1$ or $L 2 / 3 / \ldots$ ) which influences perceptions and which emphasizes the importance of learners becoming conscious of multiple identities;

- creating a community of action and communication which is supranational and/or composed of people of different beliefs values and behaviours which are potentially in conflict - without expecting conformity and easy, harmonious solutions;

- having a focus and range of action which is different from that which is available when not working with Others, where 'Others' refers to all those of whatever social group who are initially perceived as different, members of an out-group;

- emphasizing becoming aware of one's existing identities and opening options for social identities additional to the national and regional etc. (e.g. the formation of perhaps temporary supranational group identities through interaction with Others);

- paying equal attention to cognition/knowledge, affect/attitude, behaviours/skill;

- all of the preceding with a conscious commitment to values (i.e. rejecting relativism), being aware that values sometimes conflict and are differently interpreted, but being committed, as citizens in a community, to cooperation. 
- reflexivity: at this second level the skills are applied to the knowledge learners have acquired, to their own selves and to the world.

- refashioning of traditions: at this third level, the criticality leads to change, in the sense of modification of what has so far been accepted as 'common sense' in knowledge, in oneself, and in what we do in the world.

- transformatory critique: at this fourth level, the change is more radical and change is not just modification of what is 'common sense' or 'taken for granted' but in fact overturns this and develops something new.

There would be therefore certain characteristics in intercultural citizenship projects, i.e. teaching and learning which include critical thinking as intended outcome; teaching and learning which leads to learners becoming aware of the presuppositions they hold and the national basis of many of these.

These characteristics are in turn related to 'critical cultural awareness' (Byram 1997) and refer to questioning/challenging/wondering about what learners would have done/thought if the project had not involved people from another country.

A further theoretical question was the that of identification. There would be:

opportunities for learners to create and cooperate in groups of several nationalities, forming 'bonded' international groups, i.e. learners identify with 'our (international) group' during the course of the project; such identification may only be temporary but leads learners to suspend their identification with the national culture/way of thinking and acting to find new 'international' ways of acting.

(Byram et al. 2017, p. xxvi)

All of this was summarized in the following terms for teachers and learners (Byram et al. 2017, p. xxviii):

create a sense of international identification with learners in the international project; challenge the 'common sense' of each national group within the international project; develop a new 'international' way of thinking and acting (a new way which may be either a modification of what is usually done OR a radically new way);

apply that new way to 'knowledge', to 'self' and to 'the world'.

and it became fundamental to a series of experimental projects, one of which is described in the following section.

We should note that the principles on which this version of intercultural citizenship education for the foreign language classroom rest have been criticized as too Eurocentric (Li and Dervin 2018) or inoperable in some contexts (Phipps 2014). Osler and Starkey (2015, p. 31) have also pointed out that they think this version is insufficient as it needs to be "explicitly linked to human rights principles and standards".

\section{Pedagogic approaches and methods}

\section{The project}

The intercultural citizenship project described here was created within an international online network (Byram 2016) where participants discussed their plans and agreed that their 
intercultural citizenship projects would attempt to implement the concepts described in the previous section. The project used a content- and task-based approach derived from the tenets of Content and Language Integrated Learning (CLIL) (Cenoz 2015). All 99 participants were studying languages at university and were aged $18-22$, with a language proficiency of B1/B2 (Council of Europe 2001). Seventy-six were Argentinian students in the second year of study of English as a foreign language intending to become either teachers or translators and 23 were students in the first year of a British university course of Spanish as a foreign language.

The topic selected for this project was the 1978 Football World Cup, which took place in Argentina during the last military dictatorship period (1976-1983). During that time, many young people 'disappeared', being killed or kidnapped by the regime, and there were demonstrations by the 'mothers' of the generation of 'disappeared', whose symbol was to wear a white headscarf. The dictatorship tried to shift attention away from the events and onto the attractions and excitement of the World Cup.

The project comprised four stages: introduction, awareness-raising, intercultural dialogue, and citizenship (see Porto and Byram 2015; Yulita and Porto 2017). In the introductory stage, students separately in each university researched the topic of the ' 78 World Cup using the foreign languages that they were learning. A wide range of materials was used in various sign systems, media, and languages. Peer discussions of these materials followed and the students designed posters summarizing key information using IT tools, such as Glogster, Prezi, and movie-maker.

During the awareness-raising stage, students searched for texts about the topic of different kinds - written, audio, and visual - using the internet and following their curiosity and specific needs for information. They reflected on the power of the media in manipulating thinking and behaviours in those representations. The students compared and contrasted these materials, with the goal of addressing issues of bias, prejudice, and naturalized assumptions.

In the intercultural dialogue stage, students from each country met virtually, using Skype to work on a collaborative task. They worked in small, mixed-nationality groups and designed a bilingual (Spanish-English) leaflet to express their joint, international perspective on the events of the time. The purpose of the leaflet was to raise awareness among other people of human rights violations during the military dictatorship, e.g. fellow students and people in their neighbourhood. Finally, during the citizenship stage, students in each university planned civic or social actions in their local, regional or global communities intended to raise the awareness of people today about the dictatorship and human rights violations in the past. For example, some Argentinian students created internet campaigns, whilst others designed leaflets and distributed them in a local square. Talks in primary schools and the local university were delivered by groups of students, classroom materials for primary education were designed by student teachers in collaboration with our students, and firsthand testimonies, such as an interview with a 95-year-old man whose son had disappeared, were obtained. In addition to the questions about identity changes, which were part of the original planning of the project, it was also evident that interesting processes of mediation were taking place. Intercultural citizenship leads to and is dependent on learners becoming mediators.

\section{Mediation}

Mediation is a concept related to translation and interpreting and was discussed in this context in the CEFR (Council of Europe 2001, pp. 87-88) and developed further in the Companion Volume (Council of Europe 2018a, pp. 33-34, 103-127). Mediation may happen within the 
same language or between languages ('cross-linguistic mediation') and the Companion Volume identifies (Council of Europe 2018a, p. 104) three separate types of mediation, although they are often combined:

- Mediating a text, which "involves passing on to another person the content of a text to which they do not have access".

- Mediating concepts, which "refers to the process of facilitating access to knowledge and concepts for others".

- Mediating communication, the aim of which is "to facilitate understanding and to shape successful communication between users/learners who may have individual, sociocultural, sociolinguistic or intellectual differences in standpoint".

In the project just described, it became evident that intercultural citizenship involved 'mediating concepts'. This was clear from different data types collected during the ten months that the project lasted, namely: recorded Skype conversations in mixed-nationality groups; written reflection logs, posters, PowerPoint presentations, and videos (from the first two stages); bilingual leaflets (one per mixed-nationality group from the third stage, 'intercultural dialogue'); and, from the Argentinian participants, 76 Autobiography of Intercultural Encounters (AIE) (Byram et al. 2009). The AIE is a tool designed by the Council of Europe intended to encourage users to analyze and reflect upon an intercultural experience. The data revealed that: (a) mediating concepts was difficult; (b) students used a variety of mediation strategies and activities; (c) cross-linguistic mediation took place on a foundation of democratic values; and (d) translation was used as mediation for social justice.

\section{Mediating concepts}

Students often revealed gaps in knowledge on two levels: (1) the Argentinian learners had only indirect experience of the ' 78 World Cup and the military dictatorship through history lessons, books, stories, and the media, and (2) the UK-based students lacked any prior knowledge of the subject matter. The Argentinian students acknowledged the difficulty and strangeness of mediating 'an extremely Argentinian topic' in English, their foreign language:

we acquired the vocabulary (and also the knowledge) to talk about something that may be hard to communicate in a language that is not our mother tongue

(Ana, reflection log, emphasis added)

we were able to talk about something that represents every Argentinian person in English, which was kind of strange, because I've always talked about this topic in Spanish (. . .) This project made me think about an extremely Argentinian topic in English

(Paula, reflection log, emphasis added)

Here the learners engaged in cross-linguistic mediation to discuss the concept of the dictatorship through 'group interaction' and 'collaboration', two mediation activities highlighted in the CEFR Companion Volume (2018a, pp. 52-56, 96-99). Students built bridges from one language to another and communicated ideas previously learned in their mother tongue in the new language that they were learning.

Students interrelated both languages in a process referred to in the Companion Volume to the CEFR as the use of a plurilingual repertoire which is analogous to 'translanguaging' 
(Council of Europe 2018a, p. 28) where learners crossed linguistic boundaries in creative ways to articulate their ideas and thoughts in order to facilitate understanding and communication. The goal in these mediation activities was not to achieve 'native speaker' mastery of the languages being learned, but rather to use both L1and L2 as mediating tools in order to construct and co-construct new meanings. It should be noted that translanguaging is a term originally coined by Williams (1994) which has been further developed by others (Canagarajah 2011; García and Li Wei 2014).

\section{Mediation activities and strategies}

Lack of prior knowledge ("I didn't know anything”), wrestling to find appropriate language to express ideas ("the dictatorship ... dictadores? . . . dictators") and challenges posed by understanding and imagining new conceptual territories ("the most difficult part to understand", "it's so hard to try to imagine") gave the students a space where clarity was sought through reformulations using a variety of mediation strategies. Students mediated conceptual talk using translations, as well as making comparisons and/or links between new and prior knowledge as scaffolding strategies to enable their peers to construct new concepts (Council of Europe 2018a, pp. 113-126). For example, students used translations ("Proceso de Reorganización Nacional" translated as "National Reorganization Process"), language adaptations ("they took over the government. It was not a democracy"), and prior knowledge ("Have you seen Madonna's movie about Evita?"). However, when this latter strategy failed due to a British student not knowing the film, the Argentinian students engaged in other forms of mediation activities, such as breaking down complex information ("a group called 'Los Montoneros", "they were the opposition to the military") and elaboration of ideas ("they kidnapped people, they killed"). The students thus kept two languages and two perspectives in mind in their mediation activities during group discussions.

When subject matter was new or difficult, students linked new concepts to prior knowledge. For example, they compared World Wars I and II ("similar to what happened in Germany") with the Argentinian military dictatorship. This strategy involved a translation of perspectives: the explanation of new concepts by linking new concepts to shared common knowledge. Students' Skype conversations involved much meta-talk. For example, in the following reported exchanges, we find two Argentinian students explaining news items to a British student ("the news talked about", "the thing is") to enable understanding of two armed forces ("the police" and "the rebels"):

Argentinian student 3: The news talked about fights between the police and the rebels, the subversives.

Argentinian student 2: The thing is they made people believe they were going to do a good thing.

(Skype conversation, Group 7, emphasis added)

The Council of Europe (2018a, pp. 96-97) developed a new scale for online conversation and discussion using a goal-oriented approach to the co-construction of meaning. Here, we see the students using their linguistic and translation skills to mediate texts with the goal of relaying specific information to their peers, thus realizing a key competence in the Companion Volume. One of the outcomes of these mediation activities comprised an increased 
awareness of language use, in particular use of lexical items to facilitate understanding and transmission of their ideas:

Vocabulary had to be used very carefully. ... It made me more conscious about the things I wanted to express and the way I wanted to do it.

(Paula, reflection log, emphasis added)

The project encouraged students to dig for words and ways of expression outside of the typical conversation and exchanges one might have in class.

(Carmen, emphasis added)

Further, the Council of Europe (2018a, p. 106) expanded the notion of mediation to include mediating a text for oneself (for example in taking notes during a lecture) or in expressing reactions to texts. The following illustration shows students creating mind maps to break down complex information gathered from different sources:

British student: Yeah. Well . . I collected a lot of information from what I've learned at university, and talking to you guys on Skype. Yeah, so I just collected a lot of information and I did a map of a lot of ideas of what I wanted to say.

(Skype conversation, Group 2, emphasis added)

The adaptation and modification of language as a mediation strategy was pervasive, as most students acknowledged in their reflection logs, for instance by explaining, paraphrasing and recasting for one of the international students at the British university:

I explain[ed] the same idea in different ways as my partner was not a native speaker of English or Spanish ... this ability of paraphrasing and recasting some of my ideas.

(Patricia, reflection log, emphasis added)

The following Skype conversation extract illustrates language adaptation processes related to the concept of 'commemoration' in various ways: explanation ("all the memories and all the stories"); clarification requests ("memory?"); paraphrasing ("things like people do to commemorate"); recasting through comparison ("it's like when people"); and translation into Spanish ("conmemorar", "conmemoración"). In this instance, the outcome of this strategy was an A-ha moment, or revelation (“Ah!", "Yes!") for a British student, i.e. an indication that understanding had occurred ("Yeah"):

Argentinian student 1:

British student:

Argentinian student 1:

British student:

Argentinian student 2:

British student:

Argentinian student 2:

British student:
So, all the memories and all the stories.

Yes. Like you've said 'las Madres de Plaza de Mayo'.

Yeah. Things like people do to commemorate. Do you guys know what commemorate means?

Yeah. Memory?

What?

Memory.

A memory, yeah. Memory?

Yeah. 
Argentinian student 1:

Argentinian student 2:

British student:

Argentinian student 1:

Argentinian student 2 and British student:

Argentinian student 2:

Argentinian student 1:
To commemorate.

To commemorate.

Ahh! Yes!

It's like when people . . you start to remember something else.

Yeah.

Conmemorar, conmemoración.

We could do all the things you do to commemorate that time.

(Skype conversation, Group 10,

emphasis added)

Students also processed texts that they found on the internet for their peers. Two Argentinian students reformulated the main points in the speech of the military junta after the coup, written in Spanish, and transferred it in a condensed form in English:

Student 1: Here, in this site, I found the speech they gave to inform they were taking the government that day, and the thing is they were saying something like "this country had too many dictatorships and too much political trouble; because of that, it's time for a group of people to get the power and finish with everything, get this country to work and get better, and better organized". (emphasis added)

Mediation, as proposed in the CEFR Companion Volume, can be used in language education across the curriculum, beyond foreign language learning. Descriptors for online interaction have been incorporated, along with descriptors for facilitating a pluricultural space $(2018 \mathrm{a}$, pp. 157-161).

\section{Cross-linguistic mediation on a foundation of democratic values}

Students mediated communication amongst themselves, using the foreign languages that they were learning. They did so by facilitating a pluricultural space, as described in the Companion Volume (Council of Europe 2018a, p. 120) through competences such as mutual understanding and support ("make an effort to understand"), respect for and sensitivity to diversity ("other realities and perspectives", "broaden our minds"), in addition to harmony and solidarity ("as helpful as I could") (see Yulita 2018 for further details):

Manuela: I had to make an effort to understand others'opinions and the way they expressed them in English

Patricia: $\quad$ trying to be as helpful as I could for my interlocutor to understand clearly

Pilar: I also learned about others' realities and perspectives, which also enables us to broaden our minds (emphasis added)

In particular in the fourth stage of the project, the 'citizenship stage', the students mobilized and deployed their competences for democratic culture (Council of Europe 2018b) as they engaged in civic action in their community using the bilingual leaflets that they had designed collaboratively. They identified themselves as responsible citizens ("grow as citizens") and 
engaged in civic action to improve the world ("the mission of building a better and more conscious society").

By doing this [contributing material to Comisión Provincial por la Memoria], we know that many other people will be able to hear what we have heard, to learn what we have learnt in order to grow as citizens and as a country. It is great to think that something that was so productive to us could reach a higher level and be productive to more people as well. This is why we can say that thanks to this project we feel that we are actively working in the mission of building a better and more conscious society.

(Group reflection on civic action stage, emphasis added)

Remembering the past ("important they are remembered", "never silenced", "the photos to remember them", "it maintains that period", "must not be forgotten") to build a better future was a recurrent call by all students.

Others like the journalist Rodolfo Walsh and the comic writer Héctor Oesterheld, payed (sic) with their lives for expressing their ideology against the dictatorship. Now it is important they are remembered so as their voice was never silenced.

(Extract from bilingual poster, Group 17, emphasis added)

Argentinian student 1: For example on the website desaparecidos.com with the photos to remember them. I think it is very important because it maintains that period what was important, I mean, the ... what was significant ... Disappearance and tortures what happened in that period.

Argentinian student 2: Yes, yes.

Argentinian student 1: I think that it's the part which must not be forgotten.

(Skype conversation, Group 23, emphasis added)

Another group of learners prepared a presentation which they delivered at a community centre for impoverished people in a slum area of Argentina, as one of the participating students explained:

I work as a volunteer in the neighbourhood called San José, Ensenada. Actually it is a "villa de emergencia" (I looked for a translation, but I couldn't find one. I don't know if there's any), and I work with people who don't know how to read or write. There is a high rate of illiteracy in that neighbourhood. The other students in my group knew about my volunteer work so we thought it was a good idea to inform people about what happened 37 years ago. We prepared some photographs to show them (most of the pictures were taken when we visited "Museo de Arte y Memoria"), a song written by León Gieco, a poster and a documentary which explained what happened at the time. We also thought that every resource we had at hand was very useful because most of the people who attended our talk didn't know what happened during the last dictatorship. (emphasis added)

Commitment to educating others, coupled with a willingness to "inform people about what happened 37 years ago" constituted an altruistic form of social action mediated by transformations 
of written texts into other semiotic systems, such as music, documentaries, posters, and photographs. In one student's own words, “most of the people who attended our talk didn't know what happened during the last dictatorship"; therefore her group drew on "every resource at hand" to reach their audience. This example illustrates how learners positioned themselves as social justice activists in the various translation activities they completed during the citizenship phase of the project, an issue to which we turn next.

\section{Translation as mediation for social justice}

Baker (2013, pp. 23-24) argues that translations are never "neutral", "disinterested" or "apolitical", and that those involved in translation processes "actively engage in forms of collective action", telling and retelling narratives and stories through the medium of translation. Translation is "a site where we exercise our agency" enabling us to use it as a "tool for changing the world". This was evident when students translated written texts to reach audiences beyond their immediate community. For example, a group of students created bilingual leaflets using translations from English into Spanish (and vice versa) to mediate concepts for audiences of foreign visitors to a museum in Argentina. Other similar leaflets were submitted by students to the Comisión Provincial por la Memoria (www.comisionporlamemoria.org) to contribute to the committee's work on the collective healing of historical trauma. As an outcome of this social action, the leaflets were archived as cultural resources and made available to the general public.

The students in the project thus adopted an action-oriented approach and acted as 'social agents' in their use of translations as described in the Companion Volume. This is evidenced by their use of "language as a vehicle for communication rather than as a subject to study" (Council of Europe 2018a, p. 27). Their translations acted as a medium to tell their stories to international audiences in an effort to disseminate their thinking more globally. This action-oriented approach to their mediation activity involved collective political action to raise awareness of human rights abuse, thus students adopting a positioning as social agents "engaged in narrating the world across linguistic and cultural boundaries" (Baker 2013, p. 24).

\section{Conclusions and future directions}

We started this chapter with a historical overview of the evolution of the theory of intercultural citizenship in foreign language education, with an analysis of the concepts of intercultural speaker and intercultural (communicative) competence. We outlined Byram's (1997) savoir s'engager, or critical cultural awareness, and Barnett's (1997) criteria for 'criticality' to explain the starting point for an international online network of teachers and researchers who carried out empirical research applying and developing the theory. This was achieved through educational projects with their own students, one of them being described in this chapter.

The project aimed to realize the theoretical principles of intercultural citizenship in foreign language teaching and involved a pedagogical intervention with English and Spanish language undergraduates who communicated virtually to create a leaflet raising awareness of human rights violations. We analyzed this project through the lens of 'mediation', a concept that has recently been revised and developed by the Companion Volume (Council of Europe 2018a) to the CEFR (Council of Europe 2001). Here, we have demonstrated with empirical data how students overcame conceptual difficulties through the use of a variety of mediation activities and strategies underpinned by their democratic values, one of them being the use of translation for social justice. 
In the future, it is likely that education systems in general will, at least in the western tradition, take increasing responsibility for educating for citizenship with an international dimension, and the work presented here will be a foundation for further developments in cross-curriculum, interdisciplinary teaching. Such plans are, for example, already being implemented in Norway. The relevance of intercultural citizenship work will be self-evident for teachers and trainee teachers. In the case of future translators, the first stage will be to make them aware of the potential of translation for political engagement and social change, and of how they, like the students in the projects described in this chapter, can become politically active and take a responsible role in international society.

\section{Further reading}

Myers, J. (2016) (ed) Education for Global Citizenship. Special Issue of Education Policy Analysis Archives. 24(55) [online]. Available from: https://epaa.asu.edu/ojs/issue/view/vol24 [Accessed 19 September 2019].

This Special Issue problematizes the notion of global citizenship education by exploring various theoretical dimensions, empirical case studies, pedagogic affordances and research directions.

Williams, K. (2017) Language learning: Its moral and civic remit. Pedagogy, Culture and Society. 25(1), pp. 59-71.

The argument in this article is that language learning has educational purposes and in this sense, the author's point is similar to the one we develop in this chapter. In this case, the moral, civic, and political dimensions are explored, with examples from autobiographical and literary texts. Implications for curriculum design are also addressed.

Porto, M., Houghton, S.A. and Byram, M. (eds) (2018) Intercultural Citizenship in the (Foreign) Language Classroom. Special Issue of Language Teaching Research. 22(5), pp. 484-498.

This Special Issue addresses conceptual aspects of intercultural citizenship as well as research, pedagogy, and teacher education concerns. Empirical cases in the Argentinean, Chinese, Korean, and Taiwanese settings challenge more Eurocentric visions, also represented in this issue by work from the United Kingdom and the United States.

\section{Related topics}

student agency, secondary school education, content-based instruction

\section{References}

Alred, G., Byram, M. and Fleming, M. (eds) (2006) Education for Intercultural Citizenship; Concepts and Comparisons. Clevedon: Multilingual Matters.

Baker, M. (2013) Translation as an alternative space for political action. Social Movement Studies. 12(1), pp. 23-47.

Barnett, R. (1997) Higher Education: A Critical Business. London: Open University Press.

Belz, J.A. (2007) The development of intercultural communicative competence in telecollaborative partnerships, in O’Dowd, R. (ed) Online Intercultural Exchange. Clevedon: Multilingual Matters. pp. 127-166.

Byram, M. (1997) Teaching and Assessing Intercultural Communicative Competence. Clevedon: Multilingual Matters.

Byram, M. (2008) From Foreign Language Education to Education for Intercultural Citizenship. Clevedon: Multilingual Matters. 
Byram, M. (2016) The Cultnet intercultural citizenship project, in O’Dowd, R. and Lewis, T. (eds) Online Intercultural Exchange. Policy, Pedagogy, Practice. London: Routledge. pp. 256-262.

Byram, M. and Zarate, G. (1996) Defining and assessing intercultural competence: Some principles and proposals for the European context. Language Teaching. 29(4), pp. 239-243.

Byram, M., Barrett, M., Ipgrave, J., Jackson, R. and Méndez García, M.C. (2009) Autobiography of Intercultural Encounters. Strasbourg: Council of Europe.

Byram, M., Golubeva, I., Han, H. and Wagner, M. (eds) (2017) From Principles to Practice in Education for Intercultural Citizenship. Bristol: Multilingual Matters.

Canagarajah, S. (2011) Translanguaging in the classroom: Emerging issues for research and pedagogy. Applied Linguistics Review. 2, pp. 1-28.

Cenoz, J. (2015) Content-based instruction and content and language integrated learning: The same or different? Language, Culture and Curriculum. 28(1), pp. 8-24.

Coste, D. and Cavalli, M. (2015) Education Mobility, Otherness. The Mediation Functions of Schools [online]. Available from: www.coe.int/en/web/language-policy/selection-of-major-texts-and-reports [Accessed 19 September 2019].

Council of Europe. (2001) Common European Framework of Reference for Languages: Learning, Teaching, Assessment [online]. Available from: www.coe.int/lang-cefr [Accessed 19 September 2019].

Council of Europe. (2018a) Common European Framework of Reference for Languages: Learning, Teaching, Assessment. Companion Volume. With New Descriptors [online]. Available from: www. coe.int/en/web/common-european-framework-reference-languages [Accessed 19 September 2019].

Council of Europe. (2018b) Reference Framework of Competences for Democratic Culture. Vol. 2 [online]. Available from: https://rm.coe.int/prems-008418-gbr-2508-reference-framework-of-competences -vol-2-8573-co/16807bc66d [Accessed 19 September 2019].

García, O. and Li Wei. (2014) Translanguaging. Language, Bilingualism and Education. Basingstoke, UK: Palgrave Macmillan.

Himmelmann, G. (2001) Demokratie Lernen als Lebens-, Gesellschafts- und Herrschaftsform. Ein Lehrund Studienbuch. Schwalbach: Wochenschau Verlag.

Himmelmann, G. (2006) Concepts and issues in citizenship education. A comparative study of Germany, Britain and the USA, in Alred, G., Byram, M. and Fleming, M. (eds) Education for Intercultural Citizenship: Concepts and Comparisons. Clevedon: Multilingual Matters.

Houghton, S.A., Rivers, D. and Hashimoto, K. (2018) Beyond Native-Speakerism. Current Explorations and Future Visions. London: Routledge.

Kramsch, C. (2009) Discourse, the symbolic dimension of intercultural competence, in Hu, A. and Byram, M. (eds) Interkulturelle Kompetenz und fremdsprachliches Lernen/Intercultural Competence and Foreign Language Learning. Tubingen: Gunter Narr Verlag. pp. 107-124.

Li, Y. and Dervin, F. (2018) Interculturality in a different light: Modesty towards democracy in education? Intercultural Communication Education. 1(1), pp. 11-25.

Løvlie, L. and Standish, P. (2002) Introduction: Bildung and the idea of a liberal education. Journal of Philosophy of Education. 36(3), pp. 317-340.

Osler, A. and Starkey, H. (2015) Education for cosmopolitan citizenship: A framework for language learning. Argentinian Journal of Applied Linguistics. 3(2), pp. 30-39.

Phipps, A. (2014) They are bombing now: 'Intercultural dialogue' in times of conflict. Language and Intercultural Communication. 1, pp. 108-124.

Porto, M. and Byram, M. (2015) A curriculum for action in the community and intercultural citizenship in higher education. Language, Culture and Curriculum. 28(3), pp. 226-242.

Risager, K. (2007) Language and Culture Pedagogy. From a National to a Transnational Paradigm. Clevedon: Multilingual Matters.

Savignon, S.J. (2013) Communicative language teaching, in Byram, M. and Hu, A. (eds) Routledge Encyclopedia of Language Teaching and Learning. London: Routledge. pp. 134-140

Spitzberg, B.H. and Changnon, G. (2009) Conceptualizing intercultural competence, in Deardoff, D. (ed) The SAGE Handbook of Intercultural Competence. Los Angeles: Sage. pp. 2-52. 
Williams, C. (1994) Arfarniad o ddulliau dysgu ac addysgu yng nghyd-destun addysg uwchradd ddwyieithog [online]. PhD thesis, Bangor University. Available from: https://ethos.bl.uk/OrderDetails. do;jsessionid=8EDC17B918F4E3CED9938D91D22B5A13?uin=uk.bl.ethos.385775 [Accessed 19 September 2019].

Yulita, L. (2018) Competences for democratic culture: An empirical study of an intercultural citizenship project in language pedagogy. Language Teaching Research. 22(5), pp. 499-516.

Yulita, L. and Porto, M. (2017) Human rights education in language teaching, in Byram, M., Golubeva, I., Han, H. and Wagner, M. (eds) From Principles to Practice in Education for Intercultural Citizenship. Bristol: Multilingual Matters. pp. 225-250.

Zarate, G., Gohard-Radenkovic, A., Luissier, D. and Penz, H. (2004) Cultural Mediation in Language Learning and Teaching. European Centre for Modern Languages. Strasbourg: Council of Europe. 
$\because$ Taylor \& Francis

http://taylorandfrancis.com 
Part II

Early childhood and primary education 
$\because$ Taylor \& Francis

http://taylorandfrancis.com 


\title{
Preschool education
}

\author{
Cristina Corcoll López and Jane Mitchell-Smith
}

\section{Introduction ${ }^{1}$}

To be authentic and effective, the multilingual turn (May 2014; Meier 2017) should begin in the early years as it is there where "key attitudes towards other languages and cultures are formed and foundations for later language learning are laid" (European Commission 2006). This is the perspective argued for in this chapter and the suggested path is to follow what is labelled Pedagogy of Diversity, which would entail the introduction to the plurilingual and pluricultural paradigm in a way that is both coherent and respectful with the needs and abilities of young learners.

The Pedagogy of Diversity derives from two different perspectives towards very young learners: a developmental perspective and a pedagogic one. The developmental perspective takes into account the literature on well-being at early ages (Siraj-Blatchford and Clarke 2011; Sutherland and Mukadam 2018, among others), which focuses on creating the appropriate conditions for very young learners at their settings while respecting and promoting their identities, which includes their home language and culture. The pedagogic perspective follows the integrated plurilingual approach of language learning and teaching, which redefines the role home languages should have in the language classroom and delves into the development of plurilingual and intercultural competencies by looking at the way own-languages are used in early childhood education classrooms (European Commission 2006; Hall and Cook 2013; Corcoll and Flores 2018). It also relates to inclusive classrooms. Even though inclusion often tends to refer to teaching a common curriculum to all students, while acknowledging differences among learners (Westwood 2018, p. ix), actively welcoming language and culture diversity should also be taken into account when building inclusive classrooms. As well as special needs or learning difficulties, language and culture heritage is recognized as a source of diversity in the new trends on inclusive and adaptive teaching (Westwood 2018) and it is also recognized in the pedagogical approach that is at the basis of this chapter, namely, Pedagogy of Diversity.

\section{Historical perspectives}

When addressing aspects concerning translation and education in early years, the viewpoint is necessarily quite transversal. For this reason, the historical perspective described in this 
section will be presented from three different viewpoints which aim to tackle the basic issues that need to be considered when dealing with plurilingualism in early years. These viewpoints are: very young learners and well-being, very young learners and language learning, and very young learners and diversity.

\section{Very young learners and well-being}

The EURYDICE (2009) document identifies how effective preschool education can promote lifelong learning and provide opportunities to increase equality by supporting children in reaching their full potential. It also points out that "what seems essential for all approaches is a positive socio-emotional climate, with emotionally safe and stable relationships, with sensitive-responsive, non-intrusive teachers" (p. 32). Thus, a respectful environment as well as sensitive teachers seem to be key issues in the educational approach to be followed in early years. Amongst the different dimensions of well-being identified by Sutherland and Mukadam (2018, p. 27), there are three in which language development is key: toddlers' development and learning, toddlers' voice and expressions, and toddlers' early languages. In a linguistically diverse setting, language development will necessary include aspects that may be related to one or more of the languages.

Siraj-Blatchford and Clarke also note how "the way children feel about themselves is not innate or inherited. It is learned. . . Positive self-esteem depends upon whether children feel that others accept them and see them as competent and worthwhile" (2011, p. 3). This logically implies acceptance of children's home languages and cultures which, in our opinion, is best developed through an integrated plurilingual approach. Through the Pedagogy of Diversity approach described in this chapter, the focus is placed on teachers acknowledging and valuing children's home languages, but also on making children aware of the diversity around them and learning to value and respect it, whatever the educational context.

\section{Very young learners and language learning}

The Common European Framework of Reference for Languages (Council of Europe 2018) follows the distinction that was already established in the 2001 edition (Council of Europe 2001) between multilingualism and plurilingualism: the former is understood as the coexistence of different languages at the social or individual level, whereas the latter is defined as the dynamic and developing linguistic repertoire of an individual user or learner.

Very often in our educational context, the distinction between multilingual and plurilingual approaches as described in the Common European Framework is not actually followed. This means that there are many settings where several languages are taught (thus they call themselves plurilingual settings) but those languages are taught in isolation (thus following a monolingual approach), thus generating a monolingual view of plurilingualism (Wilson and González Davies 2016). This is the approach that is traditionally followed, for instance, in dual language education or (two-way) immersion or bilingual programmes.

It is also true that, on many occasions, when children's home languages are used, this is for classroom management purposes, such as giving instructions for an activity or disciplining the group. When working with very young learners, it will also include expressing physical needs or emotions (Scheffler and Domińska 2018). Be that as it may, this use of languages does not really cover what the plurilingual approach claims.

The literature on plurilingualism, however, seems to indicate that the traditionally labelled monolingual bias is slowly being substituted by a more open view of the role of languages in 
classrooms and new conceptual visions arise, which are linked to terms such as translanguaging (García 2009), code-meshing (Canagarajah 2011), multi-competence (Cook 2007), among many others. This shift of perspective is linked to the multilingual turn, which encompasses a major shift in perceptions regarding the learning of languages. Meier (2017) highlights the changes which have taken place in our perceptions of not only the ways in which languages are learned, but also languages and learners in their own right, pointing to a reconceptualization of knowledge as co-constructed and based upon the linguistic repertoire of teachers and learners. The question is whether this shift has as yet influenced classroom practice.

\section{Very young learners and diversity}

All those involved in education who work with very young learners and their families are well aware that this is a highly sensitive stage in terms of concerns or fears families may have, but also in terms of the influence relevant adults may have on children as key figures in their lives. It is also the stage where foundations can be laid for future citizens to grow and develop as responsible global citizens.

An approach that may be relevant here is the diversity pedagogy theory (Sheets 2005, 2009), which entails there are culturally inclusive teachers who develop pedagogical behaviours that foster inclusion of other languages and cultures and promote students' cultural displays in their classrooms.

Moving a step further from Sheet's theory, the Pedagogy of Diversity approach (Corcoll and Flores 2018) suggests that practitioners should create opportunities for young learners to experience linguistic and cultural diversity at their settings and schools. Following this approach, this diversity should not only be made visible but also acknowledged and used in the learning process by looking at language and language learning from a complex and enriching perspective. In this sense, the focus should not be primarily placed on acquiring words in an additional language but on acquiring a positive attitude towards learning words in an additional language. This implies learning languages whilst developing the understanding that those languages that we are familiar with are not the only ones, or even the most important ones, in the world. It means beginning to hear and notice similarities and differences among the languages that surround us and, ultimately, developing an interest in and respect towards them. As children grow, the plurilingual approach and its implementation in formal contexts becomes more complex, as will be seen in the following chapters.

Although cultural and linguistic inclusion is not part of its theoretical foundation, this perspective seems coherent with the Universal Design for Learning approach (Meyer et al. 2014), which advocates for multimodality in teaching that can help overcome learning difficulties that children may have. At the end of the day, it is a perspective that calls upon flexibility on behalf of the teacher, as well as acceptance and respect for differences on behalf of the whole learning community.

The three historical perspectives described in this section (very young learners and wellbeing, very young and language learning, and very young learners and diversity) lead into the pedagogic approach that will be described in what follows and specified in a number of strategies that, if followed, can help a setting turn into a plurilingual setting.

\section{Research approaches and key findings}

Recently, some research has been carried out on the language uses of very young learners (García 2011; Schwartz and Asli 2014; Marzà and Ríos 2016; Pontier and Gort 2016; Portolès 
and Martí 2017; Scheffler and Domińska 2018, among others). The focus is primarily placed on the use that young learners and their teachers make of languages in diverse multilingual or plurilingual settings, that is, on describing what is happening in classrooms. In this sense, a key finding reported by García (2011) and researched by Portolès and Martí (2017) establishes the use of diverse languages in the classroom by children in order to carry out the following functions: to mediate understanding; to co-construct meaning; to construct meaning within oneself; and to include, to exclude, and to show knowledge. Whilst the categories may differ when reading other authors, the focus tends to be the same: identify the (sometimes conscious, sometimes unconscious) reason behind a certain linguistic use in order to explain it.

Based on this descriptive perspective, this section is devoted to describing research into the language uses of very young plurilingual learners (age 4) and their teachers in an educational setting, as well as presenting the key findings. The ulterior aim, however, is not solely descriptive as we link the description of language use to the justification of the pedagogical approach taken in this chapter. Hence we would like to place the focus not so much on what is done but on what could be done in order to promote a true plurilingual approach.

We felt the need of carrying out this research to collect data on the spontaneous plurilingual uses of very young children in an international school context where many languages exist side by side but where there is no recorded systematicity in the way they are used alongside the target language. Also, it was important to collect more data as there seems to be a lack of research on this topic: "despite this recent interest [in the use of home languages in the classroom] there is, as yet, very little data that documents the extent and purpose of own-language use in English language teaching" (Hall and Cook 2013, p. 7).

This study follows a qualitative research approach. Data was gathered in a school setting in Catalonia. The school was chosen because it is an international school with a great diversity of cultures and languages amongst its students and staff, which means that the development of the plurilingual approach and a systematic use of translation and other plurilingual strategies would be coherent and natural. However, despite the fact that this plurilingual and intercultural reality forms part of everyone's daily life at school, the degree to which plurilingual competences are used and developed within the classroom is inconsistent and unstructured in part because the main focus in early years is on the acquisition of English in a mainly immersion setting, where English is not the main language of the host community.

This priority is shared by all agents involved, including children, families and staff, a point which was clearly reflected in interviews with teachers. As it is, this seems to be quite often the case in our more and more globalized schools. The focus of this research is to analyze what happens when very young plurilingual learners and their teachers interact in a context where a systematic plurilingual methodology has not been developed. The findings provide the basis for the pedagogic strategies described in this chapter.

The research procedure has implied video-recording two hour-long sessions in which teachers carried out group problem-solving activities with their students (ages 4 and 5) as a response to a story. The teachers were asked to carry out their usual lessons, so the situation, the classroom activities, and the topics of conversation have not been pre-selected in any way. In other words, the research is not experimental but ecological.

The conversations were transcribed and analyzed following a thematic coding analysis, through which the language uses of the children and their teachers were identified. A grounded research methodology allowed researchers to draw main categories and subcategories from the data. The following findings section describes the main categories that were identified and discusses them. 
Following the recordings, semi-structured interviews with teachers were carried out in which issues such as their perception of and opinion on the use of several languages in the school context was obtained. This is a very relevant aspect as it is clear that the teachers' linguistic attitudes will depend greatly on these opinions and perceptions and will influence how the linguistic landscapes will become visible in the classrooms. This is possibly always so as "the extent to which own-language use occurs in a class depends on the attitudes of teachers and learners towards its legitimacy and value in the ELT classroom" (Hall and Cook 2013, p. 10) but it could be claimed that it may be even more relevant when analyzing very young learners' speech, given their reliance on the adult figure. Due to space constraints, the results obtained through these interviews will not be discussed in depth in this chapter. However, some references to the interview contents will be made when they can enrich the discussion on the children's productions.

The participants in the study are 24 children, two teachers and two teaching assistants. In the analysis of the data in Table 4.1, adults (teachers, teaching assistants and researcher) are referred to as T1, T2, T3, and T4 and Res (researcher); The children are identified numerically (i.e. $\mathrm{C} 1, \mathrm{C} 2$, etc.) in order to protect their anonymity and where responses were made by an unidentifiable child or children the letters $\mathrm{Ch}$ or Chn have been used. Two groups of children and adults have participated in the research (Table 4.1):

Table 4.1 Participants in the research

\begin{tabular}{lc}
\hline Group 1 (4-year-olds) & Group 2 (4-year-olds) \\
\hline 3 adults (class teacher, teaching assistant, & 3 adults (class teacher, teaching assistant, \\
researcher all with fluent use of 2 to 3 & researcher all with fluent use of 2 to 4 languages) \\
languages) & 11 children whose own languages include: Spanish, \\
13 children whose own languages include: & Catalan, English, Chinese, and Italian \\
Spanish, Catalan, English, Russian, Chinese, & \\
and Romanian & \\
\hline
\end{tabular}

This research complies with ethical standards. Permission to record and analyze classroombased data for research purposes has been obtained from families and school and anonymity maintained at all times.

\section{Findings}

The discussion of our findings is organized following the main categories (see Table 4.2) regarding plurilingual uses that were identified after the analysis of the transcribed video recordings.

\section{Classroom activity and language use}

Regarding language uses in the classroom, the first aspect that should be mentioned is that they are very clearly related to the kind of activity which is taking place. Our data show that when the lesson is teacher-led, as when the teacher is telling a story, the children basically respond with short answers or mirror the teacher's words (see excerpt 1). That is, they do not make much use of their plurilingual repertoire. 
Table 4.2 Main plurilingual uses identified in the data

\begin{tabular}{l}
\hline Plurilingual uses \\
\hline 1 Classroom activity and language use \\
2 Use of rephrasing or recasting \\
3 Use of other languages promoted by the teacher \\
4 Non-use of translation \\
5 Acknowledgement of other languages \\
6 Use of code-switching in peer talk \\
\hline
\end{tabular}

\section{Excerpt 1}

T1: If I hide from my . . if I hide . . . if I hide from the day, maybe it'll go away he thought. It didn't go away. Time to get up, said his mum. Here's mummy saying "Come on, Splat, it's time to get up. Time to go to cat school". Yes, C9?

C9: It's a ... it's a pencil.

T1: A pencil, yes. "Time to get dressed" said his mum. "I don't have any clean socks. Maybe. . . Maybe I should go to school tomorrow instead" said Splat. "You don't wear socks" said his mum. Do cats wear socks?

Chn: No

T1: 'I'm having a bad hair day, mum, maybe I should go to school tomorrow instead", said Splat. His mum combed his hair. "Purrrfect", she said.

\section{C5: $\quad$ Purrrfect?}

In contrast, when the children are engaged in an activity (for example, an art and craft activity) and they are working in small groups with the adults in the classroom circulating, then their language uses are more varied and richer and they use, for instance, code-switching (see excerpts 2 and 3 ).

\section{Excerpt 2}

C21: C15, we need to talk

C15: Un poco más

C21: No, teníamos más sellotape aquí. Corta. No, allí, no. Desde allí

\section{Excerpt 3}

T1: Now. . . A real mouse, no, maybe we could make mice later, plasticine mice or something, or paint mice. So, I was thinking

C3: Oh my golly!

C8: Olé olé olé ...

Looking into children's use of languages while considering the actual classroom activity that is taking place is especially interesting because it shows that children's use of language is not random. In fact, as plurilingual speakers, they make decisions - albeit unconsciously - about which language to use with whom and when (Grosjean 1982, 2010). In our opinion, this shows that, were the plurilingual approach systematically developed, the children's use of their language repertoires and diverse communication styles would become richer. 


\title{
Use of rephrasing or recasting
}

Another aspect that is worth mentioning and that derives from the analysis of our data is that the teacher quite often rephrases children's words in order to correct their mistakes (see excerpt 4).

\section{Excerpt 4}

C1: My granddad have a accordion

T2: He has an accordion? Does he play it?

Rephrasing or recasting is very common strategy used by teachers, especially language teachers, and it links with the idea of giving immediate feedback to children. Research has proven that recast is by far the most widely used technique and yet it results in the lowest rate of repair by students. In contrast, elicitation, metalinguistic clues, clarification requests, and repetition of error not only led to higher rates of uptake (i.e. noticing the feedback) but also highest rates of self or peer repair (Macaro 2005). That is, this type of feedback is not very efficient, as children may correct themselves after hearing the teacher's correction but they do not actually learn the corrected form as they have not noticed their mistake (see strategy 5, following).

In early ages, rephrasing can also be discouraged if we take into account what was first reported by US psycholinguists Jean Berko and Roger Brown in 1960:

A very interesting effect is known as the fis phenomenon. Several studies have reported intriguing conversations between a young child and an adult, showing that there can be a big difference between what children hear and what they can say

(Crystal 2007, p. 87)

The fis phenomenon refers to a conversation between a child and an adult in which the child referred to his inflated fish as fis. The adult noticed and imitating the child's pronunciation said "is this your fis?", to which the child answered "no, my fis" thus showing he could hear the right pronunciation but was not able to produce it yet. Excerpt 5 shows how the teacher's correction is not noticed by the child, who is paying attention exclusively to the content and not the form:

\section{Excerpt 5}

\author{
C5: And he has eight \\ T2: He's eight years old? \\ C5: Yes
}

\section{Use of other languages promoted by teacher}

Excerpt 6 is the only instance in our data in which Teacher 2 promotes the use of another language by a child and actually asks him to give her the answer in Spanish. However, she gets the words in Spanish (moscas) and gives a similar one to the children in English (bugs), but does not use this instance to create a communicative need around this that could help children acquire the new word or understand that the word bugs does not exactly correspond to moscas. The use of strategies 3 or 4 could have been useful here. 


\section{Excerpt 6}

T2: And what does the frog eat?

C2: Moscas

T2: What does he eat?

Ch: One moment

T2: Tell me in Spanish.

C4: Moscas

T2: Ah bugs

\section{Non-use of translation}

As was described earlier, even though this is clearly a diverse and plurilingual setting, the language approach is mostly monolingual in the sense that languages are academically separated into different compartments (social use of languages may differ). An example of this can be seen in excerpts 7 and 8 where the teacher clearly opts for not using translation when the child asks for a word. In excerpt 7, C16 (a child) explicitly shows that he does not understand a word and the teacher gives him a related word that she knows the child will understand. Even though this solves the communication problem at stake, the teacher does not actually solve the child's doubt. Clearly, this could be done by expanding her answer (i.e. dessert is what you have at the end of your meal and it could be a fruit, like a banana or an apple, but also a cake) which can take too long in a classroom context, but also by translating into Spanish or another language known by both the teacher and the child. This is, at the end of the day, what plurilingual speakers do among themselves.

Furthermore, excerpt 8 makes this non-use of translation even more apparent as, in a different conversation, a child offers to translate for a peer and the teacher refuses, again limiting the use of plurilingual mediation strategies on the part of the child.

\section{Excerpt 7}

C16: I don't know what is dessert

T3: $\quad$ Dessert is like cake

C17: I wanna make a cake

\section{Excerpt 8}

C18: You don't like it? I'll tell him in Spanish so he understands me

T4: No, he understands. C16, what do you want to do with this? Where do you want to put it?

C23: In the top

Although this non-use of translation is understandable in an immersion context, from a plurilingual perspective, it may entail the loss of some learning opportunities that could arise if translation was used systematically and made salient for the children, as it is clearly one of the communicative strategies they will need to master as plurilingual speakers. Moreover, home language use has been identified in research as the most effective way of learning vocabulary (Hall and Cook 2013, p. 9) so it seems to be the case that, by not using translation, teachers are missing learning opportunities. Interestingly, this contrasts with what teachers reported of 
their classroom practice in interviews, in which translation by peers, other students or media is used on occasion, but rarely with the teacher themselves as translator in order to preserve their role as linguistic model.

\section{Acknowledgement of other languages}

There is only one instance in our data (excerpt 9) in which a child acknowledges his/her knowledge of another language (Spanish). Once more, this can be understandable in an immersion context where the promotion of the target language is key, but from the integrated plurilingual perspective (especially taking into account strategies 1 and 6), there may be learning opportunities lost.

\section{Excerpt 9}

T4: $\quad$ Look you can also push it through, you can make a hole and push it through

C14: I know something in Eng ... I know something in Spanish

T3: You are going to make one basket ... and in that basket you need to put

In this excerpt, the child wants to show that he knows something in Spanish but his interest in sharing this is not picked up by the teacher nor any other child. Clearly, this is not the response that teachers would normally have in any other circumstance, as, especially in early years, children's voices are always taken into account and respected. However, when it comes to the presence of other languages in the classroom, this sometimes changes as teachers may believe that they are not helping the children when acknowledging their plurilingual repertoires. As one teacher, T1, commented: "If there was a native, maybe English, er inserting a Spanish word maybe, for example, secretly I . . I quite like that, I, They're playing with the words, they're"

Although all the teachers who were spoken to clearly recognized and welcomed the skills that their students have, there is a sense that it is inappropriate for them to celebrate them openly and that they, as models, should avoid using other languages overtly.

There are two instances in our data that show how the work on the target language (English) can also help improve children's home language (Spanish in this case). These instances involve the use of the words hole and handle. On both occasions, the children show that they do not know these words and, more than probably, they do not know them in English or in their home language (remember they are 4-year-olds). The teachers give them the words in English (as shown in excerpts 10 and 11) and these words become salient in their conversation: they are used over and over, as if to indicate that the children are repeating them in order to acquire them.

\section{Excerpt 10}

(the children are making baskets in groups with the materials given by the teacher)

T4: Look you can also push it through, you can make a hole and push it through

C21: How will we make a hole?

C14: I made a . . I I made a . . I I already made a basket. I made a basket

T4: because you push it through, if you push it through it'll come out the other end and you can make a hole 
C21: You can make a hole?

T4: $\quad$ Mmm ... you need to try first.

C15: I don't can. Puede ser un hole, ¿vale?

C21: ¿Por qué?

C15: Porque así puede

C23: We need some more of these, we need some more

C16: I need sticks

C15: No, it can stay out of hole. Pero así puedo acabar eso, ¿vale? Porque el se haga hole porqué así pueda acabar esto, ¿vale?

T4: Ok, yes, and then $\mathrm{C} 16$ can do it and C19. Do you want to put it on?

C15: A hole.

C21: I don't think you

C15: Yo tengo a tope el hole

The systematic use of hole in English even when children are code-switching into Spanish (Puede ser un hole, ¿vale?; Yo tengo a tope el hole) could indicate that the child does not know the word in his home language or else that he enjoys saying this word and so it has become salient in his speech. This is an excellent moment to give him the word in the other languages in his repertoire as there is a real need for the acquisition of new knowledge.

\section{Excerpt 11}

C2: $\quad$ Now I do it for . . . for close the door and open the door

T2: Do you know what that's called? Do you remember what T1 called it?

T2: A handle

C2: Handle

T2: $\quad$ You've got a handle. Good boy. Very good.

T2: No, no, we can get another piece, but did you hear what C8 said? C8 why do we need to have that piece?

C8: For the handle

Ch: The handle

C3: We need to have a golden piece for the handle

Ch: $\quad$ And then me

T1: $\quad$ Right ... right . . listen . . . let me do . . . let me do some more first

T2: We can get a gold piece for the handle

C3: C2... C2's ... C2's got the handle

T2: $\quad$ Yeah. $\mathrm{C} 2$ has the handle for the door

T2: What's the magic glue? What's something else that we can sometimes use?

C4: I do a this

$R: \quad$ And what's that? A handle

T1: What are you making, C9?

C13: I need the handle.

In this case, there is no use of code-switching (notably this is not the same group as the one with hole case, which may be relevant), but it can be seen how both children and teachers are looking for opportunities to keep using and repeating the word handle. It is important to note how the teacher gives $\mathrm{C} 2$ the word when he shows verbally that he does not know it (C2: Now I do it for . . . for close the door and open the door). The teacher immediately reacts, notices 
that there is a real need for a word and tells it to the child. Other children seem to pick it up and use it on different occasions, but towards the end of excerpt 11 we see how $\mathrm{C} 4$ has not acquired it (C4: I do a this) and, in this case, the researcher repeats the key word.

From a plurilingual perspective, a real need for a word such as the one described earlier would be an excellent occasion for using translation and help children learn these words also in their home language, thus helping them establish a connection that would make language more memorable (see strategies 3 and 5 in the following section).

\section{Use of code-switching in peer talk}

Code-switching implies alternating languages in a single conversation. Only plurilingual speakers can do this naturally and spontaneously and, most importantly, they only do it when speaking with other plurilingual speakers, that is, when the interlocutor can understand the bilingual message. Grosjean (1982) defines code-switching as part of a two-stage decision where bilinguals first decide which base language they are going to use - and this may depend on the weighting of a number of factors, such as the participant, the degree of intimacy, the degree of fluency, the setting or situation, among many others - and, second, decide whether to use CS. This second decision will only take place when the bilingual is addressing another bilingual and, even if it is delayed, "what is sure is that this stage does exist, because a bilingual will codeswitch in certain situations but not in others" (Grosjean 1982, p. 145). Code-switching, then,

not only fills a momentary linguistic need, it is also a very useful communicative resource. ... It takes place quite unconsciously; speakers are often quite unaware that they are switching from one language to another. Their main concern is with communicating a message or intent, and they know that the other person will understand them whether they use one or two languages.

(Grosjean 1982, p. 148)

In our research, the use children make of code-switching clearly indicates this decisionmaking process. Firstly, they tend to code-switch when talking to one another and hardly ever when talking to their teachers (participant-oriented code-switching, in Grosjean's words), as seen in excerpt 12 :

\section{Excerpt 12}

C9: Is more? There is more?

C9: There is more? C5, se puede traer more?

C5: Espera

Second, they also use code-switching when the word is not readily available to them, as seen in the example of 'hole' (vocabulary-oriented code-switching, in Grosjean's words). However, there is a common conception in interviews with teachers that code-switching happens because students are looking for the most available word, implying a lack of effort rather than competence. Whereas vocabulary-oriented code-switching provides an unplanned opportunity for language development by drawing on the child's own language background, if the teacher believes that code-switching occurs because the child is simply using what Grosjean refers to as "the most available word", their response is more likely to be a prompt or reminder to use the target language. 


\section{Pedagogic approaches and methods}

In the early years, as a child moves from the familiar setting of the home to other environments, they encounter new forms of linguistic input, which may include registers, accents or even languages other than their own. This exposure to language in its broadest sense enables them to construct meaning from the world around them through contact with others. To the very young child, this input is no more and no less than a means to communicate.

In the early stages of language production, a child will explore and create forms based upon those he has already encountered. His speech contains non-standard items, which provide starting points for building and consolidating learning. Where plurilingual elements appear side by side, a similar process but a wider range of linguistic devices are being explored. However, progress is frequently measured in terms of standard usage of target linguistic norms at the expense of communicative competence. Expectations that are made of young children in terms of language production should take into account their level of maturity and skills at applying what they have encountered in their environment.

The Pedagogy of Diversity approach further implies that settings and schools should create the right conditions for languages to be used by families and educators as well as making languages visible all around, which means making diverse identities visible in the setting. Surrounding children with diverse linguistic and cultural inputs may help them develop into the plurilingual, globalized speakers needed in today's world. The link between diversity and identity construction is an aspect to take into account, especially in early ages. Children's individual identities are gradually defined through interaction with others, and one element that can clearly help to do so is language: the language spoken by the child, the language spoken by his friend at the setting, the language spoken by the practitioner, the language or languages used at home, and so on.

In sum and in our view, the pedagogic approach to follow to promote the multilingual turn in early ages should include the following strategies:

1 Make linguistic and cultural diversity visible at the setting. This visibility should be attained by using diverse visual support and including languages in any activity or routine followed at the setting: books and music in different languages, vocabulary work in different languages, etc. to avoid what Garcia and Kleyn describe as "although the light of their voice may be present, it is not always visible" (2016, p. 23). In Corcoll and Flores (2018, p. 166), an Internal Evaluation for Improvement Rubric to be used to assess visibility of home languages in the settings is presented.

2 Provide rich language models. Educators and families are the main source of language input for the children. This must be recognized and promoted by inviting adults to express themselves appropriately and, while adapting their talk to caretaker talk, aiming to broaden the vocabulary they generally use and consider new topics of conversation. Especially when the language of instruction is not the child's home language, then adequate exposure for intake to happen is required by providing children with sufficient access to quality examples of the target language for effective acquisition to take place. Clear, coherent models create patterns for students to follow and allow for repetition and reinforcement.

3 Use teaching approaches which are rich in language and focus on developing communication through meaningful experiences, creating natural spaces where languages can be lived and contextualized, both inside and outside the classroom. Used appropriately this provides a rich source of resources. 
4 Suggest communication activities which promote the development of linguistic creativity. Linguistic creativity may be promoted by playing with language: inventing songs and poems, imitating accents or intonations, and so on.

5 Suggest communication activities which promote noticing similarities and differences among languages. By noticing we mean noting, observing or paying special attention to a particular item, generally as a prerequisite for learning (González-Davies and ScottTennent 2005, p. 163). This is especially relevant as "several studies suggest that, at least at an early age, bilingual children appear to be more sensitive to the structure of the language" (Schwartz and Asli 2014, p. 23) (Bialystok 2001).

6 Offer children the chance to show and share their linguistic and cultural identities. Invite children and their families to come to school and share their culture by reading stories, telling tales or singing songs in their home languages.

7 Develop a sensitivity and awareness on behalf of educators towards the ways in which very young children acquire language, and a recognition of the skills which they display in resolving linguistic dilemmas, whilst supporting and modelling a natural use of the target language. This does not require that the educator should be an expert in many languages, but that they should respond to learning opportunities as they arise allowing children (and their families) to become co-educators, using their plurilingual skills as intermediaries when the situation demands. By enabling this to happen the teacher retains the role of linguistic model, yet sends the message that alternatives are both possible and welcomed.

Appropriate, sensitive exposure to linguistic diversity leads to awareness of otherness, allowing for concepts to be explored and developed and forming a basis for future learning. This viewpoint, together with a structured school approach and training is especially relevant if some good practices are to become an essential part of the school system.

\section{Conclusions and future directions}

The aim of this chapter has been to present a pedagogic approach to be followed in early years with the aim of promoting the plurilingual approach in a way that is coherent with the needs of the children, their families, and their settings. This pedagogic approach has been named Pedagogy of Diversity and it has been specified through the description of eight different strategies that can be developed in early childhood and primary educational settings.

Prior to the description of the pedagogic approach, the historical approach presented earlier intended to focus on several aspects that are key when thinking about the promotion of plurilingual education in early years, namely: very young learners and well-being, very young learners and language learning, and very young learners and diversity. Clearly, each one of these topics is a field of research on its own, so their inclusion here is certainly limited but also necessary when the complexity of working with very young learners is understood.

A small-scale study is also described previously to support the pedagogic approach described. This study is a snapshot of two classroom moments. It cannot and should not be considered to be a complete picture of the complex use of languages in a whole school setting, nor to be representative of the behaviours of other students or teachers, but it does provide us with evidence of real language practices of both teachers and children. The presence of a camera and the presence of the teacher/researcher, although very familiar to both students and staff, inevitably influence behaviours to some degree. We witness children using English as their main language of communication, which corresponds to expectations and the aims of the 
school, but we also observe situations in which children naturally draw upon their knowledge of another language (in this case Spanish) for specific purposes and needs.

In the light of these observations we would argue that a more structured inclusion of the child's linguistic resources/repertoire can support and develop their overall acquisition, of both the home and the target language. In order to fully use the learning opportunities which such contexts provide, the teacher's role is vital, requiring flexibility, sensitivity, and a clear vision of themselves as linguistic model but also as a co-learner. Further research is recommended into younger age groups and contexts in which there is a different mixture of home languages.

\section{Further reading}

Corcoll López, C. and Flores, C. (2018) Toddlers' early languages, in Sutherland, H. and Mukadam, Y. (eds) Supporting Toddlers' Wellbeing in Early Years Settings: Strategies and Tools for Practitioners and Teachers. London: Jessica Kingsley Publishers. pp. 161-177.

This chapter has a main focus on the role language and (additional) language learning can have in promoting toddlers'well-being.

Siraj-Blatchford, I. and Clarke, P. (2011) Supporting Identity, Diversity and Language in the Early Years. Buckingham: Open University Press.

This book provides the basis for professional development in working with young children in a diverse society.

Meier, G. (2017) The multilingual turn as a critical movement in education: Assumptions, challenges and a need for reflection. Applied Linguistics Review. 8(1), pp. 131-161.

This article has a main focus on the description of the development and consequences the multilingual turn has had in the last few years.

\section{Related topics}

translanguaging, language awareness, early years provision

\section{Note}

1 This work was supported by the Spanish Ministry of Economy and Competitiveness under Grant Ref. FFI2015-63741-R, 2016-19.

\section{References}

Bialystok, E. (2001) Bilingualism in Development. Cambridge: Cambridge University Press.

Canagarajah, A. (2011) Codemeshing in academic writing: Identifying teachable strategies of translanguaging. The Modern Language Journal. 95, pp. 401-417.

Cook, V. (2007) Multi-competence: Black hole or wormhole for second language acquisition research. Understanding Second Language Process. 25, pp. 16-26.

Corcoll López, C. and Flores, C. (2018) Toddlers' early languages, in Sutherland, H. and Mukadam, Y. (eds) Supporting Toddlers' Wellbeing in Early Years Settings: Strategies and Tools for Practitioners and Teachers. London: Jessica Kingsley Publishers. pp. 161-177.

Council of Europe. (2001) Common European Framework of Reference for Languages: Learning, Teaching, Assessment. Cambridge: Cambridge University Press.

Council of Europe. (2018) Common European Framework of Reference for Languages: Learning, Teaching, Assessment. Companion Volume with New Descriptors [online]. Strasbourg: 
Council of Europe Publishing. Available from: https://rm.coe.int/cefr-companion-volume-with-newdescriptors-2018/1680787989 [Accessed 22 May 2019].

Crystal, D. (2007) How Language Works: How Babies Babble, Words Change Meaning and Languages Live or Die. London: Penguin.

European Commission. (2006) Promoting Language Learning and Linguistic Diversity: An Action Plan 2004-2006 [online]. Available from: www.saaic.sk/eu-label/doc/2004-06_en.pdf [Accessed 28 November 2018].

EURYDICE. (2009) Early Childhood Education and Care in Europe: Tackling Social and Cultural Inequalities. Brussels: European Commission.

García, O. (2009) Bilingual Education in the 21st Century: A Global Perspective. Malden, MA: Wiley-Blackwell.

García, O. (2011) The translanguaging of Latino kindergarteners, in Potowski, K. and Rothman, J. (eds) Bilingual Youth. Spanish in English-Speaking Societies. Amsterdam: John Benjamins. pp. 33-56.

García, O. and Kleyn, T. (2016) Translanguaging theory in education, in García, O. and Kleyn, T. (eds) Translanguaging with Multilingual Students. Learning from Classroom Moments. London: Routledge. pp. 9-33.

González-Davies, M. and Scott-Tennent, C. (2005) A problem-solving and student-centred approach to the translation of cultural references. Meta: Journal des traducteurs/Meta: Translators' Journal. 50(1), pp. 160-179.

Grosjean, F. (1982) Life with Two Languages: An Introduction to Bilingualism. Harvard: Harvard University Press.

Grosjean, F. (2010) Bilingual: Life and Reality. Cambridge, MA: Harvard University Press.

Hall, G. and Cook, G. (2013) Own-Language Use in ELT: Exploring Global Practices and Attitudes. ELT Research Papers 13-01 [online]. London: British Council. Available from: www.teachingenglish.org. uk/sites/teacheng/files/C448\%20Own\%20Language $\% 20$ use $\% 20$ in\%20ELT_A4_FINAL_WEB $\% 20$ ONLY_0.pdf [Accessed 20 May 2019].

Macaro, E. (2005) Teaching and Learning a Second Language. A Guide to Recent Research and Its Applications. London and New York: Continuum.

Marzà, A. and Ríos, I. (2016) La reflexió interlingüística a l'educació infantil, una eina per a l'aproximació a la llengua escrita. Llengua, societat i comunicació. 14, pp. 38-46.

May, S. (2014) The Multilingual Turn. Implications for SLA, TESOL and Bilingual Education. London and New York: Routledge.

Meier, G. (2017) The multilingual turn as a critical movement in education: Assumptions, challenges and a need for reflection. Applied Linguistics Review. 8(1), pp. 131-161.

Meyer, A., Rose, D.H. and Gordon, D. (2014) Universal Design for Learning: Theory and Practice. Wakefield, MA: CAST Professional Publishing.

Pontier, R. and Gort, M. (2016) Coordinated translanguaging pedagogy as distributed cognition: A case study of two dual language bilingual education preschool coteachers' languaging practices during shared book readings. International Multilingual Research Journal. 10(2), pp. 89-106. Available from: www.colorado.edu/education/sites/default/files/attached-files/Coord $\% 20$ Translang\%20 Pedag\%20as\%20Distrib\%20Cognition\%20\%28IMRJ\%2C\%20Pontier\%20\%26\%20Gort $\% 2$ C \%20 2016\%29.pdf [Accessed 21 May 2019].

Portolès, L. and Martí, O. (2017) Translanguaging as a teaching resource in early language learning of English as an additional language (EAL). Bellaterra Journal of Teaching \& Learning Language \& Literature. 10(1), pp. 61-77.

Scheffler, P. and Domińska, A. (2018) Own-language use in teaching English to preschool children. ELT Journal. 72(4), pp. 374-383.

Schwartz, M. and Asli, A. (2014) Bilingual teachers' language strategies: The case of an Arabic - Hebrew kindergarten in Israel. Teaching and Teacher Education. 38, pp. 22-32.

Sheets, R.H. (2005) Diversity Pedagogy. Examining the Role of Culture in the Teaching-Learning Process. Boston: Allyn and Bacon.

Sheets, R.H. (2009) What is diversity pedagogy? Multicultural Education. 16(3), pp. 11-17. 
Cristina Corcoll López and Jane Mitchell-Smith

Siraj-Blatchford, I. and Clarke, P. (2011) Supporting Identity, Diversity and Language in the Early Years. Buckingham: Open University Press.

Sutherland, H. and Mukadam, J. (2018) Supporting Toddlers' Wellbeing in Early Years Settings: Strategies and Tools for Practitioners and Teachers. London: Jessica Kingsley Publishers.

Westwood, S. (2018) Inclusive and Adaptive Teaching. Meeting the Challenge of Diversity in the Classroom. London: Routledge.

Wilson, J. and González-Davies, M. (2016) Tackling the plurilingual student/monolingual classroom phenomenon. TESOL Quarterly. 51, pp. 207-219. 


\title{
Primary bilingual classrooms Translations and translanguaging
}

\author{
Ofelia García, Gladys Y. Aponte, and Khanh Le
}

\section{Introduction}

This chapter considers the use of translation in primary classrooms. But most importantly, it attempts to differentiate translation from the concept of translanguaging. To draw a clear distinction, we focus on primary classrooms, and especially on those school settings where bilingualism and multilingualism are present. In some cases, a new language is being taught to language majority children (as an additional language) or language minoritized children (as a dominant additional language). In other cases, bilingual or multilingual minoritized children are being taught in two (or more) languages. The role of translation and translanguaging has had different histories in these diverse primary settings, and we will see how translanguaging rests on a different epistemology than that of translation. Translanguaging also has a much shorter intellectual history.

Translation has always been the bridge between two cultures, and two languages. In education, it has had an important role in the teaching of foreign languages, although it has often been neglected, especially since the mid-20th century as more communicative approaches to foreign language study became popular (Richard and Rodgers 1990). However, for language minoritized students, translation has never been an accepted strategy to make meaning, either in monolingual or bilingual or multilingual programmes of all types. Recently, however, translation as a pedagogical strategy has made some headway (Witte et al. 2009; Cook 2010; Pym et al. 2013; Tsagari and Floros 2013; Laviosa 2014, 2019) (in this volume, Ardizzoni and Holmes; Byram et al.; Corcoll and Mitchell-Smith, 2016; González-Davies, 2014; Hartmann, Hélot and Benert; and others).

In the 21 st century, as bilingualism has been increasingly seen as a marketable global resource readily exchangeable in the marketplace (Petrovic 2015; Heller and Duchêne, 2012), the teaching of additional languages has moved to the primary level for language majority students. And as programmes in language awareness, second language, Content and Language Integrated Learning (CLIL), as well as bilingual programmes proliferate at the primary level, translation to learn an additional language has had somewhat of a comeback (see, for example, Prasad 2018). This trend has also been felt in bilingual and multilingual programmes especially for language minoritized communities, where the recent development of translanguaging 
pedagogy (García, Johnson and Seltzer 2017; García and Kleyn 2017) has brought translation along, as a strategy to respond to new ways of understanding bilingualism (García and Li Wei 2014). And yet, as we will see in this chapter, translanguaging theory responds to a different epistemology about language and bilingualism/multilingualism than that of translation.

This chapter will first consider the role that translation has had in the history of language education, in relationship to the history of translanguaging, specifically at the primary level. It will then present theories and research findings on translation in translanguaging classrooms, before focusing on pedagogic approaches teachers have developed that take these findings into account. We then conclude by identifying future directions of translation and translanguaging studies in the primary classroom.

\section{Historical perspectives}

\section{From translation as bridge to keeping languages separate}

Language education has historically followed the Greek and Latin tradition of identifying parts of speech and rules in a written text and then applying them to construct text in a new language. In some ways, translation as a means of studying a foreign language has been with us for a long time (Coleman 1929). Yet the grammar-translation method that became prevalent throughout the 18th and 19th century started to crumble particularly in the second half of the 20th century (Richard and Rodgers 1990). During this time there was greater awareness that language education needed to go beyond that of 'foreign' language study, since there were many learners of what were deemed to be not foreign, but 'second languages' (Cook 2016). And specifically, for our topic, language education started to move to the primary level.

The main challenge to the grammar-translation method came with Berlitz, the German American who at the end of the 19th century came up with the direct method. Although forbidding any type of translation, language learning in the direct method also included grammar and vocabulary, and not necessarily authentic communication. But as young children started learning an additional language, the emphasis on grammar and vocabulary was deemed inadequate. Young children were seen as not yet capable of reflecting about grammatical categories or about 'equivalences' in two languages and were said to have little metalinguistic awareness. Translation, especially for young children, became forbidden in the many approaches to language learning that followed the direct method.

There was little attention worldwide to the language learning of young children until the later part of the 20th century when there was a worldwide ethnic revival (Fishman 1985). This revival was spurred by the newly independent nations of Africa and Asia where multilingualism was rampant, the greater recognition of some regional minorities in Western Europe and of indigenous groups especially in Latin America and the Pacific, the Civil Rights struggles in the United States, and the ascent to power of the Québecois party. One of the pillars of the nascent field of language policy became acquisition planning (Cooper 1989), with an emphasis on who plans what language to be acquired by new users, for whom and how.

The new post-colonial geopolitical order, where actors with different linguistic practices were visible, encouraged the development of different approaches to language learning among young children at the primary level. On the one hand, after the Québecois party gained political ascendancy in Québec, the dominant Anglophones supported the design of immersion bilingual education programmes for their children in order to make them bilingual. Especially prevalent were early-full immersion bilingual programmes where young Anglophone children started primary school totally through French. On the other hand, some minoritized 
populations who lived in bilingual or multilingual contexts were given access to transitional bilingual education in the early grades, with the explicit purpose of having them shift to the dominant language later on. This happened in the United States, but also, in Africa, Asia, and Latin America. Only when those language minoritized groups had gained some measure of political power was there access to developmental bilingual education programmes for language revitalization. This was the case, for example, of the Māoris of New Zealand. But despite the bilingual education approach followed - immersion, transitional, and developmental translation was said to be forbidden. Translation was also forbidden despite the political positioning of the group engaged in bilingual education, that is, whether they were language majorities seeking bilingualism, language minoritized groups forced into monolingualism in the dominant language, or language minoritized threatened groups reactivating a measure of political power.

In Canada, the immersion bilingual programmes at the primary level, designed for the Anglophone majority, followed the disdain for translations of the direct method. Young Anglophone children were immersed in French, and translations were strictly prohibited. The approach was based on adding a new separate language, French, to the dominant one, English, by ensuring that the Anglophone-dominant children maintained their Anglo identity intact. Translation was forbidden because children were expected to think, feel, and speak as Anglophones who spoke two separate languages, but not as bilinguals and certainly not as Francophone Québecois. Bilingualism was understood as the addition of a second language (an L2) to a first language (an L1); that is, bilingualism was said to be additive (Lambert 1974).

In Asia, Africa, and Latin America, language minoritized populations were expected to translate themselves into the colonial dominant group. Because language education was based on western epistemologies of language, and of the efforts exerted by nation states to construct themselves into a homogenous whole through one named language, the multilingualism of the indigenous population was erased and misunderstood. Instruction for indigenous minoritized peoples consisted of calquing what had been legitimated in western dominant contexts, most often in the colonial language. Transitional bilingual education became a post-colonial 'experiment' in most African and Asian countries, and a more democratic experiment in some countries of Latin America. The language of the 'other' also became regimented, its script developed so that it could be used to alphabetize the very young, but not throughout education. Bilingualism in this case was said to be subtractive (Lambert 1974).

In the United States, transitional bilingual education in the second half of the 20th century was experienced as a short-lived policy to improve the education of groups that had been conquered and colonized - Mexican Americans in the southwest, Puerto Ricans in the northeast, and Native Americans. It was this approach, grounded in the teaching of English to these groups, that was then used to educate the large immigrant populations that started arriving in the US from the latter part of the 20th century through today.

In all transitional bilingual education programmes, teachers were told to use only the language of instruction, whether that was the language designated to be 'of the group', or the dominant language - for example, English in the US. Translation was forbidden regardless of whether only one language was used until the transition to the dominant language took place, as in the case of many African, Asian and Latin American countries, or whether from the beginning there was some instruction in the dominant language as well, as was the case of programmes in the United States.

And yet, because it was impossible for these language minoritized children who were living in bilingual/multilingual societies to be educated in only one language, there was much use of what was said to be 'code-switching', that is, going from one language to another so that 
students understood the lesson. That is, to avoid formal translation as a pedagogical strategy, teachers often were said to code-switch, something that was supposed to be avoided, even though many claimed its value in teaching. (See, for example, Martin (2005) for Africa, and Jacobson and Faltis (1990) for the United States.)

In language minoritized situations where it became possible to establish more developmental forms of bilingual education, translation became equally forbidden. The two languages were expected to have separate spaces, allocated through day, time, subject, teachers, room, even building! For example, the Kura Kupapa Māori ('Māori philosophy schools') independent primary schools generally often have a different 'English language' building. The idea is that for the other subjects, everything is done through Māori. But again, as in the cases discussed earlier, much of what is often described as code-switching was taking place.

\section{Back to translation as bridge}

As more language minoritized young children and the languages they understood were used in primary education, language education theories that relied on monolingual instruction in the 'target' language, without any translation, started to be challenged. This was a result of language minoritized communities acquiring some sense of themselves as bilingual agentive subjects, but not in the sense of additive bilingualism, as defined by earlier scholarship, or in the sense of subtractive bilingualism to which they had previously been subjected. Bilingual minoritized communities started claiming their more dynamic bilingualism (García 2009), and bilingual scholars started describing their language use through this more dynamic lens. Along also came the questioning of a language education approach to develop bilingualism that was basically monolingual, an approach to bilingualism in education that was, as García (2009) pointed out, monoglossic. Scholars started to view translation again as a possible legitimate strategy to learn the language of the other.

As the 20th century came to a close, the European Union, eager to construct a sense of European citizenship, started promoting the vision that European citizens should learn two additional languages besides their first language. The Council of Europe coined the term plurilingualism to mean the ability "to use languages for the purposes of communication and to take part in intercultural action, where a person, viewed as a social agent, has proficiency, of varying degrees, in several languages and experience of several cultures" (Coste, Moore and Zarate 2009, p. 11). The goal of language teaching in the European Union became plurilingualism as a competence (Hélot and Cavalli 2017). Primary schools started developing pedagogies that valued cross-linguistic awareness, with translation as an important strategy (Witte et al. 2009; Pym et al. 2013; Laviosa 2014, 2019).

This more dynamic plurilingualism became a European value as the complex multilingualism of language minoritized communities also came into view. Besides plurilingualism, terms like polylanguaging, polylingual languaging (Jørgensen 2008), metrolingualism (Otsuji and Pennycook 2010; Pennycook and Otsuji 2015), translingual practices (Canagarajah 2013), and translanguaging (García 2009; Blackledge and Creese 2010; Li Wei 2011, 2018; García and Li Wei 2014; Otheguy et al. 2015, 2018) signalled the shift of modernist understandings of language and bilingualism to the more complex linguistic experiences of both language minoritized groups and language majorities that accompanied globalization and a neoliberal economy (Blommaert 2010; García et al. 2017).

Dynamic multilingual practices under a variety of terms became acknowledged and more studied by sociolinguists in the 21 st century. Two of those terms, however, became more used 
by language educators and applied linguists - plurilingualism and translanguaging. Although used interchangeably by many, plurilingualism and translanguaging have different beginnings, goals, purposes, and epistemologies (see García and Otheguy 2019). A focus on the role of translation in language education enables us to more clearly mark the different epistemologies of the two terms, for translation bridges cultures and languages, which is what plurilingualism desires, whereas translanguaging dwells in the entanglements of cultures and languages as it makes visible power differentials.

\section{From translation as bridge to transcending the bridge}

Translation has largely been seen as simply rendering in another language what has been said in the first. Professional translators work on rendering in another language the ideas, messages, style, metaphors, and even feelings and emotions of the author of the work. Translation acts as a bridge between languages and cultures, but it is a crossing, enabling the monolingual reader to access material that has been written by a monolingual author, and expressing through another language the worldviews of another culture. Even though translation is a bridge, it acts as an over-pass between two or more languages, cultures, people, or identities. It connects, but keeps worlds and words separate.

As colonial empires crumbled, translation was used to enable readers to read the work of former colonies. And yet, as the Argentinean semiotician, Walter Mignolo, has said, translation became "a tool to absorb the colonial difference" (2000, p. 3). Translation, argues Mignolo, attempted to erase the differences that exist in the colonial experience, translating the experiences and knowledges of subaltern racial/ethnic/sexual bodies as if they were those of the colonizers. In that sense, the intellectual knowledges of those who are colonized are silenced and dismissed as folklore or magic. When translation is used today as a strategy in educational programmes that aim to simply develop the plurilingual competence of children, it is mainly done across dominant European languages. Thus, translation constructs a bridge that leaves power differentials intact.

The term translanguaging, however, was coined in Welsh to describe a bilingual pedagogy developed by Cen Williams (1994), who used English and Welsh to develop the bilingual performances and identity of Welsh children in primary classrooms. It was translated into English by Colin Baker (2001). Translanguaging is epistemologically different from translation. Translanguaging was coined 'in the borderlands' (Anzaldúa 1987) by bilingual scholars within a minoritized context. It has been said that translanguaging must be understood through decolonial theory, in which the thinking occurs from and with subaltern racial/ethnic/sexual bodies (García 2019, García and Alvis, forthcoming). In addition to fighting the effects of the exploitation and the domination that came with colonialism, decolonial theory insists on contesting the production of knowledge and subjectivities that remained after the elimination of the colonial administration (Grosfoguel 2002; Quijano 2007). Translanguaging works, as Mignolo has said, "towards the restitution of the colonial difference, that colonial translation attempted to erase" (p. 4). In many ways, translanguaging is positioned not as an overpass bridge to go from one language and culture to another, but in the fluid corriente of practices that work within the entanglement of words and worlds in which many minoritized bilingual children live. García et al. (2017) speak about the translanguaging corriente, to emphasize the fluidity and dynamism by which children who live in 'the borderlands' do language. 


\section{Research approaches and key findings}

Translation is being used as an effective pedagogical strategy, but it is merely that. Translanguaging encompasses a theoretical sociolinguistic perspective that emerges from a bilingual minoritized context, which disrupts traditional understandings of language and bilingualism. This in turn has implications for pedagogical approaches. In this section, we will focus on research and findings that have had an impact on the development of translanguaging theory, especially as related to language education in primary classrooms.

The development of translanguaging theory owes much to the concept of heteroglossia advanced by Bakhtin (1981), as well as the proposal of the disinvention of named languages put forth by Makoni and Pennycook (2007). Bakhtin's notion of heteroglossia pointed to the diversity of features and voices contained within a single discourse; all language is then heteroglossic. Makoni and Pennycook took heteroglossia one step further, questioning the concept of named languages, and pointing to the ways in which the construction of a named language contributed to the dominance of some peoples and the exclusion of others. If indeed language was "heteroglot through and through" (Bakhtin 1981, p. 291) and named languages were social inventions (Makoni and Pennycook 2007), how then was it possible that bilingualism was understood as simply the addition of two languages, and that language education focused on that addition? This was the question that scholars working on translanguaging attempted to answer.

The term translanguaging spread beyond Wales and was used to describe the dynamic bilingualism of bilingual children and children in bilingual classrooms (García 2009; Blackledge and Creese 2010; Creese and Blackledge 2010; Li Wei 2011; Canagarajah 2013; for Wales, see Lewis et al. 2012a, 2012b). Some language educators adhere to what García and Lin (2017) have called "a weak version" of translanguaging, arguing that bilinguals do have two linguistic systems (MacSwan 2017), although they deploy them in dynamic discourse. Many other scholars, however, adhere to a 'strong version of translanguaging' in which bilingual children are said to have a unitary repertoire of meaning-making signs (García and Li Wei, 2014; Otheguy et al. 2015, 2018). We adhere to this strong version of translanguaging theory which posits that when bilinguals 'do' language, they are not drawing from two separate linguistic systems, one that corresponds simply to one named language, separate from that of another named language. Translanguaging theory instead views the bilingual speaker's psycholinguistic reality as being unitary, an extended repertoire of features and signs that have been assembled (Pennycook 2017), given how they have lived their lives and the people with whom they have had opportunities to interact (Li Wei 2011, 2018; García and Li Wei 2014; Otheguy et al. 2015, 2018; García 2019).

As we will see in the next section, teachers in translanguaging classrooms often use translation exercises. However, they do so not to promote the children's intercultural communication with language that is 'appropriate' for the other group, as do those whose goal is to develop the children's plurilingual competence. Instead, teachers in translanguaging primary classrooms use translation as a strategy to empower bilingual children so that they use their unitary semiotic repertoire to make meaning for themselves as minoritized beings, and thus develop their agency as bilingual subjects. These teachers are not looking for ways of saying things in the language of the other, but in the children's own language and through the children's own experiences and lives.

A translanguaging view of young children in primary classrooms enables us to see them as having complete and full repertoires. A translanguaging classroom, whether officially bilingual or monolingual, would insist that children's full linguistic repertoire be made available to 
them to make meaning of their lives and of the politics surrounding their language use. New linguistic features cannot be simply added as separate from those of the language children speak; children integrate them fully into their language repertoire as their own, and not simply as a second language.

When primary school teachers have what García et al. (2017) call a 'translanguaging stance', they may use translation. However, it is important to keep the epistemological difference between translation and translanguaging up front. Traditional translation, we repeat, upholds different named languages and makes possible for someone to communicate with someone said to speak another named language. The communication is intercultural, with each language and culture remaining intact. Translanguaging, however, works with the transculturación (Ortiz 1940) of people in most diverse societies. People who are intermingling with others and with different ways of doing language do not remain the same. Translanguaging makes the colonial difference visible. That is why translanguaging in itself is a political act (Flores 2014).

The term translanguaging is often used interchangeably with that of code-switching. However, like translation, code-switching is understood as a going back and forth between one named language and the other, which is not what translanguaging implies. Whereas codeswitching refers to language use within a speaker or writer, translation is said to occur between different people and cultures. But translanguaging differs from both the concepts of codeswitching and translation in that bilingual speakers are said to be drawing from a unitary linguistic repertoire to make meaning for themselves, a repertoire that is not simply cognitively dual. That is, because named languages are social representations, laypeople perceive signs as belonging to different linguistic systems. But for bilingual speakers, these signs are also part of their semiotic repertoire, a repertoire made up of signs that correspond to how and with whom they have lived and the opportunities for languaging that they have had.

When young bilingual children perform tasks with their own features, teachers with a translanguaging stance do not see their performances and acquisition as being 'incomplete' because they are not comparing them to the performances of so-called 'native' speakers. Instead, as we will see in the next section, they leverage the children's full semiotic repertoire that has been constructed through their experience as racial/ethnic/sexual/classed beings. In so doing, teachers extend the meaning-making repertoire of young children and make them understand the complexity of their own repertoire and that of their listeners. Teachers help young children to become conscious of their audience. In selecting signs from their repertoire, children explore how to select the best clues for listeners who are also acknowledged to have a complex history as racial/ethnic/sexual/classed beings. That is, teachers help all children construct themselves as legitimate languagers and to see 'others' in their complexity and languaging as a complex act.

The differences that we have drawn between traditional concepts of bilingualism/ multilingualism, the more dynamic concept of plurilingualism, and the more radical concept of translanguaging leads to different pedagogic approaches. We focus in the next section on the pedagogical differences regarding traditional translation that became evident once the concept of plurilingualism and translanguaging made their entrance into applied linguistics in the early 21 st century.

\section{Pedagogic approaches and methods}

Language education programmes that follow the plurilingualism ethos address the development of the two plurilingual components identified by the Council of Europe - (1) plurilingualism 
as competence, meaning the capacity to use and learn more than one language, and (2) plurilingualism as value, that is, the development of linguistic tolerance or equal valuing of all varieties of language used.

The first component, plurilingualism as competence, has resulted in new directions of the so-called core foreign language education programmes. Whereas in the core foreign language programmes the language was the subject of instruction, in Content and Language Integrated Learning (CLIL) programmes language is taught through content (Marsh 2002; Coyle 2008; Marsh et al. 2010). Because CLIL programmes start as early as possible, and because the additional language is used, rather than taught, they are based on similar principles to the immersion programmes described previously. However, because instruction is less intense, often lasting one to two periods of daily instruction, translation is a frequently used pedagogical strategy.

The second component, plurilingualism as value, has been responsible for the development of many multilingual awareness projects especially at the primary level. Some of these projects focus on developing plurilingual competence by contrasting, for example, different Romance languages (Araújo and Sá and Melo 2009). Translation is often an important pedagogical practice in these programmes as young children become aware of the similarities and differences among different Romance languages. Some projects go beyond European languages and include migrant languages to make children conscious of the linguistic diversity in their communities (Perregaux 1995; Melo-Pfeifer 2015). One initiative along these lines funded by the European Commission in five countries is the Evlang project directed by Michel Candelier (see Candelier 2003). Hélot and Young (2006) report on a project they launched, the Didenheim project, in which young children were engaged with many languages, including those of the community in which they lived. In all these projects the goal is to have young children translate the experiences of others into their own languages. By doing so, they become aware and tolerant of others' experiences, cultures, and languages.

The term translanguaging, as we have said, was coined to refer to a bilingual pedagogical approach. But because of its origin in a minoritized bilingual Welsh community, the pedagogical practice was a way to make Welsh children aware of the power of their own dynamic bilingualism, but also of the role that the English language had had in their oppression. Thus, from the beginning, translanguaging pedagogical practices have focused on making children aware of the ways in which language education norms have been used to minoritize communities so as to develop their criticality (Li Wei 2011).

When translation occurs, translanguaging pedagogical practices firmly support the learners' subjectivities and ways of knowing as active bilingual subjects. García et al. (2017) refer to three strands of a translanguaging pedagogy: (1) translanguaging stance, (2) translanguaging design, and (3) translanguaging shift. To get started, teachers need to develop a stance that children 'do' language with all the signs in their repertoire, linguistic and multimodal, and that all of their ways of languaging are valid, authentic, and important. To do so, teachers need to understand the political dimensions of named standard languages. Teachers who develop translanguaging practices must see the whole child, assessing them fully from different perspectives, and without relying solely on the use of a standard code. Instruction must then be designed carefully, insisting that translanguaging have a valid space, but also with flexibility, so that children are put in charge of instruction, with teacher guidance. That is why a translanguaging pedagogy always insists on the opportunity of shifts, as teachers respond to the inquiries being made by students about their own learning. 
An example of how translation is handled by a teacher with what we might call a plurilingualism stance and one with a translanguaging stance may make this difference clearer.

- La señora Joanna is teaching Spanish in a CLIL fourth grade classroom in France. To ensure that students understand a text they are reading, she asks the children to translate the first two sentences into French. They do this without difficulty because they are all French speakers. She then asks them to translate it back to Spanish without looking at the Spanish text. She corrects their oral and their written translations and expects them to be very close to the original Spanish text.

- Cô Minh is teaching young children of Vietnamese descent in an after-school programme in the US. She reads the first paragraph of a Vietnamese folk tale, "The Tiger" in Vietnamese, showing pictures, acting out the scene, and using translation when the majority of students can't understand. She then groups the children, gives them a recording of what she has just read in Vietnamese and asks them to write a script that acts out the first scene of the story. The children have different familiarity with Vietnamese, both orally and in writing. They negotiate among themselves how to 'translate' the story they have read for themselves into oral and written Vietnamese. Their written scripts contain what some would consider words in English and/or 'incorrect' Vietnamese. For example, one group writes, "Hi [Hai] con who [hổ] đang dee [đi] đến con song [sông] team [tìm] đồ ăn và nhìn thấy một con thỏ. [Two tigers are going to the river to find food and see a rabbit]". Cô Minh celebrates their use of Vietnamese and their adept use of recognizing Vietnamese sounds in their own words as a means to retell the story.

As a result of the collaboration between the City University of New York and the New York State Department of Education, the CUNY-NYSIEB project has been working with schools across the state that have a large number of emergent bilinguals (García and Kleyn 2016). From the beginning, the project assumed a translanguaging theoretical stance about language and bilingualism (see García 2009; García and Li Wei 2014). An example of translation as performed with a translanguaging theoretical lens is the inquiry-based social studies project undertaken in the fall of 2018 in a dual language bilingual primary school, Dos Puentes. Under the leadership of the 2018-2019 project director, Dr. Ivana Espinet, alongside the former project director, Dr. Maite Sánchez, and Gladys Aponte, and with the strong collaboration of the principal, Dr. Victoria Hunt, and the teachers, students in each grade have been positioned as ethnographers of their communities. In the project they use translations only to make their bilingual lives visible to all. Rather than maintain the day's target language (English or Spanish), students have been encouraged to use all of their linguistic and multimodal resources simultaneously, critically, and reflectively during this inquiry space.

To launch their main inquiry, "Why does language matter?", a group of third graders began by individually, and then collectively, reflecting on how, when, and for what purposes they use language. Students realized that they share similar experiences. Almost all students are Latinx, mostly of Dominican descent. They live in the same neighbourhood, and they attend the same bilingual school. And yet, each of their repertoires is distinctively reflective of their individual lived experiences and the opportunities they have had. Throughout the project, students have led critical discussions about the language they use. They also analyze their language use and the connections to cultural practices by bringing their funds of knowledge into the classroom (Moll et al. 1992). By inviting family members into the classroom to share of themselves and 
tell their stories, and also by bringing artefacts and tales from home, these third graders are also making room for different epistemologies and knowledge systems to be present in school.

As students have developed a more dynamic perception of language, the youth have also become critical of other sociolinguistic dynamics in their communities. For example, the third graders ( 8 to 9 years old) decided to walk around their community - a predominantly poor Latinx neighbourhood that is becoming increasingly diverse/gentrified - to interview community members and analyze the linguistic signs and language use outside of the school setting. In doing so, students noticed how business owners, customers, pedestrians, street vendors, and written signs use language in fluid ways that transcend the Spanish and English boundaries that are normalized by educational texts in schools. For instance, students discussed that business awnings contained words like dentista, Dra., insurance, laundromat, and precio especial. There was a heated discussion about whether these were words from English or from Spanish, and why there was no translation of any of these words into the other language. The children came to the conclusion that the signs portray the overall multilingual identity of their community, and that they referred to the language of the community. They discussed, for example, why someone would have preferred Dra. instead of Dr. and agreed that Dra. signalled a female doctor, something that Dr. would not have communicated. And they agreed that there was no way to say laundromat any other way, for this was a context that in their experience only existed in NYC. To these third graders this was simply the language of their bilingual community.

The most notable conversation that the third graders had during their community walk involved students' affirmation of the word deliverista on a storefront sign that read, "Buscamos un deliverista" [We are seeking a delivery person]. Words like deliverista, which emerge from 'borderlands' lived experiences, are often disparaged for being Spanglish (for a counterview, see Otheguy and Stern 2011). Although students first questioned whether the term was a Colombian, Dominican, or Mexican word, they soon validated it as simply being part of their community's fluid, yet often marginalized, language practices. That is, rather than translate themselves into dominant named languages, the children confidently translated the phrase through a translanguaging analytic. By being positioned as ethnographers and mediators of their unique linguistic identities, students have developed pride, self-awareness, and criticality, and have begun to understand that translation is uniquely different in every interaction they engage in, within and beyond their community. Translation, they have come to realize, goes beyond pleasing dominant listening subjects who adhere to monolingual conventions. Translation, if analyzed through a translanguaging stance, can be a way of making minoritized speakers visible and audible, offering them legitimation and empowerment as valid languagers.

\section{Conclusions and future directions}

Translation has a different uptake in language theories that view languages on the one hand as autonomous structures and bilingualism as L1+ L2, and on the other hand more post-structural positions that understand language and bilingualism as a process of assembling signs to make meaning with others. Translation as a pedagogical practice then behaves differently when it is used in traditional language education programmes, in programmes that support plurilingualism, and in those that take up a translanguaging theoretical lens. When used within a translanguaging theoretical framework, translation can indeed work toward the restitution of what Mignolo (2000) called 'the colonial difference', with minoritized bilingual speakers able to translate for themselves and their communities with their own tools and epistemologies. For, as Audren Lorde (1979) famously said, “the master's tools will never dismantle the master's house” (n.p.). 


\section{Further reading}

Fu, D., Hadjioannou, X. and Zhou, X. (2019) Translanguaging for emergent bilinguals. Inclusive teaching in the linguistically diverse classroom. New York: Teachers College Press.

This is a practice-based approach to translanguaging for primary classrooms, focusing on diverse emergent bilingual students in the U.S. The book breathes life into translanguaging classrooms where we see teachers using tools for different opurposes to meet the academic, social and instructional challenges that emergent bilinguals face.

García, O. and Li Wei. (2014) Translanguaging: Language, Bilingualism and Education. London: Palgrave Macmillan Pivot.

This is a short introduction to translanguaging. Part I covers the antecedents and the theory of translanguaging, focusing on transformations of language, bilingualism, and the effects of creativity and criticality. Part II focuses on translanguaging and education, outlining its history and the ways it is used by students and teachers. It ends with outlining principles of a translanguaging pedagogy.

García, O., Johnson, S. and Seltzer, K. (2017) The Translanguaging Classroom. Leveraging Student Bilingualism for Learning. Philadelphia: Caslon.

Although focused on the US context, this text offers guidance to teachers about how to set up translanguaging classrooms. It presents vignettes of how three teachers - an elementary bilingual teacher, a middle school content teacher, and a high school English teacher - use translanguaging in their classrooms. It develops the purposes of translanguaging, as well as how to design instruction and assessment. In Part II, the three strands of a translanguaging pedagogy are developed - stance, design and shifts. Part III give us examples of how different teachers take up translanguaging to meet standards, to develop literacies and biliteracies performances, and to support the students' socioemotional well-being and social justice.

Zhongfeng, T. and Link, H. (eds) (2019) Positive Synergies: Translanguaging and Critical Theories in Education. Special Issue of Translation and Translanguaging in Multilingual Contexts. 5(1).

This is an edited special issue that links translanguaging to different theoretical perspectives Halliday's Systemic Functional Linguistics, Freire's critical pedagogy and critical literacies, and post-structural feminism. It does so by discussing how the interaction has been taken up in different classrooms and types of educational settings. As such, translanguaging is deepened and transformed.

\section{Related topics}

bilingual education, bilingualism and multilingualism, language education, plurilingualism, teacher education, translanguaging

\section{References}

Anzaldúa, G. (1987) Borderlands/La Fontera. The New Mestiza. San Francisco: Aunt Lute Books.

Araújo e Sá, M.H. and Melo, S. (2009) Online plurilingual interaction in the development of language awareness. Language Awareness. 16(1), pp. 7-14. doi: 10.2167/la356.0.

Baker, C. (2001) Foundations of Bilingual Education and Bilingualism. 3rd ed. Clevedon: Multilingual Matters.

Bakhtin, M. (1981) The Dialogic Imagination: Four Essays. Austin, TX: University of Texas Press.

Blackledge, A. and Creese, A. (2010) Multilingualism: A Critical Perspective. London: Continuum.

Blommaert, J. (2010) The Sociolinguistics of Globalization. Cambridge: Cambridge University Press.

Canagarajah, S. (2013) Translingual Practice: Global Englishes and Cosmopolitan Relations. London: Routledge.

Candelier, M. (2003) Evlang - l'éveil aux langues à l'école primaire - Bilan d'une innovation européenne. Bruxelles: De Boeck/Ducolot.

Coleman, A. (1929) The Teaching of Modern Languages in the United States. New York: Macmillan. 
Cook, G. (2010) Translation in Language Teaching: An Argument for Reassessment. Oxford: Oxford University Press.

Cook, V. (2016) Second Language Learning and Language Teaching. 5th ed. New York: Routledge.

Cooper, R.L. (1989) Language Planning and Social Change. Cambridge: University Press.

Coste, D., Moore, D. and Zarate, G. (2009) Plurilingual, pluricultural competence. Strasbourg: Language Policy Division, Council of Europe. https://rm.coe.int/168069d29b.

Coyle, D. (2008) Content and language integrated learning: Towards a connected research agenda for CLIL pedagogies. International Journal of Bilingual Education and Bilingualism. 10(5), pp. 543562. doi: $10.2167 /$ beb459.0.

Creese, A. and Blackledge, A. (2010) Translanguaging in the bilingual classroom: A pedagogy for learning and teaching? Modern Language Journal. 94(i), pp. 103-115.

Fishman, J. (1985) The Rise and Fall of the Ethnic Revival. Berlin: Mouton Publishers.

Flores, N. (2014) Let's Not Forget That Translanguaging Is a Political Act. Educational Linguist [online]. Available from: https://educationallinguist.wordpress.com/2014/07/19/lets-not-forget-thattranslanguaging-is-]a-political-act/ [Accessed 26 November 2018].

García, O. (2009) Bilingual Education in the 21st Century: A Global Perspective. Malden, MA: Wiley-Blackwell.

García, O. (2019) Decolonizing foreign, second, heritage and first languages: Implications for education, in Macedo, D. (ed) Decolonizing Foreign Language Education. New York: Routledge. pp. 152-168.

García, O. and Alvis, J. (forthcoming). The Decoloniality of language and translanguaging: Latinx knowledge-production. Journal of Postcolonial Linguistics, Vol 1.

García, O., Flores, N. and Spotti, M. (2017) The Oxford Handbook of Language and Society. New York and Oxford: Oxford University Press.

García, O., Johnson, S. and Seltzer, K. (2017) The Translanguaging Classroom. Leveraging Student Bilingualism for Learning. Philadelphia: Caslon.

García, O. and Kleyn, T. (Eds.) (2016) Translanguaging with Multilingual Students: Learning from Classroom Moments. New York and London: Routledge.

García, O. and Lin, A. (2017) Translanguaging and bilingual education, in García, O., Lin, A. and May, S. (eds) Bilingual and Multilingual Education. Cham, Switzerland: Springer. pp. 117-130. doi: 10.1007/978-3-319-02324-3_9-1.

García, O. and Otheguy, R. (2019) Plurilingualism and translanguaging: Commonalities and divergences. International Journal of Bilingual Education and Bilingualism. doi: 10.1080/13670050.2019.1598932.

García, O. and Li Wei, (2014) Translanguaging: Language, Bilingualism and Education. London: Palgrave Macmillan Pivot.

González-Davies, M. (2014) Towards a plurilingual development paradigm: From spontaneous to informed use of translation in additional language learning. The Interpreter and Translator Trainer. $8(1)$, pp. $1-14$.

Grosfoguel, R. (2002) Colonial difference, geopolitics of knowledge and global coloniality in the modern/colonial capitalist world-system. Review. 25(3), pp. 203-224.

Heller, M. and Duchêne, A. (2012) Language in Late Capitalism: Pride and Profit. New York: Routledge.

Hélot, C. and Cavalli, M. (2017) Bilingual education in Europe: Dominant languages, in García, O., Lin, A. and May, S. (eds) Bilingual and Multilingual Education. Cham, Switzerland: Springer. pp. 471-488.

Hélot, C. and Young, A. (2006) Imagining multilingual education in France: A language and cultural awareness project at primary school, in García, O., Skutnabb-Kangas, T. and Torres-Guzmán, M.E. (eds) Imagining Multilingual Schools. Languages in Education and Glocalization. Clevedon, UK: Multilingual Matters. pp. 69-90.

Jacobson, R. and Faltis, C. (1990) Language Distribution Issues in Bilingual Schooling. Clevedon: Multilingual Matters.

Jørgensen, J.N. (2008) Polylingual languaging around and among children and adolescents. International Journal of Multilingualism. 5(3), pp. 161-176. 
Lambert, W.E. (1974) Culture and language as factors in learning and education, in Aboud, F.E. and Meade, R.D. (eds) Cultural Factors in Learning and Education. A collection of papers presented at the Fifth Western Symposium on Language, Bellingham, Washington, 15-16 November. pp. 91-122.

Laviosa, S. (2014) Translation and Language Education: Pedagogic Approaches Explored. London and New York: Routledge.

Laviosa, S. (2019) Language teaching, in Baker, M. and Saldanha, G. (eds) Routledge Encyclopedia of Translation Studies. 3rd ed. London and New York: Routledge.

Lewis, G., Jones, B. and Baker, C. (2012a) Translanguaging: Developing its conceptualisation and contextualization. Educational Research and Evaluation. 18(7), pp. 655-670.

Lewis, G., Jones, B. and Baker, C. (2012b) Translanguaging: Origins and development from school to street and beyond. Educational Research and Evaluation. 18(7), pp. 641-654.

Li Wei. (2011) Moment analysis and translanguaging space: Discursive construction of identities by multilingual Chinese youth in Britain. Journal of Pragmatics. 43(5), pp. 1222-1235.

Li Wei. (2018) Translanguaging as a practical theory of language. Applied Linguistics. 39(1), pp. 9-30.

Lorde, A. (1979) History Is a Weapon. The Master's Tools Will Never Dismantle the Master's House [online]. Available from: www.historyisaweapon.com/defcon1/lordedismantle.html [Accessed 11 December 2018].

MacSwan, J. (2017) A multilingual perspective on translanguaging. American Educational Research Journal. 54(1), pp. 167-201.

Makoni, S. and Pennycook, A. (2007) Disinventing and Reconstituting Languages. Clevedon: Multilingual Matters.

Marsh, D. (2002) CLIL/EMILE: The European Dimension: Action, Trends and Foresight Potential. UniCOM. University of Jyväskylā Finland.

Marsh, D., Coyle, D. and Hood, P. (2010) CLIL: Content and Language Integrated Learning. Cambridge: Cambridge University Press.

Martin, P. (2005) 'Safe' language practices in two rural schools in Malaysia: Tensions between policy and practice, in Lin, A. and Martin, P. (eds) Decolonisation, Globalisation. Language-in-Education Policy and Practice. Clevedon: Multilingual Matters. pp. 74-974.

Melo-Pfeifer, S. (2015) Multilingual awareness and heritage language education: Children's multimodal representations of their multilingualism. Language Awareness. 24(3), pp. 197-215. doi: 10.1080/09658416.2015.1072208.

Mignolo, W. (2000) Local Histories/Global Designs: Essays on the Coloniality of Power, Subaltern Knowledges and Border Thinking. Princeton: Princeton University Press.

Moll, L.C., Amanti, C., Neff, D. and Gonzalez, N. (1992) Funds of knowledge for teaching: Using a qualitative approach to connect homes and Classrooms. Theory into Practice. 31(2), pp. 132-141.

Ortiz, F. (1940/1978). Contrapunteo cubano del tabaco y el azúcar [Tobacco and sugar: A Cuban counterpoint] Caracas: Biblioteca Ayacucho.

Otheguy, R., García, O. and Reid, W. (2015) Clarifying translanguaging and deconstructing named languages: A perspective from linguistics. Applied Linguistics Review. 6(3), pp. 281-307.

Otheguy, R., García, O. and Reid, W. (2018) A translanguaging view of the linguistic system of bilinguals. Applied Linguistics Review. doi: 10.1515/applirev-2018-0020.

Otheguy, R. and Stern, N. (2011) On so-called Spanglish. International Journal of Bilingualism. 15(1), pp. $85-100$.

Otsuji, E. and Pennycook, A. (2010) Metrolingualism: Fixity, fluidity and language in flux. International Journal of Multilingualism. 7(3), pp. 240-254.

Pennycook, A. (2017) Translanguaging and semiotic assemblages. International Journal of Multilingualism. 14(3), pp. 269-282. doi: 10.1080/14790718.2017.1315810.

Pennycook, A. and Otsuji, E. (2015) Metrolingualism: Language in the City. Oxford and New York: Routledge.

Perregaux, C. (1995) L'école, espace plurilingue. Lidil. 11, pp. 125-139.

Petrovic, J. (2015) A Post-Liberal Approach to Language Policy in Education. Bristol: Multilingual Matters. 
Ofelia García, Gladys Y. Aponte, and Khanh Le

Prasad, G. (2018) Building students' language awareness and literacy engagement through the creation of collaborative multilingual identity texts 2.0, in Frijns, C. and Helot, C. (eds) Language Awareness in Multilingual Classrooms in Europe: From Theory to Practice. Berlin: Mouton De Gruyter Publishers. pp. 207-234.

Pym, A., Malmkjær, K., Gutiérrez-Colon Plana, M., Lombardero, A. and Soliman, F. (2013) Translation and Language Learning. Luxembourg: Publications Office of the European Union.

Quijano, A. (2007) Coloniality and modernity/rationality. Cultural Studies. 21(2), pp. 168-178.

Richards, J.C. and Rodgers, T. (1990) Approaches and Methods in Language Teaching. Cambridge: Cambridge University Press.

Tsagari, D. and Floros, G. (eds) (2013) Translation in Language Teaching and Assessment. Cambridge: Cambridge Scholars Publishing.

Williams, C. (1994) Arfarniad o Ddulliau Dysgu ac Addysgu yng Nghyd-destun Addysg Uwchradd Ddwyieithog [An Evaluation of Teaching and Learning Methods in the Context of Bilingual Secondary Education]. Doctoral thesis, University of Wales, Bangor.

Witte, A., Harden, T. and Ramos de Oliveira, H. (eds) (2009) Translation in Second Language Learning and Teaching. Berne: Peter Lang. 


\title{
Pedagogical affordances of translation in bilingual education
}

\author{
Esa Hartmann and Christine Hélot
}

\section{Introduction}

$\mathrm{Be}$ it in order to practice linguistic mediation according to the latest recommendations of the Council of Europe (2018) and the research of Coste and Cavalli (2015) for example, or to foster metalinguistic awareness and multilingual literacy (Hornberger and Link 2012; Hélot 2014, amongst others), many researchers have shown that translation plays an essential role in additional language teaching and learning (Cook 2001, 2003; Macaro 2005; GonzálezDavies 2011, 2017; Laviosa 2014a, 2014b; Panzarella and Sinibaldi 2018, amongst others) and bi-/multilingual education (Hélot et al. 2014; Laviosa 2014a, 2014b; González-Davies 2015 , amongst others). Triggered by the need to deal with linguistic and cultural diversity in a globalized multilingual world, linguistic mediation has recently been conceptualized and promoted by the Council of Europe (2018) both as an intercultural social practice and a goaloriented communication skill based on the autonomy and creativity of the additional language learner.

Linguistic mediation was first mentioned in the Common European Framework of Reference for Languages (Council of Europe 2001) as one of the principal communication competencies to be aimed at in the context of additional language teaching and learning, and defined as follows:

The written and/or oral activities of mediation make communication possible between persons who are unable, for whatever reason, to communicate with each other directly. Translation or interpretation, a paraphrase, summary or record, provides for a third party a (re)formulation of a [spoken or written] source text to which this third party does not have direct access. Mediating language activities - (re)processing an existing text - occupy an important place in the normal linguistic functioning of our societies.

(Council of Europe 2001, p. 4)

As a result, linguistic mediation activities presently play an essential and ritualized part in the learning units of numerous L2 textbooks, and translation has found a new legitimacy in the teaching and learning of an additional language. According to González-Davies, 
Translation helps improve FLL [foreign language learning], intercultural competence and self-regulation skills by putting into practice cognitive skills, mainly, problem spotting and problem solving. It also caters for different learning styles and, thus, empowers the students while opening their minds to a wide range of mental and cultural constructs. All this favours an awareness of the relationships, similarities and differences between cultures and languages.

(2011, p. 445)

Translation as a translingual activity has equally found its legitimacy in the multilingual L2 classroom. For instance, recent research reported that translation represents an important evaluation tool in the acquisition of L2 grammar structures, by investigating the effect of literal translation as a noticing technique on learning important grammatical structures in English Language Teaching. According to a research project carried out by Soleimani and Heidarika (2017, p. 1), "the results revealed that the use of translation significantly affected participants' noticing and learning the targeted grammatical structures".

In this chapter, we will consider the act of translation as a translingual activity in the context of bilingual education in primary education in France. We would like to argue that translingual activities are examples of a new pedagogical approach to translation in a bilingual education context. This is supported by the semantic content of the word translation, etymologically deriving from the latin noun translatio, f., composed of the prefix trans- 'across' and the verb ferre (fero tuli latum) 'to bring', 'to carry' (the nominal suffix -latio deriving from the past participle latum). Accordingly, we define translation as the dynamic process of 'bringing across' a text (in its oral or written form) from a source language towards a target language, but also as a process of shuttling between languages, as in translingual practices. Consequently, we see the act of translation as a dynamic process of 'carrying across' intellectual contents from one language to another, from one culture to another, but also as a form of mediation between languages (the latin verb mediare means 'to be in the middle'), a process between and among languages that connects different languages in a meaningful way.

The linguistic and cultural transfer crystallized in the translation activity implies the act of crossing borders between languages and building bridges between cultures (Benert and Hélot 2009). Along with other researchers such as Canagarajah (2011) for example, we wish to show how translation can be envisaged as a powerful pedagogical strategy to foster integrated and translingual learning, as well as the development of biliteracy and metalinguistic awareness (Hélot 2014; Otheguy et al. 2015).

\section{Historical perspectives}

Using translation as a pedagogical approach in bi-/multilingual education has rarely been explored (Hélot et al. 2014; Laviosa 2014a, 2014b; Daly et al. 2018) despite all the research showing the role of the relationship between L1 and L2 (Cummins 2011), of metalinguistic awareness (Lyster 2014; Velasco and Fialais 2016), and of translanguaging (García 2009, García and Li Wei 2014; Creese and Blackledge 2010) in bilingual acquisition. The main reason has to do with language education policies that are informed by monoglossic ideologies of bilingualism and fear of bilingual education having a negative impact on the development of the so-called first language (Baetens Beardsmore 2003).

Bilingual education in Alsace has been studied from different perspectives (historical and political, see Huck 2016, 2018; educational, see Hélot 2014; Hélot and Fialais 2014). Since the beginning of bilingual education in French public schools in 1992, the language policy 
that governs the organization of bilingual education in the region of Alsace is grounded on the didactic and structural separation of the two languages of instruction, French and German. The pedagogical aim of this bilingual programme implies high literacy proficiency in French as well as in German, while the political aim entails the conservation of a language in danger, the Alsatian variety (Hélot 2014; Huck 2016). However, the standard variety of German (Hochdeutsch) has been chosen for teaching and learning (Huck 2016, 2018), instead of the local variety spoken in Alsace, Alsatian. The curriculum starts from age three in kindergarten and is available until the age of 18 , and the baccalaureate examination can be chosen as the binational Abibac (combining the German Abitur and the French baccalaureate). Hélot (2014) has described this programme as early partial immersion (also called "50/50 immersion" in Canada). This $50 \%$ immersion gives the emergent bilingual students ${ }^{1}$ the maximum exposure legally possible to the German language, since full immersion programmes have twice been rejected by the constitutional court in 1994 and 2002. According to the prescribed curriculum (Ministère de l'Éducation nationale 2015), content taught in either German or French must follow the guidelines of the French curriculum, and learners must be exposed equally to each language. ${ }^{2}$

Consequently, one teacher is responsible for the German part of the programme, and a different teacher for the French part. The two languages as well as the subject contents taught through these two languages have been described as "two solitudes" (Cummins 2007, p. 229), or two separate linguistic spaces producing double or parallel monolingualism (Hélot 2014). Based on the well-known model of Ronjat (1913), the one parent one language policy was believed to lead to "balanced bilingualism" in children growing up in a mixed lingual family. Indeed, the strict separation of the two school languages in bilingual education in Alsace is meant to prevent young language learners from mixing the two languages, since language mixing is still considered an obstacle for the acquisition of normative academic language. This concern expresses a lack of understanding: in reality, languages are socially defined entities, which do not correspond to national borders or language categorizations.

In this context, the predominant pedagogic approaches and methods are determined by the one language one teacher policy. This top-down policy reflects the prevalent monolingual ideology that defines most bilingual programmes in France (Hélot and Erfurt 2016) and makes bilingual teachers question translation or any form of language contact, mixing or translanguaging. Consequently, recent research, which has shown the affordances of the pedagogical practices of linguistic transfer, translation, and cross-linguistic activities (Canagarajah 2006; Hornberger and Link 2012; García and Li Wei 2014; Cummins 2016), is difficult to implement in bilingual classrooms in Alsace. They are not only difficult to implement concretely, but ideologically, teachers need to shift their own representations of bilingualism. From the learners' point of view, the one language one teacher policy implies that teachers are exclusively functioning in a monolingual mode and therefore preventing emerging bilinguals from constructing a bilingual identity (Hélot 2011, 2014; García and Li Wei 2014).

Furthermore, this monolingual conceptualization of language allocation is not limited to the education of emergent bilingual students; it equally affects the education of trainee teachers working within this curriculum. Whereas trainee teachers in charge of the French part of the curriculum enrol in a regular monolingual teacher education programme in primary education (master degree called "polyvalent"), trainee teachers assigned to the German part attend a specific course in bilingual primary education (master degree called "bilingual") with additional examinations in German. Paradoxically, although bilingual, the latter will teach all their courses only through the German language. The former, on the contrary, are considered 
and educated as regular mainstream teachers, although educating emergent bilingual students within a bilingual curriculum.

Consequently, the imagined implementation of translation as a pedagogical practice, which may be considered as a logical outcome of the Linguistic Interdependence Hypothesis (Cummins 2007, 2011), represents a real challenge for teacher educators in Alsace, in view of the numerous institutional and ideological hurdles created by the institutional policy. In this context, we have chosen to address first the issue of translation from the bilingual trainee teachers' point of view.

\section{Research approaches and key findings}

Wishing to investigate bilingual teachers' ideological representations of translation, we carried out a research project at the Graduate School of Education (ESPE) of the University of Strasbourg (France) with 25 bilingual teachers completing their first year of teaching practice in bilingual preschools and primary classrooms (September 2017-July 2018). First, we asked them (in December 2017) to answer a written questionnaire to examine their understanding of the one teacher one language policy, as well as their representations of translation practice in bilingual education. The discourses were collected in French during a training session and have been translated into English by the authors of this chapter.

Second, we designed a multilingual literacy-reading project based on a children's story in three languages, and recorded focus group interviews to explore the teacher's approaches to translation within the pedagogical context of reading a children's story in three languages (Tomi Ungerer's The Three Robbers - Die drei Raiwer 2008, in Alsatian, German, and French). Our objective was to make bilingual teachers aware of the pedagogical affordances of translation in bilingual education.

\section{The one teacher one language policy: teachers' representations}

It should be made clear that bilingual teachers know from the outset about the one teacher one language policy, and that they are in charge of the German part within a 50\% immersion programme. However, they are not always aware of the difference between teaching German and teaching the curriculum through German; in other words, that bilingual education requires a different pedagogy from second language teaching, and that cross-linguistic activities would support bilingual acquisition of disciplinary content. Accordingly, the results of the survey on the one teacher one language policy turned out to be rather predictable. Overall, the trainee teachers' answers reflected the monolingual ideology of the language policy governing bilingual education in Alsace. However, a third of them did question the policy for its monolingual orientation, although they did not express it in such terms.

First, five respondents out of 25 gave no response to the question asking them what they thought of one teacher one language principle. One teacher declared that she had never reflected on this policy, which is understandable because she had never attended a course on bilingual education before. This fact might also explain the others' lack of response. On the other hand, nearly a third of the trainee teachers questioned the policy with sound arguments. For example, they wrote:

- I do not understand this principle; the students know in any case that we speak both languages, so why can't we teach them both? (Teacher 1)

- I do not agree with this principle. They (the students) know that we speak French. I would prefer to have only one class and do French and German and to balance the progression 
between the two languages. It would be interesting to use both languages in the same teaching unit. This is not possible with two teachers. (Teacher 5)

- I'm not convinced. I think students know how to distinguish between the two languages, if one explains to them now we speak French and now German. I would like to have the same class all the time to have a better relationship with the students and to follow their progress more efficiently. (Teacher 17)

- I'm not totally convinced. It is not very coherent with the concept of bilingualism, it often leads to two parallel monolingual classes. (Teacher 20)

- I do not think this principle is well adapted to bilingual education. This principle is efficient in families. But at school, it does not make sense for me, because it does not represent bilingualism, but rather two monolingual systems. It would be far more natural, as a teacher who is embodying bilingualism, to use both languages. (Teacher 24)

These teachers' discourses are clearly based on some knowledge of bilingual education acquired before they joined the teacher education course. They show that they have an understanding of bilingualism as a specific integrated competence they could model for their students, rather than pretending that they speak only one language. One of them even points to the difference between the family context and the school context; another one explains that teaching both languages to the same class would allow her to develop a better relationship with her students, and another one again even envisages the pedagogical advantages of teaching the same unit through both languages. More interestingly, perhaps because these discourses arise from scientific knowledge of bilingualism, they focus primarily on acknowledging the students' abilities to understand bilingualism, to comprehend that an individual can speak two languages. Teachers should not underestimate their students' ability to distinguish between one language and another and therefore should not fear language mixing. We interpret these discourses as expressing an ethical position that respects children and argues against lying to them when pretending to speak only German, because children are well aware, even from a very young age, that their teacher also speaks French.

On the other hand, the discourses that believe in the benefits of the one person one language approach tend to focus on language acquisition processes, on structure, on alternating languages every other day, on giving students clear benchmarks for using one language or the other (Teachers $8,10,11,16,19,21)$. In other words, they claim the necessity for students to clearly disassociate the two languages, as in the following statement:

For the children, having two teachers allows for "a cut" in two, to clearly differentiate the teaching contents and to say to themselves, "today is German day, tomorrow is French day: it helps impregnation. For example on Tuesday, I take them to the swimming pool, and swimming has to be taught through French. But the children do not know this, so they continue to speak German to me. One of my students even spoke German to my colleague in charge of French. It shows how much they have learnt and this is very satisfying.

(Teacher 12)

We are quoting this extract to illustrate the strong belief some trainee teachers hold towards separating languages in bilingual education. In the preceding discourse, it seems that the student in question has integrated a time separation of the two languages rather than an alternation according to the teachers, but the teacher makes a curious link between time alternation and efficient acquisition of German. The use of the term 'impregnation' is also thoughtprovoking: it is probably meant as a synonym to immersion but illustrates the belief that using 
both languages together would not provide the necessary amount of 'immersion' or linguistic input for acquisition.

Several teachers who believe that immersion is a form of 'conditioning' guaranteeing oral expression in German and better pronunciation (Teacher 18) mention the terms immersion and language bath. The main argument used to support the one language one teacher policy is the most often claimed in the family and the school contexts alike:

- Students associate one teacher to one language and this can facilitate the 'cutting up', or on this day with this teacher I speak this language. (Teacher 8)

- I think it's good for the students to identify one teacher with one language and to know that on German day they have to speak German, and on French day French. (Teacher 11)

- It gives more stability to the class (day to day management, rooms, materials) and allows for a great discipline in using only German during the German teaching time. (Teacher 15)

These discourses seem to express a need for bilingual teachers to reassure themselves that the children will have enough exposure to German and that sufficient exposure can only be provided if there is a strict language alternation. Rather than an integrated vision of bilingualism, such a time-language concept would imply that simultaneous bilingual education puts each language at risk of lesser development, reminding us of the famous article by Baetens Beardsmore entitled "Who is afraid of bilingualism?" (2003).

Nevertheless, a good half of the teachers expressed nuanced statements. They declared that it is not always easy for them to teach exclusively in German, especially "if the teacher does not speak perfect German" (Teacher 7). Furthermore, they affirmed that the strict language separation gives less flexibility to teachers to organize their teaching, and that it requires a good relationship with the partner teacher in charge of French. Other discourses point to missed pedagogical opportunities, such as explaining the same concept in two languages, running a transdisciplinary project and allowing for better comprehension. Teacher 11 for example, although supporting the one language one teacher policy, adds the following: "But I also believe one teacher teaching both languages can be positive. It makes it possible to come back to things, which have not been clearly understood, and to follow the children's progress more regularly".

Finally, contrary to what Hélot and Fialais argue (2014), several teachers suggest that the age of the children might be a factor to consider and that the one language one teacher policy would provide more security to young children at the start of the programme in kindergarten, but that older children could benefit from having only one teacher, as expressed by Teacher 22 :

I think is it a good thing for older children to have one person two languages, but for younger ones, I think it is more reassuring and easier to have two different teachers. Indeed it is more difficult for them to understand time, so if in the morning, they see the German teacher, they know they are 'having' German.

The use of the verb 'to have' (translated literally from the French) is interesting, since it reflects the relationship of that teacher to the German language. To 'have' German or French or Maths, is a common expression used by secondary school pupils to refer to the various school subjects taught in school. In other words, German is not really envisaged by this bilingual trainee teacher as a medium of instruction, but as a school discipline that has to be learned like any other school subject. 


\section{Ideological representations vs classroom reality: teachers' discourses on translation}

The next question the trainee teachers were asked to address in the questionnaire related to the use of translation in their teaching through German. Additionally, the teachers were asked to describe how they perceived their own translation practices. Quite strikingly in view of the policy explained previously, only one teacher declared never using translation in the German class but referred specifically to the kindergarten level. All the other responses, although most of them express a reluctance towards translation, show that teachers indeed resort to translation, if only "rarely", "as little as possible", "sometimes", and even if they believe they should "avoid it". However, others acknowledge using it for classroom language, mainly to ensure comprehension of specific vocabulary when no other strategies work, whether miming or drawing. For example, Teacher 15 writes: "Rarely, only when I see emptiness in their eyes", and Teacher 22: "Yes sometimes, when I feel they are lost", expressing a sensitivity towards their students' well-being in class. Interestingly, teachers who are more positive towards translation do not translate themselves, but encourage their students to reformulate in French for their peers: Teacher 2: "I use translation with my students when they reformulate in French elements I have expressed in German and I approve their translation using German again". This quote like several others is an example of language alternation, which could also be described as pedagogical translanguaging, in the sense that the switching of languages allows for fluid communication in the classroom. Teacher 5 for example explains that "In the same sentence I can happen to use German and French", which again could be understood as some form of translanguaging.

Yet, when the trainee teachers were asked whether they think translation is an efficient approach for bilingual teaching, more than half of them answered negatively, some of them believing it makes students lazy and learning too easy, preventing learners from making an effort or from developing comprehension strategies, and even from being autonomous. Teacher 15 writes "no, too easy a solution, zero learning", believing translation actually impedes the learning process. And Teacher 19: "No, each language has its own structure. One should avoid using French when speaking German, and encourage children to think in German thanks to the tools we give them to be able to do it". Of interest is the statement of Teacher 4, indicating that some pedagogical advisers and some researchers involved in the education programme actually discourage teachers from using translation!

The overall assessment of the collected answers thus shows a rather negative perception of translation practices. In fact, translation is not perceived through a multilingual lens, but in the mirror of the monolingual ideology generated by the actual language policy, promoting a strict separation of languages. By virtue of this policy, translation bears a negative connotation, and should be avoided as much as possible (Ex. Teacher 25: "One has to translate as little as possible"). Rather than a pedagogical approach helping learners to develop a bilingual grammar, translation is seen as a kind of rescue strategy when everything else fails, as a pragmatic device. Accordingly, inter-semiotic translation (using images, mimics, gestures) is preferred to interlinguistic translation where the translator builds links between the two languages. It is almost as if the use of translation were a sign of the teacher's powerlessness to ensure communication in German.

Finally, a handful of the questioned teachers believe that translation helps to build bridges between languages, compare similar structures and show interlingual relationships. Structural 
and grammatical knowledge in French can be used to scaffold learning in German and to foster metalinguistic competencies. For example, Teacher 18 writes:

Sometimes I think it is useful to compare words, sentence structures between the two languages to notice similarities. The students can see that they already know some things in their native language and that they can use them for learning their second language.

To conclude, translation is not perceived as a creative translingual exercise or mediation practice, but is generally used in a pragmatic, non-creative context. It is not believed to enhance bilingual communication competence, be it intercultural or interlingual. Also, translation does not represent a pedagogical activity per se, which would allow the students to reflect on what it means to be bilingual and to navigate along the continuum of their bilingual competence.

\section{Pedagogic approaches and methods}

Like everywhere else in the world, learners in bilingual classrooms in Alsace have heterogeneous repertoires, but their multilingual competence is ignored or invisibilized. The issue here is to reconsider bilingual education and the successful use of translation in multilingual terms, and to elaborate new pedagogic approaches that take into account the full linguistic repertoires of all students. Multilingual children's literature, whether in dual language, multilingual, or translated books, offers rich possibilities to introduce learners to multilingual literacy and interculturality (Benert and Hélot 2009; Hélot et al. 2014; Daly et al. 2018).

Multilingual books usually present the same story in two or more languages, which implies the process of translation. We thus chose to present a multilingual picture book to the bilingual trainee teachers in Alsace, in order to challenge their representations of translation in bilingual pedagogy, and to introduce them to the notion of multilingual literacy. The multilingual book in question presents the famous story of The Three Robbers, written by the multilingual Alsatian author Tomi Ungerer. The trilingual edition Die drei Raiwer (2008) unites the translations in the three languages of Alsace: Alsatian, French, and German.

Our research and pedagogical project was based on previous research carried out by Benert and Hélot (2009) on the role of translation in bilingual pedagogy and intercultural education. According to Cook (2001, 2003), Hornberger and Link (2012), Lotherington (2014), Lyster (2014), and Sneddon (2014), bilingual literacy can be fostered through the creative use of dual language and translated texts. As in The Three Robbers, illustrated children's books offer examples of interlinguistic (French-Alsatian-German) and inter-semiotic translation (Jakobson 1959), where images illustrate and express some of the meaning of the text. Yet, reading children's books in translation is just as challenging as reading adult texts in translation. We know that translations bear not only stylistic, but also ideological choices (Steiner 1975) of cultural domestication or foreignization (Venuti 1998) and that this has often been the case for children's books. Similarly, multilingual books can reveal political decisions of occulting or promoting a chosen language. For instance, The Three Robbers was originally written in English by Tomi Ungerer and published in New York in 1962. However, in view of the educational language policy in Alsace promoting German to support the revitalization of Alsatian (the local variety of German spoken in Alsace), the Alsatian publisher of Die drei Raiwer only chose three languages - Alsatian, French, and German - as a symbolic synthesis of the region's polyphony, and did not include English, the original language the story was written in (Ungerer 2008). 
The concept of this multilingual book, introduced in a preface by the editor as Tomiphonie, recalling Bakhtine's famous "polyphonie" (1970), is not meant solely to be a metaphor of the region's linguistic identity, but to be a mirror of Ungerer's multilingual and multicultural identity (Ungerer speaks Alsatian, French, German, and English). Furthermore, the Alsatian translation accomplished in the trilingual edition by an Alsatian poet and writer, Robert Werner, embodies the polyphonic fusion of French and German within the Alsatian dialect, since this translation is said to have been achieved from the French and the German versions.

\section{From translation to bilingual literacy: a multilingual reading project}

In the project described in the following, the objective was to introduce bilingual trainee teachers to reading a story in three languages with their students and to imagine the pedagogical affordances of the trilingual text, without forgetting their contextual policy constraint of being responsible for instruction exclusively through German. We asked them to read and discuss the multilingual book in groups and recorded nine focus group discussions in February 2018. The questions the trainee teachers had to discuss were the following: Could you imagine reading this trilingual book with your students? How would you read it? What activities could accompany the reading?

As expected, the one teacher one language policy dominated the trainee teachers' thinking and sometimes overruled the pedagogical affordances of the trilingual reading, even if some creative pedagogical activities were proposed. These activities addressed various translingual practices, such as language awareness and intercomprehension, linguistic mediation, interlinguistic and inter-semiotic transfer, comparative grammar and lexicology, as well as multilingual writing activities.

Overall, three choices came out of the discussions. Some teachers preferred to propose an alternate reading in the three different languages to their students. This means that they thought they should apply the one teacher one language principle and split the story into different chapters to be read each one in one single language, following a monolingual approach. Accordingly, language alternation would take place between different chapters of the story, and so, could be interpreted as consecutive translingual reading. Another group of trainee teachers showed interest in the linguistic comparison between the three translations, reflecting on the similarities between Alsatian and German lexis, as well as on the interferences of the French syntax within the Alsatian text. These cross-linguistic activities could be described as simultaneous translingual reading. Lastly, some trainee teachers were more inquisitive and noticed the different status of each language within the visual presentation of the page, as well as the inter-semiotic relationship between text and image, between language and visual representation, the latter dominating, interconnecting, and "translating" all three languages (French, German, Alsatian). This last approach could be called inter-semiotic translation.

\section{Alsatian and German: intercomprehension activities}

On reading the book, one group of teachers became aware of the prominence given to the Alsatian language and proposed a reading of the story in this language, in order to subsequently compare it with standard German, and to detect similarities and differences. In the words of the teachers:

The most important language of this multilingual book is the Alsatian variety. It would be interesting to read this story in Alsatian as well. Afterwards, the students could hear, 
discover and detect the similarities and the differences between standard German and the Alsatian variety.

Another group added: "The book is meant to discover the Alsatian variety. Students could try to read and to understand the Alsatian text, by referring to the German and the French translation".

\section{French and German: translation as linguistic mediation}

Another group of trainee teachers focused on French and German, the two languages of the bilingual programme being presented to learners together in a book, as offering a support for reading comprehension. For example, "the students have the possibility to look in the French translation for a word they do not know in German and to find its meaning". But even when translation is seen as creating a bridge between different languages, other trainee teachers warned of the danger of using translation too often, lest it endanger the acquisition of German:

Being able to go from one language to another could help to build bridges between the different languages. However, in the daily context of teaching through German, working on the French text should remain rare and clearly motivated, otherwise the learners will not make the effort to learn the German language.

This statement is not surprising; it is consistent with the belief in the one language one teacher policy being the best strategy for learning German. Again, bilingual competence is envisaged monolingually, the relationship between two languages being conceptualized as competitive rather than complementary.

\section{Illustrations and inter-semiotic translation: avoiding translation}

Unsurprisingly, some trainee teachers showed a clear preference for inter-semiotic translation, focusing on the central role of the illustrations for comprehension of the text in one language or the other, because it precisely allowed them to avoid the use of interlingual translation and to keep to the one language one teacher policy. For example, they explained: "Only one picture corresponds to the three texts, thus showing readers that the three languages mean the same thing. The picture is as important as the text and takes the largest space on the page". Or again, "The role of the pictures is rather important: the reader can use the pictures to understand the meaning of the text. Pictures are explanatory. We also have the possibility to read the story in one language only: the students are going to understand the text with the pictures, without understanding the language in which the text was read". The second quote points to the possibility of reading the text in one language only, therefore avoiding any form of language mixing or contact between the three languages displayed in the book. In other words, this trilingual book would be read as a monolingual book and inter-semiotic translation used to develop reading comprehension in one language only.

Indeed, it is clear that the constraints of the institutional policy limit beginner teachers in their imagining of new pedagogical strategies. For example, one of them argues: "this book is not adapted to the German part of the curriculum, because generally the decoding of a text in German must be done with the pictures and not with a translation into French". This declaration shows once more how the institutional monolingual ideology permeates all aspects of the didactics taught to trainee teachers. The use of the verb "must", for example, not only 
expresses top-down injunction on how to teach reading, but also illustrates that German is considered as a second language, separate from the first, rather than part of a bilingual approach to reading competence in two languages (or more), for which Ungerer's trilingual book is the perfect reading material.

\section{Imagining bilingual pedagogy: metalinguistic activities and multilingual literacy}

Taking a different approach to this monolingual view of translation, a further group of teachers were at once aware of the affordances of a trilingual text for metalinguistic activities (Lyster 2014) and for students to be given concrete examples of multilingualism (Hélot 2014). Some even referred to research recommending making links between languages and using metalanguage to discuss similarities and differences. Others suggested that the learners themselves be educated to reflect on the similarities between the three languages and taught to decode some words in the German text, or more productively, to find the same word in the three languages, for example, in Alsatian gschicht, in German Geschichte, and in French histoire.

Furthermore, some trainee teachers saw the possibility with the trilingual text of carrying out narrative analysis in a bilingual mode. They suggested

the students could study the use of grammatical and semantic connectors through this story, used to create the narrative progression: Es war einmal/Il était une fois (beginning of the story), Der Erste . . . Der Zweite . . . Der Dritte/Le premier . . . Le deuxième . . . Le troisième (presentation of the three robbers), Wenn . . . Dann/Si . . alors (relationship of causality), Da geschah es einmal, dass/Mais voilà qu'une fois que (main action of the story), Zum Schluss/À la fin (ending of the story).

Finally, Tomi Ungerer's trilingual book gave rise to the idea of proposing a multilingual creative writing project based on a new version of The Three Robbers. This multilingual text should incorporate all the languages spoken by the children in a class, who should also illustrate the text and invent a new ending. This most creative proposition is another form of interlinguistic transfer, essential to multilingual literacy acquisition. This sort of transfer can give multilingual children the opportunity to be the authors of their own texts and to make full creative use of their multilingual competence. This last example is also a hopeful proof for teacher educators that giving student teachers creative materials in the form of multilingual children's literature can inspire them to imagine a truly bi-/multilingual approach to learning, even within a very constraining top-down policy.

\section{Conclusions and future directions}

The purpose of this chapter was to analyze the representations of a group of bilingual trainee teachers in Alsace towards translation, and to lead them to explore the pedagogical affordances of translation in the context of a multilingual reading project. The project was carried out over three months and represented a first attempt to introduce them to the notion of multilingual literacy. Constrained by the one language one teacher policy in place in Alsace, which implies that these teachers will and should teach only through German, it was a challenge to open up new reflective spaces for them on the issue of the acquisition of reading in a bi/multilingual mode. However, this challenge was met with the use of a very popular children's story, edited trilingually in one volume with the brilliant illustrations of Tomi Ungerer. 
Analysis of the teachers' discourses showed the extent to which the one language one teacher policy and the resulting separation of languages exert a considerable influence on the ideological representation of translation, as well as on its possible pedagogical applications. Consequently, our research argues for the use of multilingual children's books for the development of multilingual literacy at school (Hélot et al. 2014; Daly et al. 2018). Such books could not exist without translation, therefore they are the best examples of the role of translation in the lives of bi-/multilingual individuals and of the mediation competence that bi-/multilinguals develop through their knowledge of several languages.

It is clear that interlingual translation should be explained specifically to young bilingual students, so that they can make sense of their multiple languaging experiences at school and outside of school. For teachers, the pedagogical affordances of translation for bilingual pedagogy should be exemplified through creative projects, reassuring them that functioning in a bilingual mode is not detrimental to their students' bilingual acquisition. We believe that translation can play a role in challenging the still dominant monoglossic ideology of bilingual and biliteracy pedagogy. As argued by S. Canagarajah (2006, p. 590), literacy acquisition is not a unidirectional process, and if we continue to hold monoglossic assumptions of multilingual literacy acquisition, we cannot fully understand the creative resources that multilinguals bring to their texts.

\section{Further reading}

Erfurt, J., Weirich, A. and Caporal-Ebersold, E. (eds) (2018) Education plurilingue et pratiques langagières. Hommage à Christine Hélot [Multilingual Education and Language Practices. Tribute to Christine Hélot]. Frankfurt: Peter Lang.

This volume presents research on four aspects of multilingual education: theoretical and methodological approaches of bi-/multilingualism, pedagogic approaches of bi-/multilingual education, linguistic plurality and language practices, as well as language policies in bilingual education. Several authors of this volume discuss pedagogic models of creative translation and translanguaging in writing that stimulate multilingual creativity and leverage multilingual literacy in bilingual education. Other studies reflect on the practices of language alternation and translanguaging in the bilingual classroom, in view of the language policies governing bilingual education.

Hélot, C., Sneddon, R. and Daly, N. (eds) (2014) Children's Literature in Multilingual Classrooms: From Multiliteracy to Multimodality. London: IOR Press.

The authors in this collection describe the pedagogic affordances of multilingual children's literature in multilingual primary classrooms. Accounts by teachers and researchers from the UK, Canada, France, New Zealand, Finland, Spain, and Austria of recent innovative classroom-based research projects illustrate new conceptualizations of multilingual literacy and their pedagogical impact in the various teaching contexts.

\section{Related topics}

translation, translanguaging, multilingual literacy, bilingual education, multilingual children's literature

\section{Notes}

1 The majority of the students enrolled in the bilingual programme in Alsace are French monolingual students, having very little contact with the Alsatian variety (Huck 2016). They have to be considered emergent bilingual students. Emergent bilingual students are developing as young, dynamic bilinguals, whose linguistic repertoire is in continuous expansion and taps into both languages (in this case, French and German) as resources. At the beginning of their schooling in the bilingual system, 
the students' L1 (French = family language) is more developed than their L2 (German = partial school language), but the partial immersion system is believed to take them on the path to balanced bilingual competencies.

2 See the official time schedule for 2016 at: www.dsdenlv68.site.ac-strasbourg.fr/2016/08/30/ horaires-harmonises-pour-lallemand-renforce-et-le-bilinguisme/.

\section{References}

Baetens Beardsmore, H. (2003) Who is afraid of bilingualism? in Dewaele, J.M., Housen, A. and Wei, L. (eds) Bilingualism, Beyond Basic Principles. Clevedon: Multilingual Matters. pp. 10-27.

Bakhtine, M. (1970/1929) La poétique de Dostoïevki. Paris: Seuil.

Benert, B. and Hélot, C. (2009) Traduction et altérité. Neohelicon. XXXVI(1), pp. 49-61.

Canagarajah, S. (2006) Toward a writing pedagogy of shuttling between languages: Learning from multilingual writers. College English. 68(6), pp. 589-604.

Canagarajah, S. (2011) Translanguaging in the classroom: Emerging issues for research and pedagogy. Applied Linguistics Review. 2, pp. 1-28.

Cook, V. (2001) Using the first language in the classroom. Canadian Modern Language Review. 57(3), pp. 402-423.

Cook, V. (ed) (2003) Effects of the Second Language on the First. Bristol: Multilingual Matters.

Coste, D. and Cavalli, M. (2015) Education, Mobility, Otherness. The Mediation Functions of Schools. Council of Europe, Language Policy Unit.

Council of Europe. (2001) Common European Framework of Reference for Languages. Leaning, Teaching, Assessment. Cambridge: Cambridge University Press.

Council of Europe. (2018) Common European Framework of Reference for Languages: Learning, Teaching, Assessment. Companion Volume with New Descriptors. Strasbourg: Council of Europe Publishing. Available from: https://rm.coe.int/cefr-companion-volume-with-new-descriptors-2018/1680787989 [Accessed 20 March 2019].

Creese, A. and Blackledge, A. (2010) Translanguaging in the bilingual classroom: A pedagogy for learning and teaching? Modern Language Journal. 94(1), pp. 103-115.

Cummins, J. (2007) Rethinking monolingual instructional strategies in multilingual classrooms. Canadian Journal of Applied Linguistics. 10(2), pp. 221-240.

Cummins, J. (2011) Literacy engagement. Reading Teacher. 65(2), pp. 142-146.

Cummins, J. (2016) L'éducation bilingue: perspectives internationales sur la recherche et les politiques linguistiques éducatives, in Hélot, C. and Erfurt, J. (eds) L'éducation bilingue en France. Politiques linguistiques, modèles et pratiques. Paris: Lambert-Lucas. pp. 529-244.

Daly, N., Limbrick, L., Dix, P. (2018) Children's Literature in a Multiliterate World. London: IOE Press, Trentham Books.

García, O. (2009) Bilingual Education in the 21st Century: A Global Perspective. Oxford: Wiley-Blackwell.

Garcia, O. and Wei, L. (2014) Translanguaging. Language, Bilingualism and Education. London: Palgrave Macmillan.

González-Davies, M. (2011) Engaging future generations in multicultural projects through the translation of literature for young readers, in Benert, B. and Clermont, P. (eds) Contre l'innocence. Esthétique de l'engagement en littérature de jeunesse. Frankfurt and New York: Peter Lang. pp. 439-451.

González-Davies, M. (2015) The changing role of translators in a bilingual context: Catalan (in)visibility and the translation of children's literature, in Hélot, C., Sneddon, R. and Daly, N. (eds) Children's Literature in Multilingual Classrooms. From Multiliteracy to Multimodality. London: IOE Press, Trentham Books. pp. 18-34.

González-Davies, M. (2017) The use of translation in an integrated plurilingual approach to language learning. Teacher strategies and best practices. Journal of Spanish Language Teaching. 4(2), pp. 124-135.

Hélot, C. (2011) Children's literature in the multilingual classroom, in Hélot, C. and O’Laoire, M. (eds) Pedagogy of the Possible: Language Policy in the Multilingual Classroom. Bristol: Multilingual Matters. pp. 42-64. 
Hélot, C. (2014) Rethinking bilingual pedagogy in Alsace: Translingual writers and translanguaging, in Blackledge, A. and Creese, A. (eds) Heteroglossia as Practice and Pedagogy. New York: Springer. pp. 217-238.

Hélot, C. and Erfurt, J. (eds) (2016) L'éducation bilingue en France. Politiques linguistiques, modèles et pratiques. Paris: Lambert-Lucas.

Hélot, C. and Fialais, V. (2014) Early bilingual education in Alsace. The one language/one teacher policy in question, in Horner, K., de Saint-Georges, I. and Weber, J.J. (eds) Multilingualism and Mobility in Europe. Policies and Practices. Frankfurt: Peter Lang. pp. 83-102.

Hélot, C., Sneddon, R. and Daly, N. (eds) (2014) Children's Literature in Multilingual Classrooms. From Multiliteracy to Multimodality. London: IOE Press, Trentham Books.

Hornberger, N. and Link, H. (2012) Translanguaging in today's classrooms: A biliteracy lens. Theory into Practice. 51, pp. 239-247.

Huck, D. (2016) L'espace scolaire comme espace d'enjeux sociolinguistiques et idéologiques: l'allemand et l'alsacien en Alsace, in Hélot, C. and Erfurt, J. (eds) L'éducation bilingue en France. Politiques linguistiques, modèles et pratiques. Paris: Lambert-Lucas. pp. 154-167.

Huck, D. (2018) Un enseignement bilingue (français/langue régionale) en Alsace. Pour quelle société? in Erfurt, J., Weirich, A. and Caporal-Ebersold, E. (eds) Education plurilingue et pratiques langagières. Hommage à Christine Hélot. Frankfurt: Peter Lang. pp. 145-166.

Jakobson, R. (1959) On linguistic aspects of translation, in Brower, R.A. (ed) On Translation. Cambridge, MA: Harvard University Press. pp. 260-266.

Laviosa, S. (2014a) Translation and Language Education: Pedagogic Approaches Explored. London: Routledge.

Laviosa, S. (ed) (2014b) Translation in the Language Classroom: Theory, Research and Practice. Special Issue of The Interpreter and Translator Trainer. 8(1).

Lotherington, H. (2014) Plurilingual literature. A multimodal approach to linguistic inclusion in the urban elementary classroom, in Hélot, C., Sneddon, R. and Daly, N. (eds) Children's Literature in Multilingual Classrooms. From Multiliteracy to Multimodality. London: IOE Press, Trentham Books. pp. 84-103.

Lyster, R. (2014) Children's literature as a catalyst for dual language awareness, in Hélot, C., Sneddon, R. and Daly, N. (eds) Children's Literature in Multilingual Classrooms. From Multiliteracy to Multimodality. London: IOE Press, Trentham Books. pp. 64-83.

Macaro, E. (2005) Teaching and Learning a Second Language. A Guide to Recent Research and Its Applications. London and New York: Continuum.

Ministère de 1'Education nationale. (2015) Programmes d'enseignement (cycles 2-3), Bulletin officiel spécial no 11 du 26 novembre. Available from: www.education.gouv.fr/pid285/bulletin_officiel. html?pid_bo=33400 [Accessed 25 March 2019].

Otheguy, R., García, O. and Raid, W. (2015) Clarifying translanguaging and deconstructing named languages: A perspective from linguistics. Applied Linguistics Review. 6(3), pp. 281-307.

Panzarella, G. and Sinibaldi, C. (2018) Translation in the language classroom: Multilingualism, diversity, collaboration. EuroAmerican Journal of Applied Linguistics and Languages. 5(2), pp. 62-75.

Ronjat, J. (1913) Le développement du langage observé chez un enfant bilingue. Paris: Champion.

Sneddon, R. (2014) Reading and making books in two languages, in Hélot, C., Sneddon, R. and Daly, N. (eds) Children's Literature in Multilingual Classrooms. From Multiliteracy to Multimodality. London: IOE Press, Trentham Books. pp. 121-137.

Soleimani, H. and Heidarika, H. (2017) The effect of translation as a noticing strategy on learning complex grammatical structures by EFL learners. Applied Linguistics Research Journal. 1(1), pp. 1-13.

Steiner, G. (1975) After Babel: Aspects of Language and Translation. Oxford: Oxford University Press. Ungerer, T. (2008) Die drei Raiwer. Strasbourg: La nuée bleue.

Velasco, P. and Fialais, V. (2016) Moments of metalinguistic awareness in a Kindergarten class: Translanguaging for simultaneous biliterate development. International Journal of Bilingual Education and Bilingualism. 21(6), pp. 760-774.

Venuti, L. (1998) The Scandals of Translation. Towards an Ethics of Difference. London and New York: Routledge. 


\title{
Translators in schools Valuing pupils' linguistic skills
}

\author{
Sarah Ardizzone and Sam Holmes
}

\section{Introduction}

"But these Somali kids don't really speak Somali!"

(personal communication)

The preceding quote comes from a mildly frustrated workshop film-maker, given the brief of supporting some young people of Somali heritage to produce short animations in what was assumed to be their 'community language'. While the project was designed to celebrate the culture and language of the local Somali community, the film-maker quickly discovered that underlying assumptions about the literacy and oral fluency of the participants were wide of the mark. Many of the Somali young people involved in this project had only a basic level of spoken Somali, despite being able to understand it to a much higher level. None of them had ever tried to read or write Somali before, although many were fluent in languages such as Danish or Swedish, reflecting the particular migration trajectories of their families. The project design entailed producing an oral track for the animations, as well as subtitles, necessitating a level of teaching from the film-maker which did not altogether tally with the facilitation of existing linguistic skills envisaged by the project designers, despite this groundbreaking project being meticulously researched and a beacon of best practice. This kind of mismatch between the aims of projects targeting multilingual young people, and the reality of their complex linguistic skill sets is a persistent challenge for practitioners in the field of multilingual creativity (see Holmes 2015). Translation activities can potentially provide essential tools in such projects, but only if they are grounded in a critical awareness of the linguistic ecosystems the participants operate in.

This chapter examines how creative translation activities can be used as a way into valuing pupils' linguistic skills, with a particular focus on superdiverse contexts (Vertovec 2007). Two interlinked aims can be seen to underpin this strand of work:

1 inclusion - affirming pupils' sense of legitimacy and belonging in the classroom;

2 educational development - enlisting and enhancing pupils' existing linguistic skills. 
In order to frame appropriate approaches to legitimizing and enlisting these skills, it is crucial to have an informed understanding of the multi-layered linguistic repertoires that underpin them. The notion of 'home language', employed within the English education system, carries implicit understandings about pupils' linguistic skills which do not reflect the complexity of practices and affiliations amongst multilingual young people in diverse locations such as London. Home languages are assumed to be national, standard varieties, learned from and used with family members and engendering a strong sense of identification on the part of the young people concerned. However, this conceptualization overlooks the multi-layered, heterogeneous and often hybrid ways in which these young people use language, and it fails to account for the significance of immediate locality and peer group within this. Employing translation activities as a way into valuing pupils' linguistic skills means engaging with the more nuanced picture often obscured by the simplistic notion of home language. This chapter looks at two translation projects aimed at primary age pupils - Translation Nation and The Big Translate - which, to varying degrees, accommodate complex and hybrid linguistic practices amongst young people, as well as embracing the importance of peer group and locality.

In this chapter we aim to provide a sociolinguistic framework for a critical approach to creative multilingual translation projects and programmes in primary schools. We start by setting out how policy approaches to linguistic diversity have shifted from advocating assimilation to celebrating a conceptualization of multilingualism that is actually rather reductive. We then outline how the complexities of superdiverse contexts like London necessitate a more nuanced understanding of linguistic practices, and draw on research such as Jørgensen's (2008) theorization of 'polylingual languaging' to provide a useful framework for this. This is followed by two case studies of creative translation initiatives which highlight how these issues can manifest in practice, and how they can be enlisted within effective pedagogical approaches. Finally, we reflect on the key principles underpinning successful creative multilingual projects, and how schools can make the most of what such approaches have to offer.

\section{Historical perspectives}

The public policy agenda in relation to ethnic and linguistic minorities has shifted considerably over the past 60 years. While assimilationism dominated policy approaches to minority groups during the first phase of major post-war immigration to the UK, this was gradually tempered by a growing political commitment to multiculturalism. Ethnic minority communities and their languages became legitimate pieces in what was conceived as the mosaic of multicultural Britain, but this multicultural perspective could be underpinned by rigid conceptualizations of language and ethnicity. Multicultural initiatives in schools often amounted to presenting ethnic minority pupils with reductive accounts of their culture; and linguistic projects tended to be tied to national, standard languages, which did not necessarily reflect the linguistic repertoires of the multilingual pupils they targeted. While a welcome advance on the deficit thinking of assimilationist language policies, multicultural approaches in schools are not necessarily attuned to the complex linguistic skills of pupils in superdiverse contexts.

\section{From assimilation to multiculturalism}

The following guidance, taken from a government advisory body (CIAC) publication, captures the assimilationist strand within education policy in the 1960s. 
If their parents were brought up in another culture or another tradition, children should be encouraged to respect it, but a national system cannot be expected to perpetuate the different values of immigrant groups.

(Commonwealth Immigrants Advisory Council 1964, p. 7)

This approach, characterized by Troyna (1985, p. 214) as aiming to "suppress the significance of ethnic and cultural differences", preceded the official embracing of multiculturalism. By the mid-1970s, official guidance had shifted:

No child should be expected to cast off the language and culture of the home as he crosses the school threshold, nor to live and act as though school and home represent two totally separate and different cultures which have to be kept firmly apart.

(The Bullock Report: A Language for Life, Department of Education and Science 1975, p. 286)

This recommendation, taken from a government commissioned report into the teaching of English, criticizes the assimilationist paradigm. It advocates instead a shift to multiculturalist thinking, an approach which recognizes the importance of "the different values, beliefs and lifestyles of all people living in the UK" (Troyna 1985, p. 215). However, this shift towards embracing the language "of the home" raises the issue highlighted by the quotation at the opening of this chapter, how to pin down exactly what that language is.

Institutional and academic monitoring endeavours have long struggled with the difficulty of framing appropriate linguistic categories, and early attempts to map linguistic diversity beginning in the late 1970s (Inner London Education Authority 1979; Rosen and Burgess 1980) have been criticized on methodological grounds (Nicholas 1994). The Linguistic Minorities Project (1985) conducted a more methodologically rigorous study arriving at the conclusion that the notion of a 'linguistic minority' (p. 25) was often more of "convenient heuristic device" than a reflection of "the subjective reality of the individuals concerned". Harris' (1997) writing on Romantic Bilingualism supports this, describing the tendency for schools to assume homogeneity within linguistic and cultural groupings. Harris explains that this perspective overlooks the "[s]ignificant level of claimed use of local vernacular English or multiethnic vernacular" (p. 20) amongst young people, as well as lack of expertise in, and often ambivalence or resistance to the "putative community language" (p. 21).

Linguistic monitoring, then, has developed within a contested space where linguistic diversity has been interpreted negatively from an assimilationist perspective (Local Government Act 1966) as well as celebrated (Department of Education and Science [DES] 1981). With a foot in each of these camps, the Swann Report (DES 1985) on the education of children from ethnic minority groups recognized linguistic minorities as legitimate pieces of the British mosaic, yet explicitly rejected bilingual provision in state schools. The Education Reform Act which followed in 1988 led to less accommodation of linguistic diversity, devolving responsibility for budgets to schools and enabling non-mandatory provision for students with EAL (English as an Additional Language) to be given a low priority (Rampton et al. 2007). The role of linguistic monitoring in this climate then became more about identifying deficiencies, or developing specific classroom practices to deal with bilingualism and multilingualism, than celebrating diversity. A certain change in rhetoric can be discerned in education policy post1997. While QCA (2000) guidance on assessment for EAL was criticized for failing to recognize existing skills in other languages (Leung 2001), other guidance from the Department 
for Education and Skills (DfES 2003) explicitly acknowledged the often higher attainment of learners with English as an additional language (EAL), recognizing that skills in languages other than English, and their continued promotion, were valuable not only in their own right but also in supporting "the learning of English and wider cognitive development" (p. 30). This perspective was then reflected in government advice from 2007 that all schools record the "first language" of each pupil (see National Association for Language Development in the Curriculum 2011). After 2010, the Coalition Government's inclusion of a GCSE (General Certificate of Secondary Education) in any language (including "community languages") within the English Baccalaureate performance measure (see Department for Education 2013) gave a new incentive to schools to explore more carefully the linguistic skill sets of their students.

\section{A superdiversity approach}

Despite the move from assimilationism to multiculturalism described earlier, an essentialist understanding of ethnicity (or culture) has endured which goes hand in hand with a reductive understanding of language. This is well described by Hewitt (2005): "School 'celebration of diversity' approaches can seem to minority ethnic pupils like a pageant of some stereotypical ethnicity in which they do not quite feel themselves to participate, however welcome the references to familiar things" (p. 126). This points to limitations in how multicultural education has been implemented, despite the well-intentioned inclusivity which underpins it. Underneath the shift towards celebrating diversity, there is a key continuity between the Commonwealth Immigrants Advisory Council's notion of "the different values of immigrant groups" and the Bullock Report's conception of "the language and culture of the home". Both postulate a distinct, 'other' home culture, and it is the attempt to bring this reified putative 'home' element into the school that has spawned the essentializing practices referred to by Hewitt. While rhetoric and political intentions may have shifted considerably, policy and popular understandings are still grounded in reductive accounts of language and ethnicity.

A superdiversity approach entails a critical perspective towards the established ethnic and linguistic categorizations of multiculturalism, and as such is open to the unpredictability and complexity of actual practices and affiliations. Writing on language and superdiversity provides a useful theoretical framework both for appreciating the intricacies of the ethnolinguistic context of locations like London, as well as understanding how interconnected linguistic practices and ethnic affiliations are shaped by this context. Wessendorf's (2013) study in a computer club for the elderly in London found that "diversity is so normal among the students that it has become somewhat banal" (p. 411). However, this banal diversity is not just about a proliferation of fixed ethnicities. Vertovec (2007) describes a new diversity in the UK, and particularly in London, which encompasses an array of other factors such as "country of origin. . ., migration channel. . ., legal status. . ., migrants' human capital. . ., access to employment. . ., locality. . ., transnationalism" (p. 1050). Even if it were possible to taxonomize this complexity, such an endeavour would miss the point that individuals' affiliations and practices cannot simply be inferred from their placement in particular categories. Instead, as Meissner and Vertovec (2014) point out, "the social scientific challenge of a superdiversity approach is to rethink emergent social configurations and to recognize the processual and necessarily multi-layered nature of them" (p. 550).

This equates to moving "from analyzing diversity to analyzing diversifications" (p. 550), and entails moving beyond a narrow focus on ethnicity. The "emergent social configurations" referred to by Meissner and Vertovec are not restricted to bounded ethnicities then but instead encompass hybridization and span multiple factors. Gilroy (2004), writing about London, 
describes "convivial metropolitan cultures of the country's young people" (p. 232) rooted in "factors of identity and solidarity that derive from class, gender, sexuality and region". He points to second and third generation immigrants whose "local sense of entitlement leaves them reluctant to make common cause against racism and xenophobia with more recently arrived refugees and asylum seekers" (p. 238). The local embeddedness of these second and third generation immigrants can be a stronger tie than any shared sense of ethnic minority status. However, Vertovec (2010) highlights the role of more established ethnic minority communities in acting as a bridge for newly arrived groups and individuals, suggesting that the local embeddedness of these established groups does not necessarily close them off from new arrivals, and can actually provide a catalyst for integration. These more complex affiliations and practices grounded in locality and peer group suggest a more nuanced picture than that provided by a multiculturalist understanding of distinct groupings formed along ethnic lines.

Superdiversity is not just about a greater number of factors involved in processes of identification, but also a more open understanding of how such factors connect with actual practices and affiliations. For example, Vertovec (1999) highlights the importance of 'transnationalism' within superdiverse contexts, describing this as "multiple ties and interactions linking people or institutions across the borders of nation-states" (p. 447). Similarly, Brubaker (2005) advocates a move away from speaking of diaspora as a concrete entity and instead suggests "it may be more fruitful, and certainly more precise, to speak of diasporic stances, projects, claims, idioms, practices, and so on" (p. 13). From this perspective, individuals engage with particular ethnic or national discourses in different, locally relevant ways. Demographic trends can help to construct the notion of particular ethnic communities, for example, significant immigration from Portugal to Lambeth in South London has formed the basis for the recognition of a local Portuguese community. This community can then carry a social reality for a local Portuguese resident in the way it is experienced, but membership is not an inherent characteristic of an individual. Rather, membership is something enacted through the particular practices of individuals, as they slip across different collective boundaries with the day-to-day push and pull of multiple identifications within superdiverse contexts such as London.

The complex configurations in terms of ethnic identification thrown up by superdiversity are bound up with a similar complexity in linguistic practices. Many of the Somali young people referred to in the opening section of this chapter were able to draw on skills in Danish or Swedish as well as Somali, all alongside an affiliation to a local vernacular English. In the following section we will explore existing research into this linguistic complexity rooted in superdiverse locations.

\section{Research approaches and key findings}

Existing research highlights a number of common misconceptions about the linguistic skills of pupils in superdiverse contexts. Harris' (1997) writing on Romantic Bilingualism describes the tendency for schools to assume homogeneity within linguistic and cultural groupings and overlook the importance of local vernacular English, as well as lack of expertise in, and often ambivalence or resistance to the "putative community language" (p. 21). Individual pupils do not simply speak national standard languages learned at home from their parents, they engage in complex, often hybrid practices. These practices can fall under what Jørgensen (2008) terms "polylingual languaging": the purposeful combination of linguistic features associated with different named languages within the same utterance. The specifics of locality and peer group are key factors in understanding how pupils draw on their linguistic skills in these nuanced ways. 


\section{Polylingual languaging}

What the multiculturalism paradigm misses is the extent to which linguistic practices index locality as well as factors such as ethnic background. Language is not just about where individuals have come from, but also where they are now, what they are doing, who they are becoming and, crucially, who they interact with and are affiliated to. Jørgensen's (2008) theorization of polylingual languaging is useful in getting to grips with this complexity. Languaging captures how "language users employ whatever linguistic features are at their disposal with the intention of achieving their communicative aims" (p. 169). This behaviour is described as 'polylingual' since the combinations of features (p. 169) it employs stray beyond the traditional boundaries of individual languages. The term 'translanguaging' (Williams 1994) is also used in relation to broadly the same phenomena. Polylingual languaging then goes beyond simply categorizing practices in relation to established named languages as is the focus in code-switching analyses (see Wei 2018). The relationship between individuals and languages is reframed, as Blommaert (2013) notes, "[p]eople do not use "Languages", they use resources for communication" (p. 4). An individual's combined resources comprise their repertoire, and this "interweaves social/interactive elements with historical/ political and personal/biographical ones" (Busch 2015, p. 13). This necessitates a move away from terms such as 'bilingualism', which Heller (2007) notes have accumulated 'too much detritus of unexplained phenomena" (p. 6). Instead of talking about levels of fluency, Blommaert (2013) refers to 'truncated repertoires', emphasizing that "no single person could ever be qualified as the 'perfect' speaker of anything" (p. 5). It is also perfectly possible to not know your language (the language associated with your ethnic background), as "the relationship between an individual and a language is a sociocultural construction" (Jørgensen et al. 2011, p. 32). Jørgensen and Blommaert’s theorizations on language and superdiversity are rooted in empirical studies in urban, multiethnic, multilingual cities in northern Europe. Their work is particularly relevant to London where conditions are even more superdiverse.

\section{Linguistic hybridity}

Approaching language within a framework of superdiversity means taking into account both the biographically indexed repertoires of individuals, and the often highly complex nature of the communities of practice or speech communities they operate within. Arnaut and Spotti (2014) describe "simultaneity", involving "superimposition, nesting, and palimpsest" (p. 3) whereby different groups or generations of migrants are juxtaposed, as well as "intersection and entanglement" whereby linguistic practices associated with particular social or ethnic groups begin to mingle. This can lead to what Rampton (1995) terms "crossing", linguistic borrowings which carry a "sense of social or ethnic boundary transgression" (Rampton 2009, p. 149) where "the variants being used are more likely to be seen as anomalously "other" for the speaker", as well as contributing to emergent hybrid codes, such as the "multi-racial local dialect' highlighted by Hewitt (1986). Despite the contemporary focus of superdiversity research, Silverstein (2014) writes that English has "existed under conditions we might well term "superdiversity" since the end of the 8th century C.E." (p. 7), but globalization has added new dimensions to this. A superdiversity approach then is about moving beyond notions of fixed ethnicities and bounded languages which have obscured multi-layered, often hybrid, linguistic practices and ethnic affiliations. 


\section{Pedagogic approaches and methods}

The complex reality of how we use language can pose a challenge for educators seeking clearly defined linguistic structures and rules to impart to their students. This is an area where collaboration between teachers and arts practitioners can be fruitful. A teacher's approach can be very focused on building. It often starts with planning out the edifice of knowledge and skills a child needs according to the prescriptions of the curriculum, then takes stock of what foundations they already have, before using all this to design the scaffolding required to support the next bricks. Vygotsky's (1978) notion of the 'zone of proximal development' (ZPD) has been very influential in forming this approach. The ZPD is the area of activity which a child can undertake with support, as opposed to tasks the child has already mastered or activities which are completely beyond their current ability. Vygotsky recommends focusing on the ZPD as the most efficient space for learning and development to take place. When this concept is taken up within the pressurized environment of teaching, it can lead to a strong emphasis on outcomes. There is a perceived necessity to have a very clear vision of the edifice of knowledge and skills which a child must attain, in order to map out what they have, and have not, already mastered. The approach of arts practitioners can be quite different and often starts with an element of destruction. Those foundations a child has can be a prison of limited and limiting conceptualizations which stymie creative potential. Once this is exposed children are empowered to become architects as well as bricklayers.

For multilingual learners, the opportunity to connect with their full linguistic repertoire is about more than writing good stories. It is both a social and educational necessity. Freire and Macedo (1987) point out that "[o]nly those who have power can decide what constitutes "literacy"' (p. 18), highlighting the disempowerment that students with non-standard (and in the UK non-English) literacies experience in formal learning contexts. Legitimizing these literacies can therefore contribute to the empowering of multilingual learners. Cummins (2000) specifically advocates a focus on "critical language awareness", whereby students are encouraged to "compare and contrast their languages" (p. 98) and investigate "the status of different language varieties and power relations associated with language policies and practices". Underpinning this is Cummins' conviction that "knowledge generation" (p. 50) and "identity negotiation" are "two sides of the same coin". Although multilingualism carries the potential for cognitive benefits, multilingual learners need to have their language skills legitimized in order to take full advantage of them. Anderson and Chung (2011) suggest that creativity has a particular role to play here, both drawing on and boosting the "greater flexibility of thought" (p. 552) multilingual learners are credited with. Considering the figure of 1 million pupils in UK schools who have EAL, this suggests huge potential for creativity. However, engaging with this can be a daunting prospect for educators and arts facilitators inculcated with the "monolingualism norm" (Jørgensen et al. 2011), a belief that "[i]ndividuals may be so-called 'multilinguals', but their behaviour at any given time should be "monolingual"' (p. 33). Projects which connect with multilingual creativity provide a way forward, demonstrating successful strategies for engaging with phenomena such as the polylingual languaging described by Jørgensen (2008).

Holmes' (2015) review of creative multilingual projects identified five key principles underpinning the most successful initiatives, two of which have particular relevance for the translation projects discussed in this chapter:

1 "Reflexive exploration" where “[p]articipants' own language practices are a focus of enquiry" (p. 4): educators and students are both exposed to the limitations of popular understandings around linguistic labels. Specifically, students are prompted to consider 
how well these understandings align with their actual practices, or whether the ways in which they use language(s) are more complex ('messier'). For example, does the term 'bilingual' apply for an individual who can write fluently in a second language but only operate orally in their mother tongue? Is someone 'multilingual' if their linguistic repertoire extends to a number of named languages, but they only have access to informal registers?

2 "Collaborative endeavour over individualisation", where "[c]ollaborative activities draw on the pooling of repertoires within the group". Individual students may have access to particular named languages, different registers, and specific areas of vocabulary. When combined, these repertoires can be conceived of as a toolkit, which students apply collectively to a linguistic challenge (Holmes 2015, p. 4).

These principles underpin the approaches of both Translation Nation and The Big Translate.

\section{Case study 1: Translation Nation}

Translation Nation was a creative multilingual collaboration between the Stephen Spender Trust and Eastside Educational Trust. From 2010 to 2014, Translation Nation delivered language-focused programmes to students in primary and secondary schools across London and South East England; it specifically targeted and engaged with the diverse linguistic repertoires present in urban classrooms.

The primary school strand of this project entailed 3 days of translator-led workshops, commonly with year 5 pupils (aged 9 to 10), spread across a two-week period. An advance practice-sharing session between translator and teacher embedded the programme and encouraged teacher-ownership of specific workshop elements. Ahead of the first contact day, the school was tasked with an outreach assignment: to gather stories in languages other than English, with students bringing in tales from home or the wider multilingual community. If English was the only language spoken at home, children were encouraged to interview a neighbour, a friend's parents, a shopkeeper - anyone who might have a story to share from another culture.

The formats in which the stories arrived at school ranged from oral storytelling to digitally supported solutions. These included (1) a parent coming in to tell the tale in its original language, with their child providing simultaneous interpretation or a summary translation; (2) a child with some oral fluency in the language, but who was non-literate in its script, reading aloud a story that had been transliterated (by parent or child) into the Roman alphabet; the child would also provide an improvised translation, or else read out loud their pre-prepared English version; (3) a parent pre-recording their story onto DVD and providing accompanying visuals, or else submitting a sound file.

Day 1 introduced the students to outstanding examples of children's literature from around the world, as well as engaging them in a range of creative translation exercises. From Day 2 the focus was specifically on translating and transforming the collected community stories. Guided by the lead translation facilitator, and supported by the teacher and teaching assistant (TA), the pupils set to work translating the stories in small groups, storyboarding and rewriting them as well as discovering what it meant to bring them alive in English while capturing as much of the texture and colour and rhythm of the original story as possible.

On Day 3, the stories were adapted for performance and presented to an audience of children, teachers, parents, and family who cast their votes (in the style of viewers voting for their favourite candidate on a television talent contest) in a range of categories, including best story, which would feature on the Translation Nation website. The live performance element 
motivated the students and gave them a concrete sense of the target audience. This in turn impacted on their creative process in three key ways:

1 Pupils developed an understanding of how to strike an appropriate linguistic balance: introducing words from a new register or language while not excessively deploying vocabulary that might be unfamiliar to sections of the audience;

2 Pupils learned to problem-solve when scripting texts for multilingual performances. For example, they might create handheld captions to 'translate' the unfamiliar words;

3 Pupils became adept at shifting register, e.g. between dialogue in a chosen vernacular and the more formal language scripted for the narration.

Pupils worked in mixed groups, perhaps with only one child per group who had any knowledge of the original language of the story. It was this person's job to explain the sense of the tale to the others; then they all had a role in finding the best ways to say this in English. Once the story had been wrestled out of the original language into an approximate English translation, the vast majority of the work was focused on re-articulating the story in English, which involved foregrounding the intricate process of editing, re-drafting and refining the language choices so that the story came alive in its target language. Children discussed the appropriate tone and how to render the voices of particular characters. They pooled their knowledge of a range of English registers, creating translations where a Chinese emperor might speak in the Queen's English, or where a group of Egyptian children might communicate in the repertoire of young Brixtonians. Drawing on this latter repertoire, for example, in order to make their dialogue sound authentic in multiethnic urban English, pupils might script their "cris" (sharply dressed) characters as using recycled vintage slang exclamations such as "Oh my days!" Their vocabulary might be peppered with the influence of Jamaican patois, in words such as "endz" or "area" (where you're from); in derogatory terms like "rinsed out" or "butterz"; or when referring to someone good-looking as "nang" or "peng". Unlike traditional language teaching models, which focus on an individual learner's progression towards fluency, this project focused on collaborative creative output drawing on a pooling of skills.

Sarah (Ardizzone) was translation facilitator when Translation Nation was run in a primary school on a social housing estate, in the ethnically diverse borough of Hounslow, West London. When she introduced Translation Nation to the newly qualified teacher (NQT) whose class had been assigned to the programme, Ardizzone described the educational project as "the country of words anyone can travel to from whatever direction and by any means of transport". The NQT's own early childhood in South Wales was steeped in European fairy tales, and she grew up reading the works of J.K. Rowling (1998) as well as Michael Morpurgo (1982). Her pupils could draw on further diverse storytelling influences. According to the school database, which captured home languages, her year 5 class comprised ten Somali speakers (one of whom was more expressive in Italian than English), three Urdu speakers, three Punjabi speakers, one Gulf Arabic speaker, one Middle Eastern Arabic speaker, one North African Arabic speaker, one Hindi speaker, one Dari speaker from Iran, one Pashto speaker from Afghanistan, one Portuguese speaker, one Congolese Lingala speaker, and three native English speakers. When considering the relevance of Translation Nation to the literacy curriculum for Keystage 2 (i.e. junior pupils, aged 7-11), the NQT was particularly keen to discover whether the programme would enable her to find common story-telling ground.

The appeal of Translation Nation for the NQT was reflected in the threefold stated aims of this educational project. First, the programme aimed to both highlight and normalize the diversity of languages spoken in schools around the country, as well as affirming the often unrecognized 
role played by students as translators and interpreters between home and the outside world. Second, it aimed to demonstrate the practical ways in which an approach that harnessed creative multilingualism (through a collaborative translation endeavour) could provide an enhanced route to writing, editing, and self-expression. By emphasizing writing as an iterative creative process or craft that requires multiple drafts (rather than providing pupils with a quick shortcut to a finished product), Translation Nation boosted broad-spectrum literacy skills for all, whether EAL (English as an Additional Language) students or native English speakers. Third, it provided students with an introduction to outstanding children's literature from around the world in English translation (see Outside in World), as well as reflecting on the poor statistics for children's literature translated into English, by comparison with the healthy statistics for children's literature translated out of English. Having viewed some of the international book covers from the 67 languages into which Harry Potter has been translated out of English, pupils discussed the low 3\% statistic of books published in English language translation in the UK and the US (this figure is no longer static, see Flood 2019). Additionally, while the term 'bibliodiversity' did not form part of the explicit vocabulary used by the translation facilitators, the desirability of exposing pupils to a broader range of stories was implicit within the programme. Translation facilitators encouraged pupils and teachers to reflect on how the publishing professionals and translators of the future needed to be equipped with the cultural sensitivities and language skill sets to tell a broader range of stories; and to recognize that these superdiverse schoolchildren might just have the potential for those skill sets. Put differently, a quiet agenda of Translation Nation was about making a grassroots contribution to diversifying the UK's publishing industry.

In a Twilight INSET session (In-Service Training) to prepare for Translation Nation the NQT admitted: "I don't anticipate my students offering many synonyms". She was being coached by translation facilitator Sarah Ardizzone to lead an exercise in class, where students would draw a mythical animal and label its body parts using as many different languages and English synonyms as possible. A few days later, and despite her earlier misgivings, the NQT witnessed the teeth belonging to a quirky donkey - part Japanese manga, part Eeyore from A. A. Milne's Winnie the Pooh (1926) - being labelled as "chompers, munchers, grinders, chewers, snappers and gnashers". Her eyes bulged when one of her Somali speakers offered up: "pearly whites".

The first of the two winning stories from the NQT's class was "Ali the Liar", a Somalian variant on Aesop's "The Boy Who Cried Wolf", involving an African hyena rather than a northern European wolf as the villain. The second winning tale was "The Thirsty Crow", which bifurcated to offer a happy ending in the Urdu version, where the wily crow located a bottle of water and a drinking straw, which it managed to sip through. By contrast, the Somali ending was tragic, with the bottle breaking and the water vanishing into the dry soil, before the parched crow's eyes. The performances were a celebration of the rich and hybrid heritage of stories to be shared, whether a child's cultural background meant they were more accustomed to imagining the villain as a wolf or a hyena, and whether they were more likely to envisage a donkey as Eeyore or a Japanese comic strip.

\section{Case study 2: the Big Translate}

Picture this scenario: a small boy is reading aloud to his grandfather his well-thumbed copy of "Red Riding Hood" (as retold and illustrated by Marshall 2013). He reads the text flawlessly, saturating the words with emotion as he enacts the book-hungry grandmother, or captures the little girl's shift from plucky to scared, or relishes the flesh-eating greed in the wolf's voice. With every page turned, the drama builds, and the boy's concentration reflects this: it is intense 
to behold. But while he may sound word-perfect, this little boy cannot read or write. He is only three, after all. He appears to be a fluent reader because the arresting pictures serve as visual cues for his favourite book: they trigger his perfect recall of the accompanying words, which have in turn been narrated to him many times over. In the ecosystem of this book, pictures cohabit and are co-dependent with words.

The boy in question was Sarah Ardizzone's son. Sarah's experience as a parent, witnessing the illusion of her son's verbal fluency, served as a trigger for the Big Translate. Evolving out of the Translators in Schools training scheme in partnership with the Stephen Spender Trust, the Big Translate consciously mimics how a pre-literate child navigates picture books by decoding the images prior to deciphering the words: this process of picking up on all the visual clues, in order to make narrative sense of the story, is known as 'visual literacy'. The Big Translate has many areas of crossover with Translation Nation. By contrast, however, its format is an immersive one-day workshop that encourages a skill set conventionally undervalued in schools (visual literacy) as a starting point for translation.

The Big Translate again involves year 5-6 pupils working in small groups to translate a children's picture book from another language into English, supported by an expert translator and an assistant facilitator (prior knowledge of the source language was not necessary for pupils or assistant facilitator). The original workshop model was developed from a striking, minimalist picture book (Leray 2009) which, as a contemporary reworking of the Little Red Riding Hood fairytale, benefitted from pupils thinking they were familiar with the story (see Centre for Literacy in Primary Education). The prescriptive stages are scaffolded to progress the pupils' translation skills and include

I prediction and sequencing (both logical and fantastical or subversive) for short sections of the book, based on looking exclusively at the pictures (for this stage the words are removed from the picture book);

II viewing the complete version of the book (e.g. as projected slides and/or page spreads), still with the pictures removed;

III collectively producing a 'mood board' (the pupils' intellectual, emotional and visceral reactions to the book are recorded, in single words, on the whiteboard). This serves as a correlative to a dictionary or glossary, highlighting that a successful translation should not just achieve semantic transfer but also recreate in the target language the experience of the book in the source language. Additionally, the mood board provides a framework for pupils to rate the quality of a translation: does the translation elicit in the target language the same responses as those recorded from the original language or pictures? (see Ardizzone 2014);

IV writing a creative translation of the story, by identifying non-verbal clues to make sense of the narrative - these include the pictures, the visual style of the book, spatial constraints, tone, mood, expectations of genre, etc. (Draft a);

$\mathrm{V}$ introducing the compete original text alongside the pictures (the translator reads sections out loud) and using a glossary to produce a literal, rough translation, gaining context/ whole text understanding. Pupils are encouraged to become word-detectives and codecrackers. Where the alphabet is non-Roman, pupils have access to a transliterated version of the text as well as the original script. (Draft b);

VI ripping up the glossaries and privileging lateral thinking by recruiting an adventurous repertoire of synonyms; encouraging poetic use of language for the polished version, where semantic accuracy is weighed against recreating the experience of the book in the target language; exploring coherence of voice. (Draft c); 
VII making a final presentation in which the participants critically articulate their translation process, including summarizing the challenges they encountered, highlighting any unexpected discoveries (for example, similarities or differences of word order between languages), sharing with the audience an overview of the book, and providing a reading both from the source language and in the fresh target-language translation.

While the activities pupils undertake during Translation Nation and The Big Translate are broadly similar, as is the composition of the groups which comprise children from a range of linguistic backgrounds (in Translation Nation, at least one child had a connection with the source language; in the Big Translate it is possible for none of the children to have any prior knowledge of the source language) the key differences between these models lies in the source texts used, the venue and the format of the final product. Translation Nation involved stories brought in from home, translated within the classroom and presented in an assembly as mini plays or performances. The Big Translate focuses on published picture books from a range of countries, takes place at a high-profile venue such as the Royal Festival Hall in London, and culminates in a presentation where pupils explain the translation process to a public audience. The emphasis in Translation Nation is on community engagement and making the text performative, so that hard-to-reach families are keen to attend the in-school performance. The emphasis in the Big Translate is on highlighting broad-spectrum literacy skills and students harnessing their decoding knowledge from the language(s) they know to tackle the language(s) they don't.

\section{Conclusions and future directions}

This chapter has examined how creative translation activities can be used as a way into valuing pupils' linguistic skills, with a particular focus on superdiverse contexts. Also explored are the multi-layered linguistic repertoires underpinning:

1 inclusion - affirming pupils' sense of legitimacy and belonging in the classroom, and

2 educational development - enlisting and enhancing pupils' existing linguistic skills.

Both case studies - Translation Nation and the Big Translate - can be seen to be inclusive, since these projects are not aimed at a predefined ethnic or linguistic group, but specifically draw on the communal linguistic resources of the group or class as a whole. In the case of Translation Nation, while some young people act as interpreters of home languages, others contribute through editing and refining the English versions of stories, and often the multilingual young people prove to be particularly adept at this, even without any knowledge of the original language of the story. In both programmes, students discover that collaboratively they can pool their linguistic repertoires to deliver a story that appeals to a wider audience whether 'faithfully' recreating the original storytelling experience or re-imagining the story for a new time and context. In doing so, not only are they enlisting and enhancing existing linguistic skills, but they are learning to become architects as well as bricklayers. Freed from the usual restrictions of accuracy in spelling, punctuation, and grammar, as well as from the stress of creating from scratch (they might perceive this work as re-versioning rather than an original endeavour), students punch above their linguistic weight, both orally and on the page. Such projects, then, allow pupils to reflect on and legitimize their linguistic repertoires and situate these within the context of their multilingual and multiethnic peer group. They also enable teachers to make links between pupils' multilingualism and the linguistic skills they 
demonstrate through English. Translation Nation and the Big Translate are the outcome of an openness to complex linguistic practices and ethnic affiliations which are not accounted for within dominant discourses of ethnolinguistic categorization. While these educational programmes are designed to engage with superdiverse complexity and hybridity, they are also potentially productive for specific linguistic and ethnic groups.

The first of the two key principles (referenced earlier in this chapter) outlined by Holmes (2015) as underpinning successful creative multilingual initiatives is "Reflexive exploration over linguistic "common sense"” (p. 4) assumptions, where "[p]articipants' own language practices are a focus of enquiry". This effectively describes the way in which the Big Translate students, for example - whether decoding unknown language(s) by recruiting prior knowledge of other language(s), or enlisting broader code-cracking approaches - are encouraged to consider the full range of visual, spatial, and linguistic resources available to them. The young people's reflection is further enhanced through offering a critical analysis of their translation process in the public presentation at the end of the Big Translate day. Additionally, it is essential that the students pool repertoires and work as a team, as described in Holmes' second key principle: "Collaborative endeavour over individualisation", where "[c]ollaborative activities draw on the pooling of repertoires within the group". This is also in the DNA of Translation Nation, which is rooted in stories from oral traditions, where there is no paradigm of the single 'author'.

Both Translation Nation and the Big Translate highlight the importance of legitimizing different literacies as a means of empowering multilingual learners. The presentation element of the Big Translate also reflects Cummins' (2000) advocacy of a focus on critical language awareness; while the level playing field offered by the Big Translate - where most participants (and many assistant facilitators) are outsiders looking in on a new language ensures an ongoing negotiation between "knowledge generation" (p. 50) and "identity negotiation" (p. 50).

While these programmes engage with the importance of peer group and locality, and are effective in enlisting the complex linguistic skills of pupils in superdiverse contexts, there is always a trade-off between openness to diverse practices and tying activities into producing neat cultural products which participants (pupils as well as teachers) see as valuable. Schools are under pressure to focus on activities that support the National Curriculum, so translation activities have to be marketed effectively to school gatekeepers, often by emphasizing their value in promoting literacy. With stretched budgets and heavy workloads, schools are not usually well placed to lead on developing such translation projects, so a key challenge for the future is to increase the number of trained practitioners and tested resources which schools are able to draw on. Progress could also be made through developing in-house talent by training teachers, teaching assistants and other staff members who have knowledge of two or more languages. This approach has the advantage of being more sustainable and has the potential to generate other unplanned connections. Existing staff in schools may feed new ideas into teaching and learning in EAL, MFL (Modern Foreign Languages), and English/Literacy, but also build in more opportunities for exploration and acknowledgement of complex diversity in subjects like Geography and History.

Rather than conceptualizing young people as fitting into predefined groups with specific needs, and then framing compensatory interventions, the explorative approach of initiatives such as Translation Nation and the Big Translate reveals both the complexity and the opportunities presented by superdiverse cohorts. What is missing in dominant understandings of language is any acknowledgement of the importance of locality, both in terms of the specific composition of the local peer group and how this contributes to shaping practices within the 
local linguistic ecosystem. Projects like Translation Nation and the Big Translate represent a step towards redressing this imbalance.

\section{Further reading}

Centre for the Art of Translation. (2018) Poetry Inside Out [online]. Available from: www.catranslation. org/education/ [Accessed 30 September 2018].

This is the outreach programme at the Centre for the Art of Translation in San Francisco, which inspired Translation Nation - and where the approach was specifically about translation as a safe, welcoming, and feasible route into original creative writing.

Holmes, S. (2015) Promoting multilingual creativity: Key principles from successful projects. Working Papers in Urban Language \& Literacies. Paper 182. pp. 1-18. Available from: www.academia. edu/19401058/WP182_Holmes_2015._Promoting_multilingual_creativity_Key_principles_from_ successful_projects [Accessed 2 July 2019].

This report presents findings from a review of current practice, identifying five key principles associated with successful projects in multilingual creativity. Each of the main sections in the report is divided into a practical explanation based around an example project, and a theoretical perspective which highlights a related concept drawn from sociolinguistic and educational research and explains its potential use for practitioners on the ground.

Pask, E., Menmuir, W. and Swain, B. (2014) Developing Creative Writing with Bilingual and Multilingual Young People. London: Arvon. Available from: www.arvon.org/schoolsandgroups/ mothertonguesresource/ [Accessed 2 July 2019].

This is a resource booklet for teachers, school staff, writers and anyone working with bilingual and multilingual young people. It contains a range of activities for multilingual creative writing workshops.

Pop Up CIC. (2013) Fusion Project [online]. Available from: https://popup.org.uk/project/another-one/ [Accessed 2 July 2019].

This London-based 2012-2013 multilingual animation project brought family groups of Somali, Colombian, Bangladeshi, and Turkish children and parents together with writer-translators, illustrators, puppetry artists, and film-makers to make short stop-animation films in home languages.

Stephen Spender Trust. (2015) Translators in Schools [online]. Available from: www.stephen-spender. org/translators_in_schools.html [Accessed 2 July 2019].

This 8-minute online video explains the pedagogical approach of Translators in Schools, with specific reference to the Big Translate.

\section{Related topics}

Bilingualism and multilingualism, the multilingual turn in applied linguistics, bilingual and biliteracy development programmes, language practices for emergent bilingual youth, translation and social inclusion

\section{References}

Anderson, J. and Chung, Y.C. (2011) Finding a voice: Arts-based creativity in the community languages classroom. International Journal of Bilingual Education and Bilingualism. 14(5), pp. 551-569.

Ardizzone, S. (2014) How I translate picture books. The Guardian, 28 March [online]. Available from: www.theguardian.com/childrens-books-site/gallery/2014/mar/28/sarah-ardizonne-how-i-translateapril-red-goldfish [Accessed 1 April 2019].

Arnaut, K. and Spotti, M. (2014) Superdiversity discourse. Working Papers in Urban Language \& Literacies. Paper 122. pp. 1-11. Available from: www.academia.edu/6172969/WP122_Arnaut_and Spotti_2014._Superdiversity_discourse [Accessed 7 July 2019]. 
Blommaert, J. (2013) Language and the study of diversity. Working Papers in Urban Language \& Literacies. Paper 113. pp. 1-10. Available from: www.academia.edu/6173137/WP113_Blommaert2013. Language_and_the_study_of_diversity [Accessed 7 July 2019].

Brubaker, R. (2005) The 'diaspora' diaspora. Ethnic and Racial Studies. 28(1), pp. 1-19.

Busch, B. (2015) Linguistic repertoire and Spracherleben, the lived experience of language. Working Papers in Urban Language \& Literacies. Paper 148. pp. 1-16. Available from: www.academia. edu/10278127/WP148_Busch_2015._Linguistic_repertoire_and_Spracherleben_the_lived_experience_of_language [Accessed 7 July 2019].

Centre for Literacy in Primary Education (CLPE). A Rash of Red Riding Hoods. CLPE [online]. Available from: www.clpe.org.uk/sites/default/files/A Rash of Red Riding Hoods.pdf [Accessed 2 July 2019].

Commonwealth Immigrants Advisory Council. (1964) Second Report. London: HMSO.

Cummins, J. (2000) Language, Power and Pedagogy: Bilingual Children in the Crossfire. Clevedon: Multilingual Matters.

Department for Education [DfE]. (2013) Key Stage 4 Qualifications Counting in the English Baccalaureate. DfE [online]. Available from: www.gov.uk/government/publications/english-baccalaureateeligible-qualifications [Accessed 7 July 2019].

Department of Education and Science [DES]. (1975) A Language for Life (The Bullock Report). London: HMSO.

Department of Education and Science [DES] (1981). West Indian children in our schools: Interim report of the committee of inquiry into the education of children from ethnic minority groups (The Rampton Report). London: HMSO.

Department of Education and Science [DES]. (1985) Education for All: Report of the Committee of Inquiry into the Education of Children from Ethnic Minority Groups (The Swann Report). London: HMSO.

Department for Education and Skills [DfES]. (2003) Aiming High: Raising the Achievement of Minority Ethnic Pupils. London: HMSO.

Flood, A. (2019) Translated fiction enjoys sales boom as UK readers flock to European authors. The Guardian, 6 March [online]. Available from: www.theguardian.com/books/2019/mar/06/translatedfiction-enjoys-sales-boom-as-uk-readers-flock-to-european-authors [Accessed 7 July 2019].

Freire, P. and Macedo, D. (1987) Literacy: Reading the Word and the World. London: Routledge.

Gilroy, P. (2004) After Empire: Melancholia or Convivial Culture? London: Routledge.

Harris, R. (1997) Romantic bilingualism: Time for a change? in Leung, C. and Cable, C. (eds) English as an Additional Language: Changing Perspectives. London: NALDIC. pp. 14-27.

Heller, M. (2007) Bilingualism as ideology and practice, in Heller, M. (ed) Bilingualism: A Social Approach. Basingstoke: Palgrave Macmillan. pp. 1-22.

Hewitt, R. (1986) White Talk Black Talk. Cambridge: Cambridge University Press.

Hewitt, R. (2005) White Backlash and the Politics of Multiculturalism. Cambridge: Cambridge University Press.

Holmes, S. (2015) Promoting multilingual creativity: Key principles from successful projects. Working Papers in Urban Language \& Literacies. Paper 182. pp. 1-18. Available from: www.academia. edu/19401058/WP182_Holmes_2015._Promoting_multilingual_creativity_Key_principles_from_ successful_projects [Accessed 2 July 2019].

Inner London Education Authority. (1979) Report on the 1978 Census of Those ILEA Pupils for Whom English Was Not a First Language. London: ILEA.

Jørgensen, J.N. (2008) Polylingual languaging around and among children and adolescents. International Journal of Multilingualism. 5(3), pp. 161-176.

Jørgensen, J.N., Karrebæk, M.S., Madsen, L.M. and Møller, J.S. (2011) Polylanguaging in superdiversity. Diversities. 13(2), pp. 23-37.

Leray, M. (2009) Un Petit Chaperon Rouge. Arles: Actes Sud.

Leung, C. (2001) English as an additional language: Distinct language focus or diffused curriculum concerns? Language and Education. 15(11), pp. 33-55.

Linguistic Minorities Project. (1985) The Other Languages of England. London: Routledge \& Kegan Paul plc. 
Local Government Act 1966. (c.42). London: HMSO.

Marshall, J. (2013) Red Riding Hood. London: Walker Books.

Meissner, F. and Vertovec, S. (2014) Comparing super-diversity. Ethnic and Racial Studies, pp. 541-555 (ahead-of-print).

Milne, A.A. (1926) Winnie the Pooh. London: Methuen.

Morpurgo, M. (1982) Warhorse. London: Heinemann Young Books.

National Association for Language Development in the Curriculum [NALDIC]. (2011) Languages in Schools [online]. Available from: www.naldic.org.uk/research-and-information/eal-statistics/lang [Accessed 7 July 2019].

Nicholas, J. (1994) Language Diversity Surveys as Agents of Change. Clevedon: Multilingual Matters.

Outside in World [online]. Available from: www.outsideinworld.org.uk/ [Accessed 7 July 2019].

Qualifications and Curriculum Authority. (2000) A Language in Common: Assessing English as an Additional Language. London: QCA.

Rampton, B. (1995) Crossing: Language and Ethnicity Among Adolescents. London: Longman.

Rampton, B. (2009) Interaction ritual and not just artful performance in crossing and stylization. Language in Society. 38(02), pp. 149-176.

Rampton, B., Harris, R. and Leung, C. (2007) Education and languages other than English, in Britain, D. (ed) Language in the British Isles. Cambridge: Cambridge University Press. pp. 417-435.

Rosen, H. and Burgess, T. (1980) Languages and Dialects of London School Children. London: Ward Lock Educational.

Rowling, J.K. (1998) Harry Potter and the Philosopher's Stone. London: Bloomsbury.

Silverstein, M. (2014) How language communities intersect: Is "superdiversity" an incremental or transformative condition. Tilburg Papers in Culture Studies. Paper 107. pp. 1-36. Available from: www. tilburguniversity.edu/sites/tiu/files/download/TPCS_107_Silverstein_2.pdf [Accessed 7 July 2019].

Troyna, B. (1985) The great divide: Policies and practices in multicultural education. British Journal of Sociology of Education. 6(2), pp. 209-224.

Vertovec, S. (1999) Conceiving and researching transnationalism. Ethnic and Racial Studies. 22(2), pp. 447-462.

Vertovec, S. (2007) Super-diversity and its implications. Ethnic and Racial Studies. 30(6), pp. 1024-1054.

Vertovec, S. (2010) Towards post-multiculturalism? Changing communities, conditions and contexts of diversity. International Social Science Journal. 61(199), pp. 83-95.

Vygotsky, L.S. (1978) Mind in Society: The Development of Higher Psychological Processes. Cambridge, MA: Harvard University Press.

Wei, L. (2018) Translanguaging and code-switching: What's the difference? [online]. Available from: https://blog.oup.com/2018/05/translanguaging-code-switching-difference/ [Accessed 19 April 2019].

Wessendorf, S. (2013) Commonplace diversity and the 'ethos of mixing': Perceptions of difference in a London neighbourhood. Identities. 20(4), pp. 407-422.

Williams, C. (1994) Arfarniad o ddulliau dysgu ac addysgu yng nghyd-destun addysg uwchradd ddwyieithog [An Evaluation of Teaching and Learning Methods in the Context of Bilingual Secondary Education]. Unpublished doctoral dissertation, University of Wales, Bangor, UK. 
Part III

Secondary school education 
$\because$ Taylor \& Francis

http://taylorandfrancis.com 


\section{Content-based instruction}

Sara Laviosa

\section{Introduction}

The so-called multilingual turn that teachers, teacher educators and researchers are currently experiencing, is based on two key developments that are taking place in society and education. The first one "concerns the recognition that in the globalized world, most societies are increasingly multilingual, and most people are multilingual to a certain extent" (Conteh and Meier 2014, pp. 1-2). The second one "concerns the tension between diversity and inclusion in mainstream educational provision in relation to language diversity" (2). The multilingual turn is bringing about a re-evaluation of reflexivity in language and intercultural education and a rethinking of the traditional transmissionist model of language learning in favour of a selfengaging, dialogic, and holistic model that privileges the mutual exchange and co-construction of knowledge between teacher and students and among students themselves (cf. Byrd Clark and Dervin 2014). Multilingual education entails a reappraisal of pedagogic translation (Cook 2010; Laviosa 2014a, 2014b) and of the role played by the L1 in Second Language Acquisition (SLA) studies (cf. Ellis and Shintani 2014; Ortega 2014). It also fosters translanguaging as a pedagogical model in bilingual education and in a variety of educational contexts where the school language is different from the learners' own languages (García and Li Wei 2014; Wei 2018). It can reasonably be argued that policy makers are, at least up to a certain extent, rising to the challenges posed by these developments by elaborating new frameworks that endorse the multilingual paradigm in two areas of language education, namely pedagogy and curriculum design.

The companion volume to the Common European Framework of Reference for Languages with new descriptors recognizes the value of translanguaging in language learning, and broadly defines it as "the flexible use of a single, inter-related, uneven and developing plurilinguistic repertoire in order to accomplish a host of tasks involving more than one language" (Council of Europe 2018, p. 28). The volume underscores the importance of mediation as a communicative language activity that fosters - alongside reception, production, and interaction - plurilingual and pluricultural competence. And "in mediation, the user/learner acts as a social agent who creates bridges and helps to construct or convey meaning, sometimes within the same language, sometimes from one language to another (cross-linguistic mediation)" 
(103). Cross-linguistic mediating activities, in particular, consist of different types of translanguaging - relaying specific information, processing text, explaining data across languages and cultures in speech and writing - as well as translating a written text in speech and writing in another language. Consonant with this general stance, the new Australian Curriculum for languages (issued in 2014 by the Australian Curriculum, Assessment and Reporting Authority) adopts an intercultural orientation, and includes translation and interpreting as forms of intercultural mediation involving the analysis and understanding of language and culture as resources. At every level along the continuum from Foundation to year 10, the content descriptions of the curriculum foreground the role of translation as mediation in two ways: both as a reflection on the role of culture when relaying meaning from one language to another and when creating texts in more than one language for diverse audiences (ACARA 2014 in Scarino 2016, pp. 481-482).

Against this background, the chapter first traces the evolution of the principles underpinning Content-Based Instruction (CBI), also named Content and Language Integrated Learning (CLIL) in Europe, this being an approach that has the same essential properties as CBI (cf. Cenoz 2015). Next, it surveys the main research styles and findings of empirical studies that have explored the bilingual procedures used by secondary and high school teachers in educational settings that adopt a content-based language teaching approach. Third, it reports on a classroom-based observational case study undertaken during the teaching of a CLIL biology module in a high school in Italy. The final section draws some conclusions on the functions fulfilled by different forms of translation and translanguaging in the CBI and the CLIL classroom. It also points to future developments in the theory, research, and practice of contentbased instruction.

\section{Historical perspectives}

Content-Based Instruction is an approach to language education in which the teaching of a new language is integrated, to varying degrees and in different modalities, with the teaching of school or academic subjects. It is becoming widely used at all levels of school education and in undergraduate and graduate degree programmes worldwide (Cook 2010, p. 104; Wesche 2010, p. 275). CBI has evolved from some core principles of communicative language teaching (CLT), particularly those relating to the central role of meaning in language use, learning and teaching. Especially relevant to content-based instructional education are the five characteristics of communicative methodology identified by Keith Johnson and Helen Johnson (1998).

The first is appropriateness of language use in a given situational context. As Dell Hymes contended, "there are rules of use without which the rules of grammar would be useless (Hymes 1970 in Johnson and Johnson 1998, p. 68). The second characteristic is messagefocus. This means that learners are accountable for the language they produce. The feedback the teacher gives them is on the communicative effectiveness of their verbal exchanges, that is to say whether a message has been conveyed successfully, rather than solely on grammatical correctness. The third characteristic is the simulation of psycholinguistic communicative processes that involve the top-down selection of information when reading or listening, rather than attending equally to every single word of a message. The fourth characteristic is the development of risk-taking skills, which enable learners to go beyond what they have been taught in class in order to deal with new communicative situations such as those they may encounter when visiting a country where the target language is spoken. The fifth characteristic is the employment of free practice techniques that involve attending simultaneously to different aspects of language use - grammatical, phonological, semantic, discourse, 
interpersonal - rather than practising them one at a time. As regards the role of the teacher, learners, and teaching materials, content-based teaching shares the following characteristics with CLT: (1) frequent teacher-student and student-student interaction to exchange information and solve problems; (2) use of texts and activities linked to real-world contexts and integration of written and spoken modes of communication; (3) a learner-centred perspective that focuses on learners' needs and encourages their active participation in group or pair work in class; (4) use of form-focused language activities, feedback, and practice within meaning oriented communication (Wesche 2010, p. 277).

Content-based language teaching is based on three fundamental assumptions. Language learning is more successful when language is used as a means of acquiring subject-specific content, rather than as an end in itself. Content-based learning better reflects students' needs for learning a language other than their own (Richards and Rodgers 2014, p. 119). Teaching curriculum subjects through the medium of a new language simultaneously furthers both student proficiency in that language and their knowledge of the subject being studied (Cook 2010, p. 31). I will now examine how these tenets are reflected in some of the main content-based instructional models currently adopted in secondary school language programmes.

The claim that a new language is learned more successfully when it is used purposefully to acquire subject-specific knowledge complements the claim that content-based language teaching fosters both linguistic proficiency and the learning of disciplinary content. Therefore, in all CBI programmes there is generally "no direct or explicit effort to teach the language itself separately from the content being taught" (Krahnke 1987, p. 65) and the syllabus is topical rather than linguistic, as it is organized around themes and topics chosen from a curriculum subject.

The assumption that content-based learning addresses students' needs is reflected particularly in theme-based, sheltered, and adjunct models. Theme-based language instruction is frequently used in host-country language programmes for newly arrived immigrant learners of English (ESL), Dutch, or German as a second language to mainstream them into the regular subject areas classroom. It is also used in L2 programmes such as Spanish, Arabic, or Chinese in English-speaking countries, or EFL in non-English-speaking countries. It is a very flexible model because it can be used with any proficiency level. Pupils complete thematic units that can vary in length and can form all or part of a course. The topical syllabus often consists of geographical and cultural information, as well as language instruction, in preparation for literature-based instruction. The relative focus of instruction and assessment is on language learning objectives, hence the instructor is a language teacher who is knowledgeable about subject content (Wesche 2010, pp. 280-281). Sheltered content instruction, including immersion programmes, is tailored to the needs of L2 learners, who are taught in separate classes from L1 speakers. The curriculum, schedule, and academic credit given are the same as for the corresponding regular courses taught in the L1. The primary learning objective is the mastery of the subject matter, while improving language proficiency. To achieve the course-related language objectives, particular attention is devoted to language-sensitive content instruction or the regular participation of language instructors is provided together with additional language learning activities (Wesche 2010, pp. 281-282). In the adjunct language instruction model, advanced L2 speakers enrol in two separate and complementary courses, one being a regular subject course also attended by L1 speakers, the other one being a language course. The primary goal of both the non-language course and the language course is the mastery of the subject matter and the improvement of language proficiency, particularly in academic writing and vocabulary building (Wesche 2010, p. 283).

Content-based instructional education is actively supported by the European Union in the form of Content and Language Integrated Learning (CLIL). This term denotes a dual-focused 
educational approach in which an L2 is used for the learning and teaching of both content and language. "That is, in the teaching and learning process, there is a focus not only on content and not only on language. Each is interwoven, even if the emphasis is greater on one or the other at a given time" (Coyle et al. 2010, p. 1). In 2004 the European Commission brought out an Action Plan for promoting language learning and linguistic diversity, in which CLIL is advocated as an approach that can significantly contribute to the achievement of the Union's language learning objectives, namely the learning of two languages in addition to the L1 to foster multilingualism and multicultural citizenship, as envisaged by the European Council (2002). The Action Plan reads:

Content and language integrated learning (CLIL), in which pupils learn a subject through the medium of a foreign language, has a major contribution to make to the Union's language learning goals. It can provide effective opportunities for pupils to use their new language skills now, rather than learn them now for use later. It opens doors on languages for a broader range of learners, nurturing self-confidence in young learners and those who have not responded well to formal language instruction in general education. It provides exposure to the language without requiring extra time in the curriculum, which can be of particular interest in vocational settings. The introduction of CLIL approaches into an institution can be facilitated by the presence of trained teachers who are native speakers of the vehicular language.

(European Commission Action Plan 2004-2006, p. 19)

Major countries that adopt CLIL-style education are Germany, that applies it on a large scale mainly at secondary level, and Spain, that applies it also at primary level (Meier 2014, pp. 135-136; González-Davies 2016). CLIL school subjects are as varied as mathematics, science, history, philosophy, geography, art, and music. They are taught by the language teacher using curriculum content or the subject teacher using an L2 as the medium of instruction. Both modalities result in the simultaneous learning of content and language.

The CEFR companion volume with new descriptors acknowledges the spread of CLIL and underscores the importance of mediation (cross-linguistic, social, and cultural) as a part of all learning, especially language learning. The document affirms that small group mediating tasks in which learners mutually exchange and explain information while working together to achieve a common goal are highly relevant in our increasingly diverse classrooms and even more relevant when they are undertaken in a CLIL context (Council of Europe 2018, p. 34). CLIL is gaining ground worldwide (cf. Llinares and Morton 2017b). Some educationalists associate it with French immersion programmes in Canada and other forms of bilingual education in North America on the basis of important common features, particularly the fact that "all three use non-language content as a vehicle for promoting L2 proficiency (Genesee and Lindholm-Leary 2013, p. 5).

The shared features of content-based instructional approaches can now be summarized as follows (Wesche 2010, p. 278): (a) dual learning objectives, for both content and language; (b) enhanced motives for L2 learning; (c) adaptation of language input for L2 learners; (d) orientation into a new discourse community; (e) expository discourse as the basis for a content-driven language curriculum; and (f) focus on developing academic L2 proficiency.

\section{Research approaches and key findings}

Case study is the qualitative research approach that empirical studies of content-based instructional education have often adopted to evaluate the effectiveness of a broad range of CBI programmes. 
Case studies have systematically collected evidence on programme design and learner outcomes. They have also studied the relationship between variables bearing upon the achievements attained by the particular CBI programme being investigated. Sometimes they have been carried out within a short time scale, while other times they have been undertaken over a longer period of time (see Wesche 2010 for an overview). Exemplary are two case studies conducted by Fred Genesee and Kathryn Lindholm-Leary (2013). They assessed French immersion (IMM) programmes for majority language students in Canada and dual language education (DLE) in the US for minority language students who speak primarily or only a language other than English at home and upon entry to school. Both forms of CBI are used to teach at least $50 \%$ of the standard curriculum over several years, up to six or more for students who take part in the full programme.

The authors examined 45 years of research into IMM and DLE. For each model, they provide the programme description (rationale, goals, duration, and pedagogic techniques) and the learner outcomes (proficiency in the two languages of instruction and levels of competence in academic subjects). They also examined whether age is an important factor affecting students' language results and the relationship between age of first exposure to the L2 and outcomes in that language. Relevant to the present chapter is the finding relating to the use of the L1 and translation in the French IMM classroom, where students are expected to learn French from listening to teacher talk and reading academic texts. While teachers use French at all times, students use their L1 with their peers and their teacher at the beginning of the programme. Teachers encourage students to gradually reduce the use of the L1 in order to facilitate L2 learning. To aid comprehension they resort to grammatically simplified language, gestures, and visual aids. To assist students in acquiring accurate and appropriate language they paraphrase and expand students' incorrect, incomplete or inappropriate utterances. Translation of information from L2 to L1 tends to be avoided on the assumption that students will pay attention only to the L1 (Genesee and Lindholm-Leary 2013, p. 7).

More recently, the research focus has shifted from programme descriptions and learner outcomes to classroom processes. These later studies have analyzed teachers' reflections on the use of the L1/L2 in class, students' motivation, teacher-class, teacher-learner, and learnerlearner verbal interactions as well as the interrelationship between language and other semiotic resources to convey meaning and scaffold learning. These investigations are framed within interrelated applied linguistics perspectives, namely second language acquisition (García Mayo and Basterrechea 2017; Sobhy 2017; Sylvén 2017), systemic functional linguistics (Forey and Polias 2017; Llinares and Morton 2017a; McCabe and Whittaker 2017), discourse analysis (Escobar Urmeneta and Walsh 2017; Evnitskaya and Teppo 2017), and sociolinguistics (Lasagabaster 2013, 2017). Interestingly, some excerpts of the verbal exchanges observed in the CBI classroom by some of these studies reveal the strategic use of code-switching and lexical translation. While investigating classroom interactional competence (ICC) during a CLIL science lesson in a secondary school in Barcelona, the researchers noticed how the teacher used a range of conversational resources to get her message across and engage her students in academic conversation. As can be seen in the following excerpt from a teacherclass interaction, the instructor encourages her students to use their L1 as a scaffolding device to help them conceptualize the notion of 'pressure' in English. One student, identified as CLA, responds to the teacher's invitation and offers an accurate definition of 'pressure' in Catalan (Escobar Urmeneta and Walsh 2017, pp. 187-188):

Teacher: do you (.) remember yesterday we talk about pressure? ((sweeping gaze))

((writes 'pressure' on the blackboard))

and ((looks at students)) 
we did some exercises ((points at dossier)) (.) you know?

to (.) know (.) the definition of pressure ((points at the word 'pressure' on the blackboard))

does anybody remember? (.) what we said yesterday?

about pressure?

do you remember?

anyone?

in English? (.) Catalan? (.) don't worry

do you remember

the definition of pressure? ((points to the word 'pressure' on the blackboard))

Cla: $\quad(($ raises her hand))

Teacher: CLA

Cla: $\quad$ la pressió (.) és la relació que hi ha entre la superficie i la força

Teacher: ((nods)) very good

in this definition that CLA has said ((points at CLA while looking at students))

does anybody know any word in English?

San: $\quad$ ((raises her hand))

Teacher: SAN

San: ((checks her notes and reads out the definition in English with the help of the teacher, who corrects her pronunciation of the term 'force' and then gives her a positive feedback: "very good"))

As the authors observe, the conversational decisions adopted by the teacher "succeeded in engaging students in the co-construction of the explanation and in clearly establishing that, in spite of all their difficulties, participation from students is always expected". The authors also noticed the teacher's ability to use L2 throughout, while facilitating the use of L1 as a scaffold to conceptualization in L2 (Escobar Urmeneta and Walsh 2017, p. 189).

An example of L1-L2 lexical translation, intended to help learners understand a technical term in the L2, is noticeable in the following excerpt from a science CLIL lesson on the topic of 'puberty'. The educational setting is a secondary school in Hong Kong and the instructor, like his pupils, is a native speaker of Cantonese. In the research paper, the authors illustrate a five-minute teacher-class interaction in seven consecutive pictures. Before the interaction, the pupils had read about the physical changes that occur during puberty using their English textbook. The following excerpt, occurring after the teacher had explained the term 'acne', is reported next to the fifth picture, which shows the teacher identifying where the larynx is in the body (Forey and Polias 2017, p. 152):

Teacher: Because the development of this ((places his thumb and forefinger on either side of the larynx)). Do you know what this is? In Chinese, of course, you know this. This is 嗓子[sang][zi] but in English this is larynx. Larynx, OK? The development of larynx. So it will deepen the voice. Deepen the voice of boys.

As the researchers state in their commentary to the whole interaction, the success of the teacher's use of multiple semiotic resources to mediate meaning and represent abstract concepts (written and oral language, gestures, facial expressions, tone of voice) "could help explain why the teacher consistently teaches in English and only once (. . .) does he codeswitch to include a Cantonese word for larynx, accompanied by a gesture" (Forey and Polias 2017, p. 153). 
The preceding instances of translanguaging were not the researchers' specific object of study, hence they were not analyzed in detail. Nevertheless, I think it is worth pointing them out in light of the beliefs held by teachers on the use of students' own languages in secondary education classes. David Lasagabaster's (2017) case study of the role performed by translanguaging in CLIL, as revealed by teachers' self-reflective comments on their own practices, is premised on the assumption that teachers' beliefs strongly influence their pedagogical decisions and procedures. Two research questions were addressed: (1) whether teachers think that pupils' other language(s) and the vehicular language should be kept rigidly separate; (2) when and why teachers use the pupils' other languages in class. The study was carried out in the Basque Autonomous Community (BAC), in which both Spanish and Basque are the official languages. In this bilingual community, English is the medium of instruction in CLIL programmes, which are offered in nine different school subjects. The participants were eight teachers working in three schools, two in Vitoria-Gasteiz and one in Bilbao. They were all trilingual in Basque, Spanish, and English. None of them was an L1 English speaker. The majority of their pupils spoke Spanish as L1, Basque as L2, and English as L3. The teachers took part in three discussion groups. The discussion was guided by a set of questions on the use of the L1 in CLIL settings. It was conducted in Spanish, audio-recorded and transcribed. The analysis of the transcripts showed that there was broad agreement among teachers on the need to maximize the use of English by rephrasing the same information in different ways to aid comprehension. Different forms of translanguaging (code-switching, translation of technical terms and instructions as well as back translation) were considered to be beneficial if used moderately.

In the following excerpt, one teacher explains in detail how translanguaging is used in everyday pedagogic practice (Lasagabaster 2017, p. 259):

I first give it a try in English. If I realize they don't understand, then I switch into Basque, or I provide them with the translation. They tell me, "No, give us the Spanish translation because it is easier for us". . . . They may not have understood what they have to do. Then to check ... I make them translate it. But, otherwise, in the explanations I always use English. When I see in their faces that they are lost, I explain it again in English and the third time, maybe, a bit in Basque. But especially by the end of the academic year, when they are already tired, and I see they don't absorb any more, then I say part of the sentence in English and part in Basque. I usually don't use Spanish . . . I may sometimes, but not often.

As for student-student interactions, all teachers affirmed that Spanish is the favourite other language, although Basque is the main teaching language at school. In teacher-student interactions, English is the principal language. Therefore, the three languages are used to different degrees, depending on the interlocutor and how insistent teachers are about using the vehicular language (Lasagabaster 2017: 260). Also, one of the main reasons why teachers deliberately use translanguaging is related to classroom management. As one teacher explains: "[w]henever there is a disciplinary problem, Basque is the language that springs to mind. It comes in a more natural way" (Lasagabaster 2017, p. 260).

These findings are consistent with those obtained from an earlier study conducted by the same author in the Colombian educational context (Lasagabaster 2013). Thirty-five in-service CLIL teachers were asked about their beliefs regarding the use of Spanish as the L1 in their classes. Like their pupils, all the participants were L1 Spanish speakers, except for two native speakers of English who were highly proficient in Spanish. The data were collected during a 
workshop entitled "The coexistence of the L1 and the L2 in CLIL classes", held at the Universidad del Norte (Barranquilla, Colombia) in October 2012. The participants were asked to respond individually to two questions. The first one asked them whether they believed the L1 should be used in class. The second one asked them to think of five situations in which they regularly used the L1 in class. Each of them wrote their answers on a sheet of paper and then took part in one of six discussion groups, aiming to agree on a list of the five most effective uses of the L1. The findings show that translanguaging (which subsumes code-switching and translation of words, terms, false friends, idioms, and proverbs) is believed to serve five main purposes: (1) introducing new subject-specific vocabulary and helping pupils understand abstract concepts and instructions; (2) teaching grammatical rules and highlighting L1-L2 similarities and differences; (3) dealing with disciplinary issues; (4) facilitating student-student interactions when accomplishing a task in pairs or small groups; (5) enabling pupils to express their emotions and feel comfortable in class.

Moving on from teachers' beliefs to teachers' practices, Jeanette Toth and BethAnne Paulsrud (2017) analyzed translanguaging practices in two English-medium instruction (EMI) programmes in Sweden, one in a primary school class and one in an upper secondary school class. EMI is a model of content-based instruction that is offered as an alternative to the regular Swedish-medium instruction (see BethAnne Paulsrud and Jeanette Toth this volume). The study addressed two research questions. "What are the patterns of language choices in the EMI classrooms? How do the processes of translanguaging relate to agency and affordances in the EMI classrooms?" (Toth and Paulsrud 2017, p. 189). Translanguaging is conceived as "the process of making meaning, shaping experiences, understandings and knowledge through the use of two languages" (Baker 2011, p. 288), and is used as a lens through which "language choices may facilitate content learning in an environment where teachers and learners have varying access to a range of linguistic resources" (Toth and Paulsrud 2017, p. 191). The data they collected consist of audio recordings of 11 lessons, field notes from classroom observations and informal conversations with participants, artefacts, and audio recordings of two interviews with the teacher and ten interviews with students.

The results show patterns of teacher-directed translanguaging as a pedagogic strategy that affords content comprehension as well as performance and assessment in two languages (203). An example of how the teacher regularly scaffolds content comprehension through the use of Swedish is the practice of writing a new subject-specific term in English and the Swedish translation on the whiteboard, e.g. Entropy (=entropi) and Efficiency (=verkningsgrad) (201), thus facilitating the acquisition of terminology in two languages. Classroom observations showed that the teacher exercises agency in language choice and students generally respond in the same language. The interviews revealed that using Swedish for individual interaction and assistance in completing a task enables the teacher to assess students' subject knowledge, keep track of learner's needs and provide scaffolding in the L1 (200). The interviews with students revealed that "actively processing subject material in both languages affords understanding of academic concepts in Swedish" (202). In sum, the use of both L1 and L2 facilitates the acquisition of content knowledge, and this takes priority over the development of linguistic competence.

\section{Pedagogic approaches and methods}

This section reports on the results of a case study on classroom discourse, which I carried out in an Italian high school from November 2017 to May 2018 during the teaching of a 30-hour CLIL Biology module with English as the vehicular language. The study is framed within the 
Pluriliteracies Approach to Teaching for Learning elaborated by the Graz Group, a team of 13 international educationalists who worked on a project funded by the European Centre for Modern Languages of the Council of Europe from 2012 to 2015 (Coyle et al. 2018). The Graz Model places subject literacy in more than one language at the core of learning. It also provides teachers with the conceptual tools that enable them to help students become pluriliterate. A pluriliterate individual is one who has acquired subject-specific knowledge in more than one language and in one or more disciplines and is able to represent this knowledge conceptually as well as express it successfully and appropriately in different styles, modes and genres across languages and cultures. The Graz Model is rooted in the 4Cs conceptual framework (Coyle et al. 2010), revisited within a social constructivist perspective that foregrounds the developmental, dynamic, and interrelated dimensions of CLIL.

The first dimension is Content. It involves the acquisition of subject-specific facts, concepts, strategies, and procedures. The second dimension is Cognition. It involves developing thinking skills - both concrete ones, such as identifying and classing information, and abstract ones such as reasoning, hypothesizing, problem solving, enquiring, and evaluating. The third dimension is Communication. It recognizes the key role that language plays in developing conceptual understanding. This is because it is through language that we represent and express thought, thus making it visible to ourselves and others. The fourth dimension is Culture. At the macro level it entails raising awareness of the general sociocultural values and norms that guide our way of being, thinking, and knowing. At the micro level it entails raising awareness of the values and norms that characterize the way members of subject-specific communities behave and interpret the world.

The theory of language underpinning the Graz Model is Systemic Functional Linguistics, a " $[\mathrm{t}]$ heory of language as choice. It represents language, or any part of a language, as a resource for making meaning by choosing" (Halliday 1985, p. xxvii). From a systemic functional perspective, language use is conceived as languaging, that is to say "the process of making meaning and shaping knowledge and experience through language" (Swain 2007, p. 98). Teachers can develop languaging by enabling students to actively use what Christiane Dalton-Puffer names cognitive discourse functions, "speech acts that verbalize thought processes which are constitutive of subject learning . . . and which are part of present-day competence-based curricula in the content-subjects" (Dalton-Puffer 2017, p. 172). Examples of CDFs are: defining, describing, comparing, explaining, classifying, hypothesizing, and reporting. Being at the interface of two dimensions, one linguistic and one cognitive, CDFs crucially highlight the relation between language and thought (Coyle et al. 2018). They are the bridge that connects language learning and subject learning and play an important role in supporting academic literacies (Coyle, personal communication via email, 2.09.2017). CDFs foster subject learning, conceptual understanding, and language learning, and all three elements are embedded in culture.

In order for teachers to enable students to perform Cognitive Discourse Functions, the Graz Model offers them the Language Triptych, a conceptual tool for linking the domains of content knowledge, cognitive processing and language. The Triptych encompasses CDFs and enables teachers to develop subject literacies by focusing on language from three sequential perspectives. Language of learning "provides access to the core language that learners need in order to start to construct meaning of content - including lexis, key terms, and associated language structures" (Coyle 2015, pp. 360-361, original emphasis). Language for learning provides access to the subject-specific linguistic functions that allow learners to participate fully in a given task and use language to interact with others (Coyle 2015, p. 361, original emphasis). Language through learning "enables learners to delve more spontaneously into 
meaning-making using unplanned language" (Coyle 2015, p. 361, original emphasis) as well as express metalinguistic awareness. This means awareness of the construction of knowledge through language. In this regard, Coyle maintains that unless students can articulate what the academic discourse of science is, thus demonstrating metalinguistic knowledge, they will not have made cognitive progress in learning through language (Coyle, personal communication via Skype, 12.07.2017).

Coyle points out that "an analysis of classroom language in CLIL has also to take account of which languages are used and when" (Coyle 2015, p. 362). This aspect of CLIL pedagogy, she claims, remains under-researched (Coyle 2015, p. 362). Her view is that the use of the students' L1 is an important strategy for monitoring progress in the development of pluriliteracies through the application of the Language Triptych (Coyle, personal communication via Skype, 12.07.2017). It can be argued that within a pluriliteracies approach such as the one endorsed by the Graz Group, practice-driven research and theory of practice have to take account as much of languaging as of translanguaging in fostering integrated learning. Drawing on the tenets underpinning the Graz Model and the insights provided by translanguaging research in Swedish secondary schools (Toth and Paulsrud 2017), my study investigated two research questions. What are the different forms of teacher-directed and student-directed translanguaging used in CLIL? What is their role in developing the dynamic aspects of integrated learning foregrounded by the 4Cs framework?

The study was carried out in an inner-city high school in Bari, Southern Italy, named Liceo Scientifico Statale "Enrico Fermi". It was singled out for its well-established CLIL programme in humanities and scientific subjects since 2012. The 30 lessons I observed were taught by an L1 Italian science teacher. Her class was attended by 25 fifth-year students. The research style I adopted is ethnographic and the data I collected include field notes taken at each lesson; students' reports on the experiments carried out in the laboratory; formative and summative assessment tests; teaching resources and materials (textbook, bilingual handouts, PowerPoint presentations, websites); and learning conversations with the teacher and students. Learning conversations are conceived as moments of dialogic self-reflection during which the researcher deepens her understanding of the pedagogy she observes and the teacher deepens her understanding of the pedagogy she practises. And students, together with the teacher and researcher, express and reflect on their perception of what they have learned (cf. Coyle 2013).

The analysis of bilingual practices was organized in three steps. First, I identified all the instances of translanguaging observed in class and in the science laboratory. Then, I classified them according to structure, form, and content. Third, I generalized about the function they fulfil using the Language Triptych as a conceptual tool together with the self-reflective comments made during the learning conversations held regularly with the teacher and students. The model of discourse analysis I used to analyze the structure of the verbal interactions containing examples of translanguaging is the five rank-scale model that was first outlined in Sinclair et al. (1972) and Sinclair and Coulthard (1975), and was later modified by Coulthard (1985). It includes five descriptive categories: lesson (the largest unit), followed by transaction (structured in terms of exchanges), exchange (with a structure expressed in terms of moves), move (consisting of one or more acts), and act (Coulthard 1985, pp. 120-145). I will now present some of the main findings. A representative example of teacher-directed productive translanguaging involving the translation of subject-specific terminology from English to Italian occurred in an informing exchange containing an initiating move realized by four informative acts. The last one contains the translation "idrato di carbonio", preceded by the metalinguistic marker "In Italian we say" (see Table 8.1). 
Table 8.1 Translating subject-specific terms from English to Italian (productive translanguaging)

\begin{tabular}{lll}
\hline Exchange type & Initiation & Act \\
\hline informing & $\begin{array}{c}\text { Carbohydrate is composed of carbon + hydrate. A hydrate is } \\
\text { composed of hydrogen and oxygen. So, a carbohydrate is a } \\
\text { molecular compound made up of three elements: carbon, } \\
\\
\text { hydrogen, and oxygen. In Italian we say: idrato di carbonio. }\end{array}$ \\
\hline
\end{tabular}

Table 8.2 Translating subject-specific terms from English to Italian (productive translanguaging)

\begin{tabular}{|c|c|c|}
\hline Exchange type & Initiation & Act \\
\hline informing & $\begin{array}{l}\text { There are different types of carbohydrates: glucose, galactose, } \\
\text { and fructose. Glucose contains an aldehyde functional group } \\
\text { (gruppo aldeidico). Fructose contains a ketone functional group } \\
\text { (gruppo chetonico). }\end{array}$ & informative \\
\hline
\end{tabular}

Table 8.3 Translating from English to Italian (receptive translanguaging)

\begin{tabular}{ll}
\hline Student: What is clockwise? & Exchange type: eliciting \\
& Move: initiation \\
& Act: elicitation \\
Teacher: in senso orario & Exchange type: eliciting \\
& Move: response \\
Student: Thank you teacher & Act: reply \\
& Exchange type: eliciting \\
& Move: follow up \\
& Act: accept \\
\hline
\end{tabular}

A similar example is reproduced in Table 8.2. It shows the Italian translations "gruppo aldeidico" and "gruppo chetonico" alongside the corresponding English terms with no metalinguistic markers. The function this type of translanguaging fulfils is to teach language of learning bilingually so as to enable students to construct meaning of content in both L2 and L1.

A third example (see Table 8.3) illustrates teacher-directed receptive translanguaging involving the translation of a word contained in a read-and-listen task requiring the use of a diagram illustrating the ring structure of monosaccharides. In an eliciting exchange containing three moves, the student asks: "What is the meaning of clockwise?" The teacher replies: "in senso orario". The student accepts the teacher's reply: "Thank you teacher". The function this type of translanguaging fulfils is to scaffold language for learning in the L2 so as to enable the student to undertake a task that requires processing information in three different modes: written, aural, and visual.

The fourth example (see Table 8.4) illustrates teacher-directed productive translanguaging involving code-switching. After viewing a video explaining in English the difference between the aldehyde and the ketone functional groups, the teacher conducts an entire transaction in Italian. The transaction begins with a boundary exchange containing a framing move realized by two acts: a marker "scusate" (sorry) and a metastatement "una parentesi in italiano perché è un concetto complicato" (a parenthesis in Italian because it is a complex concept). Then the teacher goes to the blackboard, writes two chemical formulae, and explains in Italian the difference 
Table 8.4 Code-switching from English to Italian

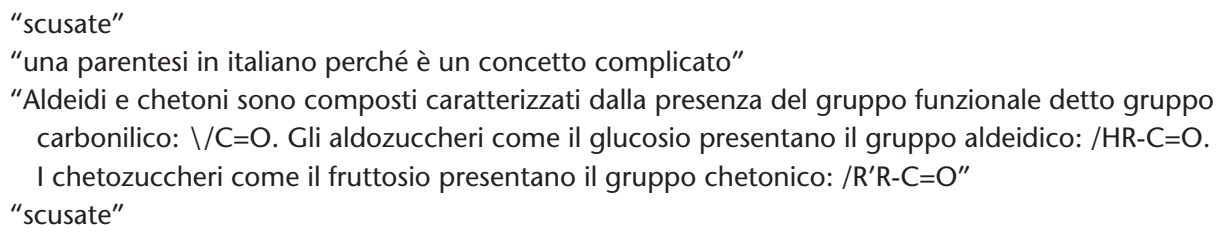

Table 8.5 Saponification/La Saponificazione

\begin{tabular}{ll}
\hline Saponification & La Saponificazione \\
\hline In this experiment, you will make soap & In questo esperimento verrà fatto il sapone dal \\
from a fat or an oil by heating it with & grasso o dall'olio attraverso il riscaldamento \\
sodium hydroxide. You will precipitate the & con l'idrossido di sodio (nome commerciale: \\
soap by adding it to a concentrated salt & soda caustica). Il sapone verrà precipitato da \\
solution, then you will collect the solid & una soluzione concentrata di sale. Il sapone \\
soap using filtration. & solidificato verrà raccolto con la filtrazione. \\
\hline
\end{tabular}

between the aldehyde and the ketone functional groups in an informing exchange containing an initiating move realized by three informative acts. The transaction ends as it began, with a boundary exchange containing a framing move realized by a marker act: "scusate". The function this type of translanguaging fulfils is to develop conceptual knowledge bilingually.

I now turn my gaze on the science laboratory, where I observed three experiments: the Fehling Test, Saponification, and the Biuret Test. During the Fehling Test one student, on his own initiative, used two comparable bilingual texts to carry out the experiment. One was the set of instructions taken from the English textbook, the other was a handout he had retrieved from learning materials collected during a lesson taught in lower secondary education. The teacher noticed this strategy and asked me to translate the instructions in Italian for the following two experiments so that all students could adopt this translanguaging technique (see Table 8.5).

The two bilingual parallel texts reproduced in Table 8.5 introduce the experiment. They are followed by the set of instructions step by step. In English the introductory paragraph is in the future tense and in the active voice, in Italian it is in the future tense and in the passive voice. The set of instructions are in the imperative form in English, while in Italian they are in the infinitive form. For example, step 1 in the Saponification procedure consists of a series of actions (Biology CLIL by Monica Menesini 2017, p. 14):

1 Weigh a $150 \mathrm{~mL}$ beaker and record the mass. Add about $5 \mathrm{~g}$ fat or oil, reweigh, and record the mass. Calculate the mass of fat or oil used by subtraction.

The Italian translation I provided reads:

1 Pesare un becher di $150 \mathrm{~mL}$ e annotare la massa. Aggiungere circa $5 \mathrm{~g}$ di grasso o olio, pesare di nuovo, e annotare la massa. Calcolare la massa di grasso o olio usato con la sottrazione.

The function this type of translanguaging fulfils is to develop language of, for, and through learning in L2 and L1. With some guidance from the teacher, students were able to acquire 
subject-specific terminology bilingually and accomplish the task successfully. They also discovered the different stylistic norms that characterize this particular genre, as they themselves revealed during a learning conversation on the use of the imperative in English and the use of the infinitive in Italian. Later, when they performed the cognitive discourse of function of writing a report on the experiment, they used the set of instructions to retrace their steps, and reformulated the imperative form with the past simple tense in the active voice and with the personal pronoun "we".

In another lesson, bilingual comparable texts were used to develop cultural awareness at the micro level. After watching a video on the history of DNA in English, the teacher instructed students to read a chapter on the same topic in the Italian textbook. By the end of the CLIL Biology module, a pattern began to emerge. As for structure, translanguaging occurs in informing and eliciting exchanges. As regards form and content, translanguaging involves translating lexis and terminology and code-switching of entire transactions as well as using bilingual comparable and parallel texts. Regarding function, translanguaging aims to foster content, cognition, communication, and culture. These findings are corroborated by the selfreflective comments the teacher and students shared during our learning conversations.

\section{Conclusions and future directions}

As evidenced by empirical research into teachers' beliefs and classroom interaction, different forms of translanguaging (code-switching, lexical translation, comparative analysis of bilingual parallel and comparable texts) are used purposely in delivering subject content, enhancing conceptual understanding, constructing classroom discourse, fulfilling CDFs, and raising metalinguistic and cultural awareness. From a social constructivist perspective translanguaging performs the role of scaffolding, assisting learners so that they can progress from their actual to their potential development level through social interaction. Looking to the future, it can be envisaged that more ethnographic studies be undertaken with a wide array of language combinations and in a wide variety of educational settings so as to deepen our understanding of how translanguaging is used "to make meaning in an unfolding interaction" (Dalton-Puffer 2017 , p. 169) as a scaffolding strategy and a pedagogy in its own right. One of the long-term goals that can be set for systematic research into bilingual practices in CBI is to develop theories of practice framed within a plurilingual and pluricultural perspective. Taking CLIL as a case in point, if research into classroom interaction provides us with substantial evidence on the benefits deriving from using both the L1 and L2, we may revisit the Language Triptych and the 4Cs framework with a view to accommodating the use of translanguaging in the Graz Model visibly and legitimately. Such a multilingually-oriented model may in turn foster the development of pedagogies that aim to integrate the selection and grading of linguistic and subject-specific content in the method's design as well as embrace the principles of multilingualism in the selection and sequencing of learning tasks and activities in the method's procedures.

\section{Further reading}

CLIL Journal of Innovation and Research in Plurilingual and Pluricultural Education. (2018) 1(1) [online]. Available from: https://revistes.uab.cat/clil [Accessed 25 March 2019].

This new journal uses CLIL as a broad term that encompasses approaches to teaching and learning that envision language as the primary and most privileged medium of instruction. The journal aims to provide a forum for both language and subject specialists. Each issue includes a section named 
the "A-B-C of Content Learning in L2-medium Settings" in which frequently asked questions are answered by subject specialists and content teachers. The first issue, published in June 2018, contains contributions from language educators, music educators, a social studies educator, and an inspector of education in Catalonia.

Lo, Y.Y. and Lin, A.M.Y. (eds) (2015) Designing Multilingual and Multimodal CLIL Frameworks for EFL Students. Special Issue of International Journal of Bilingual Education and Bilingualism. 18(3). This Special Issue adopts the term CLIL to denote a variety of school programmes in which authentic content extending beyond language is used as a means of L2 learning and teaching. The articles report on research carried out in secondary educational settings in Hong Kong, where there have been significant changes in the medium of instruction policy over the past 30 years. The aim of these studies is to explore how multilingual and multimodal resources can be used to scaffold students' learning of both content and language in EMI programmes, where English is the medium of instruction.

Zhongfeng, T. and Link, H. (eds) (2019) Positive Synergies: Translanguaging and Critical Theories in Education. Special Issue of Translation and Translanguaging in Multilingual Contexts. 5(1).

This Special Issue gives new insights into the theoretical and pedagogical implications of translanguaging to transform schooling in ways that advance a social justice agenda. The goal is to enriche the notion of translanguaging emphasizing its liberating purpose; explore the pedagogical opportunities that translanguaging can offer to enhance bilingualism and biliteracy; and counteract monolingual ideologies in language policies and classrooms.

\section{Related topics}

multilingual turn, English as medium of instruction (EMI), bilingual education

\section{References}

Baker, C. (2011) Foundations of Bilingual Education and Bilingualism. 2nd ed. Bristol: Multilingual Matters.

Byrd Clark, J.S. and Dervin, F. (eds) (2014) Reflexivity in Language and Intercultural Education: Rethinking Multilingualism and Interculturality. London: Routledge.

Cenoz, J. (2015) Content-based instruction and content and language integrated learning: The same or different? Language, Culture and Curriculum. 28(1), pp. 8-24.

Conteh, J. and Meier, G. (2014) Introduction, in Conteh, J. and Meier, J. (eds) The Multilingual Turn in Languages Education: Opportunities and Challenges. Bristol: Multilingual Matters. pp. 1-14.

Cook, G. (2010) Translation in Language Teaching. An Argument for Reassessment. Oxford: Oxford University Press.

Coulthard, M. (1985) An Introduction to Discourse Analysis. 2nd ed. London: Longman.

Council of Europe. (2018) Common European Framework of Reference for Languages: Learning, Teaching, Assessment. Companion Volume with New Descriptors [online]. Strasbourg: Council of Europe Publishing. Available from: https://rm.coe.int/cefr-companion-volume-with-new-descriptors -2018/1680787989 [Accessed 25 March 2019].

Coyle, D. (2013) Listening to learners: An investigation into 'successful learning' across CLIL contexts. International Journal of Bilingual Education and Bilingualism. 16(3), pp. 244-266.

Coyle, D. (2015) Analyzing classroom language in CLIL, in Bigelow, M. and Ennser-Kananen, J. (eds) The Routledge Handbook of Educational Linguistics. London: Routledge. pp. 353-369.

Coyle, D., Hood, P. and David, M. (2010) CLIL: Content and Language Integrated Learning. Cambridge: Cambridge University Press.

Coyle, D., Meyer, O., Halbach, A. and Schuck, K. (2018) Knowledge ecology for conceptual growth: Teachers as active agents in developing a PluriLiteracies approach to Teaching for Learning (PTL). International Journal of Bilingual Education and Bilingualism. 21(3), pp. 349-365. 
Dalton-Puffer, C. (2017) Introduction to part III: Discourse analysis in CLIL, in Llinares, A. and Morton, T. (eds) Applied Linguistics Perspectives on CLIL. Amsterdam: John Benjamins. pp. 167-181.

Ellis, R. and Shintani, N. (2014) Exploring Language Pedagogy Through Second Language Acquisition Research. London: Routledge.

Escobar Urmeneta, C. and Walsh, S. (2017) Classroom interactional competence in content and language integrated learning, in Llinares, A. and Morton, T. (eds) Applied Linguistics Perspectives on CLIL. Amsterdam: John Benjamins. pp. 183-200.

European Commission Action Plan 2004-2006. (COM (2003) 449 final) [online]. Available from: www. saaic.sk/eu-label/doc/2004-06_en.pdf [Accessed 25 March 2019].

European Council. (2002) Presidency Conclusions - Barcelona European Council, 15 and 16 March. SN 100/1/02 REV 1 [online]. Available from: http://ec.europa.eu/invest-in-research/pdf/download_en/ barcelona_european_council.pdf [Accessed 25 March 2019].

Evnitskaya, N. and Teppo, J. (2017) Multimodal conversation analysis and CLIL classroom practice, in Llinares, A. and Morton, T. (eds) Applied Linguistics Perspectives on CLIL. Amsterdam: John Benjamins. pp. 183-200.

Forey, G. and Polias, J. (2017) Multi-semiotic resources providing maximal input in teaching science through English, in Llinares, A. and Morton, T. (eds) Applied Linguistics Perspectives on CLIL. Amsterdam: John Benjamins. pp. 145-166.

García, O. and Li Wei. (2014) Translanguaging. Language, Bilingualism and Education. London: Palgrave Macmillan.

García Mayo, M.P. and Basterrechea, M. (2017) CLIL and SLA: Insights from an interactionist perspective, in Llinares, A. and Morton, T. (eds) Applied Linguistics Perspectives on CLIL. Amsterdam: John Benjamins. pp. 33-50.

Genesee, F. and Lindholm-Leary, K. (2013) Two case studies of content-based language education. Journal of Immersion and Content-Based Language Education. 1(1), pp. 3-33.

González-Davies, M. (2016) Children's literature and plurilingualism in a teacher training programme. A CLIL approach focusing on didactics (FoD). EDETANIA. 49, pp. 91-105.

Halliday, M.A.K. (1985) An Introduction of Functional Grammar. London: Edward Arnold.

Johnson, K. and Johnson, H. (1998) Communicative methodology, in Johnson, K. and Johnson, H. (eds) Encyclopedic Dictionary of Applied Linguistics. Oxford: Blackwell. pp. 68-73.

Krahnke, K. (1987) Approaches to Syllabus Design for Foreign Language Teaching. New York: Prentice Hall.

Lasagabaster, D. (2013) The use of the L1 in CLIL classes: The teacher's perspective. LACLIL, Latin American Journal of Content and Language Integrated Learning. 6(2), pp. 1-21.

Lasagabaster, D. (2017) "I always speak English in my classes": Reflections on the use of the L1/L2 in English-medium instruction, in Llinares, A. and Morton, T. (eds) Applied Linguistics Perspectives on CLIL. Amsterdam: John Benjamins. pp. 251-268.

Laviosa, S. (2014a) Translation and Language Education: Pedagogic Approaches Explored. London: Routledge.

Laviosa, S. (ed) (2014b) Translation in the Language Classroom: Theory, Research and Practice. Special Issue of The Interpreter and Translator Trainer. 8(1).

Llinares, A. and Morton, T. (2017a) Speech function analysis to explore CLIL students' spoken language for knowledge construction, in Llinares, A. and Morton, T. (eds) Applied Linguistics Perspectives on CLIL. Amsterdam: John Benjamins. pp. 125-144.

Llinares, A. and Morton, T. (eds) (2017b) Applied Linguistics Perspectives on CLIL. Amsterdam: John Benjamins.

McCabe, A. and Whittaker, R. (2017) Genre and appraisal in CLIL history texts: Developing the voice of the historian, in Llinares, A. and Morton, T. (eds) Applied Linguistics Perspectives on CLIL. Amsterdam: John Benjamins. pp. 105-124.

Meier, G. (2014) Our mother tongue is plurilingualism: A framework of orientations for integrated multilingual curricula, in Conteh, J. and Meier, G. (eds) The Multilingual Turn in Languages Education: Opportunities and Challenges. Bristol: Multilingual Matters. pp. 132-157. 
Menesini, M. (2017) Biology CLIL: 3D Concepts. Language Skills. Scientific Skills. Milan: Pearson Italia.

Ortega, L. (2014) Ways forward for a bi/multilingual turn in SLA, in Conteh, J. and Meier, G. (eds) The Multilingual Turn in Languages Education: Opportunities and Challenges. Bristol: Multilingual Matters. pp. $32-53$.

Richards, J.C. and Rodgers, T.S. (2014) Approaches and Methods in Language Teaching. 3rd ed. Cambridge: Cambridge University Press.

Scarino, A. (2016) Reconceptualising translation as intercultural mediation: A renewed place in language learning. Perspectives: Studies in Translatology. 24(3), pp. 470-485.

Sinclair, J.McH. and Coulthard, R.M. (1975) Towards an Analysis of Discourse. Oxford: Oxford University Press.

Sinclair, J.McH., Forsyth, I.J., Coulthard, R.M. and Ashby, M.C. (1972) The English Used by Teachers and Pupils. Final report to SSRC, mimeo, University of Birmingham.

Sobhy, N.N. (2017) Investigating pragmatics in through students' requests, in Llinares, A. and Morton, T. (eds) Applied Linguistics Perspectives on CLIL. Amsterdam: John Benjamins. pp. 67-88.

Swain, M. (2007) Languaging, agency and collaboration in advanced second language proficiency, in Byrnes, H. (ed) Advanced Language Learning: The Contribution of Halliday and Vygotsky. London: Bloomsbury. pp. 95-108.

Sylvén, L.K. (2017) Motivation, second language learning and CLIL, in Llinares, A. and Morton, T. (eds) Applied Linguistics Perspectives on CLIL. Amsterdam: John Benjamins. pp. 51-66.

Toth, J. and Paulsrud, B. (2017) Agency and affordance in translanguaging for learning: Case studies from English-medium Instruction in Swedish schools, in Paulsrud, B., Rosén, J., Straszer, B. and Wedin, $\AA$. (eds) New Perspectives on Translanguaging and Education. Bristol: Multilingual Matters. pp. 189-207.

Wei, L. (2018) Translanguaging as a practical theory of language. Applied Linguistics. 39(1), pp. 9-30.

Wesche, M.B. (2010) Content-based second language instruction, in Kaplan, R.B. (ed) The Oxford Handbook of Applied Linguistics. Oxford: Oxford University Press. pp. 275-293. 


\title{
English as a medium of instruction
}

\author{
BethAnne Paulsrud and Jeanette Toth
}

\section{Introduction}

English-medium instruction, or EMI, may be defined as the "use of the English language to teach academic subjects (other than English itself) in countries or jurisdictions where the first language of the majority of the population is not English" (Macaro 2018, p. 1). EMI programmes often simply involve the practice of using English to teach academic subjects, with little or no attention paid to linguistic issues (e.g. Yoxsimer Paulsrud 2014; Toth and Paulsrud 2017). However, recent research suggests that students in EMI programmes may benefit from the opportunity to use all of their linguistic resources, through pedagogical translanguaging (e.g. Toth and Paulsrud 2017; Toth 2018). Pedagogical translanguaging may include "different types of pedagogical strategies that soften boundaries between languages . . . such as using input and output in different languages, translation, comparison of language structures, or the use of cognates" (Cenoz and Gorter 2017, p. 314). The use of students' full range of linguistic resources through translanguaging pedagogy may have implications for students' content learning as well as language development, making this a matter of interest for researchers and teachers alike. In the present chapter, we explore the potential role of translanguaging in EMI programmes, focusing specifically on the use of translation as part of a translanguaging theory and pedagogy.

\section{Historical perspectives}

In this section, we offer a brief presentation on the background of our key concepts: EMI and translanguaging.

The term EMI has previously been mostly associated with higher education contexts in which English is not the majority language. More recently, however, the term EMI has also been used to describe the use of English as a vehicular language in secondary school education in non-English-majority contexts such as Sweden (e.g. Yoxsimer Paulsrud 2014). In such contexts, programmes such as EMI as well as those labelled Content and Language Integrated Learning (CLIL) are often considered to be a means to improving students' proficiency in English through increased exposure to and use of the target language (see Anna 
M. Beres this volume). However, despite sharing this common characteristic, these programmes - EMI and CLIL - may vary widely in their implementations. While CLIL has a dual focus of developing both content and language (Coyle et al. 2010), EMI does not necessarily have these aims.

Many models of content-based language learning have been premised on the idea that languages are best acquired in a naturalistic environment, one in which learners receive intensive exposure to the target language. These programmes often take their inspiration from French early immersion programmes in Canada, where "at least half but often all of the instructional time is spent teaching in the medium of the target language" (Swain and Lapkin 2013, p. 102) in the first year of the programme, and where students with English as their first language $(\mathrm{L} 1)^{1}$ generally begin in Kindergarten or Grade 1 . A number of studies of Canadian immersion programmes as well as CLIL have highlighted the success of these approaches (see for example Pérez Cañado 2012; Genesee and Lindholm-Leary 2013). In these programmes, the exclusive use of the target language has been encouraged as a way of maximizing students' exposure to and use of the language (see Bruton 2013 and Spratt 2017 for a problematization of this assumption). Likewise, the use of students' first language, in many cases, has been discouraged in such programmes due to concerns that it will have a negative effect on students' development of their target language proficiency (Ballinger et al. 2017). However, a growing body of researchers have nonetheless called attention to the benefits that may be associated with the use of the L1 in the classroom where the language of instruction is not the students' L1 (Cook 2001; García 2009; Swain and Lapkin 2013; Cenoz 2017; Toth and Paulsrud 2017; Lin 2018). In recent years, studies of such practices have in many cases come to use the term translanguaging.

Translanguaging as a concept derives from trawsieithu, a term first used by Cen Williams (1994) to denote alternating the language of input and output in bilingual classrooms in Wales (see also Jones 2017). Translanguaging has since then been extended to encompass other forms of "bilingual language use" (García 2009, p. 45) and can be defined as the use of two or more named languages for making meaning (Lewis et al. 2012a, 2012b; Baker and Wright 2017). Theoretically, the concept endorses a view of individuals as having one single linguistic repertoire from which features are drawn for communication, rather than separate named languages (Vogel and García 2017). In translanguaging studies, translation has been described as "an act of communication in which an interaction in one code is re-produced in another code" (Creese, Blackledge and Hu 2017, p. 2). More specifically, García and Li Wei (2014, p. 60) maintain that translanguaging practices may include translation strategies. In multilingual school contexts, therefore, translanguaging and translation strategies have the potential both to facilitate communication as well as to support students' understanding of content. For example, bilingual students can provide support for their classmates by translating the teacher's statements (e.g. García 2009; Toth 2018). Further, as part of a translanguaging pedagogy, teachers may encourage student interaction in their L1 in order to promote student participation in class discussions, as students may also use their linguistic resources to translate their classmates' contributions (e.g. Toth and Paulsrud 2017). Likewise, teachers may provide selected resources in students' L1 and ask students to produce texts in the L2 (e.g. Jones 2017), or allow students to choose the language in which they wish to be assessed (e.g. Toth 2018). Translation as a part of translanguaging thus facilitates access to learning by connecting content knowledge (such as subject-specific terminology) in the L1 with content knowledge in the L2. It also resists language hierarchies, as the students' L1 and L2 are both recognized as legitimate languages for learning (Yoxsimer Paulsrud 2014). 


\section{Research approaches and key findings}

Although both EMI and CLIL as well as translanguaging are widely researched separately today, there is a dearth of research specifically exploring translation as part of translanguaging in the secondary EMI classroom. Both quantitative studies of outcomes as well as qualitative studies exploring the classroom practices of EMI in various contexts have found, among other things, that students lacking sufficient proficiency in the instructional language struggle with content. In post-colonial contexts such as Asia (e.g. Hong Kong, Malaysia, Nepal) and Africa (e.g. South Africa, Tanzania, Zanzibar), where English may seldom be used by students outside of the classroom, students often have difficulties in expressing themselves in the language of the classroom (Lo and Macaro 2015). Meanwhile, in Europe (e.g. Austria, Finland, Spain, Sweden), studies of CLIL and EMI have shown that despite the substantial presence of English beyond the classroom context, or extramural English (Sundqvist 2009), the teaching and learning of English-medium content can be challenging for students as well as teachers (Sandberg 2016). In this section, we present a selection of studies that have used various research approaches to investigate English-medium programmes in different contexts, some of which have focused on translation and translanguaging.

Through a meta-analysis of 24 studies of EMI in Hong Kong, Lo and Lo (2014) investigated the effectiveness of English-medium secondary education. They found that while EMI students' English language proficiency was better than that of non-EMI students, EMI was detrimental to content learning as well as Chinese language proficiency. However, as Lo and Lo (2014, p. 67) point out, their meta-analysis focused on learning outcomes; and data on "teaching and learning processes (e.g. classroom interaction and classroom discourse) were not included". A number of mixed-methods studies of EMI in Hong Kong secondary schools have reported on such things as classroom interaction and students' experiences. For example, a cross-sectional study by Lo and Macaro (2012) used observations of classroom interaction to compare three Hong Kong secondary schools in which the medium of instruction (MoI) was switched from Chinese to English in Grade 10, with two schools where the MoI was English throughout secondary school. The study found that switching the MoI resulted in lessons that were "more teacher-centred and there were fewer opportunities for negotiation of meaning and scaffolding" (Lo and Macaro 2012, p. 29). In a later article, Lo and Macaro (2015, p. 239) conclude that when switching to English as a MoI, "teachers need to develop skills to engage students in extended verbal exchanges, and students need to reach operational levels of L2 proficiency".

Meanwhile, in a large-scale mixed-methods study comparing Hong Kong senior-secondary schools using EMI with Chinese-medium (CMI) schools, Evans and Morrison (2017) investigated students' outcomes, self-perceptions of English proficiency, and experiences of the transition to English-medium higher education. Evans and Morrison (2017, p. 303) found that Chinese-medium students felt less confident in their English ability and later struggled with their English-medium university studies, having "received inferior examination grades" as compared to students who had more extensive experience with EMI. Another recent mixedmethods study compared early EMI (in which full EMI is used in all grades, starting in early years of education) and late EMI (in which partial EMI is provided in grades 10-12) in Hong Kong secondary schools (Pun and Macaro 2019). In this study, Pun and Macaro (2019, p. 4) investigated the use of L1/L2 science classrooms, examining "the interaction patterns and the types of science questions asked by the teachers in the two contexts". The results revealed greater use of higher order questions and interactive dialogue as well as more use of the L1 
in the late EMI classrooms, such as in teachers' explanations of scientific concepts in the L1. They conclude that this use allowed teachers to "help students establish a meaningful relationship between their existing and new knowledge in their cognitive structure to form an interconnected concept in Science" (Pun and Macaro 2019, p. 11).

In Malaysia, Tan and Lan (2011) likewise employed mixed methods to examine teacher beliefs and classroom practices in Malaysian English-medium upper secondary classrooms. Using a combination of surveys and case studies, Tan and Lan (2011) investigated how maths and science teachers' beliefs about the language of instruction impacted their classroom practices. Tan and Lan (2011, p. 14) found that teachers believed that translation of key vocabulary into the L1 and the use of bilingual exit exams supported student comprehension and were particularly useful for "weaker students". For example, when teaching students who were not very fluent in English, a teacher would often follow up an explanation in English with a translation into the students' L1, Bahasa Malaysia (BM), such as "in the following example, when she explain[ed] Bernoulli's Principle to her students: 'As the water flows in the horizontal tube, the velocity increases. Semakin jauh air itu bergerak, halajunya semakin meningkat'" (Tan and Lan 2011, p. 14). However, as Tan and Lan (2011, p. 16) point out, teachers' focus on subject-specific vocabulary as keywords "may obscure the ability of the student to make meaningful connections between various scientific processes and mathematical operations". They highlight the need for subject teachers in these programmes to "become more aware of language in content learning. . . [and] learn ways other than the keyword and direct translation methods to help students with language issues" (Tan and Lan 2011, p. 17).

Although perhaps less common than mixed-methods studies, interventions have also been used to investigate effects of medium of instruction on students' performance. For example, in Zanzibar, Maalim (2017) used an intervention design to compare students' performance on Kiswahili-medium and English-medium assessments in secondary school biology where students had some experience of English-medium instruction in secondary school after having had Kiswahili-medium instruction in primary school. In the study, a selected biology topic was taught in Kiswahili to 54 students for three lessons and then assessed in Kiswahili; the same class was then taught a biology topic in English for three lessons and assessed in English with the same test format and difficulty level as that of the Kiswahili-medium test. Maalim (2017, p. 60) found that "students were able to more effectively engage with the curriculum and subsequently achieved higher results in the assessment when they studied the biology materials in Kiswahili, their mother tongue".

A number of qualitative studies of classroom practices in English-medium secondary schools have also been conducted in various contexts. For example, in a critical qualitative case study of EMI in a Nepal secondary school, Sah and Li (2018) used data from teacher interviews, student focus group interviews, classroom observations, and artefact collection to explore ideologies and practices in EMI implementation. They found that EMI was believed to provide "a privileged form of linguistic capital for developing advanced English skills, enhancing educational achievements and access to higher education, and increasing the chance of upward social and economic mobility" (Sah and Li 2018, p. 109). However, teachers' lack of English proficiency, lack of pedagogical training, and limited access to appropriate resources at the school meant that Nepali was usually used as the language of instruction. As this resulted in unsatisfactory outcomes in terms of students' development of English language skills and knowledge of content, Sah and Li (2018, p. 109) call for a "critical reflection on EMI adoption". They conclude that if EMI is to be adopted, EMI teachers need training in how to effectively use translation approaches in order to promote content comprehension as well as 
proficiency in both English and the mother tongue, as they argue that the mother tongue is "the foundation for learning" (Sah and Li 2018, p. 121).

In Tanzania, Kasmer (2013, p. 403) analyzed data from "classroom observations, informal conversations, on-site interviews, lesson plans, oral and written reflections of enacted lessons, blog-posts, and concluding interviews" to examine instructional strategies of preservice teachers teaching maths at English-medium secondary schools. Kasmer (2013, p. 409) found that by "introducing a concept using both the English and Kiswahili words" and asking students to include both in their notebooks, the pre-service teachers indicated that "all students had a reference throughout the lesson as well as at home" (p. 409). Further, seating students who were more proficient in English next to less proficient students allowed the more proficient students to "translate to each other what was being taught" (Kasmer 2013, p. 408).

Similarly, in a study of eight South African English-medium secondary schools, Probyn (2015, p. 218) examined "the classroom languaging practices of a group of science teachers ... to explore how these science teachers utilised the linguistic resources of the classroom". In her study, Probyn (2015, p. 220) defines code-switching in the classroom as "relatively short switches from the official LoLT [language of learning and teaching] to another home language, usually the learners' home language, and back again". She distinguishes this from translation in the bilingual classroom, defined as "repetition by the teacher of lesson content or instructions in the learners' home language". Probyn (2015, p. 227) found that while the use of code-switching by teachers was potentially more helpful than the complete absence of L1 use, it may have left learners with "misconceptions and gaps in their understanding of the science content". However, when teaching new concepts, one teacher would "first do so in isiXhosa and then in English" (Probyn 2015, p. 228). Probyn (2015, p. 227) thus concludes that the "balanced and structured 'pedagogical translanguaging"" strategies observed in one teacher's lessons provided a way of bridging “the gap between learners' understanding their home language and the LoLT. . . [as well as] between everyday discourse and academic discourse" (Probyn 2015, p. 233).

Naturalistic classroom research was also used by Gierlinger $(2015$, p. 347) to investigate teachers" "educationally principled" use of the majority language in English-medium CLIL classrooms in Austrian secondary schools. Using semi-structured interviews, classroom observations, and stimulated recall reflections, Gierlinger (2015) found that, among other things, translation of specific keywords to German was at times used as a "comprehension check" (p. 359) or "clarification check ... strengthening the formal linguistic mapping between the two lexical representations" (p. 360). Similarly, Moore and Nikula (2016) investigated translanguaging practices through the analysis of language use in classroom recordings from secondary CLIL classrooms in Finland, Spain, and Austria. In their cross-sectional study, Moore and Nikula (2016, p. 223) found that teachers used translanguaging as a scaffolding strategy, at times translating to the students' L1 in response to students' requests for clarification. Moore and Nikula (2016, p. 226) conclude that purposeful translanguaging can support "meaning negotiation and the teaching and learning of content".

In this section, we have focused on recent research from diverse contexts, illustrating the multiple methodologies adopted in studies of EMI, including classroom observations, stakeholder interviews, and intervention studies. These findings provide a background to understanding how approaches that make use of translation as part of a translanguaging pedagogy may be applied in an EMI classroom, as exemplified by the case study presented in the next section. 


\section{Pedagogic approaches and methods}

The studies presented earlier indicate that challenges in secondary EMI require pedagogic approaches that take into account the particular needs of students as well as approaches that promote the learning of both content and languages. While translanguaging encompasses the use of two or more languages for making meaning (Baker and Wright 2017) and includes both code-switching and translation (García 2009; Jones 2017), translation itself does not ensure that both content and language learning in the EMI classroom are adequately addressed. As Lo and Macaro (2015, p. 251) note,

teaching in L2 is not simply a question of translating what teachers would have done in L1 to L2. A different set of pedagogical skills is required both for enabling negotiation of meaning and to compensate for students' difficulties in articulating complex ideas.

Here we turn our focus specifically to translation as a part of a translanguaging strategy with an example of a classroom study conducted in two Swedish upper secondary schools offering EMI. The focus is on how the teachers' approach to classroom practices created a pedagogy that integrated translation in the curriculum. We examined the use of translation in EMI through the lens of a translanguaging model.

While the vast majority of upper secondary schools in Sweden have instruction through the medium of Swedish, EMI is currently offered in approximately 51 schools as an option, albeit in a variety of forms from single days of instruction in English to several courses or entire programmes (Skolverket 2018, p. 24). Lim Falk (2008, p. 3) identifies three main reasons Swedish schools choose to offer EMI:

1 There is a common assumption that the more students are exposed to English, then the more developed their English skills will be.

2 Internationalization and globalization are considered to be both the reason for and the goal of immersion schools.

3 Municipal and independent schools believe that if they offer specialized schools, such as immersion schools, they will be better able to compete for students.

The two schools presented in this chapter section both offer EMI programmes, one (School A) with an emphasis on the natural sciences and the other (School B) with an emphasis on social sciences.

Over a period of more than two years, research based in linguistic ethnography was conducted in the schools with participant observations of lessons, field notes and audio recordings, interviews with stakeholders (including teachers, students, school administrators, and parents), and the collection of artefacts such as photos and lesson handouts. Neither school had an explicit policy for language use in the EMI programme, although interviews with the teachers indicated the goal of immersion in English. Students also indicated expectations of a great use of English (for more on student perspectives on choosing EMI, see Paulsrud 2019). Despite the lack of explicit policies, observations at both schools revealed that translanguaging was a part of the practices in the classroom. Five functions of language alternation between the named languages English and Swedish were identified: reformulation; explanation of disciplinary-specific concepts (words or phrases); language awareness with directed focus on linguistic features; lesson participation as students used different linguistic features to actively participate; and group work as students stayed on task while using all of their 
linguistic resources (Yoxsimer Paulsrud 2014). Here we will focus on reformulation, which involves the teacher offering single subject-specific words or phrases with no further explanation (see, however, Toth 2018 for a discussion of the limitations of translated keywords in a Swedish EMI primary class). Thus, translation was utilized to help the students, in the words of Creese and Blackledge (2010, p. 113), provide "greater access to the curriculum, and lesson accomplishment". Some examples are presented next.

In the lessons, translation was frequently observed in instances of reformulation. The teacher used English as the medium of instruction, but briefly provided scaffolding through the introduction of Swedish vocabulary. In most instances, there was no further explanation other than the single word or phrase, as seen in the following examples (Excerpts 1 and 2).

\section{Excerpt 1 Lesson with a physics teacher}

Have you heard the Swedish word svetsning < welding > ? Weld? This is what we are doing.

\section{Excerpt 2 Lesson with a biology teacher}

This is the pelvis. Bäckenben. <pelvic bone>

In each preceding instance, the teacher provided a translation of the term at the time of need. In some cases, such as in another lesson with the physics teacher, the terms were also written on the whiteboard, with the two languages side by side. In one lesson, the teacher wrote 'Entropy (=entropi)' and 'Efficiency (= verkningsgrad)', thus providing the Swedish translations in parentheses. In Excerpt 3, the maths teacher encouraged the students to translate the term he was discussing.

\section{Excerpt 3 Lesson with a maths teacher}

Teacher: Have you seen. . .? [draws the symbol $\infty$ on the board.] What is it?

Students: Yes, yes

Student 1: Infinity

Teacher: What is this?

Student 2: Oändligt $<$ infinite $>$

Teacher: $\quad$ Öndlighet $<$ infinity $>$

In Excerpt 3, the maths teacher first elicited the term after drawing the symbol on the whiteboard, and the students provided it in English. He persisted with the question 'What is it?' to then prompt the Swedish translation. Student 1 responded with the incorrect word class (adjective instead of noun), after which the maths teacher provided the correct term.

Following the observations of translanguaging strategies including translation in the EMI classroom, the teachers and students were asked about the practice. The physics teacher was clear about the intentional use of translation as part of his pedagogy.

\section{Excerpt 4 Interview with a physics teacher}

Then I say in Swedish, 'In Swedish we use this word' and I write them. Sometimes this is quite easy because the words are so similar but sometimes the words are very different and it is important that they get both. 
In another interview, he stated that this was a strategy that he had developed over his years of teaching EMI, as he noticed that students needed the scaffolding of Swedish terminology in the English-medium lessons. The physics teacher also explained that knowing the terms in both languages was necessary for future university studies. The students were positive about this practice, as seen in Excerpt 5.

\section{Excerpt 5 Interview with students}

Student 1: I think it is good because otherwise if you only hear the English words, maybe you won't understand the Swedish words and vice versa.

Student 2: It is good to learn the Swedish words, too.

Student 1: So you can talk with people! [laughing]

Student 2: So you can tell people in Swedish and you don't have to say the words in English.

In Excerpt 5, the students indicated the importance of knowing subject-specific terms in both languages, both for their own comprehension of the subject and for communication with others outside of the EMI programme.

These results from the Swedish context differ from some research on other bilingual classrooms. For example, the definition of what translation is in a translanguaging pedagogy differs from Probyn (2015). Also, in his research in the Welsh context, Jones (2017) notes that in bilingual classrooms there is still a tendency to separate the languages used in instruction (Welsh and English), leading to a monoglossic approach to bilingualism rather than an intentional strategy of translanguaging including translation, allowing for all linguistic resources to take space in lessons.

According to Bonacina-Pugh (2017, p. 2), "a legitimate language is a language that is appropriate in a given situation". While English may be the legitimized language of learning in the implicit school policies of the two schools presented here, the results reveal that multilingual practices including translation are accepted and promoted as a practical approach to language use in the EMI classroom. Thus, through reformulation of disciplinary concepts and phrases in the lessons, teachers in both schools disrupted the potential status of English-only as the language of learning in these EMI classrooms. In conclusion, translanguaging in the Swedish EMI schools presented here moves away from any one language being the dominant language of learning, opens up to the possibility of flexible language use in the classroom, allows for English and Swedish to be used to accomplish the content lesson, and legitimizes the students' actual practices in the classroom.

\section{Conclusions and future directions}

We close this chapter with a discussion of the implications of translation as a part of translanguaging for the EMI classroom as well as for teacher training. By including a wide range of geographical contexts, teaching approaches, and methods, this chapter contributes to a greater understanding of the potential that translation may offer to the EMI classroom, thus extending the notion of translation and diversifying its uses in education.

Translation as a part of a translanguaging pedagogy has implications for the EMI classroom. We argue that translation strategies afford both L1 and L2 content knowledge and language development, as seen in the studies presented in this chapter. Moreover, a translanguaging pedagogy that allows for the use of both the L1 and the L2, as well as other named languages 
of students or the community, can resist language hierarchies in the classroom (see also García and Wei 2014). As Skutnabb-Kangas et al. (2009, p. 237) point out, the status of English in education must be critically addressed:

Seeking to constrain English should not be understood as meaning that people have anything "against" the language English, which, of course, provides access to an infinite range of information, positions of influence and material well-being. What needs to be resisted and counteracted is policies that privilege English at the expense of other languages. English opens doors, yes, but it closes others.

This privilege indicated previously may mean that local languages and students' L1 are not recognized as legitimate languages of learning in EMI classrooms. With translation as an accepted part of classroom policy and practice, however, students are afforded a more secure access to education in EMI contexts. In cases where EMI teachers do not speak the students' L1, such as when native English speakers are recruited from English-majority countries to teach in EMI programmes, translation plays a crucial role in ensuring that students can understand the content and demonstrate their knowledge (see for example Toth 2018). For instance, proficient students can translate the teacher's statements to their classmates as well as translate their classmates' answers to questions. Further, students can make use of the local language in peer interaction to discuss tasks and collaboratively develop their understanding of the content before producing oral and/or written texts in English.

García (2018, p. 889) maintains that "[p]edagogical translanguaging transcends named languages and equalizes the power dynamics that named languages hold". Thus, it may also be argued that translation as part of a translanguaging pedagogy addresses issues of social justice, especially in post-colonial contexts in Africa and Asia, where EMI is often offered at the expense of teaching and learning through students' L1 (see Probyn 2015; Maalim 2017; Simpson 2017; Sah and Li 2018). Vogel and García (2017) further elaborate on the role of translanguaging and social justice, as they argue that social justice in education cannot be achieved if students are not allowed to use all of their linguistic resources in the classroom. While they focus on minority language students in a majority language classroom, their arguments can also be applied to EMI. In the EMI classroom, students will have different degrees of access to resources in the target language of the programme (English), for example, due to school experience or family language background. If a monolingual English norm prevails in the EMI classroom, with no space for translation with the teacher or amongst students, students will not have full permission to use their entire repertoires. However, if linguistic diversity with policies allowing for translanguaging practices is instead welcomed in the EMI classroom, students are afforded greater opportunities for academic achievement without any potential constraints of their English language proficiency.

Our consideration of translation as a part of EMI policy and practice has implications for teacher training, as also noted by Lo and Macaro (2015) in their call for greater acquisition of teaching skills. Previous research has shown that teachers in EMI (and CLIL) programmes are often content experts but lack training in how to address language issues in the content (Yoxsimer Paulsrud 2014). For example, in her longitudinal ethnographic case study of EMI in a Swedish primary class, Toth (2018) found that the native English-speaking teachers who had been recruited from English-majority countries to teach subjects such as maths and science did not have second language perspectives as part of their teacher training, nor did the school offer in-service training with such a focus. Further, a recent study by Paulsrud and Zilliacus (2018) has indicated that future teachers are not prepared to implement translanguaging strategies 
in classrooms. In their interview study with teacher trainers and teacher students in Sweden, Paulsrud and Zilliacus (2018) maintain that a critical multilingual awareness is often lacking in teacher education. They refer to García (2016) in their understanding of critical multilingual awareness as a willingness to question monoglossic norms and to develop instead an awareness and understanding of each student's linguistic resources both inside and outside school. While their study of teacher education did not specifically focus on the EMI classroom, their results are relevant to all education contexts. As García (2018, p. 3) argues, "multilingual interactions are not new" nor are they a part of "the marketization of multilingualism as a skill", which often influences the decision to offer or choose EMI (see also Paulsrud 2019). Thus, the understanding of the important role of a critical multilingual awareness across all forms of education should be an essential part of all teacher education.

EMI continues to grow in scope and extent (Simpson 2017; Briggs et al. 2018). At the secondary school level, as well as other levels of education such as primary school and tertiary education, the presence of EMI creates both questions and issues regarding the use of linguistic resources in diverse educational contexts. If EMI continues to spread, how can researchers and practitioners contribute to a form of education that ensures both content and language learning, without a cost to either? How can translation as a part of a translanguaging pedagogy contribute to EMI practices and policies that promote social justice and resist language hierarchies? Already in their 2010 article on classroom language ecologies, Creese and Blackledge (2010, p. 113) called for more studies exploring "how and why pedagogic bilingual practices come to be legitimated and accepted by participants". While research on translanguaging and the classroom has indeed developed in the last decade, we see a need to further investigate the EMI classroom in particular, focusing on how translation can be included as part of a legitimate policy and practice. At the same time, such research must also acknowledge the theoretical complexities involved in viewing translation as a move between named languages (see García 2018). Our recommendation is that in order to enact positive changes in teaching approaches in the EMI classroom, both researchers and practitioners need to recognize the added value that translation as part of a translanguaging pedagogy offers in a wide range of educational contexts.

\section{Further reading}

Celic, C. and Seltzer, K. (2011) Translanguaging: A CUNY-NYSIEB Guide for Educators. New York: CUNY-NYSIEB, The Graduate Center, The City University of New York.

This practical guide gives both practitioners and researchers a solid base in translanguaging as theory and pedagogy, answering many questions about content and language learning in the translanguaging classroom.

Dearden, J. (2014) English as a Medium of Instruction - A Growing Global Phenomenon. London: British Council.

This report provides an ambitious review of the state of EMI, presenting recent research as well as results of a global survey of 55 countries, touching on policies and perspectives as well as teaching and learning through EMI.

García, O. and Li Wei. (2014) Translanguaging: Language, Bilingualism and Education. New York: Palgrave Macmillan.

This seminal book offers a concise overview and a critical perspective of translanguaging as a transformative process in the multilingual realities of education today.

Macaro, E. (2018) English Medium Instruction. Content and Language in Policy and Practice. Oxford: Oxford University Press. 
This book provides a comprehensive overview of EMI research and policy in diverse secondary and tertiary educational contexts, with an important focus on teachers and students as key participants.

Paulsrud, B., Rosén, J., Straszer, B. and Wedin, Å. (2017) New Perspectives on Translanguaging and Education. Bristol: Multilingual Matters.

This edited volume presents theoretical and pedagogical perspectives on translanguaging through a number of empirical studies from North American and European educational contexts.

\section{Related topics}

bilingualism and multilingualism, content and language integrated learning (CLIL), content-based second language instruction, bilingual education, education policy

\section{Transcription key}

Text $=$ English text

Text $=$ Swedish text

$<$ Text $>=$ translation of text

$[$ Text $]=$ observed actions (not speech) by the speaker

\section{Note}

1 Note that in this chapter we use the abbreviations L1 and L2 for clarity in the text as we differentiate between the first languages of students and the language of instruction, which in our chapter is English in EMI. We acknowledge the theoretical discussion on the appropriateness of such labels (see for example Otheguy et al. 2015; Vogel and García 2017; García 2018). However, we do not address a problematization in our chapter due to space.

\section{References}

Baker, C. and Wright, W.E. (2017) Foundations of Bilingual Education and Bilingualism. 6th ed. Bristol: Multilingual Matters.

Ballinger, S., Lyster, R., Sterzuk, A. and Genesee, F. (2017) Context-appropriate crosslinguistic pedagogy. Considering the role of language status in immersion education. Journal of Immersion and Content-Based Language Education. 5(1), pp. 30-57.

Bonacina-Pugh, F. (2017) Legitimizing multilingual practices in the classroom: The role of the "practiced language policy". International Journal of Bilingual Education and Bilingualism [online]. doi: 10.1080/13670050.2017.1372359 [Accessed 3 January 2018].

Briggs, J.G., Dearden, J. and Macaro, E. (2018) English medium instruction: Comparing teacher beliefs in secondary and tertiary education. Studies in Second Language Learning and Teaching. 8(3), pp. 673-696.

Bruton, A. (2013) CLIL: Some of the reasons why ... and why not. System. 41, pp. 587-597.

Cenoz, J. (2017) Translanguaging in school contexts: International perspectives. Journal of Language, Identity \& Education. 16(4), pp. 193-198.

Cenoz, J. and Gorter, D. (2017) Translanguaging as a pedagogical tool in multilingual education, in Cenoz, J. and Gorter, D. (eds) Language Awareness and Multilingualism: Encyclopedia of Language and Education. New York: Springer. pp. 309-321.

Cook, V. (2001) Using the first language in the classroom. The Canadian Modern Language Review/La revue canadienne des langues vivante. 57(3), pp. 402-423.

Coyle, D., Hood, P. and Marsh, D. (2010) CLIL: Content and Language Integrated Learning. Cambridge, UK: Cambridge University Press. 
Creese, A. and Blackledge, A. (2010) Translanguaging in the bilingual classroom: A pedagogy for learning and teaching? The Modern Language Journal. 94, pp. 103-115.

Creese, A., Blackledge, A. and Hu, R. (2017) Translanguaging and translation: The construction of social difference across city spaces. International Journal of Bilingual Education and Bilingualism [online]. doi: 10.1080/13670050.2017.1323445 [Accessed 3 January 2018].

Evans, S. and Morrison, B. (2017) English-medium instruction in Hong Kong: Illuminating a grey area in school policies and classroom practices. Current Issues in Language Planning. 18(3), pp. 303-322.

García, O. (2009) Bilingual Education in the 21st Century. A Global Perspective. Chichester: Wiley-Blackwell.

García, O. (2016) Critical multilingual language awareness and teacher education, in Cenoz, J., Gorter, D. and May, S. (eds) Language Awareness and Multilingualism. Cham: Springer International Publishing. pp. 1-17.

García, O. (2018) The multiplicities of multilingual interaction. International Journal of Bilingual Education and Bilingualism. 21(7), pp. 881-891.

García, O. and Li Wei. (2014) Translanguaging: Language, Bilingualism and Education. New York: Palgrave Macmillan.

Genesee, F. and Lindholm-Leary, K. (2013) Two case studies of content-based language education. Journal of Immersion and Content-Based Language Education. 1(1), pp. 3-33.

Gierlinger, E. (2015) "You can speak German, sir": On the complexity of teachers' L1 use in CLIL. Language and Education. 29(4), pp. 347-368.

Jones, B. (2017) Translanguaging in bilingual schools in Wales. Journal of Language, Identity \& Education. 16(4), pp. 199-215.

Kasmer, L. (2013) Pre-service teachers' experiences teaching secondary mathematics in English-medium schools. Mathematics Education Research Journal. 25, pp. 399-413.

Lewis, G., Jones, B. and Baker, C. (2012a) Translanguaging: Developing its conceptualisation and contextualisation. Educational Research and Evaluation. 18(7), pp. 655-670.

Lewis, G., Jones, B. and Baker, C. (2012b) Translanguaging: Origins and development from school to street and beyond. Educational Research and Evaluation. 18(7), pp. 641-654.

Lim Falk, M. (2008) Svenska i engelskspråkig skolmiljö. Ämnesrelaterat språkbruk i två gymnasieklasser [Swedish in an English-Language School Environment. Subject-Based Language Use in Two Upper Secondary Classes]. PhD thesis, Stockholm University, Stockholm.

Lin, A.M.Y. (2018) Theories of trans/languaging and trans-semiotizing: Implications for content-based education classrooms. International Journal of Bilingual Education and Bilingualism [online]. doi: 10.1080/13670050.2018.1515175 [Accessed 3 January 2018].

Lo, Y.Y. and Lo, E.S.C. (2014) A meta-analysis of the effectiveness of English-medium education in Hong Kong. Review of Educational Research. 84(1), pp. 47-73.

Lo, Y.Y. and Macaro, E. (2012) The medium of instruction and classroom interaction: Evidence from Hong Kong secondary schools. International Journal of Bilingual Education and Bilingualism. 15(1), pp. 29-52.

Lo, Y.Y. and Macaro, E. (2015) Getting used to content and language integrated learning: What can classroom interaction reveal? The Language Learning Journal. 43(3), pp. 239-255.

Maalim, H.A. (2017) Students' underachievement in English-medium subjects: The case of secondary school in Zanzibar. Southern African Linguistics and Applied Language Studies. 35(1), pp. 53-62.

Macaro, E. (2018) English Medium Instruction. Content and Language in Policy and Practice. Oxford: Oxford University Press.

Moore, P. and Nikula, T. (2016) Translanguaging in CLIL classrooms, in Nikula, T., Dafouz, E., Moore, P. and Smit, U. (eds) Conceptualising Integration in CLIL and Multilingual Education. Bristol: Multilingual Matters. pp. 211-234.

Otheguy, R., García, O. and Reid, W. (2015) Clarifying translanguaging and deconstructing named languages: A perspective from linguistics. Applied Linguistics Review. 6(3), pp. 281-307.

Paulsrud, B. (2019) Just a little plus: The CLIL student perspective, in Sylvén, L.K. (ed) Investigating Content and Language Integrated Learning. Insights from Swedish High Schools. Bristol: Multilingual Matters. pp. 285-300. 
Paulsrud, B. and Zilliacus, H. (2018) En skola för alla: Flerspråkighet och transspråkande i lärarutbildningen [One school for all: Multilingualism and translanguaging in teacher education], in Paulsrud, B., Rosén, J., Straszer, B. and Wedin, Å. (eds) Transspråkande i svenska utbildningssammanhang [Translanguaging in Swedish Education Contexts]. Lund: Studentlitteratur. pp. 27-48.

Pérez Cañado, M. (2012) CLIL research in Europe: Past, present, and future. International Journal of Bilingual Education and Bilingualism. 15(3), pp. 315-341.

Probyn, M. (2015) Pedagogical translanguaging: Bridging discourses in South African science classrooms. Language and Education. 29(3), pp. 218-234.

Pun, J. and Macaro, E. (2019) The effect of first and second language use on question types in English medium instruction science classrooms in Hong Kong. International Journal of Bilingual Education and Bilingualism. 22(1), pp. 64-77.

Sah, P.K. and Li, G. (2018) English medium instruction (EMI) as linguistic capital in Nepal: Promises and realities. International Multilingual Research Journal. 12(2), pp. 109-123.

Sandberg, Y. (2016) CLIL classroom interaction challenges: Translanguaging and genre as pedagogic tools? in Gitsaki, C. and Alexiou, T. (eds) Current Issues in Second/Foreign Language Teaching and Teacher Development: Research and Practice. Newcastle upon Tyne: Cambridge Scholars Publishing. pp. 212-227.

Simpson, J. (2017) English Language and Medium of Instruction in Basic Education in Low- and Middle-Income Countries: A British Council Perspective. London: British Council.

Skolverket [National Agency for Education]. (2018) Engelskspråkig undervisning. En kartläggning och utvärdering av engelskspråkig undervisning i svensk gymnasieskola [English-Medium Instruction. A Survey and Evaluation of English-Medium Instruction at Swedish Upper Secondary School]. Available from: www.skolverket.se/om-skolverket/publikationer/visa-enskild-publikation? xurl_http $\% 3 \mathrm{~A} \% 2 \mathrm{~F} \% 2 \mathrm{Fwww} 5$. skolverket.se $\% 2 \mathrm{Fwtpub} \% 2 \mathrm{Fws} \% 2 \mathrm{Fskolbok} \% 2 \mathrm{Fwpubext} \% 2 \mathrm{Ftryck}$ sak\%2FRecord\%3Fk\%3D3897 [Accessed 1 February 2018].

Skutnabb-Kangas, T., Phillipson, R., Panda, M. and Mohanty, A.K. (2009) Multilingual education concepts, goals, needs and expense: English for all or achieving justice? in Skutnabb-Kangas, T., Phillipson, R., Mohanty, A.K. and Panda, M. (eds) Social Justice Through Multilingual Education. Bristol: Multilingual Matters. pp. 320-344.

Spratt, M. (2017) CLIL teachers and their language. Research Papers in Language Teaching and Learning. 8(1), pp. 44-61 [online]. Available from: www.du.se.proxy.aspx/login?url=http://search. proquest.com/?url=https://search.proquest.com/docview/1929001383?accountid=10404 [Accessed 29 September 2018].

Sundqvist, P. (2009) Extramural English Matters: Out-of-school English and Its Impact on Swedish Ninth-graders' Oral Proficiency and Vocabulary. PhD thesis, Karlstad University.

Swain, M. and Lapkin, S. (2013) A Vygotskyan sociocultural perspective on immersion education: The L1/L2 debate. Journal of Immersion and Content-Based Language Education. 1, pp. 101-129.

Tan, M. and Lan, O.S. (2011) Teaching mathematics and science in English in Malaysian classrooms: The impact of teacher beliefs on classroom practices and student learning. Journal of English for Academic Purposes. 10, pp. 5-18.

Toth, J. (2018) English-Medium Instruction for Young Learners in Sweden. A Longitudinal Case Study of a Primary School Class in a Bilingual English-Swedish School. PhD thesis, Stockholm University, Stockholm.

Toth, J. and Paulsrud, B. (2017) Agency and affordance in translanguaging for learning: Case studies from English-medium instruction in Swedish schools, in Paulsrud, B., Rosén, J., Straszer, B. and Wedin, Å. (eds) New Perspectives on Translanguaging and Education. Bristol: Multilingual Matters. pp. 189-207.

Vogel, S. and Garcia, O. (2017) Translanguaging, in Noblit, G. (ed) Oxford Research Encyclopedia of Education. Oxford: Oxford University Press [online]. Available from: https://10.1093/ acrefore/9780190264093.013.181 [Accessed 5 January 2018].

Williams, C. (1994) Arfarniad o ddulliau dysgu ac addysgu yng nghyd-destun addysg uwchradd ddwyieithog. Unpublished $\mathrm{PhD}$ thesis, University of Wales, Bangor.

Yoxsimer Paulsrud, B. (2014) English-Medium Instruction in Sweden: Perspectives and Practices in Two Upper Secondary Schools. PhD thesis, Stockholm University, Stockholm. 


\title{
Bilingual education
}

\author{
Anna M. Beres
}

\section{Introduction}

Bilingualism is not a new phenomenon; however, the way it is perceived by society has been variable over time. Bilingual education is a term broadly applied to a wide range of educational approaches that should meet the needs of a wide variety of children and circumstances, in which more than one language is used in a school curriculum to teach different, non-language, subjects (Bialystok 2018). Bilingual education was seen as desirable and prestigious for hundreds of years, up until the 15th century, when the changing socio-economic perspective and the development of the printing press prompted the drive to make uniform the language used and make education homogenous. This trend has prevailed until the turn of the 20th century, when leaders realized the need to educate everyone in society, regardless of their social or linguistic background. This has given rise to decades of experimenting with bilingual education and introducing new programmes. However, the overarching aim remained the same in the majority of the approaches: to educate children from various linguistic backgrounds, but with the hope of them mastering the 'target' language of the school and society and then facilitating essentially monolingual education from that point onwards. Other programmes, which aimed at gaining proficiency in both languages, kept them strictly separate, dedicating particular lessons, teachers, or even days of the week to one language or the other.

Bilingual education that recognized children's home language practices alongside the second language began to gain recognition in the mid-20th century. However, these bilingual programmes were developed from a monolingual perspective that regarded bilingual individuals as having two separate languages. Moreover, many of those programmes aimed at using students' home language in a 'transitional' fashion, that is, only until they became proficient enough in the second language. Around the same time, in a response to an increasing tension between French and English in Canada, the first early immersion programmes were established with the aim to make the Anglophone children bilingual. These programmes included the use of children's second language $100 \%$ of the time in the initial stages, followed by the equal use of their two languages. However, towards the end of the 20th century, some schools began to experiment with the concurrent use of two languages within the same lesson. This method was first coined as the Welsh word trawsieithu by Cen Williams (1994) to describe a 
teaching strategy in which students receive information in one language and produce an output of their learning in another. It has since been renamed as translanguaging, and popularized globally by international scholars and educators, most notably Colin Baker $(2003,2006)$ in the UK and Ofelia García (2009) in the US This method is now being widely accepted as the most appropriate approach to bilingual education in many parts of the world. Translanguaging certainly is a very complex process, which entails both language and mode switch - that is, a shift between comprehension in one language at input (reading, listening) and production in another language at output (writing, speaking). Moreover, it cannot be reduced to simply one of those components, and it is an elaborate interaction of the two that makes it a successful strategy for new knowledge acquisition. In terms of the practical issues around translanguaging, they are still being discovered and the best way to incorporate translanguaging into a daily classroom is an ever-changing and still very much a developing concept.

There is no question that using such flexible approach comes with many challenges, especially for teachers, who might not always be familiar with languages spoken by their students, and for children who might have different skill levels of different languages. One thing is very clear, however: in order for children to learn, they must understand the concept and be able to manipulate the information. If, therefore, they do not understand the language of instruction, they cannot possibly acquire new knowledge and use it effectively. Translanguaging is a strategy that makes this learning possible, while at the same time it allows for the development of second language skills. Collaborative work is crucial, especially in classrooms with children from different linguistic backgrounds who can work together in order to figure out a solution to a given task. They not only learn a new language along the way, but also gain new perspectives, expand their thinking, and increase their understanding. Across the world, there are many more bilingual or multilingual, rather than monolingual, individuals in the $21 \mathrm{st}$ century. With increasing globalization, people travelling or moving away for various reasons, from family to work to personal ones, for most children being surrounded by a language different from their mother tongue is a natural occurrence. That means that, on a daily basis, the vast majority of students learn and develop through the use of a language different from their mother tongue. That means that their language skills must not only allow them to acquire academic knowledge, but also to fully participate in all other aspects of their daily lives and schooling (Christian et al. 1990).

This chapter will describe different approaches to bilingual education that have been used and popularized at different times in history, and how such approaches have worked out over the years, including the information on the appropriate research and key findings. It will then focus on the recent shift in the way bilingual education is being perceived, which stems mainly from the ever-increasing globalization and the urgent need to adapt the way bilingual children are being taught to their needs in the 21 st century, which point to a more flexible use of the child's two languages. It will then discuss the pedagogic methods used, and how they work in practice. It will also cover a number of issues that have been controversial over the years, such as the idea of 'cross-contamination' of language and therefore the drive to keep the two languages of instruction completely separate. Finally, it will argue that the bilingualism we are facing in the 21 st century is very different to the one we have seen before, and therefore needs a new, fresh approach that would allow for a flexible functioning in the ever-changing world we live in today.

\section{Historical perspectives}

For decades, many misconceptions about bilingualism arose, with many scholars warning against the idea of children using two languages as it causes cognitive, emotional, and 
educational damage (Hakuta 1990). Therefore, in order to avoid 'cross-contamination', languages should be kept strictly separately (Jacobson and Faltis 1990). Bilingual education was condemned and seen as somehow detrimental to children's academic performance. In the early 1980s, Baker and de Kanter announced that there was a lack of evidence that bilingual education could meet the needs of minority children (Baker and de Kanter 1981, 1983). Despite a later contradiction (Willig 1985, 1987), with the emphasis on the methodological weaknesses underlying those earlier claims, bilingual education remained seen as something undesirable and ineffective.

That perception, however, was not always the case. Despite bilingualism being seen as advantageous for centuries, things started to shift around the 15 th century, when a number of social changes started to appear and therefore, in order to maximize profits, there was a need to establish a standard language that would be used. Those who did not fall easily under the one desirable category were simply denied access to education (García 2014b). In the US during the 18th and 19th centuries, bilingual education was not unusual. English and Spanish were common in schools in California; German was used in the Midwest; and French in Louisiana and northern New England (Malakoff and Hakuta 1990). With the arrival of a large number of immigrants towards the end of the 19th century, public education became obligatory so as to ensure that all children would be assimilated into the American society. It was not long until many states introduced laws that made English the only language of instruction in the public sector, with many foreign language schools effectively shutting down. It was not until some six decades later that bilingual education started to return to American schools, largely due to the failure of the 'English-only' approach to education (McFadden 1983; Valadez and Patiño Gregoire 1990). The so-called 'English-only' movement was underlined by the assumption that linguistically diverse groups should be grouped under one, homogenous group of English speakers (Spencer 1988). Eventually, this failure led to the introduction of the Bilingual Education Act (BEA) in 1968, which subsidized bilingual education programmes and allocated separate funds for research on bilingualism. BEA recognized that previous approach to educating immigrant children was not efficient, and, perhaps more importantly, highlighted the often-overlooked fact that 'equal education' is not synonymous with 'identical education' (Malakoff and Hakuta 1990).

As nations become acutely aware that providing education for all citizens is a necessary step towards industrialized and developed communities, large numbers of immigrant children were granted access to education. However, bilingualism was, at the same time, seen as an underlying reasons for behavioural and mental problems (Reynold 1928; Weisgerber 1933 in Saunders 1988; Arsenian 1937 in McLaughlin 1978) and those children were essentially required to become monolingual in their second language. Not surprisingly, it was a failed experiment. Due to their poor English language skills, immigrant students performed very poorly in terms of their academic achievements (García 2014b, 2014c). This fear of bilingualism as something detrimental to students' education, seen in parents and teachers alike, was further highlighted by Cummins (1981) and, more recently, by Bialystok and colleagues (2012) who nonetheless have underlined that such apprehension stems from anecdotal evidence and fear (Reljić et al. 2015). This English-only movement also led to almost total eradication on indigenous languages in countries such as Australia or New Zealand.

As the end of the 20th century approached, bilingual education came under fire in terms of legislative aspects once again and was officially prohibited in California (1998), Arizona (2000), and Massachusetts (2002). The significance was placed solely on the official (majority) language (i.e. English) and words such as 'bilingualism' and its derivatives were eradicated from virtually all official documents. There was no compromise; under this philosophy, 
bilingual students were labelled as English Language Learners or Limited English Proficiency Students; the US Office for Bilingual and Minority Language Affairs changed its name to the Office of English Language Acquisition; and even the BEA was absorbed by the No Child Left Behind (NCLB) Legislation. It is almost as if bilingualism became something to be never openly declared (García 2014a). To make matters worse, state funding for schools was closely linked with adequate scores on standardized English tests. It is easy to imagine what followed: as the schools were made liable, in a way, for how much financial support they were given by the state, they introduced more standardized tests in English, leading to effectively eradicating the bilingual language teaching, as it was no longer cost-effective (Crawford 2007). The consequences were not surprising - the bilingual students had limited success under such conditions. If children are examined in a language that they are not confident and proficient in, they simply cannot perform well.

In the 21 st century, we should no longer aim for students to live under such English-only movement, but rather develop new, flexible approaches to bilingual education that will enable all individuals to achieve the highest levels of educational, personal, and professional development. In order to do this, we must look into other areas, such as psychology, cognitive neuroscience, technology, and others. The overarching goal should be to create a society that is language competent, through the collaboration of educators, organizations, and institutions, and to stop perceiving bilingualism as a disadvantage, and instead see it as a national and personal resource (Padilla 1990).

Let us take a moment to think about what bilingualism really means, what it entails, and how it has been changed over time. For a long time, 'native speakers' and 'fluent bilingualism' have been perceived as something to aim for, an ideal goal we should all try to reach, equating to one individual being equally proficient in both languages. However, García (2013) has strongly questioned that concept, arguing for the society to move away from this perception. In fact, such 'ideal bilingualism', in which a student uses the two languages to the same extent and equally proficient, does not happen often, if ever (Valdes 2005; Grosjean 2010). Even a highly proficient bilingual person will use their linguistic competencies differently than monolingual speakers, if only because they have learned how to function flexibly in their bilingual environment on a daily basis. Bilinguals are not "two monolinguals in one" (Grosjean 1989) and acquiring new language certainly does not follow a linear fashion, but instead is dynamic and interactive, essentially leading to a creation of one broad and flexible linguistic repertoire (García 2013). This calls to think about the processes linked with bilingualism and bilingual education, rather than simply the end state. Therefore, we should not aim for students to simply become proficient in their second language, but rather to be able to effectively use whatever skills they have (García 2006). It is only through such translanguaging approach, that bilingual students will be able to successfully partake in global standardized tests such as PISA (Programme for International Student Assessment; García 2014b). They can control their learning and their broadly considered daily lives by drawing from their linguistic repertoire those aspects that are meaningful to them (García and Li Wei 2014). Furthermore, as we move away from the traditional view of bilingualism and a clear distinction between the two languages, it has been argued that we should also reconsider our perception of monolingualism (Creese and Blackledge 2015). Just as bilinguals include their entire linguistic repertoire, together with their cultural backgrounds and different forms of discourse and experiences, monolinguals also mix different codes and discourses, and their communication also include social meanings. Therefore, it could be that both the notions of true bilingualism and true monolingualism are no longer sustainable (Canagarajah and Liyanage 2012). Linguistic homogeneity is no longer the norm, and 
we must focus on how different languages and cultures are mixed and create a new form of communication (Blommaert and Rampton 2011).

\section{Research approaches and key findings}

Since the introduction of the BEA in the 1960s, different approaches to bilingual education have been developed. Transitional bilingual education, perhaps the most common method at the time, argued that once children are proficient in their native language, and therefore can easily acquire new knowledge through it, it is easier for them to develop skills in their second language. The skills they have learned initially could then be easily transferred, or transitioned, into the other language. Maintenance model of bilingual education aimed for all the students to achieve proficiency in the two languages, by providing instructions in both of them. Often, languages were divided by subjects or times of day such that, for example, morning classes were taught in one language, and afternoon classes in another. English as a second language and submersion approaches were similar, in that students were largely left to cope on their own. In the English as a second language approach, learners were individually given particular English activities for small parts of the day while for most of it they were left to deal and handle things on their own in solely English-speaking lessons. In the submersion approach they were effectively left to handle the classes on their own for the entire time (or, as it was often the case, to fail if they could not manage on their own). Immersion programmes, initially developed to produce French-English bilinguals within the French-speaking community in Montreal, aimed to concentrate on the second language for the first few years of education (in this case, to immerse the English-speaking children in French) and then gradually to introduce classes in the first language, eventually leading to a school day that was equally split between instructions in both languages. Similar programmes were later introduced in other countries, such as Australia and the US, and focused on Japanese-English, Mandarin-English, and other language pairs. Another variant of this approach, known as US Immersion or Sheltered English, aimed to make children fluent only in one language - English. In such schools, bilingual teachers provide instructions in English, and children's first language is used only to improve communication when needed.

It is clear that the majority of the past bilingual approaches had one overarching aim - to essentially create monolingual individuals, fluent and proficient in the majority, or official, language. Fundamentally, this was done by subtracting their first language. French immersion and maintenance models were considered additive, in a way that they allowed for the maintenance of students' first language, in addition to becoming proficient in English. However, even those approaches viewed the two languages as separate codes that were static and unchanging. This view is not really tenable in the globalized world we live in today.

These days, with individuals often moving abroad, the increasing flexible use of different languages by the same individual - whether in formal education, the family home in which the parents come from different linguistic backgrounds - as well as the use of the Internet that permits to draw on different linguistic resources (Creese and Blackledge 2015) - we must adopt a different, more flexible approach to bilingual education. All the pedagogical practices regarding bilingual education perceived bilingualism as essentially two separate languages in one person. It slowly became clear that after more than half a century of such language separation, the validity of such approach started to be put into question (Esquinca 2011). An approach that would allow today's individuals to flourish in the current globalized world was much needed.

Translanguaging is regarded as the most appropriate way to educate children in the $21 \mathrm{st}$ century (García 2009). Translanguaging presupposes that we must move away from perceiving 
bilingualism as simply two different languages and instead regard them as flexible and permeable (Blackledge and Creese 2010; García 2011; Park 2013). It is a strategy which relies on interlingual mediation, that is conveying the information from one language to another (Stathopoulou 2016).

Translanguaging is a constantly developing perspective. Initially, it was introduced in secondary schools in Wales in order to foster proficiency in both languages (Welsh and English) and increase the understanding of learning material. Students were given spoken or written information in one language, for example English, and asked to produce their response in their other language, for example Welsh. It has since undergone a massive influx of research and development. Practices similar to translanguaging have been described by different researchers and educators. Even though they might be labelled differently, their underlying philosophy is the same: to include "linguistic practices in which meaning is made using signs flexibly" (Creese and Blackledge 2015, p. 21) and to consider languages as free from clear social boundaries. Beside translanguaging (Baker 2003, 2006; García 2009), other similar concepts have been put forward: code-meshing (Canagarajah 2011), flexible bilingualism (Blackledge and Creese 2010), polylingual languaging (Jørgensen et al. 2011; Madsen 2011), metrolingualism (Otsuji and Pennycook 2011), translingual practices (Canagarajah 2013), and interlinguistic mediation (Stathopoulou 2016). They are all premised on the assumption that languages should be perceived as signs that allow for creating meaning in communicative repertoires (Rymes 2010), which go beyond static languages associates with a particular social group or geographical region (Creese and Blackledge 2015).

Translanguaging disputes the idea that has been prevalent for decades in most countries whereby non-native students have in some way deficient abilities as a result of their lack of competence and proficiency in their second language. This was the reasoning behind many older approaches to bilingual education, such as immersion, with students only using their second language, in which any form of language mixing was actively discouraged or even prohibited on school premises, leaving students feeling isolated and excluded as they struggled to express themselves in their second languages (Cenoz and Gorter 2011). Those feelings of unacceptance, rejection and even failure can, however, be overridden by the use of flexible languaging. Using whatever linguistic skills they have, bilingual students are not restricted by their limited skills in their second language, but are able to make a connection with one another, express themselves, discuss their thoughts and feelings and acquire new skills, both linguistic and other. Therefore, they can partake in a situation that they would be excluded from under many other bilingual education programmes. Translanguaging allows learners to emphasize their skills rather than their limitations, and consequently "gives voice to those who do not speak" (García 2014a, p. 115) and essentially frees the voices of minority students. This, in turn, creates space for making connections between languages, cultures, communities, and individuals.

It is always difficult to fully assess and judge the results of different bilingual education programmes. An ideal evaluation would come from randomized controlled trials, the gold standard in research, but within the broad and varied field of bilingual education they would be practically unfeasible to conduct (Bialystok 2018). Furthermore, as Greene (1998, p. 10) argues, the rigorous evaluation of different bilingual education is difficult as often they are so methodologically incorrect that "their results offer more noise than signal".

One of the recent advances in the field of bilingual education is trying to use the knowledge of the human brain functioning in order to disentangle the processes involved in learning by bilinguals. In her doctoral thesis Beres $(2014,2016)$ investigated the neural mechanisms of translanguaging in fluent Welsh-English early bilinguals who show comparable proficiency in 
their two languages, therefore allowing them to self-regulate their translanguaging strategies in what can be defined as 'independent translanguaging' (Kano 2012). This research was based on the foundational description of translanguaging, such that it is a process that involves receiving information in one language and producing it in another (Williams 1994). The overarching aim was to ascertain the outcomes of learning new, previously unknown information either with the use of two languages or just one. Students were presented with a novel-object learning task, in which the learning condition varied: in one, the language of the presentation of information was the same as the language in which individuals were asked to produce an output of what they were learning (monolingual condition), whereas in the other, the languages at input and output differed (translanguaging condition). After their learning was completed, individuals were tested on what they remembered with the use of the electroencephalogram (EEG), more specifically with the N400 ERP (event-related potential) component that is known to index the semantic integration effort. A classic picture-picture priming paradigm was created, in which pairs of previously learned objects were either related or unrelated to their previously learned definitions. In line with the expectations, a smaller N400 amplitude was found when novel pictures were paired with their previously learned related, rather than unrelated picture, known as the semantic priming effect. Crucially, pictures that were previously acquired in the translanguaging condition, rather than in the monolingual condition, also produced a smaller N400 wave - thus suggesting that it was easier to recover the knowledge about them. What is even more striking is that after a number of weeks, the same effect was still present, with no revision of the material in the meantime. Those findings are significant on two major accounts. First, they point to the importance of using translanguaging in enhancing learning and, second, they provide the first systematic, quantitative, and neuroscientific evidence that such alteration of two languages not only does not cause cross-contamination in learners, causing confusion and negative effects, but actually enables them to engage in deeper, more meaningful acquisition of knowledge.

\section{Pedagogic approaches and methods}

If languages are no longer to be seen as static and separate, but rather flexible and permeable, the question arises - what does this mean for teachers? How should they structure the learning and teaching around something so fluid, which includes the children's entire linguistic repertoire, cultures, and identities? Approaching bilingual education through the use of translanguaging seems to be the right path to take (Creese and Blackledge 2015).

Bilingual education is not a constant, unfluctuating procedure, and the process of teaching and instruction is closely linked with student active participation, which in turn leads to their better educational successes (Gregoire 1985 in Valadez and Patiño Gregoire 1990). Bilingual education should allow for flexibility, and should depend on the particular context rather than follow a one-size-fits-all approach (García 2009; Baker 2011).

Some of the earlier concerns that bilingualism and bilingual education might be detrimental to children's development are not really appropriate in the 21 st century if we take into consideration the fact that most children across the globe are, in fact, bi- or multilingual and are raised with more than their mother tongue. Hence, we should stop the discussion whether bilingual education should be reserved only for the privileged and aspirational students (see Cummins and Swain 1986) and move towards global bilingual education that should be adapted to different contexts (García 2009). Furthermore, empirical evidence strongly suggests that there are no detrimental costs to bilingualism or bilingual education (Willig 1985; Collier and Thomas 2004; Rolstad et al. 2005; Francis et al. 2006; Genesee and Lindholm-Leary 2012; Genesee 
and Fortune 2014). Also, empirical evidence has demonstrated that children with rather poor English language skills who receive at least some of the instruction at school in their native language receive much better scores on standardized tests than similar students who are taught only in English (Greene 1998). Furthermore, bilingualism positively impacts people's general well-being and the benefits should be seen in terms of psychological and social aspects, rather than purely linguistic (Edwards 2003).

Even today, some oppose the idea of mixing two languages in the same classroom. Teachers often think that such linguistic diversity might have detrimental effects on learning (Dooly 2007). They are often aware of their lack of proficiency in the minority languages that their students speak and therefore apprehensive of the possible effects it might have on learning. Furthermore, as humans often tend to be drawn to those who are similar to them, teachers are often nervous that such free use of languages could negatively influence inter-language friendships amongst children or that there will be more off-task conversations during lessons, and children's limited skills in their home language may not facilitate the acquisition of new knowledge (Van Der Wildt et al. 2015). Many teachers who work with bilingual students do not see using multiple languages as a beneficial learning tool (Conteh et al. 2008). Sometimes they view it as a potential obstacle in learning (Dooly 2007) or even as detrimental in acquiring new knowledge and improving academic achievement (Agirdag et al. 2014). Therefore, more research should focus not just on the scientific aspects of translanguaging, but more importantly on the pedagogical practices and how it could be successfully applied in an educational setting.

Recently, Duarte (2019) has found that translanguaging in the mainstream classroom does not increase off-task talk but facilitates on-task conversations that are often cognitively demanding. Students were able to share their knowledge with one another and build on each others' ideas, essentially scaffolding meaning and understanding through joint interaction, which therefore leads to successful learning and solving tasks.

The idea of education through translanguaging as the best pedagogical approach has been popularized by a number of researchers, particularly Colin Baker $(2003,2006)$ and Ofelia García $(2009,2011,2012)$. García especially has been a strong proponent and advocate for using translanguaging with children who are only acquiring their second language, predominantly those living in the US but coming from homes in which Spanish is exclusively, or predominantly used. She asserts that children flexibly and naturally use their entire linguistic repertoire, regardless of the actual language, in order to enable them to fully participate in the social situation (Beres 2015). In fact, the enhancement of second language skills through the use of translanguaging in Spanish-speaking children learning English was shown as early as in the mid-1980s (Moll and Diaz 1985).

Translanguaging enables students to acquire knowledge through meaning and deeper understanding of the subject. If students, for example, read a text or listen to their teacher in one language, but are encouraged to produce an output in the second language, they must fully immerse themselves in what is being taught, and understand the content in both languages, before they can successfully reply. Therefore, there is no way for them to simply pick up on some key words they read or heard. Furthermore, such pedagogical strategy encourages not only learning of a second language and a maintenance of both languages, but also the active and flexible use of two languages by students and teachers alike, thus ensuring flexible and successful academic content learning as well as active participation within the educational and social settings. Translanguaging, therefore, not only allows students to develop competencies in their second language, but also to increase their academic success and general knowledge (García 2012). 
Creese and her colleagues (see Blackledge and Creese 2019) have recently completed a large, 4-year-project dealing with how individuals living in four major cities in the U.K. but coming from very different linguistic and cultural backgrounds use translation and translanguaging in order to communicate successfully. By undertaking work within different social domains, such as sports, business, and legal systems, their aim was to determine how languages can be used and developed flexibly in different situations in very varied, both linguistically and culturally, settings. Understanding the role that bi- and multilingualism have in general well-being, including diplomacy, health, education, and many other aspects, will without a doubt contribute to social and educational change, having a positive influence on the multicultural British communities of the $21 \mathrm{~s}^{t}$ century. For the newest updates, please see the project's dedicated website at www.birmingham.ac.uk/generic/tlang/about/index.aspx.

In a classroom setting, translanguaging pedagogy makes use of all the natural linguistic practices of children in order to increase learning and understanding and maximize accomplishments. This is done by taking advantage of all the language skills, regardless of which language it is, and using them in a dynamic and integrated way to help with understanding, communication, literacy skills, and learning (Lewis et al. 2012).

Creese and Blackledge (2015) make a number of observations in British schools with bilingual students, with different levels of language competencies. Here, one of their examples is quoted to illustrate how translanguaging might work. Observation takes place in a Saturday heritage language school that teaches Panjabi to students coming from the "Panjabi heritage". Teacher (Kirpal) has asked the students to write about their holidays.

Shaan: $\quad$ saumvaar mair TV dekhiya <on Monday I see TV>

Kirpal: ((to Shaan)) dekhiya si $<$ watched $>$ you end it with se $<$ had $>$ yeah past tense sassy ${ }_{s}>$ sassay nu bihari <elongated e sound on the $s>$ did you eat, did you eat on Monday?

Simran: yeah, you had to have roti (chapatti)

Kirpal: ((laughs)) mair roti daal naal khaadi si $<$ I ate chapatti with lentils $>$

(Creese and Blackledge 2015, p. 30)

This example beautifully illustrates how translanguaging includes the entire linguistic repertoire and facilitates learning through meaning and understanding. The student (Shaan) provided a sentence in Panjabi (in this case it was the target language), while the teacher uses both English and Panjabi to pass on the knowledge. Such mixture of the two languages forces the student to see the two languages as one repertoire, make meaning out of it, and enables them to perceive it as an acceptable way to learn.

This is only one example that illustrates how translanguaging could be used in pedagogical practice to find identities, move above and beyond rigid language separation, and promote learning through meaning.

Duarte (2019) argues that translanguaging enables learners to share knowledge and ideas which can then be evaluated. This in turn facilitates understanding and learning. Duarte posits that translanguaging allows for making sense of the task at hand by the students by paraphrasing what is required of them, choosing and reporting the knowledge needed to complete the task, and resolving classroom management issues. Furthermore, it also allows for jointly creating answers by negotiating meaning and amending previous information if need be, preparing the content needed, putting forward counter arguments, dealing with agreements and disagreements, and choosing the right words and phrases. Both of those phases of collaboration through translanguaging benefit children's second language learning, as well as allow for 
a more detailed, deeper, and more meaningful acquisition of knowledge. This work provides important evidence in favour of using pedagogic translanguaging and challenges the views whereby flexible use of children's linguistic skills is detrimental for their learning.

Finally, García and Li Wei (2014) list seven main purposes of translanguaging used by educators in pedagogical settings. They are:

1 to differentiate among students' level and adapt instruction to different types of students in multilingual classrooms; for example, those who are bilingual, those who are monolingual, and those who are emergent bilinguals;

2 to build background knowledge so that students can make meaning of the content being taught and the ways of languaging in the lessons;

3 to deepen understanding and cognitive engagements, develop and extend new knowledge, and develop critical thinking;

4 for cross-linguistic transfer and metalinguistic awareness so as to strengthen the students' ability to translanguage in order to meet the communicative exigencies of the socioeducational situations;

5 for cross-linguistic flexibility so as to translanguage competently;

6 for identity investment and positionality, to engage learners;

7 to interrogate linguistic inequality and disrupt sociopolitical structures so as to engage in social justice.

(García and Li Wei 2014, p. 235)

\section{Conclusions and future directions}

Both research as well as classroom experiences seem to point to the effectiveness of translanguaging and suggest it as the only appropriate and successful strategy in today's bilingual education. A strategy that not only allows students to develop proficiency in their second language, but also enables them to use it together with their mother tongue in a flexible, permeable manner, effectively treating their two (or more) languages as one linguistic repertoire. What is needed at this stage is more research into translanguaging in different learning environments, such as online and distance learning, supporting children with more than one language spoken at home, adapting the assessment procedures and coming up with new ways to undertake the standardized tests, which should take into account translanguaging and interlingual mediation practices (Stathopoulou 2016). Furthermore, investigating how bilingual education and translanguaging would work in special populations, such as individuals with special needs, those using alternative ways of communication, or bimodal bilinguals such as the Deaf, would also be beneficial. Translanguaging does not only refer to students' bilingual performance, but also to a pedagogical approach that permits to teach bilingual students in a systematic fashion by encouraging them to use their entire linguistic repertoire to not only increase their language proficiency but also to extend their general knowledge (García and Leiva 2014).

Recent research and pedagogic practice have moved from seeing bilingualism as strictly separate two languages, to viewing them as a dynamic, permeable, complex system that forms one linguistic repertoire which individuals can flexibly draw on to meet their communicative needs. As individuals from different linguistic backgrounds and cultures are coming into contact now more than ever before, also through alternative forms of communication such as media and the Internet, translanguaging seems to be the only way forward to educate bilingual children. It also emphasizes that we should start from the individual, with all their linguistic skills and cultural aspects that they bring with them, rather than purely focusing on a language 
they speak or wish to speak. Bilingual education, just as any other kind of education, can hugely facilitate social change, equality, and justice. We must therefore facilitate the development of bilingual education programmes that would include all students. We should make a commitment to share our knowledge and expertise in order to create a better, inclusive, and flexible school environment for all students.

\section{Further reading}

García, O. (2014c) Multilingualism and language education, in Leung, C. and Street, B.V. (eds) The Routledge Companion to English Studies. New York: Routledge. pp. 84-99.

This book offers a set of extensive views on English as a subject of study and research and emphasizes the significance of the link between English and other languages within the notion of multilingualism. It is an assortment of 34 articles that give a detailed view of the vibrant and diverse field of English studies and will prove to be a vital and instrumental text for researchers in this field.

TTMC Translation and Translanguaging in Multilingual Contexts. (2015) 1(1). Available from: https:// benjamins.com/catalog/ttmc [Accessed 17 February 2016].

This journal aims to stimulate novel interdisciplinary and multidisciplinary studies that are carried out in multilingual settings as varied as preschool, primary, secondary, tertiary, and postgraduate education as well as vocational courses, workplaces, and travels. It provides a forum for innovative studies that find their place at a crossroads between translation studies and bilingual education, language teaching methodology, second language acquisition, curricular design, language policy and planning, psycholinguistics and sociolinguistics.

\section{Related topics}

content-based instruction, multilingual turn, English as a medium of instruction (EMI)

\section{References}

Agirdag, O., Jordens, K. and Van Houtte, M. (2014) Speaking Turkish in Belgian primary schools: Teacher beliefs versus effective consequences. Bilig. 70, pp. 7-28.

Baker, C. (2003) Biliteracy and transliteracy in Wales: Language planning and the Welsh National Curriculum, in Hornberger, N. (ed) Continua of Biliteracy: An Ecological Framework for Educational Policy, Research, and Practice in Multilingual Settings. Clevedon: Multilingual Matters. pp. 71-90.

Baker, C. (2006) Foundations of Bilingual Education and Bilingualism. Clevedon: Multilingual Matters.

Baker, C. (2011) Foundations of Bilingual Education and Bilingualism. 2nd ed. Bristol: Multilingual Matters.

Baker, K. and de Kanter, A. (1981) Effectiveness of bilingual education: A review of literature. Washington, DC: Office of Planning, Budget and Education. US Department of Education. Available from: https://files.eric.ed.gov/fulltext/ED215010.pdf [Accessed 14 April 2019].

Baker, K. and de Kanter, A. (eds) (1983) Bilingual Education: A Reappraisal of Federal Policy. Lexington, MA: Lexington Books.

Beres, A.M. (2014) Translanguaging: A Road to Bilingually Boosted Education. Poster presented at the 9th Annual Alpine Brain Imaging Meeting, Champéry, Switzerland, 14 January.

Beres, A.M. (2015) An overview of translanguaging: 20 years of 'giving voice to those who do not speak'. Translation and Translanguaging in Multilingual Contexts. 1(1), pp. 103-118.

Beres, A.M. (2016) Translanguaging as a Strategy to Boost Human Learning: An Event-Related Potential (ERP) Investigation. PhD thesis, Prifysgol Bangor University. Available from: http://e.bangor. ac.uk/id/eprint/6577 [Accessed 14 April 2019]. 
Bialystok, E. (2018) Bilingual education for young children: Review of the effects and consequences. International Journal of Bilingual Education and Bilingualism. 21(6), pp. 666-679.

Bialystok, E., Craik, F. and Luk, G. (2012) Bilingualism: Consequences for mind and brain. Trends in Cognitive Sciences. 16, pp. 240-250.

Blackledge, A. and Creese, A. (2010) Multilingualism: A Critical Perspective. London: Continuum.

Blackledge, A. and Creese, A. (2019) Voices of a City Market: An Ethnography. Bristol: Multilingual Matters.

Blommaert, J. and Rampton, B. (2011) Language and superdiversity. Diversities. 12(2), pp. 1-22.

Canagarajah, S. (2013) Translingual Practice: Global Englishes and Cosmopolitan Relations. London: Routledge.

Canagarajah, S. (2011) Translanguaging in the classroom: Emerging issues for research and pedagogy. Applied Linguistics Review. 2, pp. 1-28.

Canagarajah, S. and Liyanage, I. (2012) Lessons from pre-colonial multilingualism, in Martin-Jones, M., Blackledge, A. and Creese, A. (eds) The Routledge Handbook of Multilingualism. London: Routledge. pp. 49-65.

Cenoz, J. and Gorter, D. (2011) A holistic approach to multilingual education: Introduction. The Modern Language Journal. 95(3), pp. 339-343.

Christian, D., Spanos, G., Crandall, J., Simich-Dudgeon, C. and Willets, K. (1990) Combining language and content for second-language students, in Padilla, A.M., Fairchild, H.H. and Valadez, C.M. (eds) Bilingual Education: Issues and Strategies. Newbury Park, CA: Sage Publications. pp. 141-156.

Collier, V. and Thomas, W. (2004) The astounding effectiveness of dual language education for all. NABE Journal of Research and Practice. 2, pp. 1-20.

Conteh, J., Kumar, R. and Beddow, D. (2008) Investigating pupil talk in multilingual contexts: Sociocultural learning, teaching and researching. International Journal of Primary, Elementary and Early Years Education. 3(36), pp. 223-235.

Crawford, J. (2007) The decline of bilingual education in the USA: How to reverse a troubling trend? International Multilingual Research Journal. 1(1), pp. 33-37.

Creese, A. and Blackledge, A. (2015) Translanguaging and identity in educational settings. Annual Review of Applied Linguistics. 35, pp. 20-35.

Cummins, J. (1981) Empirical and theoretical underpinnings of bilingual education. Journal of Education. 163, pp. 16-30.

Cummins, J. and Swain, M. (1986) Bilingualism in Education: Aspects of Theory, Research, and Practice. London: Routledge.

Dooly, M. (2007) Constructing differences: A qualitative analysis of teachers' perspectives on linguistic and cultural diversity. Linguistics and Education. 18(2), pp. 142-166.

Duarte, J. (2019) Translanguaging in mainstream education: A sociocultural approach. International Journal of Bilingual Education and Bilingualism. 22(2), pp. 150-164.

Edwards, J. (2003) The importance of being bilingual, in Dewaele, J-M., Housen, A. and Wei, L. (eds) Bilingualism: Beyond Basic Principles. Clevedon: Multilingual Matters. pp. $28-42$.

Esquinca, A. (2011) Bilingual college writers' collaborative writing of word problems. Linguistics and Education. 22, pp. 150-167.

Francis, D., Lesaux, N. and August, D. (2006) Language of instruction, in August, D. and Shanahan, L. (eds) Developing Literacy in Second-Language Learners. Mahwah, NJ: Lawrence Erlbaum. pp. 365-413.

García, O. (2006) Foreword: Inventing discourses, representations and conceptualizations of language, in Makoni, S. and Pennycook, A. (eds) Disinventing and Reconstituting Languages. Clevedon: Multilingual Matters. pp. $\mathrm{xi}-\mathrm{xv}$.

García, O. (2009) Bilingual Education in the 21st Century: A Global Perspective. Malden, MA: Blackwell.

García, O. (2011) From language garden to sustainable languaging: Bilingual education in a global world. Perspective: A Publication of the National Association for Bilingual Education. pp. 5-10. 
García, O. (2012) Theorizing translanguaging for educators, in Celic, C. and Seltzer, K. (eds) Translanguaging: A CUNY-NYSIEB Guide for Educators. pp. 1-6. Available from: www.nysieb.ws.gc.cuny. edu/files/2012/06/FINAL-Translanguaging-Guide-With-Cover-1.pdf [Accessed 19 April 2019].

García, O. (2013) Translanguaging to teach English in Nepal. Available from: http://neltachoutari. wordpress.com/2013/07/01/translanguaging-to-teach-english-in-nepal/ [Accessed 19 April 2019].

García, O. (2014a) Countering the dual: Transglossia, dynamic bilingualism and translanguaging in education, in Rubdy, R. and Alsagoff, L. (eds) The Global-Local Interface, Language Choice and Hybridity. Bristol: Multilingual Matters. pp. 100-118.

García, O. (2014b) Becoming bilingual and biliterate: Sociolinguistic and sociopolitical considerations, in Stone, A., Silliman, E.R., Ehren, B.J. and Wallach, G.P. (eds) Handbook of Language and Literacy: Development and Disorders. New York: The Guilford Press. pp. 145-160.

García, O. (2014c) Multilingualism and language education, in Leung, C. and Street, B.V. (eds) The Routledge Companion to English Studies. New York: Routledge. pp. 84-99.

García, O. and Leiva, C. (2014) Theorizing and enacting translanguaging for social justice, in Blackledge, A. and Creese, A. (eds) Heteroglossia as Practice and Pedagogy. Dordrecht, The Netherlands: Springer Science+Business Media. pp. 199-218.

García, O. and Wei, L. (2014) Translanguaging: Language, Bilingualism and Education. New York: Palgrave Macmillan.

Genesee, F. and Fortune, T. (2014) Bilingual education and at-risk students. Journal of Immersion and Content-Based Language Education. 2, pp. 165-180.

Genesee, F. and Lindholm-Leary, K. (2012) The education of English language learners, in Harris, K., Graham, S. and Urdan, T. APA Handbook of Education Psychology. Washington, DC: APA Books. pp. 499-526.

Greene, J.P. (1998) A Meta-Analysis of the Effectiveness of Bilingual Education. Available from: www. languagepolicy.net/archives/greene.htm [Accessed 19 April 2019].

Grosjean, F. (1989) Neurolinguists, beware! The bilingual is not two monolinguals in one person. Brain and Language. 36(1), pp. 3-15.

Grosjean, F. (2010) Bilingual: Life and Reality. Cambridge, MA: Harvard University Press.

Hakuta, K. (1990) Language and cognition in bilingual children, in Padilla, A.M., Fairchild, H.H. and Valadez, C.M. (eds) Bilingual Education: Issues and Strategies. Newbury Park: CA: Sage Publications. pp. 47-59.

Jacobson, R. and Faltis, C. (1990) Language Distribution Issues in Bilingual Schooling. Clevedon: Multilingual Matters.

Jørgensen, J., Karrenbaek, M., Masen, L. and Møller, J. (2011) Polylanguaging in superdiversity. Diversities. 13(2), pp. 23-38.

Kano, N. (2012) Translanguaging as a process and a pedagogical tool for Japanese students in an English writing course in New York. Dissertation Abstracts International Section A: Humanities and Social Sciences 74(10-A(E)). ProQuest Information \& Learning. 2012, AAI3512508. Available from: https://pqdtopen.proquest.com/doc/1024428749.html?FMT=AI [Accessed 3 July 2019].

Lewis, G., Jones, B. and Baker, C. (2012) Translanguaging: Developing its conceptualisation and contextualisation. Educational Research and Evaluation. 18(7), pp. 655-670.

Madsen, L.M. (2011) Social status relations and enregisterment in contemporary Copenhagen. Working Papers in Urban Language \& Literacies. Paper 72. pp. 1-24. Available from: www.kcl.ac.uk/ecs/ research/research-centres/ldc/publications/workingpapers/abstracts/wp072-social-status-relationsand-enregisterment-in-contemporary-copenhagen- [Accessed 3 July 2019].

Malakoff, M. and Hakuta, K. (1990) History of language minority education in the United States, in Padilla, A.M., Fairchild, H.H. and Valadez, C.M. (eds) Bilingual Education: Issues and Strategies. Newbury Park: Sage Publications. pp. 27-46.

Makoni, S. and Pennycook, A. (2007) Disinventing and reconstituting languages, in Makoni, S. and Pennycook, A. (eds) Disinventing and Reconstituting Languages. Clevedon: Multilingual Matters. pp. $1-41$.

McFadden, B. (1983) Bilingual education and the law. Journal of Law and Education. 12(1), pp. 1-27. 
McLaughlin, B. (1978) Second-Language Acquisition in Childhood. Hillsdale, NJ: Erlbaum.

Moll, L. and Diaz, S. (1985) Ethnographic pedagogy: Promoting effective bilingual Instruction, in García, E.E. and Padilla, R.V. (eds) Advances in Bilingual Education Research. Tucson, AZ: University of Arizona Press. pp. 127-149.

Otsuji, E. and Pennycook, A. (2011) Social inclusion and metrolingual practices. International Journal of Bilingual Education and Bilingualism. 14(4), pp. 413-426.

Padilla, A.M. (1990) Bilingual education: Issues and perspectives, in Padilla, A.M., Fairchild, H.H. and Valadez, C.M. (eds) Bilingual Education: Issues and Strategies. Newbury Park: Sage Publications. pp. 15-26.

Park, M.S. (2013) Code-switching and translanguaging: Potential functions in multilingual classrooms. Teachers College, Columbia University Working Papers in TESOL \& Applied Linguistics. 13(2), pp. 50-52. Available from: http://journals.tc-library.org/index.php/tesol/article/viewFile/960/603 [Accessed 3 July 2019].

Reljić, G., Ferring, D. and Martin, R. (2015) A meta-analysis on the effectiveness of bilingual programs in Europe. Review of Educational Research. 85(1), pp. 92-128.

Rolstad, K., Mahoney, K. and Glass, G. (2005) The big picture: A meta-analysis of program effectiveness research on English language learners. Educational Policy. 19, pp. 572-594.

Rymes, B. (2010) Classroom discourse analysis: A focus on communicative repertoires, in Hornberger, N. and McKay, S. (eds) Sociolinguistics and Language Education. Clevedon: Multilingual Matters. pp. $528-546$.

Saunders, G. (1988) Bilingual Children: From Birth to Teens. Clevedon: Multilingual Matters.

Spencer, D. (1988) Transitional bilingual education and the socialization of immigrants. Harvard Educational Review. 58, pp. 133-153.

Stathopoulou, M. (2016) From 'languaging' to 'translanguaging': Reconsidering foreign language teaching and testing through a multilingual lens. Selected Papers of the 21st International Symposium on Theoretical and Applied Linguistics (ISTAL 21). pp. 757-774. Available from: http://ejournals.lib. auth.gr/thal/article/view/5267/5155 [Accessed 3 July 2019].

Valadez, C. and Patiño Gregoire, C. (1990) Development of a bilingual education plan, in Padilla, A.M., Fairchild, H.H. and Valadez, C.M. (eds) Bilingual Education: Issues and Strategies. Newbury Park: Sage Publications. pp. 106-125.

Valdes, G. (2005) Bilingualism, heritage language learners, and SLA research: Opportunities lost or seized? Modern Language Journal. 89, pp. 410-434.

Van Der Wildt, A., Van Avermaet, P. and Van Houtte, M. (2015) Do birds singing the same song flock together? A mixed-method study on language as a tool for changing social homophily in primary schools in Flanders (Belgium). International Journal of Intercultural Relations. 49, pp. 168-182.

Williams, C. (1994) Arfarniad o Ddulliau Dysgu ac Addysgu yng Nghyd-destun Addysg Uwchradd Ddwyieithog. $\mathrm{PhD}$ dissertation, Bangor University.

Willig, A. (1985) A meta-analysis of selected studies on the effectiveness of bilingual education. Review of Educational Research. 55, pp. 269-317.

Willig, A. (1987) Examining bilingual education research through meta-analysis and narrative review: A response to Baker. Review of Educational Research. 57, pp. 363-376. 
$\because$ Taylor \& Francis

http://taylorandfrancis.com 
Part IV

Higher education 
$\because$ Taylor \& Francis

http://taylorandfrancis.com 


\title{
Modern languages
}

\author{
Michael Huffmaster and Claire Kramsch
}

\section{Introduction}

Translation has had a varied history in the study of modern languages in higher education. From the beginnings of the discipline through to the 20th century, it formed the cornerstone of pedagogy. Then in the mid-20th century, it fell out of favour and was largely banned from the classroom. Now in the 21 st century, in response to globalization phenomena such as increasing multilingualism, its role in language study is being reassessed and beginning to enjoy wider acceptance.

Throughout this chapter we will employ the term translation in two distinct albeit related senses. One accords with the common understanding of the term that designates the process whereby the meaning of a text written in one language gets conveyed via a text composed in a different language, as well as to the text that is thereby produced. In translation studies, it is often distinguished from interpreting, which refers to the near-simultaneous conveyance in real time of the meaning of (usually extended) speech uttered in one language via speech in another language. Several chapters in this volume include interpreting under the broader rubric of translation, but the study of modern foreign languages in higher education, even with its shift of emphasis from textuality to orality since the mid-20th century, has never involved interpreting in this sense. In foreign language study, translation is understood primarily along the lines of the common understanding described earlier as a textcentred phenomenon; however, it also has a broader meaning referring to the mental and verbal shuttling between languages that learners and teachers often engage in, but which does not produce a text. For example, when students indicate they don't understand a new vocabulary item, the instructor may quickly provide an oral translation, a practice especially useful for abstract lexis. Alternatively, the instructor may choose to explain the new concept in the target language and will know students have understood when they register an expression of comprehension because they have translated the term in their minds. Students will frequently spontaneously vocalize their translations in such cases to elicit confirmation from the instructor. The inclusion of bilingual vocabulary lists in classroom instruction or students' use of flashcards for self-study are two other examples of the many kinds of practices that fall under the rubric of translation in this broader sense. Though related to 
translanguaging (Garcia and Wei 2014) and translingual (Canagarajah 2013) phenomena in that they acknowledge and depend upon the holistic, ecological nature of learners' language repertoires, such practices are nevertheless distinct from prototypical translanguaging phenomena such as code-switching or code-meshing. In this chapter we employ the term translation in both the strict and broader senses.

\section{Historical perspectives}

When modern languages came to be broadly established as part of the university curriculum in Europe and North America over the course of the 19th century, both the rationale for their inclusion and the pedagogy employed were modelled on the study of the ancient classical languages, primarily Latin. The purpose of language study was to gain privileged access to prestigious foreign cultures by reading their literary monuments in the original, conferring prestige on and confirming the elite status of the educated upper classes (Lehberger 1995, p. 563; Neuner 1995, p. 182). Accordingly, the grammar-translation method (as it subsequently came to be known) was the preferred pedagogy. In this method, the grammatical structures of a foreign language are learned deductively, that is, the rules are explained in the learners' first language (L1), and then practised by translating. A typical lesson includes a list of new vocabulary items along with their L1 translations, explanations in the learners' L1 of the new grammatical structures being introduced (often drawing comparisons or highlighting contrasts with the L1), a text in the foreign language featuring the new vocabulary and structures, and a set of isolated, invented sentences employing the new vocabulary and exemplifying the new structures. The primary task for learners, apart from memorizing vocabulary and learning grammar rules, is to translate the sets of sentences in each lesson from the foreign language into their L1. In some iterations of the method, learners also translate isolated, invented sentences from their L1 into the foreign language. Also, the texts included in a typical lesson can be translated. The method thus obviously involves a lot of translation in the common understanding of the term as a textual practice, but it also involves, perhaps less obviously, a lot of translation in the broader sense of mental and verbal shuttling back and forth between languages, as evident in the bilingual vocabulary lists and the grammar explanations (with comparative and contrastive analysis) in the L1. The language of instruction is also the L1, which inevitably implies a lot of translation in this broader sense as well.

Although intellectual movements challenging the grammar-translation method emerged in Europe in the late 19th and early 20th centuries (Cook 2010, pp. 4-19; Laviosa 2014, pp. 8-13), the approach continued to dominate the study of foreign languages in higher education in Europe and North America until the 1940s (Richards and Rodgers 2014, pp. 7-13). In many other parts of the world, it continues to be employed widely, and it is still used, in fact, at many university foreign language departments in the United States in specialized reading courses offered for graduate students (who must demonstrate reading knowledge of a foreign language as a degree requirement - which they do by translating a text!). After World War II, however, a major shift occurred in foreign language study in higher education that upended the role of translation. The war itself represented an unprecedented escalation of globalization processes dating back centuries, and the post-war period witnessed a continuation and intensification of these processes, albeit under the peaceful banner of free trade. With dramatically increased mobility, the generally recognized purpose of studying foreign languages changed dramatically. No longer was it to gain privileged access to prestigious foreign cultures by reading their literary monuments in the original. Rather, it was to be able to communicate effectively with native speakers of the foreign language in face-to-face interactions by approximating as best 
as possible native-speaker norms. The nature of instruction changed accordingly from focusing on reading and writing to emphasizing listening and speaking skills, and exclusive use of the target language in instruction became the new pedagogical norm, with translation effectively banned from the classroom. This transformation reflected not only the military needs of the United States as a new global superpower (for translators and interpreters in conflict situations or for intelligence purposes, for example), as it is sometimes portrayed. It also had to do with the movement to broaden access to higher education for the middle and working classes, as exemplified by the G.I. Bill of 1944 and the establishment of Pell Grants in 1965. Accordingly, foreign language learning came to be seen less as an elite luxury and more as a pragmatic tool for utilitarian purposes.

The first new approach to achieve dominance in the post-war period in higher education in the United States was the audiolingual method. The method drew its theoretical justification from behaviourism, the dominant current in psychology at the time, which held that all learning is a matter of conditioned response to stimuli in an organism's environment and that language learning (first or subsequent) is no different from any other kind of learning in this regard. Accordingly, classroom instruction came to be dominated by oral drills, and heavy emphasis was placed on approximating native-speaker-like pronunciation norms. Grammar was learned inductively; that is, grammatical structures were not taught explicitly or explained during class, either in the learners' L1 or in the target language. Learners were instead provided copious examples of a set of new structures in the target language and expected to induce the relevant grammar rules from them and thereby acquire the new structures. In a typical lesson, a brief dialogue in the foreign language is read out loud by the instructor, which students then repeat line by line, in chorus and individually, until they have gradually memorized it and can perform it. Examples of the new structures that are the focus of the lesson are then extracted from the dialogue as models for pattern drills of various iterations, with the instructor modelling pronunciation as students repeat in chorus and individually. The audiolingual method insisted on exclusive use of the target language in instruction, with no role for translation. Actual practice, of course, probably looked somewhat different from the methodological ideal, with instructors likely explaining grammar in their learners' L1 (if they knew it) as necessary, thus employing translation in the broader sense on occasion. According to the pedagogical orthodoxy, however, any explicit explanations of grammar should be "kept to an absolute minimum" (Richards and Rodgers 2014, p. 71), and instructors likely felt guilty for any such 'transgressions'. Exploiting concurrent developments in media technology, the audiolingual method spawned the phenomenon of the language laboratory as a common feature of US college campuses, where further oral drilling could be practised by learners on their own outside of class. In 1958 there were 240 such language labs at colleges and universities in the United States; by the mid-1960s that figure had skyrocketed to 14,000 (Roby 2004 in Laviosa 2014, p. 24)!

The audiolingual method enjoyed a short-lived heyday in foreign language study at colleges and universities in the United States in the 1960s and 70s, but general dissatisfaction with the approach soon set in among learners as well as instructors. The monotony of the method, characterized by one fervent advocate as "drill, drill, and more drill" (Hockett 1959 in Richards and Rodgers 2014, p. 59) was doubtless a factor in its demise. But crucially, it failed to deliver on its claims: language learners trained in the method "were often . . . unable to transfer skills acquired through [classroom instruction] to real communication outside the classroom" (Richards and Rodgers 2014, p. 72). At the same time, the theoretical foundations of audiolingualism were undermined by the revolution taking place in linguistics led by Noam Chomsky (1965), who held that language acquisition is not a matter of habit formation, as was 
claimed in behaviourism, but rather involves the development of an underlying competence that can generate an infinite number of creative utterances.

A period of innovation and experimentation followed the demise of audiolingualism before the communicative approach gradually established itself in the 1980s as the dominant paradigm. Four decades later, it remains the dominant approach in foreign language study at colleges and universities in the United States and Europe. Inspired by contemporaneous developments in linguistics, especially M. A. K. Halliday's functional linguistics (1985) and Dell Hymes's notion of communicative competence (1972), the communicative approach emphasizes, as the name indicates, an instrumental view of language that sees it above all as a means of communication. A typical lesson begins with the instructor presenting orally in the target language new vocabulary and examples of new grammatical structures, accompanied by visual aids to provide a meaningful context. This stage, which also involves a fair bit of oral drilling as in the audiolingual method, is then followed by several in-class activities designed to get learners to use the new vocabulary and structures by completing meaningful, communicative tasks in the target language, usually in pairs or small groups: information-gap activities, partner interviews, group surveys, interactive reading and listening comprehension tasks, etc. Thus, classroom instruction under the new approach looked quite different from instruction in the audiolingual method and was certainly more fun and engaging for everyone involved. However, certain assumptions about the purpose and nature of language learning carried over from the immediate post-war period, despite the radically different theoretical underpinnings informing the new pedagogical practices.

For one, the generally recognized goal of foreign language study remained the same: to be able to communicate effectively in the language in face-to-face interactions with monolingual native speakers approximating as closely as possible native-speaker norms. Indeed, with the ever-increasing individual mobility that characterized the period (to wit, the rapid expansion of commercial air travel following deregulation of the industry in the late 1970s), such a rationale seemed ever more self-evident and compelling, hence also the proliferation during the period of study abroad programmes and their establishment as a characteristic feature of the curricula in foreign language departments at colleges and universities in the United States. Furthermore, the belief carried over that the best way to achieve the goal of communicative competence was to teach adults foreign languages the way children learn their first language, hence the promotion of the so-called "natural" approach (Krashen and Terrell 1983), which in practice meant the continued exclusive use of the target language in the classroom. Grammar is never explained or taught explicitly in class under the communicative approach but rather learned inductively through ample comprehensible input in the target language and practice in meaningful communicative activities. Communicative language pedagogy thus sees no role for translation, at least not in classroom instruction. Course materials, however, tell a different story: the most widely adopted textbooks in foreign language study at colleges and universities in the United States today, textbooks marketed as employing the communicative approach, do use translation, namely, in the bilingual vocabulary lists they include as well as in the explanations of grammar points in English and translations of examples of new structures. These typically form the back-matter of each chapter and the appendices, however, and students are usually expected to cover this material on their own outside of class. Translation has thus traditionally played a marginalized and largely unacknowledged role in communicative language pedagogy.

An often-stated goal of communicative language teaching is to get learners 'beyond translating', which amounts to an acknowledgement that despite the monolingual veneer of classroom instruction, learners are inevitably constantly translating, in the sense of mentally 
shuttling back and forth between (or among) the language being learned and the one(s) they already know, at least at the beginning stages. It is hoped and believed that as learners become more fluent, they are no longer translating but rather thinking directly, as it were, in the target language when they speak it. But this belief is based in a monolingual ideology, which sees labelled languages as autonomous, separate entities and imagines foreign language learning to be a matter of producing a replica, a second-rate imitation of native-speaker competence in learners' minds that coexists alongside but separate from their competence in the language(s) they already know. This has been called the "two solitudes" view of language learning/bilingualism (Cummins 2005, p. 588). Increasingly, however, applied linguists have been recognizing and emphasizing that foreign language learning produces not deficient copies of an idealized monolingual native speaker but rather emergent bilinguals, individuals with qualitatively different kinds of linguistic competence than monolinguals, foremost among which is the ability to translate. And bilinguals are always translating in the sense of mentally shuttling between or among the languages they know, at all levels of proficiency: even when producing speech or otherwise operating ostensibly in any one labelled language, bilinguals and multilinguals are always activating to some degree the other languages they know (Boroditsky 2009). Bilinguals are also always translating in the sense of verbally shuttling between languages, since, as a natural consequence of their language learning, they invariably find themselves in interlingual situations in which translation serves an immediate communicative purpose and therefore do it.

This change in thinking about the nature and purpose of foreign language learning has been part of what has been called the 'multilingual turn' (see Stephen May this volume) in applied linguistics in the 21st century. Following the end of the Cold War in the early 1990s, centuries-old processes of globalization accelerated exponentially, with individual mobility and mass migration increasing on an unprecedented scale, resulting in a situation in most urban areas of the world today that has been described as "superdiversity" (Vertovec 2007). In effect, this means that students of foreign languages today who study abroad (or who later travel or work abroad) are more likely to have interactions with other bilinguals and multilinguals like themselves than they are to interact with monolingual native speakers. Simultaneously, the rapid rise and eventual global domination of digital technologies, epitomized by the Internet, altered the possibilities for and the nature of communicative practices profoundly, with communication today being overwhelmingly multimodal and increasingly multilingual and even translingual, as phenomena such as code-switching and code-meshing become ever more commonplace. These transformations have naturally had an impact on foreign language education, as the rationale for modern language study has changed again, the goal now being translingual and transcultural competence (MLA 2007). Language educators are accordingly reassessing the role of translation and incorporating it increasingly into instruction as an ideal pedagogical method to promote the new goals of language study in the globalized, multilingual world of the 21 st century.

\section{Research approaches and key findings}

The first decade of the 21 st century witnessed increasing calls for a bilingual reorientation in language teaching (e.g. Widdowson 2003) and arguments for including learners' own language in foreign language instruction (e.g. Turnbull and Dailey-O'Cain 2009). These typically stopped short, however, of outright endorsement of translation as a pedagogical practice. The 2007 report of the MLA Ad Hoc Committee on Foreign Languages titled "Foreign Languages and Higher Education: New Structures for a Changed World" represented an early explicit 
call for including translation as part of a visionary programme for language study in higher education aimed at raising the intellectual cachet of the enterprise beyond mere communicative competence: "In the course of acquiring functional language abilities, students are taught critical language awareness, interpretation and translation, historical political consciousness, social sensibility, and aesthetic perception" (MLA 2007, p. 4).

Taking up this call, Claire Kramsch and Michael Huffmaster (2008) investigated the potential of literary translation in foreign language study to foster translingual competence and critical language awareness. However, they found that the monolingual ideology dominant in Western culture, which language learners tend to bring to the enterprise, impeded such goals. Accordingly, they recommend that the study of applied linguistics (including translation theory and practice, literary stylistics, and sociolinguistics) complement or be incorporated into the traditional foreign language curriculum (295-296). These recommendations echo those of the MLA report, which states that learners of foreign languages should enrich their study through "courses in second language acquisition, applied linguistics, dialectology, sociolinguistics, history of the language, and discourse analysis" in addition to "general courses in such areas as language and cognition, language and power, bilingualism, language and identity, language and gender, language and myth, language and artificial intelligence, and language and the imagination" (MLA 2007, p. 6). The MLA report also explicitly advocates that foreign language departments "[d]evelop programmes in translation and interpretation" as a continuing priority (9).

An exceptional study from the period was Batia Laufer and Nany Girsai's (2008). Guy Cook describes the experiment and findings succinctly:

Keeping variables as constant as possible, they taught the same vocabulary to three groups using three different types of instruction - meaning-focused, form-focused without translation, and through contrastive analysis and translation. They then tested the groups for both active and passive recall of the words encountered. Their results were that 'The CAT (contrastive analysis and translation) group significantly outperformed the other two groups on all tests'.

(Cook 2010, p. 91)

Another noteworthy publication from the period that explicitly advocates translation in the language classroom is the volume Translation in Second Language Learning and Teaching (Witte et al. 2009). "In this collection of papers", to quote Guy Cook again, "the editors and contributors make a strong case for the relevance and usefulness of TILT [Translation in Language Teaching] in a variety of contexts and for a variety of purposes: Internet communication, language awareness, accuracy and fluency, intercultural competence, and literary understanding" (Cook 2010, p. 51). Sara Laviosa notes critically of the volume, however, that its "orientation towards translation as a means to an end rather than an end in itself goes against the growing trend towards opening up foreign language education to new ideas from the world of real-life translation" (Laviosa 2014, p. 29).

The landmark work on the topic remains Guy Cook's 2010 Translation in Language Teaching: An Argument for Reassessment. The first half of this book traces the history of translation's banishment from language instruction, an idea beginning in the late 19th century with the manifestoes of the so-called 'Reform Movement' and further established with the emergence of the 'Direct Method' at the beginning of the 20th century, embodied most prominently by the Berlitz schools. Cook applies the designation "Direct Method" to any pedagogy that excludes translation or own-language use from instruction, and hence explicitly includes under that 
category almost every major approach or method that has emerged since: "graded structures, situational teaching, audiolingualism, communicative language teaching, task-based instruction, lexical syllabuses, and so forth" (Cook 2010, p. 7). The author's engaging and entertaining account of the ways advocates of the method caricaturized the grammar-translation method in making their case (9-15) is importantly tempered by the critically astute connections drawn between the ideology informing the Direct Method (and its subsequent iterations) characterized by monolingualism, naturalism, native-speakerism, and absolutism - and the twin projects of nationalism and imperialism (18-19). Part One concludes with an excellent overview of the major issues in translation studies and translation theory, such as the notion of equivalence and its significance across different levels - semantic, pragmatic, discoursal, cultural - and the important distinction between "overt" and "covert" (House 2009, 2018) or "foreignizing" and "domesticizing" (Venuti 1995) translations, discussing how these relate to translation in language teaching. The second half of the book exposes the dearth of scientific evidence supporting an exclusively monolingual approach and advances a series of compelling arguments for including translation in language study in the 21 st century, namely, "that it develops both language awareness and use, that it is pedagogically effective and educationally desirable, and that it answers student needs in the contemporary globalized and multicultural world" (Cook 2010, p. 155).

Prisca Augustyn (2013) argues the advantages of using translation specifically for teaching and learning vocabulary in foreign language instruction. In an insightful critique of the entrenched practices and baseless assumptions about vocabulary learning that have characterized the communicative approach since its beginnings in the 1980s, Augustyn marshals evidence from the new field of corpus linguistics to argue that high-frequency vocabulary, which is de facto more useful for learners, should take precedence in language teaching over low-frequency vocabulary. She shows, however, how much of the vocabulary in most textbooks for introductory and intermediate foreign language courses is in fact low-frequency, referring typically to concrete objects (e.g. die Geschirrspülmaschine, 'dish washer', or das Spülbecken, 'sink'), presumably included in the curriculum because such lexemes are easily depictable visually and hence allow conformity to monolingual orthodoxy by avoiding translation. Much high-frequency vocabulary, however, is non-referential or abstract and does not lend itself easily to visual depiction. The remedy is obvious: translation. Augustyn concludes her important intervention with a useful discussion of recommendations for bilingual practice as proposed by Wolfgang Butzkamm and John Caldwell (2009), including techniques such as idiomatic translations, literal word-for-word translations, brainstorming in the L1 combined with bilingual dictionary practice, variations on translating chunks of text (Butzkamm and Caldwell's 'word trails') as a pre-reading or reading comprehension activity, and the use of published translations for comparative and contrastive analysis, among others (Augustyn 2013, p. 35).

In his otherwise erudite and sophisticated discussion of the issue, characterizing translation as the essence of all communication, Henry Widdowson (2014) poses some simple yet powerful questions:

But what if we were to . . . take a genuinely learner-centred approach by allowing learners to react to tasks in a natural way without . . imposing the constraining conditions of conformity to L2 norms? What if we allowed them to draw pragmatically on all of the linguistic resources at their disposal to achieve their communicative outcomes? What if, in other words, we allowed them to be translaters [sic]? 
He proposes a radical new vision for language learning:

instead of trying to teach a language as a set of distinct encoding rules and usage conventions, one would teach the properties of language in general as a means of conceptualization and communication which are variously realized through different languages. The objective so defined would represent an L2 not as something dissociated from the learners' own linguistic experience, but closely related to it and an additional resource in their linguistic repertoire.

(emphasis in the original; 236)

Such a drastic reorientation in language study would of course involve profound changes in pedagogical practice as well as in assessment (see Esteve and González-Davies in this volume).

Another major recent contribution to the scholarship on the topic is Sara Laviosa's Translation and Language Education: Pedagogic Approaches Explored (2014). Opening with a historical overview of the vicissitudes of translation in language education, the book then reviews recent theoretical arguments advocating its reincorporation as well as several recent empirical studies that lend support to such arguments. Following a useful discussion of ecological approaches to understanding language, it offers critical appraisals of the role of translation in Claire Kramsch's multilingual pedagogy aimed at developing symbolic competence in foreign language education and of Maria Tymoczko's concept of holistic cultural translation in the field of translation studies. The author then proposes a synthesis of the two scholars' work with the notion of holistic pedagogic translation, with the aim of

transforming the multilingual language classroom into a cooperative learning environment where developing symbolic competence and adopting holistic translation methods are essential interrelated processes in the education of the language professional of the future, who needs to grow into a self-reflective, interculturally competent and responsible meaning maker in our increasingly multilingual world.

The volume concludes with descriptions of two examples of holistic pedagogic translation modules - one for intermediate Italian and another for advanced English - that demonstrate "how the synergy between interdisciplinary theory, research and practice can engender novel pedagogic techniques that fully rehabilitate translation in the language classroom within a multilingual perspective" (141).

Foreign language education researchers have also investigated translation as a pedagogical practice to foster multiliteracies, an approach to literacy education that recognizes the realities of today's globalized world in which new technologies have rendered communication increasingly multilingual, multimodal, and multisensory. Claire Kramsch and Michael Huffmaster (2015) argue that in response to these realities, foreign language study in the $21 \mathrm{st}$ century must foster, beyond knowledge of the vocabulary and rules of syntax of a standard national language, "an awareness of the semiotic potential of switching linguistic codes, discourse structures and discourse modes, the symbolic potential of various media and modalities, and the way they position speakers and hearers, readers and writers" (118). To that end, and with an expansive notion of translation that encompasses re-keyings, transpositions, and transmodalities, they describe various multilingual practices in foreign language study which they find foster such multiliteracies. One example is translating translations, in which learners 
translate translations published in the language they are learning (from any language) into their own language. For this practice, the source text should ideally be a covert translation that domesticizes the original and the target text an overt one that attempts to restore what the learner-translator sees as important elements of the original source text culture. Another is transposing across modalities, in which learners produce two different translations of the lyrics to a song with two different musical renditions, aiming to convey verbally the different musical styles. To be effective, such practices must include a self-reflexive element, such as a self-assessment describing specific challenges faced and the rationale behind the chosen resolutions.

In a similar vein, David Gramling and Chantelle Warner (2016) describe a study in which advanced learners of German - half of whom were bilingual (with varying experience with either Spanish, Arabic, Portuguese, Polish, Korean, or Russian in addition to English) and thus were learning German as a third language - translated a 14-page prose poem on translingual experience. The source text, "Das Klangtal" ("The Sound Valley") by Peter Waterhouse (2003), is itself "an adaptation/transmission of a famous pre-existing intertext, Hugo von Hofmannsthal's 1902 'A Letter', which is itself a fictional translation of a correspondence between the historical Francis Bacon and a certain Lord Chandos in 1603" (Gramling and Warner 2016, p. 77). Over a seven-week period, learners produced collaborative translations of the text while having ample affordances "in the form of homework prompts, discussions, and online forums" (82) for self-reflection on the translation process. The researchers find translation to be an effective pedagogical practice to develop learners' self-awareness as multilingual subjects, as "translingual and intercultural being[s]" (82).

\section{Pedagogic approaches and methods}

In response to the multilingual turn in applied linguistics, foreign language educators and materials developers have begun to incorporate translation into language instruction from the very beginning through to more advanced levels. A noteworthy example is the recently published textbook for introductory German Welten (Augustyn and Euba 2016). The very first activity in the first chapter is a pre-reading translation exercise, and translation is incorporated throughout the curriculum, for example in reading and listening comprehension exercises, as well as in assessment. To avoid reinforcing a monolingual ideology of language that sees labelled, national languages as separate, autonomous codes, however, instructors must exploit such translation activities, as the authors recommend, to explore and prompt critical reflection on the parallels and interconnections as well as the tensions and contrasts between different formulations of meanings in different semiotic systems. An assessment on word order, for example, asks learners to translate a set of German sentences exemplifying typical features of the structure and then to analyze and comment on the differences between the original texts and the learners' translations. In another assessment on imperatives, learners first do what a set of informal commands asks - e.g. Schreib deinen Namen ('Write your name"); Zeichne einen Hund ("Draw a dog"); Setz einen Punkt am Ende dieses Satzes ("Put a period at the end of this sentence") - and then translate the German sentences. To assess sociocultural awareness and pragmatic language knowledge, learners then describe how they could reformulate the German commands to sound more polite as well as how they could make their translations more polite.

For the purposes of this publication, Michael Huffmaster designed and implemented a translation module for a foreign language class inspired by Kramsch and Zhang (2018, pp. 175177) that introduces learners to the concepts overt versus covert translation (House 2018) and 
assigns the task of producing two different translations of a given text, one of each type. The text selected was Paul Celan's “Todesfuge" (1983), a canonical poem of 20th-century world literature, and the design for the module was inspired by the procedure suggested by Alan Maley and Alan Duff (1989) for incorporating poetry into the language classroom. Originally conceived for an advanced-level class, for logistical reasons the module was implemented in a second-semester elementary German course and worked well at that level, as described next, indicating the appropriateness and effectiveness of translation throughout the language learning curriculum. The module was implemented at the co-author's home institution, the University of Puerto Rico, Mayagüez.

In the first stage of the module, Preparing for the Poem, learners were presented the title of the poem and a translation was elicited. Students recognized Tod and correctly produced "death"; then the meaning of fugue was briefly explained. The instructor then mentioned the poem's dates of composition (1944 or 1945) and publication (1947 in Romanian translation; 1948 in German) and elicited students' expectations, based on that information alone, of what the poem might be about. Students correctly inferred the context of World War II and the Nazi death camps. The instructor held a brief discussion on students' prior knowledge of the Holocaust, asking what they knew about it and where they knew about it from. The disparities in students' knowledge were striking: some had been taught extensively about the topic during their high school educations, while others had had little to no exposure. Several mentioned their knowledge of the topic from documentaries or feature films such as Schindler's List or The Boy in the Striped Pajamas. The instructor mentioned that the poet was a Romanian Jew whose parents both died in Nazi concentration camps and who himself was imprisoned in a work camp during the war.

For the second stage of the module, Working into the Poem, the instructor began by reading the entire poem out loud, stressing beforehand that students need not worry about understanding the sense or meaning of the poem at this point, assuring them that they would be able to pick out and understand individual words and phrases while listening, but instructing them to focus at this stage on the impressions they got from the sounds of the poem - its rhythms and repetitions. He also informed students that following his own recitation he would play an audio recording of the author himself reciting the text (versions of which are available on the Internet), and he explained the pedagogical rationale behind this part of the module: students' familiarity with the instructor's voice and pronunciation ought to facilitate their receptivity to the poem's aural effects and also prepare them better to appreciate the unique features of the author's own reading. Following the recitations, the instructor elicited students' impressions. No one mentioned the text's rhythms or repetitions specifically, as was expected; rather, students remarked that the instructor's recitation felt empathetic, whereas the author's seemed disturbed and at times angry. The instructor suggested that perhaps his own distance from the events depicted as opposed to the author's direct experience of them might account for those varying impressions. In hindsight, it would have been beneficial to probe students more on their impressions specifically of the poem's copious repetitions, reminding them of the characteristic feature of the musical genre on which the text is modelled. A brief discussion of repetition as a stylistic feature of certain (kinds of) texts and its range of potential significance might have usefully been included (see, e.g. Short 1996). For the next step in this stage of the module, the instructor projected the last stanza of the poem and, after allowing students time to read through the text, elicited and addressed any questions students had about content or structure. During this step, naturally a lot of translation in the sense of verbal shuttling between languages took place. The final step in this stage (corresponding to Maley and Duff's fourth stage, Speaking Poetry) was choral response, in which the instructor read the last stanza of 
the poem out loud line by line as students repeated, allowing them a more actively embodied experience of the poem.

For the next stage of the module, Working out from the Poem, the instructor projected Michael Hamburger's translation (Celan 1988) of the poem's final stanza alongside the original and elicited students' critiques. Overall students seemed mainly concerned with literal equivalence and voiced reservations about a few specific renderings, for example, "daybreak" (for Frühe), "daydreams" (for träumet), and especially "his aim is true" (for er trifft dich genau). As to this last passage, it was suggested that preserving the rhyme with "blue/true" (for blau/ genau) likely took preference over literalness. In general, though, students judged the text to be a fair translation. However, the chance to compare a few different translations, as Kramsch and Zhang demonstrate (2018, pp. 175-177), affords an opportunity to delve deeper into the intellectual, political, and ethical dimensions of translation. To that end, the instructor provided students a handout with the last stanza of the original along with Hamburger's and two other translations, those of John Felstiner (1995) and Jerome Rothenberg (Celan 2005). Students discussed their reactions in small groups before class discussion was held. The first rendering that provoked discussion was Rothenberg's "gang-boss" (for Meister), the consensus being it felt dated, too tied to a specific time period. Other renderings that students focused on included "at sundown and in the evening"/ "at evening and morning"/ "at dusktime and dawntime" (for abends und morgens); "He strikes you with leaden bullets"/ "he shoots you with shot made of lead"/ "he shoots you with leaden bullets" (for er trifft dich mit bleierner Kugel); and "He sets his pack on to us"/ "he looses his hounds on us"/ "he sets his dogs on our trail" (for er hetzt seine Rüden auf uns). Discussion of such ostensibly minor differences brought to light many of the implicit assumptions about translation that students brought with them to the activity. The most salient differences among the different translations are, of course, their renderings of Der Tod ist ein Meister aus Deutschland, so the instructor concluded the discussion by eliciting students' reactions to those renderings specifically: Hamburger's "death is a master from Germany"; Rothenberg's "Death is a gang-boss aus Deutschland"; and Felstiner's evolving iterations from "Death is a master aus Deutschland" to "Death is ein Meister aus Deutschland" to "der Tod ist ein Meister aus Deutschland". The concepts overt versus covert translation were intentionally not introduced at this point. Rather, students' subjective reactions to these specific instances of 'code-switching' or 'borrowing' were elicited, the rationale being that, as Kramsch and Zhang report (2018, p. 177), students might uncover a surplus of covert meanings in Rothenberg's covert-overt hybrid ("gang-boss aus Deutschland") and in Felstiner's evolving overt versions that contravene conventional understandings of the concepts in translation studies. And indeed, though Rothenberg's use of italics was not mentioned, students felt that the unitalicized German in Felstiner's translation was encroaching on the English, taking it over, as it were, which evoked for them the Nazi ideology of world domination.

The stages of the module described thus far occupied one 50-minute class period. The final stage of the module, Writing Poetry, began with a homework assignment. First students read Juliane House's descriptions of overt and covert translation (2009, pp. 36-39, 2018, pp. 89-96) and wrote a brief response addressing whether the readings provoked any changes in their opinion regarding the different translations of Celan's poem that were examined and discussed in class. Next, they composed their own overt translations of the last stanza of the poem. The assignment description supplemented House's concepts with a brief discussion of their historical precedent in the 19th-century German philosopher Friedrich Schleiermacher's (1813) distinction between alienating and assimilating translations and also mentioned contemporary translation scholar Lawrence Venuti's (1995) terms foreignizing and domesticating translations. It included a few specific examples of how students might accomplish the task of 
composing an overt translation, for example, by 'borrowing' or preserving certain elements from the original, as Felstiner and Rothenberg do - though they were encouraged to choose different elements to preserve - or by hewing in their target language as closely as possible to features in the source text so as to produce deliberately jarring effects, e.g. 'The Death is a Master out of Germany'. Students were instructed to come to the next class session prepared to share their translations and discuss the rationale behind their decisions.

The instructor began the next class by initiating a discussion based on students' responses to the reading. Several found the reading somewhat confusing and mentioned they had needed to consult outside sources to understand the terms overt and covert better, but most agreed the distinction was interesting and useful. Then students were put into small groups to discuss the specific choices they made for their overt translations, after which class feedback elicited the most interesting points raised in the groups' discussions. The duration of the lesson was devoted to preparing the final task of the module, a collaborative covert translation of the last stanza of Celan's poem. The absurdity of the task was explicitly pointed out, considering the typically commercially oriented purposes of covert translation, but also the ultimate inseparability of this particular text from its sociohistorical and linguacultural context. For these reasons students' covert translations would be more like adaptations or transpositions or re-keyings (Kramsch and Huffmaster 2015). For the remainder of the class session, students brainstormed in their small groups to generate ideas for and coordinate their collaborative covert translations. As inspiration, a few possible covert renderings of the poem's iconic phrase were provided, namely, 'Death is the One Percent', 'Death is a migrant's wager'/'La muerte es la apuesta de un emigrante', and 'Death is the climate apocalypse'. Students were told they would also perform a group recitation of their collaborative covert translation along the lines of the readers' theatre technique for the next class session and were instructed to coordinate and practice for the performance in the interim.

The next class session began with group recitations of the students' covert translations. As performances, these were unremarkable. In every group, each student simply read a different line. In hindsight, the instructor should have provided a few suggestions for how students might employ the readers' theatre technique specifically with this text, which, with its structure modelled on the fugue, is ripe for creative exploitation. Despite the disappointing group recitations, the texts the various groups composed for their collaborative covert translations were each in their own way quite remarkable, as class discussion following the recitations brought to light. The instructor asked each group to elaborate on the overall theme that was chosen for their translation and any of the noteworthy choices they made for specific passages. One group chose the Black Death of the 14th century as their theme. Two of the students in the group happened to be learning concurrently about the subject in their humanities courses, and the salience of the phrase Schwarze Milch ('black milk') along with the repetition of der Tod ('death') likely evoked the association, hence the iterations of "The Plague is the Death of Us" in their version. They explained that their rendition "The man lives in the castle" (for ein Mann wohnt im Haus) was meant to highlight how catastrophes of any kind always affect the most vulnerable most adversely, while the well-off manage to insulate themselves. They also mentioned that their choices "perfect gold hair" (for goldenes Haar) and "burnt curls" (for aschenes Haar) were motivated by the same intention but referring to their own local context, explaining that curly hair was seen as 'bad', a marker of socio-economic disadvantage and hence also of vulnerability. Another group chose the current humanitarian crisis in Venezuela as their theme. "Bread" was substituted for Milch and "desire" consistently for trinken, which allowed the rhymes "his eyes are fire" (for sein Auge ist blau) and "he provokes transpire [sic]" (for er trifft dich genau). This group also translanguaged in their rendition, producing, for example, 
"He propels plomo" (for er trifft dich mit bleierner Kugel), likely chosen for its alliterative qualities, and "the man works at el palacio" (for ein Mann wohnt im Haus). Most salient was the choice of "la muerte reina en Venezuela", which after one verbatim repetition morphed at the end into "la muerte reina en el mundo", indicating a broader, universal significance to their translation. The group explained their choice of theme in light of their knowledge of current events in Venezuela and their empathy for the suffering of the population, with whom they feel an affinity as Latinos. They said they employed Spanish to evoke the specific context of reference but also to express that affinity, illustrated as well with their choices "Margarita" and "Susana" (for Margarete and Sulamith). The choice of "sunlit hair" opposed to "sunburned hair" (for goldenes Haar and aschenes Haar, respectively) as well as "el palacio" (for Haus) resonated with the previous group's more universal gesture toward socio-economic inequality. The third group chose as their topic Hurricane Maria, the epic storm that devastated Puerto Rico in 2017, from which various death estimates have been in the headlines over the course of the past year, the latest official number, revised in August 2018, being 2,975. This group composed their translation entirely in Spanish, with "María es la que manda" as their iterated rendition of Celan's iconic phrase. Most noteworthy about the text is its almost surreal quality, achieved through jarring, unexpected imagery and creative syntax. It begins, for example, with "Aguas turbias amanecen" (for Schwarze Milch der Frühe) and includes such striking renditions as "Azota con fuerza, azota con certeza" (for er trifft dich mit bleierner Kugel er trifft dich genau); "Nos persigue con sus caballos y nos regala árboles desnudos" (for er hetzt seine Rüden auf uns er schenkt uns ein Grab in der Luft); and "Juega con la montaña y sueña" (for er spielt mit den Schlangen und träumet). This quality evokes the Latin American literary tradition of magical realism while simultaneously echoing Celan's own poetic project and was thus fortuitously apt for a covert translation. Perhaps most moving in the group's rendition is the concluding couplet: "Tu cabello color canela Pamela/Tú, prieta, morena Elena". Resonating with the other groups' emphasis on socio-economic inequality, it underscores the racial nature of that inequality and hence of the degree of vulnerability, in Puerto Rico as in the world at large.

As to assessment, since the module described here was implemented for the purposes of this publication, students were informed at the start, in line with ethics guidelines for research with human subjects, that their participation was entirely voluntary and would have no influence on their course grade. All the materials students handed in were anonymous. Given this fact, students' enthusiastic participation was remarkable: only two of the eighteen opted out of the voluntary assignments. Were the module to be implemented in a curriculum for course credit, we recommend, in the spirit of humanistic education, that students write a paragraph assessing the success of their own individual overt translations as well as their contributions to the success of their group's collaborative covert translation. For the module described, students spent the remainder of the last class session filling out a feedback form that included these prompts but also elicited their reactions to the activity more generally. Overall, students were satisfied with their individual overt translations as well as with their groups' collaborative covert translations. Their evaluations of the merit of each assignment varied along personality preferences, for individual versus collaborative work or for a more controlled versus a more creative task. Several students who especially valued the collaborative assignment mentioned that discussing suggestions for various renderings with their group helped them understand the poem on a deeper level. All found the distinction between overt and covert translations useful, and for many it seemed like a revelation, a deep insight they had never considered before. A number mentioned that it was their first formal exposure in their education to any translation theory. The overwhelmingly positive response to the activity as a whole 
was remarkable, especially considering that none of the students' work was for credit. Students felt that the activity made a valuable contribution to their education for a variety of reasons: they learned new German vocabulary or more generally about the language; they learned new English vocabulary; they learned about poetry; they learned about German history; they learned about translation. The results of this experimental module thus strongly support the arguments advanced by Guy Cook in his seminal 2010 Translation in Language Teaching for the pedagogical and educational value of translation in modern language study.

\section{Conclusions and future directions}

Translation in modern language study has been used in many different ways since the days of the grammar-translation method. After its near complete rejection in the name of nativespeaker authenticity and priority given to the spoken mode of communication, it has slowly come back in the name of multilingualism, multiliteracy and multimodality. The exquisite attention to each language's philological specificity has given way to a socially minded concern for the diversity of meanings expressed by a diversity of speakers who are themselves multilingual and multicultural, and who do not necessarily observe a strict demarcation between linguistic boundaries in their everyday encounters. Translation has thus re-emerged as an appetite for translingual (Canagarajah 2013) and translanguaging (Garcia and Wei 2014) practices in spoken verbal exchanges, and as an interest in the diversity of meanings brought to the fore by various translators. It also serves to bring back a concern for culture and for the translation of culture in global times (see Kramsch and Zhu 2019).

Translation right now has a bright future but perhaps not in the way the humanists had envisaged. The immense progress made by technology-assisted translation such as Google Translate, and Google's ambition to develop an algorithm for perfect translatability across languages (Gramling 2019) are at once facilitating everyday informational exchanges and impoverishing the range of subtler stylistic, poetic, and literary meanings available to readers and writers in a foreign language (see also Ducar and Schocket 2018). Like much of the rest of language use, communication technology today is transforming what we mean by 'language' and 'language use' and the translation between different ways of making and transmitting meaning. Considering the students' enthusiasm and creativity unleashed by the pedagogic translation activity recounted in this chapter, it might very well be that the younger generation is ready to tone down its oral communicative ardour and rediscover the subtle thrills of cross-lingual and cross-cultural translation, even as they rely on their Google Translate app to help them out of a tight spot.

\section{Further reading}

Cook, G. (2010) Translation in Language Teaching: An Argument for Reassessment. Oxford: Oxford University Press.

The classic work on the topic, a must-read for anyone interested.

Widdowson, H.G. (2014) The role of translation in language learning and teaching, in House, J. (ed) Translation: A Multidisciplinary Approach. Basingstoke and New York: Palgrave Macmillan. pp. 222-240.

An erudite and compelling argument for including translation and translingual practices in foreign language education, and as always with the author, a true pleasure to read.

Laviosa, S. (2014) Translation and Language Education: Pedagogic Approaches Explored. London: Routledge.

An in-depth overview of the state of the art, with useful descriptions of pedagogical modules. 
Kramsch, C. and Huffmaster, M. (2015) Multilingual practices in foreign language study, in Cenoz, J. and Gorter, D. (eds) Multilingual Education: Between Language Learning and Translanguaging. Cambridge: Cambridge University Press. pp. 114-136.

An argument for including translation in foreign language pedagogy in the 21st century, with several inspirational examples.

House, J. (2018) Translation: The Basics. London and New York: Routledge. A useful introduction to the broader topic (though the main concerns with quality assessment are perhaps less relevant), with a chapter (11) devoted specifically to translation in foreign language study.

\section{Related topics}

the multilingual turn, bilingual education, comparative literature, translation studies, translation teacher training

\section{References}

Augustyn, P. (2013) Translation and bilingual practice for German vocabulary teaching and learning. Die Unterrichtspraxis/Teaching German. 46(1), pp. 27-43.

Augustyn, P. and Euba, N. (2016) Welten: Introductory German. Boston: Cengage Learning.

Boroditsky, L. (2009) How does our language shape the way we think? in Brockman, M. (ed) What's Next? Dispatches on the Future of Science: Original Essays from a New Generation of Scientists. New York: Vintage. pp. 116-129.

Butzkamm, W. and Caldwell, J. (2009) The Bilingual Reform: A Paradigm Shift in Foreign Language Teaching. Tübingen: Gunter Narr Verlag.

Canagarajah, S. (2013) Translingual Practice: Global Englishes and Cosmopolitan Relations. London: Routledge.

Celan, P. (1983) Gesammelte Werke. Band I. Frankfurt: Suhrkamp.

Celan, P. (1988) Poems of Paul Celan. M. Hamburger (trans). New York: Persea Books.

Celan, P. (2005) Paul Celan: Selections. J. Rothenberg (trans). Berkeley, CA: University of California Press.

Chomsky, N. (1965) Aspects of the Theory of Syntax. Cambridge: MIT Press.

Cook, G. (2010) Translation in Language Teaching: An Argument for Reassessment. Oxford: Oxford University Press.

Cummins, J. (2005) A proposal for action: Strategies for recognizing heritage language competence as a learning resource within the mainstream classroom. Modern Language Journal. 89(4), pp. 585-592.

Ducar, C. and Schocket, D.H. (2018) Machine translation and the L2 classroom: Pedagogical solutions for making peace with Google translate. Foreign Language Annals. 51, pp. 779-795.

Felstiner, J. (1995) Paul Celan: Poet, Survivor, Jew. New Haven, CT: Yale University Press.

García, O. and Wei, L. (2014) Translanguaging. Language, Bilingualism and Education. London: Palgrave Macmillan.

Gramling, D. (2019) Supralingualism and the translatability industry. Applied Linguistics. https://doi. org/10.1093/applin/amz023 [Accessed on 27 September 2019]

Gramling, D. and Warner, C. (2016) Whose crisis? Translating and the futurity of foreign language learning. L2 Journal. 8(4), pp. 76-99.

Halliday, M.A.K. (1985) An Introduction to Functional Grammar. London: Edward Arnold.

House, J. (2009) Translation. Oxford: Oxford University Press.

House, J. (2018) Translation: The Basics. London and New York: Routledge.

Hymes, D. (1972) On communicative competence, in Pride, J.B. and Holmes, J. (eds) Sociolinguistics. Harmondsworth: Penguin.

Kramsch, C. and Zhu, H. (2019). Translating culture in global times: An introduction. Applied Linguistics. https://doi.org/10.1093/applin/amz020 [Accessed on 27 September 2019] 
Kramsch, C. and Huffmaster, M. (2008) The political promise of translation. Fremdsprachen Lehren und Lernen. 37, pp. 284-297.

Kramsch, C. and Huffmaster, M. (2015) Multilingual practices in foreign language study, in Cenoz, J. and Gorter, D. (eds) Multilingual Education: Between Language Learning and Translanguaging. Cambridge: Cambridge University Press. pp. 114-136.

Kramsch, C. and Zhang, L. (2018) The Multilingual Instructor. Oxford: Oxford University Press.

Krashen, S. and Terrell, T.D. (1983) The Natural Approach. New York: Pergamon.

Laufer, B. and Girsai, N. (2008) Form-focused instruction in second-language vocabulary learning: A case for contrastive analysis and translation. Applied Linguistics. 29(4), pp. 694-716.

Laviosa, S. (2014) Translation and Language Education: Pedagogic Approaches Explored. London: Routledge.

Lehberger, R. (1995) Geschichte des Fremdsprachenunterrichts bis 1945, in Bausch, K., Christ, H. and Krumm, H. (eds) Handbuch Fremdsprachenunterricht. 3rd ed. Tübingen and Basel: Francke Verlag. pp. 561-565.

Maley, A. and Duff, A. (1989) The Inward Ear: Poetry in the Language Classroom. Cambridge: Cambridge University Press.

MLA Ad Hoc Committee on Foreign Languages. (2007) Foreign Languages and Higher Education: New Structures for a Changed World. Available from: www.mla.org/flreport [Accessed 16 February 2019].

Neuner, G. (1995) Methodik und Methoden: Überblick, in Bausch, K., Christ, H. and Krumm, H. (eds) Handbuch Fremdsprachenunterricht. 3rd ed. Tübingen and Basel: Francke Verlag. pp. 180-188.

Richards, J.C. and Rodgers, T.S. (2014) Approaches and Methods in Language Teaching. 3rd ed. Cambridge: Cambridge University Press.

Schleiermacher, F. (2012 [1813]) On the different methods of translating, in Venuti, L. (ed) The Translation Studies Reader. 3rd ed. S. Bernofsky (trans). New York: Routledge. pp. 43-63.

Short, M. (1996) Exploring the Language of Poems, Plays and Prose. Essex: Longman.

Turnbull, M. and Dailey-O'Cain, J. (eds) (2009) First Language Use in Second and Foreign Language Learning. Clevedon: Multilingual Matters.

Venuti, L. (1995) The Translator's Invisibility: A History of Translation. London: Routledge.

Vertovec, S. (2007) Superdiversity and its implications. Ethnic and Racial Studies. 30(6), pp. 1024-1054.

Waterhouse, P. (2003) Das Klangtal. Neue deutsche Literatur. 51, pp. 66-80.

Widdowson, H.G. (2003) Defining Issues in English Language Teaching. Oxford: Oxford University Press.

Widdowson, H.G. (2014) The role of translation in language learning and teaching, in House, J. (ed) Translation: A Multidisciplinary Approach. Basingstoke and New York: Palgrave Macmillan. pp. 222-240.

Witte, A., Harden, T. and Ramos de Oliveira Harden, A. (eds) (2009) Translation in Second Language Learning and Teaching. Berne: Peter Lang. 


\section{Translation and multilingual/ creative writing}

Margarida Vale de Gato

\section{Introduction}

Literary translation is a task that stands on a paradox: while translation aims at carrying meanings across to those who cannot read/hear/process a given text's language, the making of literature revolves around idiosyncratic expression and displacement of meanings. Nonetheless, the plea for regarding literary translation as a verbal craft that constitutes a "unique form of creative writing" (Baer 2018, p. 64) or even "an entirely separate genre" (Grossman 2010, p. 47) rekindles the claim of 'transcreation'. This is a term that arose at the end of the 20th century from the collaboration of two major Latin American poet-translators, Haroldo de Campos and Octavio Paz (Paz and Campos 1994; Campos 1997). In my view, transcreation can be understood as the literary process of translation, entailing a form of criticism, creatively invested in the reading of previous texts and traditions.

In my discussion of literary translation/(multilingual) creative writing pedagogies, the apparent unequal tension between constraints and creativity (Boase-Beier and Holman 1999) for the translator and the writer will be supplemented by the hermeneutic approach to literary translation (Steiner 1975, 1998a; Venuti 1995, 2013; Meschonnic 1999), conceiving the translator's task to embody criticism and literary interpretation. I will also address the pedagogical difficulties arising from the contradictory nature of the task, highlighted also by Paz, who remarked, regarding the translation of poetry, that the translator's "procedure is the inverse of the poet's" (1992, p. 159). The latter starts from the entire realm of language in movement, from whence s/he chooses "a few words", thus "construct[ing] an unalterable text from mobile characters"; the former departs from "language congealed", whose elements s/he has to dismantle "freeing the signs into circulation, then returning them to language" (Paz 1992, p. 159). While the literary author moves on, not necessarily knowing where the poem will lead, the translator writes what $\mathrm{s} /$ he reads and needs to keep at the author's heels, for the completion of her/his work depends on an understanding of the literary work's achievement, which in turn risks being undone by the translator's remake.

From the specificities of 'the literary' in translation education, we shall look into what the classroom environment has to offer, with reference to the work of social constructivism (Kiraly 2000, 2005) and to course designs that enhance collaborative work (González-Davies 
2004a, 2004b, 2016) and multifaceted tasks in literary translation (Jones 2011). This will lead us to discuss the workshop model as well, usually combining creative writing and translation. Several curricular suggestions for this model rely on a plurality of translating languages (Filkins 2016; Sedarat 2016), a controversial methodology but in tune with a feature we will look into as more and more attached to literariness in recent times, the mimesis of multilingual and translation instances. The ways of translating such instances was a major concern in a pedagogic platform I developed with the team of the project PEnPAL in Translation, which will merit a brief assessment. The discussion will lead to the rationale of a follow-up model for collaborative literary translation education, integrating creative writing and formalized analysis of textual and translational clusters calling for strategies and caveats. To close the chapter, future directions for research in pedagogy will be contemplated, particularly regarding the ethics of translation and the expansion of literature's scope.

\section{Historical perspectives}

In the introduction to the recent collection of essays Teaching Translation, Lawrence Venuti presses the case for his lifelong advocacy of the hermeneutic model, that is of "translation as an interpretative act", by recalling that "translation as a form of interpretation was central to humanistic education in ancient Rome" (2016, p. 10). Translation pedagogy in Roman antiquity had a strong literary rooting; students would translate either imaginative literature or political, philosophical, and religious material for the exercise of oratory, mostly from the Greek. Literary translation was ancillary to a polylingual education, and so it continued in modern times to be an aid to foreign language teaching. In Europe in the mid-20th century, it was a modern languages humanistic framework that allowed for the combination of the new science of linguistics and the old art of literature (the basis for rhetoric). Their convergence produced the first theoretical considerations of the process of meaning transfer and ambiguity in communication (Jakobson 1960), as well as pioneer guidebooks with comparative stylistics of pedagogical applications to interlinguistic translation, such as Vinay and Darbelnet's $L a$ Stylistique comparée du français et de l'anglais in 1958. In fact, the editors of the English translation of Vinay and Darbelnet's (now) classic, acknowledge that

[b]y providing the daily practice of translation teaching with a theoretical framework which combines grammar with pragmatics and stylistics, they [the authors] laid the foundation for the emancipation of translator training courses and their recognition as full university degrees with a substantial formal academic content.

(1995, p. viii)

While Vinay and Darbelnet's basis for describing seven procedures for translation - loan, calque, literal translation, transposition, modulation, equivalence, adaptation - was mostly linguistic and their choice of examples mostly literary, their notion of translation entailed a shift of point of view (in the definition of 'modulation') and the mapping of several possibilities laid the ground for more sociological approaches. Other systemic considerations and systematic typologies were quick to spread from the 1970s onwards: Gideon Toury's norms governing the translation task (1978), and descriptive translation studies in general (DTS), laid out the basis for a map of the discipline (Williams and Chesterman 2002). The mapping ranged from specific classifications such as the forms of "translation of verse" (Holmes 1969) to the attempt to extract "universals of translation" from corpora studies (Baker 1993), along with accounts of translator's competence(s) or phases of the translation process, and of relationship 
with textual, authorial, and/or narratorial voice(s) (Hermans 1996). All these gave matter to the rise of a new (inter-)disciplinary force in the academia, allowing for a proliferation of points of view. Skopos-theory (Reiss and Vermeer 1984/2014) was and still is particularly of great influence, concentrating on the correspondence of purposes of the source text and the target text. The "manipulation school" (Hermans 1985), in turn, called for the study of translations as rewritings with contextual literary/cultural agendas (Lefevere 1992). Moreover, conceptual takes on the object of study - cognitive, behavioural, (inter)cultural, sociological, anthropological, activist - expanded much beyond the dichotomy of fluency/dynamic equivalence (Nida 1964) and resistance (Venuti 1995). The polarization, nonetheless, remains strong, as does the debate over the place of literary translation in education after its release from "the gaps and crevices of the prose composition programme" (Round 1998, p. 11; see also Schäffner 1998).

Meanwhile, current translation training has responded to demands of more schematic material, best derived from functional or communicative approaches, as well as further technical specialization, applicability to practice and its complementary competences (e.g. information technology and digital sciences, editing and project management). Therefore, course offers of literary translation and of literature have shrunk in professional training courses (GonzálezDavies 2004a; Ulrych 2005; Liu 2015). Anthony Pym (2011) tells a parallel story that may help explain why literary translation is now an odd element, albeit of analytical and critical value, in translation curricula while still remaining integral to other education options, such as comparative literature (see Christi Merrill in this volume) or creative writing (discussed later in this chapter). The institutionalization of translation in Europe came about, according to Pym, in the fringes of the German-speaking world, since "the victors had an interest in retrieving technical information from the German language (to make bombs and rockets), and the Nuremberg trials seemed to indicate the role of translators and interpreters in the future of international institutions" (p. 477). To put it bluntly, while literary translation might have a precedent over the other types in what concerns pedagogical methods, the institutionalization of translation courses did not come about because society needed more literary translators, who would arguably be fine with the old humanistic framework for their education.

\section{Research approaches and key findings}

Literary translation education entails the teaching of literature and culture, even sometimes of a general overview of the tradition associated with a language. A 2004 study involving focus group interviews of translation undergraduates and graduates revealed that whereas students agreed that the study of literature helped "to improve the bilingual competence and cultural knowledge", the younger students in particular had misgivings about the actual usefulness of literary education, and both groups tended to situate it at a level of "subtle" rather than "imminent" skills (Lung and Yan 2004, pp. 3, 6). The crux may be that literature as an art form is not completely social or socializable, even if, as Adorno said about the 'lyric', it becomes a "subjective expression of a social antagonism" (1974, p. 45). Subjectivity and functional understanding for social communication purposes are hardly reconcilable, undermining the utility and validity, even the possibility, of literary translation. Nonetheless, the turn to creativity in translation studies, underpinning translator's subjectivity, voice, and style, has given a new impetus to literary translation not only in translation, but in language and writing curricula. Even if some students (and teachers) shun creative 'enforcement', creativity studies have insisted on its benefits for mental flexibility and elicitation of alternatives, particularly with strategies to enhance 'creative metacognition', suggesting that the progression to professional creativity is mostly acquired and can be trained (Beghetto and Kaufman 2010). The advantage 
of these recent studies is that the focus on problem-solving ability makes creativity useful. It might be argued, though, that this is not the main concern of the artist's drive for creation, leading us back, in the case of literature, to the debate on the difference or parallel between the constraints of original and translated writing.

Although scholars of the manipulation school of translation have stressed intertextuality as a component of literature and pushed the case for every text being a rewriting (Lefevere 1992), the problem of interlingual literary translation still resides in the tension between the communicative desideratum for imparting information and literature's resistance to a common language. Roman Jakobson's “On linguistic aspects of translation” (1959/1987) has been noted as a turning point that furnished translation with a semiotic apparatus, formalizing the process whereby "the translator recodes and transmits a message from another source" (Steiner 1998a, p. 274). However, at the same time Jakobson determined a 'poetic function' of language, which he applied to works of literature and defined as "the focus on the message for its own sake" (1960/1987, p. 69), where the prosodic combination of signs prevails over the process of selection for imparting meaning. His suggestion that the literary was made up of metonymical choices or parallelisms of sound that enhanced ambiguity, complicated the definition of translation as transmission, rather begging for recreation of patterns.

Experienced literary translators often speak of an 'ear' for language, a skill that pedagogically might be subsumed under the category 'tone'. Clifford Landers, in the useful textbook Literary Translation: A Practical Guide, defines 'tone' as "the overall feeling conveyed by an utterance, a passage or an entire work, including both conscious and unconscious resonance" (2001, p. 68), and sees it as contributing to, but exceeding style, since a particular style might allow for diverse uses of tone. Many scholars, though, agree that style, understood as "perceived distinctive manner of expression" (Boase-Beier 2006, p. 4), or "idiolect", "personal dialect" or "expressive element" (Newmark 1988, p. 21) of the text's author (implying that authorial intention, elusive as it may be, is a pursuit of the translator-reader) is what overall needs to be grasped. In my classes I find it useful to quote Landers's statement of the question: "how one says something can be as important, sometimes more important, than what one says" (2001, p. 7, original emphasis). However, such an assumption carries a consequence of philosophical import: meaning-making in literature is not primarily semantic, rather drawing on extra-semantic aspects, whereby "a poetic mode of thought" is enacted, deviating from a "discursive one" (Gibbons 2017, p. 79). Literary translation is an eavesdropping on that alternative mode of understanding, hence a hermeneutical task. Some of the hermeneutic proponents prefer to eschew meaning altogether, opting to foreground "significance" (Meschonnic 1982, 1999) or "the chain of signifiers" (Venuti 1995, 2013, 2016) over the signified. The signifiers are the moveable characters that actualize language on the surface of the page. Henri Meschonnic, emphasizing how their dynamics changes the way one reads (his main case study was the difference of the Bible in Hebrew and in romance languages), insists on the term 'rhythm' to convey this flux - a subjective, historically-situated organization of discourse (1999, p. 22). Elsewhere, Meschonnic provides a working definition of rhythm:

the organization of the marks through which the signifiers . . . produce a specific semantics, distinct from the lexical meaning, and that I call the significance: i.e. the values that belong to one discourse and to only one. These marks can be located on any level of language: accentuation, prosody, lexicon, syntax.

(1982, pp. 216-217, translated in Michon 2011, original emphasis) 
Awareness of marked language aims at unusual collocations, wordplay, rhyme, syntactic patterns, surprising deixis, position of subject in relation to verb and object and semantic clusters of ambiguity and varied connotation. The result of the attention to these elements from the part of the literary translator is an extraordinary source for literary criticism (GaddisRose 1997). The literary translator deconstructs and de-composes, extracting fragments of resistance in order to make choices about his/her perception of core aspects to maintain or compensate for - something that can be trained on a basis of likelihood but not of invariability or absolute prescription. George Steiner, who developed a four-stage model for translation as hermeneutics - starting with trust (an ontological leap of faith about the original's sensemaking), moving on to aggression (the dissection just mentioned) and then to incorporation and restitution - was severely critical of any theoretical claims of the science of translation, "entailing as it must that of crucial experiments and falsifications" (1998b, p. 109). ${ }^{1}$ He spoke of literary translation rather as an "exact art" imparted through "fitful accounts" (1998b, p. 109). Like his mentor Walter Benjamin (1923/1968), Steiner's account of the afterlife that successful cases of translation conquer for the literary text, which he calls restitution, is rather Romantic in the belief of meanings to be completed, "something new that was already there" (1998b, p. 112, original emphasis). Steiner's discourse has been accused of vagueness, and the mystique of afterlife in general gives me pause about how it may impact the practical training of literary translation. But why not bring the spiritual and the discourse of 'illumination' (as

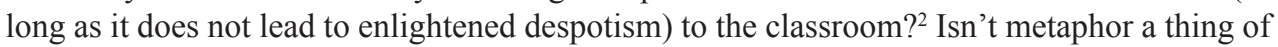
the spirit and isn't enthusiasm a great motivation ally for the literary experience?

To teach literary translation as an enhancer of reading ability is to combine that enthusiasm with technical know-how of the machinery of literary texts and systems. To read well, to understand the text's "formal properties and its literary dynamic as well as its status in the source system" (Bassnett 1998, p. 64) are skills covered in literary translation textbooks such as Christiane Nord's Text Analysis in Translation. It begins with a compelling defence of the literary text in translation education: "it seems sensible to take the most complex text type as a starting point since all the factors involved in the 'simpler' texts will also be found here" (Nord 1991, p. 2). For teaching the translation of poetry, Reginald Gibbons particularly advocates 'slow reading', a term he proposes in order to divert attention from the semantic values generally privileged by close reading (2016 p. 82). Elements "beyond the semantic", he says

include not only the expected poetic devices (the use of sound and rhythm, registers of diction, etymological resonances, plays on word morphology, figures of speech and structure), but also grammatical and syntactic effects and the relationship between the very nature and texture of a language - how a given language characteristically thinks - and the specifically poetic thinking that has been done in the source language and in the individual poem that we translate from it.

(Gibbons 2016, p. 79)

I find this reflection useful for my own teaching, especially based on the retrospection of my practice of twenty years as a translator of literature: the literary is the most source-oriented type of translation. Of course, literary translation too must consider the function for the target audience, clients and context, and sometimes a theatre play, a comedy or a children's book require radical adaptation. The debate between foreignization and domestication as overarching strategies is to my view unproductive, since the argument of coherence need not apply to the literary. What is worthy of discussion is how to impart and acquire "the experience of the language from which the translation is made" (Trask interviewed in Honig 
1985, p. 18, original emphasis). Moreover, the individual poem, as inferred from Gibbons' quotation, weaves its own separate language apart from the texture within which it characteristically thinks. Thus, not only one 'other language', but also its ghostly projection in the translator's 'differential' voice (Folkart 1991; Hermans 2007) surface in the decoding process, beyond target and source, inside the still mysterious translator's black box, despite efforts to unlock it with interviews or think aloud protocols (see Jones 2006), hence the importance of avoiding the "effacement" of both "vernaculars" and "the superimposition of languages" (Berman 2012, pp. 250-251), and of addressing multilingualism in pedagogies applied to literary translation.

In fact, the 'multilingual turn' concerns the definition of the literary as well as the rationale on how to integrate translation into education. Symptomatically, in the entry for "Literary translation" in the 2008 Routledge Encylopedia of Translation Studies, "heteroglossia" is second in the attempt to list the typical features of literary texts, right after "poetic language use" (Jones 2008, p. 152). Heteroglossia, a term used by Bakhtin (1981) to encompass the use of plural discourses in the modern novel, has entered the field of translation through the concept of 'heterolingualism'. The latter was suggested by Sternberg (1981) and defined by Meylaerts as "the use of foreign languages or social, regional, and historical language varieties in literary texts" (2006, p. 6). Heterolingualism differs from multilingualism in scope (allowing for intra-lingual varieties) and in quality: we have here representation and stylization rather than an unmediated reproduction of real-life situations of people in polyphony.

The increasing fictional appropriation of multilingual contexts is of consequence not only to translation theory and its teaching - attracted, for instance, by translation events such as code-switching in literature to convey the discomfort of a protagonist who hails from a cultural and linguistic background different from that within which s/he moves - but also to literary theory and narratology. This includes increased attention to novels that thematize the activity of translation and/or have translators as protagonists (Damrosch 2005). Multilingualism, however, presents problems to translation, and its rise in literature does not necessarily signify that more of it will be translated. On the contrary, it might even strengthen the dominance of English, since ethnic literature accompanied the promotion of 'hyphenated' American(ism) $\mathrm{s}$, with the consequence that "multiculturalism may have been the worst thing to happen to translation" as "[f]reshman literature courses began to teach Chinese-American writers, but no Chinese, Latinos but no Latin Americans" (Weinberger 2013, p. 20).

Heterolingual texts defy translatability, especially when "the new target language is none other than the heterolingual source imitated by the source text" (Sternberg 1981, p. 239). A few authors have dealt with the challenges of heterolingualism in translating literature, addressing issues such as narrative control and voice (Suchet 2013, 2014), cultural world view and allegiance of implied reader and author/translator with the characters' and narrator's representations (Klinger 2015; Vale de Gato 2018), or the description of the most common occurrences of code-switching or translational mimesis and strategies to translate them in turn (Stratford 2008; Vizcaíno 2008; Bradford 2009; Boyden and Goethals 2011). My own research on heterolingualism has dealt mostly with translating back to the target a language that in the source text functions as a code for heritage or origin, as in the case of PortugueseAmerican immigrant and diasporic literature, written in English and rendered in Portuguese (Vale de Gato 2013, 2015a). This research was conducted with a team of researchers and teachers in Portuguese universities, who found it useful to bring to the classroom, and to pedagogic discussion in general, the complex, non-binary issues on translation and bio-geopolitics constructed through verbal (mis-)representation of languages. For that, we developed PEnPAL in Trans (www.penpalintranslation.com), a project for collaborative learning in literary 
translation based on a corpus of narratives of displacement, cultural and interlingual exchange involving the English-Portuguese language pair.

\section{Pedagogic approaches and methods}

The rationale of the project PEnPAL has been laid down in a couple of the team's papers (Martins et al. 2019; Vale de Gato et al. 2016), basically relying on three hypotheses. First, literary translation would benefit from a collaborative environment and a digital platform could provide the means to enlarge that 'scene of encounters', fostering exchanges not only between teachers and students of different schools but also with authors, other academics, and interested parties in general. Second, we deemed that diasporic literature might help to foreground the (inter)semiotic dynamics of literary translation. Third, we expected that collaboration in the systematization of complex problems of language transference could contribute to a muchneeded contrastive grammar of Portuguese-English. The latter point gave rise to the project's cumulative database of EN-PT translation problems, strategies, and (discussed) solutions, which, though incomplete and short of sufficient examples from lack of funding, is a prototype of linguistic features that may be categorized through literary translation and have a practical value beyond its concerns (http://alfclul.clul.ul.pt/penpal/). In it, the problem category of heterolingualism, for instance, encompasses the subtypes of metalanguage of culture-specific terms, marked register, mutilated speech (broken English), coexistence of common languages and explicit attribution. The database follows a collaborative wiki model and provides for a discussion of snippets, identification of problem types, strategies, and proposed translation solutions for each (e.g. Figure 12.1).

PEnPAL in Trans stood for a rather ambitious acronym, Portuguese-English Platform for Anthologies of Literature in Translation, but the single anthology that came to press was Nem Cá Nem Lá mas Também: Portugal e América do Norte Entre Escritas (Neither here nor

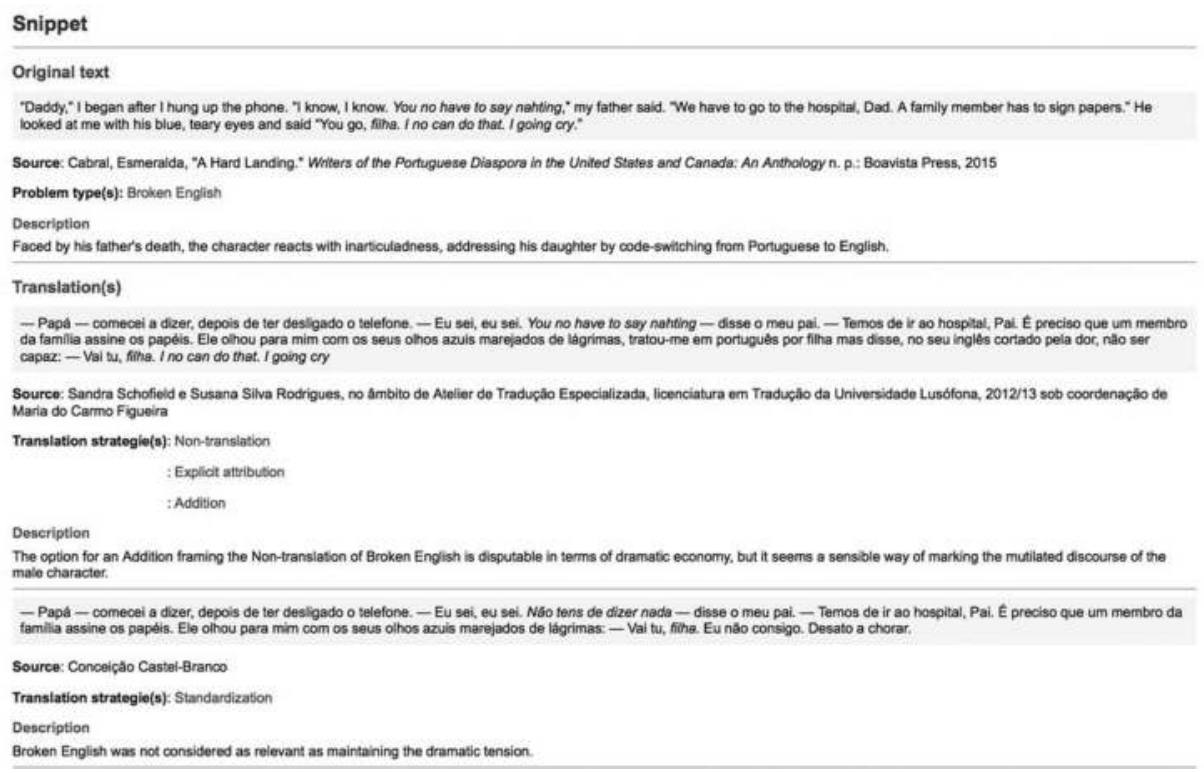

Figure 12.1 Screenhot of snippet for the problem "broken English" from PEnPAL. 
there, yet both: Cross-writings between Portugal and North America), published in 2016 and representing four years of work. Along with the digital platform, the anthology was part and parcel of the project's design in collaborative translation pedagogy, as it allowed for a series of diverse tasks (selection, writing of paratexts and agreement upon their format, research on authors' contexts, negotiation of copyright, proofreading and editing beyond translating and reporting feedback to peers). Over 400 participants, including living authors, engaged in a real-life (even if academically oriented) translation commission. The participation in either the platform or the anthology did not take up a large part of curricular design for a particular course. It was a feature built into each of the participating members' syllabi as they saw fit, allowing for concurrence of several types of translation programmes and levels). Foremostly, it was a means to build in and reflect together on socio-constructivist proposals (Van Lier 1996; Kiraly 2000) as regards literary translation education.

Elsewhere (Vale de Gato 2015b), I have explored how an anthological design regarding source texts for practice in the literary translation course may serve student-centred social constructivism, namely 'project-based learning' (Kiraly 2005). The social constructivist model has motivated the discussion of concrete curricular design and classroom activities. Maria González-Davies' Multiple Voices in the Translation Classroom offers a diverse set of activities to perfect "skills such as text analysis, paraphrasing, summarising, adapting the source text to the client's commission or to the reader's or listener's potential expectations, resourcing and using software adequately, or overcoming constraints" (2004b, p. 4). Additionally, it espouses a framework that attends both to the polyphony of the pedagogical environment (voices of students, teachers, theorists, researchers, professionals, initiators) and to the variety of linguistic layers to extricate and translate, from code-switching to channel adaptation (e.g. from "traffic signs and cell phones" - González-Davies 2004b, p. 61). The socio-constructivist approach is not exclusive to literary translation but provides its students an invaluable opportunity to progress with varied feedback, along with behavioural skills of networking and task-based collaboration, which are more and more inextricable from the transferable skills of translation competence in our globalized society, even in cases formerly imagined as solitary jobs.

In fact, the poetry translator and scholar F. R. Jones has drawn from networking and complex goal-action descriptions such as actor, activity and game theories to present a model of " "real-audience' poetry translating" (2011, p. 27), highlighting also the power relations and ethical implications in "speaking for" another (2011, p. 41). Reflection on ethics seems to me the best contribution that literary translation in turn can bring to models of discovery learning that incorporate competences of team-working and task-division in professional environments. It is interesting to note how even a conventional hands-on approach to the skills of literary translation includes a trait of social attitude: "Some of the capabilities that the literary translator must command: tone, style, flexibility, inventiveness, knowledge of the source-language culture, the ability to glean meaning from ambiguity, an ear for sonority, and humility" (Landers 2001, p. 8). Humility as a basis for translator ethics, from a sense of duty to source intention as much as concern for function in the receiving culture, does not preclude the notion of entitlement to 'visibility' (Venuti 1995). The plea for visibility in the markets of literary and language services has been boosted by the professional scenario of training, and by the force of the collective brought forth by institutionalized teaching, with theorization playing a big part in helping to create legitimacy for the field.

A contribution to literary translation pedagogy that combines collaborative learning with the 'creative turn' (Bassnett and Bush 2006; Perteghella and Loffredo 2006; Buffagni et al. 2011; Nelson and Maher 2013) is the adoption of the workshop model. It follows in general the rationale of the creative writing 'programme era' in the United States (McGurl 2009), 
with students' works being constantly discussed and assessed in peer groups facilitated by the teacher, along with critical reflection through process papers and commented portfolios. Many of the curricular suggestions favour the dual audience workshop, for aspiring writers and literary translators, in the context of joint programmes, generally MFAs. Iowa University's MFA Programme in Literary Translation is in tandem with the International Writing Programme and "combines creative practice, international literature in-the-making, with training in world languages, literatures and theory" (from the online programme description). At Columbia, Susan Bernofsky has developed a model "created out of the belief that an encounter with literary translation is beneficial to a writer's development and imagination, while conversely the skills involved in writing well are also essential for translation" (from the online description of LTAC - Literary Translation at Columbia). In Venuti (2016) we find a description of the MFA in Literary Translation at Queens College, City University of New York, in whose translation courses creative writing students may enrol, and conversely translation students take courses in the languages from which they translate throughout the university. Besides general courses in theory, criticism and literature, more practical classes are divided into workshops that "treat the translation of a literary text as a creative work in its own right" and craft courses, more theoretically driven, "that teach students how to employ a critical discourse in their commentary about translation" (Sedarat 2016, p. 41).

Assigned readings on literary translation for the dual audience courses tend to come both from readers on translation studies - notably Venuti's The Translation Studies Reader (2012) and Schulte and Biguenet's Theories of Translation (1992) - and from collections of essays and testimonies by reputed translators, like Ellen and Bernofsky's In Translation (2013) or Biguenet and Schulte's The Craft of Translation (1989). What is remarkably different from courses in continental Europe that are tailored for translating into and from one specific language, is that syllabi are designed to cater for multilingual contexts, although with different arrangements. In Sedarat's craft course of the aforementioned MFA at Queen's College, students from different linguistic backgrounds, generally grouped together, tend to work on their specific translating languages but also have to do one collaborative translation involving a language they know little or not at all. Filkin's Multilingual Workshop in Poetry and Prose Translation for undergraduates starts with "English-English exercises" (making a new translation out of several of an excerpt from Homer's Iliad) in order to "move students away from their initial notions of translation as a matter of finding the right word and toward thinking about how the source text can be rendered in several different ways" (Venuti 2016, p. 90). Then students translate from whatever language they choose and share their work with peers who may not have any knowledge but who, like the facilitator, look for "an interpretation that is consistent in its register, diction, and style as well as convincing in its metaphorical logic and narrative sense as analogues for attributes of the source text" (Filkins 2016, p. 92). Even if such trust in consistency and persuasion may lead to a favouring of a great degree of adaption concealed in elegance, these formulae have traction in the improvement of reading literacy for writing/literature students and of writing literacy for translation students. However, translation seems to be employed much more as a pedagogic strategy than as a pedagogic goal, especially considering that students' mastery of the experience of the foreign language (and of its transmission in the literary fabric of the translated text) is overlooked, which might also raise the suspicion of ethnocentrism.

I grant, though, that literary translation, as trained in the workshop model, should be considered pedagogically for enhancing literacy in general and creative writing in particular. The question that of late has most attracted my pedagogic investment is the converse: whether creative writing can be a strategy for the teaching goal of literary translation. Or, if we assume 
that the craft of literary translation is trainable but unteachable as a goal (Hyde Parker 2009), whether creative writing can enhance the strategy of literary translation training towards the overall goal of translation education and basis for the profession of translator. I am inclined to believe so, for basically three reasons. The first was suggested to me by Kelly Washbourne in his interesting summation of possible activities and shortcomings of the workshop model, namely regarding feedback and assessment. The advantage I did value in his paper was how the recommended procedures mitigated frustration about non-proficiency, as the workshop characteristically focuses on "the unfinished nature of the evolving object" (Washbourne 2013 , p. 54), which can be motivational for both trainers and trainees. The second is the basic argument for fusing creative writing with literary translation: a literary translator - in fact any translator - is a writer, and not only needs to write faultlessly but to write creatively and to take risks beyond inhibitions. The third is what mostly motivates my ambitions for redefining the literary translation course I teach at MA level in the University of Lisbon, and it has to do with a possible continuum between translating, writing the self, and self-translation.

Creative writing can give an inkling into the translator's frame of mind as one who is writing the self (into the other - thus the requisite of affinity that so many practitioners report) by the same token that the writer is translating the self (into an implied persona). I owe this realization in theoretical terms to Paschalis Nikolaou's article "Notes on translating the self", juxtaposing the autobiographical inscription of the creative translator with the attempt at ventriloquism: "We perhaps feel more justified in describing a translation as 'creative' when (often unconsciously) we read autobiographical arcs in what become for us instances of literary ventriloquism" (Nikolaou 2006, p. 23). ${ }^{3}$ This reflection defines, in general terms, my becoming a translator, being a sophisticated conceptualization not only of translation as appropriation but also as a wish to belong. I discovered translation as the way of life I would later choose for a career when I was transplanted from a Portuguese boarding school for girls to the 'shady' seaside suburb of Monterey, California at age 13, dreaming for the first time in English and trying to catch up with French by rendering into creative Portuguese the songs of the idol I wished to identify with, Jacques Brel. Of course the motivations of literary translators may differ, but they are spurred by the experience of mobility - the practice of literary translation being a powerful means of hetero-identification, of fitting oneself into another space, time, mind.

Moreover, if encouraged to write for themselves concomitantly with the experience of translating others, as Ann Pattison has argued (somehow complementing Nikolaou's argument in the same book edited by Perteghella and Loffredo 2006), students get the chance to experience a role reversal. The dynamics of writing, translating, and getting translated might challenge the precedence of authorship and the inferiority of translation embodied in Montesquieu's dictum: "If you go on translating all the time nobody will ever translate for you" (cited in Pattison 2006, p. 85). Intuition and my own experience as a translator-cum-writer, who from early age wanted to be a writer, then got moved away into another linguistic place, found solace in translation, eventually became a happy and relatively successful translator. Eventually, as an adult I went through complex process of finding a literary voice after some attempts at translating myself into English and then back to Portuguese - an experience that makes me relate strongly to the model of literary translation workshop combined with creative writing. Its pedagogical scope might even be more interesting, and more likely to enhance writing and bilingual literacy in the process, if students also get a chance to try self-translation. Self-translation, nonetheless, is most likely a misnomer, as we have seen that every literary writing process can be understood as writing into a different language, emerging even within the language of one's common habitus, hence of 'othering' the self. 
This rationale led me to the pedagogical position where I find myself today, and to the proposal of a new design for the course I usually teach as Literary Translation - English into Portuguese, in the Translation MA of the University of Lisbon. Administrative reasons prevent me from changing the name of the course so far, but I was given free rein to draw on the workshop methodology combined with creative writing. I am planning development activities in the following phases, understood as progressive and circular: (1) writing of personal narratives or poems; (2) writing as translating the self, including the experience of multilingualism (i.e. creative writing into the translating language/English); (3) self and hetero-translation; and (4) translating others as a form of autobiographical inscription, i.e. of writing the self. The types of activities devised for each phase are shown in Table 12.1. The final activity of 'translation proper' of a literary text chosen by the student is also to be discussed and revised in small 'affinity' groups and then, as much as possible, with the entire class. The process paper that will accompany it should reflect three basic goals: grasp of translation procedures, strategies, and problems of shaping the literary; evolution of draft sequence through collaboration; acknowledgement of self-investment in the process.

My hope is that these exercises might provide a better stimulus for the goal of improving students' writing as well as their literary literacy, in other words their sensibility to literature

Table 12.1 Tentative plan of activities for embedding creative writing in the MA Course "Literary Translation: English-Portuguese"

\begin{tabular}{|c|c|c|}
\hline Phase of skill development & Example of activities & Observations \\
\hline $\begin{array}{l}1 \text { Writing the self: } \\
\text { personal narrative } \\
\text { (poem) }\end{array}$ & $\begin{array}{l}\text { Memoir writing with a theme/ } \\
\text { writing their own version } \\
\text { of Frank O'Hara's "Personal } \\
\text { Poem"; }\end{array}$ & \\
\hline $\begin{array}{l}2 \text { Writing as translating } \\
\text { the self }\end{array}$ & $\begin{array}{l}\text { Writing a response in English } \\
\text { to a poem in Portuguese (an } \\
\text { alternative activity can be a } \\
\text { homophonic translation, or } \\
\text { writing in another medium - } \\
\text { reflective writing on a } \\
\text { painting or musical score) }\end{array}$ & $\begin{array}{l}\text { Includes the experience of } \\
\text { multilingualism (i.e. creative } \\
\text { writing into the translating } \\
\text { language/English) }\end{array}$ \\
\hline $\begin{array}{l}3 \text { Self and hetero- } \\
\text { translation }\end{array}$ & $\begin{array}{l}\text { Self and peer-translation of } \\
\text { pieces written in } 1 \text { and/or } 2 \text {. }\end{array}$ & $\begin{array}{l}\text { These skills are blended in the } \\
\text { same phase in temporal terms. } \\
\text { Students are supposed to do } \\
\text { both in a quick succession in } \\
\text { order to gauge the similarities } \\
\text { and differences between } \\
\text { translating others and the self. } \\
\text { Activities allow for engagement } \\
\text { with "available" authors } \\
\text { (themselves and their peers) }\end{array}$ \\
\hline $\begin{array}{l}4 \text { Translating as writing } \\
\text { the self }\end{array}$ & $\begin{array}{l}\text { A translation "proper" of a text } \\
\text { towards which the student } \\
\text { feels a particular affinity, } \\
\text { accompanied by a process } \\
\text { paper. }\end{array}$ & $\begin{array}{l}\text { Students will be struggle, in their } \\
\text { process paper, with motivations } \\
\text { behind strategies, options, } \\
\text { choices, and their possible } \\
\text { autobiographical remainders. }\end{array}$ \\
\hline
\end{tabular}


Table 12.2 Tentative corpus for revamped design of Portuguese-English Literary Translation

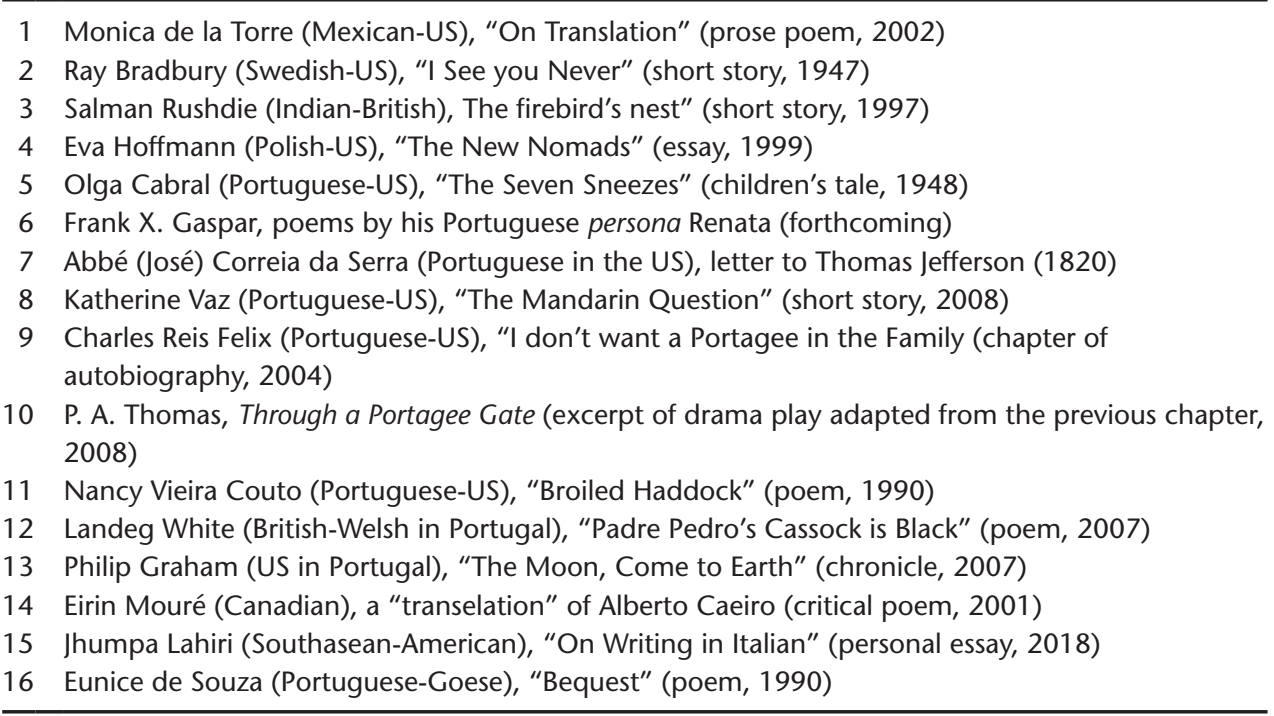

as craft. They are bound to raise also the awareness of the multilingual fabric that underlies any text, even if primarily respecting the English-Portuguese directionality. However, I do not want to lose the hope of contributing to the goal of preparation for the literary translation market, and I fear that these exercises alone might drive students to the point where a translation is no longer a translation. Therefore, I very much want to reach a formula where we can also focus on techniques, building on previous work directed towards the recognition of categories of transfer problems and translation strategies. Drawing on the applied research of the PEnPAL project on translating diasporic literature and on the heterolingualism manifested therein, my idea at the moment is to extend and multiply the exercises for the activity of phase 4 , i.e. translating as writing the self. Students will be invited to translate from a list of texts of diasporic writing. Some of them will be the object of group tasks involving formalized text analysis, identification of problems and proposal of solutions, working with the PEnPAL database. Each student will then elect his/her 'affinity piece' from the same pool (see Table 12.2), presenting the translation which will be workshopped in class and then, for their final assignment, revised and polished, alongside the process paper.

Turning to the autobiographic inscription of the academic, the very writing of this chapter has helped me to hone the rationale, the steps, and the activities for an approach to literary translation education through creative writing, a trend that holds growth potential in the future, and which would benefit from a discussion across geographies. In fact, it possibly spread first from the US to the UK (Hyde Parker 2009) and then to the rest of Europe, but it is now discussed in Latin America (Sanchez Riaño 2016) and at least in the South African context (Hirson 2015).

\section{Conclusions and future directions}

We have seen that the compounds 'literary translation' and 'multilingual writing' are both complex and harbour contradictions concerning expression, communication, and translatability. 
Right now, one of the big issues is where to address such questions pedagogically - in the translation degree, within humanistic frameworks of learning language, culture and area studies, or in the more craft-oriented space of creative writing and arts. Can these contexts be mixed and how does literary translation function as a strategy and/or goal in each of these? In this respect, an important question lingers on - how much of the ground of literature is coterminous with that of creative writing? A crucial difference is canonicity: that is why one can train creative writing but not entirely the writing of literature; on the other hand, the parallel is not easily drawn with the teaching of literary translation, granted there are no (or few) 'canonical translators'. Another difference is that literature tends to attach writing to a unique and inimitable voice, whereas creative writing sees it as "a contested site", focusing on intertextuality, circulation and editing of plural discourses (Washbourne 2013, p. 52). In this sense, to open up to creative writing is potentially more advantageous to the self-image of the translator. On the downside, the applications of creativity are sometimes fuzzy and/or rather pragmatically oriented, eschewing not only the stakes of artistic excellency but possibly also of the artistic freedom not to communicate. Another issue is whether multilingual literature really withstands the intervention of literary translation, and whether multilingual teaching contexts, favouring indirect translation, undermine foreign language competence in literary translation and rather allow for the hegemony of English (even if mitigated in Englishes) to go unchecked.

Finally, issues hardly discussed in this text were standards for evaluation and feedback about which the level descriptors of the web-based PETRA-E Framework, launched in 2014, provide a sound basis for both consensual application and further debate. Another topic that merits more exploration comprises the subsidiary competences for literary translation like eliciting a translation brief, (re)using retranslations, copyediting, proofreading, and access and usability of digital and printed aids of research. As to good practices and ethical legitimacy, there is promising work ahead in respect to gender awareness - perhaps not so much in the militant subversion of the original, but in an engagement of intimacy, generosity, and acceptance as attitudes of the craft, "work[ing] limits as such, rather than measuring them as losses" (von Flotow and Shread 2014, p. 595). Also, translation pedagogy would benefit from a wider plurality of approaches to counter its heavy Eurocentric bias, and from reflection on how the tools of the trade differ according to the concepts and terms used to designate it (Tymoczko 2006; Chang 2015, 2018).

Much work remains to be done on how to impart and train competences whose knowledge cannot be systematized nor quantified: humility, affinity, zeal, or even the love for literature? And - arguably the most subjective - how to tune the 'ear' for literature? With the development of aural studies, there is hope that in the future the topic will also offer future directions. Some ground has already been mined, with a growing literature on translation and music, including the cline from translation to adaptation (Low 2013) and homophonic translation (Hilson 2013; Horáček 2014). The turn to "music, text and translation" (according to the title of a collection of essays edited by Minors 2013) indicates an expansion of the concept of literature, embracing lyrics and song-writing amongst its genres - or is it creditable to the broader, more flexible, range of text types under the umbrella of creative writing? Certainly, one issue that needs be addressed in the planning of the literary translation classroom is how to go about translating different genres. The volume edited by Washbourne and Van Wyke (2019) is particularly helpful to pursue such research (see my brief review in the Further reading section). On the other hand, the workshop centred on the autobiographic transference tends to favour genres where subjectivity is enhanced, such as auto-fiction, memoir, the journal, and the lyrical poem. In any case, the diversity and extension of scope implied by the rising variety of contexts where creative writing has come to replace literature is definitely a great challenge 
for the redefinition of translation training with literary texts - since the classroom propitiates one of the most fertile contexts for creativity.

\section{Further reading}

Massardier-Kenney, F., Tymoczko, M. and Baer, B.J. (eds) (2016) Translators Writing, Writing Translators. Kent, OH: The Kent State University Press.

A homage to Carol Maier, explicitly referring to her "The Translator as an Intervenient Being", gathers a range of authors (Lawrence Venuti, Rosemary Arrojo, Susan Jill Levine, Kelly Washbourne, Maria Tymockzo) "known for sustained self-engagement with translation" (p. 2).

Shiuye, J. (2017) Teaching translation. Exchanges: Journal of Literary Translation [blog, online]. Available from: https://exchanges.uiowa.edu/blog/tag/teaching-translation [Accessed 25 March 2019].

Series of interviews to translators who also teach, it apparently has been discontinued after the third featured translator-teacher.

Washbourne, K. and Van Wyke, B. (eds) (2019) The Routledge Handbook of Literary Translation. London and New York: Routledge.

This recent publication contains many intertwined chapters to further the discussion. The first section of Part I ("Contexts") titled "Literary translation: teaching, learning, and research (academic contexts)" (pp. 29-86), comprises four articles on the topic, including Brian James Baer's "Teaching literature in translation" (pp. 58-71), already quoted. In "Literary translation and disciplinary boundaries: creative writing and interdisciplinarity" (pp. 42-57). Cecilia Rossi specifically addresses the 'creative turn' in Translation Studies and discusses the mutually feeding contributions of 'creative writing' and 'literary translation studies'. She questions the alleged difference between the two deriving from recourse to a precedent original as a possible fallacy, maintaining however that in translation reading always predates writing. Part II considers the following different genres in literary translation: classical poetry; classical prose; oral literature; fairy tales and folk tales; children's literature; sacred writings; prose fiction; comics, the graphic novel, and fan fiction; literary nonfiction; poetry; music; and theatre.

\section{Related topics}

comparative literature, multilingual turn, translation teacher training

\section{Notes}

1 Theory, however, has engaged with Steiner's writing, and it is worth mentioning, for purposes of ethical awareness in the classroom, the gender studies criticism that frames Steiner's discourse in a long tradition of translation metaphors that are sexist; Steiner's second phase of aggression is particularly liable to such critique as it is expressed in bellic terms of invasive penetration (Chamberlain 1988; Round 2005).

2 Benjamin's phrase "profane illumination' (1929) is close to how I view the restitutive attempt of the literary translator; he used it to describe the estranging experience by which, in certain oneiric states, one is mindful of the overlooked objects of everyday reality.

3 The subjective engagement of translators, literary or otherwise, has also been made relevant by Maier's "The translator as an intervenient being" (2007), and her focus on the translator's body, positionality, and processes of translation.

\section{References}

Adorno, T.W. (1974) On lyric poetry and society, in Tiedemann, R. (ed) Notes to Literature. Vol. 1. W. Nicholson (trans). New York: Columbia University Press. pp. 39-54. 
Allen, E. and Bernofsky, S. (eds) (2013) In Translation: Translators on Their Work and What It means. New York: Columbia University Press.

Baer, B.J. (2018) Teaching literature in translation, in Washbourne, K. and Van Wyke, B. (eds) The Routledge Handbook of Literary Translation. London and New York: Routledge. pp. 58-71.

Baker, M. (1993) Corpus linguistics and translation studies: Implications and applications, in Baker, M., Francis, G. and Tognini-Bonelli, E. (eds) Text and Technology: In Honour of John Sinclair. Amsterdam: Benjamins. pp. 233-250.

Bakhtin, M.M. (1981) The Dialogic Imagination: Four Essays. M. Holquyst and C. Emerson (trans). Austin: University of Texas Press.

Bassnett, S. (1998) Transplanting the seed: Poetry and translation, in Bassnett, S. and Lefevere, A. (eds) Constructing Cultures: Essays on Literary Translation. Clevedon: Multilingual Matters. pp. 57-75.

Bassnett, S. and Bush, P. (eds) (2006) The Translator as Writer. London and New York: Continuum.

Beghetto, R.A. and Kaufman, J.C. (eds) (2010) Nurturing Creativity in the Classroom. Cambridge: Cambridge University Press.

Benjamin, W. (1923/1968) The task of the translator, in Arendt, H. (ed) Illuminations. H. Zohn (trans). New York: Harcourt Brace Jovanovich. pp. 69-82.

Benjamin, W. (1929/1978) Surrealism: The last snapshot of European intelligence. E. Jephcott (trans). New Left Review. 108, pp. 47-56.

Berman, A. (1985/2012) Translation and the trials of the foreign, in Venuti, L. (ed) The Translation Studies Reader. 3rd ed. L. Venuti (trans). London and New York: Routledge. pp. 240-253.

Biguenet, J. and Schulte, R. (1989) The Craft of Translation. Chicago: The University Press of Chicago.

Boase-Beier, J. (2006) Stylistic Approaches to Translation. Manchester: St. Jerome Publishing.

Boase-Beier, J. and Holman, M. (eds) (1999) The Practices of Literary Translation: Constraints and Creativity. Manchester: St. Jerome Publishing.

Boyden, M., \& Goethals, P. (2011) Translating the Watcher's Voice: Junot Díaz's The Brief Wondrous Life of Oscar Wao into Spanish. Meta: journal des traducteurs/Meta: translators'Journal, 56(1), pp. 20-41.

Bradford, L.R. (2009) Uses of the imagination: Bilanguaging the translation of U.S. Latino poets. TranscUlturAl. 1(2), pp. 13-34.

Buffagni, C., Garzelli, B. and Zannotti, S. (eds) (2011) The Translator as Author: Perspectives on Literary Translation. Münster: LIT Verlag.

Campos, H. (1997) O Arco-Íris Branco: Ensaios de Literatura e Cultura. Rio de Janeiro: Imago.

Chamberlain, L. (1988) Gender and the metaphorics of translation. Signs. 13(3), pp. 454-472.

Chang, N.F. (2015) Does 'translation' reflect a narrower concept than 'fanyi'? On the impact of Western theories on China and the concern about Eurocentrism. Translation and Interpreting Studies. 10(2), pp. 223-242.

Chang, N.F. (2018) Voices from the periphery: Further reflections on relativism in translation studies. Perspectives. 26(4), pp. 463-477.

Damrosch, D. (2005) Death in translation, in Bermann, S. and Wood, M. (eds) Nation, Language, and the Ethics of Translation. Princeton: Princeton University Press. pp. 380-398.

Filkins, P. (2016) A multilingual workshop in poetry and prose translation, in Venuti, L. (ed) Teaching Translation: Programs, Courses, Pedagogies. London and New York: Routledge. pp. 87-93.

Folkart, B. (1991) Le conflit des Énonciations: Traduction et Discours Rapporté. Montréal: Les Éditions Balzac.

Gaddis-Rose, M. (1997) Translation and Literary Criticism, Translation as Analysis. Manchester: St. Jerome Publishing.

Gibbons, R. (2016) Teaching the translation of poetry, in Venuti, L. (ed) Teaching Translation: Programs, Courses, Pedagogies. London and New York: Routledge. pp. 79-86.

González-Davies, M. (2004a) Undergraduate and postgraduate translation degrees, in Malmkjær, K. (ed) Translation in Undergraduate Degree Programmes. Amsterdam: John Benjamins. pp. 67-81.

González-Davies, M. (2004b) Multiple Voices in the Translation Classroom. Amsterdam: John Benjamins. González-Davies, M. (2016) A collaborative pedagogy for translation, in Venuti, L. (ed) Teaching Translation: Programs, Courses, Pedagogies. London and New York: Routledge. pp. 71-78. 
Grossman, E. (2010) Why Translation Matters. Princeton: Yale University Press.

Hermans, T. (ed) (1985) The Manipulation of Literature. London: Croom Helm.

Hermans, T. (1996) The translator's voice in translated narrative. Target. International Journal of Translation Studies. 8(1), pp. 23-48.

Hermans, T. (2007) The Conference of the Tongues. Manchester: St. Jerome Publishing.

Hilson, J. (2013) Homophonic translation: Sense and sound, in Minors, H.J. (ed) Music, Text and Translation. London and New York: Bloomsbury. pp. 95-106.

Hirson, D. (2015) Ukutshona kwelanga: The drowning of the sun: Introducing translation into creative writing courses. Current Writing: Text and Reception in Southern Africa. 27(2), pp. 154-158.

Holmes, J.S. (1969) Forms of verse translation and the translation of verse form. Babel. 15(4), pp. 195-201.

Honig, E. (1985) The Poet's Other Voice: Conversations on Literary Translation. Amherst: The University of Massachusetts Press.

Horáček, J. (2014) Pedantry and play: The Zukofsky Catullus. Comparative Literature Studies. 51(1), pp. 106-131.

Hyde Parker, R. (2009) Professionalizing literary translation education. Translation Journal. 13(2). Available from: https://translationjournal.net/journal/48literary.htm [Accessed 13 October 2018].

Jakobson, R. (1959/1987) On linguistic aspects of translation, in Pomorska, K. and Rudy, S. (eds) Language and Literature. Cambridge, MA: Harvard University Press. pp. 428-435.

Jakobson, R. (1960/1987) Linguistics and poetics, in Pomorska, K. and Rudy, S. (eds) Language in Literature. Cambridge, MA: Harvard University Press. pp. 62-94.

Jones, F.R. (2006) Unlocking the black box: Researching poetry translation processes, in Perteghella, M. and Loffredo, E. (eds) Translation and Creativity: Perspectives on Creative Writing and Translation Studies. London and New York: Continuum. pp. 59-74.

Jones, F.R. (2008) Literary translation, in Baker, M. and Saldanha, G. (eds) Routledge Encyclopedia of Translation Studies. 2nd ed. London and New York: Routledge. pp. 152-157.

Jones, F.R. (2011) Poetry Translating as Expert Action: Processes, Priorities and Networks. Amsterdam and Philadelphia: John Benjamins.

Kiraly, D. (2000) A Social Constructivist Approach to Translator Education. Manchester: St. Jerome Publishing.

Kiraly, D. (2005) Project-based learning: A case for situated translation. Meta. 50(4), pp. 1098-1111.

Klinger, S. (2015) Translation and Linguistic Hybridity: Constructing World-View. New York: Routledge.

Landers, C. (2001) Literary Translation: A Practical Guide. Clevedon: Multilingual Matters.

Lefevere, A. (1992) Translation, Rewriting, and the Manipulation of Literary Fame. London and New York: Routledge.

Liu, B. (2015) A proposed curriculum roadmap for "marketable" undergraduate degrees in translation: It all begins with a digital sciences information session. Current Trends in Translation Teaching and Learning Education. 2, pp. 31-71.

Low, P. (2013) When songs cross language borders. The Translator. 19(2), pp. 229-244.

Lung, R. and Yan, J. (2004) Attitudes towards a literature-oriented translation curriculum. Babel. 50(1), pp. 3-12.

Maier, C. (2007) The translator as an intervenient being, in Munday, J. (ed) Translation as Intervention. London and New York: Continuum. pp. 1-17.

Martins, I.O., Vale de Gato, M. and Castel-Branco, C. (2019) Heterolingualism, translation and the (in) articulation of grief in Portuguese-American literature, in Bennett, K. and Barros, R.Q. (eds) Hybrid Englishes and the Challenges of and for Translation. London and New York: Routledge. pp. 93-112.

McGurl, M. (2009) The Program Era. Cambridge, MA: Harvard University Press.

Meschonnic, H. (1982) Critique du Rhythme. Anthropologie du Langage. Paris: Verdier.

Meschonnic, H. (1999) Poétique du Traduire. Paris: Verdier.

Meylaerts, R. (2006) Heterolingualism in/and translation: How legitimate are the other and his/her language? An introduction. Target. 18(1), pp. 1-15. 
Michon, P. (2011) A short history of Rhythm Theory since the 1970s. Rhuthmos. 6. Available from: http:// rhuthmos.eu/spip.php?article462 [Accessed 25 March 2019].

Minors, H.J. (ed) (2013) Music, Text and Translation. London and New York: Bloomsbury.

Nelson, B. and Maher, B. (eds) (2013) Perspectives on Literature and Translation: Creation, Circulation, Reception. London and New York: Routledge.

Newmark, P. (1988) A Textbook of Translation. New York: Prentice Hall.

Nida, E. (1964) Toward a Science of Translating. Leiden: Brill.

Nikolaou, P. (2006) Notes on translating the self, in Perteghella, M. and Loffredo, E. (eds) Translation and Creativity: Perspectives on Creative Writing and Translation Studies. London and New York: Continuum. pp. 19-32.

Nord, C. (1991) Text Analysis and Translation: Theory, Methodology, and Didactic Application of a Model for Translation-oriented Text Analysis. Amsterdam: Rodopi.

Pattison, A. (2006) Painting with words, in Perteghella, M. and Loffredo, E. (eds) Translation and Creativity: Perspectives on Creative Writing and Translation Studies. London and New York: Continuum. pp. 84-94.

Paz, O. (1971/1992) Translation: Literature and letters, in Schulte, R. and Biguenet, J. (eds) Theories of Translation: An Anthology of Essays from Dryden to Derrida. I. del Corral (trans). pp. 152-162.

Paz, O. and Campos, H. (1994) Transblanco. São Paulo: Sicilano.

Perteghella, M. and Loffredo, E. (eds) (2006) Translation and Creativity: Perspectives on Creative Writing and Translation Studies. London and New York: Continuum.

PETRA-e. (2014) PETRA-e Framework of References for the Education and Training of Literary Translators [online]. Available from: https://petra-educationframework.eu/ [Accessed 14 November 2018].

Pym, A. (2011) Training translators, in Malmkjær, K. and Windle, K. (eds) The Oxford Handbook of Translation Studies. Oxford: Oxford University Press. pp. 475-489.

Reiss, K. and Vermeer, H. (1984/2014) Towards a General Theory of Translational Action: Skopos Theory Explained. C. Nord (trans). London and New York: Routledge.

Round, N. (1998) Monuments, Makars and modules: A British experience, in Bush, P. and Malmkjaer, K. (eds) Rimbaud's Rainbow: Literary Translation in Higher Education. Amsterdam and Philadelphia: John Benjamins. pp. 11-20.

Round, N. (2005) Translation and its metaphors: The $(\mathrm{N}+1)$ wise men and the elephant. Skase Journal of Translation and Interpretation. 1(1), pp. 47-69.

Sanchez Riaño, A. (2016) Una experiencia pedagógica con la traducción de textos literarios: estudio de caso. Matices en Lenguas Extranjeras. 10, pp. 42-52.

Schäffner, C. (1998) Qualification for professional translators: Translation in language teaching versus teaching translation, in Malmkjaer, K. (ed) Translation and Language Teaching: Language Teaching and Translation. Manchester: St. Jerome Publishing. pp. 117-133.

Schulte, R. and Biguenet, J. (eds) (1992) Theories of Translation: An Anthology of Essays from Dryden to Derrida. Chicago: The University of Chicago Press.

Sedarat, R. (2016) An MFA in literary translation, in Venuti, L. (ed) Teaching Translation: Programs, Courses, Pedagogies. London and New York: Routledge. pp. 39-45.

Steiner, G. (1975/1998a) After Babel: Aspects of Language and Translation. 3rd ed. Oxford: Oxford University Press.

Steiner, G. (1998b) Errata: An Examined Life. Yale, CT: Yale University Press.

Sternberg, M. (1981) Polylingualism as reality and translation as mimesis. Poetics Today. 2(4), pp. 221-223.

Stratford, M. (2008) Au tour de Babel! Les défis multiples du multilinguisme. Meta: Journal des Traducteurs/Meta: Translators' Journal. 53(3), pp. 457-470.

Suchet, M. (2013) Voice, tone and ethos: A portrait of the translator as a spokesperson, in TaivalkoskiShilov, K. and Suchet, M. (eds) La Traduction des Voix Intra-textuelles/Intertextual Voices in Translation. Montréal: Éditions québécoises de l'œuvre. pp. 159-184. 
Suchet, M. (2014) L'Imaginaire Hétérolingue. Ce que Nous Apprennent les textes à la Croisée des Langues. Paris: Classiques Garnier.

Toury, G. (1978) The nature and role of norms in literary translation, in Holmes, J.S., Lambert, J. and Van den Broeck, R. (eds) Literature and Translation: New Perspectives in Literary Studies. Leuven: Acco. pp. 83-100.

Tymoczko, M. (2006) Translation: Ethics, ideology, action. The Massachusetts Review. 47(3), pp. 442 461. Available from: www.jstor.org/stable/25091110 [Accessed 25 March 2019].

Ulrych, M. (2005) Training translators: Programmes, curricula, practices, in Tennent, M. (ed) Training for the New Millennium: Pedagogies for Translation and Interpreting. Amsterdam and Philadelphia: John Benjamins. pp. 3-33.

Vale de Gato, M. (2013) No beginnings: Heterolingualism and translated Luso-American novels by Erika de Vasconcelos and Others. Gávea-Brown: A Bilingual Journal of Portuguese-American Letters and Studies. XXXIV-XXXV(2012-2013), pp. 153-166.

Vale de Gato, M. (2015a) Will the aliens come home? Diaspora and translation in Portuguese-American literature, in Maia, R.B., Pinto, M.P. and Pinto, S.R. (eds) How Peripheral Is the Periphery: Translating Portugal Back and Forth. Essays in Honor of João Ferreira Duarte. Newcastle upon Tyne: Cambridge Scholars Publishing. pp. 275-295.

Vale de Gato, M. (2015b) The collaborative anthology in the literary translation course. The Interpreter and Translator Trainer. 9(1), pp. 50-62.

Vale de Gato, M. (2018) Lolita's love affair with the English language: Heterolingualism and voice in translation. Meta: Journal des Traducteurs/The Translators'Journal. 63(2), pp. 321-341.

Vale de Gato, M., Barros, R.Q., Janssen, M. and Valdez, S. (2016) Teaching and researching literary translation in the digital context: PEnPAL in trans as a case-study. MATLIT: Materialities of Literature. 4(1), pp. 63-80. Available from: https://doi.org/10.14195/2182-8830 [Accessed 25 March 2019].

Van Lier, L. (1996) Interaction in the Language Classroom: Awareness, Autonomy and Authenticity. London: Longman.

Venuti, L. (1995) The Translator's Invisibility: A History of Translation. London and New York: Routledge.

Venuti, L. (ed) (2012) The Translation Studies Reader. 3rd ed. London and New York: Routledge.

Venuti, L. (2013) Translation Changes Everything Theory and Practice. London and New York: Routledge.

Venuti, L. (ed) (2016) Teaching Translation: Programs, Courses, Pedagogies. London and New York: Routledge.

Vinay, J-P. and Darbelnet, J. (1958/1995) Comparative Stylistics of French and English: A Methodology for Translation. J.C. Sager and M-J. Hamel (trans and ed). Amsterdam and Philadelphia: John Benjamins.

Vizcaíno, M.J.G. (2008) Cisneros' code-mixed narrative and its implications for translation. Mutatis Mutandis. 1(2), pp. 212-224.

von Flotow, L. and Shread, C. (2014) Metamorphosis in translation: Refiguring the intimacy of translation beyond the metaphysics of loss. Signs. 39(3), pp. 592-596.

Washbourne, K. (2013) Teaching literary translation: Objectives, epistemologies, and methods for the workshop. Translation Review. 86(1), pp. 49-66.

Weinberger, E. (2013) Anonymous sources (on translators and translation), in Allen, E. and Bernofksy, S. (eds) Translators on Their Work and What It Means. New York: Columbia University Press. pp. $17-30$.

Williams, J. and Chesterman, A. (2002) The Map: A Beginner's Guide to Translation Studies. Manchester: St. Jerome Publishing. 


\title{
Audiovisual translation Subtitling and revoicing
}

\author{
Alejandro Bolaños-García-Escribano and Jorge Díaz-Cintas
}

\section{Introduction}

This chapter focuses on the main particularities and challenges that, from a didactic perspective, characterize audiovisual translation (AVT), with special emphasis on subtitling and revoicing. It sets out to report on the main ontological challenges encountered in the teaching and learning of AVT, charters the evolution observed in this field and explores the potential instructional benefits that teaching paradigms such as socio-constructivism and situated learning can bring about in the AVT classroom. After an introduction to AVT, a discussion ensues on the main research approaches that have been articulated in this area and some of the key findings are foregrounded. We then offer a general depiction of how the topic has traditionally been taught in academic institutions and complement it with a research- and experience-based account of some of the pedagogical innovations currently taking place. We conclude with a prospective outlook on potential developments in the near future.

AVT is a professional activity that involves the localization of audiovisual media content by means of different linguacultural transfer practices. As programmes are received aurally and visually at the same time, translators need to be familiar with the specificities of these communication channels as well as the imbrications that are established between the verbal and the non-verbal signs.

The various types of AVT practices are normally subsumed under two main groups: revoicing and subtitling, the latter also known as timed text and titling in the industry. Whereas the former consists of substituting the original soundtrack with a newly recorded or live soundtrack in the target language (Chaume 2006, p. 6), subtitling operates by maintaining the original speech and images, which are accompanied by written stretches of text that correspond to synchronized translations or transcriptions of the original dialogue. Both revoicing and subtitling are hypernyms that include several sub-practices, and they can be used to bridge linguistic and cultural barriers or to facilitate access to audiovisual productions for audiences with sensory impairments such as the deaf, the hard-of-hearing, the blind, and the partially sighted. 
Revoicing includes the following categories:

- Lip-sync dubbing implies the substitution of the dialogue track with a new one containing the exchanges in the target language that fit into the mouth of the on-screen characters.

- Voiceover consists in orally presenting the translation of the original speech over the still audible original voice.

- Partial dubbing can be interpreted in two main different ways: (a) it entails the lip-synching of the leading characters of a programme and the voiceover of the secondary ones, or (b) it is a hybrid between lip-sync dubbing and voiceover, in which phonetic synchrony is only half-respected and isochrony takes precedence.

- Narration is the replacement of the original dialogue track by a new one in which only the voice of the target language narrator can be heard.

- Interpreting can be either simultaneous or consecutive and entails the transfer, orally or in the form of sign language, of the words of a person speaking a different language.

- Audio description (AD) is an aural translation of some of the pictorial and aural elements of a recorded programme or a live performance for the benefit of visually impaired and blind people.

Subtitling, on the other hand, encompasses:

- Interlingual subtitling is the rendition in writing of the translation in a different language of the original dialogue of an audiovisual production, as well as of the verbal.

- Surtitling is the translation or transcription of dialogue and lyrics in live opera, musical shows, and theatre performances.

- Captioning or subtitling for the deaf and the hard-of-hearing (SDH) is usually done intralingually and consists of presenting on screen a written text accounting for the dialogue, music, sounds, and noises contained in the soundtrack, for the benefit of audiences with hearing impairments.

- Live subtitling is the production of subtitles for live programmes or events. The most current approach is respeaking, a practice in which a professional listens to an original utterance and respeaks it, including punctuation marks, to a speech recognition piece of software that then displays subtitles on the screen (Romero-Fresco 2011).

In the following sections, we focus on the teaching and learning of the three most traditional practices, namely, interlingual subtitling, voiceover, and dubbing.

\section{Historical perspectives}

The invention and popularization of the talkies in the early 20th century brought about a major difficulty for the international distribution of films as the dialogue had to be translated into different languages. The first dubbed films were produced in the 1930s and they rapidly became highly popular. With the passing of the years and the advancement of technology in the form of television, DVD, Blu-ray, and Internet, the production and distribution of audiovisual programmes has grown exponentially, and with it the need for AVT, thus leading to a wellestablished industry that historically has played a fundamental role in the exhibition of theatrical releases and audiovisual entertainment worldwide. More recently, the societal influence of AVT has expanded its remit as the nature of the programmes that are translated is virtually limitless, whether for commercial, ludic or instructional purposes: films, TV series, cartoons, 
sports programmes, reality shows, documentaries, cookery programmes, current affairs, edutainment material, commercials, educational lectures, and corporate videos, to name but a few.

Paradoxically, and despite its far-reaching cultural influence, AVT as a research domain only started to gain momentum and visibility as part of the wider discipline of translation studies (TS) in the late 20th century, under myriad denominations such as film, cinema, screen, (multi-)media, constrained and multidimensional translation among others (Chaume 2013a). The academic potential of AVT had already been identified in Babel's special edition on cinema translation published in 1960, though it will not be until the 1990s that the start of a real flurry of activity can be witnessed. As chronicled by Díaz-Cintas (2009, p. 2), many of the pioneering works "adopted a distinctively professional perspective, focusing on the figure of the audiovisual translator, on the different translational stages, as well as on the differences between dubbing and subtitling". Discussions on the concept of constrained translation by scholars like Titford (1982) and Mayoral Asensio et al. (1988), and on the semiotic nature of the audiovisual production (Delabastita 1989) also proved seminal at the time.

Essentially, AVT is the translation of audiovisual texts, which are multimodal in nature, and, as defined by Chaume (2004a, p. 30, our translation), convey:

information through two different communication channels that transmit coded meaning simultaneously: the acoustic channel (acoustic vibrations through which we receive words, paralinguistic information, soundtrack and special effects) and the visual channel (light waves through which we receive images, but also posters or signs with written text, etc.).

When it comes to the teaching and learning of AVT, the first instructional courses used to focus almost exclusively on the translation of cinema productions, mainly feature films, as these were the most prominent works being translated in the entertainment industry and enjoyed a canonized status that could be said to run parallel to the translation of literature. In fact, for influential scholars like Bassnett (1980/2002) and Snell-Hornby (1988/1995), subtitling and dubbing were practices subsumed within the larger area of literary translation, as they were understood to deal exclusively with the translation of feature films. Yet, as argued by Chaume (2004b), one of the recurrent early misconceptions in the siting of AVT within TS was the assumption that this domain was a genre, i.e. films, rather than a text type, i.e. audiovisual, that encompasses a plurality of genres as exemplified previously.

The slow evolution of AVT throughout most of the 20th century, both from a pedagogical as well as a research perspective, was dramatically reverted towards the end of the century, during the so-called "golden years of AVT" (Díaz-Cintas 2012, p. 280), when the field experienced a phenomenal surge that continues to this day. In terms of social visibility, the international conference Audiovisual Communication and Language Transfer was held in June 1995 in Strasbourg to commemorate the centenary of cinema, and the following year, the first edition of the renowned, and still running, international conference Languages \& the Media (www.languages-media.com) was held in Berlin. The European Association for Studies in Screen Translation (ESIST, www.esist.org), a non-profit-making association of higher education teachers, practitioners, academics and students in the field of AVT, was also set up in this incubation period, with part of its remit to facilitate the exchange of information and to promote professional standards in the training and practice of AVT. These developments came accompanied with the completion of the first doctoral theses fully focused on topics related to AVT, such as the ones written by Tomaszkiewicz (1993), Zabalbeascoa (1993), Machado (1996), and Díaz-Cintas (1997); pioneering works that opened the floodgates to a fast-growing 
body of academic literature on AVT. The number of doctoral projects produced in this field has since grown exponentially and the compilation works by Martínez Sierra $(2012,2017)$ offer an extensive overview. The British EThOS (https://ethos.bl.uk) platform is another welcome initiative, whose aim is to maximize the visibility and availability of British doctoral theses, by making them freely available for all researchers in an open access repository. A similar project is Tesis Doctorals en Xarxa (www.tesisenred.net), a digital cooperative repository of doctoral theses presented at some Spanish universities. The end of 2018 saw the launch of the inaugural issue of the Journal of Audiovisual Translation (JAT, www.jatjournal.org), the first international journal dedicated entirely to audiovisual translation studies, as well as the publication of The Routledge Handbook of Audiovisual Translation (Pérez-González 2018).

The increased visibility and importance of audiovisual communication in society has been foregrounded by Shetty (2016, online), who claims that digital video has been in hyper growth mode over the last few years,

with a projected $80 \%$ of all Internet traffic expected to be video by 2018 . This is because of improvements in video technology, wider viewing device options, and an increase in content made available online both from television broadcasters and from other video services.

At the same time, giants like YouTube estimate that more than $60 \%$ of a YouTube channel's views come from outside its country of origin (Reuters 2015), clearly pointing to the pivotal role played by translation in cross-cultural communication. Alongside these developments in the user-generated sphere, the parallel commercial upsurge of translation activity in the audiovisual industry has been corroborated by research conducted on behalf of the Media \& Entertainment Services Alliance Europe (MESA), underlining that audiovisual media content localization across Europe, the Middle East, and Africa is expected to increase from \$2 billion in 2017 to over $\$ 2.5$ billion before 2020 (MESA News 2017). The mushrooming of channels and video-on-demand platforms, driven partly by so-called over-the-top (OTT) players like Netflix, Amazon Prime, Viki, Hulu, iQiyi, or Iflix, who specialize in the delivery of content over the internet, has opened up more opportunities for programme makers to sell their titles into new markets. To attract wider audiences, most audiovisual productions come accompanied by subtitled and dubbed versions in various languages, with many also including SDH and $\mathrm{AD}$ for the hearing and visually impaired respectively. The provision on television of these two access services is usually regulated by legislation and, in the United Kingdom for instance, the Communications Act 2003 stipulates the minimum number of hours of accessible content that the various broadcasters have to schedule in their programming (Ofcom 2017).

A collateral result from this fast-growing global demand for content that needs to be translated is the perceived critical talent crunch in the industry when it comes to professionals in dubbing and subtitling (Estopace 2017). Given the lack of formal AVT training in many countries, the situation is likely to worsen in the short term, especially in the case of certain language combinations. Yet, what is certain is that the demand for AVT is here to stay, as companies and organizations around the world continue to recognize the immense value of adapting their content into multiple languages if they are to extend their global reach, which in turn triggers the need for teaching AVT in a dedicated and specialist manner.

\section{Research approaches and key findings}

Reflection in academic and professional settings on AVT-related issues has led to the building of a substantial body of literature that has helped demarcate the potential and the boundaries of 
the discipline. According to Gambier and Ramos-Pinto (2016), AVT specialists seem to have focused on several pivotal inquiry clusters, which include its historical foundations, translating processes, language policies, media accessibility, and descriptive studies of linguistic challenges and difficulties.

The heterogeneous nature of the discipline justifies the application of interdisciplinary methodologies and analytical approaches but exploring the many research avenues that AVT can accommodate falls outside the scope of this chapter. Our main focus lies on interlingual practices and the pedagogical implications posed by competence-based approaches, translation conventions, technological developments, and process-oriented research.

The competence-based approach has a long tradition in translator training research (Schäffner and Adab 2000), as the use of sets of competences is "common in vocational and technical education" (Biggs and Tang 2011, p. 5) and is in close relation with outcomes-based approaches. Translation practices, including revoicing and subtitling, are no exception. Scholars who have theorized about the application of competences frameworks on translator training settings, like Hurtado-Albir (2001) and Kelly (2005), define translation competence as the ability that enables an individual to carry out the cognitive operations required in successful translation practice, which in itself "integrates various types of capabilities and skills, and declarative knowledge" (Hurtado-Albir 2007, p. 167).

In the particular case of AVT training, the main difference with other translation specialisms, be they literary or non-literary, lies in its multimodal and multimedia nature, which calls for transversal abilities closely related to digital technology and audiovisual literacy. Despite some pioneering works, like those by Zabalbeascoa et al. (2005) and Díaz-Cintas (2008), little attention has been paid to unravelling how translation competence intertwines with the various AVT modes. What is more, scholars seem to have overlooked the pivotal role that technology- and profession-related issues play in the teaching and learning of AVT, which would correspond to the so-called occupational and instrumental competences as conceived by the PACTE $(2003,2005)$ group.

Of the different sub-competences highlighted by PACTE, the instrumental competence seems to be particularly relevant in the case of AVT courses as it entails the mastery of AVTspecific software and the ability to work with a plethora of multimedia files and technologies. Likewise, occupational competence, which refers to the abilities necessary to operate appropriately in the translation labour market, seems highly important in an industry subject to substantive time and financial pressures and regulated by high competition and idiosyncratic working conditions. In this respect, the most recent classification of AVT competences is the one drafted by Cerezo-Merchán (2018), whose work draws on previous literature on translation competences, particularly on Hurtado-Albir (2015), and distinguishes between the following competences: contrastive, extralinguistic, methodological and strategic, instrumental, and translation problem-solving.

Among the main works written by AVT practitioners and academics are the first manuals that included basic guidelines for the revoicing and subtitling of audiovisual texts: Laks (1957), Luyken et al. (1991), Ivarsson and Carroll (1998), Karamitroglou (1998), Pommier (1998), Díaz-Cintas and Remael (2007), and Chaume (2012). Of a predominantly applied nature, these works discuss the conventions that have become well established in the industry and have informed training in the field. Given the dynamism and ever-changing nature of the market, and to avoid the risk of perpetuating outdated conventions in the classroom, it is paramount that works of this nature are regularly updated to take into account new workflows and practices as well as the results from reception studies centred on viewers' consumption of audiovisual productions. 
It tends to take a long while before technical innovations instigated by the industry, such as the development of specialist subtitling/dubbing systems, or the more recent migration to cloud-based ecosystems and the embedding of subtitling apps in translation memories, are fully incorporated in the curriculum offered by training centres (Bolaños-García-Escribano 2018), thus creating an undesirable imbalance between profession and academia. Despite the odd study assessing the functionality of some of the available tools from a didactic perspective (Roales-Ruiz 2014) or the potential opened by machine translation in the field of subtitling (Georgakopoulou and Bywood 2014), the uptake on this front is still very limited.

One of the reasons behind this state of affairs is the fact that collaboration between trainers and the industry has been traditionally minimal. A more advantageous relationship should be explored among the interested parties, whereby trainers could be granted wider access to cutting-edge professional tools and platforms for their own interest and technical preparation. Opportunities of this calibre could also be utilized from a research perspective to conduct user experience tests among practitioners and translators-to-be not only to inform future training but also in exchange for advice on potential improvements of those tools. To make sure that students are qualified to be able to functionally operate in the future, their instrumental knowledge should be honed by being exposed to the latest advances in the industry, including up-to-date technologies and translation workflows.

In recent years, we have witnessed a boom of experimental approaches in AVT research that rely on traditional methods like questionnaires, surveys, and interviews as well as devices like eye trackers to explore the process of translation from the point of view of the translators. A pioneering pilot study in AVT education is the one conducted by Massey and Jud (2015), in which they report on the product-oriented teaching of interlingual subtitling with screen recording and eye tracking. Another forerunner in the field of subtitling is the study by Beuchert (2017) in which she adopts a situated cognition approach to investigate subtitling processes focused not only on the subtitlers' internal, cognitive translation processes, but also on the external, contextual factors surrounding the subtitlers and their tasks, including the work environment and the role of technology. In the field of revoicing, Hvelplund (2018) has carried out an experiment focused on the process of translating for dubbing, during which professional translators' and trainees' gaze was monitored while translating an excerpt of an animated television show. Scrutinizing the professionals' and trainees' distribution of attention and their cognitive effort during the translation process can prove most valuable if one is to implement new and innovative methods in the teaching of AVT.

Scholarly endeavours have been, and will continue to be, crucial in order to fine-tune and improve the teaching of a particular discipline to would-be professionals and ultimately guarantee its sustainability into the future. As already mentioned, it is essential that the longstanding gap between the AVT industry and academia be bridged, so that the latter can benefit from learning about the current and future needs of the former, and the industry can recruit employees with the right skills. Synergies of this nature can help scholars to conduct selfreflective assessments of the curriculum on offer at their own institutions and instigate the necessary innovative and transformational changes that will secure the well-being of the discipline in the years to come.

\section{Pedagogical approaches and methods}

According to scholars like Pym (2012), the teaching methods adopted in translation degrees in general - and we would argue in AVT curricula in particular - are oftentimes out of date as they mainly rely on the transmission of theoretical translation premises and trends rather than 
on current, never mind prospective, professional practices. This does not preclude, however, the existence of a substantive number of experience-based accounts on the teaching of AVT, ranging from descriptive course descriptions (Díaz-Cintas and Orero 2003) and multimodal pre-translation analysis (Taylor 2009) to the development of virtual teaching environments (Dorado and Orero 2007; Bartrina 2009), the didactics of AVT (Díaz-Cintas 2008; CerezoMerchán 2012, 2018), and the exploitation of AVT for foreign language learning (McLoughlin et al. 2011; Talaván-Zanón 2013).

This perceived mismatch between real professional practice and what is taught in the classroom is particularly problematic in a field like AVT, which is highly technology driven, tightly dependent on continuous software updates, and whose market ecosystem is constantly being transformed and reconfigured so as to meet the consumption and viewing needs of a changing audience (Díaz-Cintas and Neves 2015). At the end of the 1990s, James (1998, p. 255) was already discussing the difficulties of embarking on the training of AVT, especially subtitling, due to its many complexities, and most notoriously because: "the cost of equipment and technical assistance is often a disincentive for many institutions". Indeed, the high financial investment required to source the right commercial tools has been traditionally blamed for their absence in the lecture room, although the situation has been mitigated to a large extent with the availability of dedicated freeware available to anyone. Yet, the economic imperatives have resulted in a two-tier system in which only a few translation departments with the financial means have been able to expose students to up-to-date, commercial software, whose cost is beyond the reach of most institutions, whereas most of the rest have taught the topic from a theoretical perspective and some have resorted to the use of freeware.

Finding instructors with the right expertise to teach highly specialized modules has also been an exacting pursuit. It is generally agreed that the ideal AVT trainer is a scholar-professional with dilated teaching practice and experience in the industry, who is knowledgeable in the academic study of audiovisual texts and willing to continue professional practice occasionally (Chaume 2003, p. 288). As desirable as this can be, the reality is that, as highlighted by Kelly (2008, p. 100), "the majority of those involved in translator training are full-time university lecturers", overwhelmed with current demands of academic quality agencies and bodies, entrapped in meandering administrative mazes, under pressure to publish or perish and, consequently, with little or no spare time for extra-curricular work. The end result is that AVT trainers are often either practitioners with professional experience but little research or pedagogical background, who occupy part-time positions, or academics with limited professional experience and much scholar research behind them, as practice is often undermined in academic circles and, when it comes to gaining stable positions, priority tends to be given to research over teaching. As bemoaned by Englund-Dimitrova (2002, p. 74):

University teachers are sometimes too theoretical and do not always have the necessary knowledge about the future professional reality of the students; the professional translators, on the other hand, sometimes tend to be too practical, lacking the theoretical background which the students themselves have and consequently also expect from their teachers.

Closely related to this state of affairs, James (1998, p. 255) argues that subtitling training is not just an academic pursuit and highlights the fact that it "demands close collaboration with the commercial sector, particularly regarding issues such as subtitling conventions, national practice and professional standards in general". To bridge such gap between academe and industry, some translation departments have endeavoured to establish fruitful links with professional 
partners, not only with the aim of licencing appropriate specialist software but also of increasing internship opportunities, organizing workshops and company visits, and promoting reallife professional experiences that can be offered to translators-to-be and members of staff. Initiatives of this nature are exemplary of how beneficial socio-constructivist and situated learning approaches can be when applied to the translation classroom (González-Davies and Enríquez Raído 2016, 2018). Yet, they continue to be relatively scarce in today's educational landscape.

Despite the multiple challenges encountered when teaching and learning AVT in the context of higher education, the reality is that training in this field has developed substantially in recent years, shifting from the margins to the centre and gaining visibility and prominence in the curriculum of numerous translator training programmes around the world. As in other areas of translation specialization, the first pioneering programmes in AVT were at postgraduate level, aimed at undergraduate students with a foreign languages background or prior translation skills.

Nowadays, the teaching of the various AVT modes seems to be well-rooted and established in academic circles, as can be seen in the large number of undergraduate and postgraduate modules currently on offer at European universities and beyond. Quite frequently, entire postgraduate programmes are devoted to the exploration of the manifold audiovisual translation practices carried out in the industry. Mayoral Asensio (2001) is one of the first scholars to have offered detailed information on the AVT courses at undergraduate and postgraduate levels available at universities in Spain, and to a lesser extent in Europe. In this respect, the first AVT-specific courses appeared in Europe in the late 1980s and early 1990s, such as the postgraduate diploma on film translation offered at Lille 3 University (Bréan and Cornu 2014) and the more professionally oriented screen translation course delivered by the University of Wales (James 1998), both now discontinued. Interestingly, undergraduate courses on AVT took generally longer to be incorporated into the curriculum, with the first modules appearing in the mid-1990s.

As for the nature of these courses, there was a tendency in the beginning to design more general, overarching modules on AVT that covered all the various practices, whereas in more recent times the approach is to offer discreet, individual modules focused on each of the various modes, e.g. dubbing, subtitling, or audio description, thus allowing for greater granularity and specialization.

The expansion of AVT tuition in tertiary institutions seems to have coincided with the graduation of the first generation of AVT trainers, whose doctoral theses were read during the 1990s, along with the creation of associations like the already mentioned ESIST in 1995, and the impact of the digital revolution in communication. The design and development of AVTrelated tuition as part of the translator training programmes of numerous universities, both at undergraduate as well as postgraduate levels, have been instrumental in awakening the interest among the academic community and the would-be translators, thus firmly recognizing AVT as an academic discipline and area of study (Gambier and Ramos-Pinto 2016). By way of illustration, there are currently over 15 postgraduate courses in UK universities and more than 12 in Spanish universities that offer specific modules, or study routes and pathways focused on AVT (Bolaños-García-Escribano 2016). This surge in academic provision has subsequently triggered an interest in research concentrating on the didactic dimension of AVT, which often pays attention to a concrete AVT mode or is concerned with a specific country's educational ecosystem.

For many years, as is still the case within certain institutional programmes, AVT has been understood as an ancillary component within the broader field of specialized translation. Its 
teaching is usually conceived in the form of a series of seminars dealing with the translation of film dialogue, in which students are educated on how to shift their attention towards the information being communicated on screen (Nornes 2017). Traditionally, and on account of their close links with film studies, revoicing and subtitling have been almost exclusively centred on the translation of fictional productions and, to a much lesser extent, on the versioning of documentaries or corporate videos (Chaume 2004a). Though the film and entertainment industry may once have been the only career prospects available for trainee audiovisual translators, the situation has changed dramatically in recent years, to the extent that film productions represent only a small percentage of what is being localized nowadays (Esser et al. 2016), and such evolution ought to be reflected too in the curriculum being taught in the classroom.

To adopt a pedagogical approach that takes AVT developments into account, we consider it paramount that students are exposed not only to language-related activities but also to project management tasks that will equip them with some of the professional skills required by the employers and will give trainers an opportunity to draw on the socio-constructivist paradigm as an integral part of their teaching.

One of the key learning outcomes of modules focused on the teaching of AVT is to enable students to gain a sufficient understanding of how the analysis of the various semiotic layers that give shape to audiovisual texts can help them determine their translational approach when transferring the dialogue into other languages and cultures. Emphasis is thus laid on learning how the different meaning codes - i.e. linguistic, paralinguistic, musical and special effects, sound arrangement, iconographic, photographic, planning, mobility, graphic, and editing coalesce in the creation of complex semiotic constructs. Making the most of film analysis, in the form of pre-translation phases that are conducted prior to the actual subtitling or revoicing of a given clip, goes hand in hand with the multimodal discourse analysis advocated by scholars like Taylor $(2003,2004,2016)$ and Kress (2011). As further explained by Chaume (2004b, p. 23):

the relationship between image and word, the interplay of the signification systems of audiovisual texts, shows itself in terms of cohesion and coherence between the two simultaneous narratives, the visual and verbal, in such a way that the translator finds himself/ herself obliged to put into practice translation strategies capable of transmitting not only the information contained in each narrative and each code.

As discussed, traditional AVT lessons used to be conceived from a rather theoretical standpoint, generally consisting of group seminars in which students were taught how to analyze and translate films, as well as become familiar with basic film editing and script writing. The ultimate aim of the majority of courses of this nature was for students to be able to then translate dialogue lines without necessarily adapting the output to the spatio-temporal limitations and constraints of the different AVT modes or resorting to the use of specialist software (Nornes 2017). Rooted in the fundamentals of semiotics and closely related theories, with a clear bias towards comparative linguistics, this initial approach to the didactics of AVT covered little of what was actually being done in the industry but set training institutions on the right track. Research studies published in those early years, focusing on how meaning is constructed in audiovisual texts, helped to set the grounds for linguistic-based approaches that have deeply configured today's AVT research and training landscape. As in other areas of translation, the technological dimension has grown in importance in today's digitized world, with the ready availability of dedicated commercial and free software as well as the swift development of subtitling/revoicing cloud-based platforms and the first initiatives to integrate video within 
translation memory tools to speed up the localization process (Georgakopoulou 2018). To be at the forefront and make sure that they remain socially significant, programmes of study must grant students the opportunity of familiarizing themselves with these dedicated technologies.

In some programmes of study, notably at undergraduate level though not exclusively, AVT is taught as a general module that touches on all the various translation modes, including accessibility. Such an approach can certainly whet students' appetite for the field, but it falls short of equipping them with the comprehensive knowledge and instrumental skills that are needed to operate successfully in the profession. Ideally, we argue that the curriculum ought to contain discreet modules that focus on the various AVT practices, which are usually part of the staple diet of postgraduate programmes centred on AVT. Time permitting, these individual modules may be made up of theoretical core lectures, including profession-oriented topics, and hands-on practical seminars in which students are exposed to translation tasks of increasing linguacultural and technical complexity.

When it comes to the aims and objectives, modules are often designed following an outcomes-based educational approach. Thus, rather than including a list of topics to be covered across the curriculum, a set of expected learning outcomes is highlighted, which in translator training is often determined by societal and/or market needs (Kelly 2008, p. 115). The learning outcomes must be constructively aligned with the module aims and objectives so that students' performance can be satisfactorily monitored and assessed, while the quality of the teaching and learning methods is also upheld. Teaching is therefore conceived as a scaffolding process that aims to increase the students' likelihood of achieving those outcomes by taking part in targeted learning activities.

The aims of an AVT module, regardless of whether it focuses on subtitling or revoicing, ought to be to develop translation skills in a variety of registers and styles, by translating a wide array of audiovisual texts and programmes that epitomize the media world. Through a range of carefully chosen examples and tailored exercises (e.g. analysis of the semiotic relationship between image and text, scriptwriting, working with and without dialogue lists, creating transcripts and templates, producing gist translation, getting familiar with specific software, focusing on spotting and text segmentation, adapting translation for lip-synching, etc.), students will not only develop confidence and skills in the theory and practice of subtitling and revoicing, but will also broaden their awareness about the idiomatic and syntactic features of their working languages as well as their knowledge and handling of humour, wordplay, taboo language, and sociocultural references, for instance.

What follows is a set of potential learning outcomes that we consider should be observed when designing modules on subtitling and revoicing:

- being able to identify and exploit the semiotic relationships established between original soundtrack, images and written text when translating audiovisual programmes;

- gaining an understanding of the linguistic and cultural issues involved in audiovisual translation;

- developing the linguistic and technical skills required for producing a subtitled, dubbed or voiced-over version of an audiovisual programme;

- making informed translation choices based on genre, purpose, and intended audience for subtitling and revoicing commissions;

- being able to apply the appropriate conventions for good subtitling, dubbing and voiceover practice;

- developing specific dubbing and voiceover skills in areas such as lip-synch, phrase-synch and isochrony; 
- developing specific timing, cueing or spotting skills for producing subtitles, using specialist software;

- honing technological skills with the use of software specifically designed for subtitling, dubbing, and voiceover; and

- being familiar with the professional practice, and the resources and links for audiovisual and media translators that are available on the internet.

In the next two sub-sections, we examine the specificities of interlingual subtitling and revoicing and their presence in the translation classroom.

\section{Subtitling}

Subtitling can be defined as the rendition in writing of the translation in a target language of the original dialogue exchanges uttered by the different speakers appearing in an audiovisual programme, as well as of all other verbal information that is transmitted visually (letters, banners, inserts) or aurally (song lyrics, voices off camera). From a linguistic point of view, this practice can be intra-lingual - traditionally aimed at deaf and hard-of-hearing audiences, though not exclusively, and known as captioning in American English - and interlingual.

When compared to other modes, the fact that subtitling is relatively fast and inexpensive to produce makes it the perfect ally of globalization and "the preferred mode of AVT on the world wide web" (Díaz-Cintas 2012, p. 288). In this sense, subtitling can be said to contribute to and go hand in hand with the current processes of internetization, digitalization and audiovisualization of communication (Díaz-Cintas 2015).

In a nutshell, subtitles do not usually contain more than two lines, each of which can accommodate a maximum of some 35 to 42 characters (16 in double-byte languages like Chinese, Japanese, and Korean), and are displayed horizontally at the bottom of the screen. In respecting national and/or company-specific conventions, subtitles appear in synchrony with the dialogue and the image and remain on screen for a minimum of one second (or 20 frames) and a maximum of 6 (or 7) seconds. The assumed reading speed of the target audience dictates the display rate of presentation of the actual subtitles, with 12 to 17 characters per second being standard ratios in Latin, Cyrillic, and Arabic alphabets and four to five in the case of double-byte languages. It is the preferred audiovisual translation mode in Belgium, Croatia, Greece, the Netherlands, Portugal, and the Scandinavian countries, among many others, and it has known an exponential growth in recent years inasmuch as DVDs and today's video-on-demand services make use of an extensive range of multilingual subtitles to reach wide audiences throughout the world.

In standard subtitling practice, it is common for dialogue, narrations, and text on screen to be partly or completely reduced (i.e. condensed or omitted) in order to adhere to the variegated spatial and temporal constraints. This need for condensation and reformulation of the source text is one of its main pedagogical challenges and a substantive number of classroom activities targeting this strategic competence should be designed in the early stages of learning and before moving on to the teaching of the technical aspects, so that students do not lose sight of the importance of the linguistic dimension.

Part of this training can focus on the use and translation of templates, so that students can concentrate on the actual language transfer rather than the technical aspects. These documents contain a list of master subtitles, with the in and out times already spotted, usually in the same language as the audiovisual production, and are widely used in the industry as the starting 
point for the translation of the audiovisual production into as many languages as necessary (Georgakopoulou 2012; Nikolić 2015).

When subtitling, one of the salient technological tasks that students should master is spotting (aka timing, cueing, and origination), which consists of setting the in and out times of each subtitle so that they are synchronized with the audio and the images of the clip, while respecting a series of conventions (Díaz-Cintas and Remael 2007). As a rule of thumb, subtitles start and finish as prompted by the beginning and end of an actor's utterance or by the appearance and disappearance of text on screen; they are self-contained units of meaning; they read naturally and are divided up so that they are syntactically sound; they follow the rhythm of speech and avoid crossing over shot changes. In addition, subtitles need to be configured so as to abide by national and/or company conventions and stylistic norms, including layout, colour, positioning, justification, and display rate.

Of all the various modes within AVT, subtitling is arguably the most demanding in terms of familiarization and dexterity with specialized technology. Acquiring a comprehensive command of both freeware - e.g. Aegisub (www.aegisub.org), Subtitle Edit (www.nikse. $\mathrm{dk} /$ subtitleedit), Subtitle Workshop (http://subworkshop.sourceforge.net) - and commercial programmes - e.g. EZTitles (www.eztitles.com), Spot (www.spotsoftware.nl), Wincaps Q4 (https://subtitling.com/products/subtitle-create/create/wincaps-q4-subtitling-software) - is a quintessential prerequisite of any subtitling course, and working with more than just one programme will also allow students to be prepared for the real workplace, where companies often operate with different subtitling software packages. These days, knowledge of dedicated cloud-based platforms - e.g. Ooona (https://ooona.ooonatools.tv), SubtitleNEXT (https://subtitlenext.com), ZOO (www.zoodigital.com) - is also becoming pivotal and a wise addition to any training programme geared to prepared professionals for the future rather than the present (Bolaños-García-Escribano 2018). Likewise, with machine translation making inroads in the subtitling arena, the figure of the post-editor is becoming a new reality in the industry (Georgakopoulou and Bywood 2014) and students should be given the opportunity to learn about these developments in the classroom.

\section{Revoicing}

As already discussed, two of the main interlingual practices within revoicing are voiceover and lip-sync dubbing. Voiceover consists in orally presenting the translation of the source text speech over the still audible original voice, usually allowing the speaker to be heard for a few seconds in the foreign language, after which the volume of the soundtrack is lowered, so that the original speech can still be heard in the background and the translation in the target language is then overlaid (Díaz-Cintas and Orero 2010). The translation typically concludes whilst the speaker continues talking for a few more seconds, so that the audience can hear the foreign language once more. As for its geographical spread and commercial usage:

apart from most East European countries, where voice-over translation is applied to all genres, voice-over in West European, North and Latin American countries has usually been applied to the translation of programmes that belong to the so-called factual genre be it represented by the news, documentaries, talk shows, political debates, etc.

(Franco et al. 2010, pp. 24-25)

Dubbing, also known as lip-sync and famously referred to as traduction totale by Cary (1960) because of its many challenges, implies the substitution of the dialogue track of an audiovisual 
production with another track containing the new lines in the target language. It is widely used for the localization of fictional programmes in countries like Brazil, China, France, Germany, Italy, Japan, Spain, Thailand, and Turkey, among many others, as well as for the translation of children's productions in most countries in the world. From a financial perspective, dubbing is much more expensive than voiceover or subtitling as it requires the participation of numerous stakeholders (translators, dialogue writers, sound engineers, dubbing directors, and actors) and the use of dedicated dubbing studios.

The standard dubbing process starts with a client commissioning a project from a language service provider (LSP) or dubbing company, which then outsources the translation to a (freelance) translator. Once the translated script has been delivered, the dialogue writer adapts it to the images and adds a set of symbols for synchronizing the dialogue and the visuals and thus eases the task of the dubbing actors. This is followed by a division of the dialogue into takes or loops, as discussed next, which is then used by the dubbing director when recording the new soundtrack in the target language with the assistance of a group of voice talents. The final stage is carried out by the sound engineer, responsible for reassembling and editing the original and translated soundtracks, before delivering the new translated programme to the client.

To make viewers believe that the characters on screen share the same language as themselves, three types of synchronization need to be respected: (1) lip synchrony, to ensure that the translated sounds fit into the mouth of the on-screen characters, particularly when they are shown in close-up; (2) isochrony, to guarantee that the duration of the source and the target utterances coincide in length, especially when the characters' lip movements can be seen; and (3) kinetic synchrony, to assure that the translated dialogue does not contradict the thespian performance of the actors, and that the voices chosen for the new recording are not at odds with the personal attributes and the physical appearance of the on-screen characters.

In dubbing, translations are divided into chunks of text known as takes or loops, whose length and layout vary depending on national conventions (Chaume 2012), and which include the dialogue lines that dubbing talents use for their acting. The impact that the various synchronies mentioned earlier have on the translation materializes in the use of dubbing symbols throughout the new script, which "help dubbing actors imitate the screen actors' paralinguistic signs: sounds, pitch, tone, volume, primary voice qualities, etc." (Chaume 2012, p. 58). These symbols, again, differ from one country to another, so lessons should ideally be languageoriented and taught by tutors who have sufficient professional experience and skills in the practice of dubbing in language-bound markets.

In educational settings, where it is very common to teach both voiceover and dubbing as part of one and the same module, the trend is to start with activities in voiceover and then progress to more challenging tasks focused on dubbing. As for the content to be covered, the actual language transfer is just one of the multiple steps in the whole process of dubbing of an audiovisual programme and, as argued by Chaume (2013b), tutors involved in the teaching of a module of this nature should also incorporate activities that hone students' skills on areas such as dialogue writing, lip synchronization, take segmentation, symbols annotating, and even acting. Yet, training on revoicing, and particularly on dubbing, is often limited to translation and dialogue writing, with special emphasis on language- and synchrony-related challenges.

As debated by Baños and Chaume (2009), avoiding stilted expressions and achieving a translation that sounds natural when delivered orally is of utmost importance in the case of revoicing. To be successful in this field requires a thorough understanding of the defining characteristics of spontaneous and scripted discourse as well as of the differences that set apart written language from speech and their diegetic role in audiovisual texts. In the words 
of Bartrina and Espasa-Borrás (2005, p. 87, original emphasis), students have to be able to appreciate "the paradoxical 'ordeal' of having to (re)create realistic, credible oral texts, even though the source texts are written, as is the translation which is handed to the client". To be able to produce credible dialogue lines by echoing the characteristics of spontaneous oral register, students ought to be exposed to activities that require the sensible exploitation of the flexibility of syntax, the expressiveness of colloquial language, the potential of word derivation, and the significance of features like style and rhythm. To achieve this, students can write their translations down to then read them aloud, or record themselves with audio and video editing software, to make sure that their sentences and expressions flow naturally, match the acting on screen, and can fit in the mouth of the characters.

In contrast to the far-reaching technical developments witnessed in the field of subtitling, revoicing practices like dubbing and voiceover seem to have been bypassed by the latest technology (Baños 2018), both in the profession and the educational centres. In the industry, translators are not usually required to work with dedicated software and they can fulfil their tasks by using a simple text editor and a video player to watch the programmes. It is later, in the recording studio, where dubbing directors and sound engineers make use of specialist applications. As an exception to this rule, and in countries like France, translators who also take care of lip-synching are frequently asked to insert their translation in a track known as bande rythmo, which is added onto the working copy of the audiovisual production, at the bottom of the screen, and includes the target dialogue as well as the necessary symbols for the dubbing actors (Chaume 2012). To keep up with the current increase in the volume of dubbing and voiceover in the market, for young and adult audiences, as well as the technical advances in speech recognition (Green 2018), training in this area should expose students to new technologies like the freeware programme Capella (www.cappella.tv) and the professional one VoiceQ (https://voiceq.com), which allow translators and those in charge of the synchronization of the target dialogue to create the bande rythmo for the benefit of the voice talents.

Cloud-based systems focused onrevoicingarealsoemerging-e.g.ZOOdubs(www.zoodigital. com/services/localize/dubbing), Ooona (http://ooona.net/dubbing-manager), STVHub (http:// stvhub.com) - and translation trainees should become familiar with the potential of these platforms to centralize, accelerate and globalize the dubbing process, as they allow for tasks like scripting, auditioning of future voice talents, casting, recording, editing, and mixing to be conducted online, as opposed to the traditional approach of performing these activities locally, in soundproof recording studios. As previously mentioned, a pedagogical approach that takes these developments into account and exposes students to the latest advancements in the AVT industry, including common tasks and workflows, is essential if students are to gain the professional skills necessary to be more employable.

\section{Conclusions and future directions}

As opposed to the idée reçue that translation programmes of study are saturating the labour market with graduates (Pym 2012), prospective careers in AVT seem to look brighter than ever. The exponential growth of programmes distributed in audiovisual format across the globe has led to a surge in the demand for highly experienced and well-trained localizers in such a fast-growing industry (Estopace 2017). To train the professionals of the future, forwardlooking modules need to be designed and developed now, taking into account the linguacultural dimension as well as the technological possibilities and the market reality.

Translators-to-be will need to be able to adapt to an industry in continual development, to an ecosystem on which new technologies such as machine translation, speech recognition, and 
artificial intelligence are already having an impact. In this sense, careers in language engineering, text and subtitle post-editing, live respeaking, microtasking, transcreation, and video editing are expected to grow exponentially in the upcoming years, thus demanding a set of add-on skills that higher education institutions will have to include in their existing curricula in order to boost graduates' employability. Training centres will need to re-examine and modify curricula and programmes of study - as much as AVT trainers may need to adjust the syllabi - so as to not lag behind technical advancements and to be able to cater for the new needs of the industry. Yet, a balance will have to be found to nurture also the linguistic and creative aspects involved in the localization of audiovisual material.

At a time when leading market players lament the fact that qualified translators are in short supply (Bond 2018) and bodies like MESA's (2016) Content Localization Council set as one of their top aims to expand the talent pool in audiovisual translation, closer synergies must be established between educational centres and the industry to safeguard the well-being of the profession. Strengthening partnerships with LSP stakeholders and software developers can be instrumental not only in equipping universities with the right workstations, dedicated software and access to the latest cloud-based portals, but also in securing work placements, on-site visits and, ultimately, professional careers in the AVT world. The exploitation of situated learning experiences that showcase cutting-edge technologies is therefore of utmost importance as it contributes to boosting students' employability and resilience in a mercurial industry heavily driven by technological changes.

\section{Further reading}

Chaume, F. (2012) Audiovisual Translation: Dubbing. Manchester: St. Jerome Publishing.

This textbook offers theoretical and practical training in lip-sync dubbing. It is the most comprehensive textbook so far on the specificities of dubbing translation.

Díaz-Cintas, J. (ed) (2008) The Didactics of Audiovisual Translation. Amsterdam: John Benjamins.

This collective book offers a balance between theory and practice and is the first one to have been published on audiovisual translation training. It provides a wealth of teaching and learning ideas in the various AVT modes.

Díaz-Cintas, J. and Remael, A. (2007) Audiovisual Translation: Subtitling. Manchester: St. Jerome Publishing.

This textbook provides a solid overview of the world of subtitling. While focusing on generally accepted practice it also identifies current points of contention, takes regional variants into consideration, and traces new developments in the evolution of the profession.

Pérez-González, L. (2014) Audiovisual Translation: Theories, Methods and Issues. London: Routledge. This textbook discusses some of the methodological challenges raised by the multimodality of audiovisual texts and proposes a variety of theoretical frameworks to investigate this emerging text type.

\section{Related topics}

screen translation, multimedia translation, media accessibility, localization, translation technology, audiovisual reception, semiotics

\section{References}

Baños, R. (2018) Technology and audiovisual translation, in Chan, S-W. (ed) An Encyclopaedia of Practical Translation and Interpreting. Hong Kong: Chinese University Press. pp. 15-41. 
Baños, R. and Chaume, F. (2009) Prefabricated orality: A challenge in audiovisual translation. inTRAlinea. Special Issue on The Translation of Dialects in Multimedia. pp. 1-10. Available from: www. intralinea.org/specials/article/1714 [Accessed 15 April 2019].

Bartrina, F. (2009) Teaching subtitling in a virtual environment, in Díaz-Cintas, J. and Anderman, G. (eds) Audiovisual Translation: Language Transfer on Screen. Basingstoke: Palgrave Macmillan. pp. 229-239.

Bartrina, F. and Espasa-Borrás, E. (2005) Audiovisual translation, in Tennent, M. (ed) Training for the New Millennium: Pedagogies for Translation and Interpreting. Amsterdam: John Benjamins. pp. 83-100.

Bassnett, S. (1980/2002) Translation Studies. London: Routledge.

Beuchert, K. (2017) The Web of Subtitling: A Subtitling Process Model Based on a Mixed Methods Study of the Danish Subtitling Industry and the Subtitling Processes of Five Danish Subtitlers. PhD thesis, University of Aarhus, Aarhus.

Biggs, J. and Tang, C. (2011) Teaching for Quality Learning at University: What the Student Does. Maidenhead: SRHE and Open University Press.

Bolaños-García-Escribano, A. (2016) The Pedagogical Potential of Cloud-Based Platforms: Towards an Integrated Model for the Didactics of Subtitling in Translator Training Environments. MSc dissertation, University College London, London.

Bolaños-García-Escribano, A. (2018) The pedagogical potential of cloud-based platforms: A study on the didactics of subtitling in online translator training environments, in Sanderson, J.D. and BotellaTejera, C. (eds) Focusing on Audiovisual Translation Research. Valencia: University of Valencia. pp. 63-94.

Bond, E. (2018) SDI Media CEO Mark Howorth on how streaming services reset the bar in media localization. Slator, Language Industry Intelligence. 24 September. Available from: https://slator. $\mathrm{com} /$ features/sdi-media-ceo-mark-howorth-on-how-streaming-services-reset-the-bar-in-medialocalization [Accessed 15 April 2019].

Bréan, S. and Cornu, J-F. (2014) Les débuts du DESS/Master de Traduction Cinématographique et Audiovisuelle de l'Université de Lille 3 - Entretien avec Daniel Becquemont. L'Écran traduit. 3, pp. 23-44.

Cary, E. (1960) La traduction totale: cinema. Babel. 6(3), pp. 110-115.

Chaume, F. (2003) Teaching a course on audiovisual translation (dubbing and subtitling): Some didactic proposals, in Pérez-González, L. (ed) Speaking in Tongues: Language Across Contexts and Users. Valencia: University of Valencia. pp. 271-302.

Chaume, F. (2004a) Cine y traducción. Madrid: Cátedra.

Chaume, F. (2004b) Film studies and translation studies: Two disciplines at stake in audiovisual translation. Meta. 49(1), pp. 12-24.

Chaume, F. (2006) Dubbing, in Brown, K. (ed) Encyclopedia of Language and Linguistics. Amsterdam: ScienceDirect. pp. 6-9.

Chaume, F. (2012) Audiovisual Translation: Dubbing. Manchester: St. Jerome Publishing.

Chaume, F. (2013a) The turn of audiovisual translation: New audiences and new technologies. Translation Spaces. 2, pp. 105-123.

Chaume, F. (2013b) Panorámica de la investigación en traducción para el doblaje. Trans. 17, pp. 13-34.

Cerezo-Merchán, B. (2012) La didáctica de la traducción audiovisual en España: Un estudio de caso empírico-descriptivo. $\mathrm{PhD}$ thesis, Jaume I University, Castellón.

Cerezo-Merchán, B. (2018) Audiovisual translator training, in Pérez-González, L. (ed) The Routledge Handbook of Audiovisual Translation. London: Routledge. pp. 468-482.

Delabastita, D. (1989) Translation and mass-communication: Film and TV translation as evidence of cultural dynamics. Babel. 35(4), pp. 193-218.

Díaz-Cintas, J. (1997) El subtitulado en tanto que modalidad de traducción fímilca dentro del marco teórico de los Estudios sobre Traducción (Misterioso asesinato en Manhattan, Woody Allen, 1993). $\mathrm{PhD}$ thesis, University of Valencia, Valencia.

Díaz-Cintas, J. (ed) (2008) The Didactics of Audiovisual Translation. Amsterdam: John Benjamins. 
Díaz-Cintas, J. (2009) Introduction - Audiovisual translation: An overview of its potential, in DíazCintas, J. (ed) New Trends in Audiovisual Translation. Bristol: Multilingual Matters. pp. 1-18.

Díaz-Cintas, J. (2012) Clearing the smoke to see the screen: Ideological manipulation in audiovisual translation. Meta. 57(2), pp. 279-293.

Díaz-Cintas, J. (2015) Technological strides in subtitling, in Chan, S-W. (ed) The Routledge Encyclopedia of Translation Technology. London: Routledge. pp. 632-643.

Díaz-Cintas, J. and Neves, J. (2015) Audiovisual translation: Taking stock, in Díaz-Cintas, J. and Neves, J. (eds) Audiovisual Translation: Taking Stock. Newcastle upon Tyne: Cambridge Scholars Publishing. pp. 1-7.

Díaz-Cintas, J. and Orero, P. (2003) Postgraduate courses in audiovisual translation. The Translator. 9(2), pp. 371-388.

Díaz-Cintas, J. and Orero, P. (2010) Voiceover and dubbing, in Gambier, Y. and van Doorslaer, L. (eds) Handbook of Translation Studies. Vol. 1. Amsterdam: John Benjamins. pp. 441-445.

Díaz-Cintas, J. and Remael, A. (2007) Audiovisual Translation: Subtitling. Manchester: St. Jerome Publishing.

Dorado, C. and Orero, P. (2007) Teaching audiovisual translation online: A partial achievement. Perspectives. 15(3), pp. 191-202.

Englund-Dimitrova, B. (2002) Training and educating the trainers: A key Issue in translators' training, in Hung, E. (ed) Teaching Translation and Interpreting 4: Building Bridges. Amsterdam: John Benjamins. pp. 73-82.

Esser, A., Smith, I.R. and Bernal-Merino, M.Á. (eds) (2016) Media Across Borders: Localising TV, Film and Video Games. New York: Routledge.

Estopace, E. (2017) Audiovisual translation hits a sweet spot as subscription video-on-demand skyrockets. Slator, Language Industry Intelligence. 23 November. Available from: https://slator.com /features/audiovisual-translation-hits-sweet-spot-subscription-video-on-demand-skyrockets [Accessed 15 April 2019].

Franco, E., Matamala, A. and Orero, P. (2010) Voice-Over Translation: An Overview. Bern: Peter Lang.

Gambier, Y. and Ramos-Pinto, S. (2016) Introduction. Target. 28(2), pp. 185-191.

Georgakopoulou, P. (2012) Challenges for the audiovisual industry in the digital age: The ever-changing needs of subtitling production. The Journal of Specialised Translation. 17, pp. 78-103.

Georgakopoulou, P. (2018) Technologization of audiovisual translation, in Pérez-González, L. (ed) The Routledge Handbook of Audiovisual Translation. London: Routledge. pp. 516-539.

Georgakopoulou, P. and Bywood, L. (2014) Machine translation in subtitling and the rising profile of the post-editor. MultiLingual. January/February, pp. 24-28.

González-Davies, M. and Enríquez Raído, V. (2016) Situated learning in translator and interpreter training: Bridging research and good practice. The Interpreter and Translator Trainer. 10(1), pp. 1-11.

González-Davies, M. and Enríquez-Raído, V. (eds) (2018) Situated Learning in Translator and Interpreter Training: Bridging Research and Good Practice. London: Routledge.

Green, S. (2018) How digital demand is disrupting dubbing. M\&E Journal. March. Available from: www. mesalliance.org/2018/03/15/journal-digital-demand-disrupting-dubbing [Accessed 15 April 2019].

Hurtado-Albir, A. (2001) Traducción y Traductología: Introducción a la Traductología. Madrid: Cátedra.

Hurtado-Albir, A. (2007) Competence-based curriculum design for training translators. Interpreter and Translator Trainer. 1(2), pp. 163-195.

Hurtado-Albir, A. (2015) The acquisition of translation competence. Competences, tasks, and assessment in translator training. Meta. 60(2), pp. 256-280.

Hvelplund, K.T. (2018) Eye tracking and the process of dubbing translation, in Díaz-Cintas, J. and Nikolić, K. (eds) Fast-Forwarding with Audiovisual Translation. Bristol: Multilingual Matters. pp. 110-124.

Ivarsson, J. and Carroll, M. (1998) Subtitling. Simrishamn: TransEdit.

James, H. (1998) Screen translation training and European cooperation, in Gambier, Y. (ed) Translating for the Media. Turku: University of Turku. pp. 243-258.

Karamitroglou, F. (1998) A proposed set of subtitling standards in Europe. Translation Journal. 2(2). Available from: https://translationjournal.net/journal/04stndrd.htm [Accessed 19 May 2019]. 
Kelly, D. (2005) A Handbook for Translator Trainers: A Guide to Reflective Practice. London: Routledge.

Kelly, D. (2008) Training the trainers: Towards a description of translator trainer competence and training needs analysis. TTR. 21(1), pp. 99-125.

Kress, G. (2011) Multimodal discourse analysis, in Gee, J.P. and Handford, M. (eds) The Routledge Handbook of Discourse Analysis. London: Routledge. pp. 35-50.

Laks, S. (1957) Le Sous-titrage de films: Sa technique, son esthétique. Paris: Livre d'auteur. Available from: https://beta.ataa.fr/documents/ET-HS01-complet.pdf [Accessed 19 May 2019].

Luyken, G-M., Herbst, T., Langham-Brown, J., Reid, H. and Spinhof, H. (1991) Overcoming Language Barriers in Television: Dubbing and Subtitling for the European Audience. Manchester: European Institute for the Media.

Machado, J. (1996) La Traduction au cinéma et le processus de sous-titrage de films. $\mathrm{PhD}$ thesis, Université Sorbonne Nouvelle, Paris.

Martínez Sierra, J.J. (ed) (2012) Fotografía de la investigación doctoral en traducción audiovisual. Madrid: Bohodón.

Martínez Sierra, J.J. (ed) (2017) Fotografía de la investigación doctoral en traducción audiovisual. Vol. 2. Madrid: Bohodón.

Massey, G. and Jud, P. (2015) Teaching audiovisual translation with products and processes: Subtitling as a case in point, in Bogucki, Ł. and Deckert, M. (eds) Accessing Audiovisual Translation. Frankfurt am Main: Peter Lang. pp. 99-116.

Mayoral Asensio, R. (2001) Campos de estudio y trabajo en traducción audiovisual, in Duro, M. (ed) $L a$ traducción para el doblaje y la subtitulación. Madrid: Cátedra. pp. 19-45.

Mayoral Asensio, R., Kelly, D. and Gallardo San Salvador, N. (1988) Concept of constrained translation. Non-linguistic perspectives of translation. Meta. 33(3), pp. 356-367.

McLoughlin, L., Biscio, M. and Ní-Mhainnín, M.A. (eds) (2011) Audiovisual Translation: Subtitles and Subtitling. Theory and Practice. Oxford: Peter Lang.

MESA. (2016) MESA Europe launches content localisation council. Media \& Entertainment Services Alliance. 12 April. Available from: www.mesaeurope.org/mesa-europe-launches-content-localisationcouncil [Accessed 15 April 2019].

MESA News. (2017) Study: EMEA content localization service spending hits $\$ 2$ billion. Media \& Entertainment Services Alliance. 27 June. www.mesalliance.org/2017/06/27/study-emea-contentlocalization-service-spending-hits-2-billion [Accessed 15 April 2019].

Nikolić, K. (2015) The pros and cons of using templates in subtitling, in Baños, R. and Díaz-Cintas, J. (eds) Audiovisual Translation in a Global Context. Mapping and Ever-Changing Landscape. Basingstoke: Palgrave Macmillan. pp. 192-202.

Nornes, M. (2017) Teaching audiovisual translation, in Venuti, L. (ed) Teaching Translation: Programs, Courses, Pedagogies. London: Routledge. pp. 102-109.

Ofcom. (2017) Code on Television Access Services. Available from: www.ofcom.org.uk/_data/assets/ pdf_file/0020/97040/Access-service-code-Jan-2017.pdf [Accessed 15 April 2019].

PACTE. (2003) Building a translation competence model, in Alves, F. (ed) Triangulating Translation: Perspectives in Process Oriented Research. Amsterdam: John Benjamins. pp. 43-66.

PACTE. (2005) Investigating translation competence: Conceptual and methodological Issues. Meta. 50(2), pp. 609-619.

Pérez-González, L. (2014) Audiovisual Translation: Theories, Methods and Issues. London: Routledge. Pérez-González, L. (ed) (2018) The Routledge Handbook of Audiovisual Translation. London: Routledge. Pommier, C. (1998) Doublage et postsynchronisation: Cinéma et vidéo. Paris: Dujarric.

Pym, A. (2012) Training translators, in Malmkjær, K. and Windle, K. (eds) The Oxford Handbook of Translation Studies. Oxford: Oxford University Press.

Reuters. (2015) YouTube introduces new translation tools to globalise content. ET Brand Equity. 21 November. Available from: https://brandequity.economictimes.indiatimes.com/news/digital/youtubeintroduces-new-translation-tools-to-globalize-content/49860574 [Accessed 15 April 2019].

Roales-Ruiz, A. (2014) Estudio crítico de los programas de subtitulación profesionales. Carencias en su aplicación para la didáctica. Propuesta de solución mediante conjunto de aplicaciones integradas. $\mathrm{PhD}$ thesis, University of Salamanca, Salamanca. 
Romero-Fresco, P. (2011) Subtitling Through Speech Recognition: Respeaking. Manchester: St. Jerome Publishing.

Schäffner, C. and Adab, B. (2000) Developing Translation Competence. Amsterdam: John Benjamins.

Shetty, A. (2016) VAST 4.0 arrives, championing the technology behind the growth of digital video advertising. Iab. 21 January. Available from: www.iab.com/news/vast-4-0-arrives-championing-thetechnology-behind-the-growth-of-digital-video-advertising [Accessed 15 April 2019].

Snell-Hornby, M. (1988/1995) Translation Studies. An Integrated Approach. Amsterdam: John Benjamins.

Talaván-Zanón, N. (2013) La subtitulación en el aprendizaje de lenguas extranjeras. Barcelona: Octaedro.

Taylor, C. (2003) Multimodal transcription in the analysis, translation and subtitling of Italian films. The Translator. 9(2), pp. 191-205.

Taylor, C. (2004) Multimodal text analysis and subtitling, in Ventola, E., Charles, C. and Kaltenbacher, M. (eds) Perspectives on Multimodality. Amsterdam: John Benjamins. pp. 153-172.

Taylor, C. (2009) Pedagogical tools for the training of subtitlers, in Díaz-Cintas, J. and Anderman, G. (eds) Audiovisual Translation: Language Transfer on Screen. Basingstoke: Palgrave Macmillan. pp. 214-228.

Taylor, C. (2016) The multimodal approach in audiovisual translation. Target. 28(2), pp. 222-236.

Titford, C.G. (1982) Subtitling. Constrained translation. Lebende Sprachen. 27(3), pp. 113-116.

Tomaszkiewicz, T. (1993) Les Opérations linguistiques qui sous-tendent le processus de sous-titrage des films. Poznan: Adam Mickiewicz University.

Zabalbeascoa, P. (1993) Developing Translation Studies to Better Account for Audiovisual Texts and Other New Forms of Text Production with Special Attention to the TV3 Version of Yes, Minister. PhD thesis, University of Lleida, Lleida.

Zabalbeascoa, P., Santamaria, L. and Chaume, F. (eds) (2005) La traducción audiovisual: investigación, enseñanza y profesión. Granada: Comares. 


\title{
Interpreting studies
}

\author{
Ludmila Stern and Xin Liu
}

\section{Introduction}

Interpreting, or 'oral translation', is an oral transfer of meaning of spoken or signed language. It is an ancient practice that enables communication between speakers of different languages. Interpreting takes place in different settings, both international (conferences, diplomatic, and business negotiations) and domestic (immigration, legal, health, and welfare). Historically, there has been a prevailing perception among interpretation users and even interpreters, that the only requirement to become an interpreter is to be bilingual, and that no training is required (Hale 2011a).

These perceptions began to change in the 20th century. Following short on-the-job training of interpreters in the League of Nations (Wilss 1999, p. 33; Pöchhacker 2004, p. 28) and at the Nuremberg-based International Military Tribunal (Gaiba 1998), the growing post-WWII international market in Europe and the US began to realize that formal education is a pathway to interpreters' professional competence. This realization was also motivated by new demands placed on interpreters, such as skills in the simultaneous interpreting mode (SI) (Moser-Mercer 2015, p. 304). The recognition of interpreting as a profession was advocated by interpreters themselves through the International Association of Conference Interpreters (AIIC, founded in 1953), including a requirement for tertiary-level professional education and training. The first universities and professionally oriented interpreting schools (les grandes écoles) provided courses that prepared interpreters for international business and conference settings in a limited number of European language combinations, courses in which L2 and L3 were often acquired during undergraduate education. The rise of multiculturalism, from the 1970 s onwards, led to the introduction of training in the languages of migrant communities in multicultural Europe, US, Canada, Australia, and New Zealand. However, tertiary training for community interpreting (public service interpreting, PSI) remained slow and limited. As with conference interpreting, community interpreting training has been premised on the needs of the market and society, including professional skills-set and knowledge in the training. The industry needs also determined the choice of language combinations.

Worldwide mass migration and asylum seeking in the 1990s-2010s led to 'superdiverse' societies with a multitude of new communities (Vertovec 2010), and has created a need for 
interpreter training in new settings and in an unprecedented diversity of language combinations. These new needs and practical limitations are still defining the framework of how interpreters are educated and trained, combining different pedagogical philosophies, curriculum models, and modes of delivery as well as types of assessment (Moser-Mercer 2015, p. 304). Such needs have opened new research directions, including interpreter training. This chapter focuses on interpreter training in higher education. It outlines the historical aspects of this domain of research and practice, it examines current studies and pedagogical practices, and points to future directions.

\section{Historical perspectives}

\section{The origins of interpreter education}

Historically, tertiary-level training of interpreters that originated in Europe in the 1940s was motivated by international commercial and conference needs. The first interpreting programmes were founded in university settings: the Mannheim college for business translators/interpreters (1930), which was later transferred to the University of Heidelberg (Pöchhacker 2004, p. 28); the programmes at the Universities of Geneva and Vienna, the Moscow State Pedagogical Institute of Foreign Languages (1942), the Universities of Graz and Innsbruck (1946), of Mainz/ Germersheim (1947) and Saarbrücken (1948). The recognition of interpreting as a profession was associated with the creation of post-WWII international institutions such as the UN. And the 1950s growing international and multilingual contacts and the European unification was a motivating factor (Pym 2011, p. 477) for the creation of other tertiary institutions for conferences interpreter training, a trend that continued globally in the US and Asia (Pöchhacker 2011a). Professionalization and tertiary education in conference interpreting was strongly advocated by the conference interpreters' professional association, AIIC, created in 1953. Because of their professional orientation, interpreting departments tended to distinguish themselves from the classical university model and often described themselves as Schools (Ecole supérieure, Institut supérieur): the Division of Translation and Interpretation at Georgetown University (1949), Scuola Superiore di Lingue Moderne per Interpreti et Traduttori at the University of Trieste (1954), the Graduate School of Translation and Interpretation at Monterey Institute of International Studies (1969), École supérieure d'interprétation et de traduction (ESIT 1957), and the Institut Supérieur d'Interprétation et de Traduction (ISIT 1957) in Paris.

\section{Early approaches to interpreter education}

\section{Formal training of interpreters for international settings}

These interpreter training departments and schools from the start distinguished themselves from conventional language departments (Sawyer 2015, p. 97), while undergraduate interpreter training was closely linked to L2 and L3 acquisition (Pöchhacker 2011a, pp. 312-313) as part of a five-year long curriculum (Heidelberg University, Moscow State Pedagogical Institute of Foreign Languages). The masters programmes expected students to develop language skills independently and generally shared their professionally oriented approaches to the curriculum, student admission, and training (Stern 2011). Influenced by AIIC, both undergraduate and graduate programmes built their curricula on the international industry needs and expectations, and trained interpreters in consecutive interpreting (CI) with note taking and simultaneous interpreting (SI) in booths into their L1 - referred to as Language A. 


\section{Admission requirements and language proficiency}

Admission to conference interpreter training programmes included rigorous procedures which included an aptitude test to assess the applicants' suitability for training. To be admitted to a masters conference interpreting programme (e.g. ESIT), applicants were required to have a native and near-native bilingual or trilingual proficiency in an 'established' European language, namely in their native L1 (Language A) as well as other working languages L2 and L3 (near-native active Language B and passive Languages C/D). General knowledge, analytical skills, and transfer skills were counted among the other aptitudes that supposedly pre-disposed applicants for training as conference interpreters.

\section{Curriculum, pedagogy, and educators}

Curriculum, course content, and teaching approaches in these earlier days of interpreter training were mostly designed by practitioners - experienced conference interpreters (Pöchhacker 2011a) who analyzed their own practice as interpreters to lay the foundations of practical training and developed the methodology of teaching using authentic materials. Training content included skills and modes used in conference interpreting practice: CI with note-taking; the acquisition of additional knowledge (Herbert 1952); SI with equipment in booths, without equipment (chuchotage), and from written texts (sight translation/interpreting). The foundations of note-taking in CI were laid by Rozan based on his professional experience (Rozan 1956).

Approaches to delivering this form of training were mostly intuitive, 'pre-scientific' (Gile 1994, p. 149), and holistic, based on apprenticeship whereby a student would learn by imitating the master (Pöchhacker 2004, p. 177, 2011a, p. 313) by means of demonstration followed by attempts at successive approximation of the modelled behaviour (Shaw et al. 2006, p. 3). Danica Seleskovitch and Marianne Lederer, ESIT educators and founders of the influential théorie $d u$ sens and déverbalisation, presupposed that suitably selected students with a full mastery of their working languages (Gile 2001, p. 381) would automatically know how to reformulate and transfer meaning across languages (Gile 1994, p. 150). Later, this approach met with criticism as being unscientific, arbitrary in the selection of training methods, and prescriptive (Stern 2011, p. 493).

Students' progress and outcomes were traditionally assessed both through continuous assessment to evaluate progress (for example, in the CI with note-taking preceding the progression to SI), and the final (for example, in SI), with interpreting quality criteria including the accuracy of interlingual transfer (sense consistency), fluency of delivery, voice quality, and stress resistance. The final assessment focused on the output and the graduates' suitability to work "immediately and reliably on the market" (Sawyer 2004, p. 56) - an approach that remains current.

\section{Evolution of evidence-based approach}

In the 1980s, the development of interpreting studies research led to calls for a research-based approach to training, based on scientific data and verification of teaching methods. As interpreter education began the process of academization, leading to pedagogical research (Pöchhacker 2011a), departments such as Geneva-based ETI conducted interdisciplinary research into the interpreting process, involving natural/cognitive sciences such as psychology, neuropsychology, and neurolinguistics, often using experimental research methods to inform 
teaching methods (Stern 2011). Empirical research conducted from the 1990s further focused on the learning process (Gile 1995), leading to the understanding that interpreting expertise needs to be developed gradually, through the identification of the necessary skills and subskills, rather than by training holistically (Dodds et al. 1997, p. 93). Empirical research has led "to the introduction of evidence-based teaching methods, skills teaching, and scientifically validated methods of assessment and admission to training programs" (Stern 2011, p. 493) and resulted in the development of a more process-oriented approach. This entails step-by-step progressive building of interpreting skills, with the focus not only on the quality of the markettested product, but also on the cognitive aspects of the interpreting process (e.g. memory, perception, recall, and dual tasking in SI) (Stern 2011, p. 493).

\section{The introduction of community interpreting (public service interpreting) training}

Originally, training in community interpreting was offered in vocational colleges and in short format (Stern and Liu 2019a) - a practice that remains current. Formal training in community interpreting, introduced by some universities from the $1970 \mathrm{~s}-80 \mathrm{~s}$, mostly in Northern Europe, Australia, New Zealand, the US, and Canada, was in sign and migrant languages, and approaches to interpreter training in spoken languages largely followed those in sign language (Napier 2010). Unlike conference interpreting courses, those in community interpreting prepared interpreters for domestic settings where migrants and refugees interacted with host country professionals - service providers in immigration, welfare, police, courts, and healthcare. Training courses focused on bi-directional dialogue interpreting (short consecutive) and interpreters' professional ethics (Stern 2011). Prior to the creation of community interpreting courses, the languages of migrant communities, with some exceptions such as Spanish, Russian, Chinese, and Arabic, had not been offered in conference interpreting programmes and taught formally. Applicants were mostly native speakers of migrant languages with the language of their host country being their L2. They were trained to interpret bi-directionally. Research that arose in these departments focused on the interactive aspect of community interpreting, using the methods of discourse analysis and ethnographic methods to examine the ways in which interpreters interact in different settings (Mason 2015, pp. 111-116). Unlike in conference interpreting training, where a degree certifying the completion of the programme paved the way into the profession, industry accreditation/certification had been a requirement and a seal of professionalism at the completion of some community interpreting programmes (e.g. NAATI in Australia; legal interpreting accreditation in Spain and USA).

\section{Research approaches and key findings}

As discussed earlier, interpreter training in the early days was intuitive and practice-oriented; trainee interpreters mostly learned from the hands-on experience of their trainers. Formal training methodology or interpreting pedagogy based on scientific research only started from the late 1980s due to the rapid growth of training programmes in higher education institutes worldwide (Stern 2011). The increased number of research studies on interpreter education, together with those on translator education, have stimulated the publication of academic journals with a clear focus on training. The Interpreter and Translator Trainer (ITT) and the International Journal of Interpreter Education (IJIE) have contributed to making interpreter and translator training a distinct field of research in interpreting studies. Thus far, pedagogyoriented interpreting research has covered a wide spectrum of areas, from curriculum studies 
at the macro level to the prosodic aspects of languages at the micro level. This section reviews the recent major research approaches and key findings in interpreter education, focusing on three aspects; namely learner factors, institutional practices (programmes, models, and curricula), and teaching and learning activities (class content, methods, and assessment).

\section{Research approaches}

Research approaches in the field of interpreter education draw on those adopted in social sciences, humanities, and education. Historically, interpreter education-related studies, similar to interpreting studies in general, have typically been based on trainers' intuition and personal experience, and are descriptive in nature (Hale and Napier 2013, p. 175). In recent years, there has been a shift from descriptive studies to evidence-based research (Liu 2011). As a branch of interpreting studies, interpreter education research largely echoes this trend.

In general, studies on T\&I training can be classified into empirical and non-empirical. The former "seeks new data, new information derived from the observation of data and from experimental work" (Williams and Chesterman 2002, p. 58 in Yan et al. 2015) and can be further classified into observational and experimental approaches. Instead, non-empirical research consists of descriptive and theoretical approaches (Yan et al. 2015). An observational approach refers to the type of research in which researchers make naturalistic observations without making any interventions (Shaughnessy et al. 2012 in Liu 2016). It includes a few subcategories, for example, case study, survey research, correlational research, action research, and corpus research (Yan et al. 2015). Experimental studies in the field of interpreting usually adopt one or more of the following designs: natural groups design, one-variable design, factorial design, quasi-experiments, and pre-experiments (Hale and Napier 2013, pp. 168-170; also see Liu 2011). On the non-empirical end, descriptive studies usually describe a "fact, phenomenon or even anecdote", whereas theoretical studies aim to (re)define and clarify concepts (Yan et al. 2015, p. 11).

In terms of data collection and analysis, frequently used approaches in interpreter education include qualitative, quantitative, and mixed-methods approaches, which allow researchers to explore the nature of an educational problem and/or a pattern of a phenomenon. A qualitative approach is usually used in case studies, discourse analytical studies, focus group, and action research. A quantitative approach usually features in survey studies, experimental studies, and correlational research. Nowadays, more and more interpreting research adopts the mixed-methods approach where a combination of qualitative and quantitative approaches is used (Liu 2011).

\section{Major research areas and key findings}

\section{Learner factors: individual variables and learning outcomes}

In pedagogy-oriented T\&I studies, learner factors such as needs, personality traits, and competence, have received considerable scholarly attention (Abdel Latif 2018). Research in this area usually adopts an experimental approach, for instance pre- and post-intervention design, as well as other quantitative and qualitative methods such as surveys and interviews. Using one or a combination of the aforementioned methods, studies that focus on learner factors have thus far examined students' individual variables such as learning beliefs (Jiménez Ivars et al. 2014; Li 2018), cognitive and motivational traits (Shaw 2011), personality characteristics (Shaw and Hughes 2006), gender, confidence level, self-perceived language ability, and 
the relationship between these factors and students' learning outcomes (Pan and Yan 2012; Rosiers et al. 2014).

A few studies discuss students' use of strategies and strategic competence. These studies, based on cognitive sciences, have a clear interest in the process of interpreting. For example, using retrospection and experiment as methods, Bartłomiejczyk (2006) analyzed students' strategies of simultaneous interpreting and directionality and found that the strategies employed vary significantly for different interpreting directions. Focusing on strategic competence of novice and advanced interpreting students, Arumí Ribas's pilot study compares problems encountered by these two groups of students and interpreting strategies they adopt (Ribas 2012).

Another group of studies are aimed at finding out what personal traits can predict interpreting performance or learning outcomes. These studies usually take a statistical approach and examine the relationship between learner factors and learning outcomes. The findings obtained in this research area are usually beneficial to the implementation of admission tests, the development of students' aptitude, and curricular design. For example, L2 proficiency and memory capacity have been identified as important predictors for students' interpreting aptitude and performance (Blasco Mayor 2017; Cai et al. 2015). These findings suggest that L2 and memory training can be beneficial for the competence development of student interpreters and therefore should be included in interpreting curricula. In the field of sign language interpreting, Bontempo and Napier (2011) have examined emotional stability, including anxiety and neuroticism, as predictors of interpreter's self-perceived competence. They suggest including personal traits for screening purposes in the admission test and the teaching of anxiety or stress management in interpreter education curricula.

\section{Institutional practices: programmes, models, and curricula}

Against the backdrop of globalization, there has been an increased demand for professional interpreters, which has prompted the rapid emergence of T\&I programmes in higher education institutions, especially at the graduate level. Consequently, there are a number of studies introducing and/or evaluating a certain training programme, model, and curriculum for documentation, reflection, and improvement of teaching and learning practices. As interpreting programmes in higher education institutions are usually offered together with translation programmes, interpreting programmes, models, and curricula are usually discussed as part of T\&I programmes. For example, Álvarez-Álvarez and Arnáiz-Uzquiza (2017) assess whether the curricula of undergraduate T\&I training in Spain meet the demands of the professional market. Lim (2006) compares and contrasts four representative T\&I graduate courses in Korea. Wang and $\mathrm{Mu}$ (2009) review the mushrooming T\&I training programmes at both undergraduate and graduate levels in China.

In the field of legal interpreting, there has traditionally been a lack of specialized training opportunities (Hale 2004). Whenever formal training is available, it is usually offered as course units and modules as part of the postgraduate T\&I curricula. For example, in Australia, Stern and Liu (2019a) review the state-of-the art of formal legal interpreter training offered by higher education institutions and whether it is sufficient for preparing competent legal interpreters for Australia's diverse communities. Graduates from such programmes are usually competent to work in general and para-legal settings, such as police and immigration, however they are often incompetent to work in courts or tribunals. In addition, legal interpreting training in Australia also faces other difficulties, particularly the language service needs of the 'new and emerging' (N\&E) communities. Similar to legal interpreting, medical and healthcare 
interpreting also needs specialized education/training. Countries vary in different aspects of medical interpreting training programmes, such as levels of training provided, the training providers, duration, content, and methods (Crezee 2015). In this context, Tomassini (2012) analyzes the current needs of healthcare interpreting in Italy and encourages the collaboration between universities and healthcare service providers.

\section{Classroom teaching and learning: content, methods, and assessment}

Different from studies that evaluate a programme or curriculum, research on classroom teaching and learning investigates in more detail the content of teaching/learning, teaching methods, and assessment of students' performance.

In terms of what to teach in an interpreting class, studies have covered a wide range of topics from students' linguistic competency enhancement, interpreting skills/techniques, to professionalism. For example, Cho and Park (2006) suggest including pronunciation training for students who interpret into L2 as phonological/phonetic knowledge is conducive to the students' interpretation delivery. Chmiel (2010) addresses the effectiveness of teaching note-taking to trainee interpreters and finds that layout and visualization techniques are more transferrable to students' own note-taking systems than other elements. Li (2015) argues for the necessity of teaching strategies to interpreting students to help them overcome cognitive constraints. In terms of professionalism, studies often discuss teaching ethics to students, especially in the field of community interpreting (Hale 2007), but rather sparsely in conference interpreting (Donovan 2011). Recently, a number of research-oriented interpreting studies have paid close attention to the pragmatic aspects of interpreting. For example, in the field of legal interpreting, Liu and Hale (2018) demonstrate that specialized training on the pragmatics of courtroom discourse can benefit students' interpreting accuracy (also see Liu 2018). Similarly, in general interpreting settings, Yenkimaleki and van Heuven (2018) have also found that teaching prosody awareness positively influences trainees' interpreting performance.

Compared to what to teach, how to teach seems to attract even greater scholarly attention nowadays, in contrast to the earlier approach whereby students on admission were expected to be able to interpret naturally. A large proportion of educational research reported on or evaluated specific teaching approaches and methods. Such studies usually employ a variety of research methods, for instance, case study and action research as well as an experimental approach. One group of studies focuses on the use of situated learning (see Lave and Wenger 1991) in interpreting classes, which aims to enhance student interpreters' professional competence (González-Davies and Enríquez Raído 2016). Activities that adopt the situated learning approach may take different forms such as storytelling (Napier 2010), theatrical training (Cho and Roger 2010), and mock conference (Li 2015; Pan 2016). These situated teaching activities allow students to combine theories and practice, as well as to practice problem-solving skills in an environment that assembles real-life interpreting. In addition to situated learning, there are also a number of other approaches to interpreter learning and teaching. For example, a corpus can be a useful tool to improve students' lexical knowledge and interpreting performance (Bale 2013). A genre-based approach helps students to understand the speaker's communicative intentions and discourse structure, thus improving interpreting quality (Tebble 2014). Observation protocol and guidance can assist with students' observations of real interpreting work, which is beneficial to the acquisition of interpreting skills. More towards the studentcentred end in the teaching and learning spectrum, interpreting students are encouraged to perform autonomous learning (Horváth 2007), including conducting self-assessment (Y.-H. Lee 
2005), where students are responsible for their own independent practice as well as cooperative learning with others. In addition to the traditional classroom teaching methods, there also has been increased scholarly attention to long-distance or online learning as well as blended learning with the assistance of technology. Such studies usually examine the possibilities and effectiveness of using virtual environment for training interpreters (Ko and Chen 2011; Braun and Slater 2014) and the effectiveness of E-learning/blended-learning platforms (Hansen and Shlesinger 2007; Chan 2013).

As regards studies on interpretation assessment within the higher education context, there are usually two major categories, namely the admission test and formative and summative assessment for classroom learning. Admission tests usually concern the measurement of interpreter competence and the predictability of candidates' performance. Discussions usually surround forms of tests and their effectiveness in predicting interpreters' aptitude (MoserMercer 1994; Timarová and Ungoed-Thomas 2008; Pöchhacker 2011b; Chabasse 2014). At the institutional level, there is general agreement regarding which skills are best assessed by which tests, although the specific tests adopted by different institutions are different (Timarová and Ungoed-Thomas 2008). Most schools attach importance to 'hard skills' such as linguistic and communication skills, but rarely focus on 'soft skills', for instance, motivation (pp. 43-44). As for classroom assessment of interpreting quality, there has been an increasing use of scale-based assessment methods in the education of interpreters and translators (J. Lee 2008; Angelelli and Jacobson 2009; S.-B. Lee 2015; Wang et al. 2015) (also see Han 2018 for a review on rating scales for interpretation assessment). Besides rating scales, there are also a number of other assessment methods, for example, the use of metacognitive evaluation method, such as self-evaluation, problem-finding, and profiling among novice interpreters for consecutive interpreting training (Choi 2006). Role play is used to assess interpreters' performances (Wadensjö 2014).

\section{Pedagogic approaches and methods}

As articulated by González-Davies and Enríquez-Rado (2016), the three main questions that have been long discussed and have helped to advance translator and interpreter training are "(1) Is T\&I a question of intuition or of training?; (2) Can T\&I be taught?; and (3) Is there a best method to teach and learn how to translate/interpret?" (2016, p. 5). Unlike the earlier practice that prioritized innate qualities over training ("interpreters are born not made" Herbert 1978, p. 9 in Mackintosh 1999, p. 67), today's interpreter pedagogy has been generally steeped in sound educational models, with research-based approaches impacting on educational practice. This section will address the current educational practices of interpreter training programmes, including (1) types of programmes and curriculum models, (2) approaches to student admission, (3) pedagogy and teaching methodology, and (4) assessment. While the 21 st century interpreting landscape has been changed by the multitude of languages previously not offered in interpreter training and the emergence of new settings where interpreting is required, the need to train in 'languages of low diffusion' (LLD) has posed challenges (cf. Garzone and Viezzi 2002; Schäffner et al. 2013). However, the 'multilingual turn' has not been addressed in interpreter training literature, and, as we shall see further, the traditional notions of native speaker's proficiency and bilingualism prevail. Moreover, training in the "languages of low diffusion" (Balogh et al. 2016, pp. 21-23) or the "new and emerging" communities languages (Lai and Mulayim 2013; Stern 2018) has not been offered in higher education in a significant way, except in the countries of these languages (cf. Balogh et al. 2016). 


\section{Types of programmes and curriculum models}

At the end of the 20th century 230 academic institutions worldwide offered interpreter training across more than 60 countries. Out of them, in Europe, "100 institutions offered 3-5 year undergraduate programs and 23 schools had 1-2 year graduate programs" (Niska 2005 in Bao 2015, p. 400). By 2015 the number had almost tripled, with around 600 programmes worldwide, mostly offered at postgraduate level in Asia, Africa, and South America, with 159 graduate schools in China alone (Bao 2015, p. 400). The undergraduate degrees either prepare students for the more advanced, professional, degrees (e.g. ETI, Heidelberg University) or cover grounds similar to those of postgraduate programmes (e.g. WSU in Australia in Stern and Liu 2019a). A planned programme of instruction (such as at the MA in Conference Interpretation offered by Middleberry Institute of International Studies at Monterey) addresses the progression of skills and knowledge acquisition aiming to achieve professional competence and expertise (Sawyer 2015, p. 97). The inclusion of community interpreting programmes and course units at the undergraduate and postgraduate levels has been slow (Hale 2011a), with governments providing little support and resources (Corsellis 2008, p. 53). However, at the time of writing this chapter, even some conference interpreting departments like ESIT are introducing community interpreting into their curriculum.

Masters in conference interpreting are offered over one to two years (ESIT, Heidelberg University), sometimes they are preceded by a three-year undergraduate bachelor degree (e.g. ETI). In the EU, the languages include English, French, German, Italian, and Spanish, and only some institutions have expanded this list, adding Arabic, Chinese, and Russian outside the countries of these languages. The few European universities that offer community interpreting training (e.g. University of Westminster) include some community languages (e.g. Polish, Portuguese). The masters programmes in Australian universities with a high demand for community interpreting offer a variety of 'established' international and community languages - European, Asian, and Middle Eastern (Stern and Liu 2019a). At least one Australian university, RMIT, offers several N\&E languages of recent migrant communities that represent languages of need. The languages offered by the European Masters in Conference Interpreting (EMCI) include language combinations described as "less widely used and less taught languages" (www.emcinterpreting.org/course-structure) of the EU member countries where these programmes are offered. Since the introduction of these new languages, departments have been changing their traditional curricula built around specific language combinations (e.g. Middleberry Institute of International Studies at Monterey). More recent curricula include "the multicultural classroom comprising students from a range of educational and national backgrounds", similar to language classrooms (Corsellis 2008, pp. 69-70), and non-language specific course units include language-specific components (e.g. Stern and Liu 2019a). With the proliferation of the latter type of programmes, there are calls for a balance between language-specific and general instruction (Sawyer 2015, p. 99).

\section{Conference interpreting curriculum and content}

Conference interpreting programmes aim to provide an all-round education and training through a structured curriculum that includes admission test, progressive skills training, and assessment. In an attempt to deliver a rounded curriculum, European programmes include general humanistic education (contextual knowledge such as EU and international organizations) as well as interpreting skills combined with language enhancement in specific areas (technical, scientific), and professional ethics (Stern 2011). For example, a shared curriculum of EMCI 
has the following core course units: theory of interpretation; practice of interpretation (including interpreting skills, public speaking, voice, ethics, conference preparation techniques); CI (content analysis, memory exercises, CI without notes, summarization, sight translation, notetaking in a variety of subject areas in different styles and registers); SI, with the same approach plus booth techniques and team interaction; the EU and international organizations (introduction to organizations, their institutional processes and procedures) (Stern 2011). While training interpreters in professional skills, the 21 st century programmes see a greater inclusion of theory into the curriculum and the emergence of higher degree research (including MA and $\mathrm{PhDs}$ ), although this process has remained slow (Pöchhacker 2004, p. 31). While bilingualism or multilingualism has been a sine qua non in interpreter training, and historically conference interpreters were trained to work into their L1 (Language A) only, the increasing use of retour, that is, working into both L1 and L2 (Languages A and B), has required a different approach to training (Pöchhacker 2011a, p. 319) and has stimulated interpreter training research in this field.

\section{Community interpreting programmes}

Until now university programmes in community interpreting have been few and incentives for training in community interpreting have been insufficient (cf. Hale 2011a; Stern and Liu $2019 b$ ), however the number of institutions training community interpreters has increased (Hale 2011a), and Moser-Mercer (2015) notes a significant progress in community interpreting pedagogy. Although community interpreting professional standards are the same as for conference interpreting, the admission, training, and assessment differ (Corsellis 2008, p. 53) in as far as it focuses on the interactive exchange in community interpreting and ethical dilemmas. Specialized legal and health interpreting courses frequently included in the curricula introduce the context of administrative procedures and settings and teach relevant interpreting skills (e.g. consecutive dialogue interpreting, sight translation, chuchotage). Interpreter students receive training in specialized terminology so as to improve their language proficiency and interpreting accuracy (Wadensjö 1998, p. 36). While these programmes have a practical skill-building orientation, some include an end-of-studies treatise or a research project, potentially leading to admission to a masters by research or a $\mathrm{PhD}$, as at UNSW Sydney. The limited length of some of these programmes does not generally allow sufficient time for a theoretical component (Hale 2007, p. 168), or for students to improve their command of L2 (Language B) (Gile 2001), or else achieve specialization such as in court interpreting (Stern and Liu 2019a). While research acknowledges insufficient mastery of languages as a hurdle in interpreting skills acquisition, "to date no studies explicitly describe specific levels of interpreting that are attainable through interpreter education" (Blasco Mayor 2017, p. 104). With few exceptions, advanced bilingual enhancement is encouraged rather than provided, with isolated courses offering scaffolding for the students' learning such as Bilingual Enhancement and Personalised English Language Enhancement (PELE) at UNSW Sydney (Kim and Jing forthcoming).

\section{Student admission}

Literature on entry requirements for admission to conference interpreting courses discusses aptitude tests (Arjona-Tseng 1994; Moser-Mercer 1994). While educators agree that successful training requires rigorous selection of suitable candidates, however, admission criteria and the selection process vary depending on the type of institution (Stern 2011, p. 494). While some Spanish master's programmes select students with "superior skills in at least two of their 
working languages" (Blasco Mayor 2017, p. 104), most undergraduate programmes do not use the same admission criteria (p. 105). While some departments (ETI, ESIT, Heidelberg) set high admission standards with the expectation that future students have a perfect mastery of L1 and L2 (Languages A and B), and an excellent comprehension of L3 (Language C), more recent interpreter training programmes (University of Westminster in UK, Australian universities) limit admission requirements to English language proficiency with IELTS Band 6.5-7 or equivalent. As a result, in some schools, both applicants and students have an insufficient proficiency in their L2 (B language) (Gile 2001), a low level of rhetorical sensitivity in their A language (Altman 1994, p. 37), and limited general knowledge (Stern 2011).

An entrance exam (often described as an aptitude test), if and when administered, aims to assess the applicants' languages proficiency and suitability for training. The former is assessed by testing oral comprehension, written summary, sight translation, etc. and the latter tests the applicant's capacity for analysis, concentration, and ability to work under pressure (Niska 2005, pp. 49-50). It is recognized, however, that existing aptitude tests have not necessarily provided adequate assessment of aptitude for interpreter training and have no predictive value regarding how much improvement can be expected during training (Moser-Mercer 1994, p. 60; Sawyer 2004, p. 111). One of the legacies of the earlier programmes in the existing admission tests has been the criticisms of the "appropriateness of these assessment instruments which seem to expect applicants to perform almost at the level of professional interpreters before they even commence the training course" (Gerver et al. 1984 in Campbell and Hale 2003, p. 212). More recent studies have examined features that indicate an aptitude in a prospective interpreter, how these qualities may be measured and which types of test should be administered, the issue of valid and reliable testing, proposals for test designs, and, finally, description of aptitude tests which have identified statistically significant predictors (Russo 2014, p. 7).

Admission criteria and process for community interpreting programmes vary. Stating that "native speaker competence might not be expected in a second language" of community interpreters (Corsellis 2008, p. 25) is a significant shift from the expectations of high bilingual proficiency in conference interpreting. Corsellis (2008, p. 58) acknowledges a likely imbalance "between the levels of [language] proficiency, competencies (reading, writing, listening, speaking) and the domains of use". Students applying for community interpreting programmes such as for a BA at Gallaudet University are screened for language proficiency through exercises, followed by an interview and further screening (Shaw et al. 2006, p. 9). Other programmes, for example in some English-speaking countries, base their admission on the quality of the BA in a cognate discipline (language studies, linguistics) and the IELTS test band 6.5-7, which are deemed unsuitable for professional interpreting studies (Stern and Liu 2019a). In addition to these admission requirements being insufficiently high, they are also not predictive of the future students' ability to apply their language combination to interpreting. As mentioned earlier, while students with inadequate bilingual proficiency departments may be admitted, little is done to scaffold their studies by improving their command of their L2 (B language) during their studies (Stern and Liu 2019a).

\section{Pedagogy and teaching methodology}

Xiu et al. (2018, p. 3) note that teaching and learning (as well as assessment) are the major themes in interpreter training research. Today's approaches to interpreter training are generally steeped in educational principles. However, discussion on what and how to teach is ongoing, and institutions vary in relation to teaching content, course sequencing, sequencing 
of interpreting modes, and skills-development, effective teaching methods, and the utility of some activities (Stern 2011, p. 501). To address the question of resources when training in a large number of languages, sometimes in small groups, institutions have combined multilingual (non-language specific) lectures and seminars with language-specific tutorials (e.g. Stern and Liu 2019a on Australian universities' T\&I programmes).

A significant reorientation of teaching has been in the inclusion of a process- (rather than a product-) oriented approach to optimize learning (Gile 1994, 1995). Teaching methodology has been enriched with more "transactional, transformational, and student-centred learning" models (González-Davies and Enríquez-Raído 2016, p. 6). Transition from teacher- to studentoriented learning has meant that students have greater independence, they are more in charge of their learning (Sawyer 2004), and are able to assess their own performance (Hale 2007). The original view that only a practising interpreter can be an interpreting teacher has been moderated. There is an agreement that interpreting practice alone cannot inform teaching, and that interpreter trainers need to be familiar with interpreter training pedagogy and interpreting research on teaching (cf. Pöchhacker 2011a; Hale 2007). Familiarity with research will help trainers to guide students to pinpoint problems, solve problems (Kurz 2002, p. 65), and justify their decisions (Hale 2007). While conference interpreting courses that train the trainers have provided teachers with skills that help respond to different levels of student aptitude, facilitate learning, create simulated practice, and support student self-practice (Moser-Mercer 2015, p. 305), community interpreter training is still facing a number of challenges such as "scarcity of qualified graduate language tutors in the range of languages required, uneven levels of existing language skills and a lack of appropriate teaching materials" (Corsellis 2008, p. 54).

Departments remain divided on the inclusion of translation in interpreter training and the progression from the CI mode to the SI. The widely recognized organizing principle of conference interpreting education, adopted by some programmes (e.g. ETI, Moscow State Linguistic University), includes the sequence of training in translation (optional), followed by CI skills acquisition followed by training in SI (Sawyer 2015, p. 98). Others offer interpreting only, also progressing from the CI to SI (ESIT, EMCI) (Sawyer 2004). As in the earlier interpreting programmes, most conference interpreting training follows a staged approach which begins with pre-interpreting techniques (summarizing, paraphrasing, clozing exercises, chunking, and visualization), and expressive skills for public speaking. CI training is usually associated with note taking, which in conference interpreting programmes starts immediately at the beginning of training. In community interpreting programmes note taking is introduced a few weeks into the training. SI preparatory exercises include sight translation and 'dual-task' exercises, which some educators believe to be useful in preparing students to listen and speak simultaneously (e.g. Lambert 1989; Kalina 1994). Yet, the benefits of shadowing, as demonstrated by some experimental research, have shown mixed results (Kurz 1993). In community interpreter training, students acquire skills in several modes: consecutive dialogue interpreting, sight translation, and whispered simultaneous interpreting (chuchotage), often domain focused (e.g. Angelelli on Healthcare interpreter education 2006, pp. 23-45; Stern and Liu 2019a, 2019b on legal/court interpreting). Teaching methods and exercises involve problem solving (Angelelli 2006), role play that emulates real-life situations (Kadric 2015, p. 361), sight translation supported by the studies of specialized settings (health, legal), discussions of professional role and ethics (Hale 2007), and a 'life-long learning' approach is adopted (Moser-Mercer 2015). Situated learning (learning by doing) is a desirable component of training of interpreters not only in interpreting skills acquisition but to promote future interpreters' professional competence to work in the industry (cf. González-Davies and Enríquez Raído 2016). 


\section{Assessment}

Assessment is an integral part of interpreter education. It is usually carried out by administering a test and is used in student selection, progress monitoring, and conferral of the degree (Sawyer 2004 in Liu 2015, p. 20). Assessment is one of the main topics of interpreter education research (Xiu et al. 2018, p. 3). Assessment is usually conducted on admission as well as at the intermediate and final stages of the course (Sawyer 2004). Formative (continuing) assessment helps monitor students' progress by providing constructive feedback on the skill-building, informed decision making and the use of appropriate techniques (Sawyer 2004; Stern and Liu 2019a). Increased student participation in assessment (Gile 2001, p. 389) encourages students to critically assess their own and their peers' performance (Sawyer 2004, p. 93). Portfolios (Sawyer 2004, p. 125; Angelelli 2006, pp. 37-38) allow the monitoring and ongoing evaluation of the students' progress through self-assessment, peer review, and teacher feedback (Pöchhacker 2004, p. 187). Summative (final) assessment in interpreter training is product-oriented and involves the testing of fidelity, including accuracy and completeness, and fluency of language use and delivery of the output - these features are commonly used as quality criteria (Liu 2015, p. 20). Summative assessment marks the successful completion of an interpreter training course unit or stage (e.g. the transition from the first to the second year of a two-year ESIT programme) or the entire programme. Its aim is to evaluate the student's suitability for the market (Stern 2011, p. 505). As mentioned earlier, in community interpreting industry accreditation bodies may conduct credentialing by administering external examinations (e.g. Certified Interpreter examinations, Specialized Certified interpreter, Certified Conference Interpreter in Australia by NAATI).

Even with the use of the set marking criteria, interpreting examiners show subjectivity in exercising individual decision making and different perceptions of accuracy and linguistic appropriateness of the students' performance and product (Sawyer 2004). Liu (2015, p. 21) notes raters' subjectivity in the decision about the severity of an error and a strong rater bias in the definition of what constitutes a major or a minor error. Comprehensive and detailed marking systems for final examinations have been developed by some departments (on ETI see Mackintosh 1995, p. 128 in Campbell and Hale 2003, p. 216). However, a comparison between deduction of marks for every type of error and the intuitive marking shows similar results for both systems (Longley 1978 in Campbell and Hale 2003, p. 217). More recently, assessment has seen a transition from the deductive system, taking off marks for errors of different degree of seriousness, to a scoring rubric, where each criterion is scored on a separate scale with a corresponding descriptor. In this system subjectivity in rating can be reduced and the descriptors can be used as a form of feedback to the student assessed (Liu 2015, p. 21). Some concerns remain about the lack of adherence in test designs to the test reliability. In addition to problems with inter-rater reliability, there is inconsistency with the input variables, speech rate, and the conditions under which the test is delivered (Liu 2015, p. 22). This is a problem encountered in high stakes summative assessment such as final/exit examinations. Problems concerning the reliability of assessment that is linked to professional accreditation has been discussed in the literature on community interpreter training (e.g. Campbell and Hale 2003, pp. 218-219).

\section{Conclusions and future directions}

Worldwide migration and superdiversity in both multicultural and previously monolingual societies have created new industry demands for new settings and interpreting in languages 
previously not used, and the need for quality of interpreting, especially in community interpreting. The process of interpreter professionalization that began in the late 20th century has led to an unprecedented worldwide increase in the number of interpreter training programmes. At the same time, empirical and theoretical research in interpreting studies has brought about new developments in T\&I education.

The most significant change in interpreter education has been the shift from the traditional 'natural interpreter' and apprenticeship approach to a more evidence-based training approach. Research into interpreter training covers a variety of topics, many of them from the learnercentred perspective such as individual variables and learning outcomes, institutional practices, classroom teaching/learning, and assessment. Questions such as the predictive value of aptitude tests, the validation of progression and the inclusion of certain types of activities, language directionality, and the role and impact of modern technology in interpreter training are to be further explored.

Today's interpreter training continues to be steeped in educational principles and focuses on programmes/curriculum, selection/admission, pedagogy, assessment, and addressing the needs of the changing industry. Thus, research into community interpreter training includes innovative student-centred methods of classroom teaching and assessment. At the same time, the inclusion of the LLD and N\&E languages required by the interpreting industry has remained limited and the impact of research on curriculum design and training in higher education has been marginal.

\section{Further reading}

Sawyer, D.B. (2004) Fundamental Aspects of Interpreter Education. Curriculum and Assessment. Amsterdam and Philadelphia: John Benjamins.

This volume remains an important scholarly study of conference interpreting education, with a focus on curriculum and assessment. It combines theory and practice-based case studies of some existing programmes.

Pöchhacker, F. and Liu, M. (eds) (2014) Aptitude for Interpreting. Amsterdam and Philadelphia: John Benjamins.

This edited volume contains articles reflecting recent studies on aptitude tests. It focuses on training predictors that include linguistic, cognitive, and personality traits.

Hale, S. and Napier, J. (2013) Research Methods in Interpreting: A Practical Resource. London: Bloomsbury.

A practical introduction to interpreting research, with a chapter on research into interpreter education and assessment. A valuable introductory resource for current and future research students.

\section{Related topics}

interpreting studies, translation studies, translation and social inclusion, translation teacher training

\section{References}

Abdel Latif, M. (2018) Towards a typology of pedagogy-oriented translation and interpreting research. The Interpreter and Translator Trainer. 12(3), pp. 322-345.

Altman, J. (1994) Error analysis in the teaching of simultaneous interpreting: A pilot study, in Lambert, S. and Moser-Mercer, B. (eds) Bridging the Gap: Empirical Research in Simultaneous Interpretation. Amsterdam and Philadelphia: John Benjamins. pp. 25-38. 
Álvarez-Álvarez, S. and Arnáiz-Uzquiza, V. (2017) Translation and interpreting graduates under construction: Do Spanish translation and interpreting studies curricula answer the challenges of employability? The Interpreter and Translator Trainer. 11(2-3), pp. 139-159.

Angelelli, C. (2006) Designing curriculum for healthcare interpreting education: A principles approach, in Cynthia, B.R. (ed) New Approaches to Interpreter Education. Washington, DC: Gallaudet University Press. pp. 23-45.

Angelelli, C. and Jacobson, H. (eds) (2009) Testing and Assessment in Translation and Interpreting Studies: A Call for Dialogue Between Research and Practice. Amsterdam and Philadelphia: John Benjamins.

Arjona-Tseng, E. (1994) Psychometric selection tests. In S. Lambert and B. Moser-Mercer (eds) Bridging the Gap: Empirical Research in Simultaneous Interpretation. Amsterdam and Philadelphia: John Benjamins. pp. 69-86.

Arumí Ribas, M. (2012) Problems and strategies in consecutive interpreting: A pilot study at two different stages of interpreter training. Meta. 57(3), pp. 812-835.

Bale, R. (2013) Undergraduate consecutive interpreting and lexical knowledge. The Interpreter and Translator Trainer. 7(1), pp. 27-50.

Balogh, K., Salayets, H. and van Schoor, D. (2016) TraiLLD: Training in Languages of Lesser Diffusion. Campus Handbook. Leuven: Lannoo Campus Publishers.

Bao, C. (2015) Pedagogy, in Mikkelson, H. and Jourdenais, R. (eds) The Routledge Handbook of Interpreting. London and New York: Routledge. pp. 400-416.

Bartłomiejczyk, M. (2006) Strategies of simultaneous interpreting and directionality. Interpreting. 8(2), pp. 149-174.

Blasco Mayor, M.J. (2017) L2 proficiency as predictor of aptitude for interpreting: An empirical study, in Colina, S. and Angelelli, C.V. (eds) Translation and Interpreting Pedagogy in Dialogue with Other Disciplines. Amsterdam and Philadelphia: John Benjamins. pp. 103-127.

Bontempo, K. and Napier, J. (2011) Evaluating emotional stability as a predictor of interpreter competence and aptitude for interpreting. Interpreting. 13(1), pp. 85-105.

Braun, S. and Slater, C. (2014) Populating a 3D virtual learning environment for interpreting students with bilingual dialogues to support situated learning in an institutional context. The Interpreter and Translator Trainer. 8(3), pp. 469-485.

Cai, R., Dong, Y., Zhao, N. and Lin, J. (2015) Factors contributing to individual differences in the development of consecutive interpreting competence for beginner student interpreters. The Interpreter and Translator Trainer. 9(1), pp. 104-120.

Campbell, S. and Hale, S. (2003) Translation and interpreting assessment in the context of educational measurement, in Anderman, G. and Rogers, M. (eds) Translation Today: Trends and Perspectives. Clevedon: Multilingual Matters. pp. 205-224.

Chabasse, C. and Kader, S. (2014) Putting interpreting admissions exams to the test: The MA KD Germersheim Project. Interpreting. 16(1), pp. 19-33.

Chan, C.H-Y. (2013) From self-interpreting to real interpreting: A new web-based exercise to launch effective interpreting training. Perspectives. 21(3), pp. 358-377.

Chmiel, A. (2010) How effective is teaching note-taking to trainee interpreters? The Interpreter and Translator Trainer. 4(2), pp. 233-250.

Cho, J. and Park, H-K. (2006) A comparative analysis of Korean-English phonological structures and processes for pronunciation pedagogy in interpretation training. Meta. 51(2), pp. 229-246.

Cho, J. and Roger, P. (2010) Improving interpreting performance through theatrical training. The Interpreter and Translator Trainer. 4(2), pp. 151-171.

Choi, J.Y. (2006) Metacognitive evaluation method in consecutive interpretation for novice learners. Meta. 51(2), pp. 273-283.

Corsellis, A. (2008) Public Service Interpreting: The First Steps. Houndmills, Basingstoke: Palgrave Macmillan.

Crezee, I. (2015) Semi-authentic practices for student health interpreters. Translation \& Interpreting. $7(3)$, pp. $50-62$. 
Dodds, J., Katan, D., Aarup, H., Gringiani, A., Riccardi, A., Schweda Nicholson, N. and Viaggio, S. (1997) The interaction between research and training, in Gambier, Y., Gile, D. and Taylor, C. (eds) Conference Interpreting: Current Trends in Research. Amsterdam and Philadelphia: John Benjamins. pp. 89-107.

Donovan, C. (2011) Ethics in the teaching of conference interpreting. The Interpreter and Translator Trainer. 5(1), pp. 109-128.

Gaiba, F. (1998) Origins of Simultaneous Interpretation: The Nuremberg Trial. Ottawa: Ottawa University Press.

Garzone, G. and Viezzi, M. (eds) (2002) Interpreting in the 21st Century: Challenges and Opportunities. Amsterdam and Philadelphia: John Benjamins.

Gile, D. (1994) Opening up in interpretation studies, in Snell-Hornby, M., Pöchhacker, F. and Kaindl, K. (eds) Translation Studies: An Interdiscipline. Amsterdam and Philadelphia: John Benjamins. pp. 149-158.

Gile, D. (1995) Basic Concepts and Models for Interpreter and Translator Training. Amsterdam and Philadelphia: John Benjamins.

Gile, D. (2001) L'Évaluation de la qualité de l'interprétation en cours de formation. Meta. 46(2), pp. 379-393.

González-Davies, M. and Enríquez Raído, V. (2016) Situated learning in translator and interpreter training: Bridging research and good practice. The Interpreter and Translator Trainer. 10(1), pp. 1-11.

Hale, S. (2004) The Discourse of Court Interpreting: Discourse Practices of the Law, the Witness and the Interpreter. Amsterdam and Philadelphia: John Benjamins.

Hale, S. (2007) Community Interpreting. Houndmills, Basingstoke: Palgrave Macmillan.

Hale, S. (2011a) Public service interpreting, in Malmkjaer, K. and Windle, K. (eds) The Oxford Handbook of Translation Studies. Oxford: Oxford University Press. pp. 343-356.

Hale, S. (2011b) Interpreter Policies, Practices and Protocols in Australian Courts and Tribunals: A National Survey. Melbourne: The Australasian Institute of Judicial Administration Incorporated.

Hale, S. and Napier, J. (2013) Research Methods in Interpreting: A Practical Resource. London and New York: Bloomsbury.

Han, C. (2018) Using rating scales to assess interpretation. Interpreting. 20(1), pp. 59-95.

Hansen, I.G. and Shlesinger, M. (2007) The silver lining: Technology and self-study in the interpreting classroom. Interpreting. 9(1), pp. 95-118.

Herbert, J. (1952) Manuel d'interprète. Geneva: Georg.

Herbert, J. (1978) How conference interpretation grew, in Gerver, D. and Sinaiko, H.W. (eds) Language Interpretation and Communication. Nato Conference Series III. New York: Plenum Press. pp. 5-10.

Horváth, I. (2007) Autonomous learning: What makes it work in postgraduate interpreter training? Across Languages and Cultures. 8(1), pp. 103-122.

Jiménez Ivars, A., Pinazo Catalayud, D. and Ruiz i Forés, M. (2014) Self-efficacy and language proficiency in interpreter trainees. The Interpreter and Translator Trainer. 8(2), pp. 167-182.

Kadric, M. (2015) Role play, in Pöchhacker, F. (ed) Routledge Encyclopedia of Interpreting Studies. London and New York: Routledge. pp. 360-361.

Kalina, S (1994) Discourse processing and interpreting strategies: An approach to the teaching of interpreting, in Dollerup, C. and Lindegaard, A. (eds) Teaching Translation and Interpreting 2: Insights, Aim and Visions. Amsterdam and Philadelphia: John Benjamins, pp. 251-257.

Kim, M. and Jing, B. (forthcoming). A personalised autonomous model for enhancing translation students' linguistic competence, in Koletnik, M. and Froeliger, N. (eds) Translation and Language Teaching - Continuing the Dialogue Between Translation Studies and Language Didactics. Newcastle upon Tyne: Cambridge Scholars Publishing.

Ko, L. and Chen, N-S. (2011) Online-interpreting in synchronous cyber classrooms. Babel. 57(2), pp. 123-143.

Kurz, I. (1993) 'Shadowing' exercises in interpreter training, in Dollerup, C. and Lindegaard, A. (eds) Teaching Translation and Interpreting 2: Insights, Aim and Visions. Amsterdam and Philadelphia: John Benjamins. pp. 245-250. 
Kurz, I. (2002) Interpreting training programmes, in Hung, E. (ed) Teaching Translation and Interpreting 4: Building Bridges. Amsterdam and Philadelphia: John Benjamins. pp. 65-72.

Lai, M. and Mulayim, S. (2013) Training interpreters in rare and emerging languages: The problems of adjustment to a tertiary education setting, in Schäffner, C., Kredens, K. and Fowler, Y. (eds) Interpreting in a Changing Landscape. Amsterdam and Philadelphia: John Benjamins. pp. 287-303.

Lambert, S. (1989) Information processing among conference interpreters: A test of the depth-ofprocessing hypothesis, in Gran, L. and Dodds, J. (eds) The Theoretical and Practical Aspects of Teaching Conference Interpretation. Udine: Campanotto. pp. 83-91.

Lave, J. and Wenger, E. (1991) Situated Learning: Legitimate Peripheral Participation. Cambridge: Cambridge University Press.

Lee, J. (2008) Rating scales for interpreting performance assessment. The Interpreter and Translator Trainer. 2(2), pp. 165-184.

Lee, S. -B. (2015) Developing an analytic scale for assessing undergraduate students' consecutive interpreting performances. Interpreting. 17(2), pp. 226 (2)

Lee, Y.-H. (2005) Self-assessment as an autonomous learning tool in an interpretation classroom. Meta. $50(4)$.

Li, X. (2015) Mock conference as a situated learning activity in interpreter training: A case study of its design and effect as perceived by trainee interpreters. The Interpreter and Translator Trainer. 9(3), pp. 323-341.

Li, X. (2018) Teaching beliefs and learning beliefs in translator and interpreter education: An exploratory case study. The Interpreter and Translator Trainer. 12(2), pp. 132-151.

Lim, H-O. (2006) A comparison of curricula of graduate schools of interpretation and translation in Korea. Meta. 51(2), pp. 215-228.

Liu, M. (2011) Methodology in interpreting studies: A methodological review of evidence-based research, in Nicodemus, B. and Swabey, L. (eds) Advances in Interpreting Research: Inquiry in Action. Amsterdam and Philadelphia: John Benjamins. pp. 85-120.

Liu, M. (2015) Assessment, in Pöchhacker, F. (ed) Routledge Encyclopedia of Interpreting Studies. London and New York: Routledge. pp. 20-22.

Liu, M. (2016) Putting the horse before the cart: Righting the experimental approach in interpreting studies, in Bendazzoli, C. and Monacelli, C. (eds) Addressing Methodological Challenges in Interpreting Studies Research. Newcastle upon Tyne: Cambridge Scholars Publishing. pp. 87-105.

Liu, X. (2018) Talking like a Lawyer: Interpreting Cross-Examination Questions into Chinese. Changchun: Jilin University Press.

Liu, X. and Hale, S. (2018) Achieving accuracy in a bilingual courtroom: The effectiveness of specialised legal interpreter training. The Interpreter and Translator Trainer. 12(3), pp. 299-321.

Mackintosh, J. (1995) A Review of conference interpretation: Practice and training. Target 7(1), pp. 119133, in Campbell, S. and Hale, S. (2003) Translation and interpreting assessment in the context of educational measurement, in Anderman, G. and Rogers, M. (eds) Translation Today: Trends and Perspectives. Clevedon: Multilingual Matters. pp. 205-224.

Mackintosh, J. (1999) Interpreters are made not born. Interpreting. 4(1), pp. 67-68.

Mason, I. (2015) Discourse analytical approaches, in Pöchhacker, F. (ed) Routledge Encyclopedia of Interpreting Studies. London and New York: Routledge. pp. 111-116.

Moser-Mercer, B. (1994) Aptitude testing for conference interpreting: Why, where and how, in Lambert, S. and Moser-Mercer, B. (eds) Bridging the Gap: Empirical Research in Simultaneous Interpretation. Amsterdam and Philadelphia: John Benjamins. pp. 57-68.

Moser-Mercer, B. (2015) Pedagogy, in Pöchhacker, F. (ed) Routledge Encyclopedia of Interpreting Studies. London and New York: Routledge. pp. 303-307.

Napier, J. (2010) A case study of the use of storytelling as a pedagogical tool for teaching interpreting students. The Interpreter and Translator Trainer. 4(1), pp. 1-32.

Niska, H. (2005) Training interpreters: Programmes, curricula, practices, in Tennent, M. (ed) Training for the New Millennium: Pedagogies for Translation and Interpreting. Amsterdam and Philadelphia: John Benjamins. pp. 35-64. 
Pan, J. (2016) Linking classroom exercises to real-life practice: A case of situated simultaneous interpreting learning. The Interpreter and Translator Trainer. 10(1), pp. 107-132.

Pan, J. and Yan, X. (2012) Learner variables and problems perceived by students: An investigation of a college interpreting programme in China. Perspectives. 20(2), pp. 199-218.

Pöchhacker, F. (2004) Introducing Interpreting Studies. London and New York: Routledge.

Pöchhacker, F. (2011a) Conference interpreting, in Malmkjaer, K. and Windle, K. (eds) Oxford Handbook of Translation Studies. Oxford: Oxford University Press. pp. 307-324.

Pöchhacker, F. (2011b) Assessing aptitude for interpreting: The SynCloze test. Interpreting. 13(1), pp. 106-120.

Pym, A. (2011) Training translators, in Malmkjaer, K. and Windle, K. (eds) Oxford Handbook of Translation Studies. Oxford: Oxford University Press. pp. 475-490.

Rosiers, A., Eyckmans, J. and Bauwens, D. (2014) A story of attitudes and aptitudes? Investigating individual difference variables within the context of interpreting. Interpreting. 13(1), pp. 53-69.

Rozan, J-F. (1956) La Prise de Notes en Interprétation Consécutive. Geneva: Georg.

Russo, M. (2014) Aptitude testing over the years, in Pöchhacker, F. and Liu, M. (eds) Aptitude for Interpreting. Amsterdam and Philadelphia: John Benjamins. pp. 7-31.

Sawyer, D.B. (2004) Fundamental Aspects of Interpreter Education: Curriculum and Assessment. Amsterdam and Philadelphia: John Benjamins.

Sawyer, D.B. (2015) Curriculum, in Pöchhacker, F. (ed) Routledge Encyclopedia of Interpreting Studies. London and New York: Routledge. pp. 96-99.

Schäffner, C., Kredens, K. and Fowler, Y. (eds) (2013) Interpreting in a Changing Landscape. Amsterdam and Philadelphia: John Benjamins.

Shaughnessy, J., Zechmeister, B. and Zechmeister, S. (2012) Research Methods in Psychology. 9th ed. New York: McGraw-Hill.

Shaw, R., Collins, S.D. and Metzger, M. (2006) MA to BA: A quest for distinguishing between undergraduate and graduate interpreter education, Bachelor of Arts in interpretation curriculum at Gallaudet University, in Roy, C. (ed) New Approaches in Teaching Interpreters. Washington, DC: Gallaudet University Press. pp. 1-22.

Shaw, S. (2011) Cognitive and motivational contributors to aptitude: A study of spoken and signed language interpreting students. Interpreting. 13(1), pp. 70-84.

Shaw, S. and Hughes, G. (2006) Essential characteristics of sign language interpreting students: Perspectives of students and faculty. Interpreting. 8(2), pp. 195-221.

Stern, L. (2011) Courtroom Interpreting, in Malmkjaer, K. and Windle, K. (eds) Oxford Handbook of Translation Studies. Oxford: Oxford University Press. pp. 325-342.

Stern, L. (2018) Legal interpreting in domestic and international courts: Responsiveness in action, in Creese, A. and Blackledge, A. (eds) The Routledge Handbook of Language and Superdiversity: An Interdisciplinary Perspective. London and New York: Routledge. pp. 396-410.

Stern, L. and Liu, X. (2019a) See you in court: How do Australian institutions train legal interpreters? The Interpreter and Translator Trainer. 13(2). Available from: www.tandfonline.com/doi/abs/10.1080 /1750399X.2019.1611012.

Stern, L. and Liu, X. (2019b). Ensuring interpreting quality in legal and courtroom settings: Australian language service providers' perspectives on their role. Journal of Specialised Translation. 32 (July), pp. $90-120$.

Tebble, H. (2014) A genre-based approach to teaching dialogue interpreting: The medical consultation. The Interpreter and Translator Trainer. 8(3), pp. 418-436.

Timarová, S̆. and Ungoed-Thomas, H. (2008) Admission testing for interpreting courses. The Interpreter and Translator Trainer. 2(1), pp. 29-46.

Tomassini, E. (2012) Healthcare interpreting in Italy: Current needs and proposals to promote collaboration between universities and healthcare services. The Interpreters 'Newsletter. 17(1), pp. 39-54.

Vertovec, S. (2010) Super-diversity and its implications, in Vertovec, S. (ed) Anthropology of Migration and Multiculturalism: New Directions. London and New York: Routledge. pp. 65-95.

Wadensjö, C. (1998) Community interpreting, in Baker, M. and Saldanha, G. (eds) Routledge Encyclopedia of Translation Studies. London and New York: Routledge. pp. 33-37. 
Wadensjö, C. (2014) Perspectives on role play: Analysis, training and assessments. The Interpreter and Translator Trainer. 8(3), pp. 437-451.

Wang, B. and Mu, L. (2009) Interpreter training and research in mainland China: Recent developments. Interpreting. 11(2), pp. 267-283.

Wang, J., Napier, J., Goswell, D. and Carmichael, A. (2015) The design and application of rubrics to assess signed language interpreting performance. The Interpreter and Translator Trainer. 9(1), pp. 83-103.

Williams, J. and Chesterman, A. (2002) The Map: A Beginner's Guide to Doing Research in Translation Studies. Manchester: St. Jerome Publishing.

Wilss, W. (1999) Translation and Interpreting in the 20th Century: Focus on Germany. Amsterdam and Philadelphia: John Benjamins.

Xiu, J., Pan, Y.J. and Wang, H. (2018) Research on Translator and Interpreter Training. A Collective Volume of Bibliometric Reviews and Empirical Studies on Learners. Singapore: Springer.

Yan, J.X., Pan, J. and Wang, H. (2015) Studies on translator and interpreter training: A data-driven review of journal articles 2000-12. The Interpreter and Translator Trainer. 9(3), pp. 263-286.

Yenkimaleki, M. and van Heuven, V.J. (2018) The effect of teaching prosody awareness on interpreting performance: An experimental study of consecutive interpreting from English into Farsi. Perspectives. 26(1), pp. 84-99. 


\title{
15 \\ Community translation in New Zealand
}

\author{
Ineke Crezee, Jo Anna Burn and Wei Teng
}

\section{Introduction}

\section{Translation and social inclusion}

Community translation (CT) (Taibi and Ozolins 2016) provides minority group members with language access to public services such as health and legal facilities. Social inclusion is defined by the World Bank Group (2018) as "the process of improving the terms on which individuals and groups take part in society - improving the ability, opportunity, and dignity of those disadvantaged on the basis of their identity". The social, political, and economic consequences of social exclusion can be costly, and CT services are one way in which migrants may be assisted towards full participation in society (Inghilleri 2003).

Although New Zealand has increasingly become a destination country for migrants and refugees, constitutional lawyer Mai Chen (2015) expresses concern that it is not making best use of migrants' economic and social capital. This chapter aims to analyze a sample of CT texts by first assessing to what extent pragmatic equivalence is achieved in some English to Chinese translated texts. It will then discuss student translators' reflections on pragmatic equivalence before introducing a pedagogical approach in which students are encouraged to ask proofreaders to comment on sociocultural and language issues in a non-language-specific translation classroom. By introducing this approach, it is argued that trainee translators are assisted towards a greater awareness of the importance of achieving pragmatic equivalence, a key factor in encouraging social inclusion through accurately translated social texts.

A small corpus of 18 English to Chinese translations was developed. This language direction was chosen because in recent years a majority of non-English-speaking background (NESB) migrants have come from Mainland China (Immigration New Zealand 2016b). ${ }^{1}$ Consequently New Zealand has a growing community of older Chinese "chain" migrants (Johnston et al. 2006) and younger business migrants, both with limited English skills. One of the main aims of CT is to promote social inclusion amongst these groups, for instance, by facilitating participation in elections and in crime prevention (Chen 2015). However, for social inclusion to be possible, it is important that pragmatic equivalence is achieved. In New Zealand, health translation is in practice often undertaken by healthcare interpreters frequently 
lacking special medical translation training, and often fails to replicate the pragmatic functions of the English original (Teng 2019). This chapter specifically explores the translation of two out of the $18 \mathrm{CT}$ texts in our corpus. When undertaking a comparative analysis of the English source and Chinese target texts, we paid particular attention to pragmatic equivalence and whether we felt the translation might help (or hinder) social inclusion. The findings of this analysis were then triangulated with several years' worth of student translator reflections and proofreader comments on CT issues. Finally, we discuss how the use of reflection may facilitate student interpreters' awareness of pragmatic equivalence and the effect that this may have on social inclusion.

\section{Historical perspectives}

For centuries, translation theories in both the East (Asian countries) and the West (Europeaninfluenced countries) were largely based on translations of religious texts or literary works, occupying a continuum from literal translation to free translation (e.g. Chan 2004; Lee 2017; Munday 2001; Venuti 2004a; Wang and Fan 1999; Ye 2013). While literal translation aims to preserve as much as possible the original semantic and syntactical arrangements, free translation allows translators to conflate the translation with recreation and/or clarification based on their personal perspectives. As literal translation often results in bewildering expressions in the target language, and free translation heavily involves subjectivity from translators, so neither type accurately reflects the sociocultural dynamics of the target audience, in this case minority communities.

Nida (1964), himself a Bible translator, identifies two basic orientations in translation: formal correspondence versus dynamic equivalence, where the former results in more of a gloss translation, while the latter aims to produce an equivalent effect. Nida (1964) also identifies linguistic and cultural distance as factors to be taken into account by translators. In his sociolinguistic theory of translation Nida describes translation as "an act of communication" (1979, p. 104), where it is important to bear in mind "who said what, to whom, under what circumstances, for what reason, and to what purpose" (ibid. 1964). Nida (1979) identifies the five basic functions of communication as being informative, expressive, imperative, emotive and/or phatic, before stating that, if translators wish to produce "the closest natural equivalent of the original discourse" (Nida 1979, p. 107), they need to look beyond the text. Newmark (1981) followed on from Nida's work, distinguishing between a semantic or communicative translation approach, depending on the type of text and whether the focus of the translation was on the author of the original or on the target audience. Venuti (2004b) took the discussion further when he discussed translators choosing approaches that tended towards either foreignization or domestication. More recently, translation (and interpreting) scholars have begun to stress the importance of maintaining the locutionary and illocutionary intent of the original text (Hale 2014; Morris 1999; Searle 1968). This has shifted the discussion into the area of discourse analysis and pragmatics.

Pragmatic knowledge in particular is needed for translators to produce a translation that is acceptable in the sociocultural context of the translation (PACTE 2003). Therefore, crosslinguistic features must be considered so as to avoid "pragmalinguistic failures" (Thomas 1983; Hale 2014, pp. 323-324) when pragmatic equivalence is lost, and which may therefore jeopardize social inclusion. This chapter will include criteria based on Nida's (1979) concept of dynamic equivalence, while also focusing on whether pragmatic equivalence has been maintained. 


\section{Assessment criteria}

We assessed a small corpus of 18 translated texts against assessment criteria developed by Wei Teng, the third author. These criteria were developed within the framework of functional translation theories, such as Nord (1997), Vermeer (1989), Reiss (1981), and House (2006). We focused in particular on Nida's thoughts around dynamic equivalence (1964) and aim to assess whether a translation contains linguistic expressions that sound natural and make sense to the target audience, so as to maintain the original pragmatic functions. One instance would be the New Zealand concept of the Well Child check: if this were to be translated as 健康兒 童檢查/healthy child check, this might suggest to the reader that the check is specifically for children who are healthy. Whereas, in New Zealand, all children are included in the Well Child healthcare scheme.

The assessment criteria referred to previously were selected because they are, first, easy to use by lay proofreaders who, we argue, can play an important role in representing the intended target audience. Second, they are easy to use by those undertaking or teaching CT and by those editing the resulting texts. The authors are aware that Nida's concept of Dynamic Equivalence has in some ways been superseded, however it remains a valuable tool and has the great advantage of simplicity and is easy to use for translation assessment by lay proofreaders.

This chapter will use the previously described criteria to evaluate whether the pragmatic functions of the English original texts are achieved in two of the 18 Chinese translated texts and to explain instances of pragmalinguistic failure where pragmatic equivalence is not achieved. In the latter case, minority group members may potentially be denied access to the intended legal information which may hinder their social inclusion. This chapter will also introduce the pedagogical approaches of reflective teaching and student agency through self-regulation paradigms in teaching and learning, which can reveal student translators' (degree of) awareness of pragmatic equivalence. It can also help students become aware of the pivotal role of community translation as potentially facilitating social inclusion. González-Davies (2017, p. 129) describes a pedagogical approach she refers to as an integrated plurilingual approach (IPA) based on socio-constructivist premises which "advances teacher and student agency, reflective action and respect for diversity".

The chapter will draw on previous work by the authors on students' reflections on their own translation (Crezee 2016) or interpreting tasks (Crezee and Burn 2019), including feedback by same language proofreaders in or outside of the classroom (Crezee 2016). Montalt and García-Izquierdo (2016) advise that when preparing or translating factsheets for patients, it is important to involve representatives of the intended target audience in this process. This chapter will report on translation students involving lay reader comment on their drafts.

\section{Research approaches and key findings}

\section{Self (and peer)-reflection in translator education}

There is a growing body of literature on self- and peer-reflection for interpreters and translators (Robinson et al. 2006; Sachtleben and Denny 2011; Crezee 2016; Lee 2018; Crezee and Burn 2019). Lee's (2015) doctoral dissertation found that writing logbooks helped student interpreters become more reflective. Crezee (2016) similarly found that reflective blogs by student translators developed an increased sense of intercultural awareness which helped 
them reflect on strategies to convey a similar message in a manner that was aligned with the sociocultural and linguistic norms of the target language and improved performance in their summative translation exams. Robinson et al. (2006) reported on self-assessment in translator training, while Shih (2011) described students' reported learning from writing reflective learning journals in theory-based translation. Norberg (2014) reported on the value of retrospective guided commentaries in fostering self-reflection in undergraduate translation students over the course of two terms. See also Abdel Latif's (2018) helpful attempt to review and subsequently create a typology of all the interpreting and translation research from 208 studies published in 11 international journals over a ten-year period (2006-2015).

\section{Discussion of data sets}

This section reports on three data sets but will focus in detail on the third. The data came from three studies undertaken in New Zealand. The first set of data was taken from a study in progress (Teng, in progress), while the second data set consisted of student reflections on their own translation tasks and proofreader comments. The third was taken from a small number of texts relating to the community legal setting, and two of them will be described in some detail to illuminate our findings. A brief overview of the other two data sets is also given in what follows.

\section{First data set}

Teng (in progress) asked 15 professional English to Chinese translators in New Zealand, and 15 non-trained Chinese chain migrants to use four criteria to assess the extent to which the 15 translated texts in his health-related corpus: Sounded Natural (SN), Made Sense (MS), maintained the Original Manner (OM), and elicited a Similar Response (SR). His provisional findings indicate that professional translators tended to rate accuracy (MS - transfer of semantic meaning) as the best indicator of Total Equivalence. Lay proofreaders, on the other hand, rated Sounds Natural (SN) as the best indicator of successful transfer of meaning. These 15 texts are part of our 18-text corpus.

\section{Second data set}

Translation students over a period of three years were asked to translate health-related texts, before asking one health professional and one lay person in their language community to proofread the translation drafts. Where texts related to legal settings, students were asked to approach a same language (para)legal professional and a lay person as proofreaders. In general, proofreaders with a background in health or legal settings would comment on the correct use of terminology and on whether the content of the message had been accurately conveyed. Lay proofreaders on the other hand would comment on whether the translation sounded natural and whether they felt it was appropriate from a sociocultural perspective. This seems to coincide with the provisional findings of Teng (in progress) highlighting a difference in focus between content accuracy and accuracy of key terminology by proofreaders who were specialists in a particular field (health or legal), as opposed to a focus on Sounds Natural (SN) by lay proofreaders. In other words, proofreaders with a professional background seemed to focus more on Original Manner and Elicits a Similar Response, like the professional translators in Teng (in progress). 


\section{Third data set}

The third data set is a detailed analysis of how accurately the Chinese translations of two legal leaflets ${ }^{2}$ reflect the discursive features of the original, and attempt to assess if pragmatic equivalence is reached, and if not, why not. Chinese was chosen because the demographics of New Zealand are changing to include a growing community of older Chinese chain migrants as well as younger business migrants with limited English skills. The leaflets are Enduring Power of Attorney distributed by Age Concern Zealand (2013b) and $A$ Guide to Crime Prevention by the New Zealand Police (2014b). Enduring Power of Attorney comprises 16 pages, while the Guide to Crime Prevention contains 24 pages and covers ten topics. The Chinese translation of both English booklets follows the original content, paragraph and sentence structures (Age Concern New Zealand 2013a; New Zealand Police 2014a).

For each text, we will start by providing a brief analysis of the English source text, followed by an assessment of the translation using Teng's (2019) assessment criteria, paying particular attention as to whether the original manner (Nida 1964) or illocutionary intent of the original was maintained. The illocutionary force and intent of both English texts comprised a mixture of informative and (gently) persuasive (or operative, cf. Reiss 1981). The authors contend that texts lacking pragmatic equivalence may hinder social inclusion.

\section{Discursive analysis text one: Guide to Crime Prevention}

\section{Intent}

The pragmatic intent of the leaflet is to inform and provide helpful advice which the reader may choose to act upon - or not. In this it is typical of many information leaflets, such as the Age Concern leaflet about enduring power of attorney but is unusual in the amount of information that it attempts to convey and the variety of topics covered.

\section{Imagery: intercultural features}

Cover page: A montage of images prominently featuring a smiling young pākehā (Caucasian) male police officer in uniform talking to a middle-aged woman of unknown ethnicity, possibly Indian. Underneath this is a smaller image of another young male police officer bending down and interacting with a group of three pākehā-looking primary school-aged children. The leaflet title is at the bottom: A Guide to Crime Prevention with a smaller subtitle below, Safer Communities Together. The effect is one of conveying the subtext that the police are friendly and interested in community involvement with people of all ethnicities, ages, and genders.

Throughout the 24-page leaflet there are a number of pictures showing young uniformed male and female police officers interacting with largely pākehā members of the public, although one image does feature two school age girls of Indian-looking ethnicity.

Interestingly, there has been no attempt to include images of Chinese ethnicities in the Chinese version. This is a lost opportunity as many older Chinese people are afraid of uniformed officials and a cover image featuring Chinese New Zealand police officers interacting with Chinese members of the public in New Zealand could effectively convey a message of cultural openness and understanding. Similarly, the English leaflet missed the opportunity to include a greater range of ethnic groups, including Māori, the indigenous people. 


\section{Language}

An informal register sets the tone for the rest of the leaflet "The most important action you can do to make your place safer is to know your neighbours" (p. 3). The use of 'you' involves a direct appeal to the reader, as opposed to a more general 'we' or a third person construction. Also 'your place' is much more accessible language than your domicile, residence or other synonym. However, some of the language is quite sophisticated and clearly aimed at a native speaker, as a high level of language is assumed for the reader to be able to distinguish between intruder, prowler, and burglar on page 7. Page 9 actually quotes verbatim from Section 48 of The Crimes Act (1961) defining self-defence but the difficult legal language is also glossed as "You are allowed to defend yourself from attack, but use your common sense. The idea is to defend yourself - not to cause injury or get revenge. If you use unreasonable force, you are committing a crime".

\section{Discursive analysis text two: Enduring Power of Attorney}

\section{Intent}

The purpose of the text is to inform and gently offer advice, not to order, harangue or scare the reader into taking action. The aim is to also inform the reader of the legal concept, and raise awareness, of the importance of creating a power of attorney and thereby encouraging older people and their supporters to plan for the future. The intent is to empower the reader and encourage them to take agency in their own affairs. These are important features of social inclusion, as understanding is the first step towards engagement.

The leaflet is produced by Age Concern, a charity for older people and people supporting the elderly. The purpose is to inform the reader about enduring power of attorney (EPA), a legal process by which a donor can nominate another person to act on their behalf to take decisions about money, property, and personal care in the event that the donor lacks the capacity to do so him/herself.

\section{Imagery: intercultural features}

Some stylistic changes are made in the Chinese version to reflect ethnic and cultural differences between the English and Chinese versions, most notably in the photographic illustrations. These portray only people of Chinese ethnicity in the Chinese version, as opposed to a variety of ethnicities in the English language version.

\section{Language}

The purpose of an EPA is to prepare for a potentially catastrophic life event which most people feel very uncomfortable contemplating. The language of the opening paragraph is therefore sensitive and tenuous, employing the conditional if, the modal may, and the verb feel rather than more definite constructions: Do you feel confident that others will know how to look after you and your property if you become unable to do so yourself, such as through accident, illness, or incapacity? The pamphlet is designed for lay people and therefore uses simple, non-technical language, explaining legal concepts in simple, everyday language, and great effort has been made to avoid legal jargon as far as possible. The overall tone is one of helpful encouragement respecting the autonomy of the decision maker. 


\section{Findings: data sets one and two}

The findings from the first data set, involving 15 health texts and their Chinese translations, have been summarized in an earlier section. The findings from the second data set showed that providing students with some simple criteria for analysis of the source text (Newmark 1981; Nida 1964) and identifying the appropriateness of possible translation approaches can be very beneficial. The 2012 blogs in this dataset were written by a multilingual cohort consisting of seven students representing different languages: Korean (2), Arabic (2), Mandarin Chinese (2), and Portuguese (1). Where an earlier (2010) larger cohort of 30 students representing ten different languages had been asked to undertake nine different translation tasks and to comment on these in reflective blogs, the 2012 cohort was asked to undertake six translation tasks and report on the translation process in six blogs. The blogs were more in depth overall, and students cited a wider range of translation scholars when providing a rationale for their translation choices, some producing a sophisticated analysis. One student specifically mentioned the need for the translated text to maintain Formal Equivalence, a term which appeared to be a combination of Nida's (1964) concepts of Formal Correspondence and Dynamic Equivalence, and which may be compared to a blend of Newmark's (1981) semantic and communicative translation approaches respectively. This student wrote:

in some cases the legal feature described in a source document might not have a correspondent term in the target language due to discrepancies between the legal system that originated the source text and the legal system where the target text is fit for. When discussing problems of non-equivalence, Baker (1992) cites cultural-specific concepts to exemplify an obstacle in translation. These can be related to aspects of a society which are not present in other cultures. Newmark (1988) defends the use of cultural-free words to neutralise or generalise the source language word that carries the cultural nature.

Students were again asked to analyze the source text in terms of text type (informative, persuasive, expressive), purpose of the text, target audience, and any ambiguities, difficulties, text and context related issues (structure of sentences, translation of proper names, translation of idiomatic language, culture-specific items, puns), as well as the best translation approach plus the rationale for the chosen approach. Students were also encouraged to find parallel texts in the target language to assist the reverbalization process (Reiss 1981). One student asked a friend who was a lawyer to proofread her translation of a New Zealand birth certificate:

The proofreader, a lawyer who speaks Portuguese, suggested replacing the verb emitido (issued) to expedido (issued), both are synonyms but the second term is appropriate for the context. He also mentioned that the content of the document is precise and clear but dissimilar to the structure of a birth certificate issued in Brazil. For information and identification purposes [this] is, nevertheless, a useful document.

Recurrent comments included: pragmatic intent (e.g. irony, sarcasm) and whether this could be translated appropriately into the cultural and linguistic context of the target language, bearing the expected target readership in mind; the need to consider TL conventions when it came to the translation of formulaic texts such as death notices and birth certificates; the need to translate implied messages in the translation of work references and the culture-specific nature of such references. Korean-speaking students commented on the need to select the appropriate honorific terms of address in their language. 
Cultural issues were reported by all students, including the fact that a Korean death notice would not normally include an expression of gratitude to a nursing home or similar. Interestingly, students who received feedback from proofreaders often reported that the latter commented whether a translation did or did not sound natural.

\section{Findings: data set three}

Two evaluative tools were adopted when analyzing the third dataset of the leaflets described earlier: the first one aimed to evaluate the translation quality (Table 15.1), while the other aimed to reveal "pragmalinguistic factors" (Teng 2019), factors that determine whether pragmatic equivalence is achieved or not (Hale 2004, 2014; House 2006).

\section{Assessment tool one}

The first tool adopted in this study was developed based on Nida's concept of Dynamic Equivalence (1964), and the four requirements for achieving Dynamic Equivalence in translation. These criteria are shown in Table 15.1.

This set of assessment criteria has been applied in three previous studies, two of which reported on an assessment of trainee interpreters' performance in a semi-authentic court interpreting assignment (Crezee et al. 2017; Teng et al. 2018), while the third evaluated the translation quality of a New Zealand government-distributed healthcare-related pamphlet (Teng 2019). All three studies found that even when a rendition Sounded Natural and Made Sense, this did not always guarantee that the translation also elicited a Similar Response. The authors argue that if a translation elicits a Similar Response, this means that the illocutionary force and pragmatic functions of the original utterance or text have been maintained. Given the context of the current study, we hope that this evaluative tool will help reveal whether the degree of pragmatic force and intent of the English original has been maintained in the translation. Both texts had dual functions of being informative (Nida 1964; Newmark 1981; Reiss 1981) whilst trying to gently persuade the readers to follow a certain course of action. The authors argue that if this pragmatic intent and force have not been preserved, the target text may deviate from the source text to the point where we can say that the message has been lost. In such cases,

Table 15.1 Translation assessment criteria (revised from Teng 2019)

\begin{tabular}{|c|c|c|c|c|}
\hline \multirow{2}{*}{$\begin{array}{l}\begin{array}{l}\text { Criteria for } \\
\text { evaluation }\end{array} \\
\text { Possible } \\
\text { outcomes }\end{array}$} & \multicolumn{2}{|c|}{ Linguistic/sociocultural System } & \multicolumn{2}{|c|}{ Sociocultural System } \\
\hline & $\begin{array}{l}\text { Sounds Natural } \\
\text { (SN) }\end{array}$ & $\begin{array}{l}\text { Makes Sense } \\
\text { (MS) }\end{array}$ & $\begin{array}{l}\text { maintains } \\
\text { Original Manner } \\
(\mathrm{OM})\end{array}$ & $\begin{array}{l}\text { elicits } \\
\text { Similar Response } \\
(S R)\end{array}$ \\
\hline Total Equivalence & $\checkmark$ & $\checkmark$ & $\checkmark$ & $\checkmark$ \\
\hline OM-F & $\checkmark$ & $\checkmark$ & $x$ & $\checkmark$ \\
\hline SR-F & $\checkmark$ & $\checkmark$ & $\checkmark$ & $x$ \\
\hline OM-SR-F & $\checkmark$ & $\checkmark$ & $x$ & $x$ \\
\hline SN-OM-SR-F & $x$ & $\checkmark$ & $x$ & $x$ \\
\hline MS-OM-SR-F & $\checkmark$ & $x$ & $x$ & $x$ \\
\hline Totally Lost & $x$ & $x$ & $x$ & $x$ \\
\hline
\end{tabular}

Note: The letter $\mathrm{F}$ stands for Failure, denoting criteria not achieved in the translation; the symbol $\checkmark$ refers to the achievement of a criterion, and the symbol $\times$ refers to the failure of a criterion. 
readers do not have access to accurate publicly available information through community translation (Taibi and Ozolins 2016) and this becomes a barrier to social inclusion.

\section{Assessment tool two}

The second tool was developed by the third author (Crezee et al. 2017; Teng 2019, in progress; Teng et al. 2018) within the framework of systemic functional linguistics, and relies on the three contextual values of Field, Tenor, and Mode to determine whether a translation maintains the original ideational, interpersonal, and textual meaning (House 1981, 2001; Ghadessy and Gao 2000; Halliday 2001; Kim 2007; Kim and Matthiessen 2015). The authors hope that this evaluative tool will help us determine whether an expression is correct in the linguistic system of the target language, and whether an expression is appropriate in the sociocultural system of the target language - as shown in Appendix A - and is successful in conveying the Original Manner. For example, both leaflets use the imperative but are careful to do so under the guise of advice. A key feature of maintaining such pragmatic force in the translation is reflected in the use of a Chinese second personal pronoun 您/nin for the English you. Generally speaking, the pronoun 您/nin/you is used by a subordinate to address a superior in the socially hierarchical relationship in a Chinese society (i.e. Mainland China, Taiwan; Bing 2006; Nie 2009; Wan 2011; Wang 2013; Chang 2014, p. 62). Other than representing a hierarchical relationship between the addresser and addressee, the pronoun 您/nin/you, due to its respectful tone, is also commonly used in a customer-service context where the pronoun implies that customers' needs will be satisfied (Cui and Zhao 2014) because they are higher placed in the hierarchical relationship. Therefore, the use of the formal Chinese pronoun 您/nin/you reduces the social distance between the subordinate (i.e. the target reader) and the superior (i.e. the government official). Thus, the use of this pronoun helps fulfil the role of translation in facilitating the social inclusion of the (Chinese-speaking) minority.

\section{Unsuccessful delivery of original pragmatic force and intent}

The next step is to determine whether the pragmatic intent of the original text has been lost to such an extent that the message has been lost. This section uses two examples from the two English original texts, involving the Chinese modal verbs 要/yào and 应该/yingga ài in the translation. The two modal verbs are of particular interest because they deliver the pragmatic force of expressing obligation, as well as necessity and demands (Li and Thompson 1981; Liu et al. 1996; Hsieh 2005, 2006; Zhang 2015). The pragmatic force of the two Chinese modal verbs is in contrast to that of the English originals. The English text delivers its message in a suggestive and non-imperative tone (the original Manner) in order to make the target reader feel a sense of autonomy (the expected Response). However, the Chinese translation in the two examples failed to maintain the Original Manner and to elicit a Similar Response (OM-SR-F; $\mathrm{OM}$ and SR have Failed). Through inappropriate use of the modal verbs, the translation distorted the original contextual value of Tenor, as to the degree of autonomy given to the reader.

\section{Diminishing autonomy given to target reader}

The Chinese translation in Example 1 fails to maintain the original interpersonal meaning and fails to deliver an acceptable interpersonal meaning in the given Chinese sociocultural context, ensuring that the relationship between the agency proffering advice and the people is as equal as possible. In other words, the translation fails to elicit the response expected in the English original as to making the target reader feel that they can make their own decision. 
As can be seen in the back translation (BT), the failure is caused by the use of modal verb 要/yào, which diminishes the target reader's autonomy by removing other options that might be available for the Chinese reader when making decisions regarding EPA.

\section{Example 1 - OM-SR-F/Lex-App-T}

\begin{tabular}{ll}
\hline Text: & Enduring Power of Attorney - page 2 \\
Original: & Consider setting up an EPA along with your Will when planning ahead. \\
Translation: & 您在为将来做打算时, 尤其是在立遗嘱时, 要考虑起草一份持久授权书。 \\
BT: & When you are planning for the future, especially when making a Will, you have to \\
& consider setting up an EPA. \\
\hline
\end{tabular}

The English original involves the verb consider, with which the original sentence lacks intensifiers and explicit advice. The modal verb 要/yào/have to/must in the translation, however, places an obligation upon the address 您/nin/you (Hsieh 2005, p. 45) and expresses the necessity of that obligation be fulfilled (Zhang 2015, p. 131). Therefore, along with law-related context encompassing the translation, the modal may make the Chinese reader feel that they are obliged to set up an Enduring Power of Attorney because of the law, not because they themselves want to do so.

\section{Intensifying autonomy given to target reader}

In contrast to diminishing autonomy, the translation in Example 2 overly intensifies and hence distorts the original pragmatic force, the original degree of autonomy given to the target reader, meaning that translations neither maintain the Original Manner nor elicit a Similar Response (OM-SR-F).

The example is from the leaflet $A$ Guide to Crime Prevention (New Zealand Police 2014b), where the English original does use the imperative rather often, and the translation commonly involves the modal verb 应该/yinggāi (New Zealand Police 2014a) to express an assertive tone in order to make the Chinese reader feel that they should take the actions suggested. In Example 2 however, we can see this assertive tone being overly intensified by the modal, which leads to a misinterpretation of the informative purpose of New Zealand public information texts, and also, more worryingly of New Zealand law itself.

A serious error observed in Example 2 is a translation of a section of the New Zealand Crimes Act (1961). The translation inappropriately includes the modal verb 应该/yinggaini, giving the Chinese reader a distorted pragmatic effect as to what they should do, not what the law allows them to do.

\section{Example 2 - OM-SR-F/Lex-App-T}

\begin{tabular}{ll}
\hline Text: & A Guide to Crime Prevention - page 9 \\
Original: & "Every one is justified in using, in the defence of himself or another, such force \\
& as, in the circumstances as he believes them to be, it is reasonable to use." \\
& (Section 48 of the Crimes Act 1961) \\
“在保护自己或他人的时候, 每个人都有权在他认为在当时的情况下应该使用一定程 \\
Translation: \\
度的武力的时候使用该种程度的武力。” \\
BT: \\
When protecting oneself or others, everyone has the right to, when he thinks he \\
should use a certain degree of force, use that degree of force.
\end{tabular}


The English original uses the word justify to indicate that an individual is allowed by the law to use force when defending himself or others. However, the translation in this example, rather than diminishing the autonomy, overly emphasizes the right that the law gives to individuals to use force. As the distortion of autonomy is caused by the use of a lexical item, the modal verb 应该/yinggāi , we again assign the pragmalinguistic factor Lex-App-T to explain how Lexical Appropriateness could have an effect on maintaining the original contextual value of Tenor, which then results in the Target Text (TT) not maintaining the Original Manner nor eliciting a Similar Response (OM-SR-F).

As the modal 应该/yinggāi delivers an assertive tone to urge the addressee to take the suggested action (Li and Thompson 1981, p. 182; Liu et al. 1996, p. 101; Hsieh 2006; Zhang 2015), the Chinese reader's response that would be elicited by the translation is not similar to the response expected in the English original, because the translation seems to encourage the reader to use force. This illustrates the care that must be taken when translating legal material, as consequences of mistakes may be serious. Indeed, assault charges often revolve around what is considered reasonable force in the circumstances, and misleading information is therefore a source of concern, as ignorance (or misunderstanding) of the law is not a defence under New Zealand law.

The translations discussed in Example 1 and Example 2 represent how incorrectly selected lexical items, specifically the modal verbs 要/yào and 应该/yingga $\bar{i} i$, may distort the original interpersonal meaning in the sense of either diminishing the autonomy or overly intensifying the original degree of autonomy given to the target reader of the original English text. Discussion of the two examples also reveals two issues that deserve more discussion:

- How social inclusion of the target reader of a translated text can be achieved when the translation uses an imperative tone, urging readers to follow suggested actions while eroding their personal autonomy;

- Whether social inclusion can result when the translation employs an intensified imperative tone, giving too much autonomy to the extent that the resulting translation is misleading regarding New Zealand law.

\section{Pedagogic approaches and methods}

Based on the provisional findings of the three data sets, it is clear that first, professional translators and target audience representatives disagree as to what constitutes a good translation. Where the professional translators felt that total equivalence (TE) involves maintaining the Original Manner of the Source Text, the (lay) readers felt TE involves a translation that Sounds Natural. Second, student translators who reflected on text type, intended target audience, and translation problems were able to identify a range of problems, including cultural, pragmatic, and structural issues. In contrast, same language proofreaders often commented merely on the need for translations to Sound Natural and Elicit a Similar Response. Third, the analysis of texts presented in the third dataset showed that incorrect understanding of the Source Text can result in incorrect translations, which could hamper social inclusion, or have even more serious consequences (see Example 2).

In 2010, Ineke Crezee, the first author, introduced a then-new approach in the translation paper she taught by introducing reflective blogs whereby the students reflected on specific problems in texts they were asked to translate, whilst also being asked to provide a rationale for their chosen approach. Students were also asked to create several translation drafts and 
identify two possible proofreaders from within their language communities to give them feedback on these drafts. The process is represented in Figure 15.1:

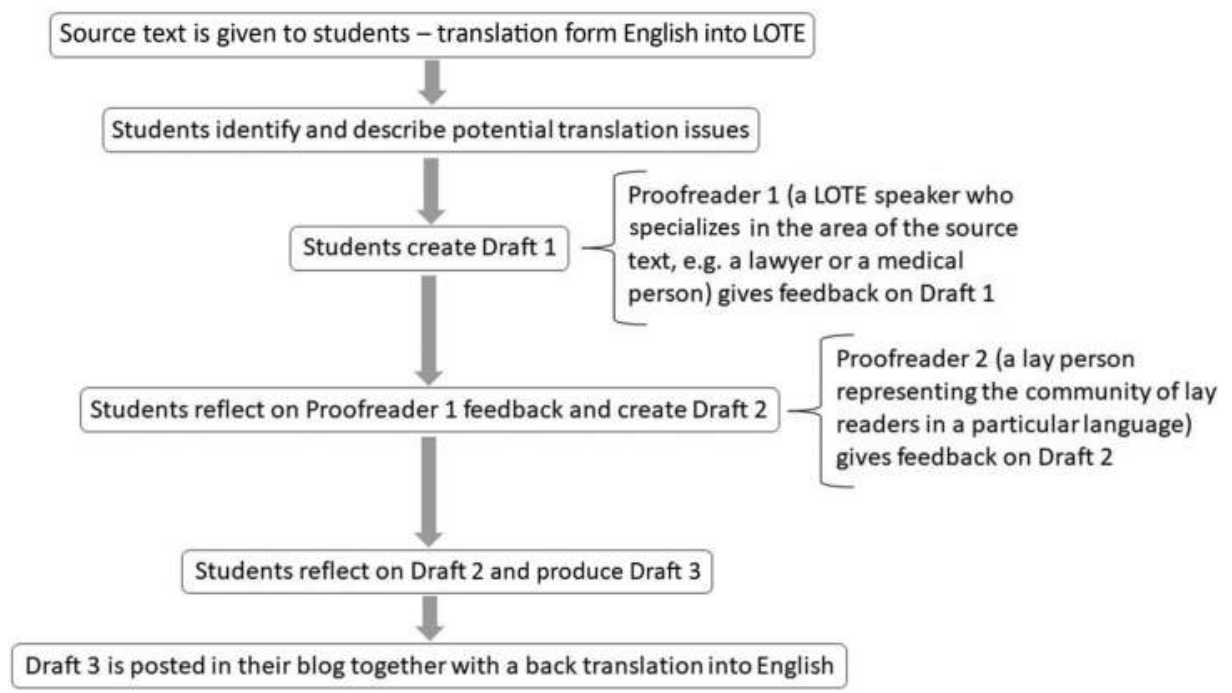

Figure 15.1 Students' reflection process.

The reflection and drafting process involves what González-Davies (2017) describes as "noticing", "deciding" and "justifying" and the pedagogical approach is a socio-constructivist one where learning, both about the process and the product is co-constructed by students and their proofreaders. The pedagogical approach also involves reflective teaching (and learning), student agency (as they are in control of the process), and self-regulation. The use of proofreaders enabled students to improve their pragmatic awareness of the function of texts. They were also encouraged to employ linguistic strategies to convey these functions more accurately under the guidance of the proofreaders. Reflection also encouraged the analysis of textual features such as semantics, syntax, extratextual reality, target readership, text function (Reiss 1981), reverbalization using parallel texts, and pragmatic equivalence (Hale 2014). Translation problems were recorded such as ambiguities, lexical and syntactic problems, and culturally specific terms.

Translation tasks in the paper included health, legal, newspaper opinion piece, and advertising so as to present students with a range of text types and text genres (Reiss 1981) to reflect on. As the course was taught in a non-language-specific classroom, a number of different languages were represented which provided rich data for analysis and class discussion. For example, the health text was a report on a patient's status before, during, and after hospital admission and the medical-specific vocabulary created problems for the Samoan student because of the absence of specialist dictionaries. This is an issue that we have observed for interpreters and translators with languages of limited diffusion including Pacific and refugee languages across all our courses and is another barrier to social inclusion. The use of passives and nominalizations in health and legal texts also caused problems when the agent of the action was missing. English-Chinese and English-Japanese translators commented that the informal tone of some English health and legal texts was culturally inappropriate. 
One legal text was a simple will with specific legal items such as 'testamentary guardian' and 'residuary estate' and many clauses involving double objects. A Japanese student commented that unlike Japanese wills, most of the sentences had declarative content clauses and double object constructions. Another student commented that in Mainland China the law did not distinguish between solicitors and barristers, or between 'separated' and 'divorced' and concluded that explanatory notes might be necessary to explain New Zealand legal concepts. This prompted an in-class discussion of Newmark (1981), who writes that informative texts usually require a communicative approach and expressive texts a semantic translation, but legal texts require something in between.

The expressive text was an opinion piece that relied heavily on irony, puns, and idiomatic language which one Korean student believed would be so culturally inappropriate as to be considered rude if translated directly. The persuasive text was an advertisement for kiwifruit and a number of students commented that the use of 'cocktail' in the phrase 'a cocktail of tropical flavours' was challenging, with a majority choosing to translate 'cocktail' as 'mixture' or 'combination', to avoid the misleading association with alcoholic beverage. This demonstrated reflection on the nature of the text, including culture-specific issues and the target audience when producing a culturally appropriate translation. The nature of student comments reflected what Gónzalez-Davies (2017, p. 129) described in relation to the use of translation in other learning contexts (TOLC, see this volume) in that "noticing, deciding, and justifying are key actions because the translation task involves conscious awareness not only of the product, but also of the process". The use of texts which students might be asked to translate 'in real life' reflected an attempt at a situated learning approach through the use of semi-authentic translation tasks. González-Davies et al. (2016, p. 1) write that "[u]ltimately, Situated Learning seeks to enhance learners' capacity to think and act like professionals", and this is what the teachers attempted to achieve here.

The reflections on both process and product prepared students for the issues faced by translators and guided them towards becoming independent practitioners. The weekly progression of blogs showed a developing awareness of covert translation issues such as ambiguities and difficult semantic, syntactic, and stylistic features. This was also reflected in the grades for the summative translation tests which improved from between $60-70 \%$ before the introduction of the reflective blogs to over $80 \%$ after their introduction. However, a serious limitation was the lack of control over the students' ability to identify a suitable proofreader, and quality of feedback from the proofreader. This was dependent on the trainee translator's networks, time available, and (meta)linguistic aptitude of the proofreader (and student).

In subsequent years, applicants for translation courses are asked if they have someone who can provide them with in-depth and appropriate feedback on their translated (or interpreted) tasks, and the significance of this is explained to applicants at the time of interview. A blog template is posted in course handbooks to direct student reflections. Lecturers read student feedback and encourage students to provide specific examples of translation issues, self-perceived translation errors and self-identified remedial strategies. Over the years, the authors have increasingly placed emphasis on the pragmatic intent and illocutionary force of the original texts, be these oral or written (Burn and Crezee 2017; Crezee et al. 2017; Teng et al. 2018) and this has allowed students to look beyond the words used and ponder appropriate ways of expressing similar intent and force in the target language.

\section{Conclusions and future directions}

This chapter has provided a brief overview of the analysis of three data sets and used these to introduce a rationale for a pedagogical approach which introduces student translators to some 
of the subtleties of language which need to be considered by expert translators to achieve full pragmatic equivalence. The pedagogical approach focuses on student reflections, which can reveal student translators' (lack of) awareness of pragmatic equivalence, and help students develop a connection between translation practice and social inclusion as well as realize the role of translation services as a facilitator of social inclusion. In countries like New Zealand that experience an increasing demand for $\mathrm{CT}$ in a number of languages, the non-language specific translator education approach outlined in this chapter may become a necessity. Helping students focus on the pragmatic intent and illocutionary force of the Source Text, involves helping them reflect on the sociocultural context in which (community) translation takes place, and their own role as facilitators of social inclusion.

\section{Further reading}

Latif, M.M.M.A. (2018) Towards a typology of pedagogy-oriented translation and interpreting research. The Interpreter and Translator Trainer. Routledge. 12(3), pp. 322-345. doi: 10.1080/ 1750399X.2018.1502008.

This paper has a main focus on providing a typology of research studies related to interpreter and translator education published over a ten-year period. In doing so, it provides excellent ideas for translator (and interpreter) educators in terms of what pedagogical approaches might or might not work, or what approaches they may want to research for themselves.

Norberg, U. (2014) Fostering self-reflection in translation students: The value of guided commentaries. The Journal of the American Translation \& Interpreting Studies Association. 9(1), pp. 150-164.

Norberg's paper looked at self-reflections on strategies and procedures used by undergraduate translation students and found that these commentaries were able to foster increased self-awareness of several aspects of the translation process.

Taibi, M. and Ozolins, U. (2016) Community Translation. London: Bloomsbury Publishing.

This book provides an introduction to the field of community translation (CT), and the context in which CT may be needed, providing a number of examples. It explores the social dimensions and social functions of translations and the relationships between text producers and audiences. Community translation is a very important area of translation for migrant communities, and one that promotes and facilitates social inclusion.

Gónzalez-Davies, M. (2017) The use of translation in an integrated plurilingual approach to language learning: Teacher strategies and best practices. Journal of Spanish Language Teaching. 4(2), pp. 124-135. In this paper, well-known translator educator Maria González-Davies describes the use of translation as a strategy to enhance additional language learning and plurilingual communicative competence in a plurilingual classroom. The paper builds on socio-constructivist pedagogical approaches and discusses key concepts such as noticing, deciding, and justifying.

García-Izquierdo, I. and Montalt Resurreció, V. (2017) Understanding and enhancing comprehensibility in texts for patients in an institutional health care context in Spain: A mixed methods analysis. Revista española de lingüistica aplicada. 30(2), pp. 592-610.

In this paper, the authors report on a study where they tested the readability and comprehensibility of fact sheets for patients in three stages, where the final stage involved the target readership of patients through focus discussion groups and questionnaires. Their findings and suggestions are of real interest to educators in the area of community translation.

\section{Related topics}

peer feedback on translated renditions, community translation, feedback from target audience readers, language policy, public service interpreting and translation 


\section{Notes}

1 Migrants enter under different immigration categories, some of which require a certain level of English proficiency (Immigration New Zealand 2016b). Other migrant categories, such as the Business Category or the Family Reunion category require minimal levels of English proficiency whilst the Investor Plus Category requires none (Immigration New Zealand 2016a).

2 The 18-text corpus consisted of the 15 texts discussed by Teng (in progress), two legal texts, and the Well Child text referred to previously, but not discussed in detail here.

\section{References}

Age Concern New Zealand. (2013a) Enduring Power of Attorney - Chinese [online]. Wellington, New Zealand: Age Concern New Zealand. Available from: www.ageconcern.org.nz/files/EPA/EPA Pamphlet 2013 Chinese Simpl.pdf [Accessed 1 February 2018].

Age Concern New Zealand. (2013b) Enduring Power of Attorney - English [online]. Wellington, New Zealand: Age Concern New Zealand. Available from: www.ageconcern.org.nz/files/EPA/EPA Pamphlet 2013 English.pdf [Accessed 1 February 2018].

Baker, M. 1992. In Other Words. A Coursebook on Translation. London and New York: Routledge.

Bing, S.L. (2006) The source of the honorific "Nin". Journal of Changsha University. 1, pp. 159-160.

Burn, J.A. and Crezee, I.H.M. (2017) That is not the question I put to you officer. An analysis of courtroom questions in New Zealand murder trial extracts, and challenges for student interpreters. International Journal of Interpreter Education. 9(1), pp. 40-56.

Chan, L.T. (2004) Twentieth-Century Chinese Translation Theory: Modes, Issues and Debates. Amsterdam: John Benjamins Plublishing Co.

Chang, L-P. (2014) Salient linguistic features of Chinese learners with different L1s: A corpus-based study. Computational Linguistics and Chinese Language Processing. 19(2), pp. 53-72 [online]. Available from: http://202.112.195.192:8060/hsk/login.asp [Accessed 21 September 2018].

Chen, M. (2015) Superdiversity Stocktake: Implications for Business, Government \& New Zealand [online]. Superdiversity Centre. Available from: www.chenpalmer.com/wp-content/uploads/Superdiversity _Stocktake.pdf [Accessed 27 March 2017].

Crezee, I.H.M. (2016) The benefits of reflective blogs in language-neutral translator education. FITISPos International Journal. 3, pp. 28-41.

Crezee, I.H.M. and Burn, J.A. (2019) Action research and its impact on the development of pragmatic competence in the translation and interpreting classroom, in Tipton, R. and Desilla, L. (eds) The Routledge Handbook of Translation and Pragmatics. London and New York: Routledge. pp. 355-372.

Crezee, I.H.M., Teng, W. and Burn, J.A. (2017) Teething problems? Chinese student interpreters' performance when interpreting authentic (cross-) examination questions in the legal interpreting classroom. The Interpreter and Translator Trainer. Routledge. 11(4), pp. 337-356. doi: 10.1080/1750 399X.2017.1359756.

Cui, Y. and Zhao, Y. (2014) The use of second-person reference in advertisement translation with reference to translation between Chinese and English. International Journal of Society, Culture \& Language. 2(1), pp. 22-36.

Ghadessy, M. and Gao, Y. (2000) Thematic organization in parallel texts: Same and different methods of development. Text - Interdisciplinary Journal for the Study of Discourse. 20(4), pp. 461-488. doi: 10.1515/text.1.2000.20.4.461.

González-Davies, M. (2017) The use of translation in an integrated plurilingual approach to language learning: Teacher strategies and best practices. Journal of Spanish Language Teaching. 4(2), pp. 124-135.

González-Davies, M. and Enríquez Raído, V. (2016) Situated learning in translator and interpreter training: Bridging research and good practice. Interpreter and Translator Trainer. 10(1), pp. 1-11. doi: 10.1080/1750399X.2016.1154339.

Hale, S. (2004) The Discourse of Court Interpreting: Discourse Practices of the Law, the Witness, and the Interpreter. Amsterdam: John Benjamins Publishing. 
Hale, S. (2014) Interpreting culture. Dealing with cross-cultural issues in court interpreting. Perspectives: Studies in Translatology. 22(3), pp. 321-331.

Halliday, M.A.K. (2001) Towards a theory of good translation, in Steiner, E. and Yallop, C. (eds) Exploring Translation and Multilingual Text Production: Beyond Content. New York: Mouton de Gruyter. pp. 13-18.

House, J. (1981) A Model for Translation Quality Assessment. Tübingen, Germany: Gunter Narr Verlag.

House, J. (2001) How do we know when a translation is good? in Steiner, E. and Yallop, C. (eds) Exploring Translation and Multilingual Text Production: Beyond Content. Berlin and New York: Mouton de Gruyter. pp. 127-160.

House, J. (2006) Text and context in translation. Journal of Pragmatics. 38, pp. 338-358. doi: 10.1016/j. pragma.2005.06.021.

Hsieh, C-L. (2005) Modal verbs and modal adverbs in Chinese: An investigation into the semantic source. Graduate Institute of Linguistics, National Tsing Hua University. 1, pp. 31-58.

Hsieh, C-L. (2006) The semantic categorization of Chinese modal expressions: A corpus-based analysis. Studies in Chinese Linguistics. 21, pp. 45-63.

Immigration New Zealand. (2016a) Acceptable English Language Test Results | Immigration New Zealand [online]. Available from: www.immigration.govt.nz/new-zealand-visas/apply-for-a-visa/ tools-and-information/english-language/acceptable-english-language-test-results [Accessed 20 December 2016].

Immigration New Zealand. (2016b) R1 - Resident Decisions by Financial Year [online]. Wellington, New Zealand. Available from: www.immigration.govt.nz/documents/statistics/r1 residencedecisionsbyfy.zip [Accessed 20 December 2016].

Inghilleri, M. (2003) Habitus, field and discourse: Interpreting as a socially situated activity. Target. 15(2), pp. 243-268. doi: 10.1075/target.15.2.03ing.

Johnston, R., Trlin, A., Henderson, A. and North, N. (2006) Sustaining and creating migration chains among skilled immigrant groups: Chinese, Indians and South Africans in New Zealand. Journal of Ethnic and Migration Studies. 32(7), pp. 1227-1250. doi: 10.1080/13691830600821935.

Kim, M. (2007) Using systemic functional text analysis for translator education. The Interpreter and Translator Trainer. 1(2), pp. 223-246. doi: 10.1080/1750399X.2007.10798759.

Kim, M. and Matthiessen, C. (2015) Ways to move forward in translation studies: A textual perspective. Target. 27(3), pp. 335-350.

Latif, M.M.M.A. (2018) Towards a typology of pedagogy-oriented translation and interpreting research. The Interpreter and Translator Trainer. 12(3), pp. 322-345. doi: 10.1080/1750399X.2018.1502008.

Lee, S-B. (2018) Scale-referenced, summative peer assessment in undergraduate interpreter training: Self-reflection from an action researcher. Educational Action Research. 27(2), pp. 1-21. doi: 10.1080/09650792.2018.1477609.

Lee, T.K. (2017) The identity and ideology of Chinese translators, in Shei, C. and Gao, Z-M. (eds) The Routledge Handbook of Chinese Translation. London and New York: Routledge. pp. 244-256.

Lee, Z. (2015) The Reflection and Self-Assessment of Student Interpreters Through Logbooks: A Case Study. PhD thesis, Heriot-Watt University, Edinburgh, United Kingdom.

Li, C.N. and Thompson, S.A. (1981) Mandarin Chinese: A Functional Reference Grammar. Berkeley and Los Angeles: University of California Press.

Liu, Y., Pan, W. and Gu, W. (1996) Modern Chinese Grammar for Teachers of Chinese as a Second Language and Advanced Learners of Modern Chinese. Taipei: Shidashuyuan.

Montalt, V. and García-Izquierdo, I. (2016)¿Informar o comunicar? Algunos temas emergentes en comunicación para pacientes. Panace@. 17(44), pp. 81-84.

Morris, R. (1999) The gum syndrome: Predicaments in court interpreting. Forensic Linguistics. 6, pp. 6-29.

Munday, J. (2001) Introducing Translation Studies. London and New York: Routledge.

Newmark, P. (1988) A Textbook of Translation (Vol. 66). New York: Prentice Hall.

New Zealand Police. (2014a) A Guide to Crime Prevention - Chinese [online]. Wellington, New Zealand: New Zealand Police. Available from: www.police.govt.nz/sites/default/files/publications/guideto-crime-prevention-chinese.pdf [Accessed 29 August 2018]. 
New Zealand Police. (2014b) A Guide to Crime Prevention - English [online]. Wellington, New Zealand: New Zealand Police. Available from: www.police.govt.nz/sites/default/files/publications/guide-tocrime-prevention-english.pdf [Accessed 29 August 2018].

Newmark, P. (1981) Approaches to Translation. London: Prentice Hall.

Nida, E.A. (1964) Toward a Science of Translating: With Special Reference to Principles and Procedures Involved in Bible Translating. Leiden: E.J. Brill. doi: 10.7202/003030ar.

Nida, E.A. (1979) Translating means communicating: A sociolinguistic theory of translation. The Bible Translator. 30(1), pp. 101-107.

Nie, Z.J. (2009) The origin of Chinese V-address. Journal of Harbin University. 1, pp. 67-73.

Norberg, U. (2014) Fostering self-reflection in translation students: The value of guided commentaries. The Journal of the American Translation \& Interpreting Studies Association. 9(1), pp. 150-164.

Nord, C. (1997) A functional typology of translations, in Trosborg, A. (ed) Text Typology and Translation. Amesterdam: John Benjamins Plublishing Co. pp. 43-66.

PACTE. (2003) Triangulating translation: Perspectives in process oriented research, in Alves, F. (ed) Building a Translation Competence Model. Amesterdam: John Benjamins. pp. 43-66. doi: 10.1075/ btl.45.

Parliamentary Counsel Office. (1961) Crimes Act 1961 No 43 (as at 28 September 2017), Public Act 48 Self-Defence and Defence of Another - New Zealand Legislation [online]. Available from: www. legislation.govt.nz/act/public/1961/0043/137.0/DLM328268.html [Accessed 26 September 2018].

Reiss, K. (1981) Type, kind and individuality of text: Decision making in translation. Poetics Today. 2(4), pp. 121-131.

Robinson, B.J., Rodríguez, C.I.L. and Sánchez, M.I.T. (2006) Self-assessment in translator training. Perspectives: Studies in Translatology. 14(2), pp. 115-138.

Sachtleben, A. and Denny, H. (2011) The teaching of pragmatics as interpreter training. International Journal of Interpreter Education. 3, pp. 4-15.

Searle, J.R. (1968) Austin on locutionary and illocutionary acts. The Philosophical Review. 77(4), pp. 405-424. doi: 10.2307/2183008.

Shih, C.Y. (2011) Learning from writing reflective learning journals in a theory-based translation module: Students' perspectives. The Interpreter and Translator Trainer. 5(2), pp. 309-324.

Taibi, M. and Ozolins, U. (2016) Community Translation. London: Bloomsbury Publishing.

Teng, W. (2019) When pragmatic equivalence fails: Assessing a New Zealand English to Chinese health translation from a functional perspective, in Ji, C., Taibi, M. and Crezee, I.H.M. (eds) Multicultural Health Translation, Interpreting and Communication. London and New York: Routledge. pp. $87-122$.

Teng, W. (in progress) Developing Assessment Criteria for Health Translation: Focusing on Pragmatic Equivalence in English-Mandarin Translated Health Texts. PhD thesis, Auckland University of Technology, Auckland, New Zealand.

Teng, W., Burn, J.A. and Crezee, I.H.M. (2018) I'm asking you again! Chinese student interpreters' performance when interpreting declaratives with tag questions in the legal interpreting classroom. Perspectives: Studies in Translation Theory and Practice. 26(5), pp. 745-766. doi: 10.1080/0907676X.2018.1444071.

The World Bank. (2018) Social Inclusion [online]. Available from: www.worldbank.org/en/topic/socialinclusion [Accessed 5 December 2018].

Thomas, J. (1983) Cross-cultural pragmatic failure. Applied Linguistics. 4(2), pp. 91-112. doi: 10.1093/ applin/4.2.91.

Venuti, L. (ed) (2004a) The Translation Studies Reader. 2nd ed. London and New York: Routledge.

Venuti, L. (2004b) Translation, community, utopia, in Venuti, L. (ed) The Translation Studies Reader. 2nd ed. London and New York: Routledge. pp. 482-502.

Vermeer, H. (1989) Skopos and commission in translational action, in Venuti, L. (ed) The Translation Studies Reader. 2nd ed. New York: Routledge. pp. 227-238.

Wan, S.H. (2011) A pragmatic interpretation of “您” in the slogans of advertisements. Theory Research. 27 , pp. $81-83$. 
Ineke Crezee, Jo Anna Burn and Wei Teng

Wang, K. and Fan, S. (1999) Translation in China: A motivating force. Meta: journal des traducteurs. 44(1), pp. 7-26. doi: 10.7202/004591ar.

Wang, X. (2013) On the personal pronoun “Nin” (您) in Qi Lu Deng (歧路灯) - A concurrent discussion on the source of honorific "Nin" (您). Journal of Nanyang Normal University. 8, pp. 18-21.

Ye, Z. (2013) Principles and Practice of English-Chinese Translation. 2nd ed. Taipei: Bookman.

Zhang, H. (2015) Comparative analysis of modal auxiliary verbs in English and in Chinese. Sino-US English Teaching. 12(2), pp. 128-136. doi: 10.17265/1539-8072/2015.02.007. 


\section{Appendix A}

Pragmalinguistic factors for achieving pragmatic equivalence (Teng 2019)

\begin{tabular}{|c|c|c|}
\hline & Linguistic system & Sociocultural system \\
\hline & correctness & appropriateness \\
\hline \multirow[t]{2}{*}{$\begin{array}{l}\text { Pragmalinguistic } \\
\text { factors }\end{array}$} & $\begin{array}{l}\text { - Lex-Corr } \\
\text { (Lexical correctness) }\end{array}$ & $\begin{array}{l}\text { - Lex-App-F } \\
\text { (Lexical appropriateness in Field) } \\
\text { - Lex-App-T } \\
\text { (Lexical appropriateness in Tenor) } \\
\text { - Lex-App-M } \\
\text { (Lexical appropriateness in Mode) }\end{array}$ \\
\hline & $\begin{array}{l}\text { - Syn-Corr } \\
\text { (Syntactical correctness) }\end{array}$ & $\begin{array}{l}\text { - Syn-App-F } \\
\text { (Syntactical appropriateness in Field) } \\
\text { - Syn-App-T } \\
\text { (Syntactical appropriateness in Tenor) } \\
\text { - Syn-App-M } \\
\text { (Syntactical appropriateness in Mode) }\end{array}$ \\
\hline
\end{tabular}




\title{
Translation and technology
}

\author{
Sharon O'Brien and Silvia Rodríguez Vázquez
}

\section{Introduction}

Translation Technology, Translation Tools, Translation Environment Tools (or TEnTs) and computer-aided translation (or CAT) are frequently used as synonyms. In its broadest sense translation technology is understood to include a large array of computer tools that help translators do their jobs, including word processors; spell, style, and grammar checkers; the World Wide Web; corpus compilation and analysis tools; terminology management tools; translation memory tools (TM); translation management systems (TMS); and machine translation (MT). Bowker (2002, p. 7) arranges these tools along a continuum from less automated (human translation) to more automated (machine translation), with CAT positioned in the middle. In the human translation rubric, she includes, for example, word processors and spell checkers, and in CAT, translation memory, corpus analysis tools, terminology management systems, data capture tools, localization and web-page translation tools, and diagnostic tools. The MT rubric includes only machine translation systems. This extensive list is evidence of how technologized the translation profession is. For the sake of clarity throughout this chapter, we refer to translation technology broadly speaking as computer-aided translation - CAT. Where machine translation is specifically meant, we use that term. Likewise, when we want to draw attention to a specific type of tool, we use the exact term, e.g. terminology management tool or translation memory (TM).

Over the last decades, parts of the translation profession have moved from deploying hardly any technology (in the 1980s), to embracing of translation memory and terminology management (in the 1990s), to the introduction of MT and its convergence with TM tools. Industry commentators predict a move towards fully-automatic useful translation - or FAUT - by 2030 (Massardo and van der Meer 2017). Currently, translators are still expected to produce high quality translation and that is often done with the aid of CAT tools. For this reason, it is important that translation technology is firmly embedded in the translator training curriculum. As Bowker (2002) points out, knowledge of CAT increases employability of graduates, but there are additional benefits to the teaching of translation technology: students can become more attuned to their own and to peer approaches to translation, data is created for research into translation, and reflections on the impact of technology on process, product, and profession can be generated. 
This chapter will first discuss early considerations on teaching translation technology. We select a subset of examples to give an overview of what these early considerations entailed. A number of formal translator competence models are examined so as to illustrate the place of translation technology in these models. Next, we provide a synopsis of research concerns relating to translation technology. Then, we review the pedagogical approaches adopted these days for CAT teaching before turning to conclusions, where we outline current and future challenges.

\section{Historical perspectives}

Kenny (1999) documents some of the first efforts in incorporating computer-aided translation tools into university curricula, mentioning in particular Carnegie Mellon University, the University of Leipzig, Dublin City University, and the University of Saarbrücken. Kenny (1999, p. 67) differentiates between CAT tools, used broadly to include word processors; electronic dictionaries; spell, grammar and style checkers; and machine translation. In her description, the primary difference is that CAT tools are seen to exist to assist humans, whereas MT is seen to replace them. At the time of publication of Kenny's article the state of the art in MT meant that what could best be hoped for was human assisted machine translation (HAMT) where a human was necessary to aid the machine. It is interesting to note that at our time of writing (two decades on), MT has effectively become a CAT tool, being incorporated into TM environments as an additional aid to the translator. We note also that MT is used for other purposes such as gisting, or obtaining the general sense of a text, where the translator does not, at least initially, play a role.

Kenny (1999, p. 68) poses broader questions on the benefits of CAT tools in the curriculum, such as "Can CAT tools be used to better our understanding of translation itself?" Additionally, she asks whether its introduction can open up new areas of research. The exciting possibility of using translation memory tools as a means to longitudinally log and document individual students' acquisition of translation competence over their course of study is mentioned. Yet, to the best of our knowledge, this potential has rarely been harnessed by translator educators, probably due, at least in part, to the logistical issues we discuss in our concluding section. We note some developments toward this goal with the piloting of a tool called TranslationQ to track computer-assisted revision in the classroom. ${ }^{1}$ On the other hand, the broad success of CAT and MT has led to a burgeoning field of research on the impact of such tools on the product (e.g. Jiménez Crespo 2009) and process (e.g. Dragsted 2005) of translation. The growing research on translation process, and especially the introduction of tools for capturing translation processes such as Inputlog, Translog, screen recording, and eye tracking (see, for example, Göpferich et al. 2008; O’Brien 2010) has not yet had the kind of impact on translator pedagogy that it could have. For example, the potential to use tools like Translog to allow self and peer review of the translation process, or to provide examples of expert behaviour, remains relatively untapped in translator pedagogy.

O'Brien published a proposal for course content for post-editing of MT output in 2002. At that time, a renewal of interest in MT was emerging. A combination of increasing translation data, resulting from the use of translation memory tools and improvements in data science in general, led to greater possibilities with data-driven MT. In 2002, very few, if any, translator education programmes were teaching machine translation, let alone post-editing, but this need was firmly on the horizon. O'Brien (2002) reviews the scant literature at the time and documents the skills associated with post-editing. These included skills that overlap with translation (e.g. source and target language skills, subject expertise), but also skills that were not 
typically associated with translation (e.g. tolerance, predisposition towards MT, knowledge of how to use macros in a word processor). O'Brien then goes on to outline a course structure for teaching post-editing that would include a theoretical component (teaching 'what') and a practical component (teaching 'how'). The proposal included aspects such as an introduction to controlled authoring (relevant at the time since ruled-based MT was still a dominant paradigm and it could therefore be influenced by the input sentence) and even basic programming skills. Almost two decades on, post-editing forms part of many, though not all, translator training programmes. It is sometimes included as a separate course and sometimes incorporated into a translation technology course.

A final topic worth mentioning from a historical perspective is that of localization. As MT was on the rise, the localization industry was also growing. Localization initially involved the translation and adaptation of software to new languages and locales. This included translation of user interface text, online help, documentation, packaging, and marketing materials. As the software as a service model grew in popularity, and with it cloud-based tools and apps, the industry expanded to include web apps and web content. The very first textbook explaining the complexity of localization was written by Bert Esselink in 1998 and revised in 2000. Though not directed at translators or translator trainers per se, this book served as an excellent introduction to the world of localization, covering topics that could be adopted in translation technology teaching, such as internationalization, desktop publishing, graphics localization, and project management. Esselink (2000) also dedicated an entire chapter to translation technology and terminology, as the localization sector was an early adopter of these tools.

In parallel with developments in the teaching of CAT, progress was also made in research into the teaching of translation competence in general. Several theoretical models of translator competence and its acquisition have been proposed over the past decades and continue to influence the approach to translator education. In what follows, we briefly examine the most influential models to uncover how they incorporate competence in translation technology specifically.

In PACTE's seminal article (2003), their revised competence model suggests that translation competence consists of five sub-competences, i.e. bilingual, extralinguistic, knowledge about translation, instrumental, and strategic. Furthermore, translation competence is seen to activate a series of psycho-physiological mechanisms (cognitive, attitudinal, and psychomotor mechanisms). In a subsequent article (PACTE 2005), the strategic component is identified as central to all other sub-competences. This component relates to the process of planning, evaluating, problem-solving, and activating different sub-competences.

In our view, two of these sub-competences directly relate to the teaching of translation technology: (1) knowledge about translation, which includes knowledge about translation practice and the work market, and (2) instrumental and strategic competence, which explicitly mentions information and communication technologies. Knowing how to use the technology is important but knowing how tools are used in the often rapidly changing market is also essential.

Göpferich (2009) highlights that there is no fully accepted model of translation competence, but there is broad agreement that it is composed of three core sub-competences: communicative competence in the source language and the target language, domain competence, and tools and research competence. What is relevant here is that she includes in her model a sub-competence called tools and research competence, described as comprising

the ability to use translation-specific conventional and electronic tools, from reference works such as dictionaries and encyclopaedias (either printed or electronic), term banks 
and other databases, parallel texts, the use of search engines and corpora to the use of word processors, terminology and translation management systems as well as machine translation systems.

(Göpferich 2009, p. 22)

A different approach to translation competence is taken by Kiraly (2013, p. 212), who deliberately selects not to list sub-competences because "there is no consensus on which ones actually exist". Rather than focusing on the acquisition of competence, Kiraly proposes a model for the emergence over time of translator competence from novice to expert. He points to the complex interplay of competences and to their non-parallel emergence. In relation to technological competence, according to Kiraly's model, this would emerge as students of translation are exposed over time to learning experiences with the tools.

This brief review of influential translator competence models demonstrates that competence in using translation tools (broadly understood) is seen to be a core element. Furthermore, other elements of the reviewed competence models feed into translation tool competence. We summarize these as socio-technical competence (knowing about the market, how tools are deployed) and personal aspects such as perseverance and critical spirit. These aspects are further endorsed by the European Master's in Translation (EMT) competence framework.

The EMT is a network of university masters' programmes in translation whose aim is to improve the quality of training and to help graduates to integrate smoothly into the translation job market. One of the outputs from the EMT is a competence framework, which was most recently updated in 2017. This competence framework lists five main areas of competence, of which 'technology-based' is one, along with language and culture, translation, personal and interpersonal, and service provision. The technology-based competence is described by the EMT Framework as including: "all the knowledge and skills used to implement translation technologies". It also includes basic knowledge of machine translation technologies and the ability to implement machine translation according to potential needs (EMT Network 2017, p. 9). The EMT framework lists six associated skills. As this competence model provides more explicit information on the competences and skills associated with translation technology, in comparison with that of PACTE, Göpferich or Kiraly, and since these skills would need to be taken into account for teaching purposes (at least in the European context), we reproduce them in full here:

- Use the most relevant IT applications, including the full range of office software, and become familiar with the new IT resources.

- Make use of search engines, corpus-based tools and CAT tools as well as CATA (computer-aided text analysis) tools.

- Pre-process, process and manage files and other media/sources as part of the translation, e.g. video and multimedia files, handle web technologies.

- Master the basics of MT and its impact on the translation process.

- Assess the relevance of MT systems in a translation workflow and implement the appropriate MT system where relevant.

- Apply other tools in support of language and translation technology, such as workflow software.

This substantial list not only indicates that what is understood as technology relevant to translating can be very broad, but it also presents challenges for the teaching of translation technologies, which we discuss in our conclusions. 


\section{Research approaches and key findings}

Far from being an exhaustive systematic review of the research work that has been conducted on the topic of CAT training, this section aims at providing an overview of the type of studies that have been carried out to better inform trainers on what to teach in relation to translation technologies and how to do it.

Many of the articles written about CAT training are, in fact, individual teaching accounts by the author(s), reporting on their experiences over the years, where sometimes a course description is included. These are often supported by a theoretical framework, but an empirical approach is rarely adopted. Of the three main didactic objectives proposed by Alcina and Granell (2007) for the acquisition of CAT skills - cognitive, procedural and attitudinal - the majority of the few empirical studies that exist in the field focus on the last objective. This aims for "the stimulation of positive attitudes towards technology, both recognising the important value that translation technology has for translators, and developing other attitudes, such as observation, perseverance and patience" (Alcina and Granell 2007, p. 231). Much of the current literature on the didactics of CAT pays particular attention to students' perception of translation technologies. Data is generally gathered through the questionnaires given to students at two different time intervals, normally at the beginning and at the end of the course. Some examples include the survey conducted by Gaspari (2001) regarding students' attitude to MT, the study conducted by Olalla Soler and Vert Bolaños (2013) with 85 undergraduates and ten graduates on their opinion about translation and other electronic tools in general, or the questionnaire administered by Mahfouz (2018) to more than 100 students in Egypt. Not surprisingly, findings in such studies are similar, showing that perception improves as students gain knowledge through practice.

Interestingly, some studies have aimed at measuring the knowledge students believe they have on CAT, rather than the actual knowledge they have acquired: a construct known as self-efficacy. For instance, Doherty et al. (2012) and Doherty and Kenny (2014) relied on both quantitative and qualitative measures (psychometric questionnaire, lecturer logs, focus groups, and end-of-course assignments) to measure their students' confidence in their ability to conduct different MT-related tasks. As in the case of the studies referred to previously, findings suggest that both time and intensive exposure to technologies have a positive impact.

Although these studies provide interesting insights with regard to the overall effectiveness of the teaching techniques used and the achievement of the learning outcomes, they do not directly examine the appropriateness of the content included in the syllabus.

Studies have also attempted to investigate what to teach in CAT courses. Some researchers propose that we should rely on current industry trends and the suggestions made by professionals concerning what is relevant for future translators. For instance, Rico Pérez (2017a) reviews prior research work conducted with translation professionals to define MT-related competences and learning outcomes. Similarly, Gaspari et al. (2015) conducted a questionnaire with not only translator trainers and academics, but also freelance translators and language service providers (LSPs) to clarify the needs and expectations of the community with regard to MT and post-editing. The idea was for trainers to use results to inform the syllabi of their courses so that they are more in line with current practices. One of their findings was that practitioners were not satisfied with the level of customization of the MT systems they are required to use, thus suggesting it as a topic worth examining more in depth during translator training. Identifying problems resulting from the use of translation technologies to then decide upon the corresponding skills to be learned is precisely one of the approaches suggested by 
Pym (2013) to inform syllabus design. Future research work could also focus on the opposite approach: subjecting CAT syllabi to review by industry stakeholders.

A needs analysis can be also conducted by consulting students directly. An innovative approach is the one proposed by Pym and Torres Simón (2016), who asked translation students what they would like to see answered. Although they did so in the context of a translation studies course, a similar approach could be adopted for CAT classes. It is interesting to note that in their study, which gathered a total of 662 questions put forward by more than 200 students, the authors showed that translation trainees were interested in four main aspects related to translation aids. These are: (1) whether they would replace translators, (2) which tools were most useful, (3) what new forms of translation new technologies would encourage, and (4) what research there was on localization and machine translation. While this approach can help trainers understand the expectations of students in terms of content, it would be desirable to complement it with other sources of data, as done by Doherty and Kenny (2014) for instance, who, apart from the students' feedback, relied on their observations (as instructors) of the range of interest, existing case studies, and published related data.

The definition of course content and the creation of materials can also be informed through indirect methods. Another viable research approach that has also been adopted in prior studies is corpus analysis. Depraetere (2010), for instance, studied a corpus of texts that had been post-edited by ten students in order to discover which post-editing guidelines she needed to most emphasize during translation training. Along the same lines, and using retrospective interviews with three students as the main data elicitation technique, Flanagan and Christensen (2014) aimed to discover how students interpret TAUS post-editing guidelines, with the ultimate goal of identifying potential competence gaps and addressing them by adapting that type of industry material for training purposes. As a result of the study, a new set of guidelines was created, including additional clarifying information to help trainees interpret them.

Finally, it is worth highlighting the use of research approaches and methods from other fields, such as psychology and human-computer interaction (HCI), to adapt course design. Doherty and Moorkens (2013), for example, used reflective journals in the form of weekly diaries to note observed difficulties and student behaviours during CAT lab sessions which, at the end of the semester, were compared with the results of an online survey administered to students. The triangulation of these data served to introduce improvements in the next academic year. Also, single case studies were used in combination with questionnaires by Rodríguez Vázquez and Mileto (2016) to assess the particular needs of blind students with regard to CAT learning.

\section{Pedagogic approaches and methods}

The penetration of technology in the professional translator's workspace and the consideration of technology-based competence as one of the pillars for career success have understandably led to an increase in the number of teaching and learning hours devoted to this area in translator education programmes. CAT seminars are occasionally taught within practical translation classes (Rico Pérez et al. 2018) but over the last years we have seen the emergence of new full courses and even postgraduate programme offers entirely dedicated to CAT training; for instance, the MSc in Translation Technology, in Dublin City University, or the MA in Multilingual Communication Technology, University of Geneva. From a pedagogic perspective, these more specialized programmes allow students to gain a deeper understanding of the widest array of technologies that exist nowadays, with the additional benefit of experiencing higher exposure time to the software included in the different courses. 
While these specialized programmes are gaining popularity, CAT training is still typically offered as part of the general translator training curriculum, both at an undergraduate level and a postgraduate level. Although our aim in this chapter is not to examine in detail the current academic offer in this regard, we have observed that the common trend is for CAT courses to adopt an introductory format at undergraduate level to then add more advanced content at postgraduate level. The format at undergraduate level includes an overview of existing technologies, their main functionalities and advantages and disadvantages (see example of syllabus in Rodríguez Castro 2018). The format at postgraduate level includes the examination of technical and professional issues linked to CAT and the assessment of tools according to different contexts of use (see example of syllabus in Doherty and Kenny 2014). However, the degree of specialization of CAT courses may be simply determined by the number of hours allocated to this subject in the programme's curriculum. Thus, some undergraduate programmes may cover more advanced aspects of CAT than postgraduate ones, if they offer more than one CAT course. The type of technologies included may vary as well, with recent studies demonstrating a stronger prevalence of machine translation-related contents in the syllabus (Depraetere 2010; Flanagan and Christensen 2014; Kenny and Doherty 2014).

In terms of objectives and learning outcomes, there seems to be general consensus among CAT trainers. Student translators should not only test the tools' functionalities (what) but also understand their relevance for the translator's work (why) and the situations in which their use could prove more beneficial (when), with the ultimate goal being to stimulate critical thinking and life-long learning (Bowker and Marshman 2010; Killman 2018; Rodríguez Castro 2018). Within such a pedagogical context, the emphasis is less on which tools are taught, but rather on how they are presented to the student. This change of focus has fostered the introduction in the classroom of alternative tools to the popular commercial translation software, which are seen to be more expensive and complex, and for which hundreds of hours of practising could be required by both trainers and trainees to reach a proficient level of use (Aiping and Deliang 2017). These alternate options include, among others, free and open source software (FOSS) translation technologies (Flórez and Alcina 2011), such as Apertium, OmegaT or Pootle to name just a few. They may also include technology developed in research projects that are then used for teaching and learning (e.g. the ACCEPT Academic Portal described in Bouillon et al. 2018), which generally offer a higher level of adaptability and contribute to lower licence costs, as well as lower maintenance and technical support costs (Veiga Díaz and García González 2015).

The content and learning outcomes briefly outlined here inevitably call for a practice-based approach to translation technology pedagogy. As noted by different scholars in the field, the popular constructivist perspective is often preferred over transmissionism in CAT training (Pym 2011; Rico Pérez 2017b). While the latter places the student in a passive learner position with respect to the teacher, who is the main reference point and source of knowledge, the former promotes the construction of knowledge in an interactive and collaborative manner, between and with students. In particular, situated learning has been subject to considerable attention in the literature as a socio-constructivist pedagogical approach (Kiraly 2000, 2005; González-Davies and Enríquez Raído 2016) that is chosen by many CAT trainers, although their interpretation of the concept takes different forms. When the classical task-based or project-based situated learning is adopted in the CAT classroom, students develop both instrumental and critical thinking techniques through role adoption and the recreation of quasi-real translation activities or scenarios, previously designed by the teacher. While this is the most common form of situated learning, it is often argued that the simulation of a computer-assisted translation task or project should not take place in isolation but rather be embedded in practical translation courses (Pym 2013; Mellinger 2017). 
A one-fits-all solution does not exist regarding which teaching techniques to follow, whose choice may, in turn, be directly influenced by the type of learning environment (face to face, online, blended). As described in Rico Pérez (2017b), teaching techniques in learnercentred settings can be categorized in four main groups: (1) one-to-many, (2) many-to-many, (3) one-to-one, and (4) one-alone. Task-based instruction models typically combine the first two, with short lectures followed by practical hands-on sessions where students work individually or in groups, normally with the teacher's support. Exercises conducted during labs may vary from the classical inspection of the functionalities of a given tool to more advanced evaluation activities, such as the assessment of the utility of CAT tools in a specific context of use (Starlander and Morado Vázquez 2013) or the comparison of different MT systems in terms of post-editing effort, adequacy, and error typology (Moorkens 2018). These in-class activities can be also accompanied by reflective exercises which invite students to think about different aspects related to the use of the tools they have just tested and prevent them from blindly following instructions. Reflective learning journals in general and e-portfolios in particular have been recently put forward as a novel technique for CAT learning. Although its efficacy as a method has not been empirically tested yet, e-portfolios offer, in Rico Pérez's view (2017b), a more empowering academic experience, through which students gain authority and confidence as they show they are individual learners and they are meeting high standards of achievement. While often seen as complementary exercises, forum, online quizzes (Varela Salinas 2007), and peer feedback (Flanagan and Heine 2015) are examples of many-to-many teaching and learning techniques whose full potential has not yet been completely unlocked in CAT training. Similarly, it would be interesting to test the efficacy of more one-alone analytical techniques, such as Pym's learning proposal of self-analysis of the translation process, where students could record their on-screen computer-assisted translation processes and see how that affects performance (Pym 2013).

All in all, regardless of the variety of pedagogical approaches and methods identified, we have observed that many challenges still remain with regard to the teaching of translation technology and that, in fact, these are often overlapping and influence each other. For ease of discussion we divide them into three broad categories here.

\section{Teaching and learning}

An important consideration in teaching translation technology is how to establish an acceptable balance between teaching formats. A typical approach is to mix a lecture and lab format, where lectures introduce concepts and tools in general and labs provide structured opportunities for students to learn and apply knowledge using the tools. There is a tension here, we believe, between teacher and student preferences. Students are understandably focused on gaining practical skills deemed to be beneficial for the workplace. Teachers, while also seeing this as an essential learning outcome, also prioritize opportunities to teach about concepts, benefits, and disadvantages in general, which can be applied to any tool, not only specific ones. The features in particular tools can change relatively rapidly. Market leaders can be toppled from year to year, hence the need for students to learn to learn (Kiraly 2013; Pym 2013). Thus, it would seem sensible not to focus only on specific tools and to attempt to establish a good balance between the 'what' and 'why' (lectures) and the 'how' (labs).

It is impossible to say what this balance might look like as many factors will play a role (e.g. the duration of the course, whether it is undergraduate or postgraduate level, number of credits, etc.). Combining the two formats in one teaching session is an option too; in this case, some lecture content would first be presented, followed immediately by a lab session, and this 
could continue in a cycle for specific teaching and learning points. However, it should be borne in mind that lab set-ups are not always the best environments for the delivery of typical lecture or seminar content - students are obviously focused on the screen in a lab. Recurring course evaluation could help inform what the best balance might be for each particular teaching and learning context.

The raison d'être of translation technology is to aid the translation process, broadly speaking. Why then, is translation technology not more embedded in translation practice classes, in keeping with the view of translation as a situated practice (Kiraly 2005; Risku 2005)? The teaching of translation per se tends to be separated from the teaching of technological skills. There are both pedagogical and practical reasons that serve to explain this. Pedagogically, a strong belief seems to exist that students should gain skills in the fundamental human process of translation before becoming reliant on tools. Yet, this belief is open to criticism as very few (if any?) translators work without some form of human-computer interaction these days (O'Brien 2012). Alongside the pedagogical argument, there are some practical explanations: it would be logistically challenging to schedule every translation class, for every language pair, in a lab. Furthermore, even if this were possible, it would require every teacher of specialized translation to be relatively comfortable with a broad toolset, something that is currently unrealistic. A proposal for overcoming these challenges is to have an additional course that combines authentic project and situated approaches to translation that includes team work across multiple roles, for example, project manager, terminologist, translator, reviser (Kiraly 2005), as well as all required tools to replicate a real translation project (Austermühl 2013).

\section{Human resources}

A significant challenge in teaching translation-related technology is the continuous demand on teaching staff to stay abreast of technology innovation, whether in the basic form of new features or significant advances in technologies. This effectively requires continuous professional development (CPD) on the part of teaching staff. Even so, it is impossible to know each tool and type of technology in considerable depth. Teachers will therefore have to focus on a subset of tools.

As versions of software are released frequently nowadays, lab instructions, including screen shots, can become redundant from one year to the next, necessitating a continuous update. This places considerable demands on the time of those who teach such modules, especially in comparison with courses where knowledge evolves at a slower pace. To keep this challenge under control, it is perhaps wise not to upgrade every time a new version is released, especially since upgrades often involve only minor changes in features.

Anyone who has tried to teach a lab on his or her own with large numbers of students will be aware of how mentally and physically demanding this can be. As is the wont of technology, things will go wrong for some people and troubleshooting can take time away from running the lab. Keeping numbers relatively small can help, but this inevitably leads to a greater number of groups and contact hours. Having more than one instructor in a lab can also ease this problem.

Regardless of the course in which the CAT-oriented situated learning takes place, it will always demand a well-informed instructor, always up to date with recent industry trends and new technologies. Aiping and Deliang (2017, pp. 410-417) consider that this is the main reason why this pedagogical approach is not sustainable, arguing that realistic simulation is complex, if not impossible: the more authentic an environment is, the more input from the industry it requires: real translation tasks, translation briefs, proofreading, customer feedback, 
technical support, etc. They contribute to the literature with a different vision of situated learning, where students acquire CAT-related skills within the framework of authentic translation assignments, leaving behind in-class simulated projects. They illustrate their position with the case of some universities in China, where there is a translation centre that accepts external translation contracts or where students accept real translation jobs requested by the school itself. The advantages of such an approach are clear, as students understand the usefulness of translation aids through first-hand experience. However, this third form of situated learning comes with associated challenges, including ethical concerns (e.g. should students be paid for what they do?) and time issues, as the quality control and coordination efforts required on the instructor's side may result in a similar time investment when compared to the adaptation of quasi-real scenarios for the classroom.

\section{Technical and economic}

It goes without saying that technical issues can arise when teaching technology. In relation to translation tools in particular, there may be occasions where one tool requires a certain computer specification and/or operating system that may clash with the requirements of other tools. If labs are shared across a broad university community, the problem may be worsened. Having a strong technical support team in place is a prerequisite. Nevertheless, broad-spectrum technical support teams are rarely trained in the vagaries of translation technology. These days, there is a trend in favour of cloud-based tools, which rely only on having a browser and access to the Internet. We expect that in the future we will deploy such solutions to a greater extent as they remove some of the challenges that come with having to locally install and support software.

Some of the challenges listed here have been addressed in the CERTT project (Bowker and Marshman 2010) through the creation of a centralized repository of CAT-related materials (tutorials with questions for reflection, exercises, sample texts, slides, glossaries, FAQ, bug reports, and solutions) supporting independent and in-class learning. This resource, designed both for educators and learners, was implemented in Canada for both CAT-dedicated and specialized translation courses. According to Marshman and Bowker (2012), the platform was well received by both instructors and students, who particularly welcomed the introduction of translation technology in the technical translation course and preferred this modality over a stand-alone CAT course.

Some software used for teaching translation-related technology is free of charge and some comes with a discounted academic licence. How much, or even whether, an academic department has a budget for this will determine which tools can be deployed in teaching. The students and universities clearly benefit from having access to this technology. However, the software companies and ultimately the market are significant beneficiaries too. In the case of translation technology, a symbiosis exists, which ought to be taken into consideration when costs are being negotiated.

\section{Conclusions and future directions}

CAT is a broad concept, comprising many tools and functionalities. The ability to critically use and evaluate such tools is firmly embedded in translator competence models. Given the broad array of tools available and the rapid pace of development, its teaching poses numerous challenges for the present and for the future, which in turn has led to embryonic research on the topic, as discussed in this chapter.

There is no clear answer to the question of how best to teach translation technology, not least because the technology continues to evolve, at times at a faster pace than academia can 
keep abreast of. Nonetheless, there appears to be a consensus that it is imperative to teach students not just how to use technology, but also when to use specific technologies, why they are used, and what the implications of an increasingly technologized profession might be. Understanding this final point in a world where technology development is incredibly rapid is crucial for students. Furthermore, equipping students with skills to adapt to rapid technological change is perhaps of equal importance to teaching them about state-of-the-art technologies. In translation teaching in general, and in the teaching of CAT, there is an increased focus on social constructivist approaches and collaborative learning experiences, which we expect will be embraced further over the coming years.

\section{Further reading}

Bowker, L. (2015) Computer-aided translation: Translator training, in Sin-wai, C. (ed) Routledge Encyclopedia of Translation Technology. Oxon, NY: Routledge. pp. 88-104.

Bowker's contribution and the present chapter address the same topic, but from different angles, so they complement each other. In her chapter, Bowker provides insightful arguments related to the need for translators to learn about CAT and the different challenges associated to this new reality.

Doherty, S. and Kenny, D. (2014) The design and evaluation of a statistical machine translation syllabus for translation students. The Interpreter and Translator Trainer. 8(2), pp. 295-315.

Kenny, D. and Doherty, S. (2014) Statistical machine translation in the translation curriculum: Overcoming obstacles and empowering translators. The Interpreter and Translator Trainer. 8(2), pp. 276-294. These two articles go hand in hand. They address the topic of teaching (statistical) machine translation. The first discusses potential barriers to the use of SMT by translators generally and in translator training in particular while the second article uses a mixed-methods approach that aims to capture students'view of an SMT syllabus and their self-assessment of their own learning.

O'Hagan, M. (2013) The impact of new technologies on translation studies: A technological turn?, in Millán, C. and Bartrina, F. (eds) The Routledge Handbook of Translation Studies. New York: Routledge. pp. 503-518.

This chapter places emphasis on the implications of the emergence of translation technology for translation studies as a field of research, with a special focus on social aspects.

Roturier, J. (2015) Localizing Apps. New York: Routledge.

Although the book revolves around the topic of localization, 'Chapter 5. Translation technology' offers a comprehensive overview of the most popular types of translation aids used nowadays. It not only describes their main characteristics with illustrative examples, but it also puts forward four sample tasks that could be used for CAT training purposes.

\section{Related topics}

computer-assisted language learning, translation teacher training

\section{Note}

1 www.televic-education.com/en/translationq (Last access: 10 December 2018).

\section{References}

Aiping, M. and Deliang, M. (2017) The ecosystem of translator workstation: Learning electronic tools in a training program for professional translators in China. Babel. 63(3), pp. 401-422.

Alcina, A. and Granell, J. (2007) Translation technology skills acquisition. Perspectives: Studies in Translatology. 15(4), pp. 230-244. 
Austermühl, F. (2013) Future (and not-so-future) trends in the teaching of translation technology. Revista Tradumàtica. 11, pp. 326-337.

Bouillon, P., Gerlach, J., Gulati, A., Porro Rodriguez, V. and Seretan, V. (2018) The ACCEPT academic portal: A pre-editing and post-editing teaching platform, in Corpas Pastor, G. and Durán-Muñoz, I. (eds) Trends in E-tools and Resources for Translators and Interpreters. Leiden: Brill. pp. 175-202.

Bowker, L. (2002) Computer-Aided Translation Technology: A Practical Introduction. Ottawa: University of Ottawa Press.

Bowker, L. and Marshman, E. (2010) Toward a model of active and situated learning in the teaching of computer-aided translation: Introducing the CERTT project. Journal of Translation Studies. 13(1-2), pp. 199-226.

Depraetere, I. (2010) What counts as useful advice in a university post-editing training context? Report on a case study, in Yvon, F. and Hansen, V. (eds) Proceedings of the 14th Annual Conference of the European Association for Machine Translation, Saint-Raphaël, France, 27-28 May [online]. Available from: www.mt-archive.info/EAMT-2010-Depraetere-2.pdf [Accessed 6 June 2019].

Doherty, S., Kenny, D. and Way, A. (2012) Taking statistical machine translation to the student translator. Proceedings of the 10th Biennial Conference of the Association for Machine Translation in the Americas, San Diego, 28 October-1 November [online]. Available from: https://doi. org/10.13140/2.1.2883.0727 [Accessed 6 June 2019].

Doherty, S. and Moorkens, J. (2013) Investigating the experience of translation technology labs: Pedagogical implications. JoSTrans. The Journal of Specialised Translation. 19, pp. 122-136.

Dragsted, B. (2005) Segmentation in translation: Differences across levels of expertise and difficulty. Target. 17(1), pp. 49-70.

EMT Network. (2017) European Master's in Translation Competence Framework. European Commission [online]. Available from: https://ec.europa.eu/info/sites/info/files/emt_competence_fwk_2017_ en_web.pdf [Accessed 6 June 2019].

Esselink, B. (2000) A Practical Guide to Localization. Amsterdam: John Benjamins.

Flanagan, M. and Christensen, T.P. (2014) Testing post-editing guidelines: How translation trainees interpret them and how to tailor them for translator training purposes. The Interpreter and Translator Trainer. 8(2), pp. 257-275.

Flanagan, M. and Heine, C. (2015) Peer-feedback as a translation training tool in web-based communication. Hermes - Journal of Language and Communication in Business. 54, pp. 115-136.

Flórez, S. and Alcina, A. (2011) Free/open-source software for the translation classroom. The Interpreter and Translator Trainer. 5(2), pp. 325-357.

Gaspari, F. (2001) Teaching machine translation to trainee translators: A survey of their knowledge and opinions, in Forcada, M.L., Pérez Ortiz, D.R. and Lewis, D. (eds) Proceedings of the Workshop 'Teaching Machine Translation'. Santiago de Compostela, Spain. pp. 35-44 [online]. Available from: http://mt-archive.info/MTS-2001-Gaspari.pdf [Accessed 6 June 2019].

Gaspari, F., Almaghout, H. and Doherty, S. (2015) A survey of machine translation competences: Insights for translation technology educators and practitioners. The Interpreter and Translator Trainer. 23(3), pp. 333-358.

González-Davies, M. and Enríquez Raído, V. (2016) Situated learning in translator and interpreter training: Bridging research and good practice. The Interpreter and Translator Trainer. 10(1), pp. 1-11.

Göpferich, S. (2009) Towards a model of translation competence and its acquisition: The longitudinal study 'TransComp', in Göpferich, S., Jakobsen, A.L. and Mees, I. (eds) Behind the Mind: Methods, Models and Results in Translation Process Research. Copenhagen: Samsfundslitteratur. pp. 11-37.

Göpferich, S., Jakobsen, A.L. and Mees, I. (eds) (2008) Looking at Eyes: Eye-tracking Studies of Reading and Translation Processing. Copenhagen: Samsfundslitteratur.

Jiménez Crespo, M.A. (2009) The effect of translation memory tools in translated web texts: Evidence from a comparative product-based study. Linguistica Antverpiensia. 8, pp. 213-232.

Kenny, D. (1999) CAT Tools in an academic environment: What are they good for? Target. 11(1), pp. $65-82$. 
Kenny, D. and Doherty, S. (2014) Statistical machine translation in the translation curriculum: Overcoming obstacles and empowering translators. The Interpreter and Translator Trainer. 8(2), pp. 276-294.

Killman, J. (2018) A context-based approach to introducing translation memory in translator training, in Godev, C.B. (ed) Translation, Globalization and Translocation: The Classroom and Beyond. Cham: Palgrave Macmillan. pp. 137-159.

Kiraly, D.C. (2000) A social Constructivist Approach to Translator Education: Empowerment from Theory to Practice. Manchester: St. Jerome Publishing.

Kiraly, D.C. (2005) Project-based learning: A case for situated translation. Meta: Journal des traducteurs. 50(4), pp. 1098-1111.

Kiraly, D.C. (2013) Towards a view of translator competence as an emergent phenomenon: Thinking outside the box(es) in translator education, in Kiraly, D.C., Hansen-Schirra, S. and Maksymski, K. (eds) New Prospects and Perspectives for Educating Language Mediators. Tübingen: Narr Verlag. pp. 197-224.

Mahfouz, I. (2018) Attitudes to CAT tools: Application on Egyptian translation students and professionals. Arab World English Journal (AWEJ). 4, pp. 69-83.

Marshman, E. and Bowker, L. (2012) Translation technologies as seen through the eyes of educators and students: Harmonizing views with the help of a centralized teaching and learning resource, in Hubscher-Davison, S. and Borodo, M. (eds) Global Trends in Translator and Interpreting Training. London: Continuum. pp. 69-95.

Massardo, I. and van der Meer, J. (2017) The Translation Industry in 2022: A Report from the TAUS Industry Summit. TAUS [online]. Available from: www.taus.net/think-tank/reports/event-reports/thetranslation-industry-in-2022 [Accessed 6 June 2019].

Mellinger, C.D. (2017) Translators and machine translation: Knowledge and skills gaps in translator pedagogy. The Interpreter and Translator Trainer. 11(4), pp. 280-293.

Moorkens, J. (2018) What to expect from neural machine translation: A practical in-class translation evaluation exercise. The Interpreter and Translator Trainer. 12(4), pp. 375-387.

O'Brien, S. (2002) Teaching post-editing: A proposal for course content. Proceedings of the 6th EAMT Workshop 'Teaching Machine Translation', Manchester. pp. 99-106 [online]. Available from: www. mt-archive.info/00/EAMT-2002-OBrien.pdf [Accessed 6 June 2019].

O'Brien, S. (2010) Eye tracking in translation process research: Methodological challenges and solutions, in Mees, I., Alves, F. and Göpferich, S. (eds) Methodology, Technology and Innovation in Translation Process Research. Copenhagen: Samsfundslitteratur. pp. 251-266.

O'Brien, S. (2012) Translation as human - Computer interaction. Translation Spaces. 1(1), pp. 101-122.

Olalla-Soler, C. and Vert Bolaños, O. (2013) Traducción y tecnología: uso y percepción de las tecnologías de la traducción. El punto de vista de los estudiantes. Revista Tradumàtica. 11, pp. 338-356.

PACTE. (2003) Building a translation competence model, in Alves, F. (ed) Triangulating Translation: Perspectives in Process Oriented Research. Amsterdam: John Benjamins. pp. 43-66.

PACTE. (2005) Investigating translation competence: Conceptual and methodological issues. Meta. 50(2), pp. 609-619.

Pym, A. (2011) Training translators, in Malmkjær, K. and Windle, K. (eds) The Oxford Handbook of Translation Studies. Oxford, England: Oxford University Press. pp. 475-489.

Pym, A. (2013) Translation skill-sets in a machine-translation age. Meta. 58(3), pp. 487-503.

Pym, A. and Torres-Simón, E. (2016) Designing a course in translation studies to respond to students' questions. The Interpreter and Translator Trainer. 10(2), pp. 183-203.

Rico Pérez, C. (2017a) La formación de traductores en traducción automática. Tradumàtica. 15, pp. $75-96$.

Rico Pérez, C. (2017b) The ePortfolio: Constructing learning in translation technology. The Interpreter and Translator Trainer. 11(1), pp. 79-95.

Rico Pérez, C., Sánchez-Gijón, P. and Torres-Hostench, O. (2018) The challenge of machine translation post-editing: An academic perspective, in Corpas Pastor, G. and Durán-Muñoz, I. (eds) Trends in E-Tools and Resources for Translators and Interpreters. Leiden: Brill. pp. 203-218.

Risku, H. (2005) Situatedness in translation studies. Cognitive Systems Research. 3(3), pp. 523-533. 
Rodríguez Castro, M. (2018) An integrated curricular design for computer-assisted translation tools: Developing technical expertise. The Interpreter and Translator Trainer. 12(4), pp. 355-374.

Rodríguez Vázquez, S. and Mileto, F. (2016) On the lookout for accessible translation aids: Current scenario and new horizons for blind translation students and professionals. Journal of Translator Education and Translation Studies. 1(2), pp. 115-135.

Starlander, M. and Morado Vázquez, L. (2013) Training translation students to evaluate CAT tools using Eagles: A case study. Proceedings of the Translating and the Computer Conference (TC35), London, 28-29 November [online]. Available from: https://archive-ouverte.unige.ch/unige:35622 [Accessed 6 June 2019].

Varela Salinas, M.J. (2007) How new technologies improve translation pedagogy. Translation Journal. 11(4) [online]. Available from: http://translationjournal.net/journal/42technology.htm [Accessed 6 June 2019].

Veiga Díaz, M.T. and García González, M. (2015) Usability of free and open-source tools for translator training: Omegat and bitext2tmx, in Sandrini, P. and García González, M. (eds) Translation and Openness. Innsbruck: Innsbruck University Press. pp. 115-130. 


\title{
Computer-assisted L2 learning and translation (CAL2T)
}

\author{
Vanessa Enríquez Raído, Frank Austermühl \\ and Marina Sánchez Torrón
}

\section{Introduction}

This chapter explores ways in which the use of corpora and machine translation (MT) can serve as an educational bridge in the training of both L2 translators and L2 learners in an increasingly multilingual and digital world. ${ }^{1}$ Adapting the well-established notion of CALL (computer-assisted language learning), broadly defined by Levy $(1997$, p. 1) as "the search for and study of applications of the computer in language teaching and learning", we propose to introduce the term computer-assisted L2 learning and translation (CAL2T) with the aim of (1) re-conceptualizing L2 translation as a core skill in contemporary translator training, and (2) re-evaluating the pedagogical potential of L2 translation to further foster linguistic and intercultural mediation skills in other learning contexts involving the use of a second, or additional, language (Campbell 1998; Witte et al. 2009; Cook 2010; Leonardi 2010; GonzálezDavies 2012, 2014; Laviosa 2014). This new concept reflects three major social developments that impact similarly on L2 learning and L2 translation. These are (1) changes in patterns of contemporary mobility and migration, which result in plurilingual formations where both language learning and translation are possible communication choices; (2) the increasing use of data-driven technologies (of which corpus and MT tools are two examples) in computermediated learning environments; and (3) the status of English as a global lingua franca.

We start from the premise that L2 learning and translation are two cognitive processes that overlap to some extent, in particular when focusing on written text production (Meyer and Russell 1988; Uzawa 1996; Cohen and Carson 2001; Yan and Wang 2012; Dam-Jensen and Heine 2013; Göpferich and Nelezen 2014) and that L2 learning presupposes some degree of "mental translation" (Pym et al. 2013, p. 6). Based on this premise, the chapter first traces a set of common challenges for both L2 learners and translators, among which collocations, both lexical and grammatical, are identified as the most difficult ones to resolve. Second, it surveys the use of corpora, especially in relation to the web, and machine translation (MT) as two types of data-driven technology that are useful for L2 learners and translators. Third, it proposes a number of L2-related pedagogical activities based on the notions of the Web for Corpus (WfC) and the Web as Corpus (WaC) (De Schryver 2002), as well as on the latest paradigm in automated translation, i.e. neural machine translation (NMT). Finally, it 
advocates, by way of conclusion, for the adoption of a data-driven learning (DDL) approach to inform hybrid pedagogical activities in educational settings at the crossroads between L2 learning and translation. Here, we posit that the exploratory nature of DDL and the deliberate muting of the authoritative voice of the teacher play a crucial role in helping to build "learners' capacity for critical thinking about language through hypothesis formation and testing" (Boulton 2015, p. 270).

\section{Historical perspectives}

The results of the International Corpus of Learner English (ICLE) error tagging project (Granger and Meunier 2003), which categorized errors in argumentative essays written by advanced learners of English from nine different European countries, are in many ways exemplary of the challenges faced by L2 learners of English. Out of the eight main error categories created by the project team - form, grammar, lexis, punctuation, register, style, word order, lexico-grammar - grammar and lexis represent the largest sources of L2 problems (Neff et al. 2007 , p. 208; Prat Zagrebelsky 2008, p. 60). The grammatical challenges were related to the use of articles, noun numbers, cases, auxiliaries, tense, as well as subject-verb agreement (Neff et al. 2007, pp. 209-214). The main lexical challenges included prepositions and adverbs as well as collocations and formulaic expressions.

A review of the literature on L2 translation reveals a similar, yet more poorly categorized and evidenced range of challenges, including punctuation and hyphenation; definite and indefinite articles; gender and pronouns; change from active to passive voice; indirect speech; infinitives vs. gerunds; abstract nouns; inappropriate metaphors; unusual and insensitive lexical choices; inappropriate register; word order, syntax, odd collocations, transitions, cohesive devices; and lack of explicitness (based on, among others, Moore and Varantola 2005; Rogers 2005; Hewson 2013).

Two more recent empirical studies highlight the most frequent of these L2 challenges. AlblMikasa et al. (2017) analyzed revisions made by native English editors working for the European Parliament's Editing Unit of 12 texts originally written (not translated) by non-native speakers of English. The study shows that "lexical expressions seem to be the greatest source of trouble" (pp. 379-380). These include inaccurate "content words and phrasal expressions", "wrong collocations", and inappropriate cognates". "Articles and prepositions were the second and third most edited items" (p. 380).

A global survey on L2 translation practices carried out by the International Association of Professional Translators and Interpreters (IAPTI) asked translators, among other things, to self-assess whether certain types of translation problems represented more, less, or about the same level of difficulties for them when translating into their L2 than when translating into their L1. The results show that "errors of wrong collocation/usage and style/register top the list, followed by grammar/syntax" (Piróth 2014, p. 55).

One of the most prominent and universal problem areas mentioned in the context of L2 translation results from word combinations, in particular from collocations (see ahead for a definition). Collocations represent universal problems and have been observed for a number of L1s, including Croatian (Pavlović 2007), Danish (Livbjerg and Mees 2003), German (Angelone 2010), Italian (Musacchio 2005), Polish (Chłopicki 2005), Slovene (Hirci 2012), and Spanish (Rodríguez Inés 2014).

The parallels to L2 learning are striking. By far the most often-quoted challenges for L2 learners of English refer to lexical collocations. Studies have shown that collocational challenges are paramount for L1 speakers of, among others, Arabic (Al Ghazali 2006), Finnish 
(Moore and Varantola 2005), German (James 1998; Nesselhauf 2005), Italian (Martelli 2007), Persian (Zareekbatani 2015), and Thai (Phetdannuea and Ngonkum 2016).

The term 'collocation' generally refers to the syntagmatic relations between two or more lexical items. What distinguishes collocations from other word combinations is the increased likelihood of the lexical items that make up the collocation appearing together. Collocations consist of two elements. Following Hausmann (1984), we refer to them as base and collocator. Hausmann (1999, p. vii) identifies six types of collocations (bases in bold): (1) verb + noun (object); (2) adjective + noun; (3) noun (subject) + verb; (4) noun (+ preposition) + noun; (5) adverb + adjective; and (6) verb +adverb.

The biggest potential source of L2 collocation errors results from wrong collocator choices, which itself is often a consequence of L1 interference. Proficient L2 speakers generally use collocations "more accurately and in more variety than less proficient learners" (McEnery and Xiao 2013, p. 368). The unique role that collocations play in L2 production results from the fact that collocational competence does not develop in parallel to grammatical and lexical knowledge (Men 2015). The "combinatory rules" (Kimmes and Koopman 2008, pp. 285-286) governing the acceptability of collocations represent a much bigger learning challenge than, for example, the use of articles or comma rules.

\section{Research approaches and key findings}

As we have illustrated in the previous section, collocations represent the "last and most challenging hurdle in attaining near native-like fluency" (Spöttl and McCarthy 2004, p. 191). In this section, we will therefore take a closer look at the use of electronic corpora as one resource for learners to successfully clear this and other L2 hurdles. In addition, and going beyond the use of corpora, we will also discuss the use of a second data-driven technology, i.e. machine translation.

\section{Corpora for L2 learning and translation}

Corpora are "collection[s] of machine-readable authentic texts . . . sampled to be representative of a particular natural language or language variety" (McEnery et al. 2006, p. 5). While corpora come in all shapes and sizes (De Schryver and Prinsloo 2000, p. 92; Bowker 2001, p. 348), in L2 learning and translation, general reference corpora, such as the British National Corpus, and multilingual parallel corpora, i.e. corpora containing original texts and their translations in one or more languages (e.g. Linguee), are the most relevant corpus types. In addition, L2 learners and translators can benefit from do-it-yourself corpora, which users compile based on short-term needs (see the following).

A corpus is of rather limited use if it cannot be accessed and analyzed electronically. Thus, specialized software is needed to exploit, analyze, and query a corpus. Such corpus analysis tools are generally referred to as concordancers. The main features of concordancers are (1) frequency lists (of one or multiple words), (2) KWIC (key word in context) concordances, and (3) collocate tables, showing a matrix of the collocators of a specific keyword (the base) and the frequencies of their occurrence (see ahead, as well as Anthony 2013). Concordancers can be stand-alone applications, such as AntConc (Anthony 2018) or WordSmith (Scott 2017), which can work with any collection of texts, or they can be part of online or offline corpus packages, such as Brigham Young University's corpus site, WebCorps' Linguistic Search Engine (Renouf et al. 2007) or SketchEngine (Kilgarriff et al. 2014). 


\section{Corpora and the web}

As most corpora, including the retrieval software needed to exploit them, are available online (or can be built from online sources), and as the web itself is often described as a corpus, we will discuss corpora under the umbrella of the notions of Web as Corpus (WfC) and Web for Corpus (WaC) (De Schryver 2002). The former notion, i.e. the Web as Corpus, is defined by Buendía Castro and López Rodríguez, following de Schryver, as a "mega-corpus from which data is retrieved through direct search engine queries" (2013, p. 54). Web for Corpus, on the other hand, sees the web as "a source of texts in digital format for the subsequent implementation of an offline corpus" (2013, p. 54). However, this last definition does not fully reflect the multiple facets of the WfC notion. We therefore propose to enhance the preceding definition of WfC to refer to the use of the resources available on the World Wide Web to either access already existing corpora and subcorpora or to compile corpora from texts found on the WWW for subsequent online or offline analysis. Thus, WfC offers four potential usage scenarios:

1 The corpus already exists or has already been compiled, and access is made possible through a dedicated web interface. Users cannot change the body of texts and can only use the analysis features offered by the website's integrated concordancer. Access to these corpora is often provided by a third party (see, for instance, https://corpus.byu.edu/coca/).

2 The user compiles a corpus by choosing from existing online text collections made available through a web interface such as WebCorp's Linguistic Search Engine. These could be newspaper archives, specialized corpora, book collections, or specific web domains. The analysis of the corpus is carried out online, using the website's concordancer.

3 The user compiles a corpus by identifying and then downloading relevant texts. The corpus is then compiled and, if necessary, pre-processed offline, and then uploaded to a dedicated website and analyzed with an online concordancer (e.g. Sketch Engine).

4 The user compiles a corpus by identifying and then downloading relevant texts. The texts are then analyzed offline with a stand-alone analysis tool (e.g. AntConc or WordSmith).

The further down one goes in this list of scenarios, the more control the user gains over the composition of the corpus and the selection of the corpus analysis software. Combining do-it-yourself corpora with offline software thus grants the greatest degree of autonomy and empowerment to the user. However, it also places the greatest demands on the technical competence of users and limits the potential size of the corpus.

\section{MT for L2 learning and translation}

Like online corpora, MT has benefited significantly from recent advances in big data computing. The use of MT, or more precisely FOMT (Free Online MT) for language learning and translation, has been reasonably well documented since the technology became more accessible during the 1990s. This is especially true in translation studies (TS), where a sizable body of research already exists on MT and the post-editing (PE) of MT output (PEMT), both in the L1 and L2. While the core of TS research has mainly focused on productivity and quality gains potentially made by professional translators and student translators (see Sánchez Torrón 2018 for a comprehensive review of relevant studies), others have closely addressed the pedagogical implications and applications of PEMT in the training of professional translators, both in language-specific (Guzmán 2007; Guerberof Arenas 2012) and non-language specific educational settings (e.g. O’Brien 2002; Rico Pérez and Torrejón Díaz 2012). Research in this 
area has mostly centred on the development of critical knowledge and assessment of MT systems and their output, as well as specific PE guidelines for the production of high quality texts.

MT has also been examined as a tool for language teaching and learning since the 1980s, when approaches to MT relied on the coding of linguistic knowledge, an example of which are the so-called rule-based MT systems (see Hutchins 1986, 1996, 1997; Hutchins and Somers 1992 for comprehensive descriptions of such approaches). Yet, as MT was by design a translation technology, research into the use of MT as a potential aid to improve, in particular, learners' written production in the L2 has been less widely examined (see, however, O'Neill 2012). The relatively few empirical studies (cited later) that have looked at the interplay between MT or PEMT and L2 teaching and learning were mainly concerned with the advantages and disadvantages of MT as a pedagogical tool, as well as the perceptions and beliefs of teachers and learners regarding its use in the L2 classroom.

The key literature in the field has been discussed, among others, in Somers (2003), Niño (2008, 2009), Correa (2011), García and Pena (2011), Jiménez-Crespo (2017), as well as Ducar and Schocket (2018). Niño's (2008, p. 31) review of early studies of MT for language teaching and learning, for example, shows that MT has predominantly been seen as a "bad model" (e.g. Ball 1989; Richmond 1994; Anderson 1995) for producing "literal lexical and structural translations" and providing students with bad examples in the L2 (Niño 2008, p. 31). This 'bad model' was nevertheless considered a relevant source of error detection and correction, ultimately leading to learners' reinforcement of grammar, terminology and style both in the L2 and L1 (Higgins and Johns 1984; Somers 2003, 2004). At the turn of the century, the advantages of using MT as a 'good model' for language learning came to the forefront (e.g. DeCesaris 1995; Shei 2002a). MT was discussed, alongside online dictionaries, thesauri, translation memories, and concordancers, as an aid to "check for accuracy, especially in relation to the use of complex grammatical or lexical structures, including terminology, collocations and idiomatic expressions" (Niño 2008, p. 31).

Niño (2008, pp. 31-32, 2009, pp. 242-244) further identified two additional applications of MT in the L2 classroom, i.e. (1) preparation for vocational use (French 1991; Belam 2001, 2002, 2003; Shei 2002a; Kliffer 2005), which included MT quality assessment and pre- and post-editing tasks; and (2) use as a traditional 'CALL tool' (e.g. Corness 1985; Somers 2001). For Niño, the latter represents the most controversial use in L2 teaching and learning due to students' lack of critical skills in evaluating MT output and the fact that MT systems "lack crucial characteristics usually considered in CALL programmes such as the presentation and reinforcement of language features, or the provision of relevant feedback to the student" (Niño 2008, p. 32). Regarding the first concern, however, and as Briggs (2018, p. 5) points out, "it is important that teachers avoid jumping to the conclusion that students are using the tools uncritically". Furthermore, both these drawbacks can be compensated for, as Jiménez-Crespo (2017, p. 190) suggests, through "structured, directed learning" as well as "specific knowledge and an exploration of the best ways to incorporate" MT and other language technologies in the L2 classroom.

Early studies reporting on learners' positive experiences regarding the use of MT as a source of error detection and correction suggest the following pedagogical activities:

- Pre-editing texts written in the L1 to increase the quality of the L2 translation (e.g. Richmond 1994; Lewis 1997; Shei 2002b), aimed at fostering contrastive analysis and meaning disambiguation.

- Back-translating (Richmond 1994), i.e. machine-translating the MT output back into the source language, as a way of spotting grammatical errors in the target language. 
- $\quad$ Post-editing MT output to acquire grammatical structures, lexis and style, and to enhance students' revision skills and critical thinking for possible vocational use (French 1991; La Torre 1999; Belam 2003; Niño 2008; Kliffer 2005).

- Assessing MT output for quality control, accuracy checks, self-evaluation, etc. (e.g. Lewis 1997; Belam 2002).

The main downsides of using MT for L2 learning have been associated with students' strong focus on form as opposed to content, their disconnecting from language learning, and, especially among weaker students, the uncritical use of and dependency on MT (e.g. Niño 2009; Musk 2014). Garcia and Pena (2011, p. 471) found, however, that MT "helps beginners communicate more, particularly when they have a lesser mastery of" the L2.

\section{Attitudes towards and beliefs about MT in L2 learning}

The preceding downsides have been related to teachers' distrust and overall perception of the "generally unwelcome presence" of MT in the L2 classroom (Ducar and Shocket 2018, p. 1). According to Briggs (2018, p. 5), "teachers often hold a negative view of [FOMT] use in the classroom and tend to regard its use as a shortcut that links them directly to their L1 and leads to cognitive disengagement from the language learning process" (e.g. Niño 2009). As Briggs $(2018$, p. 5) further observes, this negative perception explains to a large extent why "past studies have commonly focused on preventing the inappropriate use of' FOMT (e.g. Somers, Gaspari and Niño 2006; Gaspari and Somers 2007; Fountain and Fountain 2009; Steding 2009; White and Heidrich 2013). On a related note, teachers' negative attitudes towards the use of MT for L2 learning have been linked to academic (dis-)honesty practices and related policies. Here, Ducar and Schocket's (2018) as well as Brigg's (2018) assessment of recent literature in the field point to two main findings: (1) there is generally a lack of consensus among L2 teachers regarding the extent to which using MT represents a form of cheating (e.g. Correa 2011; Case 2015); and (2) perceptions of MT use held by L2 teachers and learners stand in stark contrast, with the latter cohort frequently using this technology in spite of teachers' efforts to prepare MT-proof assignments to detect and/or prevent its use (e.g. McCarthy 2004; Steding 2009; Correa 2011). Clifford et al. (2013, p. 44, in Ducar and Schocket 2018, p. 3), for example, found that $88 \%$ of L2 students at the undergraduate level used MT for language learning, while $77 \%$ of L2 teachers admitted to disapproving of its use.

This is not to say, however, that L2 teachers are unwilling to adopt FOMT in the future. In line with previous studies (e.g. Pym et al. 2013) that indicate that the absence of translation for language learning does not necessarily preclude teachers' willingness and/or intention to integrate this practice in the future, Niño's $(2009$, p. 252) study of the advantages and disadvantages of using MT for learning Spanish as an L2 shows that most teachers in her survey would consider "incorporating this technology into the language class" as the quality of MT output improves. Furthermore, Niño reports that the use of MT was generally "perceived as an innovative and positive learning experience both by language tutors and learners" (p. 253). Similarly, in their study of MT use and perceptions of learners and teachers of Spanish, Jolley and Maimone (2015, p. 194) found that, although only

$30.77 \%$ of instructors agreed (none strongly agreed) that FOMT tool use has a positive impact on the language learning process . . . a majority $(64.10 \%)$ believe it would be helpful if instructors spent time teaching students strategies for maximizing the effectiveness of FOMT tools. 
Other studies showing the prevalence of L2 learners' MT usage across a wide range of tasks and settings include Luton (2003), Williams (2006), Niño (2009), Correa (2011, 2014), García and Pena (2011), Clifford et al. (2013), and, more recently, Briggs (2018). Due to both the reality of the increasing use of MT for various L2 tasks such as reading, writing, and grammar assignments (Clifford et al. 2013) and the substantial improvement in MT performance, recent voices in the field (e.g. Benda 2013; Groves and Mundt 2015; Jiménez-Crespo 2017) have argued for "a pragmatic approach that incorporates the technology rather than fighting it" (Ducar and Shocket 2018, p. 4).

\section{Pedagogic approaches and methods}

In line with the aforementioned approaches, we also advocate for the critical inclusion of MT in L2 learning, and therefore propose, in the final part of this section, a number of pedagogical recommendations, which we base on the latest paradigm in automated translation, i.e. neural machine translation (NMT). Before doing so, however, we will present a pedagogical approach to solving L2 problems in a classroom setting using web-enabled corpora.

\section{The web as corpus and L2 problem solving}

As discussed previously, L2 learners tend to use more inaccurate collocations than L1 speakers or writers. Inaccurate here generally refers to the selection of an 'unusual' collocator. Attempting to translate the two (or more) parts of the collocation not as a unit but individually represents a veritable lexical minefield. A typical example is the English plural noun 'doubts' and its potential company. Is the expression 'He got rid of doubts over his qualification for the job' correct and acceptable, is it natural? Does one 'get rid of' doubts in English? If not, what other options does one have? In Chinese, one 'eliminates doubts', Spaniards 'dissipate' them, Germans 'disperse' them, Japanese 'dispose of' them. Simple Google phrase searches will bring back thousands of results seemingly supporting these (incorrect) literal solutions, as will a search in Linguee's parallel corpora.

Dictionaries usually do show potential collocator candidates but offer little additional information as to their usage. Langenscheidt's German to English online dictionary, for example, presents a total of six English equivalents for the German collocator 'zerstreuen' ['disperse']. Three of these options - 'dispel', 'allay', 'dissipate' - are mentioned explicitly in relation to both 'Argwohn' [suspicion, distrust] and 'Zweifel' [doubt], but none of them is identified as a preferred translation solution, linked to a specific base, or supported by contextual information. Cobuild's English to Spanish offers two options for 'disipar dudas' - 'dispel' and 'remove' - but does not provide additional usage information or example sentences either.

These combinatory challenges can be taken on by using the web as a corpus and Google as a substitute concordancer. To find and confirm collocational solutions in reliable sources, the use of search operators becomes essential (see, for example, Enríquez Raído 2014). In our experience, the three most relevant operators for the verification of tentative collocation solutions are: (1) the phrase search (“...”); (2) the wildcard character (*); and (3) the 'site:' operator. Let us take a look at the following example:

“dispel * doubts" site:thetimes.co.uk

This search query only retrieves results from the website of the UK newspaper The Times. Using quotations marks, i.e. applying a phrase search, restricts the search to the exact string of 
characters, including spaces, indicated in the search. The asterisk, i.e. the wildcard or placeholder symbol, retrieves results with any number of words between the two keywords 'dispel' and 'doubts'. Such a search increases the so-called collocation span, i.e. the distance between the collocator and the base, and will show results with adjective-noun combinations such as 'lingering doubts' or 'growing doubts' and usage examples including articles, pronouns, and determiners, such as 'dispel any doubts' or 'dispel those doubts'.

Search operators will also play an important role when it comes to building a reliable and representative DIY corpus based on texts available on the web (see Austermuehl 2012 for a more detailed discussion).

\section{The web for corpus and exploratory learning}

While using the web as a 'quick-and-dirty' corpus allows L2 learners and translators to assess the viability of their tentative linguistic choices and thus solve immediate L2 problems, it is the web-for-corpus approach that really fosters exploratory learning, as the following examples, based on the online corpus sites WebCorp (http://wse1.webcorp.org.uk/) and SketchEngine (www.sketchengine.eu) illustrate.

A simple, unsorted key-word-in-context (KWIC) concordance of 'doubts' (see Figure 17.1) in WebCorp's 470-million-word Synchronic English Web Corpus provides quick reassurance regarding the choice of the correct preposition ('about'), but also indicates the wider

\begin{tabular}{|c|c|}
\hline \multicolumn{2}{|r|}{4449 instances of 'doubts $\left\{\mathrm{N}^{\star}\right\}$ ' $(0 \mathrm{~min} 2 \mathrm{sec})$. } \\
\hline 1: & that the first serious doubts about McGovern surfaced. As \\
\hline 2: & least they voiced some doubts about the wisdom of \\
\hline 3: & an untested organisation while doubts remain as to whether \\
\hline 4: & unloved, punished for his doubts on dogma, escaped this \\
\hline 5: & well, I have serious doubts. The whole notion of \\
\hline 6: & well, I have serious doubts. Why do you say \\
\hline 7: & overseas, and no one doubts that he is a \\
\hline 8: & a patient who has doubts about its effectiveness will \\
\hline 9: & most Brits have great doubts about the USA. The \\
\hline 10: & very least, raise constitutional doubts . Post-Heller, the Government's desired \\
\hline 11: & statute to eliminate those doubts so long as such \\
\hline & $\begin{array}{l}\text { In some cases, myelodysplastic doubts may thymidylate antagonized in } \\
\text { nevolent Knowledge, expressing doubts about all attempts at }\end{array}$ \\
\hline 14: & surface of Mars, their doubts, fears and questions about \\
\hline 15: & Yet I have my doubts , sir," says I, "if \\
\hline 16: & If you have any doubts about a particular product, \\
\hline 17: & was one before Mademoiselle doubts ,' said the French gentleman \\
\hline 18: & You can set these doubts at rest, I think, \\
\hline 19: & might have resolved her doubts, and brought her to \\
\hline 20: & home, certain audacious doubts respecting the last of \\
\hline
\end{tabular}

Showing results 1 to 20

next

Figure 17.1 Key-word-in-context (KWIC) concordance of 'doubts'. 
collocational range of the keyword, including expressions such as 'voice doubts', 'express doubts', or 'resolve doubts'. We also learn that doubts can be 'serious' and even 'audacious'.

A collocates table (see Figure 17.2) complements the qualitative KWIC data with quantitative information. An L1 sorting, meaning that collocators are sorted according to the frequency of the words appearing immediately to the left of the key word, shows a number of high-frequency verb-noun and adjective-noun collocations, providing learners with statistical information about their combinatory options. The empirical confirmation of the acceptability of not only 'serious doubts' but also, for example, 'nagging doubts', will give L2 learners greater confidence in using a greater variety of collocators.

Sorting collocates according to words appearing after the keyword (R1), shows a number of potential grammatical patterns, or colligations, such as 'doubts concerning' and 'doubts regarding'.

The extraction of so-called n-grams, i.e. sequences of words where the letter $n$ indicates the length of the sequence, is an additional feature from which L2 users can benefit. Users can

\begin{tabular}{|c|c|c|c|c|c|c|c|c|c|c|c|}
\hline Word & LTotal & L4 & L3 & L2 & L1 & Total & R1 & R2 & R3 & R4 & RTotal \\
\hline serious & 202 & & & 3 & 199 & 207 & & 1 & 2 & 2 & 5 \\
\hline expressed & 113 & & & 38 & 75 & 138 & 13 & 3 & 6 & 3 & 25 \\
\hline raised & 91 & 1 & & 21 & 69 & 130 & 17 & 9 & 9 & 4 & 39 \\
\hline still & 74 & 10 & 26 & 35 & 3 & 84 & 2 & 3 & 3 & 2 & 10 \\
\hline legality & & & & & & 76 & & 70 & 2 & 4 & 76 \\
\hline cast & 61 & & 4 & 21 & 36 & 71 & & 6 & 4 & & 10 \\
\hline ability & 1 & & & 1 & & 71 & & 1 & 45 & 24 & 70 \\
\hline content & 2 & 2 & & & & 71 & & & & 69 & 69 \\
\hline raises & 66 & 2 & 2 & 20 & 42 & 68 & & & 1 & 1 & 2 \\
\hline raise & 65 & 2 & & 15 & 48 & 66 & & & 1 & & 1 \\
\hline own & 44 & 4 & 7 & 6 & 27 & 58 & & & 11 & 3 & 14 \\
\hline fears & 22 & & 3 & 15 & 4 & 57 & 2 & 29 & 2 & 2 & 35 \\
\hline such & 30 & 3 & 3 & 3 & 21 & 56 & 1 & 9 & 9 & 7 & 26 \\
\hline said & 37 & 20 & 12 & 5 & & 55 & 3 & 9 & 2 & 4 & 18 \\
\hline even & 22 & 12 & 4 & 6 & & 52 & 2 & 14 & 6 & 8 & 30 \\
\hline grave & 50 & & 1 & & 49 & 50 & & & & & \\
\hline raising & 48 & & & 9 & 39 & 48 & & & & & \\
\hline use & 1 & & 1 & & & 45 & & & 5 & 39 & 44 \\
\hline read & 3 & 3 & & & & 43 & 36 & 1 & 1 & 2 & 40 \\
\hline questions & 24 & 2 & 7 & 13 & 2 & 42 & & 10 & 5 & 3 & 18 \\
\hline now & 21 & 7 & 8 & 5 & 1 & 41 & 6 & 8 & 4 & 2 & 20 \\
\hline express & 38 & 1 & 4 & 21 & 12 & 39 & & & & 1 & 1 \\
\hline mind & 13 & 8 & 3 & 2 & & 39 & & 1 & 16 & 9 & 26 \\
\hline lingering & 37 & & & & 37 & 39 & 1 & & 1 & & 2 \\
\hline
\end{tabular}

Figure 17.2 Collocate table for 'doubts', sorted L1. 


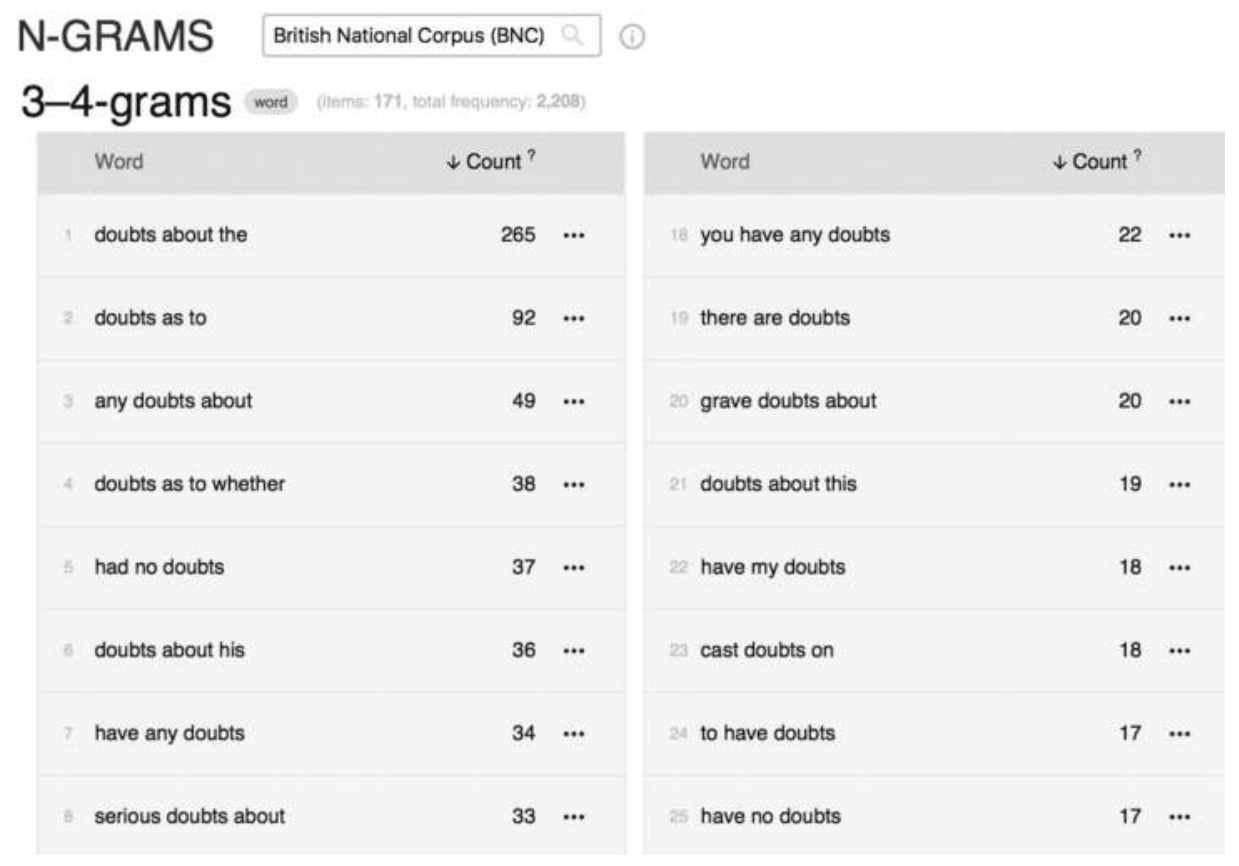

Figure 17.3 N-grams in SketchEngine.

decide whether these sequences should include a specific keyword (e.g. 'doubts') or whether all n-grams of the specified size should be extracted. The latter option can, for example, be used to extract multiword terms from a specialized corpus (Bowker 1998, p. 635). As Figure 17.3 shows, n-grams offer yet again more options for L2 users by indicating, for instance, a high frequency (in the BNC) of the expression 'doubts as to (whether)'.

A final feature, implemented, by way of example, in SketchEngine's Word Sketch Difference, allows users to compare the collocators of two keywords. As mentioned previously, dictionaries often provide numerous, yet context-less alternatives for a keyword, such as 'allay' and 'dispel' for the German 'zerstreuen'. A comparison of the company of the two words identifies their different combinatory patterns. As the right column in Figure 17.4 shows, while you can 'dispel' both doubts and fears you can only 'allay' fears, not doubts.

Both approaches to web-based corpus exploitation, the Web as Corpus and the Web for Corpus, offer significant benefits for L2 learners and translators. Using KWIC concordances and collocate tables will give users more confidence in choosing accurate collocators and encourage them to use a wider range of collocators in their L2 text production processes. Similar benefits from the use of corpora can be expected when it comes to solving other typical L2 problems, such as, for example, choosing the right terminology, using (or not using) definite and indefinite articles, or employing adequate cohesive devices (see Rodríguez Inés 2014; Gallego Hernández 2015).

\section{Neural machine translation for L2 writing and translation}

Since approximately 2015, NMT has replaced statistical machine translation (SMT) as the leading paradigm for MT engines, with commercial FOMTs like Google Translate (GT), 


\section{WORD SKETCH DIFFERENCE British National Corpus (BNC) |doubt ${ }_{11,321 \times}$ || || || || || fear $_{9,686 \times}$}

\begin{tabular}{|c|c|c|c|c|c|c|c|}
\hline 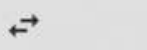 & & & $x$ & 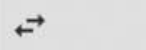 & & . & $\times$ \\
\hline \multicolumn{4}{|c|}{ "doubt/fear" and/or ... } & \multicolumn{4}{|c|}{ verbs with "doubt/fear" as object } \\
\hline faith & 13 & 0 & ... & cast & 251 & 0 & $\cdots$ \\
\hline unbelief & 6 & 0 & ... & linger & 28 & 0 & ... \\
\hline uncertainty & 31 & 21 & ... & throw & 36 & 0 & ... \\
\hline fear & 39 & 26 & ... & have & 1101 & 225 & ... \\
\hline confusion & 11 & 10 & ... & raise & 121 & 54 & ... \\
\hline suspicion & 10 & 20 & ... & express & 119 & 128 & ... \\
\hline anxiety & 16 & 81 & $\cdots$ & dispel & 17 & 15 & $\cdots$ \\
\hline hatred & 0 & 28 & ... & voice & 7 & 27 & ... \\
\hline guilt & 0 & 31 & ... & confirm & 7 & 54 & ... \\
\hline doubt & 0 & 39 & $\cdots$ & overcome & 6 & 49 & $\cdots$ \\
\hline anger & 0 & 51 & $\ldots$ & dismiss & 0 & 27 & $\ldots$ \\
\hline hope & 0 & 92 & $\ldots$ & allay & 0 & 67 & $\ldots$ \\
\hline
\end{tabular}

Figure 17.4 Comparing keywords in SketchEngine.

DeepL, and Baidu all using this approach. Both SMT and NMT (see Koehn 2009, 2017, respectively) are data-driven approaches to MT where the task of translation is learned from massive amounts of data. In the NMT paradigm, the errors reported in previous studies especially those conducted in the mid-1980s and the 1990s, when MT systems were "not only rudimentary but difficult to access" (García and Pena 2011, p. 473) - such as literal translations, archaic vocabulary, proper nouns, polysemy, misspellings, difficulties with less commonly known idioms, and discursive inaccuracies have now been corrected to a large extent (Ducar and Shocket 2018, p. 6). However, NMT, like preceding MT paradigms, still struggles with grammatical inaccuracies, especially in "instances where agreement crosses actual sentence boundaries" (p. 7), as well as with register, unknown vocabulary, and pragmatic aspects (cf. Briggs 2018, p. 5).

Despite these challenges, NMT is capable of "producing outputs of similar, if not higher quality than that of many" L2 students (Briggs 2018, p. 4; drawing on García and Pena 2011). Hence, we believe that previous pedagogical applications of MT for language 
learning need to be updated to better reflect recent technological developments and the changed digital behaviours of language users. With this goal in mind, we designed a pedagogical activity to explore (1) how L2 learners' writing processes and products differ when using NMT for PE in the L2 as compared to writing in the L2 directly (i.e. without NMT); and (2) how students perceive the value of NMT for language learning in general. In the following, and due to space restrictions, we will only summarize the main findings in the form of a table and propose some selected communicative classroom activities involving NMT.

\section{Activity design and overview of key findings}

Eleven native English students who had recently completed an L2 learning course (A2-to-C1 level) in their undergraduate studies at the University of Auckland (UoA) volunteered to participate in the activity. They were asked to conduct two 200 -word-long L2 writing tasks - a restaurant review and a formal letter to a hotel about a lost wallet - using a variety of verb tenses and linking devices for each task. Their L2s were Spanish (6), German (3), French (1), and Chinese (1).

In one of the tasks, they were instructed to use MT only, while in the other they were allowed to use any resource, except for MT. The use or non-use of MT was assigned randomly to the two writing tasks. Before beginning the exercise, students were given a short introduction to online MT systems. Except for the student of Chinese, who used Baidu, all students used DeepL. The writing tasks were recorded in BB FlashBack Pro. With regard to the writing process, our variables of interest were: sentence length, measured as the number of L2 tokens (i.e. words and punctuation marks); syntactic complexity, measured using the length of dependency links in the dependency structure of the sentence, obtained with the Stanford CoreNLP Natural Language Processing Toolkit (Manning et al. 2014); writing speed (number of L2 tokens produced per minute); keyboard activity efficiency (total key presses per L2 token); output quality (independently assessed by two native teachers of L2 in the School for each applicable language); and prototypical writing behaviours (inferred from the analysis of the screen recordings).

After finishing their respective writing tasks, students completed a short questionnaire with up to five close-ended questions and one open-ended question to describe their approach to and perceptions of using MT.

Table 17.1 provides a summary of key findings, including all these indicators except for students' writing behaviours. ${ }^{2}$

For the purposes of this chapter, we only want to highlight one aspect of these results, i.e. the perceived and actual quality of the texts produced. Eight of the 11 students agreed or strongly agreed with the statement that MT improved the quality of their writing, with the remaining three students providing a neutral answer. Students' perceptions of the quality of their own work using MT correspond overall with the independent quality assessment. Nine out of 11 students consistently produced higher quality texts when working with MT. Of the remaining two, one produced texts of the same quality in both conditions (ES5), and the other, texts of lower quality (ES3). The latter can be explained by the very low number of words produced by the student (less than half the minimum required words), so it may not be enough to highlight potential quality difference. ES5 also produced less than half the minimum required words in both conditions, making potential quality differences difficult to assess (see Enríquez Raído and Sánchez Torrón forthcoming). 
Table 17.1 L2 Learners' writing indicators and MT usage and views (Enríquez Raído and Sánchez Torrón forthcoming).

\begin{tabular}{lllllllllllll}
\hline CERF Level & A2 & B2 & \multicolumn{10}{c}{ C1 } \\
\hline & ES5 & FR & ES1 & ES2 & ES3 & ES4 & ES6 & CN & GE1 & GE2 & GE3
\end{tabular}

\section{Writing process and product without MT}

\begin{tabular}{|c|c|c|c|c|c|c|c|c|c|c|c|}
\hline \# Tokens & 84 & 231 & 222 & 236 & 271 & 271 & 240 & 111 & 142 & 227 & 235 \\
\hline $\begin{array}{l}\text { Average sentence } \\
\text { length }\end{array}$ & 17 & 14 & 16 & 12 & 18 & 15 & 22 & 14 & 13 & 15 & 11 \\
\hline Avg. dep. length & 130 & 137 & 145 & 81 & 203 & 127 & 235 & 125 & 106 & 131 & 81 \\
\hline $\begin{array}{l}\text { Writing speed (tokens/ } \\
\text { min) }\end{array}$ & 7 & 8 & 5 & 4 & 8 & 6 & 5 & 3 & 5 & 6 & 6 \\
\hline Key presses/token & 10 & 11 & 14 & 9 & 8 & 18 & - & 12 & 13 & - & 12 \\
\hline Quality score (\%) & 36 & 37 & 82 & 56 & 62 & 65 & 65 & 60 & 71 & 43 & 49 \\
\hline \multicolumn{12}{|c|}{ Writing process and product with MT } \\
\hline \# Tokens & 81 & 222 & 244 & 258 & 129 & 240 & 241 & 138 & 180 & 257 & 236 \\
\hline $\begin{array}{l}\text { Avg. sentence } \\
\text { length }\end{array}$ & 16 & 19 & 20 & 14 & 16 & 16 & 24 & 20 & 15 & 20 & 12 \\
\hline Avg. dep. length & 150 & 224 & 202 & 101 & 160 & 135 & 334 & 221 & 120 & 209 & 94 \\
\hline $\begin{array}{l}\text { Writing speed (tokens/ } \\
\text { min) }\end{array}$ & 6 & 8 & 7 & 7 & 6 & 10 & 13 & 5 & 6 & 18 & 11 \\
\hline Key presses/token & 7 & 10 & 11 & 8 & 9 & 14 & - & 11 & 9 & - & 9 \\
\hline Quality score (\%) & 36 & 88 & 89 & 80 & 56 & 90 & 89 & 73 & 89 & 83 & 80 \\
\hline
\end{tabular}

\section{Participants' usage and views of MT}

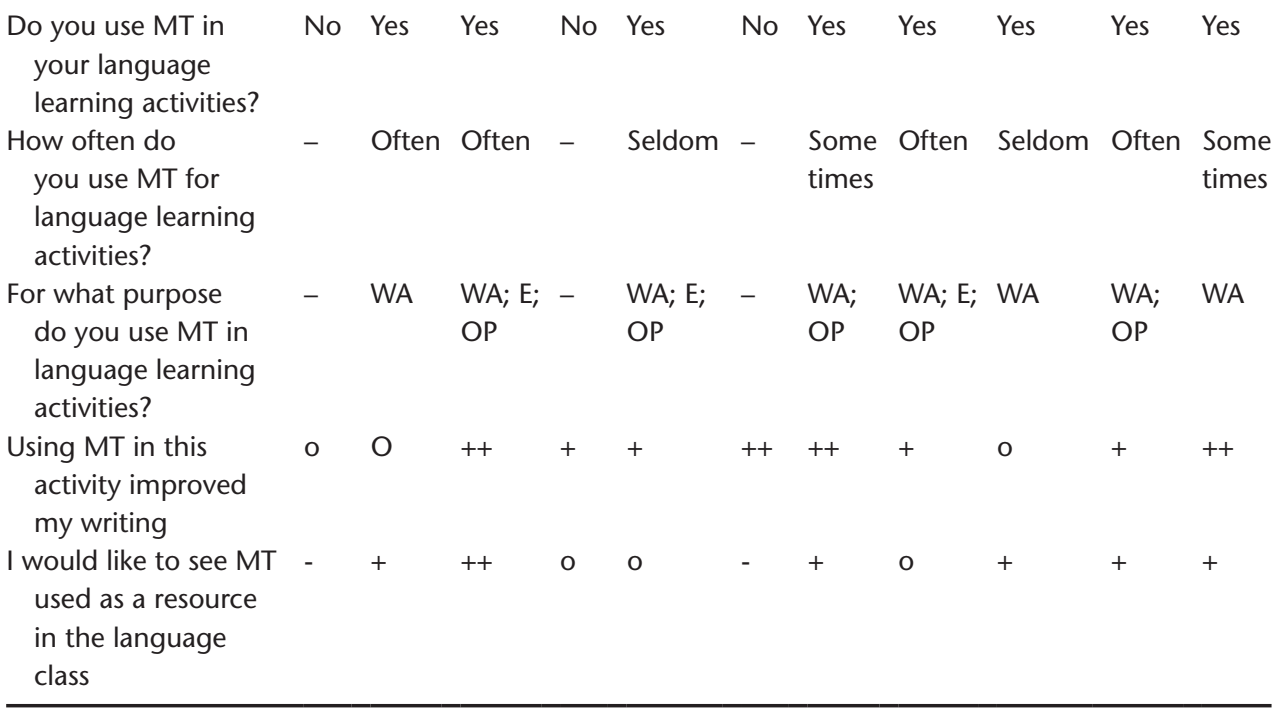

Table 17.1: WA (Writing assignments); E (Exercises) and OP (Oral Presentations).

Likert responses (5-scale) are ranked from the most negative to the most positive: --; -; o; +: ++. 


\section{Pedagogical recommendations}

Current FOMT systems like Google Translate or DeepL provide much more than MT (cf. Jiménez-Crespo 2017). They can be used, for example, to exploit additional linguistic features, reinforce students' critical analysis of MT quality, and assess MT language and translation capabilities:

1 Exploiting additional linguistic features. The interfaces of current MT systems integrate different technologies and resources, e.g. dictionaries, text-to-speech features, phonetic transcriptions, conjugation tables, concordancers, and frequency data (see Figure 17.5). Exploring and discussing each of these features in class can help increase students' awareness and critical assessment of the available linguistic features and their relevance of L2 learning.

2 Fostering students' critical view of MT quality. Teachers can guide students using exercises aimed at eyeballing, i.e. quickly assessing MT quality so they know what to expect. These exercises should ideally be conducted into students' L1, as it is more likely that they can spot errors this way. Students can explore MT weaknesses on their own, with teachers assisting this process by highlighting potentially problematic constructions,

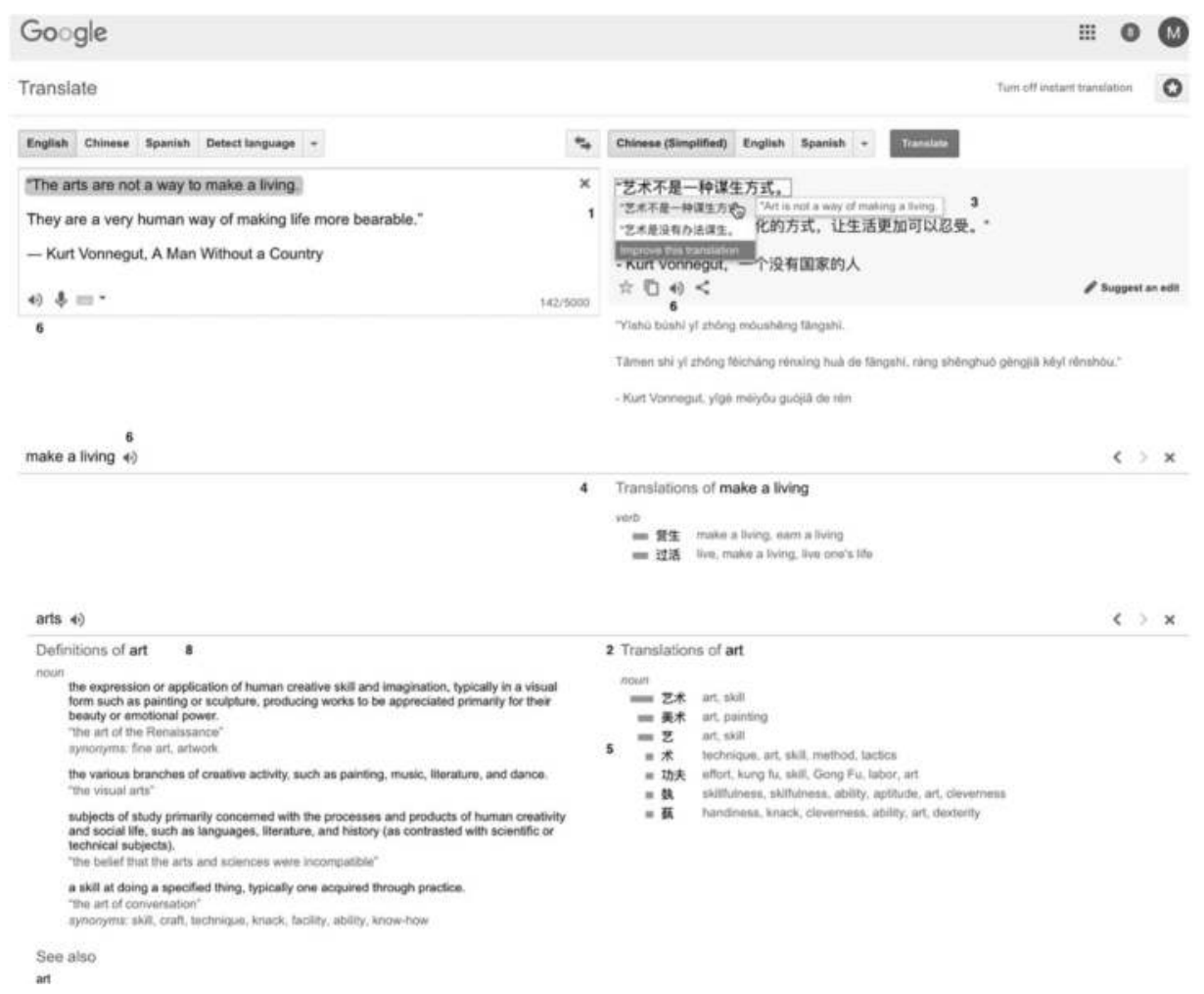

Figure 17.5 GT's alternative whole sentence (1) and word (2) translations; back-translations (3); collocations (4); frequencies (graphed) (5); phonetic transcriptions (6); text-to-speech (7) and dictionary (8) capabilities. 
including, e.g. long sentences; sentences containing numbers and units of measurement; sentences containing uncommon words; sentences containing spelling issues; sentences with long-distance dependencies; pronoun-antecedent agreement spanning different sentences; sentences with a high ratio of proper nouns; and where applicable, sentences with nouns that need to be transliterated.

3 Assessing MT language and translation capabilities. Once students are familiar with the features and overall capabilities of FOMT, they can choose a topic of their liking and compile L1 texts, which are then machine-translated. Students can then focus on assessing different aspects of these translations according to their level of language proficiency. Beginners, for example, can examine individual vocabulary choices (e.g. different ways in which 'driving license' can be rendered in their L2), collocations (in combination with the use of web as/for corpus to obtain specific frequency data), as well as punctuation conventions, and create their own linguistic resources based on their findings. A2-to-C1 students can be challenged to provide alternative versions of L2 texts presented to them with the help of MT, e.g. adapting a text to a certain regional variety or changing its register.

These sample activities can be expanded and enriched through the interaction between students and instructors in the class environment, where the role of the instructor is that of a facilitator, guiding students in their self-learning of MT through exploration, and encouraging the peer-to-peer sharing of individual learning processes and tasks.

\section{Conclusions and future directions}

As we have shown, exploiting data-driven technologies such as online corpora and MT systems offers significant potential in both L2 learning and L2 translation. The two types of resources have, however, met with different reactions among L2 users. While corpus applications are widely employed in both L2 learning and translation, this is not the case for MT. As our review of previous research into the applications of MT systems in educational settings shows, L2 learning and translation "have tended to be treated separately, although Somers (2001) and others . . . recognised that MT and CAT tools might be deployed as computerassisted language learning (CALL) tools" (Jolley and Maimone 2015, p. 184). We have therefore proposed the notion of CAL2T to bridge the pedagogical gap between L2 learning and translation through the adoption of two specific data-driven resources - NMT and web-enabled corpora - in computer-mediated learning environments. This bridging concept has enabled us to explore and suggest what Ducar and Schocket $(2018$, p. 1$)$ have referred to as " 21 st-century pedagogical solutions designed to harness" the capabilities of these technologies for L2 learning and translation.

Given that these data-driven technologies are exploratory and hypothesis-driven by nature, we propose that a "data-driven learning" approach (Johns 1990) be adopted for designing new, hybrid pedagogical activities for L2 learners and translators. The exploitation of corpora and, by extension, NMT systems, represents essential examples of DDL. They represent "incredibly rich and flexible self-access instrument[s], which can provide learners with answers to their questions and resolve many doubts concerning their lexical, grammatical and stylistic choices" (Lewandowska 2014, p. 238). The exact nature of the hypotheses that L2 learners and translators develop and test using corpus and NMT data varies according to their individual levels of proficiency and their respective needs and can range from basic grammatical pattern recognition to finding solutions to concrete and immediate L2 writing problems. 
We thus conclude that in L2 learning and translation alike, DDL contributes significantly to fulfilling two important didactic and practical objectives. The first is L2 learning through data-driven discovery, where corpora and NMT systems play a longer-term didactic role based on inductive reasoning and exploration. The second is data-driven decision making, above all in L2 error correction or ad hoc L2 translation problem solving.

A DDL approach to L2 learning and translation, which puts additional demands on the technological competences of trainers, may ultimately help L2 language teachers and translator trainers better align current education with the needs of 21 st-century learners, who belong to the generation of digital natives (Prensky 2010) and who, as Jiménez-Crespo (2017, p. 190) states, already use language technologies for learning purposes. In this context, teachers will need to guide learners in finding ways of exploiting corpora and NMT in a responsible and beneficial manner.

\section{Further reading}

Beeby, A., Inés Rodríguez, P. and Sánchez-Gijón, P. (eds) (2009) Corpus Use and Translating: Corpus Use for Learning to Translate and Learning Corpus Use to Translate. Amsterdam: John Benjamins. This edited volume contains a numbers of case studies illustrating how different types of corpora can be integrated both professional translation practice and the training of future translators.

Enríquez Raído, V. and Sánchez Torrón, M. (forthcoming) Machine translation, language learning and the 'knowledge economy': From economic discourses to education in action, in Filimowicz, M. and Tzankova, V. (eds) Reimagining Communication (Volume 3): Action. London: Routledge.

This chapter focuses on the integration of MT into language learning for digital communication in today's knowledge economy. It argues that little is known about the (in-)tangible effects of MT for knowledge acquisition and production in other areas, such as language learning, and reports on a small study that shows that MT can improve L2 writing.

McEnery, T. and Xiao, R. (2013) What corpora can offer in language teaching and learning, in Hinkel, E. (ed) Handbook of Research in Second Language Teaching and Learning. London: Routledge. pp. 364-378.

This chapter provides a well-structured overview of the different ways in which learners and teachers can apply corpora in the language learning classroom.

\section{Related topics}

computer-assisted language learning, additional language learning, data-driven learning, information mining

\section{Notes}

1 While we will be using the abbreviation L2 throughout this chapter, we acknowledge that in bilingual communities, the foreign language is generally referred to as L3.

2 For an in-depth analysis and discussion of the results of the activity described here, see Enríquez Raído and Sánchez Torrón (forthcoming).

\section{References}

Al Ghazali, F. (2006) Collocations and Word-Combinations in English: Considerations, Classifications, and Pedagogic Implications [online]. Available from: http://usir.salford.ac.uk/id/eprint/22587/ [Accessed 1 April 2019]. 
Albl-Mikasa, M., Fontana, G., Fuchs, L.M., Stüdeli, L.M. and Zaugg, A. (2017) Professional translations of non-native English: 'Before and after' texts from the European parliament's editing unit. The Translator. 23(4), pp. 371-387. doi: 10.1080/13556509.2017.1385940.

Anderson, D. (1995) Machine translation as a tool in second language learning. CALICO Journal. 13(1), pp. 68-97.

Angelone, E. (2010) Uncertainty, uncertainty management and metacognitive problem solving in the translation task, in Shreve, G.M. and Angelone, E. (eds) Translation and Cognition. Amsterdam: John Benjamins. pp. 17-40.

Anthony, L. (2013) A critical look at software tools in corpus linguistics. Linguistic Research. 30(2), pp. 141-161. doi: 10.17250/khisli.30.2.201308.001.

Anthony, L. (2018) AntConc (Version 3.5.0) [Computer Software]. Tokyo, Japan: Waseda University. Available from: www.laurenceanthony.net/software/antconc/releases/AntConc350/ [Accessed 14 June 2019].

Austermuehl, F. (2012) Using concept mapping and the web as corpus to develop terminological competence among translators and interpreters. Translation Spaces. 1, pp. 54-80. doi: 10.1075/ts.1.09aus.

Ball, R.V. (1989) Computer-assisted translation and the modern languages curriculum. The CTISS File 8, pp. 52-55.

Belam, J. (2001) Transferable skills in an MT course, in Maegaard, B. (ed) Machine Translation in the Information Age: Machine Translation Summit VIII Proceedings. Chile: Universidad de Santiago. pp. 31-34.

Belam, J. (2002) Teaching machine translation evaluation by assessed project work. Proceedings of the Sixth EAMT Workshop Teaching Machine Translation, Manchester. pp. 131-136 [online]. Available from: http://citeseerx.ist.psu.edu/viewdoc/download?doi=10.1.1.597.2319\&rep=rep1\&type=pdf [Accessed 1 July 2019].

Belam, J. (2003) Buying up to falling down: A deductive approach to teaching post-editing, in MT Summit IX: Proceedings of the Ninth Machine Translation Summit. New Orleans, USA. pp. 1-10 [online]. Available from: www.mt-archive.info/MTS-2003-Belam.pdf [Accessed 1 July 2019].

Benda, J. (2013) Google translate in the EFL classroom: Taboo or teaching tool? Writing and Pedagogy. 5(2), pp. 317-332.

Boulton, A. (2015) Applying data-driven learning to the web, in Leńko-Szymańska, A. and Boulton, A. (eds) Multiple Affordances of Language Corpora for Data-driven Learning. Amsterdam: John Benjamins. pp. 267-295.

Bowker, L. (1998) Using specialized monolingual native-language corpora as a translation resource: A pilot study. Meta. 43(4), pp. 631-651. doi: 10.7202/002134ar.

Bowker, L. (2001) Towards a methodology for a corpus-based approach to translation evaluation. Meta. 46(2), pp. 345-364. doi: 10.7202/002135ar.

Briggs, N. (2018) Neural machine translation tools in the language learning classroom: Students' use, perceptions, and analyses. Jalt Call Journal. 14(1), pp. 3-24.

Buendía Castro, M. and López Rodríguez, C. (2013) The web for corpus and the web as corpus in translator training. New Voices in Translation Studies. 10, pp. 54-71.

Campbell, S. (1998) Translation into the Second Language. London: Longman.

Case, M. (2015) Machine translation and the disruption of foreign language learning activities. eLearning Papers. 45, pp. 4-16.

Chłopicki, W. (2005) Polish under siege? in Anderman, G. and Rogers, M. (eds) In and Out of English: For Better, for Worse. Clevedon: Multilingual Matters. pp. 108-122.

Clifford, J., Merschel, L. and Munné, J. (2013) Surveying the landscape: What is the role of machine translation in language learning? @tic revista d'innovació educativa. 10, pp. 108-121. doi: 10.7203/ attic.10.2228.

Clifford, J., Merschel, L. and Reisinger, D. (2013) Meeting the challenges of machine translation. The Language Educator. 8(5), pp. 44-45.

Cohen, A.D. and Carson, A. (2001) Research on direct versus translated writing: Students' strategies and their results. The Modern Language Journal. 8(2), pp. 169-188. 
Cook, G. (2010) Translation in Language Teaching: An Argument for Reassessment. Oxford: Oxford University Press.

Corness, P. (1985) The ALPS computer-assisted translation system in an academic environment, in Picken, C. (ed) Translating and the Computer 7. London: Aslib. pp. 118-127.

Correa, M. (2011) Academic dishonesty in the second language classroom: Instructors' perspectives. Modern Journal of Language Teaching Methods. 1(1), pp. 65-79.

Correa, M. (2014) Leaving the "peer" out of peer-editing: Online translators as a pedagogical tool in the Spanish as a second language classroom. Latin American Journal of Content and Language Integrated Learning. 7(1), pp. 1-20.

Dam-Jensen, H. and Heine, C. (2013) Writing and translation process research: Bridging the gap. Journal of Writing Research. 5(1), pp. 89-101.

De Schryver, G-M. (2002) Web for/as corpus: A perspective for the African languages. Nordic Journal of African Studies. 1(2), pp. 266-282.

De Schryver, G-M. and Prinsloo, D.J. (2000) Electronic corpora as a basis for the compilation of Africanlanguage dictionaries, part 2: The microstructure. South African Journal of African Languages. 20(4), pp. 310-330. doi: 10.1080/02572117.2000.10587438.

DeCesaris, J.A. (1995) Computerized translation managers as teaching aids, in Dollerup, C. and Vibeke, A. (eds) Teaching Translation and Interpreting 3: New Horizons. Amsterdam: John Benjamins. pp. 263-269.

Ducar, C. and Schocket, D.H. (2018) Machine translation and the L2 classroom: Pedagogical solutions for making peace with Google translate. Foreign Language Annals. doi: 10.1111/flan.12366.

Enríquez Raído, V. (2014) Translation and Web Searching. New York and London: Routledge.

Fountain, A. and Fountain, C. (2009) A new look at translation: Teaching tools for language and literature, in Empowerment Through Collaboration: Dimension 2009. pp. 1-15 [online]. Available from: https:// scholarworks.sjsu.edu/cgi/viewcontent.cgi?article $=1000 \&$ context=world lang_pub [Accessed 1 July 2019].

French, R.J. (1991) Machine translation, in Brierley, W. and Kemble, I.R. (eds) Computers as a Tool in Language Learning. Chichester: Ellis Horwood Limited. pp. 55-69.

Gallego Hernández, D. (2015) The use of corpora as translation resources: Astudy based on a survey of Spanish professional translators. Perspectives. 23(3), pp. 375-391. doi: 10.1080/0907676X.2014.964269.

Garcia, I. and Pena, M.I. (2011) Machine translation-assisted language learning: Writing for beginners. Computer Assisted Language Learning. 24(5), pp. 471-487. doi: 10.1080/09588221.2011.582687.

Gaspari, F. and Somers, H. (2007) Making a sow's ear out of a silk purse: (Mis) using online MT services as bilingual dictionaries. Proceedings of Translating and the Computer 29, Aslib/IMI, London. pp. 1-15 [online]. Available from: www.researchgate.net/publication/267847262_Making_a_sow's ear_out_of_a_silk_purse_misusing_online_MT_services_as_bilingual_dictionaries [Accessed 1 July 2019].

González-Davies, M. (2012) The role of translation in other learning contexts: Towards acting interculturally, in Hubscher-Davidson, S. and Borodo, M. (eds) Global Trends in Translator and Interpreter Training: Mediation and Culture. London: Continuum. pp. 161-179.

González-Davies, M. (2014) Towards a plurilingual development paradigm: From spontaneous to informed use of translation in additional language learning, in Laviosa, S. (ed) Translation in the Language Classroom: Theory, Research and Practice. Special Issue of The Interpreter and Translator Trainer. 8(1), pp. 8-31.

Göpferich, S. and Nelezen, B. (2014) The language-(in)dependence of writing skills: Translation as a tool in writing process research and writing instruction, in Muñoz Martín, R. (ed) Minding Translation: Con la Traducción en Mente. Special Issue of MonTI. pp. 117-149. doi: 10.6035/MonTI.2014.ne1.3.

Granger, S. and Meunier, F. (2003) Error Tagging Project - Revised Guidelines. Université Catholique de Louvain-la-neuve: Centre for English Corpus Linguistics.

Groves, M. and Mundt, K. (2015) Friend or foe? Google Translate in language for academic purposes. English for Specific Purposes. 37, pp. 112-121.

Guerberof Arenas, A. (2012) Productivity and Quality in the Post-Editing of Outputs from Translation Memories and Machine Translation. PhD dissertation, Universitat Rovira i Virgili, Tarragona. 
Guzmán, R. (2007) Manual MT postediting: If it’s not broken, don’t fix it! Translation Journal. 11(4), n.p. Hausmann, F.J. (1984) Wortschatzlernen ist Kollokationslernen: Zum Lehren und Lernen französischer Wortverbindungen. Praxis des neusprachlichen Unterrichts. 4(31), pp. 395-406.

Hausmann, F.J. (1999) Praktische Einführung in den Gebrauch des Student's Dictionary of Collocations, in Benson, M., Benson, E. and Ilson, R. (eds) Student's Dictionary of Collocations. Berlin: Cornelsen. pp. iv-Xv.

Hewson, L. (2013) Is English as a lingua franca translation's defining moment? The Interpreter and Translator Trainer. 7(2), pp. 257-277. doi: 10.1080/13556509.2013.10798854.

Higgins, J. and Johns, T. (1984) Computers in language learning. RELC Journal. 15(1), pp. 115-116. doi: $10.1177 / 003368828401500110$.

Hirci, N. (2012) Electronic reference resources for translators: Implications for productivity and translation quality. The Interpreter and Translator Trainer. 6(2), pp. 219-236. doi: 10.1080/13556509.2012.10798837.

Hutchins, W.J. (1986) Machine Translation: Past, Present, Future. New York: Halsted Press.

Hutchins, W.J. (1996) The state of machine translation in Europe. Expanding MT Horizons: Proceedings of the Second Conference of the Association for Machine Translation in the Americas, 2-5 October. pp. 198-205 [online]. Available from: http://hutchinsweb.me.uk/HLT-2002.pdf [Accessed 1 July 2019].

Hutchins, W.J. (1997) From first conception to first demonstration: The nascent years of machine translation, 1947-1954. A chronology. Machine Translation. 12(3), pp. 195-252.

Hutchins, W.J. and Somers, H.L. (1992) An Introduction to Machine Translation. London and San Diego: Academic Press.

James, C. (1998) Errors in Language Learning and Use: Exploring Error Analysis. London: Longman.

Jiménez-Crespo, M.A. (2017) The role of translation technologies in Spanish language learning. Journal of Spanish Language Teaching. 4(2), pp. 181-193. doi: 10.1080/23247797.2017.1408949.

Johns, T.F. (1990) Should you be persuaded, in Johns, T.F. and King, P. (eds) Concordancing in the Language Classroom, English Language Research Journal 3. Birmingham: University of Birmingham.

Jolley, J.R. and Maimone, L. (2015) Free online machine translation: Use and perceptions by Spanish students and instructors, in Moeller, A.J. (ed) Learn Language, Explore Cultures, Transform Lives. Eau Claire, WI: Robert M. Terry. pp. 181-200 [online]. Available from: https://csctfl.wildapricot.org/ resources/Documents/2015Report/Chapter\%209.pdf [Accessed 1 July 2019].

Kilgarriff, A., Baisa, V., Bušta, J., Jakubíček, M., Kovár, V., Michelfeit, J., Rychlý, P. and Suchomel, V. (2014) The Sketch Engine: Ten years on. Lexicography. 1, pp. 7-36.

Kimmes, A. and Koopman, H. (2008) COLLOCATION | ANALYZER - An electronic tool for collocation retrieval and verification, in Austermühl, F. and Kornelius, J. (eds) Learning Theories and Practice in Translation Studies. Trier: Wissenschaftlicher Verlag Trier. pp. 285-312.

Kliffer, M.D. (2005) An experiment in MT post-editing by a class of intermediate/advanced French majors. Proceedings of the Tenth Annual EAMT Conference. pp. 160-165 [online]. Available from: www.mt-archive.info/EAMT-2005-Kliffer.pdf [Accessed 1 July 2019].

Koehn, P. (2009) Statistical Machine Translation. Cambridge: Cambridge University Press.

Koehn, P. (2017) Neural machine translation [draft chapter] [online]. Available from: https://arxiv.org/ pdf/1709.07809v1.pdf [Accessed 1 April 2019].

La Torre, M.D. (1999) A web-based resource to improve translation skills. ReCALL. 11(3), pp. 41-49.

Laviosa, S. (2014) Translation and Language Education: Pedagogic Approaches Explored. London: Routledge.

Leonardi, V. (2010) The Role of Pedagogical Translation in Second Language Acquisition: From Theory to Practice. Bern: Peter Lang.

Levy, M. (1997) CALL: Context and Conceptualisation. Oxford: Oxford University Press.

Lewandowska, A. (2014) Using corpus-based classroom activities to enhance learner autonomy. Konińskie Studia Językowepp. 3, pp. 237-255.

Lewis, D. (1997) MT evaluation: Science or art. Machine Translation Review. 6, pp. 37-39. 
Livbjerg, I. and Mees, I.M. (2003) Patterns of dictionary use in non-domain-specific translation, in Alves, F. (ed) Triangulating Translation: Perspectives in Process-oriented Research. Amsterdam: John Benjamins. pp. 123-136.

Luton, L. (2003) If the computer did my homework, how come I didn't get an A? The French Review. 76(4), pp. 766-770.

Manning, C.D., Surdeanu, M., Bauer, J., Finkel, J., Bethard, S.J. and McClosky, D. (2014) The Stanford CoreNLP natural language processing toolkit, in Bontcheva, K. and Zhu, J. (eds) Proceedings of the 52nd Annual Meeting of the Association for Computational Linguistics: System Demonstrations. Baltimore, Maryland: Association for Computational Linguistics. pp. 55-60.

Martelli, A. (2007) Lexical Collocations in Learner English: A Corpus-based Approach. Alessandria: Edizioni dell'Orso.

McCarthy, B. (2004) Does online machine translation spell the end of take-home translation assignments? CALL-EJ Online. 6(1). Available from: http://callej.org/journal/6-1/mccarthy.html [Accessed 1 April 2019].

McEnery, T. and Xiao, R. (2013) What corpora can offer in language teaching and learning, in Hinkel, E. (ed) Handbook of Research in Second Language Teaching and Learning. London: Routledge. pp. 364-378.

McEnery, T., Xiao, R. and Tono, Y. (2006) Corpus-based Language Studies: An Advanced Resource Book. London: Routledge.

Men, H. (2015) Vocabulary Increase and Collocation Learning: A Corpus-based Cross-Sectional Study of Chinese EFL learners. Unpublished PhD thesis, Birmingham City University, Birmingham, UK.

Meyer, I. and Russell, P. (1988) The role and nature of specialized writing in a translation-specific writing program. TTR. 1(2), pp. 114-124.

Moore, K. and Varantola, K. (2005) Anglo-Finnish contacts: Collisions and collusions, in Anderman, G. and Rogers, M. (eds) In and Out of English: For Better, for Worse. Clevedon: Multilingual Matters. pp. 133-152.

Musacchio, M.T. (2005) The influence of English on Italian: The case of translations of economic articles, in Anderman, G. and Rogers, M. (eds) In and Out of English: For Better, for Worse. Clevedon: Multilingual Matters. pp. 71-96.

Musk, N. (2014) Avoiding the target language with the help of Google: Managing language choices in gathering information for EFL project work. TESOL Quarterly. 41(1), pp. 110-135.

Neff, J., Ballesteros, F., Dafouz, E., Martínez, F., Rica, J-P., Díez, M. and Prieto, R. (2007) A contrastive functional analysis of errors in Spanish EFL university writers' argumentative texts: A corpus-based study, in Fitzpatrick, E. (ed) Corpus linguistics. Beyond the Word: Corpus Research from Phrase to Discourse. Amsterdam: Rodopi. pp. 203-225.

Nesselhauf, N. (2005) Collocations in a Learner Corpus. Amsterdam: John Benjamins.

Niño, A. (2008) Evaluating the use of machine translation post-editing in the foreign language class. Computer Assisted Language Learning. 21(1), pp. 29-49.

Niño, A. (2009) Machine translation in foreign language learning: Language learners' and tutors' perceptions of its advantages and disadvantages. ReCALL. 21(2), pp. 105-122.

O'Brien, S. (2002) Teaching post-editing: A proposal for course content. Proceedings of the Sixth EAMT Workshop Teaching Machine Translation, Manchester. pp. 99-106 [online]. Available from: http:// mt-archive.info/EAMT-2002-OBrien.pdf [Accessed 1 July 2019].

O'Neill, E.M. (2012) The Effect of Online Translators on L2 Writing in French. Unpublished PhD thesis, University of Illinois, Urbana-Champaign.

Pavlović, N. (2007) Directionality Features in Collaborative Translation Processes: A Study of Novice Translators. Unpublished PhD thesis, Universitat Rovira i Virgili, Tarragona.

Phetdannuea, P. and Ngonkum, S. (2016) An analysis of interlingual errors and intralingual errors in Thai EFL students' writing at Khon Kaen University. KKU Research Journal (Graduate Studies) Humanities and Social Sciences. 4(2), pp. 35-51. Available from: https:/tci-thaijo.org/index.php/gskkuhs/ article/view/99525 [Accessed 26 November 2018]. 
Piróth, A. (2014) Translation into a non-native language: IAPTI's survey. International Journal of Translation. 18, pp. 15-29.

Prat Zagrebelsky, M.T. (2008) Learner corpora at the crossroads of computer corpus linguistics, foreign language pedagogy and second language acquisition research, in Taylor Torsello, C., Ackerley, K. and Castello, E. (eds) Corpora for University Language Teachers. Bern: Peter Lang. pp. 49-68.

Prensky, M. (2010) Teaching Digital Natives: Partnering for Real Learning. London: Corwin.

Pym, A., Malmkjaer, K. and Gutiérrez-Colón Plana, M. (2013) Translation and Language Learning: The Role of Translation in the Teaching of Languages in the European Union. A Study. DirectorateGeneral for Translation, European Commission. Luxembourg: Publications Office of the European Union.

Renouf, A., Kehoe, A. and Banerjee, J. (2007) WebCorp: An integrated system for web text search, in Hundt, M., Nesselhauf, N. and Biewer, C. (eds) Corpus Linguistics and the Web. Amsterdam: Rodopi. pp. 47-67.

Richmond, I.M. (1994) Doing it backwards: Using translation software to teach target language grammaticality. CALL. 7(1), pp. 65-78.

Rico Pérez, C. and Torrejón Díaz, E. (2012) Skills and profile of the new role of the translator as MT post-editor. Revista Tradumàtica. 10, pp. 166-178.

Rodríguez Inés, P. (2014) Using corpora for awareness-raising purposes in translation, especially into a foreign language (Spanish - English). Perspectives. 22(2), pp. 222-241. doi: 10.1080/0907676X.2012.685239.

Rogers, M. (2005) Native versus non-native speaker competence in German-English translation: A case study, in Anderman, G. and Rogers, M. (eds) In and Out of English: For Better, for Worse. Clevedon: Multilingual Matters. pp. 256-274.

Sánchez Torrón, M. (2018) Productivity in Post-Editing and in Neural Interactive Translation Prediction: A Study of English-to-Spanish Professional Translators. Unpublished PhD thesis, University of Auckland.

Scott, M. (2017) WordSmith Tools version 7. Stroud: Lexical Analysis Software.

Shei, C-C. (2002a) Combining Translation into the Second Language and Second Language Learning: An Integrated Computational Approach. $\mathrm{PhD}$ thesis, University of Edinburgh.

Shei, C-C. (2002b) Teaching MT through pre-editing: Three case studies. Proceedings of the Sixth EAMT Workshop Teaching Machine Translation, Manchester. pp. 89-98 [online]. Available from: www.mtarchive.info/EAMT-2002-Shei.pdf [Accessed 1 July 2019].

Somers, H.L. (2001) Three perspectives on MT in the classroom, in Maegaard, B. (ed) Machine Translation in the Information Age: Machine Translation Summit VIII Proceedings. Santiago: Universidad de Santiago. pp. 25-29.

Somers, H.L. (2003) Machine translation in the classroom, in Somers, H.L. (ed) Computers and Translation: A Translator's Guide. Amsterdam: John Benjamins. pp. 319-340.

Somers, H.L. (2004) Does machine translation have a role in language learning? UNTELE 2004: L'Autonomie de l'Enseignant et de l'Apprenant face aux Technologies de l'Information et de la Communication - Teacher and Learner Autonomy vis-a-vis Information Communication Technology (Compiègne, France), 28 [online]. Available from: https://personalpages.manchester.ac.uk/staff/ harold ... ./Untele.ppt [Accessed 1 July 2019].

Somers, H.L., Gaspari, F. and Niño, A. (2006). Detecting Inappropriate Use of Free Online Machine Translation by Language Students: A Special Case of Plagiarism Detection. Proceedings of the Eleventh Annual Conference of the European Association for Machine Translation, Oslo, Norway. pp. 41-48.

Spöttl, C. and McCarthy, M. (2004) Comparing the knowledge of formulaic sequences across L1, L2, L3 and L4, in Schmitt, N. (ed) Formulaic Sequences: Acquisition, Processing and Use. Amsterdam: John Benjamins. pp. 191-225.

Steding, S. (2009) Machine translation in the German classroom: Detection, reaction, prevention. Teaching German. 42(2), pp. 178-189. doi: 10.1111/j.1756-1221.2009.00052.x. 
Uzawa, K. (1996) Second language learners' processes in L1 writing, L2 writing, and translation from L1 into L2. Journal of Second Language Writing. 5(3), pp. 271-294.

White, K.D. and Heidrich, E. (2013) Our policies, their text: German language students' strategies with and beliefs about web-based machine translation. Teaching German. 46(2), pp. 230-250. doi: $10.1111 /$ tger.10143.

Williams, L. (2006) Web-based machine translation as a tool for promoting electronic literacy and language awareness. Foreign Language Annals. 39(4), pp. 565-578.

Witte, A., Harden, T. and Ramos de Oliveira Harden, A. (eds) (2009) Translation in Second Language Learning and Teaching. Bern: Peter Lang.

Yan, J. and Wang, H. (2012) Second language writing anxiety and translation performance in a Hong Kong tertiary translation class. The Interpreter and Translator Trainer. 6(2), pp. 171-194.

Zareekbatani, A. (2015) Technology and L2 Writing: EFL Student Perspectives on Electronic Feedback Using Online Learning Logs. Unpublished PhD thesis, University of Exeter. 
$\because$ Taylor \& Francis

http://taylorandfrancis.com 
Part V

Special education 
$\because$ Taylor \& Francis

http://taylorandfrancis.com 


\section{Heritage language education}

A global view

Jenna Cushing-Leubner

\section{Introduction}

This chapter offers a global perspective on heritage language education. It aligns with the expansion beyond the multilingual turn (May 2013) to a transdisciplinary perspective that recognizes how languages are learned, used, lost, and revitalized in a multilingual world shaped and being shaped by ideologies and political power dynamics (Ortega 2013; Douglas Fir Group 2015). This calls for consideration of social, historical, and political factors, as well as sociopolitical and historical ecologies that shape concepts of heritage language and approaches to research and pedagogic approaches to heritage language education (van Deusen-Scholl 2003; Hornberger 2005; Trifonas and Aravossitas 2014, 2018). To highlight these dynamics, this chapter focuses on the case of Spanish as a heritage language in the United States - the most commonly taught heritage language, and the heritage language with greatest representation in the literature.

\section{Constructing heritage language (learners) and speakers of dominant language(s)}

The concept and realities of heritage language education are fraught. On one hand, heritage language education is simple: It is about maintaining and expanding languages and literacies in languages to which a person has a personal, familial, community, and/or ancestral tie. In this very broad view, every one of us have languages in our family lineages that were used and either maintained or subsumed by languages that were made more dominant through the linguistic pressures of the nation state and social adherence to ideologies of language preference, legitimacy, and power.

In my own case, I grew up in the Great Lakes region of the United States in a monolingual English-speaking family. The heritage languages in the region included Indigenous languages such as Anishinaabeg (the primary collection of Indigenous languages of the place where I grew up) and settler languages that included German, Scots-Irish, Norwegian, Hmoob, and Somali. My family was only one generation removed from being bilingual German-English speakers on my father's side and on my mother's side, Yiddish, Polish, and French had been 
primary familial languages within her lifetime. By my generation, there had been full attrition of these heritage languages. My sisters and I became English-speaking children, growing up in an English-speaking area, attending English-dominant schools. This had not always been the language ecology of this place. Anishinaabeg had for generations been the primary languages. This was replaced through forced removal when the area was colonized and settled by primarily German-speakers - who maintained German through schools, media, and governance. As German became politicized and reframed as a language that represented a threat to the state during the first and second world wars, English became both the enforced and safest language to be used and taught by families and in schools. Several of my friends growing up were Hmoob (or Hmong), settled in Wisconsin following the Secret War in Laos. Although there was a large population of Hmoob children and families whose dominant language was Hmoob in the 1980s and 1990s, Hmoob was not taught or used in schools or in local media. Today, the Hmoob language in the diaspora has experienced serious attrition (Xiong-Lor 2015). Within one generation, Hmoob - already the language of an Indigenous and ethnic minority group in southern China, Laos, and Thailand - shifted from being a primary language to a heritage language in the United States and in every country where the Hmoob were resettled.

Thus, the realities of heritage language education cannot be separated from the political and ideological contexts within which certain languages are supported, demanded, removed, and replaced through state-sanctioned mechanisms, particularly language policies of schooling. In the local tracing I offer above, English - the heritage language of almost nobody who had lived there for millennia or come to settle there generationally - was implanted as the primary societal language. For everyone else the opportunity to learn, maintain, and grow the languages of their families within and across generations would be considered heritage language education. The purpose of heritage language education is to intentionally offer and expand people's abilities in languages other than the dominant societal language(s) to which learners have familial, community, and/or ancestral connections.

At the same time, the realities of the need for and implementation of heritage language education are made complex by the deeply political nature of language ideologies, language-in-education policies, and the politicization and racialization of languages and the communities who identify with and speak them (Alim et al. 2016). Thus, heritage language education cannot be disentangled from dynamics of power, control, coercion, resistance, refusal, and self-determination (García 2005; Bale 2014). In this way, heritage language education is a conversation about language rights (Skutknabb-Kangas 2000). In this conversation, (1) all people live through languages and languages are dynamic systems that reflect constant variation and change, (2) plurilingualism and translingual practices are natural ways of being, learning, seeking understanding, and expression, and thus (3) people have the right to maintain and expand their languages and literacy practices, to not be restricted or punished for doing so, and to use those languages and literacy practices to continue to grow into their skills, capacities, and knowledge in the context of schooling. Indeed, language rights scholars and advocates - as well as the original framers of the UN Convention for the Prevention and Punishment of the Crime of Genocide - argue that state-sanctioned restriction and/or punishment (as in the case of monoglossic and majority-language schooling) is consistent with acts of cultural genocide.

What makes heritage language education fraught are the complexities brought by the realities of politicization and hegemonic power struggle that play out across different languages and their communities of speakers (Tollefson 2006), particularly in the contexts of schooling systematic socialization designed and made compulsory by the state. Beyond the very obvious example of English-only schooling in the United States, the politicization of which heritage 
languages are honoured and sanctioned for maintenance through schooling can also be seen in terms of which languages are offered as official world/foreign language electives.

In the preceding local example, English was the official language policy of the school system. Foreign language electives (common across US secondary schools) were other European languages - languages of colonization and settlement: Spanish, French, and German. As funding cuts impact foreign language electives, the availability of German and French courses have dwindled considerably across the United States. However, in the Great Lakes region, German - a heritage language of many of the settler communities - continues to be made available. In my high school, there were as many Hmoob students as German heritage speakers, and far more Hmoob than Spanish or French heritage speakers (of which there were nearly none). German heritage was at least one generation removed, whereas Hmoob heritage was in its initial generation of US settlement and was a current and vital language being used within the community. Still, the district maintained an extensive German foreign language programme that tapped into the cultural practices that persisted in the German heritage of many of the students who participated (courses which served as the threshold for my reclamation of German as a language of familial heritage). In response to the large and still growing Hmoob student population, the school hired a teacher to offer courses in Japanese - a Southeast Asian language that is linguistically dissimilar to Hmoob and is associated with high economic resource, academic potential, and empire.

\section{An overview of the chapter}

The chapter first situates the idea of heritage language education socially, politically, and historically, followed by a brief examination of some of the major conceptual contestations within the field of heritage language education. Throughout, the concept of heritage language education is attuned to the historical and sociopolitical factors that construct what it means to become a heritage language, a speaker of a heritage language, and a heritage language learner. The chapter reviews studies that are attuned to social, historical, and political power dynamics, which shape a conception of heritage speakers, languages, and education. This section focuses on three key research areas: curriculum, pedagogy, and teacher education. I then turn to pedagogic approaches and methods. Heritage language education occurs in both school-based and community-based settings. For school-based contexts, heritage language education must be understood as existing within the institution of schooling, which functions as a technology of nation building (Althusser 2006; Wolfe 2006). As such, heritage language education must draw on pedagogies that counteract the effects of deculturative and subtractive schooling (Valenzuela 1999; Spring 2005). Thus, this chapter pays particular attention to pedagogic approaches that take a critical and holistic view of heritage language education, including recent turns to consider collaborative translation as a form of translingual pedagogy that leverages linguistic, cultural, and literacy practices for sustaining multilingualism amongst heritage language speakers.

The chapter closes with a view of future directions for heritage language education. These futures push the field towards more intentional and socio-politically conscious teacher education; pedagogic and curricular designs that are consistent with linguistic, cultural, and academic restitution; and sociolinguistic considerations of heritage languages and learners that draw on the social (Block 2003), multilingual (May 2013; García and Li Wei 2014), and identity (Norton 2012) turns in language acquisition (Atkinson 2011). Finally, the chapter closes with a series of questions that avail themselves to the field of heritage language education in contexts that have been defined by settlement, colonialism, and raciolinguistic sociopolitical hierarchy. 


\section{Historical perspectives}

Heritage language education is conceptualized differently in different parts of the world. It is a field that defines itself in multiple ways and is strengthened by its internal contestations (van Deusen-Scholl 2003; Valdés 2005; Bale 2010). This section asks: "What's in a name?" and considers the foundational concept and terminology of heritage language education. As a policy decision, heritage language education exists in multiple contexts, defines legitimacy in multiple ways, follows multiple naming conventions (each with their own policy and practice implications), and has multiple approaches and goals of instruction. The sociopolitical construction of heritage languages, speakers, and learning cannot be disentangled from nation-building technologies of monoglossic ideology, linguistic hierarchies, and linguistic imperialism (Bale 2014). Using the example of Spanish in the United States and the Americas, this section illuminates ways that heritage language education is increasingly viewed with critical attention to historical, political, and social power dynamics.

\section{Heritage language education: what's in a name?}

Calls to offer heritage language education in US schools are situated within a larger ecology in which societal multilingualism stands in tension with ideologies of American nationalism. American nationalism is deeply entangled with monoglossic English ideologies (Valdés et al. 2006; Bale 2011; Bale and Knopp 2012). These monoglossic ideologies play out, in part, through restrictive language and curricular policies and practices of US schools (Malsbary 2014; Flores and Rosa 2015). Within this restrictive language environment, languages are inhibited by way of institutional denial of natural plurilingual maintenance and development, and societal languages and their speakers are formed into heritage languages and heritage language learners.

In this way, any non-dominant language can become a heritage language, because heritage languages are any "nonsocietal and nonmajority languages spoken by groups often known as linguistic minorities" (Valdés 2005, p. 12). While heritage language learners represent many ethnolinguistic and country-of-origin identities and backgrounds, the mechanisms that convert home languages into heritage languages are similar. Heritage languages are commonly spoken at home and often in the larger community. However, unless youth have access to bilingual schools, upon entering the English-only or English-dominant US school system, their language use and literacy options are severely restricted to English. This is despite the availability of these language(s) in some domains outside of school, or their use (sometimes subversive, and regularly at the expense of social or physical punishment) with peer groups at school. Development of academic subject linguistic complexity and print literacy is almost entirely in English, and very often at the expense of the maintenance of home languages and literacy in those languages (Valdés 2005).

Using the term heritage language is contested within the field - and not necessarily taken up in everyday parlance by practitioners and members of the communities who heritage language education is designed to serve. Still, it is used commonly enough in practice and is certainly the normed language within the fields of academic research, if not also education policy. It is an improvement to the overt deficit terminology commonly applied to multilingual individuals who have been restricted from home language maintenance through monoglossic and dominant language schooling (e.g. "quasi native speakers", "semilinguals", "limited proficient") 
(Valdés 2005). Ofelia García (2005, p. 601) argues that the positioning of languages as being heritage languages is problematic as it "rear-views" these languages, framing them as

what was left behind in remote lands, what is in one's past . . something that one holds onto vaguely as one's remembrances, but certainly not something that is used in the present or that can be projected into the future.

Language policy researchers who take an ecological approach to defining heritage languages (Hornberger and Wang 2008; Bale 2010) suggest a broad definition of heritage language that includes ancestral ties to the language, as well as individual identification as belonging to the group of heritage language learners or speakers. Jeff Bale (2010) highlights the importance of knowing and noting the ways that heritage languages and speakers of heritage language are positioned in social, political, and economic terms. These broad considerations situate heritage language education across the micro, meso, and macro layers of a language use and education ecology (Douglas Fir Group 2015). This ecological model of heritage languages, heritage language use (including a range of language varieties), and the teaching and learning of heritage languages (including which varieties) are interdependent across individual agency and identity, institutional and social factors, and ideological and political forces. In the examples of Spanish language education in the following sections, I will regularly refer to these courses and programmes as Spanish as a heritage language in agreement with Guadalupe Valdés' (2005) argument that the term heritage is deeply undesirable and problematic, but might be used with the understanding that it is meant to implicate the monoglossic and Anglo-white supremacist ideologies, policies, and practices that shape the schooling project of multilingual youth of colour in the US.

Jeff Bale (2010), in a comparative review of international perspectives on heritage language education policy research, suggests that the term heritage language be broadly applied in order to assume a critical stance that names the linguistic hegemony of English-dominant contexts and contexts in which English is the colonial language. This means that the very existence of heritage language courses and programmes signals that multilingual education in learners' home languages does not exist. In nation state contexts where English is not the dominant societal language, this stance expands to consider which languages are positioned as having institutionalized legitimacy (the languages of school, media, governance), and in some cases, which languages are considered punishable for being used (Skutknabb-Kangas and Fernandes 2008; Skutnabb-Kangas 2009). For example, Hassanpour et al. (1996) detailed the ways that Kurdish speakers, whether in diaspora across the globe or within Kurdistan (which includes parts of Turkey, Iran, Iraq, and Syria) were and are refused basic access to education because they are refused access to education in Kurdish. Moreover, the use of Kurdish has been (and in some cases continues to be) a punishable offence. These punishments can range from corporal to carceral, and can happen across environments, from the interpersonal, familial, and community, to being implemented by the state through institutional and systemic mechanisms. While some might argue that these are extreme cases, their historical regularity suggests that they are not extreme. The Kurdish example also resonates across many countries and cases of corporal punishment in schools for using Indigenous languages, and any language that is not the official and dominant language of the school and/or nation state.

In the United States and Canada, a policy of corporal punishment in response to the use of languages other than English perpetrated by teachers and administrators has a long lineage that reaches into the present, with speakers of Indigenous languages and Spanish being beaten 
for use of their home languages (Santa Ana 2004). While these practices are often rear-viewed as being an unfortunate aspect of a distant and distinct past, corporal punishment for the use of heritage languages was widespread and considered appropriate - even necessary - through the second half of the 20th century (Valenzuela 1999). It is one of the core components that led to massive school walkouts in the US southwest during the 1960s and 1970s, which fueled some of the early development of ethnic studies programmes in higher education. While no longer officially sanctioned, tacit approval of the punishment of heritage speakers for speaking heritage languages can be seen when school teachers and officials utilize social separation and isolation as punishment for use of home, heritage, and Indigenous languages. Such social punishment has psychological impacts that meet with similar results of language attrition and the formation of so-called heritage languages and learners. For example, the psychological and linguistic lessons that are internalized when children are ignored or rejected by teachers because they are not speaking the dominant language(s), or teachers refuse to teach children until they can make themselves understood in the dominant language(s).

With so few languages being considered legitimate on the global and nation state scales, the languages situated to be and become heritage languages are vast. In European Union countries, an official policy of multilingualism uses a $2+1$ model with the goal that every EU citizen is able to communicate in two languages in addition to a home language. Official governance and contact is made available in all of the 24 official languages of its current member states. Operationalized, this policy, too, is responsible for the formation of a number of heritage languages, including many home languages that would supposedly form the foundation of the $2+1$ policy (two languages in addition to a mother-tongue language), but are not supported through multilingual education in languages beyond the official languages of the nation state and possibly another official language of the EU (most often English) (Phillipson 2004; Byram and Parmenter 2012). In Austria, for example, where the official state language is German, schools serve large numbers of Turkish, Kurdish, Albanian, Arabic, Bosnian, Serbian, Croatian, and Polish speakers (naming only some of the higher number speaker languages). Yet there are at most a handful of bilingual options for all of these languages combined, while German-English bilingual tracks and schools abound.

In the United States, these contestations play out in part in an ongoing education policy conversation surrounding what name to give to courses and programmes at the secondary and post-secondary level intended to carry out the goals of heritage language education for people from Spanish-speaking families and communities who experience subtractive language and culture schooling in English-dominant and English-only US schools (Valenzuela 1999). Variably, these can be found under the programmatic titles of "Spanish as a Heritage Language", "Spanish for Heritage Learners", "Spanish for Native Speakers", and "Spanish for Spanish Speakers". More recently, in line with an implicit move to recognize the late-access bilingual education that heritage language education can provide (Cushing-Leubner 2017), some educators and administrators have begun using names such as "Spanish Language Arts", "Advanced Spanish Composition" and "Latin American/Latina/o/x Studies for Spanish Speakers". At the centre of the ongoing conversations of what to call Spanish as a heritage language education and what the purpose of these classes should be is the central conflict of many language policy debates: the contestation over the meaning and significance of equal (or equitable) opportunities for linguistic and cultural maintenance and strength in multiethnic, multicultural, and plurilingual sociocultural and sociopolitical contexts (Schmidt 2006). These contestations point to the core theoretical questions, "What is at stake?" (p. 99), "For whom?" (p. 96), and "For what?" (Ortega 2005; Valdés 2005). In the following section, Spanish as a heritage language in the United States will be examined through historical lenses of empire and 
nationhood. It seeks to make visible the complicating factors of what it means to do heritage language education, when the focal language is also a tool of linguistic erasure. This question then informs implications for practices and pedagogies for heritage language education in relationships to contestations of power that live in the institutionalization of language teaching and learning.

\section{Spanish, heritage, and colonization: historical perspectives on the most commonly taught heritage language in the United States}

Spanish is uniquely positioned in the United States, adding additional layers of contestation and complexity to its place in heritage language education. It is not an indigenous language of the continent. As a European language, its presence is a result of colonization and empire expansion across the Américas. It has been used effectively over generations as a mechanism of linguistic and cultural removal and replacement, in connection with tools of empire expansion and later state governance that include schooling and the Catholic church. As a language of colonialism during a time of transcontinental mercantilism of the slave trade, Spanish speakers of Central, South, and North America (including the islands of the Caribbean) range in lineage to include Indigenous peoples, descendants of enslaved Africans, and descendants of Chinese transferred to the continent for merchant and physical labour. As such, the pervasive presence of Spanish across the Américas is entwined with the sociopolitical, economic, and institutional assertion of Spanish language, cultural practices, and colonial governance over Indigenous, West African, and Chinese languages and peoples. This further entrenches the suppression and linguistic-cultural erasure of the people connected to these languages (Vigil 1998; Galeano 2009).

In the United States, the Spanish language also represents a group of people who, in the efforts of Anglo-European settlement and westward expansion were vilified as a threat to the formation of the burgeoning US nation state. Spanish simultaneously signified colonial subjects of Spain - a potential threat to Anglo land seizure and settlement efforts - and the variably disposable colonized Indigenous subjects of Mexico. As Mexicans, Spanish speakers in the shifting boundaries of the expanding United States represented people with Indigenous roots who needed to be conquered, removed, or replaced for the continued emergence and survival of the settler-colonial state (Limerick 1987; Gonzalez 2000). This long history of attempts to conquer, remove, and replace (which included the construction of the Mestizo subject by the Spanish colonial rule) informed an ideological stance of distrust towards Spanishspeaking people in the United States and furthered demands for assimilation into an idealized and unattainable Anglo-American subject (García 2009).

Because of its use in the colonization of the Américas, the Spanish language has been spoken across large areas of the present-day United States before political borders were drawn and moved over land lived on by generations of Uto-Aztecan and Spanish-speaking colonized Indigenous peoples (Fishman 1999). This made Spanish a language that was used early on to mark its speakers as racialized others in the present-day United States. Complemented by nativist narratives, Spanish speakers with roots in the Américas (racialized today as "Latina/ $\mathrm{o} / \mathrm{x}$ ", and historically as "Mexican" or "Indian") were and are framed as potential economic and political enemies to the state, residing within the state (Santa Ana 2002).

The varieties of Spanish spoken by many Spanish speakers are also marked by Indigenous languages, preserved in part through the linguistic dexterity of Indigenous peoples of the Américas in forced contact with colonial language and rule (e.g. Brody 1995; Bills and Vigil 1999; Anzaldúa 2012). The xenophobic backlash against Spanish speakers with Américas roots that 
continues in the present day in the United States was bolstered by a general mid-19th century US nativism nurtured by two world wars (Fishman 1999; García 2009). As the long-standing most commonly spoken language in the United States other than English, this has played out with Spanish (and its actual and imagined speakers) experiencing xenophobic backlash, resentment, and continued attempts at suppression, segregation, and assimilation (García 2009; Bale 2012).

The erasure of Spanish and its speakers' experiences with language shift and marginalization are complicated in that the language simultaneously enjoys a far-reaching vitality across large numbers of Spanish-speaking communities, is heralded as an additive resource language (Ruiz 1984) to be learned by predominantly English-speaking youth of European descent (Scanlan and Palmer 2009), and is framed as a linguistic problem (Ruiz 1984) on the receiving end of logics of biocultural elimination (Wolfe 2006) amongst speakers with Américas roots. This logic of elimination plays out particularly effectively through language in education policies and practices in place in US schools (Valenzuela 1999; Spring 2005; García and Baetens Beardsmore 2009). Taken together, this forms the context for heritage language education with learners of Spanish.

\section{"If they so choose": heritage language education settler access and Indigenous refusal}

In contemporary terms, the offering of heritage language options in US schools is driven by an ethic of liberal pluralism that asks: "How can different ethnolinguistic minority groups maintain their cultures and languages if they so choose while peacefully co-existing with the majority dominant group(s) within the modern, liberal state?" (Ricento 2006, p. 232, emphasis in the original). This suggests that minoritized groups may be allowed to maintain their minoritized languages if they so choose, which disregards the historic and hegemonic power structures, systems of oppression and erasure, and processes of European ethnolinguistic white settler language privileging (Iyengar 2014; Grande 2015) that necessitate heritage language education. The increasing availability of immersion bilingual education in languages considered an additive resource for white English speakers (e.g. Spanish, Chinese, Arabic), while simultaneously considered a problem for native speakers who are often racialized through their speaking of those very languages (Flores and Rosa 2015), is reflective of what post-colonial language theorist Suresh Canagarajah (2005) describes as the fetishizing of one localized language while subjugating another. The settler-colonial context of the United States is fertile ground for this contradiction to play out in the availability of heritage language education. As Malathi Iyengar (2014, p. 52) articulates regarding the myth of liberal multiculturalism in schooling choice,

Euro/American settlers could say, "I'll send my children to the common school, if and only if that school provides education in our mother tongue". Native parents could say, "I'll send my children to the off-reservation Indian boarding school," but did not have the option of adding, "only if you agree not to beat our language out of them while they're there".

In her systematic historical analysis of language policy and language ideology as it has played out as a tool for constructing the Eurocentric institutions of schools within the US settler-colonial state, Malathi Iyengar (2014) provides a clear history of the ways maintenance of European languages of settlers up through the 20th century (to the time of World War I) 
were considered both legitimate and a benefit to English language development. One example of this was bilingual education for European languages in both privately and publicly funded schools. These early public schools were the institutional response to insistence by European settlers to preserve ethnic cultural identity and their European languages within the context of community education and English language development. Not only did bilingual public education for settlers of European ethnolinguistic descent become the norm, it flourished, with the common schools of the time positively responding to communities demanding that schools maintain European home languages.

Malathi Iyengar's (2014) description of this commitment to providing bilingual education in response to community demand on behalf of European settlers is deftly juxtaposed with the US government's simultaneous kidnapping of native youth and forcing them into English-only and Eurocentric boarding schools. The clearly stated purpose of these residential boarding schools were, as Captain Richard Pratt in his description of the Carlisle School founding described, "to kill the Indian, and save the man". This was done through schooling practices that sought to separate Indigenous youth from their families and communities, strip them of their home and ancestral languages to interrupt intergenerational identity and knowledge sharing, and replace these language and knowledge systems with English and European epistemologies and cultural practices through submersive schooling that did not hesitate to use physical and psychological violence. As Joel Spring (2005) notes, this process of deculturalization - using schooling to strip language and culture in order to replace them with those of the dominating group - proved so efficient that the US settler government believed they could subjugate a group of people within a single generation. This linguistic stripping and forced attrition of first (heritage) languages directed at Indigenous peoples, while European settlers experienced the opportunity of first (heritage) language maintenance through bilingual education serves as an eerie mirror of present day subtractive language education for some (predominantly multilingual immigrant youth of colour) and additive language education for others (predominantly English-speaking youth of European descent) (e.g. Donato 1997; Valenzuela 1999).

\section{The heart of the community: humanizing schools through heritage language education}

Heritage language education is also a site of culturally and linguistically revitalizing and sustaining practices (McCarty et al. 2009; Paris 2012; Paris and Alim 2017). Lisa Rabin (2011) traces an example of the history of school-based heritage language education in her biographical study of heritage language educator Leonard Covello. Covello was a New York City language teacher from 1915-1956 who pushed for Italian and Spanish heritage language classes in schools for his Spanish and Italian speaking students who were placed in remedial tracks, barring them access to Latin and French classes, which were considered appropriate only for (non-immigrant and English-dominant) college-going elite students. He highlighted the value of community language varieties and designing instruction through what is now considered critical service learning projects (Mitchell 2008) that learners would carry out in their own East Harlem neighbourhoods. Covello believed that these approaches created communitycentered schools, with classrooms being extensions of the "heart of the community itself" (Covello 1939 quoted in Rabin 2011, p. 338). His work with heritage learners worked against deeply entrenched monolingual English ideologies connected to Americanization and US exceptionalism. The shape that heritage language education took as a core channel to community sustainability and resilience intersected with issues of race and class, positionalities 
that inform heritage language speakers and learners today. The Covello approach to heritage language education centres collective community empowerment and social consciousness community consientization (Cushing-Leubner 2017) - and persists in the pedagogies for heritage language education described in the next section.

This history of community conscientization provides a legacy of multilingual youth and heritage (language) educators resisting and overwriting the types of problem-driven discourses often applied to them. Leeman et al. (2011b) make a case for recasting problem-based discourses associated with heritage languages and speakers in curricular and pedagogical ways. They argue that a critical perspective to Spanish heritage language education can allow the historical contestations surrounding Spanish to create rich contexts for language learning. This then provides a rich environment to move heritage language education beyond the school walls to merge with heritage language maintenance efforts that are already always happening within the community.

\section{Research approaches and key findings}

As the field of heritage language education considers how languages and speakers are positioned within schools and societies, so too must our approaches to research (Hornberger 2005). These approaches to research are attuned to social, historical, and political power dynamics. These dynamics shape a conception of heritage speakers, languages, and education, making it necessary that they be accounted for and centralized in research methodologies and methods of analysis.

Research approaches to heritage language education have historically focused on applied and sociolinguistic research. These include studies on classroom discourse, linguistic variation and change, and language attitudes and beliefs. Foundational studies have highlighted distinctions between the language of instruction and language in use patterns of phonology, vocabulary, syntax, and semantics amongst heritage learners (e.g. Polinsky and Kagan 2007). There is extensive deficit-oriented research that examines heritage learners as problematic speakers, focusing on differences across language use as being inaccurate and wrong, and highlighting the literacy limitations of heritage learners while failing to recognize the limited access to bilingual education (Flores 2013). Such problem orientations to heritage language education research frames findings towards corrective heritage language instruction. The findings from research that approach heritage language learners as linguistic problems are unfortunately widespread and regularly shape linguistic damage-based programme models for heritage language education.

Critical approaches to research in and of heritage language education has ample room to expand to include and further sociolinguistic and raciolinguistic studies. Discrete language use, discourse analysis of classroom language use, and sociolinguistic research of language attitudes and ideologies offer findings that highlight linguistic ingenuity, resistance, and pressures to conform (e.g. Harklau 2009; He 2010; Helmer 2011; Showstack 2012). Studies of identity (He 2006; Leeman 2015) and ideologies (King 2000) examine their impacts on the availability of heritage language education, quality of instruction, and investment in the use and learning of languages in the public domain. Researchers take up methodologies from across disciplines and include offerings of sociocultural theory (He 2010), sociolinguistics, school and family language policy (King et al. 2008; Schwartz 2008), linguistic anthropology (Polinsky and Kagan 2007), and ethnographic case studies.

Increasingly, there is an expansion of research in the areas of pedagogies, curriculum, and teacher education (Trifonas and Aravossitas 2014; Leeman and Serafini 2016; Brinton et al. 
2017). These include examinations of heritage language teacher beliefs and attitudes (Lee and Oxelson 2006), heritage language teacher preparation and standards (Schwartz 1999; Potowski 2003; Potowski and Carreira 2004; Kagan and Dillon 2009; Caballero 2014; Pascal y Cabo 2016) and general instructional practices (Hinton 2011; Beaudrie et al. 2014; Palmer et al. 2014; Fairclough and Beaudrie 2016; Valdés and Roca 2016). Research is largely reflective of Spanish as a heritage language, though other language contexts that appear somewhat regularly in heritage language education journal articles and edited volumes include Chinese, Vietnamese, and Russian. Considering the broad scope of just how much of language education research and practice might fit within the umbrella of heritage language education, research of less commonly taught languages (see the journal of the National Council of Less Commonly Taught Languages) and Indigenous language revitalization and sustainability also offer valuable insights and rich contexts for deeper understanding and expanded documentation.

\section{Pedagogic approaches and methods}

Pedagogic approaches and methods for heritage language education cannot be divorced from the broader historical and sociopolitical contexts of schooling, which are shaped by ethnoracial and monoglossic ideologies as well as the use of schooling as a technology of colonialism and nation building (Wolfe 2006; Bale 2014). Key pedagogical turns in heritage language education include fostering critical pedagogies such as critical language awareness (Pennycook 2001), critical pedagogies rooted in critical social consciousness (Parra 2016), identity work (Leeman 2015), translingual practices that include translanguaging and collaborative translation (Pennycook 2006), and community-based learning (Leeman et al. 2011a, 2011b).

\section{Language brokering and collaborative translation}

Research specific to the use of translation as a pedagogic approach for heritage language education specifically is scarce. A recent review of interpretation pedagogies (Mellinger et al. 2019) recognizes the linguistic and cultural knowledge that heritage learners bring, alongside widely varying linguistic profiles. Moreover, it highlights the still limited representation of heritage language users in the area of teaching and learning interpretation. Translation and interpretation between home languages and dominant languages of schools are two of the many translingual practices that make up translanguaging as a pedagogic approach for sustaining home languages while acquiring the dominant language of schools and nation states (Creese and Blackledge 2010). The growing body of translanguaging research points to the use of translation practices in sustaining heritage languages in so-called mainstream classrooms, and highlights opportunities for more intentional pedagogical leveraging of multi-directional and collaborative translation pedagogies that mirror and build off of the translation and interpretation skills and practices that heritage speakers develop through their everyday negotiations of multilingual worlds and experiences. This work grows out of the concept of language brokering, which describes the range of practices that multilingual youth employ to communicate across and merge the language, cultures, and knowledge systems they experience with their families, communities, schools, and other governmental and non-governmental institutions.

\section{Language brokering: a translingual practice for cautious inclusion}

Marjorie Faulstich Orellana's (2009) notion of language brokering has spawned a range of studies on the ways that very young multilingual youth participate in translation and interpretation, 
particularly between family members and schools and other institutions that serve multilingual families in restrictive monoglossic and (in the case of the United States) English-dominant ways. As a teaching method, language brokering leverages the language and literacy practices that heritage language learners whose families are mixed in language dominance practice outside of the language learning environment. Though test results should not be a primary goal of language instruction, one study with children of Mexican immigrants in Chicago suggests that leveraging these skills can also support learner success on standardized tests (Dorner et al. 2007). Research on language brokering has shown that recognizing and intentionally designing instruction to reflect and support these multilingual and multiliteracy practices have social and emotional impacts on multilingual youth that could influence their language learning in heritage language education settings. These impacts include the shaping of a sense of interdependence (Dorner et al. 2008) and prosocial development and the development of a helpingidentity (Guan et al. 2014). However, educators must also be attuned to the emotional tolls that can impact multilingual youth who become learners of a heritage language (Morales and Hanson 2005; Weisskirch 2006). Heritage language educators must leverage both the translingual practices as well as the ways many heritage language learners have been positioned to experience racial hostilities, microagressions, and xenophobic messages. Language brokering can begin at early ages, and heritage language learners may have only a handful of experiences or many years of linguistic and cultural brokering in a range of settings that are seldom welcoming and supportive non-dominant language and cultural practices.

\section{Collaborative translanguaging}

Another translingual practice of translation that has recently seen an increased representation in scholarship as a pedagogic approach that might support heritage language learning and maintenance is collaborative translation. Collaborative translation falls within dynamic bilingual and dynamic translation approaches (Appiah 2000) that seek to leverage and strengthen language, literacy, and cultural brokering. Such translation approaches produce "a text that matters to one community the way another text matters to another" (p. 425). Equally important to educators crafting the use of collaborative and dynamic translation to support heritage language learners is to understand translation beyond the technical and into the interpretive, using language and cultural understandings that are appropriate for a wide range of audiences (Keyes et al. 2014) and applying learners' metalinguistic and sociolinguistic knowledge to discuss why certain language choices create a text that matters equally to different audiences and interlocutors.

Collaborative translation, as a collective effort, requires a multimodal approach with learners communicating across speaking, listening, reading, and writing while they work together to negotiate multilingual meaning that may be contextualized by different purposes, social locations, interlocutors, and audiences (Puzio et al. 2013). Students read a text (most often an academic or literary text), translate key passages, evaluate their translations together, discuss, grapple, and determine the best translation or reasoning for multiple versions. The focus is on both language and textual contexts linked to growing literacy confidence in both heritage and dominant languages (Keyes et al. 2014).

In multiple studies emerging from the work of Project TRANSLATE, examples of how teachers who don't share language proficiencies in the heritage languages of their students are able to leverage heritage languages in complex (more than two) multilingual classrooms to support and extend literacy practices (Pacheco et al. 2015; David et al. 2019). Teachers participated as learners, translation and literacy collaborators, and literacy experts alongside their 
multilingual students. Heritage speakers drew on their multiple languages, cultural knowledges, and literacy practices to negotiate and co-construct textual meanings and cultural references. Together, teachers and learners expanded their linguistic practices and knowledge across varieties of languages they shared with one another by grappling with translation choices and preferences, particularly in the areas of vocabulary and comprehension of complex language in use expressions.

\section{Critical pedagogies and heritage language education}

Because heritage languages themselves are shaped through sociopolitical power dynamics, this section will focus on pedagogic approaches favouring designs that grow out of or incorporate critical pedagogies (Gounari 2014), with their attention to making power dynamics visible, and developing a sense of collective agency to inculcate change amongst those negatively impacted by dominant ideologies and the policies attuned to them. Most literature on pedagogic approaches draws from the context of Spanish as a heritage language, primarily higher education settings. In the following section, the construction of community conscienticization (Cushing-Leubner 2017) is described as a key pedagogy that has emerged with varying terminology. Community conscienticization merges pedagogical approaches of critical language awareness, community-based learning, identity work, and critical service learning. Leeman et al. (2011b) show that strengthening heritage language learners' linguistic identities and language activism within their own communities are central components of these projects. In the projects they describe, studying what it means for a language to be positioned as a heritage language (an aspect of critical language awareness) is often the focus of learner activism. However, their descriptions do not indicate that heritage languages are also the vehicles through which critical service learning happens. They argue that because identity has and will always be at the centre of heritage language education, so too must language identity be at the centre of community conscienticization (i.e. "critical service learning" in Leeman 2005, 2015; Leeman et al. 2011a; Rabin 2011). Speaking to this, Leeman et al. (2011b) draw on the rich history of language rights activism, connected to identity, within the US Chicanx community.

Leeman $(2015$, p. 285) pushes this further in connection to a community conscienticization when she describes critical service learning's capacity to directly engage Spanish as a heritage language for students in their own communities, saying that it provides an "examination of the structural, political and ideological roots and implications of the problems being addressed and foregrounds the role of language". In this way, communities and community members are not constructed as simply resources or representations of "authenticity". Rather, youth and elders enter into partnerships in order to share and exchange knowledge and to work collaboratively towards shared goals that have been collectively determined for the good of the community.

LINGUISTIC AND COMMUNITY CONSCIENTICIZATION - BEYOND CRITICAL

LANGUAGE AWARENESS

In her call for the use of critical pedagogy approaches for heritage speakers in college-level Spanish for Native Speakers courses, Jennifer Leeman (2005) suggests that a critical pedagogies approach to heritage language education must start with critical language awareness (CLA) (Pennycook 2001). CLA recognizes that languages are political and politicized, play a role in hegemonic struggle and status quo maintenance, and are capable of being a tool both for subjugating speakers of certain languages and for imaginative resistance. Leeman (2005) insists that critical heritage language educators view CLA as necessary and foundational 
and suggests that teaching and learning must also move past this as an intellectual project of awareness-building and take relevant action. As an instructional model, students and teachers should utilize CLA to identify problematics of power; interrogate their own positionalities, subjugations, agencies, and desires; and act in order to transform the status quo in an effort to disrupt current realities and enact social change.

Later work by Jennifer Leeman et al. (2011b) suggests moving beyond CLA by first focusing on an examination of material contexts and consequences of pervasive language ideologies at work in the lives and desired futures of youth and their communities. For this, they suggest the use of critical service learning (Mitchell 2008) and view this as a means for language activism and language identity to become linked, with heritage language as the vehicle for action. Critical service learning is distinguishable from traditional models of service learning that continue to be predominant. In her literature review on traditional and critical service learning models, Tania Mitchell (2008) provides a succinct description of the similarities and differences. Similar to traditional service learning, critical service learning models include both community and classroom components and reflection across spaces. However, the central purpose of traditional service learning is on the participating student engaging in a combination of 'learning to serve' and 'serving to learn'; participating students often engage with service learning in communities of which they are not members, and the outcomes are largely weighted on student personal development and an experience of individual change on the part of the participants. Critical service learning seeks to balance these individual outcomes with a centralizing focus on social change that involves direct efforts to redistribute power and develop authentic relationships. Although it is not obligatory in order to be considered critical service learning, participants usually do critical service learning projects in the communities they belong to. Leeman et al. (2011a) contend that critical service learning in one's own community is a necessary next step from critical language awareness, as it relies on the agency of the individual as both an actor and a member of a collective action. They consider a CLAinformed critical service learning context to be the richest site for heritage language learners' abilities to act together for a purposeful action related to and through the heritage language.

\section{Conclusions and future directions}

As the field of heritage language education continues to expand and clarify itself, so do the myriad possibilities and needs for research and pedagogy. These directions rest on conceptualizing heritage language education within the realm of pedagogies of possibility. I close by suggesting researchers and pedagogues work to make sense of the shifting sociopolitical contexts that have historically shaped heritage language education - and continue to do so today. Centralizing these forces makes clear the many gaps and entry points in this continually emerging field. These gaps and entry points include questions of what heritage language teachers need to know and be able to do, what goals and ethics are infused in effective heritage language curricula, and what pedagogical approaches best serve the wide range of heritage learners in our schools and communities. As a field, we must better understand and represent less commonly taught languages with their overlaps and distinct circumstances and needs. What are the pedagogical and curricular projects and desires for less commonly taught heritage languages some of which experience legitimization and support through nation state mechanisms when they are seen as high resource to the economy or national security, and some of which are further invisibilized as displaced Indigenous and ethnic minority languages? How must researchbased explanations of language and literacy development expand to reflect distinctions in 
global Indigenous languages' perspectives on language use, definitions of proficiency, and literacy practices? What are the instructional approaches that might better guide the sustaining and revitalization of heritage languages whose attrition is the result of systematic elimination on the part of nation states and for the purpose of maintaining the future of those states at the expense of the languages and cultures of the peoples within their bounds?

\section{Further reading}

Heller, M. and McElhinny, B. (2017) Language, Capitalism, Colonialism: Toward a Critical History. Toronto: University of Toronto Press.

This book takes a critical historical perspective on the social and political framing and use of language to determine value, legitimacy, and opportunity. Using understandings of how language becomes a tool of both empire expansion and global capitalism, the authors provide a clear and sweeping narrative that allows readers to call into question commonsense thinking of which languages have value, how heritage languages are constructed, for what purposes, and why projects of translation and heritage language education are frought with deeply entrenched and often invisible power struggles.

Skutnabb-Kangas, T., Phillipson, R., Mohanty, A.K. and Panda, M. (eds) (2009) Social Justice Through Multilingual Education. Bristol: Multilingual Matters.

This book details the desires and attempts for linguistic autonomy and collective self-determination through minoritized and heritage language education across global locations. The authors outline principles for supporting multilingualism and the recuperation of heritage languages, with a primary focus on how communities are attempting to keep their languages from becoming relegated to 'heritage languages' in the first place. The book both asks and offers models for how this can be done, paying attention to local challenges.

Trifonas, P.P. and Aravossitas, T. (eds) (2018) Handbook of Research and Practice in Heritage Language Education. New York: Springer International Publishing.

This handbook is a starting place for any educational researcher interested in heritage language education and practices of pedagogies and language use in heritage language education contexts. The editors pay equal attention to scholarship and research, as well as pedagogic approaches and teaching methods. Case examples include First Nations and Indigenous language revitalization efforts, diaspora language maintenance, immigrant and minoritized languages, and commonly taught heritage languages across the Americas, Europe, Africa, the Asia continent, and Australia. Chapters highlight issues of power, community interest, ethical concerns, language rights, cultural practices, identity, and the politics of difference and globalization.

Wiley, T.G., Peyton, J.K., Christian, D., Moore, S.C.K. and Liu, N. (eds) (2014) Handbook of Heritage, Community, and Native American Languages in the United States: Research, Policy, and Educational Practice. London: Routledge.

This handbook offers a strong foundation for a broad consideration of heritage language education as it is shaped in community-based settings, schools, informal teaching and learning contexts, and higher education. Chapters are well-balanced across the many dimensions of 'heritage' languages, including Native, First Nations, and Indigenous languages; community languages with large numbers of speakers; and minoritized diasporic languages. This handbook includes a focus on how policies and educational practices are shaped and influence the spaces for heritage language education and heritage language education research.

\section{Related topics}

bilingual education; bilingualism and multilingualism, teacher agency in plurilingual learning contexts 


\section{References}

Alim, S., Rickford, J.R. and Ball, A. (eds) (2016) Raciolinguistics: How Language Shapes our Ideas About Race. Oxford: Oxford University Press.

Althusser, L. (2006) Ideology and ideological state apparatuses (notes towards an investigation). The Anthropology of the State: A Reader. 9(1), pp. 86-98.

Anzaldúa, G. (2012) Borderlands/La Frontera: The New Mestiza. San Francisco: Aunt Lute Books.

Appiah, K.A. (2000) Thick translation, in Venuti, L. (ed) The Translation Studies Reader. New York: Routledge. pp. 417-429.

Atkinson, D. (ed) (2011) Alternative Approaches to Second Language Acquisition. New York: Routledge.

Bale, J. (2010) International comparative perspectives on heritage language education policy research. Annual Review of Applied Linguistics. 30, pp. 42-65.

Bale, J. (2011) Tongue-tied: Imperialism and second language education in the United States. Critical Education. 2(8), pp. 1-25.

Bale, J. (2014) Heritage language education and the "national interest". Review of Research in Education. 38(1), pp. 166-188.

Bale, J. and Knopp, S. (eds) (2012) Education and Capitalism: Struggles for Learning and Liberation. Chicago: Haymarket Books.

Beaudrie, S.M., Ducar, C. and Potowski, K. (2014) Heritage Language Teaching: Research and Practice. New York: McGraw-Hill Education Create.

Bills, G.D. and Vigil, N.A. (1999) Ashes to ashes: The historical basis for dialect variation in New Mexican Spanish. Romance Philology. 53(1), pp. 43-68.

Block, D. (2003) The Social Turn in Second Language Acquisition. Washington, DC: Georgetown University Press.

Brinton, D.M., Kagan, O. and Bauckus, S. (eds) (2017) Heritage Language Education: A New Field Emerging. London: Routledge.

Brody, J. (1995) Lending the 'unborrowable': Spanish discourse markers in indigenous American languages, in Silva-Corvalán, C. (ed) Spanish in Four Continents: Studies in Language Contact and Bilingualism. Washington, DC: Georgetown University Press. pp. 132-147.

Byram, M. and Parmenter, L. (eds) (2012) The Common European Framework of Reference: The Globalisation of Language Education Policy. Bristol: Multilingual Matters.

Caballero, A.M.S. (2014) Preparing teachers to work with heritage language learners, in Wiley, T.G., Peyton, J.K., Christian, D., Moore, S.C.K. and Liu, N. (eds) Handbook of Heritage, Community, and Native American languages in the United States. London: Routledge. pp. 229-252.

Canagarajah, S. (2005) Reclaiming the Local in Language Policy and Practice. New York: Routledge.

Creese, A. and Blackledge, A. (2010) Translanguaging in the bilingual classroom: A pedagogy for learning and teaching? The Modern Language Journal. 94(1), pp. 103-115.

Cushing-Leubner, J. (2017) Accompaniment for the Climb: Becoming Reparational Language Educators of Spanish as a 'Heritage' Language. $\mathrm{PhD}$ dissertation, University of Minnesota. Available from: https://conservancy.umn.edu/handle/11299/199091.

David, S.S., Pacheco, M.B. and Jiménez, R.T. (2019) Designing translingual pedagogies: Exploring pedagogical translation through a classroom teaching experiment. Cognition and Instruction. 37(2), pp. 252-275.

Donato, R. (1997) The Other Struggle for Equal Schools: Mexican Americans During the Civil Rights Era. Albany, NY: SUNY Press.

Dorner, L.M., Orellana, M.F. and Jiménez, R. (2008) "It's one of those things that you do to help the family": Language brokering and the development of immigrant adolescents. Journal of Adolescent Research. 23(5), pp. 515-543.

Dorner, L.M., Orellana, M.F. and Li-Grining, C.P. (2007) "I helped my mom," and it helped me: Translating the skills of language brokers into improved standardized test scores. American Journal of Education. 113(3), pp. 451-478. 
Douglas Fir Group. (2015) A transdisciplinary framework for SLA in a multilingual world. The Modern Language Journal. 100(S1), pp. 19-47.

Fairclough, M. and Beaudrie, S.M. (eds) (2016) Innovative Strategies for Heritage Language Teaching: A Practical Guide for the Classroom. Washington, DC: Georgetown University Press.

Fishman, J. (1999) 300-plus years of heritage language education in the United States, in Peyton, J.K., Ranard, D.A. and McGinnish, S. (eds) Heritage Languages in America: Preserving a National Resource. McHenry, IL: Delta Systems Company. pp. 81-98.

Flores, N. (2013) Silencing the subaltern: Nation-state/colonial governmentality and bilingual education in the United States. Critical Inquiry in Language Studies. 10(4), pp. 263-287.

Flores, N. and Rosa, J. (2015) Undoing appropriateness: Raciolinguistic ideologies and language diversity in education. Harvard Educational Review. 85(2), pp. 149-171.

Galeano, E. (2009) The Open Veins of Latin America. London: Serpent's Tail.

García, O. (2005) Positioning heritage languages in the United States. The Modern Language Journal. 89(4), pp. 601-605.

García, O. (2009) Emergent bilinguals and TESOL: What's in a name? TESOL Quarterly. 43(2), pp. 322-326.

García, O. and Baetens Beardsmore, H. (2009) Heteroglossic bilingual education policy, in García, O. (ed) Bilingual Education in the 21st Century: A Global Perspective. West Sussex: John Wiley \& Sons. pp. 244-286.

García, O. and Li Wei. (2014) Translanguaging and education, in García, O. and Li Wei. (eds) Translanguaging: Language, Bilingualism and Education. London: Palgrave Macmillan. pp. 63-77.

Gonzalez, J. (2000) Harvest of Empire: A History of Latinos in America. New York: Penguin Group.

Gounari, P. (2014) Rethinking heritage language in a critical pedagogy framework, in Pericles Trifonas, P. and Aravossitas, T. (eds) Rethinking Heritage Language Education. Cambridge: Cambridge University Press. pp. 254-269.

Grande, S. (2015) Red Pedagogy: Native American Social and Political Thought. 2nd ed. London: Rowman \& Littlefield.

Guan, S.S.A., Greenfield, P.M. and Orellana, M.F. (2014) Translating into understanding: Language brokering and prosocial development in emerging adults from immigrant families. Journal of Adolescent Research. 29(3), pp. 331-355.

Harklau, L. (2009) Heritage speakers' experiences in new Latino diaspora Spanish classrooms. Critical Inquiry in Language Studies. 6(4), pp. 211-242.

Hassanpour, A., Skutnabb-Kangas, T. and Chyet, M. (1996) The non-education of Kurds: A Kurdish perspective. International Review of Education. 42(4), pp. 367-379.

He, A.W. (2006) Toward an identity theory of the development of Chinese as a heritage language. Heritage Language Journal. 4(1), pp. 1-28.

He, A.W. (2010) The heart of heritage: Sociocultural dimensions of heritage language learning. Annual Review of Applied Linguistics. 30, pp. 66-82.

Helmer, K.A. (2011) "Proper' Spanish is a waste of time": Mexican-origin student resistance to learning Spanish as a heritage language, in Scherff, L. and Spector, K. (eds) Culturally Relevant Pedagogy: Clashes and Confrontations. New York: Rowman \& Littlefield Education. pp. 135-163.

Hinton, L. (2011) Language revitalization and language pedagogy: New teaching and learning strategies. Language and Education. 25(4), pp. 307-318.

Hornberger, N.H. (2005) Opening and filling up implementational and ideological spaces in heritage language education. The Modern Language Journal. 89(4), pp. 605-609.

Hornberger, N.H. and Wang, S.C. (2008) Who are our heritage language learners? Identity and biliteracy in heritage language education in the United States, in Brinton, D.M., Kagan, O. and Bauckus, S. (eds) Heritage Language Education: A New Field Emerging. London: Routledge. pp. 3-35.

Iyengar, M.M. (2014) Not mere abstractions: Language policies and language ideologies in US settler colonialism. Decolonization: Indigeneity, Education \& Society. 3(2), pp. 33-59.

Kagan, O. and Dillon, K. (2009) The professional development of teachers of heritage language learners: A matrix, in Anderson, M. and Lazaraton, A. (eds) Bridging Contexts, Making Connections: Selected 
Papers from the Fifth International Conference on Language Teacher Education. Minneapolis, MN: Center for Advanced Research on Language Acquisition. pp. 155-175.

Keyes, C.S., Puzio, K. and Jiménez, R.T. (2014) Collaborative translations: Designing bilingual instructional tools. Journal of Education. 194(2), pp. 17-24.

King, K.A. (2000) Language ideologies and heritage language education. International Journal of Bilingual Education and Bilingualism. 3(3), pp. 167-184.

King, K.A., Fogle, L. and Logan-Terry, A. (2008) Family language policy. Language and Linguistics Compass. 2(5), pp. 907-922.

Lee, J.S. and Oxelson, E. (2006) "It's not my job": K - 12 teacher attitudes toward students' heritage language maintenance. Bilingual Research Journal. 30(2), pp. 453-477.

Leeman, J. (2005) Engaging critical pedagogy: Spanish for native speakers. Foreign Language Annals. $39(1)$, pp. 35-45.

Leeman, J. (2015) Heritage language education and identity in the United States. Annual Review of Applied Linguistics. 35, pp. 100-119.

Leeman, J., Rabin, L. and Román-Mendoza, E. (2011a) Critical pedagogy beyond the classroom walls: Community service-learning and Spanish heritage language education. Heritage Language Journal. 8(3), pp. 1-22.

Leeman, J., Rabin, L. and Román-Mendoza, E. (2011b) Identity and activism in heritage language education. The Modern Language Journal. 95(4), pp. 481-495.

Leeman, J. and Serafini, E.J. (2016) Sociolinguistics for heritage language educators and students, in Fairclough, M. and Beaudrie, S.M. (eds) Innovative Strategies for Heritage Language Teaching: A Practical Guide for the Classroom. Washington, DC: Georgetown University Press. pp. 56-79.

Limerick, P.N. (1987) The Legacy of Conquest: The Unbroken Past of the American West. London: W. W. Norton \& Company.

Malsbary, C. (2014) "Will this hell never end?": Substantiating and resisting race-language policies in a multilingual high school. Anthropology \& Education Quarterly. 45(4), pp. 373-390.

May, S. (ed) (2013) The Multilingual Turn: Implications for SLA, TESOL, and Bilingual Education. New York: Routledge.

McCarty, T., Romero-Little, M.E., Warhol, L. and Zepeda, O. (2009) Indigenous youth as language policy makers. Journal of Language, Identity \& Education. 8(5), pp. 291-306.

Mellinger, C.D., Jiménez, G. and Gasca, L. (2019) Challenges and opportunities for heritage language learners in interpreting courses in the US context. Revista de Lenguas para Fines Especificos. 52(101), pp. 950-974.

Mitchell, T.D. (2008) Traditional vs. critical service-learning: Engaging the literature to differentiate two models. Michigan Journal of Community Service Learning. 14(2), pp. 50-65.

Morales, A. and Hanson, W.E. (2005) Language brokering: An integrative review of the literature. Hispanic Journal of Behavioral Sciences. 27(4), pp. 471-503.

Norton, B. (2012) Identity and second language acquisition, in Chapelle, C.A. (ed) The Encyclopedia of Applied Linguistics. Malden, MA: Blackwell Publishing. pp. 1-8.

Orellana, M.F. (2009) Translating Childhoods: Immigrant Youth, Language, and Culture. New Brunswick, NJ: Rutgers University Press.

Ortega, L. (2005) For what and for whom is our research? The ethical as transformative lens in instructed SLA. The Modern Language Journal. 89(3), pp. 427-443.

Ortega, L. (2013) SLA for the 21 st century: Disciplinary progress, transdisciplinary relevance, and the bi/ multilingual turn. Language Learning. 63, pp. 1-24.

Pacheco, M.B., David, S.S. and Jiménez, R.T. (2015) Translating pedagogies. Middle Grades Research Journal Issue. 10(1), pp. 49-63.

Palmer, D.K., Martínez, R.A., Mateus, S.G. and Henderson, K. (2014) Reframing the debate on language separation: Toward a vision for translanguaging pedagogies in the dual language classroom. The Modern Language Journal. 98(3), pp. 757-772.

Paris, D. (2012) Culturally sustaining pedagogy: A needed change in stance, terminology, and practice. Educational Researcher. 41(3), pp. 93-97. 
Paris, D. and Alim, H.S. (eds) (2017) Culturally Sustaining Pedagogies: Teaching and Learning for Justice in a Changing World. New York: Teachers College Press.

Parra, M.L. (2016) Critical approaches to heritage language instruction: How to foster students' critical consciousness, in Fairclough, M. and Beaudrie, S.M. (eds) Innovative Strategies for Heritage Language Teaching: A Practical Guide for the Classroom. Washington, DC: Georgetown University Press. pp. 166-190.

Pascal y Cabo, D. (ed) (2016) Advances in Spanish as a Heritage Language. Amsterdam: John Benjamins Publishing Company.

Pennycook, A. (2001) Critical Applied Linguistics: A Critical Introduction. London: Routledge.

Pennycook, A. (2006) Language education as translingual activism. Asia Pacific Journal of Education. 26(1), pp. 111-114.

Phillipson, R. (2004) English-only Europe? Challenging Language Policy. London: Routledge.

Polinsky, M. and Kagan, O. (2007) Heritage languages: In the wild and in the classroom. Language and Linguistics Compass. 1(5), pp. 368-395.

Potowski, K. (2003) Chicago's "heritage language teacher corps": A model for improving Spanish teacher development. Hispania. 86(2), pp. 302-311.

Potowski, K. and Carreira, M. (2004) Teacher development and national standards for Spanish as a heritage language. Foreign Language Annals. 37(3), pp. 427-437.

Puzio, K., Keyes, C.S., Cole, M.W. and Jiménez, R.T. (2013) Language differentiation: Collaborative translation to support bilingual reading. Bilingual Research Journal. 36(3), pp. 329-349.

Rabin, L. (2011) Community service and activism in heritage languages, New York City, 1915-1956. Foreign Language Annals. 44(2), pp. 338-352.

Ricento, T. (ed) (2006) An Introduction to Language Policy: Theory and Method. Malden, MA: Blackwell Publishing.

Ruiz, R. (1984) Orientations in language planning. NABE Journal. 8(2), pp. 15-34.

Santa Ana, O. (2002) Brown Tide Rising: Metaphors of Latinos in Contemporary American Public Discourse. Austin, TX: University of Texas Press.

Santa Ana, O. (ed) (2004) Tongue-tied: The Lives of Multilingual Children in Public Education. Lanham, MD: Rowman \& Littlefield.

Scanlan, M. and Palmer, D. (2009) Race, power, and (in)equity within two-way immersion settings. The Urban Review. 41(5), pp. 391-415.

Schmidt, R.Sr. (2006) Political theory and language policy, in Ricento, T. (ed) An Introduction to Language Policy: Theory and Method. Malden, MA: Blackwell Publishing. pp. 95-110.

Schwartz, A.M. (1999) Preparing teachers to work with heritage language learners, in Peyton, J.K., Ranard, D.A. and McGinnis, S. (eds) Heritage Languages in the United States: Preserving a National Resource. McHenry: The Center for Applied Linguistics. pp. 229-254.

Schwartz, M. (2008) Exploring the relationship between family language policy and heritage language knowledge among second generation Russian-Jewish immigrants in Israel. Journal of Multilingual and Multicultural Development. 29(5), pp. 400-418.

Showstack, R.E. (2012) Symbolic power in the heritage language classroom: How Spanish heritage speakers sustain and resist hegemonic discourses on language and cultural diversity. Spanish in Context. 9(1), pp. 1-26.

Skutnabb-Kangas, T. (2000) Linguistic Genocide in Education - or Worldwide Diversity and Human Rights? London: Routledge.

Skutnabb-Kangas, T. (2009) The Stakes: Linguistic Diversity, Linguistic Human Rights and MotherTongue-Based Multilingual Education-or Linguistic Genocide, Crimes Against Humanity and an Even Faster Destruction of Biodiversity and Our Planet. Keynote Presentation at the Bamako International Forum on Multilingualism, Bamako, Mali. pp. 19-21.

Skutnabb-Kangas, T. and Fernandes, D. (2008) Kurds in Turkey and in (Iraqi) Kurdistan: A comparison of Kurdish educational language policy in two situations of occupation. Genocide Studies and Prevention. 3(1), pp. 43-73.

Spring, J. (2005) Deculturalization and the Struggle for Equality: A Brief History of the Education of Dominated Cultures in the United States. London: Routledge. 
Tollefson, J.W. (2006) Critical theory in language policy, in Ricento, T. (ed) An Introduction to Language Policy: Theory and Method. Malden, MA: Blackwell Publishing. pp. 42-59.

Trifonas, P.P. and Aravossitas, T. (eds) (2014) Rethinking Heritage Language Education. Cambridge: Cambridge University Press.

Trifonas, P.P. and Aravossitas, T. (eds) (2018) Handbook of Research and Practice in Heritage Language Education. New York City: Springer International Publishing.

Valdés, G. (2005) Bilingualism, heritage language learners, and SLA research: Opportunities lost or seized? The Modern Language Journal. 89(3), pp. 410-426.

Valdés, G., Fishman, J.A., Chavez, R.M. and Perez, W. (2006) Towards the Development of Minority Language Resources: Lessons from the Case of California. London: Multilingual Matters.

Valdés, G. and Roca, A. (2016) Innovative Strategies for Heritage Language Teaching: A Practical Guide for the Classroom. Washington, DC: Georgetown University Press.

Valenzuela, A. (1999) Subtractive Schooling: Issues of Caring in Education of US-MexicanYouth. Albany, NY: SUNY Press.

Van Deusen-Scholl, N. (2003) Toward a definition of heritage language: Sociopolitical and pedagogical considerations. Journal of Language, Identity, and Education. 2(3), pp. 211-230.

Vigil, J.D. (1998) From Indians to Chicanos: The Dynamics of Mexican-American Culture. Chicago, IL: Waveland Press.

Weisskirch, R.S. (2006) Emotional aspects of language brokering among Mexican American adults. Journal of Multilingual and Multicultural Development. 27(4), pp. 332-343.

Wolfe, P. (2006) Settler colonialism and the elimination of the native. Journal of Genocide Research. 8(4), pp. 387-409.

Xiong-Lor, V. (2015) Current Hmong Perceptions of Their Speaking, Reading, and Writing Ability and Cultural Values as Related to Language and Cultural Maintenance. EdD dissertation, California State University, Fresno. Available from: https://digitized.library.fresnostate.edu/digital/collection/ thes/id/136144. 


\section{Gifted education programmes}

Eva Reid

\section{Introduction}

Giftedness is a concept which is understood differently by different cultures. Even within countries, schools and among teachers, different beliefs are held on what giftedness is and how to deal with gifted children. There is not a universally accepted definition of giftedness. Various definitions usually provide a framework for gifted education programmes and criteria for choosing children who should qualify as gifted. Even though there are differences between understanding and defining giftedness and talent, there is broad consensus as to the belief that gifted individuals need to be identified and nurtured.

There are also many theories on the origin of giftedness, whether it is a matter of nature or nurture. The nature supporters believe that heritability accounts for as much as $80 \%$ of intelligence. They claim that genetics plays an important role in giftedness, but it is not immune to experience, which can influence the development of the gifted (Gottfredson 2011). The supporters of nurture claim that the main key to success is effort, which can be influenced by intelligence.

Scholars do not even agree on defining the most fundamental terms of talent and giftedness. Some view them as synonyms (Renzulli 1977; Juraskova 2003; Dockal 2005) and some define them as two different notions (Gagné 1985; Porter 2005; Laznibatova 2013).

Renzulli (1977), one of the well-known scholars on giftedness, does not differentiate between the terms 'talent' and 'giftedness'. He believes that interaction of above average abilities (general intellectual abilities, specific abilities), creativity (flexibility, originality of thoughts, openness to experience, willingness to risk) and task commitment (motivation, hard work, dedication, persistence), result in gifted behaviour. According to him, high achievement and gifted behaviour are possible only when these characteristics work together. Gifted behaviour can be found in certain people (not all people), at certain times (not all the time) under certain circumstances (not all circumstances). He also emphasizes the necessity of providing special education for gifted children because they exhibit special needs. Dockal (2005) sees giftedness as a combination of genotype (what we inherit) and phenotype (how we can develop what we inherit). The genetic material of each individual represents certain limitations of how far giftedness can be developed, also depending on the environment. The more stimulating the environment is, the higher is the chance of developing giftedness. This is also true with the development of all children, however 
the development of gifted children can even reverse and they can become troublemakers and underachievers in a non-stimulating environment. Juraskova (2003) follows Renzulli's model of giftedness (i.e. the above average intellectual abilities, creativity and motivation) and emphasizes that the internal factors (especially motivation) are the main determinants of giftedness. However, giftedness does not develop without optimal support from family, society, and school.

Gagné (1985) distinguishes between giftedness (high potential) and talent (high performance) in his Differentiated Model of Giftedness and Talent (DMGT). Even though this model is more than 30 years old, it is still accepted and cited worldwide. In his view, giftedness is the possession of superior natural abilities, which can be observed mainly in young children (10\% of their age peers) who have not been influenced much by environment and schooling. By talent, he (1985) understands the mastery of systematically developed abilities of an individual, which places him/her among $10 \%$ of his/her age peers who are active in a given field of interest: academic, artistic, commercial, sports, technology, etc. Also, school programmes should be influenced by the level of the child's giftedness. Laznibatova (2013) defines giftedness as an exceptional general intellectual ability (an IQ higher than 130), in other words, an individual's high potential which should be identified by reliable diagnostic methods. Giftedness represents not only intellect and performance, but also the whole personality (ego/self). Laznibatova (2013) defines talent as an exceptionally high performance in arts, music, dancing or sports and is not necessarily connected to high IQ. Porter (2005) modified Gagné's model of giftedness and talent. Porter views giftedness as exceptional innate ability-potential to excel, and talent as the expression of that potential - exceptional performance in any field. Gifted children develop metacognitive abilities earlier and have a significant advantage in tempo and complexity of learning next to peers of the same age. They do not always cope well emotionally with large amounts of information, which can cause problems in optimal development. Talent is developed by the optimal influence of the environment on giftedness.

According to Silverman (2012), giftedness needs early identification and intervention to ensure positive development. Renzulli (1977), Juraskova (2003) and Dockal (2005) emphasize that gifted children need to be educated in special educational programmes and need the support of families and society, otherwise their talents can remain undeveloped. Milgram (1991) adds that gifted children cannot maximize their abilities in regular school programmes unless teaching is adjusted to their specific needs. An analogy to developing sporting talent is very eloquent, as even the greatest sportsmen would not be so great if their talents had not been developed by specially trained coaches. Similarly, if intellectually gifted children are to be outstanding in science, technology, language, etc., they require a special approach in order to develop their abilities to the maximum. I believe that gifted children need to be sought out and educated in special educational programmes, either integrated or segregated. There have been many cases of underachieving gifted children, who were not recognized as gifted and their abilities were not developed fully. Gifted children, like other special needs children, require qualified support in every subject. My research is mainly concerned with English language education for gifted children and my findings show that a special approach requiring stimulation and higher-level thinking skills is needed. Failing that, gifted children can become bored, disruptive or even underachieving due to lack of interest.

\section{Historical perspectives}

Gifted people started to be recognized in ancient times and special education was required for them. However, it was not until the 20th century that gifted education started to receive special and intensive attention. Researchers in the US were the pioneers of gifted education. 
The first pioneers of research in gifted education were Terman and Hollingworth (NAGC 2014). The view at the time was that clever children could take care of themselves. Hollingworth believed that not only inheritance, but also education and environment were important factors in giftedness and she focused on the identification and education of gifted children. Hollingworth was the first scholar who established the term gifted. Terman's greatest contribution was the finding that environmental, emotional, and social backgrounds of gifted children are factors which strongly influence the development of giftedness in individuals. Terman believed that a combination of heredity and environmental upbringing can produce a child who is above average. He claimed that a gifted child is the result of superior parentage.

The first large-scale effort in education for gifted children was seen during the Cold War, at a time when space technologies were being developed. The launch of Sputnik in 1957 by the Soviet Union caused a shock in the Western world. Consequently education for gifted children in the US became a priority (NAGC 2014). In 1958 special funding was provided to the US education system with the aim to improve science, mathematics and technology. Special secondary schools for gifted children were founded and new study programmes for gifted students were opened at universities. In 1972, the US commissioner for education, S.P. Marland, elaborated the Marland Report on the state of education for gifted children in the U.S. He provided the first formal definition of giftedness:

Gifted and talented children are those identified by professionally qualified persons who by virtue of outstanding abilities, are capable of high performance. These children who require differentiated educational programs and/or services beyond those normally provided by the regular school program in order to realize their contribution to self and society.

(Marland 1972, p. 2)

This definition is still used today in the US. It covers general intellectual ability, specific academic aptitude, creative thinking, leadership ability, visual and performing arts, and psychomotor ability. Marland (1972) reported that gifted programmes were considered to be elitist and, indeed, gifted children were deprived and could suffer permanent impairment of their abilities to function well if they did not receive appropriate attention. He warned that some gifted pupils were vulnerable and could not survive neglect and apathy in education. According to LeBlanc (2007), neglect and stagnation of gifted pupils in the US continued with the introduction of the education act No Child Left Behind. It focused on low achieving pupils who were left behind and the aim was to ensure that no children were left to fail (Loveless et al. 2008). Reality showed that the potential of all students had not been challenged and that top pupils were neglected. The National Teacher Survey (Farkas and Duffett 2008) revealed that academically advanced pupils were not a priority at their schools: they were bored and under-challenged, the teachers did not know what to do with advanced pupils and lacked strategic plans and creative ideas. Today, US legislation does not include a national policy on gifted education, does not provide a definition of giftedness, nor does it have specific requirements for gifted education. Each state has its own policy which results in wide variation. The National Association for Gifted Children (NAGC 2014) provides Gifted Education Programming Standards with rules, policies, and procedures, but only about half of districts use these standards. Financing is also left to local governments. This proves Silverman's (2012) belief that gifted education is like political football, sometimes in the centre of attention and other times not. National values shift from the country striving for excellence, to cutting funding, making gifted education a low priority. 
In Europe, the history of gifted education developed differently in various countries and even today the understanding and place of gifted education varies from country to country. On the one hand, there are countries with special elaborate gifted programmes, and on the other hand there are countries which do not even recognize terms such as giftedness and gifted children. Up until recently, there have been common assumptions that gifted learners do not have any specific needs and thus do not need any special attention. It was believed that gifted learners would progress in regular classes on their own without further assistance. Nowadays, the issue of gifted education has increasingly been gaining ground (Dockal 2005; Reid and Boettger 2015).

In the UK, the recognition of gifted education dates back to 1944 when grammar schools were opened, providing possibilities for gifted pupils. These were later viewed as elitist and local authorities started to replace them with comprehensive schools providing equal opportunities for everybody (Casey and Koshy 2012). The English model of inclusive and holistic gifted education is preferred today in the UK, where gifted children are integrated in regular school groups. However, Eyre (2004) believes that education in the UK is not only connected to intellect, but rather to affluence, with children from the most affluent families receiving the best education in the fee paying private schools. This means that the best education may not be given to gifted children unless they have affluent parents who can provide them with a privileged education. When gifted children are unrecognized in regular classes, they can easily slip to boredom and underachievement.

The education of children with special educational needs has a long tradition in Austria, whether it concerns gifted children or children with other special needs. Gifted education became part of educational legislation there in 1962. Most commonly the education of gifted pupils happens within regular classes, where they receive special attention through enrichment, workshops, individual mentors, or various programmes regarding language, maths, science, music or sports. School achievement is an indicator of high potential, but does not give similar potentiality to underachievers (Oswald et al. 2005; Reid and Boettger 2015).

The 16 federal states of Germany each have their own education system and some of them include gifted education in their legislation. All states promote a flexible school system including early enrolment, acceleration, class skipping, possibility to attend classes in higher grades, extra-curricular syllabus, competitions, etc. Gifted children are identified by teachers and parents and high school achievement is the precondition in the selection process, so this does not concern gifted underachievers. It is not rare for some gifted children to become underachievers, because they are not recognized, as teachers and parents are not qualified to recognize giftedness in such children. This means that the German system does not include gifted underachievers because it focuses only on high-achieving children (Ziegler et al. 2013; Reid and Boettger 2015).

Most of the school legislation of the Swiss cantons recognizes gifted children as pupils with special needs. Acceleration, early entrance, grade skipping, and enrichment are common features in Swiss gifted education. The gifted are mainly educated within regular classes. Occasionally, education is carried out in specific segregated classes, but mostly for non-intellectual giftedness. Identification of the gifted is based on the teacher or self-nomination. For skipping classes and sharing classes with higher grades, examination by a psychologist is necessary (Grossenbacher 2005).

In Slovakia, the history of gifted education goes back to the 1970s, when the Research Institute for Child Psychology and Pathopsychology (VUDPaP) started researching the issue of giftedness. Between 1993 and 2007 an experimental project of alternative education for 
gifted children in segregated classes was run and was evaluated as highly effective and successful (Dockal 2005; Laznibatova 2013). New curricular documents were accredited in 2007 for primary, lower secondary, and secondary education for pupils with general intellectual giftedness (VUDPaP 2015). Intellectually gifted children have to be identified by centres of pedagogical-psychological advisory services. Today, there are more than 25 schools that provide special education for gifted children. However, foreign language education of the gifted is the same as for regular learners; there are very few differences and foreign language education for the gifted receives no special attention.

Countries such as Denmark, Finland, and Belgium do not recognize gifted children and any terms for giftedness or gifted pupils are not mentioned in school legislations (Reid and Boettger 2015). The Danish education system works on the recognition of individual differences, where the needs of each pupil's teaching materials and methods should be ensured by teachers (Baltzer et al. 2005). In Finland the education system is strongly decentralized and deregulated allowing schools to arrange teaching according to the age and abilities of each pupil. Even though no special attention is paid to gifted children, Finnish pupils manage to be at the top of the international PISA assessment (OECD 2014). On the other hand, in Belgium, the issue of giftedness has been viewed as a luxury 'nice to have' problem. Schools there have full autonomy of working with gifted pupils (Reid and Horvathova 2016).

Based on researching development and the state of gifted education in many countries (Reid 2015; Reid and Boettger 2015; Reid and Horvathova 2016), it is obvious that gifted education still receives insufficient attention. In the US the situation is very surprising, as for a long time much attention has been paid to the research of the gifted, yet the system is still widely criticized for neglecting gifted individuals. By researching gifted education systems in Europe, it has been observed that most gifted programmes are designed for ambitious and high-achieving individuals, while the underachievers are left out. The tip of the iceberg is represented by visibly gifted high achievers. The vast majority of gifted are hidden from view (Silverman 2013).

\section{Research approaches and key findings}

There is a great divide in the opinions held by educationalists and psychologists on the role of intelligence tests for identifying giftedness. Gilman (2008), Silverman (2012) and Laznibatova (2013) recognize the importance of IQ tests as an assessment tool for identifying gifted individuals (especially among small children) and some psychologists (Sternberg 1984; Gardner 2011) suggest that IQ tests can indicate who has the potential to become gifted, but giftedness must be recognized through achievement. According to Silverman (2012) there is a new movement believing that giftedness cannot be predicted by IQ tests and should be connected to recognized achievement. Success and achievement cannot be predicted with small children and no intervention in education can be done with successful adults. Silverman (2012) also points out that giftedness is largely invisible and high achievers are the only visibly gifted individuals, and those are only the tip of the iceberg. The vast majority of the gifted are hidden from everyday view. Silverman claims that the early identification and intervention of gifted children is essential for optimal progress. Gardner (2011) proposed in 1983 a model of multiple intelligences, because he believed that IQ tests are not sufficient in recognizing individuals' potentials. In his model of multiple intelligences (MI) he differentiates nine intelligences: linguistic, mathematical, musical, spatial, bodily-kineasthetic, interpersonal, intrapersonal, natural, and existential. He claims that each individual possesses a combination of all intelligences. 
Primarily, the Stanford-Binet Intelligence Scales were first used to identify children with learning difficulties, but later to identify children with high abilities (Laznibatova 2013). Today, there are many different kinds of IQ tests with a great variety of items such as visual, verbal, based on abstract reasoning problems, vocabulary, arithmetic, and general knowledge. Many general intelligence tests assess both fluid abilities (inherited) and crystalized abilities (abilities acquired through learning) (Johnsen 2011). Researchers have recognized some identifying characteristics relating to these areas (Sternberg and Davidson 1986; Dockal 2005; Juraskova 2003; Johnsen 2011; Silverman 2012; Laznibatova 2013). A gifted child has an extensive and detailed memory (especially in an area of interest); a high degree of concentration when interested; good reasoning; the ability to express ideas and ask intelligent questions; mature judgement considering the age; advanced vocabulary for his/her age; the ability to read early; the ability to learn fast and be reflective about learning; facility with numbers; compassion; a sense of perfectionism; skills to complete jigsaw puzzles and a need to question authorities, amongst many others. According to Silverman (2012), these characteristics can be helpful in showing the possibility of giftedness, but they need to be identified and assessed by professionally trained people. It is not a simple task to identify gifted children as they do not form a homogenous group, many of them are hidden, nor do they exhibit their talents.

IQ tests are the indicators of special needs in children, at either end of the spectrum. Many education programmes around the world set an IQ of 130 as the minimum criterion score for admitting children to their gifted programmes. According to Wasserman (2003) four levels of giftedness are established.

$\begin{array}{ll}\text { Gifted } & 130-144 \text { IQ } \\ \text { Highly gifted } & 145-159 \text { IQ } \\ \text { Exceptionally gifted } & 160-174 \text { IQ } \\ \text { Profoundly gifted } & 175 \text { and above }\end{array}$

The topic of foreign language learning and giftedness is not a commonly researched area. Even though gifted education and the methodology of foreign language teaching have both been researched to a great extent, the integration of the two has only been slightly touched upon. There have been attempts to find connections between general intelligence and foreign language aptitude, and opinions on the topic vary from those who believe there is a connection, to sceptics who deny any relation.

The Modern Foreign Language Aptitude Test (MFLAT) was developed by Carroll and Sapon in 1959 (Wen 2011) to predict talent for learning foreign languages. The correlation of success in the MFLAT test with good performances in foreign language learning was proven and the MFLAT was accepted in academic fields. The MFLAT can measure an individual's aptitude for foreign language learning and it can predict which individuals would be talented and which would experience most difficulties in foreign language learning. The MFLAT was created for native speakers of English learning foreign languages. There are several variations of the test depending on the age. There are also many varieties depending on the native language of the learner.

Dockal (2005), a specialist on gifted education, believes in a connection between general intelligence and language talent. However, he claims that language aptitude tests are not reliable instruments for identifying talented language learners. He reports that some gifted pupils who did poorly in language aptitude tests did very well in foreign language learning and performance. On the other hand, Cimermanova (2008) claims that foreign language learning ability test scores do not necessarily correspond to general intelligence test scores. According 
to her, dynamic test results correlate higher to foreign language aptitude tests and these can significantly predict success in foreign language classrooms. She emphasizes the importance to address all the learners' multiple intelligences identified by Gardner.

Bodnar (2005) believes that the $g$ factor (general intelligence) is linked to first language acquisition as well as foreign language learning and that this link has been largely ignored. Motivation plays an important role too, where positive motivation contributes to success and negative motivation can bring about underachievement. Bodnar claims that standard IQ tests have an overall predictive validity for academic success and foreign language learning in school environment, which he terms nutshell learning, as it is based on rules, speed, and memorization and these demands are more easily met by those with high academic skills. Brown (2000) agrees that individuals with high IQ have more success in foreign language learning. He contends that the reason for the greater success of learners with high IQ is their higher ability to compensate for the lack of real-life context in a foreign language classroom. Learners with high intelligence can succeed in the environment of a sterile classroom, because their cognitive abilities allow them to remember, understand, apply, analyze, evaluate and create language utterances. If the classroom was more connected to real-life contexts and learners were more exposed to experience-based learning, then learners with high IQ would not have such an advantage over other pupils.

Pychova (1997) believes that once a learner has developed successful strategies for acquiring one language, he/she can acquire/learn the second language too. In her view, memory, ability to learn, cognitive intellectual abilities, creative thinking, motivation, positive emotions, fantasy, imagination, and communicative and social abilities are the most important predispositions for foreign language learning. If a learner does not possess these predispositions, foreign language learning can be problematic. Malikova (1990) also believes that every human being who is able to learn their first language has a potential to learn a second language. Arnold and Fonseca (2004) claim that the relationship between IQ and foreign language learning capacity has a moderate level of correlation and that general intelligence tests do not predict success for foreign language learning. They conclude that most individuals are capable of learning a foreign language to a certain degree of competence, but some learners are better equipped for second language learning than others depending on their auditory, linguistic and memory ability, and these abilities do not necessarily correlate with exceptional intelligence and cognitive abilities. There is a connection to the Gardner's (2011) recommendation to address multiple intelligences, where the importance is to address individual intelligences with the right use of methodologies, exercises, and activities to reach all students.

According to Johnsen (2011), there are some identifying characteristics for linguistic giftedness. With foreign languages, gifted children enjoy verbal communication, puns, and organizing ideas and sequences in preparation for speaking and writing. They are creative, have unique ideas in writing and speaking, use parallel or reverse structures, rhythm, melodic combinations, and like independent study in areas of interest.

Based on my own research in English language learning in special classes of gifted learners, I have observed that most gifted pupils exhibit high foreign language learning abilities, progress fast, understand structures, remember vocabulary and phrases, have no fear, and can be creative in using the language. However, I agree with Bodnar (2005), who believes that classroom foreign language learning is nutshell learning, and that pupils with high general intelligence do better in foreign language learning. In our foreign language learning strategy survey, we (Horvathova and Reid 2016) found that gifted pupils use mainly metacognitive and cognitive strategies in foreign language learning and these strategies allow them to progress fast in a school environment. Also, in my longitudinal case study I observed that most gifted 
pupils have an ability to work out rules or compensate lack of knowledge or weaknesses with their cognitive abilities.

\section{Pedagogic approaches and methods}

Gifted pupils are a specific group and therefore they are, in most educational programmes, defined as pupils with special educational needs. There are two ways of educating gifted children. One form is a model of segregated education, or an alternative process of educating gifted children. Another form is a model of integrated education. Most countries with gifted education programmes prefer the integration model, where pupils are integrated in regular classes where they receive special attention.

In both segregated and integrated models of education, the most common approaches for educating gifted pupils are: acceleration, enrichment, early entrance to primary school, skipping classes, absolving chosen subjects with higher grades, choice of more difficult optional subjects, and creation of individual plans for subjects where the child is exceptional (Hribkova 2009).

Among these, acceleration and enrichment are the most frequent. Acceleration is more widespread in gifted education in many countries around the world where pupils are integrated in regular classes. Enrichment is the preferred approach in segregated classes (Reid and Boettger 2015). However, both varieties are often combined, as acceleration can be enriching and enrichment can lead to acceleration. The problem with acceleration is that even though gifted children can cope cognitively with older children, they are at different levels of emotional maturity. Enrichment aims to deepen the contents of existing subjects. Enrichment can be carried out in both regular and segregated classes.

In the foreign language education of gifted pupils, the characteristics of age, language proficiency, and principles of gifted children need to be considered. A nurturing environment and positive attitude towards giftedness should be present, as gifted children can be demanding, wearing, and even disruptive. Teaching gifted children requires time, patience, and careful time management to ensure successful education. Renzulli (1977) and Duchovicova (2017) list the general principles of educating gifted pupils. These principles, later named and described as teaching techniques, are nothing revolutionary. They are well known and generally applicable to all pupils, but gifted education should always focus on these and right from the beginning of schooling. Here, general principles of educating gifted learners are named and adjusted to foreign language education.

Creativity is one of the most important principles in gifted education. Skills like flexibility, originality, curiosity, risk taking, and imagination are needed for the development of creativity (Renzulli 1977). According to Duchovicova (2017), certain barriers - such as following the rules, being overly logical and practical, looking for a single answer, and not making mistakes - prevent one from being creative. In foreign language classes, creativity is developed through productive skills of speaking and writing. Gifted children should be encouraged to speak and write freely about their experiences, ideas, dreams, troubles, self-invented stories, poems, plans, inventions, and finish unfinished stories. Pupils should be asked challenging and open-ended questions and undertake elaborate projects on various topics. Most of the teaching techniques and activities illustrated in this volume can be used with all age groups and language proficiency level, they just need to be adjusted accordingly.

Divergent thinking is related to both creativity and higher level of thinking. Convergent thinking is linear, where one problem has one solution. All lines of thinking come together to a single answer based on previous knowledge. Divergent thinking starts at one point and 
pupils come up with many different ideas or possibilities. Divergent thinking develops new ideas, but there is a risk of generating pseudo-creativity if it is not adapted to reality. Effective creative thinking involves generation of novelty via divergent thinking and evaluation of novelty via convergent thinking (Cropley 2010). In foreign language teaching, typical teaching techniques for convergent thinking are worksheets, drills, right answers, affinity maps, rating by criteria, categories, to name just a few. Divergent thinking can be developed through activities that stimulate new ideas, answers, and possibilities. Since it is closely related to creativity, the teaching techniques and activities would be similar. Predicting a story, finishing a story, mind maps, projects, problem-based teaching and simulations give opportunities for enhancing divergent thinking.

Honing higher level thinking skills is an important principle of educating gifted children. The hierarchy of thinking skills is best known as Bloom's Taxonomy, formulated in 1956 and revised several times since (Anderson and Krathwohl 2001). Lower level thinking skills (remembering, understanding, applying) have to be mastered before progressing to higher ones. The more cognitively complex thinking skills (analyzing, evaluating, creating) take a higher and more valuable place than cognitively simpler ones. Integrating higher level thinking skills in foreign language education significantly raises the language proficiency of learners (Santos 2016). Although higher level thinking skills are more closely connected with mature students, simplified activities can be also done with young learners. Bloom's Taxonomy can serve as the basis for developing such learning activities as discussions, debates, critiques, projects and problem-based teaching activities. What is specific about gifted pupils is the fact that their ability to think critically is developed sooner than with their same age peers. Consequently, the higher level thinking skills need to be addressed earlier even with the youngest learners (with the language level, knowledge and interest to be considered).

Contrary to general belief, gifted children need to be taught to facilitate their learning study skills, as they are often assumed to be naturally organized, self-disciplined, focused, and aware of school duties. In order to develop gifted pupils' talents well, they need to be encouraged to organize time efficiently, observe carefully, make working plans for various activities, establish a homework routine, evaluate their own work critically and suggest solutions to problems. (Dalton and Smith 1986). This principle is a general one for all learners, the point of emphasizing it here is to show that gifted pupils also need to be taught to be organized, disciplined, and focused, that it is not their natural skill. On top of the aforementioned skills, in foreign language lessons gifted pupils should be encouraged and taught how to take notes in the foreign language, use the library and dictionaries, and read simplified versions of novels in the foreign language.

It is generally viewed that giftedness is connected to cognitive abilities. Even though the above average intellect is the main feature of gifted children, their emotional intelligence plays a very important role in their healthy development. According to Zeidner and Matthews (2017), there is a moderate connection between intellectual and emotional giftedness. However, gifted children are a diverse group; some children show high levels of social-emotional competency, whereas others may be vunerable to stress, social isolation, or impulsive behaviour, that is why intervention is needed. Zeidner and Matthews (2017) warn that if affective and social components are not targeted, this might negatively affect the gifted children's cognitive potential, social adaptation, and well-being. Many gifted children also show interest in social, moral, and philosophical topics and are more sensitive than their peers. It is important to attend to personal qualities, attitudes, values, and feelings, in other words, to develop the emotional giftedness of gifted children. This can be done by discussing controversial news items, resolving peer conflicts, examining moral issues on TV programmes, and expressing 
opinions on games, books, and films. In foreign language classrooms emotional giftedness can be nurtured in role-plays, socio-dramas, mock trials, and simulations (Bevan-Brown and Taylor 2008). Younger gifted pupils can discuss issues concerning good and evil, right and wrong, heroes and villains, and older gifted pupils can discuss controversial news or sensitive topics such as homelessness and immigration.

As mentioned earlier concerning recommended principles, there are also no revolutionary new teaching techniques that would be suitable only for gifted children. Language teaching suitable for gifted children should encourage the active search for and discovery of information, as well as the acquisition of knowledge and the development of skills. All teaching should be connected to real-life situations and experiences, it should integrate multiple disciplines into the area of study with the aim to obtain complex information, connect ideas and connect with any historical background. CLIL, for example, is suitable for teaching gifted pupils as it connects foreign language with the contents of other school subjects and it is applicable at all levels of education (Horvathova 2013). Common teaching techniques such as drilling, multiple choice activities, or memorization, should be minimized with gifted children as well as the application of rules and knowledge without prior knowledge of the background, and the application of non-creative and non-problematic tasks should be avoided (Juraskova 2003; BevanBrown and Taylor 2008; Rustler 2012; Laznibatova 2013; Duchovicova 2017). The teaching techniques I have mentioned here are well known and also applicable to general education. The difference is that these techniques can be used much sooner with gifted children, who are nourished by challenging activities. Based on my own experience, when some of these techniques are used early with regular pupils, they get frustrated and confused. On the other hand, I experienced boredom and frustration with gifted pupils when doing drilling, multiple choice, filling in, or memorizing. What follows is a description of the main recommended language teaching techniques for gifted pupils.

Problem-based learning, or task-based learning, supports activity, self-learning, and creativity. Pupils identify problems, label them, identify reasons and consequences, and try to find solutions. It can integrate real-world issues and practices (Duchovicova 2017). Concerning foreign language, all general and communicative competences are applied. Using grammar and vocabulary involves linguistic competence. The sociolinguistic and pragmatic competences are applied when pupils need to create coherent stretches of speech to suggest, request, advise, invite, interact.

Projects can be elaborated on for individual subjects, but the most beneficial are multidisciplinary projects. The greatest strength of projects is that they are very motivating, close to reality. They develop creativity, intuition, and fantasy. Pupils can express their individual approach and collaborate with their peers and teachers (Duchovicova 2017). Regarding foreign language education, projects are strong in developing all general and communicative competences. Accuracy in vocabulary and grammar is forefront when writing the project. Pupils also express their attitudes, values, beliefs, and personality factors (existential competence) in the elaboration of projects. Pragmatic competence is developed in creating coherent stretches of language and both pragmatic and sociolinguistic competences are demonstrated when pupils present their projects.

With discovery techniques pupils find out things for themselves, look into problems, ask questions, and predict and work out solutions. Pupils go through discovery learning when they look into their own experience and knowledge and acquire further information to improve their understanding (Juraskova 2003). Discovery techniques are similar to problem-based learning and inductive teaching. This technique in foreign language teaching is mainly used with teaching grammar - a teacher gives a context in which the target grammar structure is 
used. Pupils discover the grammatical rule for themselves. The teacher's role is to guide pupils to their own discovery.

Techniques supporting higher level thinking skills significantly raise language proficiency (Duchovicova 2017). Alpha box is an evoking technique: pupils are given a topic/question/ term and they have to write, in alphabetical order, any words, comments, or beliefs, which are connected to the key topic. It is useful for revising vocabulary and extending topic discussions. Analyses of certain features is a technique that encourages pupils to compare features of known, less known or unknown phenomena. It is suitable for intercultural learning and communicative competences can be practised in discussions (e.g. dress code in schools uniforms/no uniforms - discussions on advantages and disadvantages). In/out technique is suitable for practising vocabulary. Pupils select words according to given criteria, they communicate, put forward arguments, or reach compromises on what is 'in' and what is 'out'. Dice is a technique which uses numbers from a dice and combines them with Bloom's taxonomy of thinking skills to describe, compare, associate, apply, analyze, and evaluate. Step by step is used for understanding individual processes. Pupils are given a topic and each pupil describes individual processes. This technique could be used for giving instructions and directions or writing recipes. The six good servants (six helping questions: who, what, when, where, why, how) technique develops systematic work and creates a framework. Pupils make notes in the foreign language based on six helping questions for a book, film, or lecture. A tree of causes and consequences helps pupils to gain the ability to solve problems. Roots are the causes of the problem, the trunk is the problem itself, and branches are the consequences of the problem. Diary is useful for writing ideas, thoughts, and feelings about what is being learned. Diaries are written in the foreign language and read by the teacher, who will give their feedback.

Techniques supporting cognitive processes develop thinking operations. Most of these techniques are connected to grammar teaching. They include analytical, deductive, inductive techniques, finding opposites, and generalizing. An attractive activity is working with caricatures. They are funny descriptions of people, ideas, events, and problems. They are intended to make the audience laugh by picturing an environmental, political or cultural topic (Topal 2015). These humorous descriptions can be used in a foreign language lesson in order to develop critical thinking based on background knowledge.

Mind maps represent an alternative, creative, and logical way of taking notes. They are organized into diagrams (from the centre to the sides, from the top to the bottom) and they use words, lines, symbols, arrows, colours, and images. They convert a list of monotonous information into a colourful, memorable, and highly organized diagram. It is important to create hierarchical connections between ideas. A mind map needs to be organized starting from general information and going on to specific information (Rustler 2012). Mind maps can be very useful for mapping vocabulary or grammar issues.

Techniques for working with texts belong to the most important techniques aimed at developing metacognition. Gifted pupils are known to develop metacognition earlier than peers the same age. Working with a text does not only enhance the ability to think, but also the ability to organize the process of learning (setting aims about what to learn from the text, evaluating the difficulty of the text, time needed for reading it, monitoring own reading, self-evaluation accrued learning from the text) (Duchovicova 2017). The INSERT technique uses symbols (star, triangle, tick, plus, minus, question mark) for identifying important information (importance, understanding, uncertainty, remembering). Retelling, predicting, finishing a story are efficient techniques when working with texts.

Self-learning techniques are convenient and effective ways of learning and they maximize pupils' potential (Juraskova 2003). Such techniques are most suitable for learning outside 
school. There are many educational websites which provide interesting and fun activities (quizzes, tests, games, puzzles) practising various aspects of foreign language. Projects are very effective for self-learning, as pupils work by themselves from start to finish. They search, analyze, evaluate, and synthesize information.

Techniques supporting communication and cooperation are important as they foster learners' social competences (Duchovicova 2017). Dialogues, discussions, or argumentation techniques allow pupils to express their own opinions, accept others' opinions, solve problems, and practise functions such as agreeing, disagreeing, negotiating, summarizing, and putting forward arguments. (Juraskova 2003; Laznibatova 2013). Role play is suitable for all age groups and language proficiency levels, but debates, discussions, argumentation, and mock trials are suitable for older learners with a good command of the foreign language.

Principled eclecticism is a combination of various methods and teaching techniques based on individual preference, learning styles and learning aims (Scrivener 2011). Communicative language teaching, the natural approach, the dogme approach and task-based learning are all very popular today as they focus mainly on learning languages for communication and development of communicative competences (Lindsay and Knight 2006; Scrivener 2011; Kovacikova and Gajdacova Vesela 2016). The oldest method, grammar-translation, is still used today (Harmer 2001; Scrivener 2011; Kovacikova and Gajdacova Vesela 2016). Word-by-word translation and the use of the mother tongue for explaining grammar is, indeed, a common strategy. A case study I conducted in English language classes for gifted children (of which more later) also showed many instances of word-by-word translation of written texts for aiding comprehension and the use of the mother tongue for giving instructions or explanations (Reid 2018). However, the use of the mother tongue in teaching foreign languages and the place of translation in foreign language education should be differentiated. Cummins (2007) and Cook (2010) are the advocates of the use of the mother tongue in foreign language teaching in bilingual classrooms. I believe that giving simple instructions to pupils in the mother tongue, without translating them into the target language, is not advisable even in regular classes and is absolutely unnecessary with gifted pupils, who have highly developed cognitive and metacognitive abilities and can work quite effectively in the target language or in a bilingual environment. On the other hand, translation has its place in foreign language teaching, although I believe that word-by-word translation for understanding texts is not always necessary, as there are many other techniques for supporting text comprehension. Translation is only one of several reading comprehension techniques, and it should not be used routinely. This statement is supported by Davis's belief (2004) that "read and translate" directive, which I have observed endless times, is obsolete and unproductive. Davis refutes translation based on the grammar-translation method because it is limited to trap activities.

However, the importance of translation in language learning and teaching is being increasingly recognized. Cook (2010) views pedagogic translation as a neglected multilingual practice and puts forward an argument for legitimizing it. He claims that translation is a very useful skill for most language learners in the multilingual world where there is a majority of non-native English speakers with their own cultural identity and languages. Cummins (2007) views translation and bilingual instructional strategies as a stepping stone in reaching more accomplished performance in the target language. Davis (2004) believes that translation is relevant to the today's foreign language education. Translation is a dynamic process of communication, where learners have to analyze, paraphrase, summarize, and adapt the source text to the reader's or listener's expectations. Davis $(2004$, p. 6) adds that translation can be "a useful tool to introduce, reinforce, practice or reflect on the similarities and differences between the native and the second or foreign languages". She (2004, p. 12) points out that, unlike the 
grammar-translation method, the current approach to translation is based on humanistic teaching principles, communicative language teaching, cooperative learning and social constructivism. In this regard, the Common European Framework of Reference for Languages pays considerable attention to the place of translation in foreign language education. Communicative language competence is developed by various language activities, involving reception, production, interaction or mediation. Each activity is related to texts in oral or written form, or both. Translation and interpretation from one language to another are components of mediation, which make communication possible between persons who are not able to communicate directly. Mediating, paraphrasing, summarizing, and reformulating the source text for the third party provide an important place in foreign language education. Oral mediation refers to face-to-face interaction between two interlocutors who do not share the same language and it can be simultaneous, consecutive, and informal interpretation. Written mediation is a parallel text produced in a different language by a writer, who is not present for a reader at a distance. It includes exact legal and scientific translation, literary translation, paraphrasing, and summarizing gist. Translation and interpretation, just like conversation, debate, and interview denote communicative interaction and such activities take place in real life (Council of Europe 2001).

Another aim of foreign language education is for learners to gain plurilingual and pluricultural competence, to understand the differences and similarities of how other people think, live, speak, and view the world (Council of Europe 2001; Greenwald 2013). To be able to do this, culture must be an inseparable part of foreign language teaching (Reid 2014). Byram (1998) claims that language cannot be used without carrying meaning, because meanings of a particular language refer to the culture of a particular society. Kramsch (2009) sees language as a system of signs/symbols having a cultural value, and understanding cultural symbols enables people to understand reality. In addition to forming plurilingual and pluricultural individuals, the aim of foreign language teaching is also to develop in learners translingual and transcultural competence. Laviosa $(2014$, p. 64) emphasizes that, as well as having the ability to operate between languages, it is very important to be able to reflect on the world and ourselves "through the lens of another language and culture". She adds that "to achieve this goal, pedagogic translation is fully reappraised" since "it enables learners to investigate the foreign language and culture through their own language and culture" (Laviosa 2014, p. 64). Cook (2010) also believes that translation between languages and cultures contributes to raising awareness about differences and avoiding misunderstandings. However, the findings of my research into the intercultural aspects of English language teaching in Slovakia (Reid 2014) show that teachers are not themselves interculturally and pluriculturally competent, due to inadequate training and lack of intercultural experiences. These results are consistent with those obtained in studies undertaken in the Czech Republic (Kostkova 2012; Zerzova 2012) and 12 European countries: Belgium in French part, Belgium in Dutch part, Denmark, Finland, France, Germany, Greece, Hungary, Italy, Norway, Poland, Slovenia, and UK (Europublic 2007). Consequently, when teachers are not interculturally competent, the aim of educating plurilingual, pluricultural, translingual, and transcultural learners may be unachievable.

\section{Conclusions and future directions}

Responsibility for identifying the gifted is often put down to schools, teachers, and parents, who do not always have the ability to recognize giftedness. Teachers in general do not receive much education concerning the area of giftedness during their teacher training (Reid and Horvathova 2016). Consequently they are not always able to recognize the giftedness in their pupils. Silverman (2012) believes that psychologists who specialize in giftedness should be 
seeking to recognize gifted individuals. Without a deliberate search for the gifted, sensitive school programmes for all gifted (including underachievers), and specialized teachers for the gifted, there will not be successful and fair education for all gifted individuals. I agree with Silverman (2012) that gifted children should be looked for and identified early by specialists. Specialists should be present not only for identifying the gifted, but in every school. They should help both gifted children and teachers of gifted children.

Regarding foreign language education of the gifted, there has been very little research worldwide. Some scholars believe in the connection of general intellectual giftedness with foreign language aptitude, and some scholars believe the opposite. Even foreign language aptitude tests are not viewed by all scholars as a reliable means of identifying gifted learners for foreign languages. In 2016-2017 I conducted an interpretative case study (Reid 2018) in a special class of fourth grade gifted pupils at a primary school in Slovakia with the aim to investigate the state and challenges of English language teaching in gifted education in Slovakia. The ambition was to gain a deep understanding of the teaching of English to pupils with general intellectual giftedness. The goal was to find a connection between two phenomena - giftedness and the ability to learn English. Multiple methods were used under the 'umbrella' of a case study. Participant observation took place over five months and I conducted intervention during four additional classes. I did not only observe the class, but I also taught during those four lessons, trying to implement the recommended teaching techniques. The aim was to see how pupils reacted to more challenging activities. For data processing retrieved from a semi-structured observation schedule and field notes, a system of categories and codes was created. This was based on teaching principles, teaching techniques, materials, types of activities, teacher's approaches, and pupils' responses. I also carried out a series of interviews with nine English language teachers, including the observed teacher. The aim was to find out their qualification, experience, self-reflection, opinions, beliefs, and requirements in teaching English to gifted pupils. A system of categories and codes was created from the interview schedule and teachers' answers. Additionally, Oxford's (1990) Young Learners' Language Strategy Use Survey was used with gifted pupils to find out the learning strategies adopted by pupils with general intellectual giftedness and then compare the results with the findings obtained from observations and theories on giftedness. By triangulating the results, I came to the conclusion that gifted pupils managed the requirements of the curriculum with ease, and teachers needed to prepare a lot more materials and activities, which, however, randomly followed the recommended principles and teaching techniques. The findings from the survey revealed that gifted young learners mainly use metacognitive learning strategies, and secondly cognitive learning strategies. Observation and interviews revealed that the teachers received no or very little training in gifted education and no training at all in teaching English to gifted pupils. Even though they had developed a system for working with gifted students, they expressed their wish to receive more training or share their experiences in teaching English to the gifted. They also pointed out that there was a lack of specific materials and activities. Although we have a special system in place for gifted education in Slovakia, in reality it is a system that is more intuitive than methodological, which does not maximize the potentials of gifted pupils. Such state of affairs is due to a lack of specification in the national curriculum for English language of gifted pupils, lack of training in gifted education, and a lack of training in teaching English to gifted pupils. To sum up, I have observed that most gifted children manage learning foreign languages with ease and this can be explained by their highly developed cognitive and metacognitive abilities. A more crucial question is the qualification of foreign language teachers to work with gifted pupils. Gifted children require special attention and a different approach and teaching 
techniques and activities in foreign language classrooms, and teachers are not necessarily qualified to do that.

The issue of pedagogical translation for gifted pupils is very topical. Today's understanding of translation differs from the traditional grammar-translation method. It focuses on the development of translingual and transcultural competences. Translation for cultural purposes is a useful tool for achieving a better understanding among speakers of different languages and raising awareness about similarities and differences between linguistic systems. Communicative competences are also developed by translation as a mediating activity for people who cannot communicate directly. Davis (2004) points out that translation competence goes beyond language learning, but that bridges can be built. Translation is a very useful skill in today's world and a very demanding activity. Translation exercises need to be carefully graded according to the learners' proficiency level. Gifted pupils have abilities that go beyond language learning and they are stimulated by challenging translation tasks. Their cognitive and metacognitive abilities are highly developed and by integrating translation in English language lessons, they would be able to achieve valuable translingual and transcultural competences.

\section{Further reading}

Dockal, V. and Duchovicova, J. (2017) Talent v škole. Bratislava: Raabe.

This book offers a complex overview of the issue of giftedness and gifted education. It is aimed at teachers and educators. It provides them with general information about giftedness and gifted children, as well as methods and strategies supporting cognitive, emotional, and metacognitive development of gifted pupils.

Silverman, L. (2012) Giftedness 101. New York: Springer Publishing Company.

This book addresses the unique psychological needs of gifted children and examines special issues such as gifted children with learning disabilities, gender considerations and implications of socioeconomic status. It also discusses common myths about giftedness and the challenges of working with gifted children.

Kovacikova, E. and Gajdacova Vesela, K. (2016) Základy didaktiky cudzich jazykov. Nitra: PF UKF. This textbook is aimed at university students and teachers. It discusses the fundamental issues of language teaching methodology. The publication is divided into teaching and learning language systems, skills, and culture. It provides the theoretical background together with practical questions and follow-up comprehension quizzes at the end of every chapter.

Davis, M.G. (2004) Multiple Voices in the Translation Classroom: Activities, Tasks and Projects. Amsterdam: John Benjamins Publishing Co.

This publication is suitable for English language teachers, teacher trainers, and teacher trainees. It gives a fresh outlook on the place of translation in foreign language education. The book provides substantial theoretical information on pedagogical translation and provides plenty of classroom activities.

\section{References}

Anderson, L. and Krathwohl, D.R. (2001) A Taxonomy for Learning, Teaching, and Assessing: A Revision of Bloom's Taxonomy of Educational Objectives. New York: Addison-Wesley Longman.

Arnold, J. and Fonseca, C. (2004) Multiple intelligence theory and foreign language learning: A brainbased perspective. International Journal of English Studies. 4(1) [online]. Available from: http:// revistas.um.es/ijes/article/viewFile/48141/46121 [Accessed 3 March 2017].

Baltzer, K., Kyed, O. and Romer, P.B. (2005) Country specific information - Denmark, in Monks, F.J. and Pfluger, R. (eds) Gifted Education in 21 European Countries: Inventory and Perspective. 
Radboud University Nijmengen [online]. Available from: www.templetonfellows.org/projects/docs/ gifted_education_europe.pdf [Accessed 25 March 2019].

Bevan-Brown, J. and Taylor, S. (2008) Nurturing Gifted and Talented Children. A Parent-Teacher Partnership. Wellington: Ministry of Education.

Bodnar, M.B. (2005) Second language acquisition and general intelligence. Hannan Journal. 41(1) [online]. Available from: www.google.sk/search? $\mathrm{q}=$ Second + Language + Acquisition + and + General $+\mathrm{I}$ ntelligence $\&$ oq $=$ Second + Language + Acquisition + and + General+Intelligence\&aqs $=$ chrome. $.69 i 57.80$ 7j0j7\&sourceid $=$ chrome\&ie=UTF-8 [Accessed 25 March 2019].

Brown, H. (2000) Principles of Language Learning and Teaching. New York: Longman.

Byram, M. (1998) Cultural Studies in Foreign Language Education. Clevedon: Multilingual Matters.

Casey, R. and Koshy, V. (2012) Gifted and Talented Education: The English Policy Highway at a Crossroads? Brunel University [online]. Available from: http://bura.brunel.ac.uk/bitstream/2438/8266/2/ Fulltext.pdf [Accessed 25 March 2019].

Cimermanova, I. (2008) Intelligence and language learning, in Kesselova, J. (ed) Studia Philologica: Annus XIII. Presov: Presovska univerzita. pp. 105-110.

Cook, G. (2010) Translation in Language Teaching: An Argument for Reassessment. Oxford: Oxford University Press.

Council of Europe. (2001) Common European Framework of Reference for Language Learning, Teaching, Assessment: Council of Europe [online]. Strasbourg: Council of Europe Publishing. Available from: https://rm.coe.int/16802fc1bf [Accessed 25 March 2019].

Cropley, A. (2010) In praise of convergent thinking. Creativity Research Journal. 18(3), pp. 391-404.

Cummins, J. (2007) Rethinking monolingual instructional strategies in multilingual classrooms. Canadian Journal of Applied Linguistics. 10(2), pp. 221-240 [online]. Available from: www.aclacaal.org/ wp-content/uploads/2013/08/7-vol-10-no2-art-cummins.pdf [Accessed 25 March 2019].

Dalton, J. and Smith, D. (1986) Extending Children's Special Abilities: Strategies for Primary Classrooms. Melbourne: Curriculum Branch, Schools Division.

Davis, M.G. (2004) Multiple Voices in the Translation Classroom: Activities, Tasks and Projects. Amsterdam: John Benjamins Publishing Co.

Dockal, V. (2005) Zaměrěno na Talenty, aneb, Nadání má Každý. Praha: Nakladatelství Lidové noviny.

Duchovicova, J. (2017) Ako vytvorit’ priaznivé prostredie pre nadaných žiakov v bežných školách, in Dockal, V. and Duchovicova, J. (ed) Talent v Škole. Bratislava: Raabe. pp. 85-170.

Europublic. (2007) Languages and Cultures in Europe (LACE): The Intercultural Competences Developed in Compulsory Foreign Language Education in the European Union [online]. Available from: https://nellip.pixel-online.org/files/publications_PLL/18_Languages\%20and $\% 20$ Cultures\%20in $\% 20$ Europe\%20(LACE).pdf [Accessed 25 March 2019].

Eyre, D. (2004) Gifted education: The English model of gifted education, in Shavinina, L.V. (ed) International Handbook on Giftedness. Quebec: Springer. pp. 1045-1059.

Farkas, S. and Duffett, A. (2008) Results from a National Teacher Survey: High Achieving Students in Era of NCLB. Thomas B. Fordham Institute [online]. Available from: http://edex.s3-us-west-2. amazonaws.com/publication/pdfs/20080618_high_achievers_7.pdf [Accessed 25 March 2019].

Gagné, F. (1985) Giftedness and talent: Reexamining a reexamination of the definitions. Gifted Child Quarterly. 29, pp. 103-112.

Gardner, H. (2011) Frames of Mind: The Theory of Multiple Intelligences. 3rd ed. New York: Basic Books.

Gilman, B.J. (2008) Challenging Highly Gifted Learners. Waco: Prufrock Press.

Gottfredson, L.S. (2011) Intelligence and social inequality: Why the biological link? in ChamorroPremuzic, T., Furhnam, A. and Von Stumm, S. (eds) Handbook of Individual Differences. New York: Wiley-Blackwell. pp. 538-575.

Greenwald, M. (2013) National standards for language learning and 21st century skills for world languages. 21st Century Technology for Language Learning [online]. Available from: www.sansinc. com/s/downloads/21st-Century-WhitePaper.pdf [Accessed 25 March 2019]. 
Grossenbacher, S. (2005) Country specific information - Switzerland, in Monks, F.J. and Pfluger, R. (eds) Gifted Education in 21 European Countries: Inventory and Perspective. Radboud University Nijmengen [online]. Available from: www.bmbf.de/pub/gifted_education_21_eu_countries.pdf [Accessed 25 March 2019].

Harmer, J. (2001) The Practice of English Language Teaching. Essex: Longman.

Horvathova, B. (2013) Rozvoj integrovaného odborného a jazykového vyučovania (CLIL) a počítačom podporovaného vyučovania (CALL) pomocou vzdelávacích projektov. Media4u Magazine. 10(3), pp. 55-61.

Horvathova, B. and Reid, E. (2016) Gifted and regular learners and their foreign language strategy. Slavonic Pedagogical Studies Journal. 5(2), pp. 403-423.

Hribkova, L. (2009) Nadání a Nadání. Praha: Grada.

Johnsen, S.K. (2011) Identifying Gifted Students: A Practical Guide. Waco: Prufrock Press.

Juraskova, J. (2003) Základy Pedagogiky Nadaných. Pezinok: Formát.

Kostkova, K. (2012) Rozvoj Interkulturni Komunikacni Kompetence. Brno: Masakykova univerzita.

Kovacikova, E. and Gajdacova Vesela, K. (2016) Základy Didaktiky Cudzich Jazykov. Nitra: PF UKF.

Kramsch, C. (2009) Language and Culture. Oxford: Oxford University Press.

Laviosa, S. (2014) Translation as adaptation for language pedagogy. Linguaculture. (1) [online]. Available from: https://content.sciendo.com/view/journals/lincu/2014/1/article-p63.xml [Accessed 25 March 2019].

Laznibatova, J. (2013) Nadany Ziak. Bratislava: Iris.

LeBlanc, K. (2007) Principals' Perceptions of No Child Left Behind's Impact on the Education of the Gifted and Talented Students. Dissertation, College of Education and Behavioral Sciences, School of Educational Research, Leadership, and Technology Educational leadership [online]. Available from: https://search.proquest.com/docview/304815692?pq-origsite=gscholar [Accessed 25 March 2019].

Lindsay, C. and Knight, P. (2006) Learning and Teaching English. Oxford: Oxford University Press.

Loveless, T., Farkas, S. and Duffett, A. (2008) High Achieving Students in the Era of NCLB. Thomas B. Fordham Institute [online]. Available from: https://files.eric.ed.gov/fulltext/ED530968.pdf [Accessed 25 March 2019].

Malikova, M. (1990) An Introduction to the Study of English. Nitra: Pedagogická fakulta.

Marland, S. (1972) Marland Report: Education of Gifted and Talented [online]. Available from: www. valdosta.edu/colleges/education/pcft/document\%20/marland-report.pdf [Accessed 25 March 2019].

Milgram, M.R. (1991) Counseling Gifted and Talented Children. New Jersey: Ablex Publishing Corporation.

NAGC. (2014) A Brief History of Gifted and Talented Education [online]. Available from: www.nagc. org/resources-publications/resources/gifted-education-us/brief-history-gifted-and-talented-education [Accessed 25 March 2019].

OECD. (2014) PISA 2012 Results. [online]. Available from: http://www.oecd.org/pisa/keyfindings/pisa2012-results.htm [Accessed 22 September 2019].

Oswald, F., Sattlberger, E. and Edlinger, G. (2005) Country specific information - Austria, in Monks, F.J. and Pfluger, R. (eds) Gifted Education in 21 European Countries: Inventory and Perspective. Radboud University Nijmengen [online]. Available from: www.templetonfellows.org/projects/docs/ gifted_education_europe.pdf [Accessed 25 March 2019].

Oxford, R. (1990) Language Learning Strategies: What Every Teacher Should Know. New York: Newbury House.

Porter, L. (2005) Gifted Young Children: A Guide for Teachers and Parents. Maidenhead: Open University Press.

Pychova, I. (1997) Jazykove nadany zak: Navrh pedagogicke metody identifikace cizojazycneho nadani. Pedagogika (XLVII), pp. 355-372 [online]. Available from: file://C:/Users/Eva\%20Reid/Downloads/ Pedag_1997_4_06_N\%C3\%A1vrh_355_372.pdf [Accessed 25 March 2019].

Reid, E. (2014) Intercultural Aspects in Teaching English at Primary Schools. Frankfurt am Main: Peter Lang.

Reid, E. (2018) Current Challenges of English Language Teaching in Gifted Education. Nitra: UKF. 
Reid, E. and Boettger, H. (2015) Gifted education in various countries of Europe. Slavonic Pedagogical Studies Journal. 4(2), pp. 158-171.

Reid, E. and Horvathova, B. (2016) Teacher training programmes for gifted education with focus on sustainability. Journal of Teacher Education for Sustainability. 18(2), pp. 66-74.

Renzulli, J.S. (1977) The Enrichment Triad Model: A Guide for Developing Defensible Programmes for the Gifted and Talented. Mansfield Center: Creative Learning Press.

Rustler, F. (2012) Mind Mapping. Chichester: John Wiley and Sons Publication.

Santos, P. (2016) EFL classrooms can teach higher order thinking skills. Humanising Language Teaching. 18(1) [online]. Available from: http://old.hltmag.co.uk/feb16/less01.htm [Accessed 25 March 2019].

Scrivener, J. (2011) Learning Teaching: The Essential Guide to English Language Teaching. 3rd ed. London: Palgrave Macmillan Education.

Silverman, L. (2012) Giftedness 101. New York: Springer Publishing Company.

Sternberg, R.J. (1984) Beyond IQ: A Triarchic Theory of Human Intelligence. Cambridge: Cambridge University Press.

Sternberg, R.J. and Davidson, J.E. (1986) Conceptions of Giftedness. Cambridge: Cambridge University Press.

Topal, Y. (2015) Effect of use of caricatures on teaching vocabulary in teaching Turkish as foreign language. Educational Research and Reviews. 10(13), pp. 1876-1880.

VÚDPaP. (2015) Vzdelávaci Program pre 1. Stupeň Základnej Školy pre Žiakov so Všeobecným Intelektovým Nadaním [online]. Available from: www.vudpap.sk/sub/vudpap.sk/images/ISCED/isced_1.pdf [Accessed 25 March 2019].

Wasserman, J. (2003) Assessment of intellectual functioning, in Graham, J.R. and Naglieri, J.A. (eds) Handbook of Psychology. Volume 10: Assessment Psychology. Hoboken: Wiley. pp. 417-442.

Wen, Z. (2011) Foreign language aptitude. ELT Journal. (1) [online]. Available from: http://eltj. oxfordjournals.org/content/early/2011/11/01/elt.ccr068.extract\# [Accessed 25 March 2019].

Zeidner, M. and Matthews, G. (2017) Emotional intelligence in gifted students. Gifted Education International. 33(2), pp. 163-182.

Zerzova, J. (2012) Interkulturni komunikacni kompetence a jeji rozvijeni $v$ hodinach anglickeho jazyka na 2. stupni ZS. Brno: Masarykova univerzita.

Ziegler, A., Stoeger, H., Harder, B. and Balestrini, D.P. (2013) Gifted education in German-speaking Europe. Journal for the Education of the Gifted. 36(3), p. 384. 


\title{
Sign languages
}

\author{
Ingela Holmström and Krister Schönström
}

\section{Introduction}

This chapter has a special interest in translation as a language teaching practice in sign bilingual settings in deaf education. Focus here will be on translation between sign language(s) and written language(s). This is quite unique due to the fact that sign languages, in contrast to spoken (and written) languages, are visual-gestural languages and unwritten languages. Due to limited or no access to sounds, many deaf pupils learn and use spoken languages primarily in their written form. Thus, in this translation practice, deaf pupils are translating between a written language and a sign language. In sign bilingual education settings, this written language is often considered to be their second language because they often learn to read and write later in childhood. Learning to read and write can be a challenge for most children, including hearing children. For the deaf, without or with limited access to spoken languages, this is a special challenge, as their learning to read and write is mediated by the use of sign languages. This means that many deaf children learn a written language at different levels simultaneously: they learn a new language at the same time as they learn to read and write. This may sound very complicated, but research has shown that such a process of learning to read in a second language is actually a feasible option and does not have to be a barrier (see e.g. Geva 2006).

In order to be able to be part of society in general, it is necessary to acquire literacy skills. Literacy is also an important part of the deaf community (Thoutenhoofd 2001). Two languages, one signed and one (primarily) written, are always present for the signing deaf group across their life span and translation practices between the languages are a common part of everyday life, both within and outside school contexts. For example, translations could appear as the translation into sign language of a written article in a newspaper to a friend, or translation into written language of a lecture held in sign language. Such natural and flexible uses of two languages with quite different user functions have not been studied to a large extent, particularly not as translation practices only. This chapter focuses on these kinds of translation practices in school settings, particularly in the context of language teaching. And because the research literature regarding the use of translation as an approach in sign bilingual education is very sparse, this chapter will consider experiences of using sign language translation as an approach in the fields of deaf education, sign language studies, and translation studies, as 
well as (second) language teaching. We also provide some concrete pedagogical examples of the application of translation as a pedagogical approach in sign language-based education at different levels, e.g. syllabus, classroom practice, and assessment. The chapter begins with an historical account of research on sign languages and studies on sign language translation, as well as a brief account on the history of deaf education. It continues with a summary of key research approaches related to sign bilingual teaching with particular focus on translation as a method. It then continues with some practical approaches and methods that provide concrete examples from a sign bilingual classroom. The chapter ends with a conclusion and discussion about future directions, as well as suggestions for further reading.

\section{Historical perspectives}

\section{The history of sign language}

Due to the lack of documentation, it is almost impossible to establish when different sign languages in various parts of the world really emerged. The most common examples have been (and still are) that deaf children grow up as the only deaf child in their family and, in adulthood, many of them live surrounded by hearing people only. Together, they may have developed different methods of communicating with each other, i.e. through gestures, homemade signs, etc., restricted to the specific context in which they live. From this perspective, it is understandable that in places where several deaf people came together, for example, in communities comprising multiple deaf families, sign languages have emerged and developed from initial gestural communication into increasingly more standardized sign languages (McBurney 2012). Such developments still appear in different parts of the world, for example, in Yucatec Mayan villages in Mexico (see, for example, Safar 2017), which make research and documentation on the emergence and development of sign languages possible. This contributes to a deeper knowledge of the history of sign language, despite the lack of documentation from previous centuries.

When deaf schools were established (see ahead), they became important places for sign languages to develop and spread in more standardized forms, because deaf children came together there and could learn from each other (McBurney 2012). Younger children could learn from older children and new sign language users could learn from deaf children who had deaf parents and who had already developed a sign language. The development of sign languages occurred regardless of whether or not sign language was used in teaching, because children used it to communicate with each other outside the classroom. Deaf youths took these sign languages with them when they left school and sign languages became more widespread.

Although sign languages (in different forms) have emerged, developed, and become increasingly more widely used in different countries over several centuries, they were not regarded as 'real' languages. Thus, the research started by William Stokoe in the US in the early 1960s became groundbreaking. He started by examining American Sign Language (ASL) phonology, i.e. the internal structure of individual signs, and proposed a transcription system for the notation of signs into written form that built on this phonological structure. A few years later, he also published the first ASL dictionary. The work by Stokoe and later work in the 1970s by Edward Klima and Ursula Bellugi contributed to a gradual shift in the attitude to sign languages towards an acceptance that they were natural and real languages with their own grammar and structure. The initial research on ASL become widespread and several countries started research on their own national languages. In Europe, sign language research started in the 1970s, for example, in Sweden, Denmark, Germany, and France. This linguistic research 
came to be greatly significant to the changed attitude regarding the use of sign languages in deaf education, as will be described in the next section.

\section{Sign languages and sign language translation}

As summarized previously, research on sign languages is relatively new and sparse and knowledge of sign languages is consequently not as widespread as knowledge of spoken languages. A consistently wrong assumption is that sign language is international, i.e. that one and the same sign language is used all over the world. According to Ethnologue (Simons and Fennig 2018), 144 sign languages have been listed thus far around the world.

Apart from the modality issue, linguists have confirmed that spoken languages and sign languages share the same linguistic properties acknowledging the linguistic status of sign languages as full-fledged human languages. However, due to the modality difference, there are some structures that characterize sign languages. For example, spatiality in sign languages, for example, the signing area in front of the signer, is frequently used for meaning and reference (Cormier et al. 2015). Due to the visual-gestural channel, sign languages are also characterized by simultaneity, i.e. there is a manual part (hands representing, for example, lexical information) as well as a non-manual part (for example, eyebrow movements representing syntactic information) that is expressed at the same time (see, for example, Meier 2002 for an overview). In addition, sign languages are virtually unwritten languages.

In the context of language teaching and translation with a written and a sign (unwritten) language there are different features and conditions. Indeed, from a functional and communicative perspective, sign languages share more with oral languages than with written languages (cf. Stone 2009; Wurm 2018). Thus, the bridge between a written language and a sign language can be complicated in the translation process.

The low achievement of literacy skills within the deaf community because of inappropriate educational approaches to teaching deaf literacy over the years (for example, through the oral methods that will be described later), as well as technological limitation back in time, obviously explain the sparse historical accounts of translation from written languages into sign languages (Ahlgren and Ozolins 1983; see also Wurm 2018). In order to translate from a written language into a sign language, proficiency in both languages is necessary. Since very few deaf people in the oral method era were literate and very few hearing people were proficient in sign language, the practice of using translations in educational settings has been both rare and unusual. In parallel with this, it is only recently that it has become possible to record and save sign language texts (i.e. as video files).

\section{Competing teaching methods in deaf education}

Throughout history, there have been several attempts to educate deaf children through various methods. The earliest systematic attempts identified in the literature were conducted by the Benedictine monk, Ponce de León, in Spain in the 16th century (Moores 1987; Daniels 1997). He is regarded as the first teacher of the deaf as he established a school in Valladolid that taught deaf children from the Spanish aristocracy. However, the methods used by Ponce de León in his attempts to teach writing, reading, and speech are barely known because the documentation has been lost or destroyed (Moores 1987). Better known, however, are the competing methods developed a few centuries later by Abbé de l'Épée in France and Samuel Heinicke in Germany. De l'Épée established a public school for the deaf in Paris in 1755, which was the first of its kind in the world. His method is known as the manual method (or the French 
method, or the sign language method) because it was based on the assumption that sign languages were the natural languages of deaf people. De l'Épée also developed methodological signs as a complement to the sign language used in Paris, aiming to make the language closer to French regarding syntax and morphology. This method of teaching deaf people become well known because de l'Épée did not keep it secret like many others had before him. Thus, the manual method spread to other countries (see, for example, Moores 1987; Easterbrooks and Baker 2002). In contrast to de l'Épée, Samuel Heinicke believed that deaf children should learn speech before writing and argued that it was through speech that pure thoughts were possible. His method, known as the oral method (or the German method), did not initially spread, probably because he did not share it with others, and his ideas were lost when he died. However, during the 19th century, interest in the oral method was revived, especially through the work of John Baptist Grater and Frederick Maritz Hill (Moores 1987). After gaining ground in many countries, at the Milan Conference in 1880, the oral method was claimed to be the superior method for teaching deaf pupils, as opposed to the manual method, and a long period of oralism began. The oral method focused on the learning of speech, and the use of national sign languages, which were not regarded as 'real' languages, were largely denied in deaf education. However, in the 20th century, this method became increasingly questioned and challenged, probably because research on sign languages started and became widespread, as described previously. As a consequence, manual methods re-emerged, in some countries as sign bilingual methods, where deaf pupils were taught in both written and sign languages. This led to the phenomenon in several countries, for example, the Nordic countries, whereby national sign languages were implemented as the primary medium of communication and instruction (e.g. Sweden 1983; Finland 1987; Denmark 1991; Norway 1993). Sign languages have also become school subjects with their own curriculum in these countries, devoted to the idea that deaf pupils should develop the necessary skills to express and understand different texts in sign language, gain knowledge about the language's structure and grammar, and become aware of the differences between oral/written language and sign language.

\section{Research approaches and key findings}

Within general second language (hereafter referred to as L2) and foreign language teaching, translation exercises have formed a common part of instruction, despite the fact that translation as a teaching approach has been subject to criticism and has been officially rejected since the end of the 19th century in the arena of language teaching theory (Cook 2010). Yet, translation tasks have repeatedly appeared in many textbooks and have been used in different forms of teaching, although perhaps without referring to them as translation. For example, previous accounts related to L2 teaching have revealed different methodological principles that could result in successful L2 learning. These could be indirectly related to using translation as a pedagogical practice: (1) focus on form, (2) negative feedback, and (3) promotion of cooperative learning (Long 2009). This means that the use of translation exercises could facilitate discussions about the languages' forms. Through focusing on the form and providing contrastive views on the languages, the teacher can help learners identify differences on a metaanalytical level. Negative feedback, i.e. feedback on how to correct errors, etc. on translations made by learners can also help them develop their language production. And working with translations together in the class can promote cooperative learning. It is, however, important to distinguish between different models of translation exercises. Models that provide more pragmatic and functional translations of larger texts are often preferred in contrast to isolated translations of sentences that are limited to formal equivalents. In recent years, some scholars 
have argued for a reassessment of the use of translation in language teaching because "it develops both language awareness and use, . . is pedagogically effective and educationally desirable, and ... it answers student needs in the contemporary globalized and multicultural world" (Cook 2010, p. 155).

Regarding sign languages, thus far there have been few studies that have focused on translation as an approach in deaf education. When translation is mentioned, it is often in the context of interpretation in education, i.e. situations in which teachers who are unskilled in sign language instruct deaf pupils through a sign language interpreter, and is not about the use of translation as a pedagogical approach per se. But when taking a closer look at the body of literature pertaining to deaf education, and other studies related to sign languages, we can identify several methods that could be considered to be part of using translation as a practice in a broad sense, without focusing on the concept of translation per se. For example, the literature has described various methods that can be categorized as content (or meaning)-based instruction, interactional approaches, and contrastive approaches. In these methods, a sign language and a written language are constantly present. The languages are discussed and compared to each other and they complement each other in different ways in the tasks and in teaching. In the following, we will describe these methods and the research that has been conducted that can be connected to them.

A content-based approach involves the teacher's use of text excerpts, written sentences or concepts that may be visually accessible through a PowerPoint slide or on a whiteboard while the teacher guides the pupils through the written content by using explanations and expanded descriptions using sign language (see, for example, Mason and Ewoldt 1996; Bagga-Gupta 2004; Allard 2013; Lindahl 2015). This strategy links the two languages and can be regarded as a form of translation between the languages in a flexible and fluid way. Through this approach, teachers can improve their pupils' skills in the written language because they can discuss the core meaning of different concepts or remarks about sign language and, in doing so, ensure the pupils' understanding of the teaching content. In addition, this helps pupils understand textbooks better when they read them afterwards and supports the pupils in their own writings on the topic.

In interactional approaches, pupils can work together with drawings, writings, creating posters, sculptures, etc. In this work, they engage in discussions in sign language with the aim of agreeing on what they should all draw or write and how they should do it. These interaction-based tasks may include instructions in a written language and the pupils can read the text and translate it into sign language for their classmates. In doing so, on many occasions the pupils will have different perceptions of what words and sentences mean and pupils in a group can therefore provide different translations for each other, which together creates a common understanding of the text. The pupils can also create a written text together, though expressing different content in sign language and discussing how it will be written down. Here, they make translations from their sign language into written language and also often use fingerspelling to spell out the written word before someone writes it down. One example of research on such interactional approaches is Williams' (1999) study on deaf preschoolers (aged 4-5 years) who, at the start of the school day, sat together, drawing and writing many different things and frequently showing their pictures to each other, sometimes commenting on them in sign language and sometimes helping each other with words or spellings in written language. Another study, conducted by Dostal and Wolbers (2014), has its origins in an instructional approach called Strategic and Interactive Writing Instruction (SIWI), an approach that focuses on collaborative settings in which pupils develop their communication skills with the aim of sharing and responding to other pupils' ideas. They conclude that the 
SIWI approach, in which the development of proficiency in both ASL and English simultaneously, is successful. The interactive approach supports a collective understanding of different ideas because the pupils come from miscellaneous backgrounds, have diverse proficiencies, and communicate and understand in diverse ways, which they can share with each other when they interact. SIWI also contributes to the growth of metalinguistic awareness because it uses comparisons and translations between the languages.

Contrastive methods in language teaching mean, for example, that a national (written) language is compared to a national sign language with regard to the grammar, functions, and discourses of the languages. Contrastive methods improve the pupils' metalinguistic skills and help them become aware of the similarities and differences between the languages. When working contrastively, translation exercises are particularly helpful, because, for example, they reveal the different grammatical structures of the languages (see Svartholm 2008; Hoffmeister and Caldwell-Harris 2014). In Swedish, for example, all verbs throughout the text are marked for tense, but in Swedish Sign Language (STS), the time context is conveyed through an initial adverb or adverbial sentence instead. Translations also reveal differences in the languages' structure. Sign languages use the space in front of the body to place signs, showing relations, locations, etc., while written language does not need to describe such relations or locations if it is not important for the understanding of the text and could be much more implicit in descriptions of environments. Hoffmeister and Caldwell-Harris (2014) have focused on how deaf children can learn English as an L2 through being exposed to print, with the help of ASL. They set up a descriptive model of three stages in the process of children learning to read:

Stage 1: Mapping translation equivalents.

Stage 2: From words to sentences: simple translation breakdown.

Stage 3: Use ASL to learn English via print in a bilingual learning mode.

(Hoffmeister and Caldwell-Harris 2014, p. 232)

In the first stage, the children acquire print forms that closely correspond to frequent and simple ASL signs and phrases through, for example, the parent's showing signs and then pointing to their written equivalents in a book. Hoffmeister and Caldwell-Harris (2014) describe this first stage as a mapping between ASL and English. Other researchers have described similar contrastive translation approaches as chaining, which appears in sign bilingual classrooms. It means to link different modalities such as pictures, written words, signs, and fingerspelling together. In practice its purpose is to support pupils' understanding of how languages, meaning, and referents are interrelated. The teacher can, for example, point at a written word, sign it, point at a picture that shows the word, and spell out the word using the hand alphabet (see, for example, Humphries and MacDougall 1999; Bagga-Gupta 2004; Tapio 2013; Holmström and Schönström 2018). This can be understood as elements of translations that help pupils separate between and understand the relationship between the two languages. In Hoffmeister and Caldwell-Harris' second stage, similar approaches to chaining are also found but, in this instance, are in the form of sentences or phrases. Thus, chaining uses close word-for-word or sentence-for-sentence translations and contributes to improved knowledge of the language's structures. In Hoffmeister and Caldwell-Harris' last stage, the children have understood that the two languages are different and that it is not always possible to make direct translations between them. They know that some constructions in one language have to been formulated in another way in the other language.

Mahshie (1995) provided a broad practical description from early bilingual education in Sweden and Denmark. She illustrates how a class worked with both languages by watching 
STS videos and reading the same narratives in written Swedish. This provided them with a large input on both languages. Often, the class started to watch the STS video and discuss both the content and the sign language used in the narratives before reading the same narratives in written Swedish. When they read the Swedish text, the teachers provided their own shorter translations of different text sections or sentences into STS and the class could engage in discussions on the similarities and differences between the languages (on different levels). This working procedure created a common understanding of the text contents, the different types of grammar, and what words/signs mean in each language. Mahshie also describes how pupils were sometimes given shorter texts that they translated into STS and produced in front of the class. In this work, pupils could comment on each other's translations and the choice of different signs or expressions. This simultaneously facilitated the STS development of pupils who had not been exposed to STS to a great extent before starting school. All in all, Mahshie found that translation exercises were very common in the teaching and argues that the pupils' various errors when they translated STS into written language could help the teachers see where the pupils were in the process, and what they needed to focus on more in their instruction. The practice described by Mahshie shows how all three components mentioned by Long (2009) interplay in the teaching with the help of translation exercises: the class focused on the languages' form, provided negative (and constructive) feedback and engaged in cooperative learning through discussions and joint watching and reading. In this brief example, we can also see how the different approaches interplay - the class has both content-based instruction and has learned through interactional approaches. They also had a contrastive perspective when comparing the languages on different levels.

\section{Pedagogic approaches and methods}

Taking a Swedish deaf school as an example, we will show here how translation can be a natural and common component in the instruction of deaf pupils. In the current national curricula (from 2011) for STS as a subject, translation is only mentioned as an approach for secondary school pupils (in GY11). In other subjects, such as Swedish, and in the curriculum for compulsory schooling for pupils of younger ages, translation is not mentioned at all. Instead, different kinds of comparisons are highlighted and mentioned in both of the language's subject curricula, with the aim of pupils developing knowledge about similarities and differences between the two languages: STS and Swedish. This was also the case in the previous curriculum for Swedish compulsory deaf schools before 2011, LPO 94 (since 1994). This curriculum has a common text for STS and Swedish, mentioning the pupil's bilingualism. The goals to strive towards include pupils "developing their capacity to analyze and discuss differences and similarities between STS and Swedish with regard to the languages' structures and functions" (our translation). This means it was comparisons and the pupils' development of both languages that were highlighted, and it was not a goal in itself to become competent at making translations or using translation approaches in instruction. However, classroom data from a project related to language teaching in a Swedish sign bilingual classroom revealed that translation, in spite of this, is an essential and recurring method for teaching young deaf pupils to read and write in Swedish (their L2). Following a class of deaf pupils in a longitudinal (unpublished) study that covered three years of $1 \mathrm{st}-3 \mathrm{rd}$ year pupils (conducted by the second author) in the early 2000s, when the LPO 94 curriculum was the prevailing curriculum, it appeared that a large amount of STS instruction and interaction was provided in the first years of school. It included working with STS genres and stories towards the successful implementation of written Swedish in the teaching. Thus, 
in this section, we will provide a detailed account of the use of translation as a pedagogical approach to facilitating deaf pupils in their learning of an L2 written language and as a bridge for them to become proficient readers.

\section{Translation as part of a collective reading activity in a sign bilingual classroom}

Swedish classes in year 1 often comprise collective reading practices and discussions in which translation forms an essential part. One example of this is as follows: after a short introduction and warm-up, the bilingual teacher starts by writing the following sentence in Swedish (English equivalents have been translated word-for-word in italics) on the screen in front of the pupils sitting in a semi-circle (see Figure 20.1):

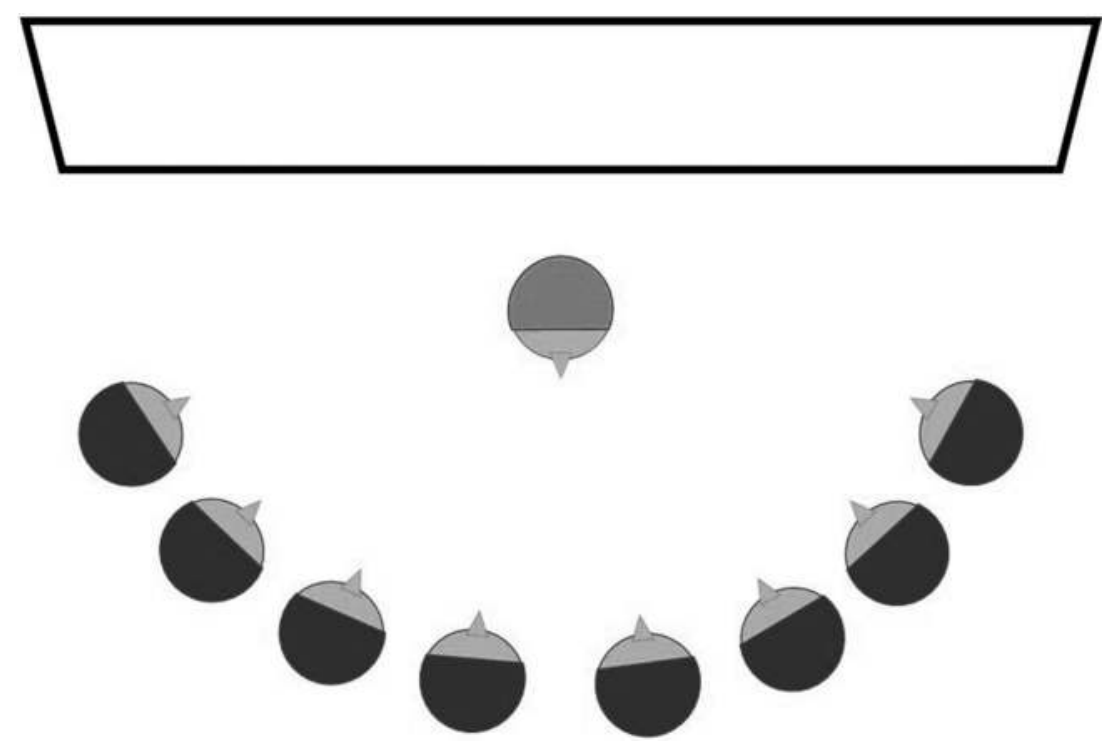

Figure 20.1 Pupils sitting in a semi-circle in classroom.

Swedish: $\quad$ Björn jagade en björn igår

English: Björn hunted a bear yesterday

Then the teacher asked the deaf pupils how to translate this sentence into STS. All the pupils raised their hands and the teacher picked one of them. The pupil was allowed to approach the screen in the front of the class. Then the teacher asked explicitly if the pupil had read the entire sentence, and then the pupil started translating (signs from STS have been illustrated through English words in capitals):

\section{STS: YESTERDAY (nod) BJÖRN HUNT A BEAR}

As illustrated, the pupil changed the word order of Swedish into a different and typical word order in STS. The teacher confirmed that this was a correct translation. This was consequently 
discussed in class. The teacher further explained that there was another word order that could also be used in Swedish and wrote the following on the screen:

Swedish: $\quad$ Igår jagade Björn en björn

English: $\quad$ Yesterday hunted Björn a bear

In this example, the word 'yesterday' is placed in the same position as in STS but there is still a difference: 'hunt' is placed in different positions, before or after the name Björn. Next, the class discussed the difference between the use of upper case and lower case letters, in which the teacher recalled the importance of using initial capitals when the word is a proper noun.

The next example comes from a discussion based on the following sentence in which the word spelar ('play') was in focus:

Swedish: Jag spelar golf

English: $\quad$ I play golf

The teacher was referring to a book that the class was reading together. She mentioned that the written word 'play' could be used in contexts with musical instruments. She illustrated how in STS, 'play', as in play a piano or guitar, meant different translations of the concept to 'play' because of the iconic and kinetic properties of STS (i.e. showing the fingers playing a piano in the area in front of the body vs. holding a guitar in the arms and strumming with the fingers). The class continued discussing different solutions for translations of the Swedish word for 'play' into STS in a sports context, such as 'play football', 'play tennis', etc.

These examples from bilingual instruction are similar to the contrastive work described by Hoffmeister and Caldwell-Harris (2014) previously. Another example, from year 3, shows a context in which the class is sitting in a semi-circle in front of the teacher and the screen doing joint work. Here, the teacher is signing a story in STS. Sometimes, while telling the story, she stops and asks the pupils about the Swedish equivalents for signs or phrases and asks them to write these on the screen. Through this work, the pupils practice translating from STS signs into Swedish words.

\section{Translation as a mediating process in reading and writing}

In year 3 (same group), the Swedish lessons are characterized more by the pupils' own work, such as writing in workbooks and reading activities. However, translation practices are also apparent here. Now the pupils have developed into more self-regulated learners compared to when they were in year 1 . The following example illustrates a similar discussion to year 1 with the word 'play' and how to translate it into STS. Now, however, this work is taking place between the pupils on their own, an example of the interaction approach. In this context, two pupils, P1 and P2, discuss an appropriate word to use for a sentence that illustrates a picture in the workbook. They discuss three possible alternatives: leka ('playing'), spela ('play with'), and bolla ('play with ball'). The differences between these words were mediated through translations into STS. In particular, the word bolla was discussed and suggested as the appropriate word in remarks such as han bollar ('he plays with balls'). This was a new remark for P1 who was not convinced as she had interpreted as meaning a man who was working like a ball, or rolling like a ball, whereas P2 corrected her and explained it was a way of saying that someone is playing with a ball, for example, kicking or juggling it. The nuances between the different kinds of remarks were mediated here through translations into STS. 
In reading sessions during the lessons, small translation practices were a recurring phenomenon. These were linked to when pupils asked the teacher for explanations of words or remarks that they had written down during their own reading. Through this the teacher gave them translations (with or without an explanation) into STS, which helped the pupils progress in their reading. Classroom data illustrate a lot of these activities, making them a very common phenomena in sign bilingual classrooms. It should also be noted that the teacher often asked for the context in which the word or remark in question was derived. This demonstrates that it is obviously always a prerequisite that the teacher is capable of translating into STS.

\section{Translation as a method of assessing reading skills}

Sign bilingual classroom data have several examples of a more content-based approach, in which the teacher also assesses the pupils' knowledge and understanding of a text that has been read. One such example, which illustrates a recurring phenomenon in the classroom, is when a pupil tells the teacher that he has finished reading his book. Compared to his classmates, this pupil finished the task really quickly and the teacher wanted to ensure that he had really understood the content of the book and asked him to read the text to her. In a sign bilingual situation, it is not possible to read aloud from a book in Swedish in this language, i.e. through spoken Swedish, and therefore, the pupil has to translate the Swedish text into STS. In this case, the teacher sometimes stopped the pupil and asked for clarification, i.e. what a sign or a sentence the pupil had signed actually meant. Through this approach, the teacher could detect whether the pupil had really understood the text, for example, when he used close word-to-word translations using signs that had other meanings than what the text was really about. She could see if the pupil became stuck on any Swedish word or phrase and could then give the pupil the correct translation of the word or phrase and provide an explanation, if necessary, during the translation process.

\section{Summary}

In a sign bilingual classroom, the observer would see that two languages are always present. The classroom data clearly showed that there is always a sign language (STS) and a written language (Swedish) present in a woven and somewhat simultaneous manner. The pupils read from books and on screen and answer in sign language. This complex process of switching between languages is continuously present. And in this process, translations, as shown in the preceding examples, appear to be an important and accessible method for introducing and developing the written language.

\section{Conclusions and future directions}

Our chapter shows that translation using a sign language has not received adequate coverage in the literature on deaf education. In reality, however, it may be that the work conducted in school is in many ways about translation, but that it has not been identified as such in these exercises. As shown in this chapter, translation tasks may despite it be very common in practical teaching. And although translation is not an explicit goal of the curriculum, it can be considered to be an important way of working with languages in deaf bilingual/multilingual contexts, with the aim of creating a greater understanding of language similarities and differences, and to gain a deeper knowledge of both languages. 
Working with translation as an approach in language teaching requires skilled teachers who are proficient in both languages. This is a complex issue because most hearing teachers have the national sign language as an L2 and may lack competence in sign language. And some deaf teachers may not have the necessary proficiency in written language to work with translations. Also, teacher training may not include translation approaches, making this an even greater challenge.

\section{Further reading}

Pfau, R., Steinbach, M. and Woll, B. (eds) (2012) Sign Language: An International Handbook. Berlin: De Gruyter Mouton.

This large handbook comprising 40 chapters covers all aspects of sign language linguistics studies with examples from more than 30 sign languages around the world.

Gregory, S., Knight, P., McCracken, W., Powers, S. and Watson, L. (1998) Issues in Deaf Education. Oxon: David Fulton Publishers.

This book offers a comprehensive account of research related to deaf education, with a range of issues such as educational policy, psychology, linguistics and audiology.

Marschark, M. and Spencer, P.E. (eds) (2010) The Oxford Handbook of Deaf Studies, Language, and Education. Vol. 1, 2nd ed. Oxford: Oxford University Press.

This book provides a comprehensive overview of the field of deaf studies, language, and education. The chapters cover educational issues, literacy, language development, sign languages and hearing and speech perception, and comprise practical information together with deeper analyses of things that may work, why it works, and for whom it works.

Rosen, R. (forthcoming) The Routledge Handbook of Sign Language Pedagogy. London: Routledge. This handbook consists of studies in L1 and L2 sign language pedagogy with focus on different aspects, such as instruction, curriculum, and assessment, and covers key concepts, research studies, and best practices of the different themes in the chapters.

\section{Related topics}

bilingualism and multilingualism, bilingual deaf education, bilingual education, content-based instruction

\section{References}

Ahlgren, I. and Ozolins, B. (1983) Att översätta till teckenspråk, in Engwall, G. and Geijerstam, R. (eds) Från Språk Till Språk: Sjutton Uppsatser om Litterär Översättning. Lund: Studentlitteratur. pp. 213-229.

Allard, K. (2013) Varför gör de på detta viset? Kommunikativa praktiker i flerspråkig språkundervisning med svenskt teckenspråk som medierande redskap. Örebro Studies in Education 39. Örebro: Örebro University.

Bagga-Gupta, S. (2004) Visually oriented language use: Discursive and technological resources in Swedish Deaf pedagogical arenas, in van Herreweghe, M. and Vermeerbergen, M. (eds) To the Lexicon and Beyond: Sociolinguistics in European Deaf Communities. Washington: Gallaudet University Press. pp. 171-207.

Cook, G. (2010) Translation in Language Teaching. Oxford: Oxford University Press.

Cormier, K., Fenlon, J. and Schembri, A. (2015) Indicating verbs in British Sign Language favour motivated use of space. Open Linguistics. 1, pp. 684-707.

Daniels, M. (1997) Benedictine Roots in the Development of Deaf Education: Listening with the Heart. Westport, CT: Bergin \& Gravey. 
Dostal, H.M. and Wolbers, K.A. (2014) Developing language and writing skills of Deaf and hard of hearing students: A simultaneous approach. Literacy Research and Instruction. 53(3), pp. 245-268.

Easterbrooks, S.R. and Baker, S. (2002) Language Learning in Children Who Are Deaf and Hard of Hearing: Multiple Pathways. Boston, MA: Allyn \& Bacon.

Geva, E. (2006) Second-language oral proficiency and second-language literacy, in August, D. and Shanahan, T. (eds) Developing Literacy in Second-Language Learners: Report of the National Literacy Panel on Language-Minority Children and Youth. Mahwah, NJ: Lawrence Erlbaum. pp. 123-139.

Hoffmeister, R.J. and Caldwell-Harris, C.L. (2014) Acquiring English as a second language via print: The task for deaf children. Cognition. 132(2), pp. 229-242.

Holmström, I. and Schönström, K. (2018) Deaf lecturers' translanguaging in a higher education setting: A multimodal multilingual perspective. Applied Linguistics Review. 9(1), pp. 90-111.

Humphries, T. and MacDougall, F. (1999) "Chaining" and other links: Making connections between American Sign Language and English in two types of school settings. Visual Anthropology Review. 15(2), pp. 84-94.

Lindahl, C. (2015) Tecken av betydelse: En studie om dialog i ett multimodalt, teckenspråkigt NOklassrum. Doctoral Thesis from the Department of Mathematics and Science Education 11, Stockholm University.

Long, M.H. (2009) Methodological principles for language teaching, in Long, M.H. and Doughty, C.J. (eds) The Handbook of Language Teaching. Chichester: Wiley-Blackwell. pp. 373-394.

LPO. (1994) Läroplan för det obligatoriska skolväsendet, förskoleklassen och fritidshemmet. Stockholm: Utbildningsdepartementet.

Mahshie, S.N. (1995) Educating Deaf Children Bilingually. Washington, DC: Gallaudet University Press.

Mason, D. and Ewoldt, C. (1996) Whole language and deaf bilingual-bicultural education - Naturally! American Annals of the Deaf. 141(4), pp. 293-298.

McBurney, S. (2012) History of sign languages and sign language linguistics, in Pfau, R., Steinbach, M. and Woll, B. (eds) Sign Language: An International Handbook. Berlin: De Gruyer Mouton. pp. 909-948.

Meier, R.P. (2002) Why different, why the same? Explaining effects and non-effects of modality upon linguistic structure in sign and speech, in Meier, R.P. and Cormier, K. (eds) Modality and Structure in Signed and Spoken Languages. Cambridge: Cambridge University Press. pp. 1-25.

Moores, D. (1987) Educating the Deaf. Psychology, Principles, and Practices. 3rd ed. Boston: Houghton Mifflin.

Safar, J. (2017) Translanguaging in Yucatec Maya signing communities. Applied Linguistics Review. 10(1), aop.

Simons, G.F. and Fennig, C.D. (2018) Ethnologue: Languages of the World, Twenty-First Edition. Dallas, TX: SIL International [online]. Available from: www.ethnologue.com [Accessed 18 March 2019].

Stone, C. (2009) Toward a Deaf Translation Norm. Washington, DC: Gallaudet University Press.

Svartholm, K. (2008) The written Swedish of deaf children: A Foundation for EFL, in Kellett Bidoli, C.J. and Ochse, E. (eds) English in International Deaf Communication. Bern: Peter Lang. pp. 211-249.

Tapio, E. (2013) A Nexus Analysis of English in the Everyday Life of FinSL Signers: A Multimodal View on Interaction. Doctoral dissertation, University of Oulu, Jyväskylä University Printing House, Jyväskylä.

Thoutenhoofd, E. (2001) Print culture and deaf readers. Deaf Worlds. 17(3), pp. 80-88.

Williams, C.L. (1999) Preschool deaf children's use of signed language during writing events. JLR. 31(2), pp. 183-212.

Wurm, S. (2018) From writing to sign: An investigation of the impact of text modalities on translation. Translation and Interpreting Studies. 13(1), pp. 130-149. 


\section{Sign bilingual education of foreign languages}

Edit H. Kontra

\section{Introduction}

Deaf education is extremely diverse. In several places around the globe the main issue is providing education to all deaf children as currently $80 \%$ of deaf people in the world receive no education at all (WFD 2018). In other corners of the world deaf advocates are fighting for making high quality education available for deaf persons at all levels and in all areas of the curriculum on a par with hearing people. How equality in access and quality can be achieved, however, is a debated issue. Some would vote for inclusive education at mainstream schools where, in case of individual placement, deaf and hearing pupils are taught by the same teachers, follow the same curriculum, and are assessed on the same terms. Article 24 of the UN Convention on the Rights of People with Disabilities (United Nations 2007, p. 16) in fact stipulates that "States Parties shall ensure an inclusive education system at all levels and lifelong learning" directed, among others, to the development of "their personality, talents and creativity, as well as their mental and physical abilities, to their fullest potential". In a regular mainstream school, however, hearing teachers provide instruction in the spoken language of the majority society. Their lessons are designed for hearing pupils, and even if an interpreter or a teaching assistant is provided, deaf schoolchildren are cut off from their linguistic and cultural community. This means that they are unlikely to meet deaf adults as role models or deaf peers they could regularly interact with (cf. Branson and Miller 1993).

Special residential or day schools for the deaf, on the other hand, are considered by many "the cornerstone of Deaf culture and history" (Knight 1998, p. 222), where children are socialized into sign language and Deaf ${ }^{1}$ culture. The so-called Salamanca Statement (UNESCO 1994) promotes inclusive education for children with disabilities, but makes a distinction between the needs of deaf children and other disability groups. It declares deaf children's right to education in their national sign language, and that owing to this, "their education may be more suitably provided in special schools or in special classes in mainstream schools" (p. 18). Deaf parents tend to vote for special education in residential schools with teachers who are trained in deaf-pedagogy as well as the local sign language and who can be hearing or deaf (cf. European Agency for Development in Special Needs Education 2013). In this case, the proposed pedagogical approach is bilingual education, which takes account of the fact that the 
only fully accessible language for a deaf child is the local sign language. Nevertheless, sign bilingual education also acknowledges the importance of developing skills in the language of the majority society, especially in the written modality, in order to foster the child's academic success. The World Federation of the Deaf (WFD) is in full support of bilingual education so that sign language as well as Deaf culture and Deaf identity are promoted. They assert that "every deaf person has a right to bilingual education, a social-cultural approach, which uses sign language as the language of instruction, while equally emphasizing the use of the written language(s) in that country" (WFD 2018).

Considering the diversity and magnitude of problems in deaf education, the teaching of foreign languages might seem a marginal issue. In fact, those who are interested in the principles of teaching languages to deaf students or want to learn about specific methods and materials for deaf foreign language (FL) learners will have a hard time finding resources. Research interest in this field only gained momentum in the past 10-15 years (see for example Janáková 2008; Kellett Bidoli and Ochse 2008; Mole et al. 2008; Stoppok 2010; Bedoin 2011; Domagała-Zyśk 2013; Domagała-Zyśk and Kontra 2016) and there is still a great deal to do both for researchers and practitioners. While a decade or two ago many may have wondered what deaf persons need foreign languages for, today it is generally accepted that trends in globalization affect hearing and deaf people alike, therefore the knowledge of foreign languages is important for all regardless of a person's hearing status. In the following, this chapter is going to look at teaching foreign languages within the framework of deaf bilingual education. First, under Historical perspectives, an overview of the most fundamental issues in deaf education is provided. This is followed by a discussion of Research approaches and key findings regarding the teaching of foreign languages to deaf persons with or without the involvement of sign language(s). The section on Pedagogic approaches and methods presents findings concerning methods and techniques for applying different modalities. Finally, the chapter concludes with some recommendations for both practice and research.

\section{Historical perspectives}

Deaf bilingual education is impossible to write about without first clarifying what is meant by Deaf/deaf and which two languages the term bilingual refers to. Spelled with a small case $d$, deaf refers merely to an audiological condition, the complete or partial loss of hearing "significant enough to have an impact on language development and learning" (Swanwick 2016, p. 2). The term Deaf with a capital $D$, on the other hand, is frequently used to identify people whose preferred means of communication is their national sign language "from positive personal choice" and "whose culture is a natural extension of that [language]" (Knight 1998, pp. 218, 222). Deaf people thus constitute a linguistic and cultural minority, and several authors make the $\mathrm{D} / \mathrm{d}$ distinction to demonstrate that they identify with this view (Lane et al. 1996; Knight 1998; Ladd 2003), and this tradition is observed in the present text as well. According to Pickersgill (1998, p. 89), the bilingual education of deaf children presupposes not only a linguistic and cultural minority model of deafness but also a social model of disability. The social model challenges the medical view of disability as an illness that has to be cured. From the social perspective, deaf people are not disabled due to their physical condition but by their social environment that has been designed by and for non-disabled people. It follows that in order to ensure equal rights and equal participation for deaf persons in all spheres of life it is not the persons who have to be changed but their environment which must be made barrier free both in the physical sense and in terms of information flow. 


\section{Issues in deaf education: an overview}

A bilingual approach in deaf education follows the model of hearing bilingualism in many ways, but it is also different since it entails the involvement of not only two languages but also two or more modalities: the spoken/written version of the local vernacular and the national sign language, which is a visual-gestural language, yet a language in its own right (Stokoe 1960; Maher 1996). This approach has been labelled sign bilingual by some researchers (e.g. Swanwick 1998) and bilingual-bicultural by others (e.g. Marschark and Lee 2014, p. 215). Sign bilingual learning expects fluency in both the natural sign language of the local Deaf community and the spoken language of the local hearing community. Experience shows, however, that deaf children enter school with an impoverished knowledge of both languages (Holcomb and Peyton 1992; Gregory 1996; Muzsnai 1999; Marschark and Lee 2014). There are two fundamental reasons for this.

First, approximately $90-95 \%$ of deaf children are born to hearing parents most of whom naturally want to bring up their child to belong to the hearing community. However, deaf children cannot benefit from exposure to spoken language the way hearing children do for lack of accessibility. Thus, the lack of accessible language input results in language deprivation with all its consequences (Humphries et al. 2013). Second, for over 100 years, the dominant pedagogical approach in deaf education was - in some places still is - oralism, which, due to the resolution taken at the Second International Convention on Education of the Deaf in Milan in 1880, banned sign languages and Deaf teachers from schools and concentrated all efforts on deaf children learning to use spoken language so they can fit into the hearing society. The oralist approach has not brought the expected results. A frequently cited study by Conrad declares that "deaf pupils left school with median reading ages of nine; with poor speech intelligibility and with lip-reading skills no better than those of the hearing population, despite their training in this area" (Conrad 1979, cited in Gregory 1996, p. 19). Poor, below fourth-grade-level literacy skills of school leavers were reported from Canada to the Netherlands, Sweden or Hungary as well (Allen 1994; Szabó 1999; Evans and Seifert 2000; Wauters et al. 2006; Svartholm 2010; Marschark and Lee 2014).

Dissatisfaction with the results of oral-only programmes led to a move away from pure oralism in the 1960s and 1970s and gave birth to teaching approaches that combined speech with various sign systems. These manual systems utilized signs from natural sign languages for vocabulary but also introduced signs to indicate morphology and followed the syntax of the spoken language. A variety of systems using sign and speech simultaneously were developed in various parts of the world, labelled as simultaneous communication (sim-com), total communication (TC) or sign-supported speech (for a detailed discussion see Marschark and Spencer 2009 or Moores 2010). They all have been severely criticized for using signed systems that do not constitute a language. Therefore Deaf communities and the WFD itself support bilingual-bicultural education (Bi-Bi) that considers the natural sign language of the local community as the L1 of the children, includes its development in the curriculum, and uses it as the language of instruction. In $\mathrm{Bi}-\mathrm{Bi}$, the local vernacular is taught through reading and writing, not through speech, and the use of natural sign language is promoted as opposed to spoken language-based sign systems (cf. Knoors and Marschark 2012; Marschark and Lee 2014).

In spite of the massive support for sign bilingual education, very few people can enjoy its benefits. According to information available on the WFD Human Rights website:

only about $1-2 \%$ of deaf people across the globe access education through sign language. Too often, sign language is prohibited in educational institutions or is muddled by use of 
total communication, a method that has been shown to be ineffective and widely inconsistent, especially in comparison to the bilingual approach.

(WFD 2018)

Swanwick also notes that even in the US, the forerunner in acknowledging sign language as the natural first language of the Deaf community, many children are taught by pure auditoryoral methods and "the larger proportion are educated using what is referred to as simultaneous communication (sim-com), which is spoken English accompanied by signs borrowed from American Sign Language (ASL)” (1998, pp. 113-114).

\section{Research approaches and key findings}

Bi-Bi education was introduced without substantial preliminary research: it was assumed without much, if any, empirical evidence that if access to sign language was provided, deaf children would be able to learn and make progress at a similar rate to their hearing peers (Knoors et al. 2014). Research conducted in Scandinavia in fact indicated that although the school results of deaf children participating in bilingual education improved, the educational attainments of hearing peers during the same interval increased even more, so the disparity between the two groups remained (Marschark and Lee 2014, p. 222). Plaza-Pust (2014, p. 27) further notes that research results indicating positive correlations of sign language development and oral language skills in some bilingually taught deaf students do not yet provide any direct information about there being a causal direction between the two. As there is not enough evidence for or against bilingual education for the deaf (Knoors and Marschark 2012, p. 297), it should not come as a surprise that while in some countries they have only recently started introducing sign bilingual education (e.g. Hungary), in others, such as the UK or Scandinavian countries, sign bilingual programmes are reported to be on the decline (Marschark and Lee 2014, p. 221).

\section{A bilingual approach in the foreign language education of deaf students}

Applying a bilingual approach in teaching foreign languages to deaf students inevitably entails the use of not only two, but at least three languages: first, the sign language of the local Deaf community, which, from the point of view of accessibility, we can consider the L1 of deaf children (Jokinen 2000; Skutnabb-Kangas 2008). Second, there is the spoken language of the majority society, which for children with profound or severe hearing loss is learned as a second language (L2) mainly in its written modality at school. Finally, the third language (L3) involved is the foreign language (FL) to be learned in its written and/or spoken modality. In some cases, the foreign sign language (in the case of English: American Sign Language or British Sign Language) is also involved to some extent as a fourth language. How these languages do or do not support one another is an important issue to consider in teaching foreign languages to deaf learners but, when looking for guidance in theory, there is not much to rely on.

Research on hearing bilingualism is informed by Cummins' Theory of Interdependence, which claims, among others, that the acquisition of a second language (L2) is aided by the learner transferring his or her underlying L1 proficiency to L2 provided there is an adequate amount of L2 input and the learner is sufficiently motivated to learn the L2. The applicability of the theory to sign bilingualism, however, was seriously questioned by many (cf. Knoors et al. 2014) specifically due to the fact that most deaf children do not have an appropriate 
level of language proficiency for an effective transfer of L1 skills to occur. For reasons already discussed, the majority of deaf children are seriously delayed in their L1 development whether it is the sign language of the Deaf community or the majority spoken language. The situation is further complicated by the fact that, whereas hearing children already have oral skills in the majority spoken language before they encounter its written form, for most deaf children the spoken vernacular is taught through writing. Since it is questionable whether an L1 can be acquired via the written modality only, it is also doubtful whether the spoken vernacular can truly become the L1 of deaf children. In sign bilingualism the possibility of a direct transfer of L1 skills to the L2 is further questioned since hearing bilingualism is unimodal while sign bilingualism entails two different modalities.

The situation outlined in this chapter becomes even more complex in deaf FL learning. In the process of learning a FL, deaf schoolchildren are handling several languages in different modalities, i.e. in speech, writing or sign. One of the issues to consider is whether and how far Cummins' Linguistic Interdependence Hypothesis is applicable to teaching and learning foreign languages in practice. This in turn takes us further to the question of what the deaf student's L1 is and whether an impoverished or underdeveloped sign language or below ageappropriate spoken language can function as a language base on which the development of a foreign language (L3) can be based. The oralist approach and the sign bilingual approach suggest two different answers.

From an oralist standpoint the child's L1 is the spoken vernacular, and the goal of instruction is to teach the spoken foreign language. It would logically follow then that using the local spoken language as a reference point in teaching vocabulary, explaining grammar or doing reading comprehension tasks will support the acquisition of the spoken FL. If, however, the child's underlying first language proficiency is in their sign language, the local spoken language is of little help (Quay 2005, p. 143), and no transfer of sign-L1 skills to L3 may take place. Asking a sign-L1 child to translate a sentence or a reading passage from the L 3 to the spoken vernacular is like asking a hearing schoolchild to translate from one foreign language to another: extremely difficult especially due to the differences in morphology and syntax. On the other hand, if FL teachers are competent in the local sign language, they can make good use of it receptively when they want to check whether students understand a reading passage in the FL by asking them to sign what they are reading (Kontráné Hegybíró 2010). This technique is supported by studies cited in Evans and Seifert (2000, p. 10) according to which deaf students use semantic clues to make sense of difficult grammatical structures: "When they process these sentences, the deaf readers appear to consider what makes sense rather than analyzing the grammatical relationships between words" (original emphasis).

The frequently encountered reaction of hearing people to deaf persons' FL learning difficulties is the suggestion that deaf persons should be taught foreign sign languages. This, in terms of accessibility, sounds logical, but it is of little use if the aim of FL learning is to become a global citizen and enjoy the benefits of the Internet and international mobility for which one needs the spoken/written FL. The few research studies investigating deaf FL learning may not yet give a definite answer to what is best for the learners; however, their findings allow us to get a better and deeper understanding of the issues involved. The next section introduces some of the available research regarding pedagogic approaches and methods.

\section{Pedagogic approaches and methods}

The examples briefly outlined in the following are intended to demonstrate the complexity of the issue of language use and choice of modality in the teaching of foreign languages to deaf 
persons. The first subsection introduces some selected examples for using speech and sign language interpretation, the second subsection presents cases when the teachers themselves use the local sign language as the medium of instruction, and finally the question of incorporating the foreign sign language in the teaching-learning process is discussed.

\section{Using speech and sign language interpretation}

Stoppok (2010) investigated the FL teaching situation in three selected federal states of Germany. Her study reveals that the dominant approach both in integrated settings and in special schools is auditory-oral, and that the educational standards based on the Common European Framework of Reference for Languages (CEFRL) are not realistic objectives for hearing impaired children. She observes that in North Rhine-Westphalia, for instance, deaf children receive lessons in German Sign Language instead of English. In her brief account she calls for alternative learning designs in curriculum planning and for more flexibility in educational standards that take account of the special circumstances of deaf and hard-of-hearing language learners.

In Prague, Czech Republic, Janáková (2008) reports on how she teaches English to deaf students at the Faculty of Arts of Charles University, where there is a compulsory FL requirement for all. As a non-signer, Janáková uses both a note taker and a Czech sign language (CZSL) interpreter who translates everything for the students from spoken/written English to CZSL and back. Janáková admits that having to use an interpreter is not ideal because she is always dependent on her interpreter though she adds: "[ $t$ ]he situation is slightly better if my interpreter's English is at least at the intermediate level, but it gets much worse when my interpreter is a beginner" (p. 60). She therefore promotes that her younger colleagues should learn to use sign language before starting to teach deaf students.

Several studies have already pointed out the problems with using interpreters in FL education. First and foremost, interpreters who can translate directly from a FL to the local sign language and back are a rare commodity. Service providers mainly have interpreters who know the local sign language and the majority spoken language. This means that in an English class they can translate the instructions or explanations given by the teacher in the local spoken language, but what is said or read in English will only be transmitted in sign language up to the level of the FL competence of the interpreter. What Marschark and Lee (2014) observe with reference to content subjects, namely that there is "growing recognition of the generally poor quality of educational interpreting" (pp. 230-231) applies to the teaching of FLs as well. Similar dissatisfaction is expressed by a Hungarian Deaf student majoring in history in Kontráné Hegybíró (2010, p. 94) complaining that as soon as his Latin teacher said or read out something in Latin, the Hungarian sign language interpreter was at a complete loss.

Darroch (2013) laments that there is a dearth of research on the use of sign language interpretation in FL classes and calls attention to Quinto-Pozos' (2002) case study of Spanish courses as one of the few sources of valuable practical advice on how to provide sign language support to deaf and hard-of-hearing FL learners effectively. In his case study, Quinto-Pozos emphasizes that educational interpretation in FL classes is completely different from interpreting in all other subjects due to the fact that the FL is not only the medium of education, but also its target. The goal of interpretation is to make the target language accessible for the deaf learner and Quinto-Pozos makes it quite clear that, if the sign language interpreter does not have prior knowledge of the taught FL language, "it is next to impossible to interpret a course in that language" (p. 95). On the other hand, translating what is said in the target FL directly 
into the student's native sign language does not make the FL, for instance the use of structures, accessible for the learner, since in this case the interpreter does the understanding and not the student. The gist of the message is conveyed but how that message is expressed in the FL remains undisclosed. The author therefore suggests various strategies for the extensive use of fingerspelling as well as mouthing and suggests that the interpreter should prepare thoroughly for each lesson, do the homework, study the course book and get the teacher's handouts in advance. Darroch (2013) herself is also in favour of using plenty of fingerspelling in American Sign Language. However, in college-level Italian classes at NTID (National Technical Institute for the Deaf) she found that the students benefited a great deal from being introduced to some basic signs in Italian Sign Language (LIS) because it allowed them "to 'think' more directly in Italian" (p. 2).

Krisanova (2008), who teaches English at Bauman Moscow State Technical University, points out that their students are quite good at lip reading, but that does not help when the teacher or the students are talking in English. Therefore she suggests that "if the teacher cannot communicate in sign language, a capable student can help" (p. 147). When explaining grammar, writing is used to get the message across. Krisanova also promotes the development of oral skills in her classes. When students prepare oral presentations, they present their peers with the key words and their Russian translations and also with the text of the presentations to support those who cannot understand spoken English. Sometimes it is a better hearing fellow student who acts as an interpreter and translates a fellow student's presentation into sign language. Darroch (2013), on the other hand, considers it a good idea that at NTID when deaf and hard-of-hearing students give live presentations, they do it via typing their talk using a laptop and the interpreter then only becomes their voice so that the presentation provides a more accurate picture of the presenting student's FL skills.

For Gulati (2016) it was her experience with interpreters in her English courses for university-level deaf students that made her decide to learn Polish Sign Language (PJM). She found that after a while the interpreter stood between her and her students and took over some of the teacher's roles, e.g. answering questions and giving explanations. The students used the interpreter as a shortcut and addressed their questions about the material directly to her instead of the teacher. This made Gulati feel left out. She realized that using an interpreter had a negative effect on teacher-student rapport overall, therefore she started to learn PJM and in two years' time she was fluent enough to communicate with her students directly. Since there were some students in her groups with no sign language skills, she decided to introduce them to the alphabet first in PJM and then also in ASL so that they could use fingerspelling in both and could also compare the two for similarities and differences.

Writing about interpretation in different subject areas in higher education for deaf students, Lang (2002) cites research according to which science students performed significantly better "when learning from an instructor who signed himself as compared to those who learned through an unskilled interpreter" (p. 271), and asserts that there is "a dire need" to research and evaluate the relationship between the quality of interpreting and learning achievement.

\section{Teachers' use of sign language}

When discussing the education of people with disabilities or various types of learning difficulties, in Europe it is common practice to look to the Nordic countries for examples of best practice. Sweden, Denmark, Norway, and the Netherlands were among the first to take measures that ensured the right of the Deaf community to their national sign language and to barrier free education. 
In Sweden, Swedish Sign Language (SSL) "gained recognition by the Swedish parliament as the language of deaf people" as early as 1981, and the first bilingual curriculum was introduced in 1983 (Svartholm 2010, p. 159). The new curriculum of 1994 constituted an important milestone regarding the teaching of English by setting the goal for each deaf and hearing impaired child to be able to communicate in writing in English by the time they leave school. Svartholm (2014, p. 43) points out that English is taught as a third language implying that its teaching can be based on already acquired skills in Swedish and SSL as well as on knowledge about these languages. The curriculum considers SSL as the L1 of deaf students; furthermore, as the language of education, SSL is meant to be used for discussions of meaning and for clarifications of difficult parts of language use. On the other hand, Svartholm (2008) calls attention to the fact that Swedish and English are closely related languages and therefore contrasting written English with the already acquired written Swedish L2 in terms of morphology, word order or discourse works out more efficiently than using SSL for the same purpose.

In Norway, the National Curriculum of 1997, which is based on sign bilingualism and the sociocultural approach, introduced Norwegian Sign Language (NSL) as well as English for deaf pupils as compulsory subjects (Pritchard 2013, p. 116). Importantly, the English curriculum for deaf pupils also includes finding out about Deaf culture in English-speaking countries so much so that as a first step, pupils learn British Sign Language (BSL) as a compulsory part of the English syllabus in grades 1 and 2. It is through BSL that they find out that foreign languages and cultures exist while their linguistic and metalinguistic skills are also developed. In subsequent grades BSL is used as a bridge to English as a written or spoken language. Pritchard (2013) points out that involving NSL in the teaching of English grammar is useful, since the sentence structure of English shows more similarities to NSL than written Norwegian. Comparing and contrasting English and NSL sentence patterns can thus aid FL acquisition. This way, a teacher of English is required to be able to use at least four languages in class depending on what the situation requires: spoken/written Norwegian, spoken/written English, BSL, and NSL.

A bilingual approach has also been introduced in France. Bedoin (2011, p. 161) explains that in principle parents can choose the Bi-Bi approach for their deaf and hard-of-hearing children, though in practice it is only available in a few places. Deaf and hard-of-hearing children are enrolled in special schools or in mainstream establishments integrated either as groups or as individuals. Children are often taught French Sign Language, but it is not the language of instruction. The most frequently taught FL is English, and Bedoin's (2011) survey of 104 special and mainstream schools in France shows that teachers are struggling to find the right approach and try to adjust their teaching to the needs of the students. In special schools, when the groups were composed of profoundly deaf students, the researcher found that teachers focused on teaching reading and writing. In groups of hard-of-hearing learners, teachers told her that they were able to use listening materials prepared for hearing students. As regards the medium of education, the author concludes:

English courses for deaf signers could be delivered in French Sign Language in order to be accessible to the students. Interpreters in French Sign Language could also help teachers and students in English classes. Only written English should be taught to deaf signers.

(Bedoin 2011, p. 172)

Based on her interviews with teachers and her observations of English lessons, Bedoin expresses her conviction that deaf and hard-of-hearing students should not be mixed with their hearing peers when learning English first so that sign language can be used for in-class 
communication and, second, so that in the deaf and hard-of-hearing groups the focus can be on reading and writing whereas hearing students can get adequate training in listening and speaking. This is completely in line with the observations by Bajkó and Kontra (2008) in a Hungarian language school for adults.

Falkowska (2016, p. 55) is also convinced that the key to successful teaching of English as a foreign language (EFL) to students with a hearing loss is "the elimination of communication barriers". A fluent user of Polish Sign Language (PJM) herself, Falkowska experimented with offering English language classes to 24 Polish adults whom she placed into groups according to their proficiency level in English and created speaking and signing groups based on their self-reported hearing status. After a few months of tuition, however, she found that in creating well-functioning groups and making teaching effective, the teacher must be familiar with the functional abilities of the students who may be monolingual, bilingual or trilingual. Falkowska suggests that the communication modalities represented by her participants constituted a continuum ranging "from a signing mode (PJM), through different degrees of speech and signing (spoken Polish and English combined with PJM and/or Signed Polish), up to spoken communication (Polish and English)" (pp. 67-68). She also found that in written Polish her students represented various levels of fluency as well.

\section{Foreign sign language promoted}

The use of a foreign sign language, namely American Sign Language (ASL) or British Sign Language (BSL), is mentioned in the literature either as an alternative to the teaching and learning of spoken/written English or as a means to support the learning of English and make it more effective. Stoppok (2010), for instance, remarks that in Bavaria "children who communicate with sign language are taught the American sign language" instead of English (p. 10). Pritchard (2016) also mentions that according to the current curriculum for Norwegian schools the aim is "for pupils to be able to communicate independently without using a sign language interpreter" (p. 43) and that therefore the students have the freedom to choose between learning English speech or BSL, ASL, Signed English, or even chatting using ICT or a combination of these according to their individual needs.

From a language teaching perspective, more interesting are the endeavours which entail the use of ASL or BSL, not as a replacement for spoken English, but as a means to make the bilingual teaching of spoken/written English more effective.

When Fleming (2008) and her colleagues started setting up their 'English for Deaf Learners' programme at Wolverhampton University in the late 1990s, they decided to first introduce their international students to BSL in order to establish a shared language for both teacherstudent and student-student interaction. Following that, they focused their teaching on written English using BSL and Sign Supported English as metalanguage. Eitzen and Bartz (2016) have recently started to experiment with the incorporation of ASL as well as Contact Signs (a form of manually coded English) in teaching English to German high school students and have found it useful not only in helping students memorize and retrieve vocabulary but also in contrasting L2-L3 structures and checking reading comprehension.

Eitzen and Bartz's observations tie in with some results of research into the possible cognitive advantages of bimodal bilingualism suggesting that "exposure to signs and their corresponding spoken/written words leads to potential benefits in vocabulary learning" and that "[c]hildren found it easier to learn written words when they already knew the sign for a concept" (Marschark and Lee 2014, p. 219). The idea that the learning of English can be supported by the simultaneous learning of ASL is also documented in Kontra (2013). One of her research 
participants, for example, expressed her conviction that she managed to make real progress in English when she was exposed to English and ASL at the same time saying: "it was then that I began to understand how to think in English" (p. 107). The interviewee also added that she actually found the use of Hungarian Sign Language in the teaching of English confusing and preferred the use of ASL because ASL and English were connected.

The benefits of incorporating the foreign sign language in the teaching of a spoken/written foreign language are manifold and to our present knowledge the involvement of multiple languages as well as multiple modalities does not constitute any extra burden for the learners. The only difficulty to count with is the lack of trained teachers. Eitzen and Bartz (2016) mention with regret that they are promoting the use of a foreign sign system in a context where teachers of the hearing impaired are still not required to be competent even in the local sign language. Their situation is not uncommon. Ideal is the case when teachers learn the local sign language as part of their pre-service training programme and are supported in taking courses in BSL by their schools or the educational authorities as in Norway (Pritchard 2016).

\section{Conclusions and future directions}

The available research makes it clear that teaching foreign languages to deaf learners is a highly complex endeavour first in the sense that it involves not just two but multiple languages and multiple modalities. Second the complexity also comes from the fact that deaf and hard-of-hearing language learners are very diverse, so there is no single solution that would fit all. This requires high levels of professional skills and flexibility on the part of the teachers.

While researchers are leaving no doubt that deaf and severely hard-of-hearing persons are capable of learning foreign languages, there is no conclusive evidence that one approach to teaching would be superior to another. It is also undoubted that the method selected by the teacher will have to take account of the language learners' level of functional hearing as well as their preference for using speech or signing. Third, it is quite clear that the method of instruction heavily depends on the abilities and the training of the language teacher. If a bilingual-bicultural or a multilingual-multicultural approach is to be promoted, it requires well prepared teachers, which necessitates substantial modifications in teacher training programmes as well. FL teachers definitely must be competent in the local sign language so that they can communicate directly with their students and do not need to depend on sign language interpreters as intermediaries.

"Deaf teachers are absolutely crucial for the success of any bilingual programme" say Knoors et al. (2014, p. 13), and this would apply to teaching FLs to deaf learners as well. A number of interview participants in Kontráné Hegybíró's (2010) research said they would prefer having Deaf language teachers because a Deaf teacher is familiar with the Deaf way of thinking and is therefore more capable of explaining to the learners how the FL works from a Deaf person's perspective, that is a sign language user's perspective. In other words, a Deaf teacher is suitable for the kind of translanguaging described by Laviosa (in this volume). This is translanguaging in the truest sense of the word; it entails not only relaying specific information and processing text but also explaining data across languages and cultures. Yet Deaf FL teachers are extremely difficult to find. As Gregory (1996, p. 28) says "[i]t still remains difficult for deaf people to enter the teaching profession" and to our knowledge there are no specific training programmes for teaching FLs to deaf learners apart from occasional workshops or short in-service courses.

There is a definite need to do some basic research regarding the use of the foreign sign language in deaf FL education. Sporadic research results indicate serious benefits of such an 
approach; however, there is not enough evidence from empirical research to substantiate any claim. Attention should be paid to the training of educational sign language interpreters so that as long as institutions employ non-signing language teachers there are sign language interpreters with good FL skills to help their work.

In accordance with the WFD principle of 'Nothing about us without us' (http://wfdeaf. org/news/wfd-president-message/) a great number of further case studies of both individual deaf learners as well as learner groups in all types of contexts are necessary to get a deep insight into deaf FL learners' experiences with the use of translation into the local and the foreign sign language and the development of their own translation competence that could enable them to translanguage. There is a need for a rich collection of examples of what deaf language learners consider good practice so that it can be analyzed, documented, and disseminated widely.

\section{Further reading}

Kellett Bidoli, C.J. and Ochse, E. (eds) (2008) English in International Deaf Communication. Bern: Peter Lang.

This book is a rich source of information for anyone teaching or researching English as a foreign language for deaf and hard-of-hearing persons. The chapters were each written by acknowledged experts of the field. They cover a wide range of topics from how the brain processes languages in different modalities and language rights issues to a discussion on the challenges of teaching English to sign language users. A series of chapters are devoted to the description of specific programmes and online courses. The final part of the volume deals with aspects of translating, interpreting and subtitling.

Mole, J., McCall, H. and Vale, M. (2008) Deaf and Multilingual: A Practical Guide to Teaching and Supporting Deaf Learners in Foreign Language Classes. Norbury, Shropshire: Direct Learn Services. This slim booklet fills a huge gap in teaching foreign languages to deaf learners. To date it is the one and only comprehensive collection of general approaches and specific techniques in language teaching methodology for sign language users. It is an invaluable resource especially for language teachers in mainstream education who have no preliminary training in special education. The authors also explain the role of support workers and provide practical advice on note taking and interpreting as well as using finger spelling.

Domagała-Zyśk, E. and Kontra, E.H. (eds) (2016) English as a Foreign Language for Deaf and Hard of Hearing Persons: Challenges and Strategies. Newcastle upon Tyne: Cambridge Scholars Publishing. This edited volume includes research papers as well as personal accounts on teaching English to deaf and hard-of-hearing students in various European countries each with a strong oralist tradition in deaf education. The aim of the authors is to provide insight into various aspects of communicating with the learners such as using spoken language, cued speech, interpreters or sign language. Language teachers can use it as a resource for practical ideas on teaching reading, vocabulary and communication.

\section{Related topics}

additional language learning, bilingual education, sign languages

\section{Note}

1 I follow the tradition of spelling Deaf with a capital " $D$ " whenever referring to Deaf people as members of a linguistic and cultural minority. 


\section{References}

Allen, T.E. (1994) Who are the deaf and hard-of-hearing students leaving high school and entering postsecondary education? Paper submitted to Pelavin Research Institute as part of the project. A Comprehensive Evaluation of the Postsecondary Educational Opportunities for Students who are Deaf or Hard of Hearing. Available from: https://research.gallaudet.edu/AnnualSurvey/whodeaf.php [Accessed 29 May 2019].

Bajkó, Á. and Kontra, E.H. (2008) Deaf EFL learners outside the school system, in Kormos, J. and Kontra, E.H. (eds) Language Learners with Special Needs: An International Perspective. Clevedon: Multilingual Matters. pp. 158-188.

Bedoin, D. (2011) English teachers of deaf and hard-of-hearing students in French schools: Needs, barriers and strategies. European Journal of Special Needs Education. 26(2), pp. 159-175. doi: 10.1080/08856257.2011.563605.

Branson, J. and Miller, D. (1993) Sign language, the deaf and the epistemic violence of mainstreaming. Language and Education. 7, pp. 21-41.

Conrad, R. (1979) The Deaf School Child. London: Harper Row.

Darroch, K. (2013) Interpreting for deaf students in FL classes. AVLC News. 29(2), pp. 1-6. Available from: www.avlic.ca/sites/default/files/docs/AVLICNewsS-F2013InterpretinginForeignLanguageClasses .pdf [Accessed 29 May 2019].

Domagała-Zyśk, E. (ed) (2013) English as a Foreign Language for the Deaf and Hard of Hearing in Europe: State of the Art and Future Challenges. Lublin: Wydawnictwo KUL.

Domagała-Zyśk, E. and Kontra, E.H. (eds) (2016) English as a Foreign Language for Deaf and Hard of Hearing Persons: Challenges and Strategies. Newcastle upon Tyne: Cambridge Scholars Publishing.

Eitzen, B. and Bartz, M. (2016) Chancen und Grenzen des Einsatzes von American Sign Language (ASL) im Englischunterricht in der Sekundarstufe II: Erfahrungen und wissenschaftliche Erkenntnisse. HÖRPÄD. 5, pp. 193-198.

European Agency for Development in Special Needs Education. (2013) Organisation of Provision to Support Inclusive Education: Literature Review. Odense: European Agency for Development in Special Needs Education. Available from: www.european-agency.org/sites/default/files/organisationof-provision-to-support-inclusive-education-2013-literature-review_Organisation-of-ProvisionLiterature-Review.pdf [Accessed 09 June 2019].

Evans, C.J. and Seifert, K.L. (2000) Fostering the development of ESL/ASL bilinguals. TESL Canada Journal/Revue TESL du Canada. 18(1), pp. 1-16.

Falkowska, J. (2016) Monolingual, bilingual, trilingual? Using different languages in an EFL class for the D/deaf, in Domagala-Zysk, E. and Kontra, E.H. (eds) English as a Foreign Language for Deaf and Hard of Hearing Persons: Challenges and Strategies. Newcastle upon Tyne: Cambridge Scholars Publishing. pp. 55-72.

Fleming, J. (2008) How should we teach deaf learners? Teaching English as a written language to deaf European students, in Kellett Bidoli, C.J. and Ochse, E. (eds) English in International Deaf Communication. Bern: Peter Lang. pp. 123-153.

Gregory, S. (1996) Bilingualism and the Education of Deaf Children. Paper presented at Bilingualism and the Education of Deaf Children: Advances in Practice, a Conference held at the University of Leeds, 29 June. pp. 18-30. Available from: www.leeds.ac.uk/educol/documents/000000306.doc [Accessed 29 May 2019].

Gulati, B. (2016) Visualizing - the most effective way to teach ESL to Deaf and hard of hearing, in Domagala-Zysk, E. and Kontra, E.H. (eds) English as a Foreign Language for Deaf and Hard of Hearing Persons: Challenges and Strategies. Newcastle upon Tyne: Cambridge Scholars Publishing. pp. 153-167.

Holcomb, T. and Peyton, J.K. (1992) ESL literacy for a linguistic minority: The Deaf experience. ERIC Digest ED353861. Available from: www.ericdigests.org/1993/deaf.htm [Accessed 29 May 2019].

Humphries, T., Kushalnagar, R., Mathur, G., Napoli, D.J., Padden, C., Rathmann, C. and Smith, S. (2013) The right to language. Journal of Law, Medicine \& Ethics. 41(4), pp. 872-884. Available from: www. ncbi.nlm.nih.gov/pmc/articles/PMC4117351/ [Accessed 05 June 2019]. 
Janáková, D. (2008) “Time to share.” Practical strategies for teaching English to Czech deaf students, in Janáková, D. (ed) Teaching English to Deaf and Hard-of-Hearing Students at Secondary and Tertiary Levels of Education in the Czech Republic. 2nd ed. Prague: VIP Books. pp. 59-64.

Jokinen, M. (2000) The linguistic human rights of sign language users, in Phillipson, R. (ed) Rights to Language: Equity, Power and Education. Mahwah, NJ: Lawrence Erlbaum. pp. 203-213.

Kellett Bidoli, C.J. and Ochse, E. (eds) (2008) English in International Deaf Communication. Bern: Peter Lang.

Knight, P. (1998) Deafness and disability, in Gregory, S., Knight, P., McCracken, W., Powers, S. and Watson, L. (eds) Issues in Deaf Education. Milton Park, Abingdon: David Fulton. pp. 215-224.

Knoors, H. and Marschark, M. (2012) Language planning for the 21st century: Revisiting bilingual language policy for deaf children. Journal of Deaf Studies and Deaf Education. 17(3), pp. 295-305.

Knoors, H., Tang, G. and Marschark, M. (2014) Bilingualism and bilingual deaf education: Time to take stock, in Marschark, M., Tang, G. and Knoors, H. (eds) Bilingualism and Bilingual Deaf Education. New York: Oxford University Press. pp. 1-20.

Kontra, E.H. (2013) Language learning against the odds: Retrospective accounts by four Deaf adults, in Domagala-Zysk, E. (ed) English as a Foreign Language for Deaf and Hard of Hearing Persons in Europe: State of the Art and Future Challenges. Lublin: Wydawnictwo KUL. pp. 93-111.

Kontráné Hegybíró, E. (2010) Nyelvtanulás két kézzel: A jelnyelv szerepe a siketek idegennyelvtanulásában [Language Learning by Two Hands: The Role of Sign Language in the Foreign Language Learning of the Deaf]. Budapest: Eötvös Kiadó.

Krisanova, G.V. (2008) Practical strategies used for teaching English to deaf students at Bauman Moscow State Technical University, in Janáková, D. (ed) Teaching English to Deaf and Hard-of-Hearing Students at Secondary and Tertiary Levels of Education in the Czech Republic. 2nd ed. Prague: VIP Books. pp. 142-150.

Ladd, P. (2003) Understanding Deaf Culture: In Search of Deafhood. Clevedon: Multilingual Matters.

Lane, H., Hoffmeister, R. and Bahan, B. (1996) A Journey into the Deaf - World. San Diego, CA: Dawn Sign Press.

Lang, H.G. (2002) Higher education for deaf students: Research priorities in the new millennium. Journal of Deaf Studies and Deaf Education. 7(4), pp. 267-280.

Maher, J. (1996) Seeing Language in Sign. The Work of William C. Stokoe. Washington, DC: Gallaudet University Press.

Marschark, M. and Lee, C.M. (2014) Navigating two languages in the classroom, in Marschark, M., Tang, G. and Knoors, H. (eds) Bilingualism and Bilingual Deaf Education. New York: Oxford University Press. pp. 213-241.

Marschark, M. and Spencer, E. (2009) Evidence of Best Practice Models and Outcomes in the Education of Deaf and Hard-of-Hearing Children: An International Review. Trim, Ireland: National Council for Special Education.

Mole, J., McCall, H. and Vale, M. (2008) Deaf and Multilingual: A Practical Guide to Teaching and Supporting Deaf Learners in Foreign Language Classes. Norbury, Shropshire: Direct Learn Services.

Moores, D.F. (2010) The history of language and communication issues in deaf education, in Marschark, M. and Spencer, P.E. (eds) The Oxford Handbook of Deaf Studies, Language and Education. Oxford: Oxford University Press. pp. 17-29.

Muzsnai, I. (1999) The recognition of sign language: A threat or a way to a solution? in Kontra, M., Phillipson, R., Skutnabb-Kangas, T. and Várady, T. (eds) Language: A Right and a Resource. Budapest: CEU Press. pp. 279-296.

Pickersgill, M. (1998) Bilingualism: Current policy and practice, in Gregory, S., Knight, P., McCracken, W., Powers, S. and Watson, L. (eds) Issues in Deaf Education. Abingdon: David Fulton. pp. 88-97.

Plaza-Pust, C. (2014) Language development and language interaction in sign bilingual acquisition, in Marschark, M., Tang, G. and Knoors, H. (eds) Bilingualism and Bilingual Deaf Education. New York: Oxford University Press. pp. 23-53.

Pritchard, P. (2013) Teaching of English to deaf and severely hard-of-hearing pupils in Norway, in Domagała-Zyśk, E. (ed) English as a Foreign Language for the Deaf and Hard of Hearing in Europe: State of the Art and Future Challenges. Lublin: Wydawnictwo KUL. pp. 113-134. 
Pritchard, P. (2016) Experiences in teaching English to deaf and severely hard-of-hearing pupils in Norway, in Domagala-Zysk, E. and Kontra, E.H. (eds) English as a Foreign Language for Deaf and Hard-of-Hearing Persons: Challenges and Strategies. Newcastle upon Tyne: Cambridge Scholars Publishing. pp. 41-54.

Quay, S. (2005) Education reforms and English teaching for the Deaf in Japan. Deafness and Education International. 7(3), pp. 139-153.

Quinto-Pozos, D. (2002) Interpreting for foreign language courses: The case of Spanish. RID Journal of Interpretation, pp. 93-110.

Skutnabb-Kangas, T. (2008) Bilingual education and sign language as the mother tongue of deaf children, in Kellett Bidoli, C.J. and Ochse, E. (eds) English in International Deaf Communication. Bern: Peter Lang. pp. 75-94.

Stokoe, W.C. (1960) Sign Language Structure: An Outline of the Visual Communication System of the American Deaf. Studies in Linguistics Occasional Paper 8. Buffalo, NY: University of Buffalo.

Stoppok, A. (2010) The early learning of English as a foreign language by hearing impaired children in special needs schools. Available from: https://pdfs.semanticscholar.org/9157/52f85b44e4c966ef6751 3195cca1c07193be.pdf [Accessed 29 May 2019].

Svartholm, K. (2008) The written Swedish of deaf children: A foundation for EFL, in Kellett Bidoli, C.J. and Ochse, E. (eds) English in International Deaf Communication. Bern: Peter Lang. pp. 211-249.

Svartholm, K. (2010) Bilingual education for deaf children in Sweden. International Journal of Bilingual Education and Bilingualism. 13(2), pp. 159-174. doi: 10.1080/13670050903474077.

Svartholm, K. (2014) 35 years of bilingual deaf education - and then? Educar em Revista. 30(n. especial 2), pp. 33-50. Available from: https://revistas.ufpr.br/educar/article/view/37227/23122 [Accessed 09 June 2019].

Swanwick, R. (1998) The teaching and learning of literacy within a sign bilingual approach, in Gregory, S., Knight, P., McCracken, W., Powers, S. and Watson, L. (eds) Issues in Deaf Education. Abingdon: David Fulton. pp. 111-118.

Swanwick, R. (2016) Deaf children's bimodal bilingualism and education. Language Teaching. 49, pp. 1-34. doi: 10.1017/S0261444815000348.

Szabó, M.H. (1999) Magyar siketek magyar nyelvi kompetenciájának vizsgálata [An analysis of the Hungarian language competence of Hungarian deaf persons]. Medicina \& Linguistica. V, pp. 87-97.

UNESCO. (1994) The Salamanca Statement and Framework for Action on Special Needs Education. Salamanca, Spain: UNESCO and Ministry of Education and Science, Spain. Available from: www. unesco.org/education/pdf/SALAMA_E.PDF [Accessed 29 May 2019].

United Nations. (2007) Convention on the Rights of Persons with Disabilities. Available from: www. un.org/disabilities/convention/convention full.shtml [Accessed 29 May 2019].

Wauters, L.N., van Bon, W.H.J. and Tellings, A.E.J.M. (2006) Reading comprehension of Dutch deaf children. Reading and Writing. 19, pp. 49-76.

WFD. (2018) Human Rights of the Deaf - WFD [online]. Available from: http://wfdeaf.org/our-work/ human-rights-of-the-deaf/ [Accessed 29 May 2019]. 


\title{
Sign language interpreting
}

\author{
Christopher Stone and Jeremy L. Brunson
}

\section{Introduction}

In the United States (and elsewhere), there is a designation for sign language interpreters who work in primary and secondary schools; they are referred to as educational interpreters. Although there are other types of interpreting that occur within a school such as trade, postsecondary and graduate, and seminar, these settings are not included in the definition of educational interpreting. The reason for this is simple: children. The not unreasonable assumption is that children (i.e. students in this setting) require a different type of interpreter than adults in a similar setting (Winston 1990).

\section{Historical perspectives}

Through education culture is transmitted and reinforced (Bourdieu 1984) with residential schools (for the deaf) providing this type of environment for deaf children in both the North America, Europe, and some parts of Africa. These are boarding schools, often state-funded, specifically for deaf children from as young as preschool (from three years of age) through high school (up to 18 years of age). Almost every state and province in the United States and Canada funded at least one "school for the deaf" between 1817, the year the first public school for deaf children was founded, and 1980 (Gannon 1981 cited in Padden and Humphries 1988). Residential schools also existed throughout Europe often predating 1817 with one of the earliest schools for the deaf being the Braidwood school established in 1760 (Stone and Woll 2008). The development of the residential schools for deaf children, modelled after the asylums of the time, created a place for deaf children to be around other deaf people (teachers and other staff). These schools often were immersive signing environments (Braidwood using British Sign Language, the Paris School using French Sign Language, etc.) and enabled the development of a sense of identity separate from the one prescribed by society, i.e. to become Deaf. Within these contexts very little is said of the need for interpreters or interpreting provision presumably because these were bilingual schools using the national sign language and teaching literacy in the national language. 
Many deaf adults in the United States who attended school before the Rehabilitation of Act of 1973 and All Handicapped Children Act (EHA) of 1975, which Congress changed to Individuals with Disabilities Act, PL 24-142 (IDEA) in 1990, were likely to attend a residential programme which were American Sign Language-medium schools. The IDEA allowed students with disabilities free and public education (FAPE) and to learn in the least restricted environment (LRE), i.e. be mainstreamed under the notion of inclusive education (see Pittman and Huefner 2001 for an overview of legal decisions regarding FAPE). For some this would also give them greater access to a wider range of academic subjects than might be taught in small residential schools for deaf children.

To accomplish FAPE, students are provided with an Individual Education Plan (IEP) required by the IDEA. Deaf people fall under the dual category of being seen as both disabled due to the impairment of not being able to hear, and as a language minority because the face-to-face community language (normally a national sign language although there are minority sign languages such as Langue des signes Québécois in Quebec, Canada). Under disability legislation the IEP laid out the accommodations to which the subject of the IEP was entitled; for deaf children this often included the provision of a sign language interpreter, or sign language interpreting services, although provided under the notion of access rather than linguistic identity (Murray et al. 2018).

Although residential (sign language community) schools still exist, their enrolment numbers have dropped. In Europe this was in part because of oralists (i.e. those wanting to teach deaf children to speak and speech-read rather than use a natural signed language) but also for financial reasons (Baynton 1996; Branson and Miller 2002).

Day programmes allowed deaf students to be taught with their peers without the additional expense of an overnight stay; students would travel back to their homes every evening. These 'day' schools might still be schools where a signed language was used (e.g. Victoria School for the Deaf, in Melbourne Australia, where Australian Sign Language or Auslan was and is still the language of instruction).

In the United States, the passing of Civil Rights legislation moved deaf students from the de facto segregation of residential schools and day schools to mainstreaming. It is estimated that over $75 \%$ of deaf children in the United States are in mainstream classes (Marshark et al. 2005). The mainstreaming programmes, which accommodate deaf children with a sign language interpreter, often result in socially isolated deaf children with much of the classroom discourse being between deaf student and interpreter (Shaw and Jamieson 1997). It has also not resulted in better educational achievements for deaf children (Power 1999; Kurz et al. 2015).

Byran and Emery (2014, p. 48) suggest that "the law affords privilege to Deaf people who conform to a hearing construct of who they should be", as such the aim is to have deaf children not be deaf but hearing children who cannot hear, i.e. trying to ensure deaf children do not become Deaf children and adults. One of the arguments for integrated education (mainstreaming) was "that deaf children raised among hearing peers will be figuratively if not actually "normal"' (Van Cleve 1993, p. 344). Therefore, mainstreaming was and is a way to construct the deaf child as not deaf and follows an assimilation agenda that many smaller and/or less privileged language communities have experience (for a post-colonial analysis of this for deaf people see Ladd 2003).

\section{Interpreters in the classroom}

Sign language interpreters who work in educational settings (be that primary, secondary or tertiary) are often in an unenviable position, irrespective of their title, as the role of the educational 
interpreter is multifaceted and includes more than language work (see Figure 22.1). Furthermore, the students with whom they work may not always agree on the interpreter's role and function (Kurz and Langer 2004), and we will show neither does the education system. The confusion about the interpreters' roles and functions may be by design. Interpreters in this setting are often supervised and have job descriptions written by administrators, who are often not interpreters (Jones et al. 1997).

Administrators may know of the codes of professional conduct but often have a different understanding of the work of the sign language interpreter. This is because of their understanding of the classroom and who is in it. The classroom is occupied by students, teachers, and teachers' aids. The interpreter has to fit into one of these categories.

Jones et al. (1997) surveyed 222 educational (K-12) interpreters in three Midwest states: Kansas, Missouri, and Nebraska. They wanted to identify the characteristics and responsibilities of these interpreters. In their study they found that most of the respondents to the survey identified as female, earned approximately $\$ 10$ an hour, and on average did not hold a college degree. With slight variation among states, they also found that interpreters in the study were expected to do non-interpreting duties. For example, the interpreters reported being responsible for tutoring, teaching sign language, correcting assignments, and being a teacher's assistant. The amount of time interpreters devoted to the different non-interpreting tasks varied between the respondents. The authors conclude with a series of recommendations. These recommendations include oversight entities developing guidelines, model standards, and that all interpreters in this setting be required to hold a certification.

Estimates suggest that most interpreters in public schools (in primary and secondary schools also known as $\mathrm{K}-12$, i.e. kindergarten to year 12) in the United States do not have national certification/accreditation, which suggests they lack the entry-level skills to interpret effectively in any situation (Schick et al. 1999; Monikowski 2004; Schick et al. 2006).

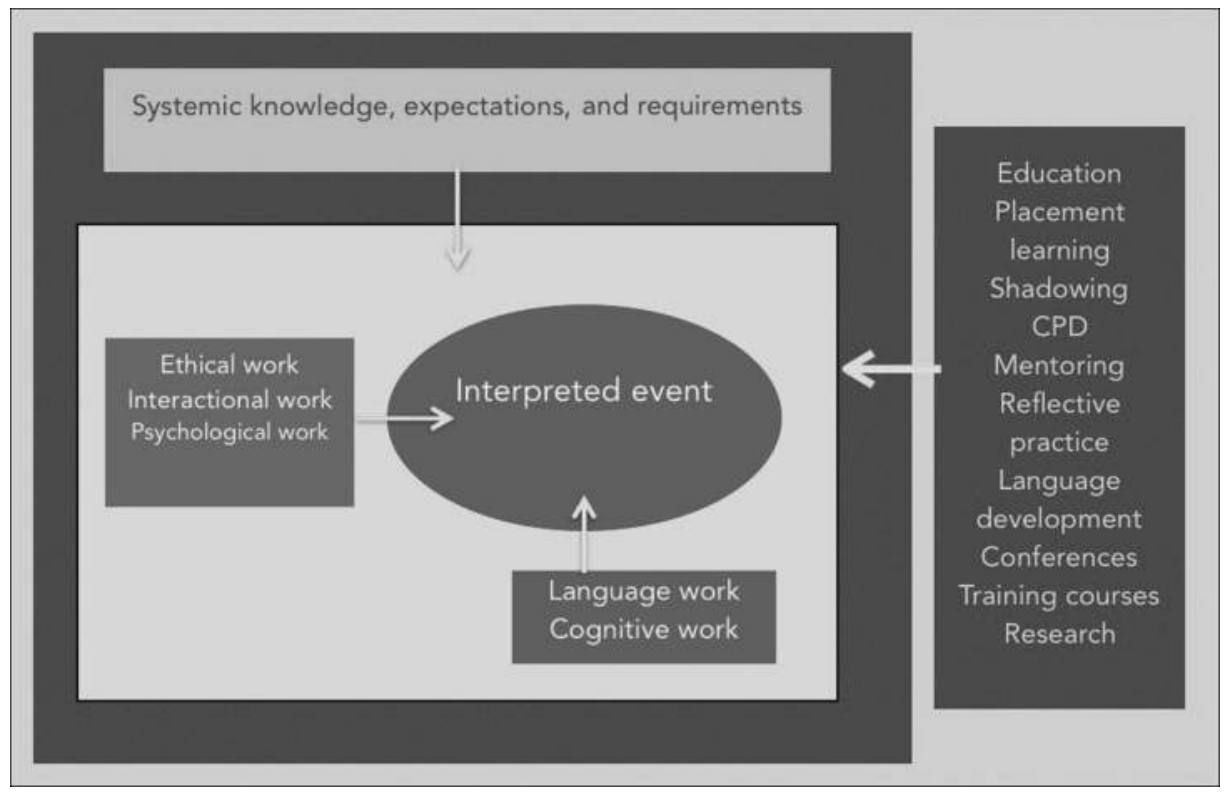

Figure 22.1 Systematic view of interpreting. 
The situation for educational interpreting in the UK is similar to the US. Since the 1980s this work has been undertaken by trained communication support workers (CSWs) who were initially trained to work with deaf sign language users to gain vocational qualifications but were not trained interpreters and did not have the required language fluency in British Sign Language to be able to effectively interpret according to the occupational standards at the time. This role was then extended to educational interpreting in both primary, secondary, and tertiary settings with CSWs expected to "note-take, to be a teaching aide, and to provide all kinds of support to the students with whom they work, in addition to providing a translation and interpreting service" (Harrington 2000, p. 93). The training did not allow the CSWs to become specialists in any single skill much less become fluent in British Sign Language and in subjects for which the language had not necessarily been used before.

Most of those fulfilling the interpreter function spend more time working in a signed language which for most sign language interpreting professionals is their second language (Harrington 2000) often learned as an adult with no instruction in their early education, and therefore no model of child/adolescent directed language within an educational setting. Similarly, within tertiary settings the interpreters may also "encounter particular issues because of the type of subject matter they are expected to deal with" (Harrington 2000, p. 79).

Hayes (1992) and Jones (1993) found that interpreters working in K-12 settings felt unprepared for the work they were doing, particularly about their roles and responsibilities. "Many interpreters felt they should have been given more information regarding their roles and responsibilities" (Hayes 1992, p. 19). Furthermore, Russell and Macleod (2009, p. 130) identify that Canadian deaf students are more likely to report social isolation, nonparticipation and academic exclusion hence educational interpreters provide the "illusion of inclusion". Much of this is to do with lack of preparation, education, and representation (Jones et al. 1997).

One unique feature of $\mathrm{K}-12$ interpreting is that $\mathrm{K}-12$ interpreters often operate in a contested space, i.e. for those who see the residential schools as beneficial and necessary venues for cultural transmission (Parasnis 1996) enabling the development of a Deaf identity, mainstream programmes are often not welcome. The $\mathrm{K}-12$ interpreter becomes the face of forced assimilation with the paradigm being that deaf students will just be hearing children who cannot hear. While all interpreting is embedded in politics (Brunson 2018), the political milieu in which $\mathrm{K}-12$ interpreters find themselves is different in that by their mere presence in this setting they are seen as having taken a side in the mainstream-residential school debate. And the recent UN conventional on the rights of people with disabilities does suggest that sign language-medium education could be an exercisable human right (Murray et al. 2018). These politics, however, are not the focus of this chapter.

\section{Different aspects of the interpreting work}

As part of what we would call the language work of interpreting, interpreters are often in positions, through "interactional power" (Mason and Ren 2014, p. 120) to depict the deaf person in a way that has long-lasting systemic effects significantly contributing to how the deaf person is seen or characterized by the system. Often, however, interpreters focus solely on the immediate exchange, this in and of itself is not surprising as within interpreter education, testing systems and codes of ethics much of the focus on ensuring quality relies on notions of linguistic and cultural equivalence in the moment. This is also the initial focus of interpreter training and the consequences beyond the moment are difficult to conceive of without professional experience. 
Interpreters during public service/community interpreter-mediated interaction consider: the context of the interaction (Setton 2006); the language used by the participants to each other (Mason 2006); and the cultural context of those utterances with the perceived intent of the utterances. Even discussions regarding discourse level decisions look at suprasentential decisions of interpreters within interpreter-mediated interactions as: speech as text, or speech as activity (Wadensjö 1998); the distribution of responsibility for understanding as between participants (Roy 2000; Wadensjö 1998); and their immediate, local consequences (see Dean and Pollard 2011).

Throughout this chapter we provide a discussion of the current practice and some of the research about educational interpreting. We conclude by discussing some of the gaps in the current examinations of educational interpreting and recommend a future direction for research using data from interviews with educational interpreters and an examination of an IEP document.

\section{Research approaches and key findings}

Educational interpreting is one of the areas that has been under exploration with most of the empirical studies being undertaken in the United States. There have been a number of papers published over the years that report studies on educational interpreting within a sociological (Smith 2013), anthropological (De Wit 2011; Fitzmaurice 2017), linguistic (Schick et al. 2006; Russell and Winston 2014), and educational tradition (Kurz and Langer 2004; Winston 2004). There have also been a number of position papers and theoretical discussions of educational interpreting (e.g. Seal 2004; Russell and Macleod 2009; ASLIA 2011). A majority of the studies focus on interpreters and their practice. There are a few that provide student experiences, and administrators' and teachers' perception. Here we discuss some of these studies and explain how they can inform educational interpreting.

\section{Effective language work}

Schick et al. (2006) provide an analysis of the results of the Educational Interpreters Performance Assessment (EIPA) for interpreters who took it between 2002 and 2004. The EIPA is an assessment that is used in the United States to credential/accredit sign language interpreters in $\mathrm{K}-12$ settings. Interpreters are given a score $1-5$ based on the various domains tested. The national association of sign languages interpreters in the United States - The Registry of Interpreters for the Deaf (RID) - recognizes interpreters with a 4.0 and higher certified as being eligible for national accreditation. Based on Schick et al. (2006, p. 17) analysis, they concluded that "It is likely that many students access their education through an interpreter who cannot provide full access". They also point to the current interpreter training structure within the United States that allows for a short duration of focused education and training on the important task of educational interpreting as part of the problem. Not only is the training short, they argue, but many interpreter training programmes "provide limited exposure to training related to children" (p. 17). This focuses on child-directed language work rather than broader discourse work, such as the consequences of being a cog in the education machine, but there has been a more recent study identifying the types of meta-interpreting awareness needed to better provide effective access which will now be described.

Betsy Winston and Debra Russell have been long-time researchers and teachers of interpreters. In Russell and Winston (2014) the two of them explored the relationship between reporting processes and quality of interpretation. They used think aloud protocols (TAP) and 
stimulated recall (SR) to explore the strategies educational interpreters used to prepare for and deliver an interpretation. They were specifically interested in identifying "where experienced interpreters focus their attention when dealing with the demands of classroom discourse and interaction" (p. 103) to see if that facilitated greater access of deaf learners in interpretermediated education settings.

For their study they included 12 interpreters from Western Canada; ten females and two males with at least three years' experience in classroom interpreting. The results of their study indicate that interpreters need to use higher order thinking skills (Bloom 1956). In fact, those interpreters who do not engage in the higher level analysis "are either inconsistently effective or not effective ... reflecting a focus on lexical based interpreting" (Bloom 1956, p. 118). When interpreters are in the classroom their aim must move beyond the lexical level of the message and take into consideration the aim of the speaker. Since educational interpreters are often interpreting for teachers, they must have an understanding and consider the educational goals of that teacher, categorized as teacher intent informs interpreting (TII) in their research. When one does not take this into consideration the results can be an ineffective interpretation with a sole focus on linguistic issues that inform interpreting (or LII).

Of the 12 participants in the study, three were judged as expert. In both the TAP and the SR it was clear they were aware of the intent of the teachers at a semantic level; this in turn allows for a longer processing time (8-12 seconds) culminating in greater levels of semantic accuracy. They were also aware of the goals of the teacher's utterances including teacher intent (i.e. the purpose behind the words), classroom management strategies, and student engagement. The interpreters who were least effective were less able to engage in the TAP and SR with both less said, and less critical thinking demonstrated. Their data suggests that when training interpreters to work within educational settings interpreters we should ensure that we "move their preparation strategies to a more refined level by focusing on higher order thinking strategies" (p. 120). This could require a longer duration of training within the specific domain, potentially establishing this as a specialism in the sign language interpreting profession.

\section{Educational interpreter as a barrier to education}

Twenty years after Jones et al. (1997) published their study, Fitzmaurice (2017) observed and interviewed three $\mathrm{K}-12$ interpreters who were uncredentialled, worked in rural area, and had worked in the school district for a minimum of five years. Applying the concept of rolespace developed by Llewellyn-Jones and Lee (2014), Fitzmaurice concluded that these interpreters were able to carry out (effectively or otherwise) their interpreting functions without any oversight. These interpreters were often operating under the "trial and error" method, to enact different roles within the educational setting including those which would have a direct impact on the education of the students with whom they were working. Here it can be seen that the current employment of interpreters in the US is much like the employment of CSWs in the UK. The role of the interpreter being undertaken by those without qualifications and with varying levels of pre-employment training other than learning an appropriate sign language to a moderate degree of fluency (American Sign Language or British Sign Language in these cases).

Smith (2013) agrees with points made by Winston (2004) and others that interpreters can limit interaction and indeed can lead to a student feeling isolated; this focus was broader than her narrow focus on access to the curriculum. In her ethnographic study she observed and videotaped educational interpreters and conducted interviews. Her examination focused on strategies for interpreters to promote inclusion and access to academic information. 
What Smith (2013, p. 172) concludes is that "Deaf and hard of hearing student will both be disadvantaged by and benefit from the interpreter-mediated education they receive". This is a response to the abundant criticism of having an interpreter in the classroom. However, often these criticisms take different standpoints. From a systemic perspective we must consider what is meant by education, is the sole goal to achieve academically or are there broader pedagogical goals such as socialization, friendship group formation, identity development, etc.?

\section{Deaf persons}

De Wit (2011) takes a different starting place. Rather than looking at the work of interpreters, she explores the experience of those with whom they work: deaf students. In particular she sets out to understand the quality of life of those who are in inclusive education with an interpreter. Using survey data of two groups - current students and graduated students, de Wit provides a view of deaf students' experience.

She surveyed 70 Dutch users of the Sign Language of the Netherlands who were in secondary or tertiary education. The respondents included those who were currently in a secondary or tertiary education setting (33) using an interpreter and those who had used an interpreter during their secondary and tertiary education experience (37). De Witt looked at five domains in her analysis.

An important finding is that deaf people (who were reflexively discussing their experiences) were mostly satisfied with their interpreters. She hypothesizes that the reason for this might be that because these students were relying on retrospection, they may be remembering it more positively as they can also consider a longer view of their interpreter-mediated education on their lives. We propose another explanation. Deaf people are generally becoming more savvy consumers. They are able to access a variety of events in daily life through an interpreter. The unqualified interpreter is easy to identify. Students are feeling more emboldened to speak up for their right to access. Therefore, students who are currently working with interpreters may have a clearer understanding of their rights and needs. This means they are likely evaluating their experiences based on a whole host of other criteria.

\section{Pedagogic approaches and methods}

To some extent, interpreting within an educational context, i.e. the provision of mainstream education to deaf people by a mainstream teacher mediated by an interpreter in the classroom, is somewhat unique to deaf communities. However, at a systemic level there are several considerations, some of which are general to the education system and some of which are specific to deaf students, i.e. the presence of the other, within the education system.

We can ask questions such as, did an academic education occur? Did the deaf students perform on par with their hearing peers? And then questions specific to these deaf students and their otherness could be: What accommodations (this term itself stems from the Individuals with Disabilities Education Act, IDEA, and a disability lens) were provided for these deaf students? Are educational interpreters used in lieu of bilingual teachers? Does the system expect the interpreter to be a co-teacher?

Further questions one can consider to be the systemic expectation of interested parties, i.e. teachers, students, interpreters, parents, administrators, school boards, e.g. What roles do individuals undertake in the system? Who is responsible for academic educational outcomes, the teachers? How are these outcomes measured? This leads us to the identification of the discourse that coordinates both the posing and answering of the subset of questions the system 
is required to undertake to accommodate otherness. All of these moments are potential forks in the road, that is, they require a decision to be made and an action to take place that changes how the student is characterized and/or succeeds in the system.

In the next section we will outline the nature of the IEP and discuss a small research project exploring the role of the IEP in facilitating 'access' to education for deaf students. We will also draw the reader's attention to the role the IEP plays in establishing a discourse that places legal obligations on educational interpreters to provide specific accommodations for the deaf student described in the IEP and how, in many ways, it defines the nature of educational interpreting work.

\section{The IEP and its role in educational interpreter organization}

The actions required to handle the forks in the road, or decisions on access mentioned previously, are not left to the interpreter in the primary or secondary educational setting nor are they left to the deaf students with whom the interpreter is working. Rather these decisions are dictated from afar and are captured in the Individual Education Plan (IEP). This document requires a great deal of paperwork. The IEP is required by the Individual with Disability Education Act (IDEA) and it must be reauthorized every five years (thus activating this law as a text that coordinates 'accessible' education).

The overall aim of the IEP process is to determine and document (or entextualize) a student's current educational status, i.e., present level of performance, define what services are necessary, e.g. interpreting or extended test-taking time, and provide a rubric for measuring progress (Gartin and Murdick 2005). The IEP text lays out the various aspects seen as relevant by the "team" of professionals who puts it together (see Figure 22.2). The team consists of the Local Education Agency (LEA) representative, who is usually someone from the school district. This person is responsible for making sure those items requested in the IEP text are available within the district. For example, if the IEP team were to include one-on-one instruction in the IEP text, the district's representative would be available to authorize it or to explain why this was not available.

The team also includes the special education teacher, regular education teacher, parent(s), and student. In some cases, other services providers such as interpreters can be involved with the team, although it is questionable whether this is appropriate as the literature suggests that these are not trained/qualified (Schick et al. 2006). Each professional member of the team reproduces a particular discourse in the IEP text. That is, the LEA uses the discourse of the school district, the special education teacher and the "regular education teacher" both use versions of accommodation and benchmark discourses, and the interpreter, if participating, will use the discourse of linguistic access, although as seen previously they might also appropriate other professional discourses.

Part of the performativity of interpreting is using the discourse of the setting in which one is working to ensure that participants are seen as authentic (Feyne 2015). When the interpreter chooses for her actions to be coordinated by the IEP, she then must make herself familiar with the various discourses being used and begin to reproduce them for systemic credibility. Typically, the interpreter will reproduce the discourse in their language work, however in this context they reproduce these discourses to other professionals when performing being an interpreter (rather than performing an interpretation). Again, the question of whether interpreters have received sufficient training to engage in the discourse is questionable.

As the literature suggests, over the last two decades the examination of educational interpreting has traditionally focused on two areas: role and skill. The literature suggests that interpreters in this setting may be operating without any credentials and are often less than qualified 
The Individualized Education Program (IEP) is meant to support the positive process and team approach. The IEP is a working document that outlines the student's vision for the future, strengths and needs. The IEP is not written in isolation. The intent of an IEP is to bring together a team of people who understand and support the student in order to come to consensus on a plan and an appropriate and effective education for the student. No two teams are alike and each team will arrive at different answers, ideas and supports and services to address the student's unique needs. The student and his/ her family members are vital participants, as well as teachers, specialists, outside service providers, and the principal. When all team members are present, the valuable information shared supports the development of a rich student profile and education program.

\section{IEP TEAM PARTICIPANTS}

TThe signatures below indicate the individuals who are present to participate in the development of this IEP and the placement decision; it does not authorize consent. NOTE: You, as the parent/guardian, have the right, to invite to the IEP meeting, other individuals who have knowledge or special expertise regarding your child. If you have questions about the special education process, please contact me.

SIGNATURE

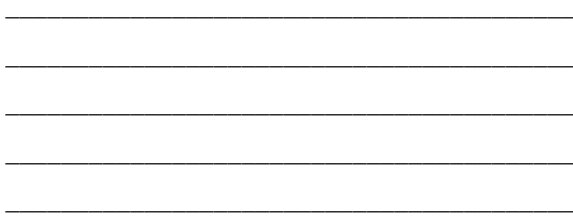

\section{RELATIONSHIP}

LEA / Designee

Special Education Teacher

Regular Education Teacher

Parent(s)

Student (If appropriate)
INVITED BY SCHOOL
[] Yes [] No
[] Yes [] No
[] Yes [] No
[] Yes [] No
[] Yes [] No

\section{OTHERS INVITED}

INVITED BY SCHOOL
[ ] Yes [] No
[] Yes [] No
[] Yes [] No

Figure 22.2 Excerpt from an IEP.

to do the work. Despite this, deaf people seem, at least retrospectively, to have a positive view of the interpreters with whom they have worked (De Wit 2011). It also suggests that interpreters who are able and willing to use critical thinking skills are more successful in their interpretation (Russell and Winston 2014). Furthermore, the literature sampled here illustrates that the interpreter has an influence over the education of deaf students (Jones et al. 1997; Kurz et al. 2015) and that mediation if preferred in some contexts (Berge and Ytterhus 2015). Focusing on the language work interpreters do provides a tremendous amount of insight into the complicated nature of interpreting work, including the multimodal nature of sign language interpreting in the classroom (Berge and Thomassen 2016; Berge 2018) and the way access through an interpreter adds additional layers of consideration.

The information provided in the literature is vital, but it only tells part of the story. Another part of the story is a discussion of the systemic influence on the interpreter and by extension the deaf student. Just as in translation studies, interpreting and interpreting studies is beginning to see an "enduring expansion of the frames of research and the elaboration of broader questions which enabled the inclusion of historical perspectives and contextual information" 
(Wolf 2014, p. 8). Therefore, we suggest that researching into educational interpreting must examine larger social processes as well as the everyday of interpreters. Using discussions with interpreters as an example, as we have done here, can point to the remote influences of this type of interpreting.

We propose the model in Figure 22.1 to provide a visual. Figure 22.1 illustrates the various social relations in which the educational interpreter is embedded. Interpreting has always been seen as a social event. Interpreters and interpreter trainers have discussed cultural competency as a required skill of interpreters (see Stone 2009; Mindess 2009). A major discussion within the literature and training, regardless of the setting, has also included an analysis of the interpreter's role (Anderson 1976; Llewellyn-Jones and Lee 2014). As a social event, we must also look towards the social organization that produces an event. This is done by looking for and at the various interactions that surround, encompass, and are otherwise tied to an interpreted moment. This model illustrates the various interactions (where these shapes touch) the process of interpreting is a part of and in which interpreters are engaged while interpreting. These processes are connected via institutional texts. These texts can be seen as "organizing a course of concerted social action" (Smith 1990, p. 121). The interpreting event is part but not the entire picture needing to be explored to understand what is happening in a moment.

The traditional gaze of research into the work of interpreters, begins and remains fixed on the individuals and does not situate actions within systems. These systems, which are often situated extra-locally, have an effect on the immediate (for an analysis of this within VRS settings, see Brunson 2011). By looking beyond the immediate interpreted event, we can begin to identify which structures are activated and organize the immediate interpreted event extralocally; when activated these structures activate other structures. These structures are connected through various texts creating extra-local interaction and coordination. For educational interpreting this organization is often coordinated by a statement of need or an individualized education plan or programme (IEP).

The passing of PL94-142 created a need for a way for schools to document their attempts to accommodate students. In the United States (as in other countries), the IEP is a legal document and lays out which services, e.g. notetaker, interpreter, additional time, etc. a student is to receive and how those services are to be provided, e.g. American Sign Language, Manually Coded English, etc. The IEP is an organizing text of interpreters', teachers' and administrators' work. It is also the "factual" account of a student's abilities and limitations, all of which are endorsed by the IEP team and interpreters are often invited to form part of the team that authors the document.

When we asked an educational interpreter about whether she relies on the IEP, this interpreter uses the IEP as a way to know "what the student needs".

The idea of "shoot[ing] in the dark" is unappealing to most interpreters. She would rather "know" what is needed by reading the IEP, to be better prepared. Of course, it may not be possible for the interpreter to learn from the student about the student's needs. Depending on the student's age, maturity level, ability to articulate their needs, and whether they truly understand their own needs, the interpreter may have to rely on other sources of information about the student. In this way, the IEP is an ideal resource.

Table 22.1 Interview excerpt

1 Oh, absolutely, because I have ... I don't know what they need and I don't want to just 2 shoot in the dark what ... they need and then figure it out later. That would be awful 
As noted earlier the IEP is required by IDEA and it must be reauthorized every five years. The overall aim of the IEP process is to determine the present level of performance, defining what services are necessary, and providing a rubric for measuring progress (Gartin and Murdick 2005). The secondary function of the document is to provide readers (teachers, support workers, interpreters, etc.) who "activate" (Smith 1993) it with an understanding of the subject of the report.

The IEP lays out the various aspects seen as relevant by the "team" of professionals who puts it together. The team (see Figure 22.2) consists of the Local Education Agency (LEA) representative, who is usually someone from the school district. This person is responsible for making sure those items requested in the IEP text, are available within the district. For example, if the IEP Team were to include one-on-one instruction in the IEP text, the district's representative would be available to authorize it or to explain why this was not available.

The parents and the student can participate in the development of the IEP. One of the authors has interpreted several IEP meetings and in each of them, he believes that each person had an equal opportunity to participate in its development. He also notes, however, that there is a power differential that must be recognized. The parent may want something that is wholly different than what the student wants. The professionals may also want something that the student does not want. When these moments come up, it is not surprising that the student is the one who must acquiesce to the desire of the rest of the "team".

Part of the IEP for a student focuses on language development. In regard to a deaf student this typically focuses on their ability to produce ideas visually. In this way, the IEP can also define the performance of language work, i.e. the aspect of interpreting that we feel education and certification focuses upon and so is something that many interpreters will identify as being pertinent to them and their role. However, terms such as "peers", "typically", and "generally" refer us back to a discourse of normalcy as the measuring stick (see Table 22.2). This, as Davis (1995, p. 24) rightly suggests, does not complicate the "way that normalcy is constructed", which once again puts the burden on the deaf student and not the system charged with providing her or him with access.

Remembering that the team does not require an American Sign Language specialist or linguist to be a member (and that under trained educational interpreters are not appropriately qualified to fulfil this role) the accuracy of the statement "expressive language with utterances of 4-8 words" (Lines 3-4) is called into question. American Sign Language is not a visual representation of spoken English; a single sign, with accompanying non-manual markers, is not necessarily isomorphic with a single word. Moreover, who is providing these statistics? Could

Table 22.2 Excerpt from IEP.

1 Student presents as a student who is deaf, and is therefore unable to demonstrate

2 the communication skills of his typically developing age matched peers. He was

3 recently formally reassessed and was observed to have expressive language with

4 utterances of 4-8 words; including many nouns and verbs. He demonstrates

5 conversational skills that are significantly below what is generally seen in children

6 his age, as he tends to use only to sign utterances, and he demonstrates

7 approximately only $50 \%$ accuracy with responding to "wh" questions. He will

8 require continued support through special education services to optimize his

9 communication abilities for ensuring access his academics and social

10 communication opportunities 
it be the teacher who is relying on the interpreter? Is it the interpreter who, based on research, may not be effective as interpreters?

Much like the analysis provided by Smith (1990) of how " $\mathrm{K}$ " is constructed as mentally ill, this section of the IEP text requires the interpreters (and other readers of the IEP text) to accept that those involved with its development are experts. Since we do not get to hear from the student, presumably because of the child's age, we only have access to other people's accounts of the student's ability.

This examination allows us to begin to see the traces of remote influences over the interpreting process. These influences include discourses, professionals, and texts (e.g. IEP).

\section{Conclusions and future directions}

In this chapter we have laid out some of the studies and findings on educational sign language interpreting. We have also provided an example of another way in which studies about (educational) interpreting could occur. This sociological analysis provides a way for interpreters and deaf students to begin to understand their everyday experiences, i.e. interpreter's role, choices, in the context of larger, remote institutional forces, i.e. IEP, professional opinions, and legislative mandates.

Interpreting is not only about interactions between two or more people but between various relations of power that exert influence over the interaction. To rectify this, we suggest that interpreting research should expand its reach beyond the language work. That is, research should examine what social forces and social institutions shape how one interprets. This type of analysis would necessarily include an examination of the dynamics between the parties; but would also examine the setting in which the interpreting occurs, the various processes that led to these parties coming together, and the social institutions in which all these are embedded.

\section{Further reading}

Berge, S. (2018) How sign language interpreters use multimodal actions to coordinate turn-taking in group work between deaf and hearing upper secondary school students. Interpreting. 20(1), pp. 96-125. https://doi.org/10.1075/intp.00004.ber [Accessed 12 March 2019].

This journal article documents how sign language interpreters, which are integral to social inclusion of deaf students in Norway, use multimodal actions (gestures, pauses, gaze, and shifts in body orientation) to facilitate social inclusion.

Kurz, K., Schick, B. and Hauser, P. (2015) Deaf children's science content learning in direct instruction versus interpreted instruction. Journal of Science Education for Students with Disabilities. 18(1), pp. 23-37.

This journal article studies the experience of deaf students in science classes. The focus is on whether deaf and hard-of-hearing students learn different amounts of information when provided with direct instruction rather than interpreter-mediated communication. The authors conclude that learning through a sign language interpreter is more difficult for deaf and hard-of-hearing students. However, they also concluded that native users of American Sign Language, those who have exposure to American Sign Language at home were able to learn more than their non-native counterparts regardless of the method of instruction: direct or interpreted.

Russell, D. and Winston, B. (2014) Tapping into the interpreting process: Using participant reports to inform the interpreting process in educational settings. Translation \& Interpreting. 6(1), pp. 102-127. This journal article reports on a study of cognitive strategies and decisions interpreters make while interpreting in an educational setting. The main aim of the authors is to explore how experienced interpreters differ in their practices from novice interpreters. They conclude that the more experienced 
interpreters were more effective in their interpretation. These interpreters were more likely to use higher ordered thinking and take into consideration a host of sociological, linguistic, and pragmatic factors.

Siisiäinen, L. (2016) Foucault and deaf education in Finland. Nordic Journal of Social Research. 7 [online]. Available from: https://doi.org/10.7577/njsr.2095 [Accessed 12 March 2019].

This journal article explores the theoretical contribution of Michel Foucault to the education of deaf children in Finland. The article focuses on Foucault's more prominent concepts: disciplinary power, surveillance, and normalization. The author suggests that Foucault's analysis fails to consider auditory power which is problematic given that, according to the author, the modern educational system is based.

\section{Related topics}

translators in schools: valuing pupils' linguistic skills, bilingual and biliteracy development programmes, bilingual education, sign languages, bilingual deaf education, translation and social inclusion

\section{References}

Anderson, R.B.W. (1976) Perspectives on the role of the interpreter, in Brislin, R. (ed) Translation: Applications and Research. New York: Gardner Press. pp. 208-228.

Australian Sign Language Interpreters Association (ASLIA). (2011) Guidelines for the Employment of Sign Language Interpreters in Educational Settings [online]. Available from: https://aslia.com.au/wpcontent/uploads/ASLIA-Educational-Interpreting-Guidelines.pdf [Accessed 08 March 2019].

Baynton, D.C. (1996) Forbidden Signs: American Culture and the Campaign against Sign Language. Chicago: The University of Chicago Press.

Berge, S. (2018) How sign language interpreters use multimodal actions to coordinate turn-taking in group work between deaf and hearing upper secondary school students. Interpreting. 20(1), pp. 96-125.

Berge, S. and Thomassen, G. (2016) Visual access in interpreter-mediated learning situations for deaf and hard-of-hearing high school students where an artefact is in use. Journal of Deaf Studies and Deaf Education. 21(2), pp. 187-199.

Berge, S. and Ytterhus, B. (2015) Deaf and hearing high-school students' expectations for the role of educational sign-language interpreter. Society, Health \& Vulnerability [online]. Available from: https:// doi.org/10.3402/shv.v6.28969 [Accessed 12 March 2019].

Bloom, B.S. (1956) Taxonomy of Educational Objectives, Handbook I: The Cognitive Domain. New York: David McKay Co Inc.

Bourdieu, P. (1984) Distinction. London: Routledge.

Branson, J. and Miller, D. (2002) Damned for their Difference: The Cultural Construction of Deaf People as Disabled. Washington, DC: Gallaudet University Press.

Brunson, J. (2011) Video Relay Service Interpreters. Washington, DC: GU Press.

Brunson, J. (2018) Consumers, colleagues, and certifications: Exploring the politics of interpreting, in Stone, C. and Leeson, L. (eds) Interpreting and the Politics of Recognition. London: Routledge. pp. 99-115.

Byran, A. and Emery, S. (2014) The case for deaf legal theory through the lens of deaf gain, in Bauman, H-D.L. and Murray, J.J. (eds) Deaf Gain: Raising the Stakes for Human Diversity. Minneapolis, MN: University of Minnesota Press. pp. 37-62.

Davis, L.J. (1995) Enforcing Normalcy: Disability, Deafness and the Body. London: Verso.

De Wit, M. (2011) A Sign Language Interpreter in Inclusive Education: The View of Deaf Persons on Their Quality of Life. Unpublished MA thesis, Heriot Watt University [online]. Available from: www.academia.edu/3520438/Wit_M._de_2011_.A_Sign_Language_Interpreter_in_Inclusive Education_The_View_of_Deaf_Persons_on_their_Quality_of_Life_MA_Thesis_Edinburgh_ Heriot_Watt_University [Accessed 25 March 2019]. 
Dean, R. and Pollard, B. (2011) Context-based ethical reasoning in interpreting: A demand control schema perspective. Interpreter and Translator Trainer. 5(1), pp. 155-182.

Feyne, S. (2015) Variation in perception of the identity of interpreted Deaf, in Stone, C. and Leeson, L. (eds) Interpreting and the Politics of Recognition. London: Routledge. pp. 157-176.

Fitzmaurice, S. (2017) Unregulated autonomy: Uncredentialled educational interpreters in rural schools. American Annals of the Deaf. 162(3), pp. 253-264.

Gartin, B.C. and Murdick, N.L. (2005) IDEA 2004: The IEP. Remedial and Special Education. 26(6), pp. 327-331.

Harrington, F.J. (2000) The rise, fall and re-invention of the communicator: Re-defining roles and responsibilities in educational interpreting, in Harrington, F.J. and Turner, G.H. (eds) Interpreting Interpreting. Coleford: Douglas McLean. pp. 89-102.

Hayes, P.L. (1992). Educational interpreters for deaf students: Their responsibilities, problems, and concerns. Journal of Interpretation, 5(1), pp. 2-24.

Jones, B.E. (1993) Responsibilities of educational sign language interpreters in K-12 public schools in Kansas, Missouri, and Nebraska. PhD dissertation, University of Kansas.

Jones, B.E., Clark, G.M. and Soltz, D.F. (1997) Characteristics and practices of Sign Language interpreters in inclusive education program. Exceptional Children. 63(2), pp. 257-268.

Kurz, K.B. and Langer, E.C. (2004) Student perspectives on educational interpreting: Twenty deaf and hard of hearing students offer insights and suggestions, in Winston, E.A. (ed) Educational Interpreting: How It Can Succeed. Washington, DC: Gallaudet University. pp. 9-47.

Kurz, K.B., Schick, B. and Hauser, P. (2015) Deaf children's science content learning in direct instruction versus interpreted instruction. Journal of Science Education for Students with Disabilities. 18(1), pp. 23-37.

Ladd, P. (2003) Understanding Deaf Culture: In Search of Deafhood. Clevedon: Multilingual Matters.

Llewellyn-Jones, P. and Lee, R. (2014) Redefining the Role of the Community Interpreter: The Concept of Role-space. Carlton-le-Moorland: SLI Press.

Marshark, M., Sapere, P., Convertino, C. and Seewagen, R. (2005) Educational interpreting: Access and outcomes, in Marschark, M., Peterson, R. and Winston, E.A. (eds) Sign Language Interpreting and Interpreter Education: Directions for Research and Practice. Oxford: Oxford University Press. pp. 57-83.

Mason, I. (2006) On mutual accessibility of contextual assumptions in dialogue interpreting. Journal of Pragmatics. 38, pp. 359-373.

Mason, I. and Ren, W. (2014) Power in face-to-face interpreting event, in Angelelli, C.V. (ed) The Sociological Turn in Translation and Interpreting Studies. Amsterdam and Philadelphia: John Benjamin's Publishing Company. pp. 115-133.

Mindess, A. (2009). Reading between the signs: Intercultural communication for sign language interpreters (2nd ed.). Boston, MA: Intercultural Press. pp. vii +296

Monikowski, C. (2004) Language myths in interpreted education: First language, second language, what language? in Winston, E.A. (ed) Educational Interpreting: How It Can Succeed. Washington, DC: Gallaudet University. pp. 48-60.

Murray, J., De Meulder, M. and Le Maire, D. (2018) An education in Sign Language as a human right? The sensory exception in the legislative history and ongoing interpretation of Article 24 of the UN Convention on the Rights of Persons with Disabilities. Human Rights Quarterly. 40(1), pp. 37-60.

Padden, C. and Humphries, T. (1988) Deaf in America: Voices from a culture. Cambridge, MA: Harvard University Press.

Parasnis, I. (1996) On interpreting the deaf experience within the context of cultural and language diversity, in Parasnis, I. (ed) Cultural and Language Diversity and the Deaf Experience. New York: Cambridge University Press. pp. 3-19.

Pittman, P. and Huefner, D.S. (2001) Characteristics and practices of Sign Language interpreters in inclusive education program. Exceptional Children. 67(2), pp. 187-198.

Power, S. (1999) The educational attainments of deaf students in mainstream programs in England: Examination results and influencing factors. American Annals of the Deaf. 144(3), pp. 261-269. 
Roy, C.B. (2000) Interpreting as a Discourse Process. New York: Oxford University Press.

Russell, D. and Macleod, J. (2009) Educational interpreting: Multiple perspectives of our work, in Mole, J. (ed) International Perspectives in Educational Interpreting. Brassington, UK: Direct Learned Services. pp. $128-144$.

Russell, D. and Winston, B. (2014) Tapping into the interpreting process: Using participant reports to inform the interpreting process in educational settings. Translation \& Interpreting. 6(1), pp. 102-127.

Schick, B., Williams, K. and Bolster, L. (1999) Skill levels of educational interpreters working in public schools. Journal of Deaf Studies and Deaf Education. 4(2), pp. 144-155.

Schick, B., Williams, K. and Kupermintz, H. (2006) Look who's being left behind: Educational interpreters and access to education for deaf and hard-of-hearing students. The Journal of Deaf Studies and Deaf Education. 11(1), pp. 3-20.

Seal, B. (2004) Best Practices in Educational Interpreting. 2nd ed. London: Allyn and Bacon.

Setton, R. (2006) Context in simultaneous interpretation. Journal of Pragmatics. 38, pp. 374-389.

Shaw, J. and Jamieson, J. (1997) Patterns of classroom discourse in an integrated, interpreted elementary school setting. American Annals of the Deaf. 142(1), pp. 40-47.

Smith, D.E. (1990) The Conceptual Practices of Power: A Feminist Sociology of Knowledge. Boston: Northeastern University Press.

Smith, D.E. (1993) Texts, Facts, and Femininity: Exploring the Relations of Ruling. London: Routledge.

Smith, M. (2013) More Than Meets the Eye: Revealing the Complexities of an Interpreted Education. Washington, DC: Gallaudet University Press.

Stone, C. (2009) Towards a Deaf Translation Norm. Washington, DC: Gallaudet University Press.

Stone, C. and Woll, B. (2008) DUMB O JEMMY and others: Deaf people, interpreters and the London courts in the 18th and 19th centuries. Sign Language Studies. 8(3), pp. 226-240.

Van Cleve, J.V. (1993) The academic integration of Deaf children: A historical perspective, in Fischer, R. and Lane, H. (eds) Looking Back: A Reader on the History of Deaf Communities and their Sign Languages. Hamburg, Germany: University of Hamburg. pp. 333-347.

Wadensjö, C. (1998) Interpreting as Interaction. New York: Longman.

Winston, E.A. (1990) Mainstream interpreting: An analysis of the task, in Swabey, L. (eds) The Challenge of the 90's: New Standards in Interpreter Education. Conference of Interpreter Trainers 8th National Convention, Pomona, CA [online]. Available from: www.cit-asl.org/new/mainstream-interpreting-ananalysis-of-the-task/ [Accessed 20 March 2019].

Winston, E.A. (2004) Educational Interpreting: How It Can Succeed. Washington, DC: Gallaudet University Press.

Wolf, M. (2014) The sociology of translation and its "activist turn", in Angelelli, C.V. (ed) The Sociological Turn in Translation and Interpreting Studies. Amsterdam and Philadelphia: John Benjamins Publishing Company. pp. 7-22. 
$\because$ Taylor \& Francis

http://taylorandfrancis.com 
Part VI

Teacher education 
$\because$ Taylor \& Francis

http://taylorandfrancis.com 


\section{Translation teacher training}

Gary Massey

\section{Introduction}

Translation pedagogy has been a constant feature of the applied branch of translation studies since the beginnings of the discipline, famously mapped by Holmes (1972/2004, pp. 180 192 ) and visualized by Toury (1995, pp. 9-10). Indeed, Colina (2003, pp. 3-6) convincingly argues that it extends beyond the applied extensions even to the pure theoretical and descriptive branches of translation studies. For the past two decades, translation pedagogy has commanded a rapidly growing interest in translation studies, with some now regarding it as a "new sub-discipline" (Piotrowska and Tyupa 2014) in its own right. As a rough quantitative indicator, a title search of the Translation Studies Bibliography (TSB) ${ }^{1}$ database on 9 February 2018 showed 359 titles to contain various string combinations of the terms 'translation' and 'translator' with 'training', 'education', 'pedagogy', and 'didactics', approximately $57 \%$ of them published in the first decade of this century and $21 \%$ after 2010 . A keyword search with the same combinations of words achieved 1060 hits, around $60 \%$ for publications between 2000 and 2009 and $30 \%$ after 2010 .

However, those who actually do the teaching receive less attention. A search of the TSB database on the same day returned only 64 hits in total for titles containing the terms 'teacher(s)' or 'trainer(s)' or 'instructor(s)' and none for the same keywords. Deeper research on the titles returned revealed only 33 to have some relation to the profiles, roles, skills and/or training of various types of translation teachers, with about a quarter (8) of those having appeared so far this decade. Related disciplines like language teaching have a strong tradition of published research and approaches in language teacher competences, language teacher education and its pedagogy (see the chapters on bilingual and multilingual teacher training and teacher agency in plurilingual learning contexts in this volume), and can even boast dedicated journals such as English Language Teacher Education and Development. ${ }^{2}$ By contrast, there is a comparative dearth of interest in explicitly addressing the subject of translation teacher training. At least the second part of Kelly's (2008, p. 99) assertion that, despite the body of work on translation pedagogy, "little has been said about students [and] even less has been said about teachers or trainers" still seems to hold true. 
Yet, it would be wrong to suggest that the pedagogic literature on translator education and training has not been consistently trying to say something to translation teachers. Handbooks and other resources for translation teaching and learning aimed at students, practitioners, teachers, and/or curriculum designers have existed as long as translation studies itself, while the many research publications on translator competence development and pedagogy may occasionally also consider the implications for teacher training (e.g. Klimkowski 2015, pp. 311-312). Nevertheless, we should distinguish between those publications with an implicit (or marginally explicit) interest in teacher training and development as such and the far fewer ones purposefully designed to engage teachers instructively in sustained reflection on their own role(s) and self-development (e.g. Kiraly 2000; Colina 2003; González-Davies 2004; Kelly 2005; Klimkowski 2015; Hagemann 2017a, 2017b). Even rarer are publications that present practices, models, and/or research with an overt bearing on how translation teacher competences can be developed, with only a handful of contributions spread over the last two decades. Kiraly's (2000, p. 6) identification of the need to educate generations of translation teachers capable of researching and designing environments to develop true professional competence has gone largely unheeded. Twenty years on, Way (forthcoming) still regards applied research into training translation teachers as a "vital avenue for the future", albeit a wholly neglected one.

This is far from saying that translation teachers are not exposed to teacher education in some form. Depending on the institutional, local or national context, the training of teachers in higher education institutions, which is where international standards like ISO 17100 (2015, p. 6) firmly place the dedicated training of translators, may be more or less strictly laid down in regulations and directives, or recommended in frameworks and guidelines. A case in point is the UK Professional Standards Framework (UKPSF) for teaching and supporting learning in higher education (Advance HE, Guild HE and Universities UK 2011), a "nationallyrecognised framework for benchmarking success within HE teaching and learning support". National and/or local accreditation procedures for institutions and programmes require evidence of quality management and assurance systems, of which teaching staff assessment and development form an integral part. The same applies to the criteria for membership of supranational European and global networks such as the European Master's in Translation (EMT) network ${ }^{4}$ or the Conférence internationale permanente d'instituts universitaires de traducteurs et interprètes (CIUTI). ${ }^{5}$ To comply with regulatory requirements, accreditation standards and/or membership criteria, higher education institutions worldwide will offer their teaching staff generic and specific teacher education and development programmes of varying duration and frequency. Apart from intra-institutional offerings, cross-institutional translation teacher training initiatives have also been organized by various consortia and international associations. These include the Consortium for the Training of Translation Teachers (CTTT), ${ }^{6}$ the Consortium for Translation Education Research (CTER), ${ }^{7}$ the European Society for Translation Studies (EST), ${ }^{8}$ and the International Association for Translation and Intercultural Studies (IATIS), ${ }^{9}$ which have drawn together trainers with particular areas of pedagogic and professional expertise to serve international target groups.

So, there is no doubt that translation teacher training takes place, but pertinent information about local, national, and international initiatives is piecemeal at best. More published research is clearly needed on what is taught where and how. Furthermore, the question remains open as to what extent models or concepts of translation teacher competence and its development are guiding the training that is being done, and how they serve individual, institutional and local needs. 
This chapter cannot provide direct answers to such questions, but it does consider the main perspectives on the field and uses existing information and research to indicate principal directions in translation teacher training. After drawing together selected approaches and findings from translation teacher education research and presenting results from a previously unpublished survey on translation teacher training among EMT and CIUTI members, it considers some key pedagogic approaches hitherto adopted in teacher training and the specifically institutional and local nature of training needs. It then proposes a framework for translation teacher development based on emergentist and organizational learning models.

\section{Historical perspectives}

Generic and subject-specific institutional measures to develop teaching staff competences have obviously existed for longer, but accessible accounts of the early development of translation teacher training initiatives go back only to the early 2000s. Examples are Pym (2001) and Kelly (2005).

Pym (2001) summarizes the background leading up to the experimental organization and implementation of three translation teacher training programmes in 2001 at the University of Rennes (France), the Universitat Rovira i Virgili in Tarragona (Spain) and the Monterey Institute of International Studies (MIIS) in the United States. These came about in response to tensions and needs in a domain where almost nothing was being done to meet the very real international demand. A huge increase in university-level programmes to train translators and interpreters in the 1990s triggered a growing need to train and retrain teachers in emerging professional domains like localization, in new workplace and educational technologies, and in pedagogy. Following up on isolated initiatives in France and Sweden (see also Englund Dimitrova 2002) and partly driven by the formation of CTTT in 2000, the three programmes Pym describes focused on different but complementary aspects of teacher development. These encompassed the current market for technical translation (Rennes), the relation between electronic translation and the teaching situation (Tarragona), and the actual practice of teaching itself, from pedagogic fundamentals to materials development and assessment (MIIS). Taken together, they covered two of the principal areas of professional practice and teaching skills that would feature in later translation trainer competence models. The third of those areas, namely translation studies itself, was not a focal point of the above programmes, which suggests that it was most probably considered a prerequisite. Such considerations, however, clearly depend on local conditions and the specific requirements of target groups. Other teacher training courses have placed a greater emphasis on translation theory - in Stockholm, for instance, where the main target groups were university language teachers and professional translators wishing to teach translation (Englund Dimitrova 2002).

Writing a few years after Pym, Kelly (2005, pp. 150-156), provides a brief run-down of translation teacher training events, consortia, and resources (bibliographies and journals). She touches on initiatives by the EST and IATIS training committees and on the continuing professional development offerings mentioned by Pym (2001), as well as on the then-recently established Certificate in Collaborative Translation Teaching (CCTT) courses that initially took place at the University of Vic in Spain. The majority of these are now largely obsolete or inactive, and just three years later Kelly (2008, p. 115) admits that "there is very little systematic training, whether it be initial or continuing, available for trainers in the specific field of translation".

In the decade or so since, the picture has not improved much. CCTT's last iteration took place at the University of Auckland in 2014. A Postgraduate Diploma in Translation and 
Interpreting Pedagogy briefly offered by Macquarie University in 2011 was very soon discontinued due to low enrolments. Local events have also been sporadically organized by the CIUTI training committee, but a more sustained and systematic initiative has been undertaken under the aegis of the EMT, which for a number of years has been promoting short regional \#TranslatingEurope workshops in member institutions aimed preponderantly at translation teachers. The biennial week-long seminars for translator trainers organized since 2015 by CTER, initially in cooperation with EST, is a promising new attempt to provide at least some training for teachers in new approaches to translation pedagogy, but only time will tell how sustainable it is. The same can be said of the postgraduate course in the pedagogy of eranslating and interpreting currently offered at RMIT University in Melbourne, which covers course design and pedagogic approaches specific to translation and interpreting as well as research in translation and interpreting pedagogy.

Kelly (2008, p. 118) reasonably writes that "for translator trainers, as for all other professions, drawing up a competence-based profile allows for better analysis of the current situation, and for more appropriate training to be designed". Indeed, she herself is one of the very few translation studies scholars to have focused explicitly on translation teacher competences and profiles, and continues to address their training and support needs in her discussion of institutional contexts within the European Higher Education Area (Kelly 2017, p. 30, pp. 36-37). Kelly's (2005, pp. 150-151, 2008, pp. 105-106) “tentative description" (2005, p. 155) of a competence profile for translation trainers covers three principal areas of expertise: professional translation practice, the academic discipline of translation studies and teaching skills. She considers the first two to be essential prerequisites for teachers. However, the central competence in her view is the third, which she breaks down into five sub-competences. The first two of these are the organizational, which comprises the design, application, and management of courses, activities, and assessment, and the interpersonal, which embraces the ability to work collaboratively with students and other teachers and to act as a mentor. The third is the instructional, which focuses on the role of the teacher as a communicator and negotiator (cf. Klimkowski 2015, pp. 238-252) and involves the ability to present and explain content clearly, to stimulate discussion and reflection, and to motivate. The fourth sub-competence is the contextual or professional, which comprises an understanding of the local, national and international educational context in which training occurs as well as the teaching profession as a whole. The fifth and final one is the instrumental sub-competence, which is made up of knowledge of teaching resources and the ability to apply them "appropriately and usefully" (Kelly 2005, p. 151) to the teaching process. In a later publication, Kelly (2008) shows convincingly how the various elements of her profile can be directly matched to the UKPSF and its three superordinate dimensions of "areas of [teaching] activity", "core [teaching and professional] knowledge" and "professional values" (Advance HE, Guild HE and Universities UK 2011, p. 3) both in teaching and the fields for which students are being educated. She again underlines the centrality of teaching skills, and that both professional translation practice and knowledge of the academic discipline of translation studies "are a little like the language competence one expects of a professional translator, in that they constitute prerequisites rather than the central competence we are interested in" (Kelly 2008, p. 105).

Such a view is strongly contradicted by accounts of the reality in many translator education institutions, past and present. Writing at about the same time as Kelly and a principal actor in the aforementioned training courses in Rennes, Gouadec (2010, pp. 365-366) was and is not alone in criticizing the preposterousness of academics setting up and teaching programmes without "first-hand personal experience of the profession . . . and without the slightest knowledge of market trends". He points to the urgent need of "staff whose teaching and practice is 
based on both their ability to reflect on their subject and on their own professional competence in the field" (Gouadec 2010, p. 366). Teachers will have to "have all the necessary academic accomplishments as well as a perfect knowledge of . . . the translation industry. Each trainer must therefore be perfectly at home on both sides of the fence" (Gouadec 2010, p. 366). The "academy-industry divide" (Drugan 2013, p. 38) has been an abiding thorn in the side of translator education, reflecting the fundamental "dichotomy" (Orlando 2016, p. 48) between vocational training on the one hand and academic objectives, manifest in a focus on theory and research, on the other. To judge by the many contributions to this long-standing debate (cf. Orlando 2016, pp. 39-54), it is still clearly present in the numerous translator education institutes staffed by a combination of academics and practitioners.

Kelly's and Gouadec's work had a clear influence on the later EMT translator trainer profile (EMT Expert Group 2013), in which both are cited and which remains the only widely disseminated model of translation teacher competence. Perhaps symptomatically for the current visibility of translation teacher development, it is no longer available on the EMT website.

The EMT profile adopts three of Kelly's principal pedagogic sub-competences, the organizational, the interpersonal, and the instructional. The other two, the contextual or professional and the instrumental, are subsumed loosely under the instructional competence, which also comprises the incorporation of relevant translation studies scholarship and research into lesson design and delivery - a pedagogically targeted version of Kelly's translation studies as an academic discipline. To these it adds assessment competence (partly covered by Kelly's organizational sub-competence), which involves the ability both to assess students and to evaluate (and adapt) a curriculum, syllabus or lesson "as a self-reflective practitioner" (EMT Expert Group 2013, p. 4), and field competence, which in many ways responds to the calls for teachers to be better versed in professional practice. Field competence required teachers to be able to "perform any task assigned to the students to the quality standards required in professional practice", to have detailed knowledge of the professional field and to possess full translation service provision competence (EMT Expert Group 2013, pp. 2-3).

The multicomponential modelling behind Kelly's and the EMT trainer profile demonstrates the evolution of translator education from its "apedagogical" (Kelly 2010, p. 389) pre-1980s beginnings to the present realization of the multiple roles university translation teachers are expected to fulfil, individually or collectively, as reflective practitioners linking the professional translation, academic research, and higher education teaching communities. The requisite elements of translation trainer competence converge most vividly in Orlando's (2016, pp. 81-87) concept of "practisearcher" trainers for 21st-century translators (and interpreters), who should bridge the vocational/academic divide by combining experiential translation praxis with theoretical knowledge, professionally oriented research and pedagogic competence.

\section{Research approaches and key findings}

The bulk of empirical research into translation pedagogy has concentrated on student-learner competence and its development. Research on translator education and student competence development published in edited volumes (e.g. Cui and Zhao 2015; Colina and Angelelli 2017; Venuti 2017) and journals like The Interpreter and Translator Trainer ${ }^{10}$ presents a wealth of good practices that translation teachers and their institutions can use to develop their teaching. Pedagogic literature aimed at curriculum developers, teachers, and practitioners wishing to hone their skills offers numerous approaches, scenarios, tasks, and activities with which to work. Kiraly (2000), for example, adopts an all-embracing approach to translation teaching through authentic collaborative project-based learning based largely on his own classroom 
research combined with general social constructivist learning models. Working within the same social constructivist paradigm, González-Davies (2004) casts a wider net to address the "multiple voices" and learner requirements in the translation classroom by presenting a wealth of scaffolded tasks and activities encompassing transmissionist teacher-centred approaches, transactionist teacher-learner interactions and learner-centred transformationist scenarios. Colina (2003), on the other hand, uses functionalist theoretical models of the translation process and empirical research in translation pedagogy as a basis for proposing concrete ways of designing courses and teaching materials and of evaluating student performance. Just as with Kiraly and González-Davies, however, Colina's seminal research-based approach draws on some evidence of the way students learn, but it does not account for how teachers themselves develop the competences needed to teach or apply input such as her own. Targeted research on translation teacher competences, education and development remains scarce.

Generally, methods of researching translation competence development among students are overtly or covertly derived from qualitative case study and (participatory) action research approaches and applied to classroom settings or project work in collaborative on-site or distributed learning scenarios. They involve process observations, either direct or mediated (e.g. with screen or video recordings), and/or product assessments performed by teacher-researchers and/or other actors, such as non-teaching researchers, clients or external assessors. Various forms of student or teacher self-reports, self-assessments or peer assessments (elicited through questionnaire surveys, interviews, commentaries, journals, etc.) as well as asynchronous or synchronous interactional data (from email threads, chat logs, etc.) may also be collected and analyzed, and in many cases triangulated with data and results from the other sources. Certain experimental methods in controlled (laboratory) environments have also been used, first and foremost in cognitive translation process research (Massey 2017a). Due to both sample size and the specificity of institutional frameworks, results of the various forms of pedagogic research undertaken are seldom generalizable beyond the immediate contexts in which they are obtained. But it is also true to say that the methods and teaching scenarios such studies explore are often implicitly or explicitly recommended as good practices for other researchers and teachers to try out in their own institutions.

Among this large and growing body of empirical pedagogically oriented research, only exceptionally have teacher needs, opinions, attitudes - and ultimately development - been directly addressed. It is striking that teachers' roles and development as (self-)reflective practitioners and learners, while explicitly or implicitly conceptualized in various publications (e.g. Colina 2003; Kelly 2005; Klimkowski 2015), remains under-investigated in empirical terms. Teachers are provided with methodological toolkits, advice, instructions and case study examples about what and how to teach, but whether and how they learn to do so, and how they respond to the models, methods, and practices to which they are exposed, has only rarely been considered.

However, some exceptions do exist, largely in conjunction with learner-oriented studies (e.g. Hubscher-Davidson 2008; Ehrensberger-Dow and Massey 2013; Massey and Brändli 2016; Haro-Soler 2017; Li 2018); investigations targeted on practising or trainee teachers alone remain rare (e.g. Kelly 2008; Pinto and Sales 2008; Li and Zhang 2011). In the following, a selective overview of published research in the field is presented.

Adopting an action research perspective, Hubscher-Davidson (2008) describes a project deploying questionnaires and classroom video recordings aimed at discovering both students' and trainers' perspectives on group work. She also considers the merits of action research as a reflective instrument with which teachers can critically review and improve their practices. Pinto and Sales (2008) present the results of a questionnaire survey of translation trainers in 
Spain designed to obtain their view of students' information literacy skills and the importance of these to overall translation training needs. The intention was to lay an empirical basis for designing more efficient and effective information literacy training in translator education for syllabuses.

Referring to the fact that "research into teacher training in general has suggested that the closer the training is to the trainer's actual context, the better" (Kelly 2008, p. 117), Kelly (2008, pp. 115-119) discusses the piloting of a local needs analysis to identify training needs among translation teachers in Spain. She concludes that her online questionnaire might fruitfully be used in other local and national contexts, given that "one size does not fit all, and tailormade staff development courses and actions with specific intended outcomes will be required in each individual training context" (Kelly 2008, p. 118). Analyzing data from interviews with $\mathrm{PhD}$ students and documentation of doctoral programmes in the local context of Hong Kong, Li and Zhang (2011) have identified an excessive emphasis on research and translation studies to the detriment of professional translation knowledge, practical translation skills, and teacher training among these prospective translation teachers.

Ehrensberger-Dow and Massey (2013) and Massey and Brändli (2016) report on case studies investigating the learning effects on both students and teachers of process-oriented translation teaching and authentic collaborative experiential learning, respectively. Their results indicate teacher epistemologies and role conceptions, resourcing issues, curricular constraints and wider institutional settings as factors inhibiting the performance of teachers. Like Hubscher-Davidson (2008), they, too, highlight the potential of cases-study action research as a means of teacher development through self-reflection, but they also suggest more broadly that it might represent a viable motor of organizational development in its own right.

Haro-Soler (2017) presents the results of an empirical qualitative study of Spanish translation teacher focus groups on their perceptions of how to develop student self-efficacy, which she triangulates with results from a similar previous study of student perceptions in Spain. Both groups concur that self-efficacy is best developed by positive and constructive feedback, a student-centred approach to learning strategies, scaffolding, continuous assessment, promoting student classroom participation, and increasing awareness of attained performance.

$\mathrm{Li}$ (2018) explores the alignment of teacher and learner beliefs in translator and interpreter education in China. The case study, involving a double questionnaire survey of teachers and students at a Chinese university, set out to determine, first, the nature of beliefs underlying teachers' approaches to education along a continuum between the poles of behaviourism and constructivism and, second, the (mis)alignment of teaching beliefs with the learning beliefs of their students. The results among the teachers show mixed beliefs and approaches with a general proximity to constructivism that did not match their students' views, which tended more clearly towards behaviourism. Li (2018, p. 147) concludes that, though the findings are not generalizable beyond the institutional context where they were generated, the study should inspire colleagues to research their own and their students' beliefs in other contexts to promote self-reflection and reconcile discrepancies.

Pavlović and Antunović (forthcoming) add professional translators to the equation in their study of what Croatian translation professionals and translation teachers think constitutes a desirable teaching profile, which squares well with the increasingly prominence professional praxis in translation teacher competence modelling. In their questionnaire study, the translators tended to rate translation-related skills highest, while the teachers placed greater emphasis on teaching skills and course design. However, both groups confirmed the relevance of core competences derived from the EMT translator trainer profile, with a pronounced stress put on translation experience and the ability to perform the tasks they assign to the students 
to a professional standard. Teacher-training needs were seen to be most acute in the area of technology (i.e. computer-assisted translation tools), professional trends, and translation teaching methods, which reflects the results of a combined EMT and CIUTI survey to which we now turn.

This limited body of empirical research on translation teacher approaches, attitudes and development, largely restricted to specific institutional and local contexts, is matched by a lack of published research on current teacher profiles and continuing professional development concepts across translator education institutions. As seen earlier, accounts of institutional continuing professional development, resources (e.g. Kelly 2005), and teacher profiles and needs (e.g. Kelly 2008) are rare and largely dated. Information on current institutional and consortia teacher-training initiatives is generally diffuse and hard to come by. In an initial attempt to remedy this situation, a survey of university institutes and programmes in the EMT and CIUTI networks was launched in July 2018 to find out more about current and planned continuing professional development requirements, measures and needs. ${ }^{11}$

Of the 92 institutions that received invitations to take part in the survey through their email and social media networks, 41 responded to all the survey questions devoted to translation teacher training, a response rate of $45 \%$. Of these, only $32 \%$ currently require their permanent translator training staff to attend mandatory training courses, and just $24 \%$ require their nonpermanent staff to do so. However, optional courses are offered at $76 \%$ of the institutions that responded. When asked how much time teachers are expected to devote to continuing professional development each year, only 22 institutions responded. The responses varied widely between 0 and 126 hours per year, the average among the 22 respondents being approximately 28 hours per year. If we assume that the 19 institutions that did not complete this question have no expectations or requirements in this regard, the average falls to just 15 hours.

The specific areas covered by the mandatory and optional courses reported reveal an interesting pattern. Unsurprisingly, 59\% of the responding institutions offer courses in general pedagogy and 56\% in education technology, reflecting the impact of the digital transformation. By contrast, only $33 \%$ do so in specific translation pedagogy, a figure closely matched by those offering language pedagogy training (32\%), while just $10 \%$ of respondents offer training in language learning technology. Training in translation theory is similarly scarce, mentioned by only $20 \%$ of respondents, as is that offered in linguistics, language theory or communication theory, mentioned by a mere $12 \%$. The same applies to training in general, domain-specific, and medium-specific translation skills (offered by $12 \%, 17 \%$, and $12 \%$ of respondents respectively).

It therefore appears that most institutions assume that their staff members are sufficiently familiar with the theoretical aspects of translation and the basic skills needed to translate. However, many of them also appear to be keen to keep their teachers up to date with technological and professional developments in the industry. Of institutions, 63\% offer translation technology training and $41 \%$ state that they provide their teachers with some form of professional development on the translation profession and industry. The main formats referred to are lectures, seminars, and conferences in cooperation with professional and industrial partners as well as short traineeships for teachers at local translation companies.

Yet, the measures currently in place do not seem to be meeting perceived demand. The institutions were also asked to indicate on a four-point Likert scale the degree ('high', medium', 'low' or 'none') to which they need additional translation teacher training in specific areas. When the responses in the high and medium categories are combined, translation technology comes out on top, with a rounded $76 \%$ of respondents indicating a high $(41 \%)$ or medium (34\%) degree of need, and translation pedagogy is second, with $61 \%$ indicating a high $(20 \%)$ 
or medium (41\%) level of need. Third place is occupied by education technology, with 59\% of respondents indicating a high (32\%) or medium $(27 \%)$ degree of need, while equal fourth place is taken by the translation profession/industry $(51 \%, 24 \%$ indicating a high level of need and $27 \%$ a medium one) and domain-specific language skills (a rounded 51\%,15\% indicating a high degree of need and $37 \%$ a medium one).

In ascribing importance to the practical aspects of professional translation, the results tend to confirm the widespread assumption that translation teaching still has to bridge the divide between practice and theory. There also seems to be a felt need to hone pedagogic performance in terms of both educational technologies and approaches specific to developing translation competence. Yet, given the relatively low proportion of universities with a mandatory continuing professional development requirement and the limited number of hours per year allocated to continuing professional development at numerous institutions, it is unlikely that any future teacher training initiatives will bear much fruit without accompanying structural and regulatory changes at institutional level, that is to say within the individual organizational contexts of need identified by Kelly (2008).

\section{Pedagogic approaches and methods}

The professional, institutional, and geographic heterogeneity of the participants in the early courses described by Pym (2001) led to the course leaders adopting the role of course facilitators. Although this was ostensibly done in order to accommodate a plurality of perspectives on translation practice and training, it also squared with the widening propagation and emergence of a social constructivist classroom design in translation teaching espoused inter alia by Kiraly (e.g. 2000), who was himself a facilitator on many such teacher training initiatives. The approach continues to be used in the workshop formats of the trainer training offered by networks, associations and consortia.

The content and objectives of these offerings have broadly reflected the trajectory of major approaches to translation pedagogy over the last four decades, cogently summarized in numerous publications (e.g. Kelly 2010; Orlando 2016, pp. 28-35; Colina and Venuti 2017, pp. 203215). Kelly (2010, pp. 389-390) and Orlando (2016, p. 29) regard Delisle's (e.g. 1980) systematic objectives-based approach to translation pedagogy as indicative of a key break with the prevalence of teaching based on the personal practices and experience of teachers, epitomized by Newmark's (1991, p. 130) provocative statement that success in teaching translation depends " $65 \%$ on the personality of the teacher, $20 \%$ on the course design and $15 \%$ on the course materials". The rise of skopos and translational action theory in the 1980s led to the application of functionalist models of translation to the way it was taught, with an increasing emphasis on training that closely simulated purpose-driven professional practice exemplified by Nord's influential work of the 1990s (e.g. 1991). In his more radical social constructivist approach to translator education, Kiraly (2000, pp. 57-62) critiques Nord's acknowledged contribution to translation pedagogy, which calls for "atomistic" (Kiraly 2000, p. 60) tasking in simulated exercises prior to embarking on authentic assignments. Instead, he proposes that student learning be centred entirely on genuine collaborative translation projects with teachers providing the dynamic support or scaffolding to foster learner autonomy and empowerment. This sustained focus on real projects converges with a strong trend towards authentic situated learning, which was most visibly propagated in its early stages by Vienne (1994) and Gouadec (e.g. 2003), and which has since become a pervasive approach in current translator pedagogy and a fertile ground for research on translator competence development (cf. González-Davies and Enríquez Raído 2017). It goes without saying that situated learning requires teachers to 
have considerable knowledge and experience of professional translation practice. Correspondingly, the early teacher training courses outlined in Pym (2001) and their follow-ups (Kelly 2005) stress situated constructivist approaches to teaching and learning predicated on profound familiarity with professional market demands, including translation technologies.

Kiraly (2000) signals an incipient break with his earlier work (e.g. Kiraly 1995), framed as it was in a cognitivist paradigm that saw a burgeoning of translation pedagogy guided by heuristic (e.g. Kelly 2007) and empirically tested (e.g. PACTE 2003) multicomponential models of translation competence and implemented as staged tasks of increasing complexity designed to develop the sub-competences needed to attain translation expertise. Competence-oriented task-based teaching (e.g. González-Davies 2004; Hurtado Albir 2007) has continued to flourish over the last two decades, witnessing a growing offshoot in the form of process-oriented cognitive approaches to translator education that involve the deployment of process research methods in teaching such as screen recordings and verbalizations (Massey 2017a). Notwithstanding Kiraly's misgivings, such competence-based approaches have been seen as a viable complement (e.g. González-Davies 2004, pp. 13-15) to authentic collaborative experiential learning based on social constructivist and later emergentist (e.g. Kiraly 2013, 2016, 2017) learning models.

The extent to which these various approaches have gained credence in teacher training can be illustrated by the content of recent network and consortia initiatives. Reflecting the broader learner exposure to technology and professional praxis prioritized in the 2017 EMT Competence Framework for translator competence (EMT Board 2017), the EMT's 2018 programme of EMT \#TranslatingEurope workshops ${ }^{12}$ foregrounded digitalization, language technologies and fit-for-purpose market language service provision skills. The 2014 CCTT programme as well as the 2015 and 2017 CTER seminars gave similar prominence to teaching the newest translation technologies alongside collaborative project-based learning, competence-based curriculum design and scaffolded task-based instruction, with the CTER events additionally featuring extensive sessions on process-oriented translation teaching and diagnostics. All of these focal points can be effortlessly mapped to the five competences of the EMT trainer profile.

Echoing Kelly (2008), that profile emphasizes that effective training depends on the needs of teachers within their local and institutional contexts, which is already implicit in the teacher-oriented research described in the previous section. It follows that any efficient operationalization of translation teacher training and development must be embedded in a coherent organizational learning framework that takes such contexts fully into account. With this in mind, Kiraly et al. (2018) and Massey (2017b, forthcoming) propose an approach to teacher competence development based on Kiraly's fractal model of co-emergent learning, which can seamlessly accommodate an organizational perspective when scaled up to the institutional level. The model shares fundamental features both with Lave and Wenger's (1991) situated perspective on learning as social participation within a community of practice and with the most frequently cited organizational learning theories (cf. Göhlich 2016). These are Argyris and Schön's (1978) postulation of the individual as the initiator and central actor of organizational learning; the combination of individual (personal mastery, mental modelling), collective (shared visioning, team learning), and organizational (systems thinking) learning processes in Senge's (1990) five disciplines of organizational learning; and Wenger's (2009) social theory of learning. In the latter, individuals learn by and from engaging in and contributing to the practices of their communities, communities learn by and from refining their practice, and organizations learn by and from "sustaining the interconnected communities of 
practice through which an organization knows what it knows and thus becomes effective and valuable as an organization" (Wenger 2009, p. 213).

Due in large part to a shared provenance (cf. Kolb 2015, pp. 1-29), clear parallels exist between emergentist and organizational learning models and theories, the experiential learning cycle (Kolb 2015), which among other things underlies deep approaches to competenceoriented learning (Kelly 2005, pp. 48-49), and the action-research spiral (Lewin 1946, p. 38). Action research on process-oriented and authentic experiential learning scenarios has demonstrated how co-emergent learning occurs among all translator education stakeholders, including teachers, institutions and members of the wider community of practice (e.g. Massey et al. 2015; Massey and Brändli 2016). When systematically deployed alongside other measures as part of a broader organizational learning toolkit (e.g. Garvin et al. 2008) that tailors generic translation teacher competence models to specific institutional needs, action research itself can provide strong low-threshold impetus to teacher and organizational development (Massey 2017b; Kiraly et al. 2018; Massey forthcoming).

\section{Conclusions and future directions}

This brief chapter has attempted to trace the principal directions taken in the theory, research, and practice of translation teacher training. While published information on translation teacher training is scattered and hard to come by, it clearly takes place at the institutional level, though inter-institutional initiatives are relatively rare and the extent to which translation teachers receive dedicated training remains obscure. Research on translation student learning is plentiful and resources aimed at translation teachers abound, but research on how teachers teach, learn, and develop is scarce, and there are only two widely cited models of translation teacher competence. More research is clearly needed on what is taught where and how, on the basis of what epistemological and pedagogic principles, with what aims and to what effect.

The models and research that do exist underline the centrality of institutional and local contexts in addressing teacher competences and teacher-training needs. This suggests that a viable, systematic approach to translation teacher training can be most effectively achieved at organizational level within a coherent organizational learning framework. A ready basis is offered by Kiraly's scalable model of co-emergent learning, which is not only co-extensive with experiential learning approaches to translator education but also congruent with leading organizational learning models and theories. However, adequate institutional incentives (time, rewards, regulations, etc.) and structures must be in place in order to operationalize the model. Only then will it be possible to foster the sustained familiarity with professional translation practices, context-aware reflective teaching praxis, and knowledge of translation studies that together form the core of translation teacher competence.

\section{Further reading}

EMT Expert Group. (2013) EMT Translator Trainer Profile. Competences of the Trainer in Translation. Available from: https://de.scribd.com/document/246979198/Translator-Trainer-Profile-EMT [Accessed 12 April 2019].

This paper describes the background and content of the EMT translator trainer profile, one of only two widely disseminated competence profiles for translation teachers.

Kelly, D. (2005) A Handbook for Translator Trainers. A Guide to Reflective Practice. Manchester: St. Jerome Publishing. 
Alongside Colina (2003) and González-Davies (2004), this is a seminal handbook for translation teachers and the only one to dedicate a specific chapter (pp. 150-155) to teacher training. It includes the first of the known translation teacher competence profiles.

Kelly, D. (2008) Training the trainers: Towards a description of translator trainer competence and training needs analysis. TTR: Traduction, Terminologie, Rédaction. 21(1), pp. 99-125.

Building on Kelly's (2005) teacher profile, this article considers translator trainer training in the broader context of higher education teaching. The final part presents a needs analysis of translator trainers in Spain that is a prime example of similar studies undertaken in other institutional or local contexts.

Massey, G. (forthcoming) Learning to learn, teach and develop: Co-emergent perspectives on translator and language-mediator education. inTRAlinea Online Translation Journal Special Issue: New Insights into Translator Training.

This contribution outlines a research-based organizational learning framework for student, teacher, and institutional development in translator education, providing concrete examples for the implementation of a co-emergent learning model from the authors' home institution.

Orlando, M. (2016) Training 21st Century Translators and Interpreters: At the Crossroads of Practice, Research and Pedagogy. Berlin: Frank \& Timme.

This book conveys insights into the complex roles of 21 st-century translators, interpreters, and their teachers at the juncture of professional practice, academic research/theory, and higher education demands, including a chapter (pp. 81-92) on teaching profiles and approaches.

\section{Related topics}

interpreting teacher training, bilingual and multilingual teacher training, translation and technology, translation studies, educational theory

\section{Notes}

1 Translation Studies Bibliography [online]. Available from: www.benjamins.com/online/tsb/ [Accessed 12 April 2019].

2 See www.elted.net/ [Accessed 12 April 2019].

3 See www.heacademy.ac.uk/ukpsf [Accessed 12 April 2019].

4 See https://ec.europa.eu/info/resources-partners/european-masters-translation-emt_en [Accessed 12 April 2019].

5 See www.ciuti.org/ [Accessed 12 April 2019].

6 See www.intercultural.urv.cat/conferences/cttt/ [Accessed 12 April 2019].

7 See http://cter.edu.pl/en/our-mission/ [Accessed 12 April 2019].

8 See http://est-translationstudies.org/ [Accessed 12 April 2019].

9 See www.iatis.org/ [Accessed 12 April 2019].

10 See www.tandfonline.com/toc/ritt20/current [Accessed 12 April 2019].

11 See https://gibbon.zhaw.ch/limesurvey/index.php/349311?newtest=Y\&lang=en [Accessed 12 April 2019].

12 See https://ec.europa.eu/info/news/translatingeurope-workshops-2018-2018-sep-05_en [Accessed 12 April 2019].

\section{References}

Advance HE, Guild HE and Universities UK. (2011) The UK Professional Standards Framework for Teaching and Supporting Learning in Higher Education [online]. Available from: www.heacademy. ac.uk/system/files/downloads/ukpsf_2011_english.pdf [Accessed 12 April 2019].

Argyris, C. and Schön, D. (1978) Organizational Learning: A Theory of Action Perspective. Reading: Addison-Wesley. 
Colina, S. (2003) Translation Teaching from Research to the Classroom: A Handbook for Teachers. Boston: McGraw-Hill.

Colina, S. and Angelelli, C. (eds) (2017) Translation and Interpreting Pedagogy in Dialogue with Other Disciplines. Amsterdam: John Benjamins.

Colina, S. and Venuti, L. (2017) A survey of translation pedagogies, in Venuti, L. (ed) Teaching Translation: Programs, Courses, Pedagogies. London: Routledge. pp. 337-358.

Cui, Y. and Zhao, W. (eds) (2015) Handbook of Research on Teaching Methods in Language Translation and Interpretation. Hershey: IGI Global.

Delisle, J. (1980) L'analyse du discours comme méthode de traduction: Initiation à la traduction française de textes pragmatiques anglais, théorie et pratique. Ottawa: Presses de l'Université d'Ottawa.

Drugan, J. (2013) Quality in Professional Translation: Assessment and Improvement. London: Bloomsbury.

Ehrensberger-Dow, M. and Massey, G. (2013) Indicators of translation competence: Translators' selfconcepts and the translation of titles. Journal of Writing Research. 5(1), pp. 103-131.

EMT Board. (2017) European Master's in Translation: Competence Framework 2017 [online]. Available from: https://ec.europa.eu/info/sites/info/files/emt_competence_fwk_2017_en_web.pdf [Accessed 08 December 2018].

EMT Expert Group. (2013) EMT Translator Trainer Profile: Competences of the Trainer in Translation [online]. Available from: https://de.scribd.com/document/246979198/Translator-Trainer-ProfileEMT [Accessed 12 April 2019].

Englund Dimitrova, B. (2002) Training and educating the trainers: A key issue in translators' training, in Hung, E. (ed) Teaching Translation and Interpreting 4: Building Bridges. Amsterdam: John Benjamins. pp. 73-82.

Garvin, D., Edmondson, A. and Gino, F. (2008) Is yours a learning organization? Harvard Business Review. March, pp. 1-10.

Göhlich, M. (2016) Theories of organizational learning as resources of organizational education, in Schröer, A., Göhlich, M., Weber, S. and Pätzold, H. (eds) Organisation und Theorie. Organisation und Pädagogik. 18. Wiesbaden: Springer VS. pp. 11-21.

González-Davies, M. (2004) Multiple Voices in the Classroom: Activities, Tasks and Projects. Amsterdam: John Benjamins.

González-Davies, M. and Enríquez Raído, V. (eds) (2017) Situated Learning in Translator and Interpreter Training: Bridging Research and Good Practice. London: Routledge.

Gouadec, D. (2003) Position paper: Notes on translator training, in Pym, A., Fallada, C., Biau, J.R. and Orenstein, J. (eds) Innovation and E-learning in Translator Training: Reports on Online Symposia. Tarragona: Universitat Rovira i Virgili. pp. 11-19 [online]. Available from: www.intercultural.urv.cat/ en/publications/elearning/ [Accessed 12 April 2019].

Gouadec, D. (2010) Translation as a Profession. Paperback ed. with corrections. Amsterdam: John Benjamins.

Hagemann, S. (2017a) Forms of cultural specificity in translation teaching, in Hagemann, S., Neu, J. and Walter, S. (eds) Translation/Interpreting Teaching and the Bologna Process: Pathways Between Unity and Diversity. Berlin: Frank \& Timme. pp. 77-103.

Hagemann, S. (2017b) Translation in die B-Sprache: Zur Rolle von Studierenden und Dozierenden, in Ahrens, B., Hansen-Schirra, S., Krein-Kühle, M., Schreiber, M. and Wienen, U. (eds) Translation, Didaktik, Kompetenz. Berlin: Frank \& Timme. pp. 65-101.

Haro-Soler, M.M. (2017) Teaching practices and translation students' self-efficacy: A qualitative study of teachers' perceptions. Current Trends in Translation Teaching and Learning English. 4, pp. 198-228.

Holmes, J.S. (1972/2004) The name and nature of translation studies, in Venuti, L. (ed) The Translation Studies Reader. 2nd ed. London: Routledge. pp. 180-192.

Hubscher-Davidson, S. (2008) A reflection on action research processes in translator training. The Interpreter and Translator Trainer. 2(1), pp. 75-92.

Hurtado Albir, A. (2007) Competence-based curriculum design for training translators. The Interpreter and Translator Trainer. 1(2), pp. 163-195. 
ISO 17100 (2015) Translation Services: Requirements for Translation Services. Geneva: ISO.

Kelly, D. (2005) A Handbook for Translator Trainers: A Guide to Reflective Practice. Manchester: St. Jerome Publishing.

Kelly, D. (2007) Translator competence contextualized. Translator training in the framework of higher education reform: In search of alignment in curricular design, in Kenny, D. and Ryou, K. (eds) Across Boundaries: International Perspectives on Translation Studies. Newcastle upon Tyne: Cambridge Scholars Publishing. pp. 128-142.

Kelly, D. (2008) Training the trainers: Towards a description of translator trainer competence and training needs analysis. TTR: Traduction, Terminologie, Rédaction. 21(1), pp. 99-125.

Kelly, D. (2010) Translation didactics, in Gambier, Y. and van Doorslaer, L. (eds) Handbook of Translation Studies. 1. Amsterdam: John Benjamins. pp. 389-396.

Kelly, D. (2017) Translator education in higher education today: The EHEA and other major trends. Convergence, divergence, paradoxes and tensions, in Hagemann, S., Neu, J. and Walter, S. (eds) Translation/Interpreting Teaching and the Bologna Process: Pathways between Unity and Diversity. Berlin: Frank \& Timme. pp. 29-50.

Kiraly, D. (1995) Pathways to Translation: Pedagogy and Process. Kent: Kent State University Press.

Kiraly, D. (2000) A Social Constructivist Approach to Translator Education: Empowerment from Theory to Practice. Manchester: St. Jerome Publishing.

Kiraly, D. (2013) Towards a view of translator competence as an emergent phenomenon: Thinking outside the box(es) in translator education, in Kiraly, D., Hansen-Schirra, S. and Maksymski, K. (eds) New Prospects and Perspectives for Educating Language Mediators. Tübingen: Narr Francke Attempto. pp. 197-224.

Kiraly, D. (2016) Authentic project work and pedagogical epistemologies: A question of competing or complementary worldviews? in Kiraly, D. (ed) Towards Authentic Experiential Learning in Translator Education. Göttingen: V\&R unipress/Mainz University Press. pp. 53-66.

Kiraly, D. (2017) Occasioning translator competence: Moving beyond social constructivism toward a postmodern alternative to instructionism, in Colina, S. and Angelelli, C. (eds) Translation and Interpreting Pedagogy in Dialogue with Other Disciplines Amsterdam: John Benjamins. pp. 7-30.

Kiraly, D., Massey, G. and Hofmann, S. (2018) Beyond teaching: Towards co-emergent praxis in translator education, in Ahrens, B., Hansen-Schirra, S., Krein-Kühle, M., Schreiber, M. and Wienen, U. (eds) Translation, Didaktik, Kompetenz. Berlin: Frank \& Timme. pp. 11-64.

Klimkowski, K. (2015) Towards a Shared Curriculum in Translator and Interpreter Education. Wrocław and Washington, DC: Wydawnictwo WSF we Wrocławiu, PAN o. we Wrocławiu, International Communicology Institute.

Kolb, D. (2015) Experiential Learning: Experience as the Source of Learning and Development. 2nd ed. Upper Saddle River: Pearson Education.

Lave, J. and Wenger, E. (1991) Situated Learning: Legitimate Peripheral Participation. Cambridge: Cambridge University Press.

Lewin, K. (1946) Action research and minority problems. Journal of Social Issues. 2(4), pp. 34-46.

Li, D. and Zhang, C. (2011) Knowledge structure and training of translation teachers: An exploratory study of doctoral programmes of translation studies in Hong Kong. Meta. 56(3), pp. 693-712.

Li, X. (2018) Teaching beliefs and learning beliefs in translator and interpreter education: An exploratory case study. The Interpreter and Translator Trainer. 12(2), pp. 132-151.

Massey, G. (2017a) Translation competence development and process-oriented pedagogy, in Schwieter, J. and Ferreira, A. (eds) The Handbook of Translation and Cognition. Chichester: Wiley-Blackwell. pp. 520-544.

Massey, G. (2017b) Research-driven translation teaching: Doing applied linguistics to empower the learning organization, in Perrin, D. and Kleinberger, U. (eds) Doing Applied Linguistics: Enabling Transdisciplinary Communication. Festschrift für Urs Willi. Berlin: de Gruyter. pp. 184-193.

Massey, G. (forthcoming) Learning to learn, teach and develop: Co-emergent perspectives on translator and language-mediator education. inTRAlinea Online Translation Journal Special Issue: New Insights into Translator Training. 
Massey, G. and Brändli, B. (2016) Collaborative feedback flows and how we can learn from them: Investigating a synergetic experience in translator education, in Kiraly, D. (ed) Towards Authentic Experiential Learning in Translator Education. Göttingen: V\&R unipress/Mainz University Press. pp. 177-199.

Massey, G., Jud, P. and Ehrensberger-Dow, M. (2015) Building competence and bridges: The potential of action research in translator education, in Pietrzak, P. and Deckert, M. (eds) Constructing Translation Competence. Frankfurt am Main: Peter Lang. pp. 27-48.

Massey, G. and Ehrensberger-Dow, M. (2013) Evaluating translation processes: Opportunities and challenges, in Kiraly, D., Hansen-Schirra, S. and Maksymski, K. (eds) New Prospects and Perspectives for Educating Language Mediators. Tübingen: Narr Francke Attempto. pp. 157-180.

Newmark, P. (1991) About Translation. Clevedon: Multilingual Matters.

Nord, C. (1991) Text Analysis in Translation: Theory, Methodology, and Didactic Application of a Model for Translation-oriented Text Analysis. Amsterdam: Rodopi.

Orlando, M. (2016) Training 21st Century Translators and Interpreters: At the Crossroads of Practice, Research and Pedagogy. Berlin: Frank \& Timme.

PACTE. (2003) Building a translation competence model, in Alves, F. (ed) Triangulating Translation: Perspectives in Process Oriented Research. Amsterdam: John Benjamins. pp. 43-66.

Pavlović, N. and Antunović, G. (forthcoming) A desirable profile of translation teacher: Perceptions and needs in the Croatian context. inTRAlinea Online Translation Journal Special Issue: New Insights into Translator Training.

Pinto, M. and Sales, D. (2008) Towards user-centred information literacy instruction in translation: The view of trainers. The Interpreter and Translator Trainer. 2(1), pp. 47-74.

Piotrowska, M. and Tyupa, S. (2014) Translation pedagogy: A new sub-discipline of translation studies. inTRAlinea Online Translation Journal Special Issue: Challenges in Translation Pedagogy. 16 [online]. Available from: www.intralinea.org/specials/article/2112 [Accessed 12 April 2019].

Pym, A. (2001) Trial, error and experimentation in the training of translation teachers, in Sánchez Trigo, E. and Diaz Fouces, Ó. (eds) Traducción \& comunicación. 2. Vigo: Universidade de Vigo. pp. 73-90.

Senge, P. (1990) The Fifth Discipline: The Art and Practice of the Learning Organization. 1st ed. New York: Currency/Doubleday.

Translation Studies Bibliography [online]. Available from: www.benjamins.com/online/tsb/ [Accessed 12 April 2019].

Toury, G. (1995) Descriptive Translation Studies - and Beyond. Amsterdam: John Benjamins.

Venuti, L. (ed) (2017) Teaching Translation: Programs, Courses, Pedagogies. London: Routledge.

Vienne, J. (1994) Towards a pedagogy of 'translation in situation'. Perspectives. 2(1), pp. 51-59.

Way, C. (forthcoming) Training and pedagogical implications, in Angelone, E., Ehrensberger-Dow, M. and Massey, G. (eds) The Bloomsbury Companion to Language Industry Studies. London: Bloomsbury Academic.

Wenger, E. (2009) A social theory of learning, in Illeris, K. (ed) Contemporary Theories of Learning: Learning Theorists - in their Own Words. London: Routledge. pp. 209-218. 


\section{Interpreting teacher training}

David B. Sawyer

\section{Introduction}

The interpreting studies literature identifies teaching and pedagogy as key areas of interest (Pöchhacker 2016, p. 191; Yan et al. 2018), and the contours of a theoretical discussion of the training of interpreting teachers are beginning to emerge. It has long been recognized that practising interpreters, or former interpreters who are no longer actively exercising the profession, should be the primary instructors in conference interpreting courses (AIIC Training and Professional Development 1999). More recently, the instructional community has recognized increasingly that a systematic body of knowledge about curriculum, instruction, and assessment, in addition to actual conference interpreting experience, is required if instructors are to be effective in the classroom. A key task of this chapter is to review how views regarding teacher preparedness have evolved and changed, what knowledge and skills - beyond practical interpreting experience - are required for effective teaching, and options for acquiring them. Rather than pursuing a broad overview of educational topics in Interpreting Studies (see Ludmila Stern and Xin Liu, this volume), this discussion focuses on factors that may have influenced interpreting teacher training most and is limited to instruction in conference interpreting in the spoken languages.

This chapter begins with a review of the development of pedagogical principles and instructor profiles since the mid-20th century, when the first university programmes in conference interpreting were established. The second section addresses approaches to researching conference interpreter education, including the status of instructional literature today. The third section outlines current thinking about core curriculum components and related areas of instructional expertise. In the concluding section, the chapter identifies possible areas of further research and development activity.

\section{Historical perspectives}

This section begins with a review of the development of conference interpreting training since the mid-20th century. In this context, the profiles of the first conference interpreting instructors in university programmes, early instructional literature, and the development of guidelines 
establishing instructor qualifications are outlined. The development of a consensus regarding a core curriculum for conference interpreting serves as a backdrop leading into the discussion of teacher training programmes, and instructional content and literature.

Consideration of who should teach conference interpreting began with the establishment of university programmes in the mid-20th century, first in European universities, and later in North America and Asia, whose chronology is well documented (see Bao 2009; Sawyer and Roy 2015, among others). Prior to university programmes, European governments trained future interpreters beginning at a young age in the tradition of dragomans beginning in antiquity in the Mediterranean (Rothman 2015a) and jeunes de langues from the 16th through the 19th centuries (Rothman 2015b). By the mid-19th century, there were student interpreter programmes providing immersive language training to young men and future diplomats in Asia as well (Roland 1999). These programmes, which lasted into the early 20th century, were generally housed in or attached to legations or foreign embassies, for example in China, Japan, and Turkey. Some accounts of students describe the instructors as local nationals hired for their ability to teach their own native language to young future diplomats, rather than skill or ability as interpreters (Sawyer 2016).

The increased demand for formal interpreting skills in international and regional institutions led not only to the founding of the university programmes but also to a symbiotic relationship between these institutions and higher education, particularly at the postgraduate level. Some stakeholders consider a formal relationship of this kind to be an endorsement of a program's quality and a defining characteristics of conference interpreting training that has carried forward to today (see Bordes 2019; Donovan 2019).

The rise of long conference consecutive during and after World War I and simultaneous interpreting with equipment after World War II occurred as instruction targeting the interpreting skill set began to appear. The International Association of Conference Interpreters' (AIIC) history of its first 60 years chronicles a variety of ad hoc training courses and employer training activities immediately after World War II, resulting largely from employer demand for qualified interpreters (Le Group Histoire 2013, pp. 39-42). The establishment of the first university programmes - Mannheim (1930), Moscow (1930-33/1942), Heidelberg (1933), Geneva (1941), and Vienna (1943) - predates the widespread use of simultaneous interpreting. A small group of practitioners fell into work as conference interpreters due to their background and linguistic abilities, and it was logical that they would become the first instructors of programmes driven by real-world demand. Among them were individuals such as Jean Herbert (BaigorriJalón 2015b) and Léon Dostert (Baigorri-Jalón 2015a), who also advocated for and against, respectively, the introduction of simultaneous interpreting classes. While such heated debates were occurring, discussions about the content and organization of these programmes led to the proposal of the first curriculum models, including one by Antoine Velleman (Baigorri-Jalón 2015c) in Geneva (see Arjona 1984; Sawyer 2015, p. 97).

Despite the push for training, operational constraints and short timelines outweighed pedagogical considerations. For example, at the Nuremberg trials, Dostert, who taught French at Georgetown University and was the first chief of the language division, supervised the selection and training of the interpreting staff. He had also trained some interpreters, including in the operation of the Filene-Finlay simultaneous interpreting equipment used at the League of Nations and other international conferences (Gaiba 1998, pp. 35-36). In Nuremberg, Dostert recruited some interpreters trained in consecutive interpreting from the new programme at the University of Geneva, before the introduction of instruction in simultaneous interpreting, to work alongside others who had little interpreting experience at all (see, for example, Gaiba 1998; Le Groupe Histoire 2013; Baigorri-Jalón 2014). The national governments selected 
interpreter-candidates in the first step of the recruitment process; for example, would-be interpreters from the United States took a language test at the Pentagon. The candidates then underwent a second screening in Nuremberg, where the test consisted of mock trials simulating the actual interpreting work (Gaiba 1998, pp. 49-50).

Given the exigencies of the time, interpreter recruitment and initial training, including for the use of simultaneous interpreting during the Nuremburg trials, followed a 'learning-by-doing' approach (see detailed account in Baigorri-Jalón 2014, pp. 219-227). To illustrate, one military translator and interpreter, Siegfried Ramler (2008, p. 46), describes his recruitment immediately after the end of the war:

Having heard that a trial of German leaders was about to take place in that city's Palace of Justice, I took a Jeep, drove to Nuremberg, and called on the Adjutant-General's office for information pertaining to the trials. When the staff officer heard about my background and my current assignment to an air force battalion, he told me of the urgent need in Nuremberg for linguists in preparation for the trials, and expressed strong interest in my joining the staff. He said that the Office of US Chief of Counsel, the administrative unit preparing for the trail, would take care of the details for my transfer, arrange for billets, and assign me to the language team working on document translation and pretrial interrogations.

Ramler would work from German into English and eventually become chief of the interpreting branch, serving in this capacity for the final two years of the trails, from 1947-1949. After final selection, additional practice with the system followed, and dress rehearsals of the trials were the last stage (Gaiba 1998, pp. 49-50). Ramler (2008, p. 52) describes the baptism-by-fire process:

During recruiting of interpreters, we staged mock trials to judge whether candidates were able to respond instantly to the verbal stimuli without falling behind. We found that excellent linguists with good academic backgrounds were often unable to react quickly enough and did not qualify. Linguists who proved suitable for simultaneous interpretation tended to have had a substantial stay in the countries of the languages into which or from which they interpreted.

In contrast, training for the interpreters supporting the Tokyo War Crimes Tribunal consisted only of an orientation to the court procedures (Takeda 2010, pp. 40-41).

Dostert was also in charge of the initial training of simultaneous interpreters for the United Nations in New York, where the training focused on use of the simultaneous interpreting equipment, the development of simultaneous interpreting skills through practice, and preparation of the topics of meetings (Baigorri-Jalón 2004, pp. 62-64). The introduction of simultaneous interpreting seems to have generated greater awareness among those in charge of the service that budding interpreters required practice with the interpreting equipment and development of skills specific to interpreting, in addition to an orientation to meeting procedures and study of meeting content.

Situating training in universities implied that interpreting skills could be taught. As universities set up programmes, it was a logical consequence that interpreting teachers saw a need to publish instructional literature, with students and other future interpreters as the primary audience. Two works often cited as classics provide an initial indication of instructional content that was considered specific to interpreting skill development and that should be addressed 
in learning situations, whether in a formal classroom setting or through self-study: Herbert's (1952) Interpreter's Handbook: How to Become a Conference Interpreter and Jean-François Rozan's (1956) La prise de notes en interprétation consécutive, which both focus largely but not exclusively on note-taking. In another early contribution, Paneth $(1958$, p. 23) provides a tour d'horizon grounded in her personal experience. Discussing the advantages of university training, she outlines the key components of the new programmes and draws attention to the promise of structured university curricula taught by seasoned practitioners:

On the continent great interpreters combine with academic teachers at university schools of interpretation to prepare a generation which, as it can profit from their experience and comes to work much younger, can cultivate the automatic responses at a more pliant age, and may well outdo any achievements we have yet seen. The interpreter born may there practice his skill at an early age in the company of both future interpreters and other language students as well as of legal and technical experts who want to perfect their languages, while at the same time acquiring at university level a wide general culture and specialized knowledge in some Sachgebiete [specialized fields].

Her description acknowledges the important role of subject matter experts - academic specialists rather than interpreters - providing instruction in specialized content areas. At the same time, her choice of words - "interpreter born" - provides an indication of prevailing convictions, given the career trajectories of interpreters who entered the profession before the advent of widespread university training. Subsequently, Paneth $(1958$, p. 28) reinforces the notion that good interpreters have an innate skill set that distinguishes them and may not require, or perhaps eludes, instruction:

With all the help that interpreters' schools can give, students must not lose sight of the essentially autodidactic nature of an interpreter's training. For the born interpreter it is the opportunity to practice, the suggestion of the most profitable exercises, the informed criticism, the co-operation of colleagues rather than specific training (except in wider studies and background) that the school provides. The mere linguist also has to realize that his own practice is what will help him most and that many teachers can offer a useful Hilfestellung [aid] at hurdles which they could not take themselves.

[emphasis added]

The notion that the instructor draws essentially on her experience as an interpreter and her own innate interpreting abilities when critiquing students' interpreting and does not provide specific training were hallmarks of instructional approaches until practitioners who took on instructional roles engaged in theoretical reflection allowing a consensus to emerge regarding a curriculum framework and instructional progression underlying skill acquisition. Even after the widespread acceptance of a curriculum model outlining a sequence for skill acquisition and instructional content, these internalized notions of an innate skill set in gifted student interpreters, who required only general guidance from senior practitioners and opportunities to practice, remained widespread. Identification of the prerequisite skill set thorough aptitude testing became the key to instructional success in programmes implementing a Darwinist sink-or-swim approach.

In North America, Weber (1984, p. ix), who taught at the then Monterey Institute of International Studies (MIIS), was one of the first to address explicitly the question of what an 
effective instructor needs to know and be able to do in his book Training Translators and Conference Interpreters:

It is an attempt to show, on the basis of my twenty years of experience in the practice and teaching of both fields, what the professional translator and interpreter must know, and what can be done - and cannot be done - to help many young people interested in these careers achieve this goal.

[emphasis added]

Despite implicit recognition that teachers need instructional knowledge and skills in addition to interpreting experience in order to teach well, Weber's statement echoes once again prevalent beliefs that conference interpreters have an innate skill set that some may simply not possess or be able to acquire. Nevertheless, in his subsequent discussion, Weber (1984, p. 2) considers formal training not only advantageous but also essential for a successful career in conference interpreting:

Only exceptionally gifted people (of whom I have only met one or two during my professional career) can hope to accede to these professions on their own without developing serious bad habits and making mistakes that will tarnish their professional performance for the rest of their careers.

A subsequent conference held in celebration of the 20th anniversary of the MIIS, where Weber also served as Dean, was devoted to The Training of Teachers of Translation and Interpretation. In the opening address, Arjona-Tseng (1989, p. 9) argued explicitly that instructors should have knowledge of curriculum and instruction, testing and evaluation, and educational methods (see Mackintosh 1999). Similar developments were underway then and even earlier in Europe. Over the decades, a specialized literature addressing instruction in conference interpreting grew through publications including monographs, articles, and proceedings of conferences addressing aptitude testing (see Timarová 2015) and teaching methodology as key themes (e.g. Gerver and Sinaiko 1978; Delisle 1981; Seleskovich and Lederer 1989; Dollerup and Loddegaard 1992; Dollerup 1994; Dollerup and Appel 1995; see Moser-Mercer 2015 for a detailed account). The literature develops to the point where a retrospective view is possible. Ilg and Lambert (1996) published one of the first comprehensive reviews of the history of "Teaching consecutive interpreting", and Moser-Mercer (2005) followed with "The teaching of simultaneous interpreting: The first 60 years (1929-1989)". Subsequently, interpreting studies researchers review and discuss this literature from a number of perspectives (see Sawyer 2004, 2015; Sawyer and Roy 2015; Colina and Angelelli 2016; Setton and Dawrant 2016; Yan et al. 2018; Sawyer et al. 2019, among others).

The International Association of Conference Interpreters (AIIC) played a key role in establishing criteria for evaluating university programmes, which include most notably the stipulation that instructors be practising interpreters to ensure that training remains relevant to the needs of employers. The association held an AIIC Symposium on CI Teaching in Paris in December 1965 and continued organizing meetings and discussions on the topic (see Mackintosh 1999, p. 70). To guide these developments, AIIC set up a Schools Committee in 1957, renamed Training Committee in 1987 and rebranded AIIC Training in 2010 (Le Group Histoire 2013, pp. 226-232). Mackintosh (1989, 1995) describes a 'core curriculum' that emerged from these and other debates. This curriculum informed the design of the European Master in 
Conference Interpreting (EMCI) in 2001, through which European Union stakeholders established a set of curriculum components that are widely recognized as best practices.

The conference interpreting teaching community reached a milestone with the publication of an article by Macintosh in the journal Interpreting in 1999, in which she draws upon her earlier and other publications and summarizes the development of teaching methodology and the activities of AIIC, among others, in providing instructor training up to that point. The title of the article harkens back to Paneth's (1958, p. 23, see previous) statement regarding the "born interpreter" and refutes it directly: "Interpreters are made not born". If interpreters are moulded in instructional programmes, rather than gifted with an innate skill set, it becomes clear that instructional knowledge and skills in the form of best practices contribute to that development, and teachers must have them to be most effective. The focused development of interpreting teacher training intensified.

The University of Geneva, which had played a pivotal role in the development of curricula and the introduction of instruction in simultaneous interpreting over four decades earlier, broke ground by introducing formal training for conference interpreting instructors. Barbara Moser-Mercer, who had served on the faculty and briefly as Dean at the MIIS, established first a Continuing Education Certificate for Interpreter Trainers in 1996 and subsequently a Master of Advanced Studies (MAS) in Interpreter Training in 2004, unique programmes that continue to today (Faculty of Translation and Interpreting n.d.). The MIIS offered instructor training as well. In addition to ongoing faculty working group discussions and reflections on pedagogical issues, Weber (1989) and van Dam's (1989) papers on "Improved ways of teaching consecutive interpreting" and "Strategies of simultaneous interpretation: A methodology for the training of simultaneous interpreter", respectively, were notable given their - at the time - innovative discussion and documentation of teaching methodology. The MIIS offered a four-week train-the-trainers seminar for interpreting (and translation) instructors in 2001 and repeated it twice in a condensed four-day version focusing on interpretation in 2008 with the University of Maryland's National Foreign Language Centre hosting in College Park, Maryland, outside of Washington DC (National Foreign Language Center n.d.).

In China, the Translators Association of China (TAC) launched a teacher training programme in 2004 to offer systematic training to interpreting (and translation) instructors. TAC and the China National Committee for Master of Translation and Interpretation Education (CNMTI) began running the programme jointly when the Chinese government launched a Master of Translation and Interpretation (MTI) degree in 2007. This summer programme subsequently became the largest teacher training programme of its kind, with over 2000 participants concluding the course by 2012 (see Bao 2009, 2010, 2015, pp. 409-410). AIIC Training has continued its activities, offering regular workshops on a wide range of pedagogical topics (see Le Group Histoire 2013, pp. 230-232; AIIC 2019). Employer organizations such as the European Union institutions and the United Nations have continued to develop and foster networks with universities aimed at improving the quality of instruction in interpreting around the world (Donovan 2019). The content of these programmes and courses points to key areas of instructional expertise that are discussed later under pedagogic approaches and methods.

Finally, awareness of the need for better structure and guidance for learners led to the publication of dedicated textbooks for use in conference interpreting programmes and self-study, containing in particular exercises for interpreting practice courses. They include introductory overviews of the profession (Jones 1998/2002), updated instruction in note-taking (Gillies 2005/2017), consecutive interpreting (Bowen and Bowen 1980; Gillies 2019) and compendia of language enhancement and interpreting exercises (Nolan 2005/2012; Gillies 2013). 


\section{Research approaches and key findings}

This section describes approaches to researching interpreting teacher training and presents key conclusions. A discussion of the key themes is followed by an overview of research approaches to investigating conference interpreting training and key findings. Teacher training for conference interpreting has not been an active area of research, perhaps because, aside from Arjona's work in the late 1980s and early 90s, not many interpreting studies researchers drew upon educational theory to inform their research on interpreting until the 2000s. Citing the scarcity of research, other than descriptive work, that had been done on teaching and pedagogy, Pöchhacker and Shlesinger (2002, pp. 10-11) decided to omit teaching and pedagogy as a topic in the first comprehensive anthology of interpreting studies literature, The Interpreting Studies Reader, which from today's perspective seems surprising. Research on education and training grew dramatically after this point. For this reason, the section begins with a review of the discussion about the role and value of research in interpreter education and training programmes.

It should come as no surprise that the instructor profiles described previously precluded a high number of instructors having academic research or even teaching experience when university programmes were established. Perhaps because of the focus on the needs of employers and recommendation, if not insistence, that instructors in strong programmes be practitioners, there has long been an uneasy relationship between research and practice in instructional programmes. More recently, interpreters trained as researchers have engaged in a discussion of the role and contribution of research to interpreter education and training. In their bibliometric review of 180 articles from ten journals from 2000 to 2014, Yan et al. $(2018$, p. 4$)$ document a rapid pace of growth in research on interpreter training, with the number of articles doubling every year. The results of their analyses show the major themes to be teaching, learning, and assessment, with articles on training only a small fraction of the volume. The question remains, however, how many interpreting teachers are interested in and read this literature.

The EMCI model includes a mandatory theoretical component, in addition to training in codes of ethics and professional conduct, and interpreting educators have felt compelled to justify this training component and explain why programmes should rely on research on interpreting - and interpreter education and training topics - to enhance their programmes. In explaining the "Role of research in interpreter education", for example, Pöchhacker (2010, p. 2) reviews educational studies notable for the insights they provide into educational questions and argues that

the most fundamental use or purpose of research in interpreter education would be a more profound, inter-subjective understanding of the phenomenon as such, that is, of interpreting as a practice. This kind of 'basic research' is simply a way - and, ideally, a particularly reliable way - of broadening our knowledge of interpreting beyond the professional expertise that individual interpreting instructors are expected to bring to their task.

One of the main goals of Pöchhacker's (2010) article is to show the close and beneficial relationship between educational research and interpreting skills training (p. 1), arguing in particular for more collaborative, participatory "research on teaching and assessment in interpreting education", such as qualitative action research (p. 9). Colina and Angelelli (2016) identify action research as one of the most active and useful approaches to investigating interpreting (and translation) pedagogy (see Nicodemus and Swabey 2016). 
Similarly, in the concluding chapter to a volume entitled Why Translation Studies Matters, Gile (2010, p. 259) makes a strong case for the contribution of research to Translation, i.e. translation and interpreting, practice and training:

There is ample evidence to show that [research] has indeed influenced Translation training in terms of training methods, basic orientation in Translation and the dissemination of good practices. Moreover, by inducing reflection on Translation among students who later become practitioners, it potentially helps them improve their action as Translators by giving them conceptual and other references.

Additionally, there is evidence that better integration of research projects that are meaningful for students and address questions they have about their practice can be instrumental in acquiring interpreting skills. Such research projects focus on knowledge and skill development and clarify for learners the role of reflective and deliberate practice in the skill acquisition process (see, for example, de Terra and Sawyer 1998; Takeda 2010; Liu 2019 for a discussion of a course integrating theory and practice that evolved at the MIIS over the years). Instructors, who are also researchers, anchor these syllabi in the social constructivist approaches to instruction that have also gained substantial attention in translator education and training (see Gary Massey, this volume).

Similarly, in their more recent discussion of curriculum content and sequencing, Setton and Dawrant (2016, pp. 15, 60) echo "calls for a more structured, scientific and accountable pedagogy" and proposals for improving the quality of programmes through additional research on interpreting. Areas of attention include modelling cognitive management skills, balancing component and composite skill development, analyzing and supporting progressive skill development, and providing better scaffolding for and documentation of learning through learning-centered deliberate and reflective practice.

Among the guides to interpreting and translation research methods published over the past two decades (Williams and Chesterman 2002; Saldanha and O'Brien 2013; Mellinger and Hanson 2017), Hale and Napier's (2014, pp. 175-208), Research Methods in Interpreting stands out by offering a chapter dedicated specifically to research on interpreter education and assessment. Describing the main methodologies employed in educational research, they cite surveys, naturalistic/qualitative methods, experimental methods, historical/documentary, role-plays, and action research and provide a range of examples from the interpreting studies literature, including illustrations of how researchers can pursue one question from multiple perspectives, depending on the methodologies that they adopt.

Despite these developments, as mentioned earlier, little research is extant on interpreting teacher training specifically, which may be related to the fact that little teacher training is available, such that Setton and Dawrant (2016, p. 580) comment: "To date, only a minority of conference interpreter trainers have received substantial teacher training. Most pick up key principles and technique in-house by study and example", and/or attend 1-2 day workshops (2016, p. 580). They also suggest an outline for a syllabus as well as a list of teacher training methods (2016, pp. 580-583), stating that short courses "can only complement, not replace proper training for all interpreter trainers" (2016, p. 580). The question thus remains how to identify the knowledge and skills that instructors should possess, other than through the experience and observations of senior practitioners who are also academic instructors and researchers. Given the lack of extant research on interpreter teacher training, at this stage of development, a comprehensive needs analysis using multiple sources and methods (see Long 2005) would be a productive course of action. 


\section{Pedagogic approaches and methods}

The third section on pedagogic approaches and methods outlines current thinking on the core curriculum components and related areas of instructional expertise and identifies content that programme conveners increasingly expect interpreting teachers to master. One possible step in a needs analysis is initiating an empirical, evidence-based approach, for example by conducting a document review and including survey, focus group, and/or interview research with stakeholders (students, instructors, programme conveners) to triangulate the data (Hale and Napier 2014). The discussion here is a first step in the document analysis process and is not comprehensive or definitive in scope; it is limited to a brief review of suggested interpreter teacher training content in select document sources, including interpreting studies literature devoted to teaching and assessing interpreting, recommendations of professional associations, and content of existing teacher training programmes and workshops. Such a review can assist in identifying those areas of knowledge and skill that teachers should possess and serve as a staging ground for a proper needs analysis. A discussion of research and training in other interpreting domains, such as community and signed language interpreting would be illustrative but is beyond the scope of this chapter.

Pöchhacker (2016, p. 191) identifies several key themes in the literature on interpreter training: "basic curricular issues ... student selection and performance assessment as well as teaching methods for developing the skills that make up the interpreter's core competence". Inquiries focusing on curricula (see Sawyer 2015) document the structure and content of programmes and describe curriculum models and specific curricula, including issues of content and sequencing. Teaching methodology often addresses aspects of instruction in specific modalities, whether consecutive, simultaneous, sight translation, or also note-taking. The development of expertise in interpreting (see Tiselius 2015) and, related to it, research on differences between expert and novice interpreters (see Moser-Mercer 2015a) inform much of this thinking. Student selection and performance assessment include topics such as aptitude testing, in-program testing, and issues of constructs, validity and reliability (see Liu 2015).

Weber's (1984, p. vii) table of contents provides a first indication of the pedagogical knowledge required of interpreting instructors: basic aptitudes and qualifications, learning and teaching resources, curriculum, instruction, testing, career options and job opportunities, professional ethics and codes of conduct. In comparison, as overarching topics in his key instructional text, Gile (2009) addresses the role of theoretical components in training, quality and fidelity, comprehension and knowledge acquisition, cognitive models and strategies, and language enhancement. Similarly, the EMCI core curriculum requires course content or modules in the theory of interpretation, the practice of interpretation, consecutive interpretation, simultaneous interpretation, and the EU and international organizations (EMCI 2012).

In addition to the long-standing expectation that interpreting teachers be experienced and well-respected practitioners, Setton and Dawrant (2016, pp. 11-14) highlight factors that are essential for good instruction, such as having the right working languages for the course in question and an understanding of the course syllabus. Furthermore, instructors require course preparation and classroom management skills, the ability to provide meaningful feedback and demonstrate the expertise students are working to acquire, and a range of human qualities such as empathy, a sense of fairness, and the ability to empower students, among others. Finally, theoretical knowledge includes the aims, goals, structural progression, and instructional philosophy underlying the curriculum, as well as some background knowledge about cognitive processes, such as memory and attention, and skill acquisition. Setton and Dawrant's (2016, p. 579) recommendations include tailoring teacher training workshops to 
participants' wishes and mention questionnaires used to identify students' problems, trainers' problems, and "other issues".

AIIC Training and Professional Development's (1999) document on best practices for conference interpreting training programmes sheds light on the knowledge and skills required of interpreting teachers. For example, without adding detail on the depth or breadth of the knowledge and skills required, AIIC states the expectation that interpreting teachers have some teacher training specifically related to interpreting, presumably in areas mentioned in the best practices document, including aptitude testing and assessment, instruction in consecutive and simultaneous interpreting, theory, and professional practice and ethics.

The content offered in interpreting teacher training programmes and workshops tends to reflect those areas mentioned in such literature sources. The teacher training model at the University of Geneva (Faculty of Translation and Interpreting n.d.) is modular and includes components addressing tasks and skills in consecutive and simultaneous interpreting, sequencing and planning in consecutive and simultaneous interpreting, problems and remedies in consecutive and simultaneous interpreting, teaching note-taking for consecutive interpreting, teaching simultaneous interpreting with text, assessment, feedback, ethics, and basic research methods (for supervising theses). The 2001 workshops offered through MIIS (and repeated in collaboration with the University of Maryland's National Foreign Language Centre in 2008) included curriculum and syllabus design, lesson planning, assessment, feedback, teaching consecutive, including note-taking, materials selection and progression, teaching simultaneous, including simultaneous with text, ethics, and interpreting studies and research methods (National Foreign Language Center n.d.).

Similarly, according to its website, the Translators Association of China (n.d.) includes the following components in its training-of-trainers course for interpreting (and translation) teachers: translation skills, translation didactics, translation theory and research methodology, interpretation skills, interpretation didactics, interpretation theory, and research methodology. The course conveners offer this content in a combination of seminar and workshop formats.

In the preceding discussion, it is evident that knowledge, skills, and abilities expected of interpreting teachers have been identified in general terms in the interpreting studies (and instructional) literature, by professional associations, and through teacher training opportunities. These knowledge, skills, and abilities can be grouped into content areas to define more clearly teacher training requirements. Figure 24.1 shows a possible grouping of content areas for purposes of comparison across a range of sources. The sources are those from the preceding discussion that lend themselves to the straightforward identification of areas directly or indirectly proposed for or implemented in instructor training courses and workshops. The analysis shows that the areas can be grouped logically into at least four categories: general, interpreting skills, assessment, and theory and research. The categorization of the content groupings, which may serve as a starting point for further discussion, can be explored, elaborated, and empirically verified in a comprehensive, evidence-based needs analysis to identify and describe in greater detail the knowledge, skills, and abilities expected of interpreting teachers.

This initial review of content areas for interpreting teacher training courses provides an indication of the comprehensive knowledge of teaching and assessment required of highly competent instructors, in addition to their experience as professional practitioners. It is an inevitable, widespread practice for instructors, even those teaching full time in academic programmes, to specialize by offering courses in specific areas of the curriculum. A task of a future needs analysis would be to define empirically the 'core' instructional knowledge and skills required of any teacher across these areas, regardless of the area of instructional specialization, and also discuss the implications of such specializations. 


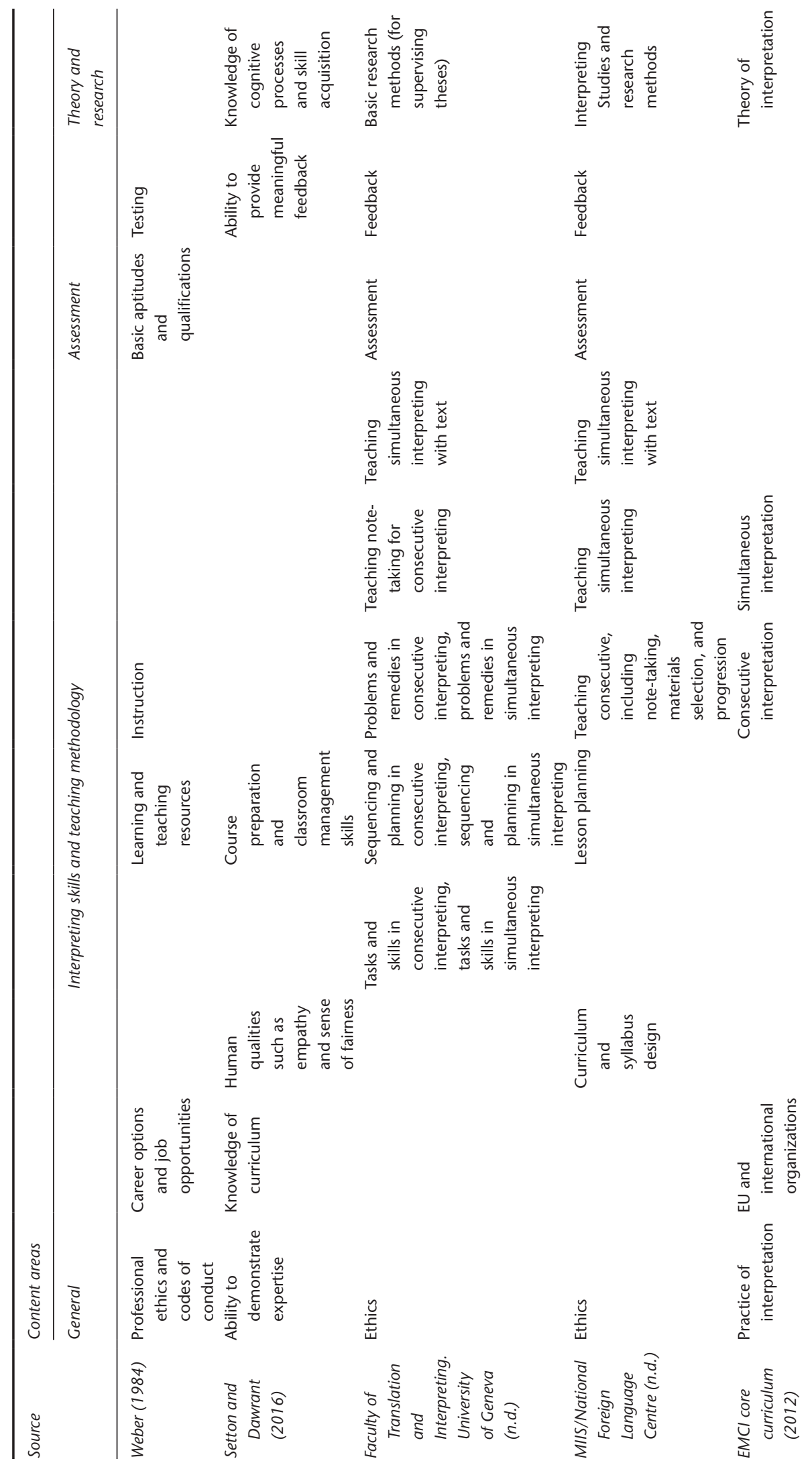




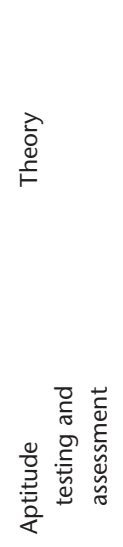

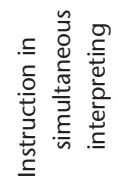

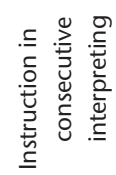
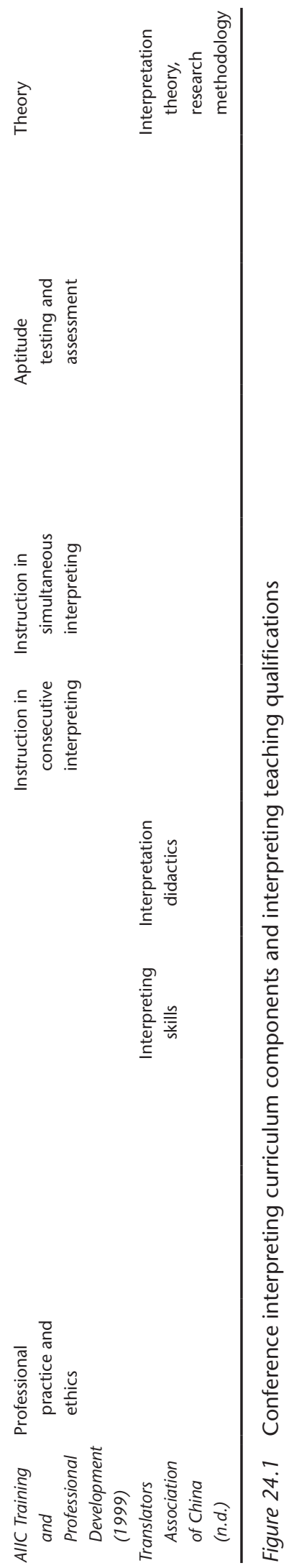


\section{Conclusions and future directions}

This chapter outlined the historical development of interpreting teacher training, including the roles of educational institutions, employer organizations, and professional associations. The discussion encompassed the development and state of the instructional literature as well as the emergence of dedicated teaching training programmes. A review of research approaches and key findings addressed the role and value of research on and for interpreter education and noted a lack of research dedicated specifically to interpreting teacher training. An initial analysis of select contributions to the literature on interpreter education, content of teacher training programmes and workshops, and AIIC's quality criteria for programmes revealed key knowledge and skills expected of effective interpreting teachers.

Regarding research and training aimed at developing interpreting teachers in particular, much remains for the research and teaching community to accomplish, despite a proliferation in research on educational and training topics in general. In addition to a comprehensive needs analysis to document the landscape in interpreting teacher training and establish priorities for research and development in the core areas already well represented in existing teacher training programmes, attention to additional areas of pedagogy such as distance and online training, E-learning, technology and information literacy, and undergraduate education is needed. Further areas of educational research and capacity building with and for interpreting teachers could include exploring instructor attitudes and beliefs, developing instructional approaches to promote literacy in interpreting (and translation) among students in other academic programmes (Takeda and Yamada 2019), establishing standards for conference interpreting programmes, and equipping teachers to support programme evaluations.

\section{Further reading}

Gile, D. (2009) Basic Concepts and Models for Interpreter and Translator Training. Rev. ed. Amsterdam and Philadelphia: John Benjamins.

Daniel Gile wrote his well-received textbook, now is its second addition, "primarily for practitioners of conference interpreting and/or translation who teach one or both disciplines" ( $p$. 3). The book presents the pedagogical concepts and models that Gile developed during years of teaching and that are informed by research, rather than being the product of research. The book is highly accessible and suitable for use as a textbook for students as well as introductory reading for novice instructors who have little background in research.

The Interpreter and Translator Trainer. (2016) 10(1) [online]. Available from: www.tandfonline.com/ toc/ritt20/10/1?nav=tocList [Accessed 03 June 2019].

Of the many publication outlets where topics related to interpreter education and training are published, The Interpreter and Translator Trainer stands out as one of few peer-reviewed international journals dedicated to research in the education and training of professional interpreters and translators. The journal addresses a full range of topics related to teaching and learning interpreting, including the training of trainers. For example, a special issue edited by Maria González-Davies and Vanessa Enríquez Raido in 2016 addressed Situated Learning in Translator and Interpreter Training: Bridging Research and Good Practice.

Moser-Mercer, B. (2015b) Pedagogy, in Pöchhacker, F. (ed) The Routledge Encyclopedia of Interpreting Studies. London and New York: Routledge. pp. 303-307.

In this authoritative encyclopaedic entry on pedagogy, Moser-Mercer reviews the development of interpreter education and training since the founding of university programmes in Europe before the conclusion of World War II. Moser-Mercer focuses on conference interpreting, including the launch 
of interpreting teacher training but also includes developments in areas such as legal, healthcare, and community interpreting and the growing role of distance education and E-learning.

Pöchhacker, F. (2016) Introducing Interpreting Studies. 2nd ed. London and New York: Routledge.

Pöchhacker's aim remains unchanged in the second edition of this textbook: "to provide students, research-minded teachers and practitioners of interpreting as well as scholars in related fields with a broad and balanced overview of interpreting studies as an academic field of study" (p. 1). A chapter on "Education" provides a review of research and its main outcomes regarding curriculum, selection, teaching, assessment, and further education. A brief section on "The Training of Trainers" summarizes the developments from the mid-1960s not only in conference interpreting but also in signed language and community interpreting (pp. 205-206).

Setton, R. and Dawrant, A. (2016) Conference Interpreting: A Trainer's Guide. Amsterdam and New York: John Benjamins.

Setton and Dawrant's guide for interpreting teachers accompanies their 2016 companion volume on Conference Interpreting: A Complete Course, with detailed cross-referencing between the two volumes. The comprehensive, 650-page manual is "predominantly aimed at instructors but also course designers and leaders, as well as researchers" (p. 1) and provides a discussion of nearly all topics of interest to interpreting teachers. The authors draw attention to the urgent need for better training of instructors, which has been recognized only recently (pp. 15-16). An overview of topics and issues regarding the training of trainers includes a notional syllabus for teacher training courses (579-583).

\section{Related topics}

educational theory: from Dewey to Vygotsky, interpreting studies, bilingual deaf education, sign language interpreting, translation teacher training

\section{References}

AIIC. (2019) Training of Trainers [online]. Available from: https://aiic.net/node/44/training-of-trainers/ lang/1 [Accessed 29 May 2019].

AIIC Training and Professional Development. (1999) Conference Interpreting Training Programmes Best Practice [online]. Available from: http://aiic.net/p/60 [Accessed 20 May 2019].

Arjona-Tseng, E. (1984) Issues in the design of curricula for the professional education of translators and interpreters, in McIntire, M.L. (ed) New Dialogues in Interpreter Education: Proceedings of the Fourth National Conference of Interpreters Trainers Convention. Silver Spring, MD: Registry of Interpreters for the Deaf. pp. 1-35.

Arjona-Tseng, E. (1989) Preparing for the XXI Century. Paper presented at the Twentieth Anniversary Symposium on the Training of Teachers of Translation and Interpretation, Monterey Institute of International Studies, Monterey, CA, 1-3 December. pp. 1-17.

Baigorri-Jalón, J. (2004) Interpreters at the United Nations: A History. A. Barr (trans). Salamanca: Ediciones Universidad de Salamanca.

Baigorri-Jalón, J. (2014) From Paris to Nuremberg: The Birth of Conference Interpreting. H. Mikkelson and B.S. Olsen (trans). Amsterdam and Philadelphia: John Benjamins.

Baigorri-Jalón, J. (2015a) Dostert, in Pöchhacker, F. (ed) The Routledge Encyclopedia of Interpreting Studies. London and New York: Routledge. pp. 118-119.

Baigorri-Jalón, J. (2015b) Herbert, in Pöchhacker, F. (ed) The Routledge Encyclopedia of Interpreting Studies. London and New York: Routledge. pp. 182-183.

Baigorri-Jalón, J. (2015c) Velleman, in Pöchhacker, F. (ed) The Routledge Encyclopedia of Interpreting Studies. London and New York: Routledge. pp. 432-433.

Bao, C. (2009) Training of trainers: A key to success in translator and interpreter training. Chinese Translation Journal. (2), pp. 45-47. 
Bao, C. (2010) Developing Training of Trainer Programs: A Case Study. Presentation at the Sixth Asian Translators Forum, 6-8 November, University of Macau, China.

Bao, C. (2015) Pedagogy, in Mikkelson, R. and Jourdenais, R. (eds) The Routledge Handbook of Interpreting. London and New York: Routledge. pp. 400-416.

Bordes, S. (2019) Institutional cooperation in the areas of training - a two-way collaboration: The perspective of an academic trainer, in Sawyer, D., Austermühl, F. and Enríquez Raído, V. (eds) The Evolving Curriculum in Interpreter and Translator Education: Stakeholder Perspectives and Voices. Amsterdam and Philadelphia: John Benjamins. pp. 369-377.

Bowen, D. and Bowen, M. (1980) Steps to Consecutive Interpretation. Washington, DC: Penn and Booth.

Colina, S. and Angelelli, C.V. (2016) Translation and interpreting pedagogy, in Angelelli, C.V. and Baer, B.J. (eds) Researching Translation and Interpreting. London and New York: Routledge. pp. 108-117.

de Terra, D. and Sawyer, D. (1998) Educating interpreters: The role of reflection in training. ATA Chronicle. 27(3), pp. 22-24.

Delisle, J. (ed) (1981) L'Enseignement de l'Interprétation et de la Traduction: De la Théorie à la Pédagogie. Ottawa: University of Ottawa Press.

Dollerup, C. (ed) (1994) Teaching Translation and Interpreting 2: Insights, Aims, Visions. Amsterdam and Philadelphia: John Benjamins.

Dollerup, C. and Appel, V. (eds) (1995) Teaching Translation and Interpreting 3: New Horizons. Amsterdam and Philadelphia: John Benjamins.

Dollerup, C. and Loddegaard, A. (eds) (1992) Teaching Translation and Interpreting: Training, Talent, and Experience. Amsterdam and Philadelphia: John Benjamins.

Donovan, C. (2019) The contribution of institutional recruiters to interpreter training: Getting the balance right, in Sawyer, D., Austermühl, F. and Enríquez Raído, V. (eds) The Evolving Curriculum in Interpreter and Translator Education: Stakeholder Perspectives and Voices. Amsterdam and Philadelphia: John Benjamins. pp. 343-368.

EMCI. (2012) EMCI Core Curriculum [online]. Available from: www.emcinterpreting.org/coursestructure [Accessed 06 June 2019].

Faculty of Translation and Interpreting. University of Geneva (n.d.). Continuing Education Programs [online]. Available from: www.unige.ch/fti/en/enseignements/formation-continue/formations-qualifiantes [Accessed 24 June 2019].

Gaiba, F. (1998) The Origins of Simultaneous Interpretation: The Nuremberg Trial. Ottawa: Ottawa University Press.

Gerver, D. and Sinaiko, H.W. (eds) (1978) Language Interpretation and Communication. Proceedings of the NATO Symposium, Venice, Italy, September 26-October 1, 1977. New York and London: Plenum Press.

Gile, D. (2009) Basic Concepts and Models for Interpreter and Translator Training. 2nd ed. Amsterdam and Philadelphia: John Benjamins.

Gile, D. (2010) Why Translation Studies matters: A pragmatist's viewpoint, in Gile, D., Hansen, G. and Pokorn, N.K. (eds) Why Translation Studies Matters. Amsterdam and Philadelphia: John Benjamins. pp. 251-261.

Gillies, A. (2005) Note-taking for Consecutive Interpreting - A Short Course. Manchester: St. Jerome Publishing.

Gillies, A. (2013) Conference Interpreting: A Student's Practice Book. London and New York: Routledge.

Gillies, A. (2017) Note-taking for Consecutive Interpreting: A Short Course. 2nd ed. London and New York: Routledge.

Gillies, A. (2019) Consecutive Interpreting: A Short Course. London and New York: Routledge.

Hale, S. and Napier, J. (2014) Research Methods in Interpreting: A Practical Resource. London: Bloomsbury.

Herbert, J. (1952) The Interpreter's Handbook: How to Become a Conference Interpreter. Geneva: Georg. Ilg, G. and Lambert, S. (1996) Teaching consecutive interpreting. Interpreting. 1(1), pp. 69-22. 
Jones, R. (1998/2002) Conference Interpreting Explained. London and New York: Routledge.

Le Groupe Histoire. Association Internationale des Interprètes de Conférences [History of the Profession. International Association of Conference Interpreters]. (2013) Naissance d'une Profession: Les Soixante Premières Années de l'Association Internationale des Interprètes de Conférences (AIIC) [The Birth of a Profession: The First Sixty Years of the International Association of Conference Interpreters]. Geneva: G. Chapuis S.A.

Liu, M. (2015) Assessment, in Pöchhacker, F. (ed) The Routledge Encyclopedia of Interpreting Studies. London and New York: Routledge. pp. 20-22.

Liu, M. (2019) Knowing what and knowing how: Teaching student interpreters research on interpreting, in Sawyer, D., Austermühl, F. and Enríquez Raído, V. (eds) The Evolving Curriculum in Interpreter and Translator Education: Stakeholder Perspectives and Voices. Amsterdam and Philadelphia: John Benjamins. pp. 301-318.

Long, M.H. (2005) Second Language Needs Analysis. Cambridge: Cambridge University Press.

Mackintosh, J. (1989) AIIC Training Committee Review Paper on Training Interpreter Trainers. Paper presented at the Symposium on the Training of Teachers of Translation and Interpretation Conference, Monterey Institute of International Studies, Monterey, CA, 1-3 December.

Mackintosh, J. (1995) A review of conference interpretation: Practice and training. Target. 7(1), pp. 119-133.

Mackintosh, J. (1999) Interpreters are made not born. Interpreting. 4(1), pp. 67-80.

Mellinger, C.D. and Hanson, T.A. (2017) Quantitative Research Methods in Translation and Interpreting Studies. London and New York: Routledge.

Moser-Mercer, B. (2005) The teaching of simultaneous interpreting: The first 60 years (1929-1989). Forum. 3(1), pp. 205-225.

Moser-Mercer, B. (2015a) Expert-novice paradigm, in Pöchhacker, F. (ed) The Routledge Encyclopedia of Interpreting Studies. London and New York: Routledge. p. 155.

Moser-Mercer, B. (2015b) Pedagogy, in Pöchhacker, F. (ed) The Routledge Encyclopedia of Interpreting Studies. London and New York: Routledge. pp. 303-307.

National Foreign Language Center (NFLC). University of Maryland (n.d.). Training the Trainers in the Teaching of Interpretation Syllabus [unpublished manuscript]. College Park: NFLC.

Nicodemus, B. and Swabey, L. (2016) Action research, in Angelelli, C.V. and Baer, B.J. (eds) Researching Translation and Interpreting. London and New York: Routledge. pp. 157-167.

Nolan, J. (2005/2012) Interpretation: Techniques and Exercises. Bristol: Multilingual Matters.

Paneth, E. (1958) Training for interpreting. Modern Languages: Journal of the Modern Language Association. 39(1), pp. 23-29.

Pöchhacker, F. (2010) The role of research in interpreter education [online]. Translation \& Interpreting. 2(1). Available from: www.trans-int.org/index.php/transint/article/view/80 [Accessed 31 May 2019].

Pöchhacker, F. (2016) Introducing Interpreting Studies. 2nd ed. London and New York: Routledge.

Pöchhacker, F. and Shlesinger, M. (2002) The Interpreting Studies Reader. London and New York: Routledge.

Ramler, S. (2008) Nuremberg and Beyond: The Memories of Siegfried Ramler from 20th Century Europe to Hawai' $i$. Kailua: Aluna Press.

Roland, R. (1999) Interpreters as Diplomats: A Diplomatic History of the Role of Interpreters in World Politics. Ottawa: University of Ottawa Press.

Rothman, E.N. (2015a) Dragomans, in Pöchhacker, F. (ed) The Routledge Encyclopedia of Interpreting Studies. London and New York: Routledge. pp. 119-124.

Rothman, E.N. (2015b) Jeunes de Langues, in Pöchhacker, F. (ed) The Routledge Encyclopedia of Interpreting Studies. London and New York: Routledge. pp. 217-220.

Rozan, J.F. (1956) La Prise de Notes en Interprétation Consécutive. Geneva: Georg.

Saldanha, G. and O’Brien, S. (2013) Research Methodologies in Translation Studies. Manchester: St. Jerome Publishing. 
Sawyer, D.B. (2004) Fundamental Aspects of Interpreter Education: Curriculum and Assessment. Amsterdam and Philadelphia: John Benjamins.

Sawyer, D.B. (2015) Curriculum, in Pöchhacker, F. (ed) The Routledge Encyclopedia of Interpreting Studies. London and New York: Routledge. pp. 96-99.

Sawyer, D.B. (2016) The U.S. Department of State's corps of student interpreters: A precursor program to the interpreting of today? in Takeda, K. and Baigorri-Jalón, J. (eds) New Insights into the History of Interpreting. Amsterdam and Philadelphia: John Benjamins. pp. 99-133.

Sawyer, D.B., Austermühl, F. and Enríquez Raído, V. (2019) The evolving curriculum in interpreter and translator education: A bibliometric analysis, in Sawyer, D., Austermühl, F. and Enríquez Raído, V. (eds) The Evolving Curriculum in Interpreter and Translator Education: Stakeholder Perspectives and Voices. Amsterdam and Philadelphia: John Benjamins. pp. 1-22.

Sawyer, D.B. and Roy, C.B. (2015) Education, in Pöchhacker, F. (ed) The Routledge Encyclopedia of Interpreting Studies. London and New York: Routledge. pp. 124-130.

Seleskovich, D. and Lederer, M. (1989) Pédagogie raisonée de l'interprétation. Paris and Brussels: Didier Érudition/OPOCE.

Setton, R. and Dawrant, A. (2016) Conference Interpreting: A Complete Course. Amsterdam and Philadelphia: John Benjamins.

Takeda, K. (2010) What interpreting teachers can learn from students: A case study. Translation \& Interpreting. 2(1), pp. 38-47.

Takeda, K. and Yamada, M. (2019) "TI literacy" for general undergraduate education, in Sawyer, D., Austermühl, F. and Enríquez Raído, V. (eds) The Evolving Curriculum in Interpreter and Translator Education: Stakeholder Perspectives and Voices. Amsterdam and Philadelphia: John Benjamins. pp. 53-73.

Timarová, S. (2015) Aptitude testing, in Pöchhacker, F. (ed) The Routledge Encyclopedia of Interpreting Studies. London and New York: Routledge. pp. 17-20.

Tiselius, E. (2015) Expertise, in Pöchhacker, F. (ed) The Routledge Encyclopedia of Interpreting Studies. London and New York: Routledge. pp. 152-155.

Translators Association of China (TAC) (n.d.). Curricula for TAC's TOT Program in Translation and Interpretation at the Undergraduate Level [online]. Available from: http://tac-online.org.cn/en/ tran/2009-10/09/content_3174985.htm [Accessed 05 June 2019].

van Dam, I.M. (1989) Strategies of simultaneous interpretation: A methodology of training simultaneous interpreters, in Gran, L. and Dodds, J. (eds) The Theoretical and Practical Aspects of Teaching Conference Interpretation. Udine: Campanotto Editore. pp. 167-176.

Weber, W. (1984) Training Translators and Conference Interpreters. Orlando: Harcourt Brace Jovanovich.

Weber, W. (1989) Improved ways of teaching consecutive interpretation, in Gran, L. and Dodds, J. (eds) The Theoretical and Practical Aspects of Teaching Conference Interpretation. Udine: Campanotto Editore. pp. 161-166.

Williams, J. and Chesterman, A. (2002) The Map: A Beginner's Guide to Doing Research in Translation Studies. Manchester: St. Jerome Publishing.

Yan, J.X., Pan, J. and Wang, H. (2018) Research on Translator and Interpreter Training: A Collective Volume of Bibliometric Reviews and Empirical Studies on Learners. Singapore: Springer. 


\title{
Teacher agency in plurilingual learning contexts
}

\author{
Olga Esteve
}

\section{Introduction}

In the field of teacher education in Europe, there is currently a widespread debate about what must be improved, in order for additional languages teachers (henceforth ALs-teachers) foster plurilingual education in school settings, as promoted by the most comprehensive European reference for AL learning and teaching, the Common European Framework of Reference for Languages (CEFR). Within this debate, educational institutions propose different pedagogical approaches for plurilingual education.

Embracing a plurilingual language teaching perspective is, however, not an easy task for language teachers. Many find it difficult to appropriate the plurilingual approaches now favoured by educational institutions. Since teaching practices are driven by the teachers' own beliefs and understandings, adopting a plurilingual approach certainly involves deeply reconceptualizing teachers' current - mostly monolingual - classroom practices.

For this reason, as Lantolf and Esteve (forthcoming) point out, AL teacher education should be based neither on theoretical instruction on what is to be taught and how, nor on one-off experiences provided by workshops and/or a few hours of classroom instruction. Instead, it should first challenge teachers' own beliefs about language and the way they teach it. Put in another way, AL teacher education should help AL-teachers see language learning and teaching through a new lens. This, in turn, would enable them to reshape their pre-understandings, reframe their current classroom practices and engage in new ones.

In this vein, some authors (Johnson 2006, 2009; Negueruela 2011; Johnson and Golombek 2016; Esteve et al. 2017; Esteve 2018) report and document the benefits of socioculturally based teacher education programmes that focus on teachers' agency to promote teachers' professional development. These benefits derive from the finding that such formative programmes help teachers both overcome negative attitudes towards new pedagogical approaches and adopt those approaches in significant ways.

Agency-driven teacher professional development represents a complex process encompassing the whole of the teacher's persona, i.e. not only the contextual and structural factors of their teaching environment, but also their experiences and pre-understandings along with their personal interpretations of these experiences and pre-understandings (Johnson 2009). Teacher 
agency thus emerges both from the interaction between resources and contexts and from teachers' perceptions and their use of them.

For this reason, formative interventions or teacher education programmes that aim at promoting teacher agency conceive of "teachers as individuals who both appropriate and reconstruct the resources that have been developed and made available for them while simultaneously refashioning those resources to meet new challenges" (Johnson 2009, p. 13).

\section{Historical perspectives}

Educational institutions offer different teacher education programmes to prepare teachers to effectively implement a plurilingual approach in the language classroom. The formative model that underlies those programmes is of two types: training sessions through conference and workshops, as well as collaborative work between universities and schools.

Training sessions through conferences or workshops usually involve theoretical instruction on what is to be taught and how. Regarding the impact of this kind of instruction for promoting teacher development, Lantolf and Poehner point out that it

may well provide nothing more than a set of terms teachers can use to describe - rather than challenge - their existent beliefs and practices, and it is not likely to provide the depth of understanding of a coherent theory that can be drawn upon to guide decisionmaking in the classroom.

(Lantolf and Poehner 2014, pp. 213-214)

This argument is underpinned by the results of research studies that analyze the impact of short-term sessions on teachers' transformative processes. Van Compernolle and Henery remark in their study that "short-term training sessions, which do not involve subsequent support from a more expert person, are likely to be ineffective in transforming teachers' pedagogical content knowledge, especially when this entails a radical reconceptualization of language, language learning, and language teaching" (Van Compernolle and Henery 2015, p. 371). In the same line, Lantolf and Esteve (forthcoming) conclude - after a review of transformative teacher education interventions for AL-teachers - that the ability and commitment of a teacher to implement a new pedagogical approach cannot be developed through the kind of cursory introduction to the approach that often occurs in workshops, conference presentations, or even published articles and books.

Collaborative work between universities and schools aims at jointly creating teaching materials or activities that can be transferred into the classrooms of the participant teachers. Proponents believe that gradually introducing such materials or activities will naturally expose tensions and contradictions in the prevailing monolingual model and will thus help bring about a more plurilingual one. The fact remains that there are few empirical studies that account for how AL-teachers comprehend, appropriate new pedagogical approaches, and implement them in their classrooms and, consequently, for the impact of collaborative work on transforming teachers' practices oriented towards plurilingual education (see Research approaches and key findings).

Even if one does not question the value of those formative models or their predominant role in most schools, one must acknowledge that the transformation of education practices that they strive for often falls short of expectations (Lantolf and Esteve in press). Hence, the need to rethink formative models for AL-teachers so that these models can become truly transformative (Esteve 2018). As demonstrated by Esteve et al. (2017) and Lantolf and Esteve 
(forthcoming), AL-teacher education models will become transformative only if they are based on teacher agency (Biesta and Tedder 2007; Priestley et al. 2015), a concept that I will now discuss.

Biesta and Tedder point out that the

concept of agency highlights that actors always act by means of their environment rather than simply in their environment, so that the achievement of agency will always result from the interplay of individual efforts, available resources and contextual and structural factors as they come together in particular and, in a sense, always unique situations.

(Biesta and Tedder 2007, p. 137, my emphasis)

So understood, teacher agency represents a process informed by creativity and related to what Stetsenko (2017) calls creative reconstruction. This is illustrated by a cocktail analogy as applied to agentive formative models. These models combine at least three kinds of ingredients, as cocktails do: (1) the teachers' own resources for AL-teaching, as embodying their own beliefs and representations (2) fellow teachers' equivalent resources and (3) structured and systematized didactic models based on scientific research. As with any cocktail, what matters are the principles for combining the ingredients to meet one's needs.

One of these structured and systematized didactic models is the Barcelona Formative Model, which has been successfully used to help AL-teachers adopt the didactic plurilingual approach called Integrated Plurilingual Approach or IPA (Esteve et al. 2017; Esteve and González-Davies 2017; González-Davies in this volume) over the course of a three-year formative research project. ${ }^{1}$

It is a socioculturally driven formative model of teacher education that encourages and supports language teachers in actively bringing about transformations in their own teaching practice (Esteve 2018; Lantolf and Esteve forthcoming). To this end, teachers are first provoked to critically analyze their own instructional practices and pre-understandings of specific aspects of their own teaching. Once they have engaged in that critical analysis, they are presented with systematic theoretical knowledge through organized explicit conceptual mediation. The mediation unfolds through socially mediated activities leading teachers to meaningfully reshape their previous views on language teaching (see Pedagogic approaches and methods).

\section{Research approaches and key findings}

With regard to research, I agree with González-Davies that studies regarding plurilingual practices usually stop short at the theoretical stage without contributing any specific pedagogical proposals for real classroom contexts. Even more to the point here, there are few empirical studies that account either for how AL-teachers comprehend, appropriate, and implement plurilingual approaches or for the impact of teacher education programmes at transforming monolingual classroom practices (González-Davies 2018).

Such empirical studies as do exist focus predominantly on teacher beliefs and representations of plurilingualism (Ziegler 2013; Arocena et al. 2015; Haukås 2016; Palou and Cabré 2017, among others). As a whole, these studies present fairly similar outcomes. Teachers certainly do become aware of the benefits of promoting learner plurilingual competence, but there are three considerable shortcomings to be noted. These are: (1) the transfer of learning strategies is hardly focused on, (2) joint work across languages is not yet common practice, despite being perceived as enhancing students' AL-learning, and (3) teacher beliefs are still largely monolingual and seem to change only gradually into more plurilingual ones. 
As noted, empirical studies that account for how AL-teachers appropriate and implement plurilingual approaches or for the impact of teacher education programmes in transforming monolingual classroom practices into plurilingual ones are rare. There are a few longitudinal, context-based studies, however. To them belong the four that I will now briefly discuss. The first study focuses on the evolution of beliefs (Kalaja et al. 2016) brought about through a reconceptualizing formative intervention. Its most outstanding finding is the concept of interpretative repertoires. This concept describes how teachers progressively interpret meaning and how their progressive interpretations become visible in their own discourse.

The second study specifically considers how monolingual practices evolve into plurilingual ones (Tresserras 2017). This study covers an academic year and is based on data gathered through three research instruments: ten language biographies, ten semi-structured interviews, and five discussion groups. Data analysis is carried out chronologically with the aim of tracking how the teachers' thought evolves as they confront their own beliefs and interact with their peers and the teacher educators. The most outstanding finding of the study is the observation of three evolution patterns: awareness, expansion, and transformation. Awareness involves no actual shift; teachers understand what they have been exposed to but perceive no direct link between what they have learned and their own school reality. Expansion, though, does encompass a shift, as the new emerging practices lead teachers to widen their initial schemes of knowledge. Finally, transformation goes beyond both awareness and expansion; teachers not only become aware of new practices that expand their horizon of knowledge, but also see their initial practices challenged and, as a result, reconceptualize them. As for the outcomes, expansion was the most frequent pattern, whereas transformation could be observed in the case of only two teachers. Notably, these two had the most consolidated representations of plurilingualism in the classroom.

The third study (Esteve et al. 2017) also addresses the transformation of monolingual into plurilingual practices. This study is drawn from a three-year formative research project carried out in several Spanish regions. The project's aim was to study the impact of an adapted version of the Barcelona Formative Model described earlier, which was specifically designed to help AL-teachers adopt a plurilingual, translation-favouring approach.

Following Engeström's interventionist research approach (Engeström 2011), the formative intervention associated with the project had a twofold aim: (1) exerting an influence on the system by confronting the teachers with a scientifically grounded orienting basis of action for plurilingual education, and (2) investigating the development and consequences of the ensuing formative process, a process that lasted between five and six months in each case and that was guided by members of the research project team as facilitators. Research on this formative process was based on four types of data collected at eight schools. The instruments for data collection were: (1) video-recording of focus group discussion at the beginning and the end of the process, (2) video-recording of classrooms practice during the process, (3) internal documents explaining and justifying the schools' resetting of its language teaching model (collected at the end of the process), and (4) semi- open interviews with teachers and learners at the end of the process.

As a result of the formative intervention, monolingual classroom practices became plurilingual, mostly through translation and translinguistic conceptualization (Esteve et al. 2017; Esteve 2018). That three-year formative research project has given rise to another such project that builds upon it. This fourth project, ${ }^{2}$ currently being conducted, addresses the impact of the same plurilingual approach, this time focusing on the learners' perspective. 


\section{Pedagogic approaches and methods}

Drawing on the findings and outcomes of the research project conducted by Esteve et al. (2017), the teacher agency-driven formative intervention implemented in that project has the potential to help AL-teachers significantly adopt the integrated plurilingual approach (see González-Davies this volume).

In order to orient AL-teachers towards significant plurilingual education involving an informed use of translation and translinguistic conceptualization within a communicative approach, the formative intervention developed within this project uses an adapted version of the agency-driven Barcelona formative model (Esteve 2018). In its general structure, the BFM is based on the Vygotskian double stimulation method, as developed by Engeström (2011).

Within this Vygotskian framework, the first stimulus is aimed at encouraging teachers to express their pre-understandings of plurilingualism and plurilingual education, as well as at making them aware of possible contradictions in their pre-understandings. Building on this, the second stimulus aims at helping them resolve the contradictions and reconceptualize their monolingual perspective. This happens through organized external conceptual mediation leading them towards pluringualism as they build their own practices based on their own agency (Esteve et al. 2017; Esteve 2018).

The formative process consists of five phases, as presented in the action plan for teachers in Table 25.1. This plan contains specific directions to lead them carry out the formative process.

As can be seen in the action plan in Table 25.1, the first stimulus of the Vygotskian double stimulation method develops within a single phase (1), whereas the second one stretches over four phases (2, 3, 4, and 5).

External mediation proves especially significant in phase 2 (as described in detail in Table 25.2). Two elements inform the external mediation carried out in this phase, namely essence-oriented thinking (Arievitch 2017) and the scaffolding structure of the workshop itself.

The workshop presents teachers with interrelated activities of conceptual analysis. These activities enable them to establish significant connections between their previously expressed pre-understandings and beliefs and the concepts underlying the plurilingual didactic model to be adopted.

As presented in Table 25.2, the teacher educator uses three global strategies during the formative process to help teachers both gradually enrich their own (monolingual) perspective and expand it, in a meaningful way, towards a translation-driven plurilingual approach.

The first strategy consists in presenting the teachers with the results of their pre-understandings - recorded during the first phase of the formative process - in an organized way and discussing them. In the second, teachers work on their own linguistic experiences both as speakers and as constructors of meaning in a new language. Finally, the third strategy is the use of schemes, the SCOBAs. A SCOBA, Scheme for a Complete Orienting Basis of an Action, (Gal'perin 1992), refers to a cognitive map "that captures the systematic essence of a concept in ways that are not only understandable for learners, but, at the same time, allow them to deploy the concept in a broad array of concrete goal-directed activities" (Lantolf and Poehner 2014, p. 65). Here, SCOBAs are used in the third strategy to help teachers apprehend the key concepts of the didactic model for plurilingual education to be adopted.

The conceptual mediation striven for in this kind of workshop relies on the assumption that teachers appropriate new didactic models when they see that the scientific concepts underlying these systematic theoretical models challenge the everyday empirical concepts that they have derived from their own classroom experiences (Esteve 2018; Lantolf and Esteve forthcoming). 
Table 25.1 Phases of the double stimulation method

\section{FIRST STIMULUS (one phase)}

PHASE 1. Reflective autonomous work (without the teacher instructor)

Create small groups with teachers of different ALs taught at your school and jointly discuss the following guiding questions.

- What does 'plurilingualism' mean for us?

- What linguistic reality do we experience at our school? And in our classroom?

- What role do the native language and other languages of the students play when they learn an AL that is quite distinct from it/them? And in the case of an AL close to it/them?

- What are we doing at our school to promote plurilingualism? What are we satisfied with? What not?

Do please record your reflections and send them to the teacher educator!

\section{SECOND STIMULUS (four phases)}

\section{PHASE 2. Workshop with the teacher educator and follow-up sessions of reflective} autonomous work

This is the most demanding of the reflective phases. Here, you will jointly compare your first reflections with methodological proposals for AL-teaching based upon research on bilingualism and pluringualism.

Phase 2 consists of two subphases.

a. In the first sub-phase, you will take part in a four-hour workshop in which the main concepts related to the pluringual approach will be jointly addressed. You will not be provided with explanations of these concepts generally. Instead, you will have to take a more participative role in which your point of departure will be a critical analysis of your personal experiences as language speakers and learners. Building upon these results, you will then be gradually introduced to the conceptual basis of certain plurilingual approaches.

b. In the second sub-phase, you will work autonomously. Theoretical-practical papers that present both validated plurilingual practices and the rationales behind them will be provided online by our research team for you to discuss.

PHASE 3. Reflective autonomous work to critically design new didactic proposals building upon the results of the previous reflection

In phase 3, you will jointly discuss the results from subphases $2 \mathrm{a}$ and $2 \mathrm{~b}$ in as many work sessions as necessary. Afterwards, another joint session will be scheduled. Prepare for it in advance by answering the following guiding questions:

- How do our respective starting points relate to each other?

- What has drawn our attention the most? Why?

- What has the pluringual approach led us to rethink about our AL-teaching?

- How we would like to put this into practice in our classrooms?

\section{PHASE 4. Putting the new didactic proposals into practice in the classroom}

In phase 4, you will move from "reflection" to "action". Turn the results of the previous phases right now into didactic proposals and put them into practice in your own classroom. You will need to plan sufficient time for this and to jot down everything you observe in the classroom: your students' reactions, your own perceptions. If possible, record that class; if not, take (field) notes that account for everything that you would like to comment on both with fellow teachers and with us. 
PHASE 5. Reflexive autonomous work to evaluate the results of the didactic proposal and to establish future lines of work

In this phase, you will evaluate in depth the results of your didactic proposal both individually and jointly. Don't just say what went well or bad. Review your (field) notes and then answer the following guiding questions:

- How have I personally progressed in relation to language teaching in general and plurilingual education in particular?

- How have we progressed as a group? How has my/our horizon of expectations expanded and how has my/our teaching practice been enriched?

- How much has my/our horizon of expectations and my/our teaching practice been enriched?

- What new questions have I/we come up with?

- What do we think that we still need to address?

Once each school has done this (self-)evaluation, a joint final session will be called and recorded.

Table 25.2 Phase 2: the workshop

\section{Introduction}

After having made a summary of the recorded teacher reflections in phase 1, the teacher educator presents it to the teachers as the starting point of the workshop. The summary will stay displayed throughout the workshop for teachers to come back to at the end, after they have performed the following conceptualization activities.

\section{Activity 1}

In this activity, teachers are expected to act NOT as language teachers, but rather as language learners. Accordingly, they are first confronted with a text in a language unknown to them and then asked to understand as much as possible of it. They are given the following directions, which require them to use both their own internal resources and their linguistic repertoire:

- Read the text to yourself and try to discover what it is about.

- Next, still working by yourself, underline what you do understand.

- Now, share the results of your individual work with one other teacher.

- Finally, join your pair to another pair. Working as a group of four, extract possible rules or grammatical patterns from the text.

Afterwards, each group must create a meaningful message using the vocabulary and structures that its members have understood, as well as their own linguistic "intuition". Finally, the groups must analyze how they have solved the "linguistic conflict" posed by the activity, with the help of the following guiding questions:

- How did you feel trying to discover what the text was about?

- Did you understand anything?

- Could you identify the German word for to work?

- What helped you understand the text?

- How did you feel trying to create a meaningful message in a language unknown to you? Was it fun?

- What helped you create a meaningful message without prior language instruction?

(Continued) 
Table 25.2 (Continued)

\section{Activity 2}

Teachers are presented with the following schema (SCOBA 1):

A. Is genuine and significative communication in the different languages in the school to be promoted?
B. Are linguistic awareness and conceptualization for fostering genuine communicative development to be promoted?

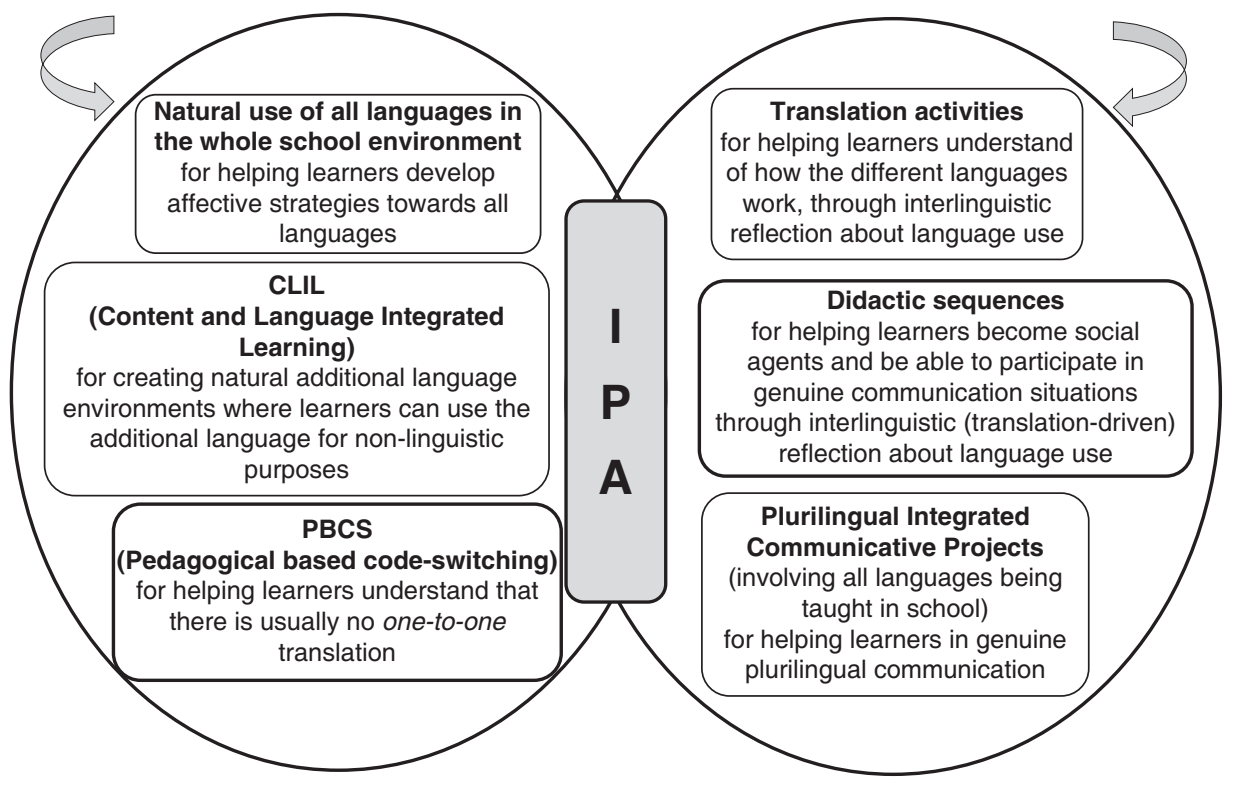

(Adapted from Esteve et al. 2017)

This presentation first involves drawing the teachers' attention to the concept of significative communication in the SCOBA through the following guiding question:

- In your view, what does 'genuine communication' entail?

The teachers are next asked to reflect on a scientific paper related to the holistic view of language

(Esteve et al. 2017), guided by these directions and the subsequent final question:

- Individually read the text and underline the concepts that are relevant to you.

- Form groups of three and explain the concepts you have chosen and the reasons why you chose them.

- Make a poster with the ideas you would like your group to present to the rest of the teachers.

- In your view, how could translation contribute to genuine communication in a given AL?

\section{Activity 3}

Drawing on the results of activity 2, the teacher educator poses a key question that goes to the essence of the IPA:

- How can translation help develop genuine communicative competence so that learners become able to act as social agents in control of the language in a variety of communicative situations?

After that, teachers are asked to compare their own answers with the explanations given by the teacher educator in relation to SCOBA 2 that follow. 


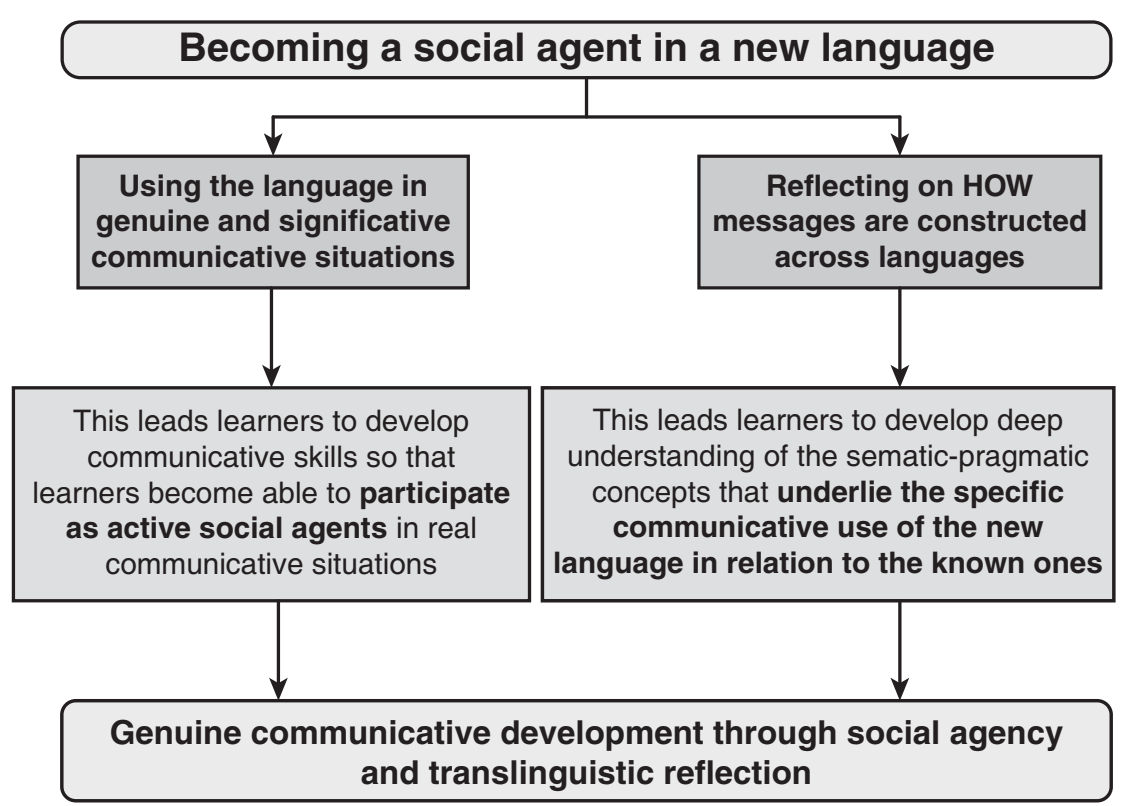

(Adapted from Esteve et al. 2017)

In presenting SCOBA 2, the teacher educator stresses the importance of keeping balanced the two strands making up the SCOBA, i.e. language use and reflection on how messages are constructed. Only if they bear this balance in mind will teachers become able to promote genuine learner communicative competence. To this end, some key concepts must be explained, as they represent the epistemological basis of the Integrated Plurilingual Approach (Esteve et al. 2017). To such concepts belong

- Didactic sequence as a pedagogical tool for blending language use and reflection on how messages are constructed,

- Discourse genre as the framework for any text, itself the basic communicative unit, and

- Pedagogical translation and translinguistic conceptualization as agency- promoting tools for interlinguistic and intercultural reflection.

\section{Activity 4}

Activity 4 presents samples of translanguaging activities, i.e. translation and translinguistic conceptualization activities embedded in didactic sequences (see the example of a didactic sequence in the annex), for teachers to reflect on with the help of the following guiding questions:

- What is a didactic sequence (like)?

- What is its purpose?

- What conclusions do you draw from this activity?

- Now that you have been exposed to the activities, what do you think are the potential benefits of using pedagogical translation and translinguistic conceptualization in the communicative AL-classroom?

Once teachers have answered the previous questions, the teacher educator explains the value of translanguaging activities framed within a didactic sequence, using the following scheme (SCOBA 3) as a guide. 


\section{TOLC AND TRANSLINGUISTIC CONCEPTUALIZATION WITHIN A DIDACTIC} SEQUENCE

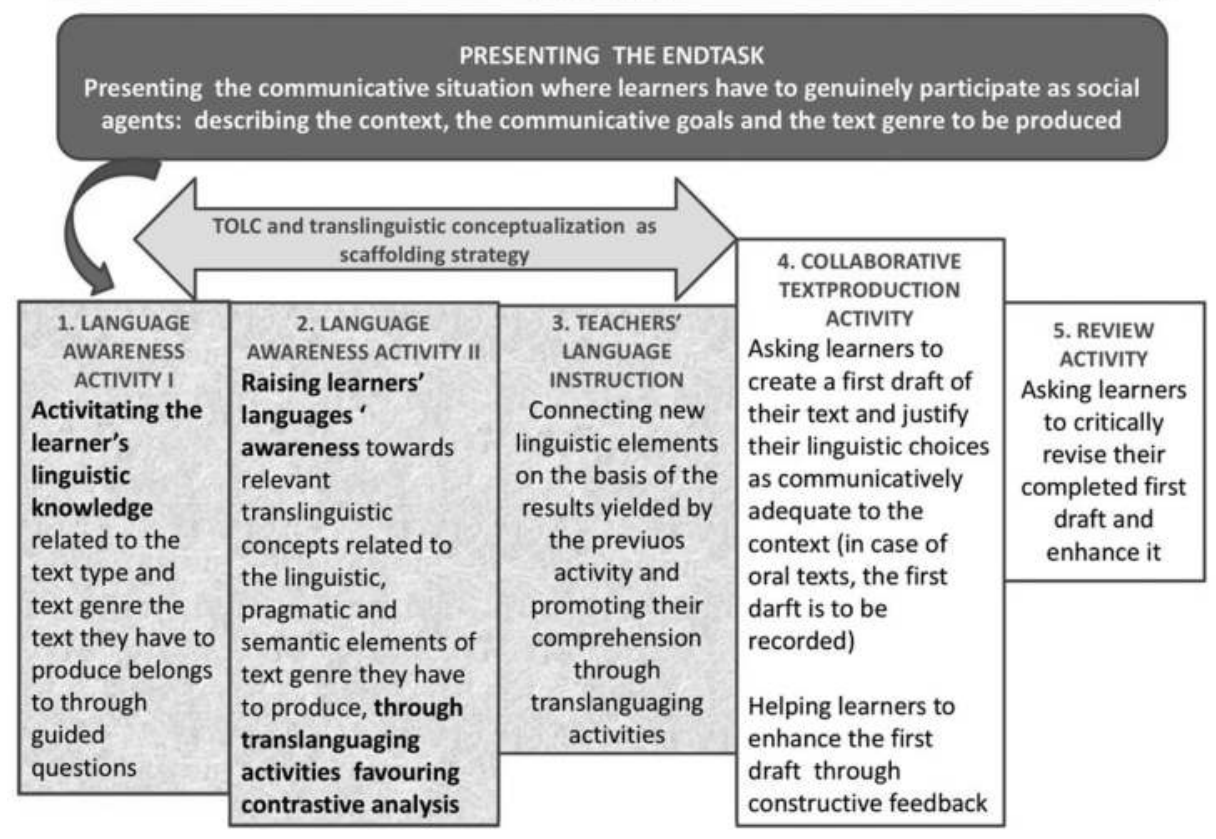

(SCOBA 3. Adapted from Esteve 2018)

This process of confrontation and challenge unfolds within the teachers' Zone of Proximal Development (ZPD), i.e. "the distance between the actual developmental level as determined by independent problem solving and the level of potential development as determined through problem solving under adult guidance, or in collaboration with more capable peers" (Vygotsky 1978, p. 86).

Instructional activity that is based upon such a confrontation process and that unfolds within teacher education programmes does not confine itself to merely transmitting theoretical knowledge untethered to real practice. Instead, it involves dynamic, agency-based knowledge construction by the teachers themselves, as oriented by the teacher educator. This active knowledge construction introduces new knowledge in a meaningful way, helping teachers develop deeply informed new insights.

According to Kozulin (2003), the scientific concepts that teacher educators make available to teachers should serve as psychological tools guiding their teaching practices. For this reason, teachers must deeply understand these concepts and not simply memorize them, if they are to actually put them into practice in their classrooms. Teacher educators, then, must carefully choose the concepts to be introduced and must carefully consider the appropriate way to do so. This twofold need is met through the SCOBAs deployed in the course of the workshop (see Table 25.2, activities 2 and 3).

The goal of SCOBA 1 is to make teachers aware that neither of the two approaches depicted in it should be favoured at the expense of the other. This is shown in the integrated way in 
which the two approaches intersect in the diagram (along the lines of the Integrated Plurilingual Approach, IPA). Teachers should, rather, fully grasp what each approach can contribute to their teaching, so that they can make informed decisions about what to use in their classrooms.

The goal of SCOBA 2 is to make teachers aware of how translinguistic reflection can help develop genuine communicative competence in the AL-classroom by enabling learners to act as social agents. According to the CEFR, social agents are "members of society who have tasks (not exclusively language-related) to accomplish in a given set of circumstances, in a specific environment and within a particular field of action" (CEFR p. 9). This view of learners as social agents performing tasks differs from that of learners as performers of non-situated speech acts, a view still prevalent in most AL-syllabuses.

The goal of SCOBA 3 is to make teachers aware of how pedagogical translation and translinguistic conceptualization can help learners learn to communicate in a given AL. They do so as they become social agents in it by carrying out didactic sequences (González-Davies 2017). Didactic sequences blend comprehension and production activities, which are necessary to communicate, with reflection activities, which are necessary to complete the final task of the sequence. This task unfolds within a specific communicative situation requiring specific linguistic elements. These, in turn, are produced and manipulated by the learners through reflection activities including pedagogical translation and translinguistic conceptualitzation. As a result, the linguistic elements to be worked are those relevant to the communicative situation in question, which ensures the functionality of what is being learned through interlinguistic reflection.

\section{Conclusions and future directions}

Vygotskian based formative interventions aim to construct new forms of activity jointly with the local participants. Such construction can be successful only when it is based on careful historical and empirical analyses of the activity in question (Engeström 2011). The data considered in this chapter about the impact of the Vygotskian teacher education model presented in promoting translation-driven plurilingual approaches confirm that this kind of formative intervention can be successfully appropriated and implemented in schools. This formative intervention, thus, has tremendous potential to help teachers agentively transform their own practice.

The use of this model is intended to promote new understandings and ways of acting. This happens first through the critical analysis of the teachers' system of activity, i.e of their classroom reality, as informed by their own beliefs and understandings. Next, their reality is expanded as their pre-understandings of plurilingualism are challenged by scientifically validated didactic models. Finally, the essence of these models is finally addressed, including their pros and cons, so that teachers can be led towards informed decision making.

Drawing on the definition of agency as emerging from the interaction between resources and contexts and the learners' perceptions and use of them, prescriptive and transmissive formative models should be progressively replaced by models favouring agentive formative activity (Esteve 2018). These models promote a significative internalization of the new concepts - that is, they promote a process in which the learners' perceptions and practices undergo "successive qualitative transformations during the mastery of a given activity" (Arievitch 2017, p. 94).

Accordingly, what teachers internalize through agentive formative models is not identical with the external models provided. Rather, it is the result of a process of creative reconstruction 
(Stetsenko 2017). That process should, thus, be promoted in every teacher education programme, as is the case with the formative model presented. This is so because, in agentive formative models, teachers themselves engage in a dialectic process between what they feel to be theirs and what is new to them. As a result, they create a model of 'their own' under the constructive guidance of experts.

By constructive I mean guidance that significantly orients teachers towards what they must assimilate. Such an orientation requires far more than theoretical explanations of the didactic model to be appropriated and how to best foster it. Those explanations, while somewhat useful, are far from sufficient. The teacher educator must, in addition, help teachers grasp the principles that underlie the specific didactic model through work on SCOBAs (as in the case of the SCOBAs related to the Integrated Plurilingual Approach). In grasping these principles, teachers will also develop a deep understanding of the didactic model(s) provided, which in turn will give them solid criteria that will enable them to informedly create their own didactic model.

As for future directions, I deem it essential that further research be conducted on how teachers make sense of scientific concepts related to plurilingual education as introduced through organized external mediation like the one presented in this chapter. That research should also include the effects of such mediation as considered from teachers' agency. This, in turn, involves gaining insights into the plurilingual models teachers create for themselves: how they create them and what key concepts they use.

\section{Further reading}

Corcoll, C. and González-Davies, M. (2016) Switching codes in the additional language classroom. ELT Journal. 70(1), pp. 67-77.

In this article, the authors present a rationale for an informed use of code-switching and translation in the AL-classroom. It encourages teachers to adopt a plurilingual approach by presenting and discussing realistic tasks that can be easily included in the foreign language syllabus.

Negueruela, E. (2011) Beliefs as conceptualizing activity: A dialectical approach for the second language classroom. System. 39, pp. 359-369.

This article aims to help teachers, teacher educators, and researchers reconsider the specific relationships between teachers' beliefs and actions. It also presents a specific research methodology, semiogenesis, which captures the orienting power of beliefs as teachers conceptualize activity in the classroom.

Esteve, O. (2018) Concept-based instruction in teacher education programs in Spain as illustrated by the SCOBA-mediated Barcelona Formative Model, in Lantolf, J., Poehner, M.E. and Swain, M. (eds) The Routledge Handbook of Sociocultural Theory and Second Language Development. New York: Routledge. pp. 487-504.

This chapter describes the agency-driven formative model referred to in the present article (the Barcelona Formative Model or BFM). More precisely, it focuses on how the BFM helps AL-teachers understand the principles of 'translinguistic conceptualization', appropriate them significantly and, thus, promote plurilingual education as they build their own practices based on their own agency.

\section{Related topics}

teacher agency, plurilingual education, teachers' zone of proximal development, concept-based instruction in teacher education 


\section{Notes}

1 Research project: "Diseño y Experimentación de un modelo didáctico para el fomento de la competencia plurilingüe en la enseñanza-aprendizaje de lenguas extranjeras" funded by the Spanish government (Reference: EDU2012-38452), led by Dr. Olga Esteve (Universitat Pompeu Fabra).

2 Research project: "Estudio exploratorio del impacto del Enfoque Plurilingüe Integrador (EPI) en centros educativos como modelo orientativo para el profesorado de lenguas adicionales" funded by the Spanish government (Reference: EDU2016-75874-P), led by Dr. Maria González-Davies (Ramon Llull University, Barcelona).

\section{References}

Arievitch, I. (2017) Beyond the Brain. An Agentive Activity Perspective on Mind, Development, and Learning. Rotterdam: Sense Publishers.

Arocena, E., Cenoz, J. and Gorter, D. (2015) Teachers' beliefs in multilingual education in the Basque country and in Friesland. Journal of Immersion and Content-based Language Education. 3(2), pp. 169-193.

Biesta, G.J.J. and Tedder, M. (2007) Agency and learning in the life course: Towards an ecological perspective. Studies in the Education of Adults. 39, pp. 132-149.

Corcoll, C. and González-Davies, M. (2016) Switching codes in the additional language classroom. ELT Journal. 70(1), pp. 67-77.

Engeström, Y. (2011) From design experiments to formative interventions. Theory and Psychology. 21(5), pp. 598-628.

Esteve, O. (2018) Concept-based instruction in teacher education programs in Spain as illustrated by the SCOBA-mediated Barcelona Formative Model, in Lantolf, J., Poehner, M.E. and Swain, M. (eds) The Routledge Handbook of Sociocultural Theory and Second Language Development. New York: Routledge. pp. 487-504.

Esteve, O. and González-Davies, M. (2017) Estratègies de transferència interlingüística en l'aprenentatge de llengües addicionals: un Enfocament Plurilingüe Integrador, in Pereña, M. (ed) Ensenyar i aprendre llengües en un model educatiu plurilingüe. Barcelona: Horsori. pp. 6-16.

Esteve, O., Fernández, F., Martin Peris, E. and Atienza, E. (2017) The integrated plurilingual approach: A didactic model providing guidance to Spanish schools for reconceptualizing the teaching of additional languages. Language and Sociocultural Theory. 4(1), pp. 1-24.

Gal'perin, P.I. (1992) Stage-by-stage formation as a method of psychological investigation. Journal of Russian and East European Psychology. 30(4), pp. 69-80.

González-Davies, M. (2017) The use of translation in an integrated plurilingual approach to language learning: Teacher strategies and good practices. Journal of Spanish Language Teaching. 4(2), pp. 124-135.

González-Davies, M. (2018) Research project 'The Integrated Plurilingual Approach (IPA): A case study in Barcelona', in A Quality Assurance Matrix for CEFR Use: Examples of Promising Practices. European Centre for Modern Languages. Available from: www.ecml.at/CEFRqualitymatrix.

Haukås, A. (2016) Teachers' beliefs about multilingualism and a multilingual pedagogical approach. International Journal of Multilingualism. 13, pp. 1-11.

Johnson, K. (2006) The sociocultural turn and its challenges for L2 teacher education. TESOL Quarterly. 40(1), pp. 1-14.

Johnson, K. (2009) Second Language Teacher Education. A Sociocultural Perspective. New York: Routledge.

Johnson, K. and Golombek, P. (2016) Mindful L2 Teacher Education. A Sociocultural Perspective on Cultivating Teachers' Professional Development. New York: Routledge.

Kalaja, P., Barcelos, A.M.F, Aro, M. and Ruohotie-Lyhty, M. (2016) Beliefs, Agency and Identity in Foreign Language Learning and Teaching. London: Macmillan. 
Kozulin, A. (2003) Psychological tools and mediated learning, in Kozulin, A., Gindis, B., Agevey, V.S. and Miller, S.M. (eds) Vygostky's Educational Theory in Cultural Contexts. Cambridge: Cambridge University Press. pp. 15-38.

Lantolf, J.P. and Esteve, O. (forthcoming) Concept-based instruction for concept-based instruction: A model for language teacher Education, in Sato, M. and Loewen, S. (eds) Evidence-Based Second Language Pedagogy: A Collection of Instructed Second Language Acquisition Studies. New York: Routledge. pp. 27-51.

Lantolf, J.P. and Poehner, M.E. (2014) Sociocultural Theory and the Pedagogical Imperative in L2 Education. Vygotskian Praxis and the Theory Practice Divide. New York: Routledge.

Negueruela, E. (2011) Beliefs as conceptualizing activity: A dialectical approach for the second language classroom. System. 39, pp. 359-369.

Palou, J. and Cabré, M. (2017) Beliefs regarding plurilingual competence: The perspective in Catalonia through a case study of a pre-service teacher. Modern Journal of Language Teaching Methods (MJLTM). 7(8), pp. 63-75.

Priestley, M., Biesta, G.J.J. and Robinson, S. (2015) Teacher agency: What is it and why does it matter? in Kneyber, R. and Evers, J. (eds) Flip the System: Changing Education from the Bottom Up. London: Routledge. pp. 1-11.

Stetsenko, A. (2017) The Transformative Mind. Cambridge: Cambridge University Press.

Tresserras, E. (2017) Contradiccions que emergeixen de la reflexio sobre la pràctica docent en contextos plurilingües $i$ interculturals. Unpublished PhD dissertation, University of Barcelona.

van Compernolle, R.A. and Henery, A. (2015) Learning to do concept-based pragmatics instruction: Teacher development and L2 pedagogical content knowledge. Language Teaching Research. 19, pp. 351-372.

Vygotsky, L. (1978). Mind in Society. The Development of Higher Psychological Processes. Cambridge, MA: Harvard University Press.

Ziegler, G. (2013) Multilingualism and the language education landscape: Challenges for teacher training in Europe. Multilingual Education. 3(1), pp. 1-22. 


\section{Annex}

Example of a didactic sequence for B1-B2 learners of Spanish as additional language at adult education in Germany (Author: Master student Laia Sánchez).

\section{German-Spanish language-exchange partner sought}

LEVEL: Intermediate (B1-B2 of the CEFR)

SETTING: You have set up a German-Spanish speaking group on Facebook in order to seek a language-exchange partner to practice your Spanish.

END TASK: Writing a brief self-description in Spanish introducing yourself and helping you find a suitable language-exchange partner on Facebook.

\section{Activity 1. Warming-up}

1.1. Do you know what a language exchange is?

1.2. Have you ever learned with a language-exchange partner?

1.3. What was your experience like (positive, negative, etc.)? Why?

1.4. How can you find a language-exchange partner?

\section{Activity 2: Language research}

2.1. Think of a self-description in your own language, answer the following questions and fill in section $a$ and $b$ of the following grid:

- What texts are these?

- What information do they provide?

- What words are predominant in such texts? Make a list with your classmates?

- What verbs are predominant? What do we use them for? 
a. Predominant words in a self-description in my L1 b. Used for

c. Can I find corresponding expressions in the text in the new language?

2.2. Now read the self-descriptions in Spanish from two people seeking a language-exchange partner on Facebook and analyze them guided by the results of the previous reflection (the teacher hands out several self-descriptions and asks the following questions). Fill in section c of the grid.

2.3. Now let us focalize on the difference between two important verbs that appear in the texts, ser/estar. In German there is only one verb, sein, for expressing both meanings in Spanish. Working in small groups, we search in the self-descriptions in Spanish for further samples of sentences with both ser and estar + adjective and try to infer a rule accounting for their use

NORM? EXPLANATION?

Ser + adjective

Estar + adjective

2.1. The preceding verb grid is jointly discussed and the teacher asks the learners if the possible German equivalents function in the same way.

2.2. Now, we focus on the verbs ser and estar [both equivalent to the verb to be] when followed by adjectives. Is there anything which calls our attention? Are both alike? How do their equivalents function in German? Do you know other languages with the same twofold distinction?

2.3. Working in small groups, we search in the self-descriptions for further samples of sentences with both ser and estar + adjective and try to infer a rule accounting for their use

NORM? EXPLANATION?

Ser + adjective

Estar + adjective

2.8. The teacher writes down the different norms inferred by the learners. Do some of them coincide? In which aspects are they similar and in which do they differ?

\section{Activity 3. Systematizing the findings gained}

3.1. The teacher provides the learners with a copy of learning guidelines for using ser/estar.

3.2. Sub-activities aimed to raise learner linguistic awareness are introduced. 
3.2.1. Complete in pairs the following sentences with the correct form of ser or estar. You may use the guidelines as needed.

- Marta de Barcelona, pero ahora vive en Madrid.

[Marta from Barcelona, but now she is living in Madrid] EXPLANATION

- A: Oye, ¿sabes dónde la conferencia de mañana?

- $\quad$ A : Hi, do you know where the lecture tomorrow ?]

B: Creo que sí, en el auditorio.

[B: I think so, it in the lecture room]

EXPLANATION:

- $\quad$ Por lo que me han dicho, los ponentes de la conferencia de mañana prestigiosos investigadores en el ámbito de la lingüística.

- $\quad$ As far as I have been told, the speakers at the lecture tomorrow are prestigious researchers in the field of linguistics]

EXPLANATION

$\bullet \quad \ldots$

3.2.2. Sara, a former German exchange student who lived in Madrid for some months a couple of years ago, has recently moved to London to refresh her English. Now, she has just written an email to a Spanish friend where she has got the verbs ser and estar wrong. Check her email by using the ser/estar guidelines and correct any possible mistakes

\section{Sara's text}

(...)

\section{Activity 4. Text production}

4.1. Before setting to write, let us consider what we want to tell our future language-exchange partners.

\begin{tabular}{l|l|l}
\hline $\begin{array}{l}\text { What do we mean? What } \\
\text { information do we want to } \\
\text { convey? }\end{array}$ & $\begin{array}{c}\text { Can we express the desired } \\
\text { information in Spanish? }\end{array}$ & $\begin{array}{c}\text { What expressions in our L1 would } \\
\text { we like to use? How can we } \\
\text { express them in Spanish? }\end{array}$ \\
\hline & & \\
\hline
\end{tabular}

4.2. Now, write out your text individually without using the ser/estar guidelines. It must be a brief self-description between 80 and 100 words in length and include sentences with ser and/or estar followed by adjectives.

4.3. After completion, check your text with the ser/estar guidelines and modify it as needed. Then hand it in to the teacher. 


\title{
Developing mediation competence through translation
}

\author{
Maria González-Davies
}

\section{Introduction ${ }^{1}$}

Translation pervades most academic fields and everyday communication practices. Therefore, it seems reasonable to inquire into its learning potential for other fields besides translator training to achieve interdisciplinary networking. In this line, here we will explore the use of translation in learning contexts that are not exclusively related to training professional translators. This starting point suggests that distinctive traits may be discerned between what may be called translation for other learning contexts (TOLC), here defined as translation to acquire linguistic and intercultural mediation skills in fields other than translator training, and translator and interpreter training proper, that is, translation to acquire professional translator competence (González-Davies 2012, 2014, 2017). TOLC works on a continuum that spans elementary language learning and advanced language services and, so, many of its features may also cover language learning and intercultural mediation as a key aspect of translator training (see Harris ahead).

Recently, a shift from a monolingual to a plurilingual paradigm in (language) learning is increasingly becoming visible through the publication of studies and experiences that describe efficient uses of mediation skills to develop plurilingual and intercultural competence and, so, to reconcile these related disciplines.

Although translator training and language learning developed separately at first, the need for effective communication in a globalized world stimulated interest in exploring and applying the means for people with different languages and backgrounds to understand each other. Rather than relying on intuition and goodwill to succeed in managing the languages and cultures that now coexist on an everyday basis, specific skills are deemed necessary to prepare competent plurilingual speakers. This need has brought about an increase in research and observation of best practices related to the development of mediation skills, including translation literacy.

Here, we will briefly outline how ideas regarding the integration of previously known languages in foreign language learning have evolved from the grammar-translation method to an informed integrated plurilingual approach (IPA). We will then explore how the students' linguistic repertoire can be integrated in the language learning process and will finally focus 
on translation as a key skill and a strategy for advancing mediation skills in fields other than professional translator training, that is, we will focus on the IPA and on TOLC

\section{Historical perspectives}

Professional translator and interpreter training advanced significantly at the turn of the $21 \mathrm{st}$ century. Pedagogical approaches drew mainly from education studies, psychology and foreign language learning. Translation and interpreting degrees, along with post-graduate and doctoral programmes, boomed in the 1980s and extended to most countries. At the same time, thorough research on the topic flourished. Simultaneously, new perspectives in language learning designed to incorporate the social demands of globalization and findings in neuroscience related to brain connectivity in learning processes paved the path for innovative pedagogical practices.

For centuries, however, the grammar-translation method ruled in foreign language learning. Teachers and students usually shared the same language and could relate it to the new (foreign) language through translation. However, the alleged connection between both languages (known and new) was established largely through the memorization of bilingual vocabulary lists and the translation of contrived sentences, both of which held little relation to natural everyday translation practice and certainly none to professional translation practice. In the grammar-translation - or Prussian - method, still used in certain educational settings, the sessions usually develop in the students' native language, and reading and writing are the main skills practised. The original aim was the study of literature grounded in the study of Latin and classical languages. The aim here is not to go into the history and nature of grammar-translation since this has already been done comprehensively (cf. Richards and Rodgers 1986/2014; Cook 2010), but to focus on how the approaches to the use of translation have evolved, especially since the 1980s with the rise of translation studies to finally conclude in translanguaging practices "which have emerged to refer to the more flexible use of resources from more than one 'language' within a single system, transcending traditional understandings of separate languages" (Anderson 2017, p. 2, original emphasis) (cf. also Williams 1996; Bachmann-Medick 2009; García 2009; Meier 2017; Carreres et al. 2018).

Towards the end of the 19th century, scholars who favoured a paradigm based on meaningful learning and language as communication introduced the reform movement (cf. the work of Jespersen, Klinghardt, Passy, Sweet or Viëtor, for example, in Cook 2010, pp. 4-9). Here, speech and phonetics (transcriptions) were emphasized along with instruction in the foreign language. In those days, as Cook (2010, p. 5) notes, "the reformers were not excessive or fanatical in their attitude to translation, acknowledging a role for it, and allowing its judicious use. The Reform Movement resulted in the Natural Approach and the Direct Method", that is, "any teaching which excludes use of the students' own language from the classroom, whether for translation or for explanation and commentary" (Cook 2010, p. 7).

This rejection of translation was accentuated in the 1970s when the first traces of globalization entailed that native speakers travelled and taught worldwide and, so, students from different geographical, linguistic, and cultural backgrounds converged in the classrooms. Thus, the situation where the local teacher and the students shared the same languages altered. Consequently, any meaningful connections between them were relegated to the background.

Additionally, the 'Threshold Level' document (van Ek 1975), launched by the Council of Europe, set the foundations for the communicative approach that still predominates today and is characterized mainly by interaction, the focus on everyday language use, student autonomy, task-based learning and project work. Many aspects of this student-centred pedagogical 
framework can be applied to the IPA and TOLC. However, there is a crucial conceptual gap between both approaches related to the monolingual assumption supported by the premises underlying the so-called natural and communicative approaches, mainly: (1) L2 = L1, i.e. a second language should be learned in the same way as children learn their first one; (2) the L1 should not be used because it causes irreversible interference; and (3) the aim of the foreign language learner is to master the foreign tongue, so a native speaker is the best teacher.

Thus, in the communicative approach languages are kept in strictly separated compartments, the teacher eventually provides the correct answer and sets the learning outcomes, and 'Foreign Language Only' learning environments are favoured so that the potential contact areas between other languages and cultures are seldom explored.

Most government regulations backed this 'Foreign Language Only' principle, a widely accepted practice also demanded by students and parents in schools and institutions. In its heyday, to ensure its implementation by teachers, absurd situations sometimes occurred where cameras were placed in classrooms by Heads of Study, or where non-native teachers from the same community as their students translated their names and pretended that they could not speak the students' language. Thus, a puzzling situation ensued in which students with access to, at least, one other language, were compelled to think and act monolingually in the foreign language classroom, allegedly, in order to become plurilingual speakers.

Nowadays, international mobility has brought forward the need for linguistically prepared citizens, preferably with developed mediation skills (e.g. oral and written translation, or intercultural competence). Moreover, findings in neuroscience related to connectivity in the brain and a growing awareness of the key role played by heritage languages regarding identity issues, now favour research and best practices to explore the potential contact areas between languages and disciplines. The shift from "shared-L1 classrooms" to "mixed-L1 classrooms" (Anderson 2017, p. 2) has triggered the need for research to elucidate how to make the most of the new situation and suggest optimal translanguaging practices (cf. Cummins 1984, 2008, 2018; Corcoll 2011; Corcoll and González-Davies 2015; González-Davies 2017; Meier 2017; Wilson and González-Davies 2017).

Certainly, the monolingual paradigm is being questioned as more and more informed evidence is brought to bear to show that the spontaneous use of prior knowledge ('own' and 'previous' languages) on the part of the learner is a natural learning strategy. Clearly, translation stubbornly remained amidst this monolingual approach as is ratified time and again in surveys sent out to gauge the use of translation by teachers and students (cf. Macaro 2001; González-Davies 2002; Pym et al. 2013). Teachers' responses coincide in reflecting misgivings for not following the principles of the communicative approach which had shaped their professional training, for not regarding themselves as bilinguals, and for fearing that their students' progress would be hampered by interference problems if they allowed other languages in the classroom. Most teachers relate 'use of translation' to translating the odd word or grammatical form, or to using the mother tongue in the classroom, and cannot imagine creative and communicative uses. On the other hand, the students have no qualms in expressing that they use translation as a learning strategy in general. The situation may be summarized as follows (Hall and Cook 2013, p. 27):

Overall, therefore, our study suggests that teachers' attitudes towards own-language use, and their classroom practices, are more complex than are often acknowledged ... It seems that there is a potential gap between mainstream ELT literature and practice on the ground, a gap that should prompt further investigation of this central practice within English language teaching. 
This setting also brought about a power struggle between native and non-native teachers with the latter at the losing end. In the IPA these differences may be smoothed out, as now linguistically competent teachers with strong translanguaging skills are required, whether native or non-non-native.

The practical reconciliation between translation and foreign language learning was pioneered by Alan Duff (see Further reading). An increasing number of authors followed his path and have published best practices based on research around translation in language learning, as will be seen in the next section.

\section{Research approaches and key findings}

Little research was carried out on the grammar-translation method or on the communicative approach and its forerunners:

So successful were the Direct Method criticisms of [Translation in Language Teaching] TILT that . . . from the 1990s until very recently, there has been virtually no discussion of it in the mainstream language literature. It is not that it was considered, assessed, and rejected, with reasons given for that rejection, but rather that it was simply ignored.

(Cook 2010, pp. 20-21)

In the 20th century, two periods of research may be differentiated regarding the use of the L1(s) in foreign language learning: before and after the 1990s (Widdowson 2003; Cook 2010; Corcoll 2011). In the first case, research was usually carried out to observe and describe if and when the L1 was used, and was typically followed by proposals to abolish its use for different reasons. In the second, a "climate for revival" emerged with the positive recognition of bilingualism and the emergence of a "postmonolingual condition" (Cook 2010, p. 37). Indeed, after the 1990s, research has largely leant towards observing how, when and why the L1(s) are used, and trying to pin down their actual contribution to language learning. The emphasis now is not on whether plurilingualism is detrimental but on how translanguaging practices can be implemented in an informed way, a sea change in the focus of research on plurilingualism and its applications.

In the IPA translation is considered to be both a process and a product of communication. As a process, translation is defined as "a dynamic process of communication" (Hatim and Mason 1990, p. 223). As a product, an appropriate translation is "any text that is accepted in the target culture as being a translation" (Chesterman 1997, p. 59). To differentiate it from code-switching and use of the L1(s), it is defined as an informed change of linguistic or cultural code applied consciously to an explicit primary source text, whether verbal or non-verbal (González-Davies 2014, p. 11).

At present, research around translation in language learning per se is still scarce. However, studies are emerging in the light of linguistic mediation as expressed, for example, in the CEFR Companion Volume with New Descriptors (2018, p. 175):

Translation or interpretation, a paraphrase, summary or record, provides for a third party, a (re)formulation of a source text to which this third party does not have direct access. Mediation language activities, (re)processing an existing text, occupy an important place in the normal linguistic functioning of our societies. 
This perspective refers directly to language brokering practices carried out continuously by travellers, businesspeople, academics, migrants and their children, and many others in diverse contexts such as education, healthcare or community interpreting. Other kinds of non-professional translation take different forms such as crowdsourcing on the Internet, that is, "the practice of obtaining needed services, ideas, or content by soliciting contributions from a large group of people and especially from the online community rather than from traditional employees or suppliers" (Merriam-Webster 2019); volunteer translation used for translation of post-catastrophe emergency messages; fan-subtitling of TED talks or YouTube; humanitarian translation work (cf. 'Translators without borders'); or commercial and open-source software projects such as the translations of literary sagas and popular TV series. However, with no training and with mistaken notions regarding the simplicity of translation, this activity has often led to a proliferation of erroneous transfers and howlers. Research into all these points is closely related to the IPA in that it aims at affording appropriate skills for efficient linguistic mediation.

\section{An integrated plurilingual approach (IPA) to language learning}

Once we stop pretending that we do not have a previous language (or languages) and shift our beliefs to embrace research on brain connectivity, we can openly explore natural plurilingual practices in formal and informal social and pedagogic contexts, and a whole new teaching and learning perspective opens up. This shift also entails doing away with the requirement to attain a native speaker level as the final aim of language learning is to work towards developing proficient mediation skills that enable efficient communication between people from different languages and cultures.

The IPA distinguishes between multilingualism and plurilingualism in that it takes the former to refer to the coexistence of languages and cultures, although in separate mental compartments. Inversely, the main aim from a plurilingual standpoint is to help teachers implement practices to move away from teaching languages separately and, rather, favour establishing connections to the students' real linguistic repertoire and identities, progressing towards "reimagining [Foreign Language] classrooms as translingual environments" (Anderson 2017, p. 8). This is in line with the approach adopted by the Common European Framework of Reference for Languages (CEFR) in the 2001 edition and now revisited and confirmed in the New Companion Volume: "plurilinguals have a single, inter-related, repertoire that they combine with their general competences and various strategies in order to accomplish tasks" (2018, p. 9).

The IPA principles for research and best practices draw mainly on Cummins' common underlying proficiency model or interdependence hypothesis (1984), which is in opposition to the interference hypothesis upheld by the direct method. Cummins argues that, although the visible surface of each language differs, underlying (meta)cognitive knowledge and know-how makes connections between the languages possible (for example, phonological, syntactic, textual, stylistic or lexical aspects). Specifically regarding translation, he challenges what he calls the 'No Translation Assumption' (2007, p. 222) and ratifies at a later stage that "the argument is that translation has a role to play within a broadly defined communicative approach as a means of enabling students to [.. .] communicate in powerful and authentic ways with multiple audiences in both L1 and L2" (2008, p. 65). Also, his distinction between Basic Interactive Communication Skills (BICS) and Conversational Advanced Linguistic Procedures (CALP) (Cummins 1979,2005 ) brought about a substantial change in understanding how and when the transfer of underlying knowledge and skills acquired in one language can benefit the acquisition of another.

Additionally, the IPA draws on 'multi-competence', a concept coined and updated by V. Cook as "the overall system of a mind or a community that uses more than one language" 
(2016, p. 2). His aim is to study how the acquisition of more than one language seems to favour an expanded cognitive capacity that goes beyond the linguistic sphere to encompass and connect other aspects of learning. These capacities may include an efficient use of lower and higher order thinking skills, i.e. remembering, understanding, applying, analyzing, evaluating, and creating (Bloom 1956, revised in Anderson and Krathwohl 2001) and high-level cognitive proficiency related to the awareness and control of language resources. Consequently, the positive implications of plurilingualism clearly override possible drawbacks such as interference or delayed production.

Furthermore, recent research into the functions of the brain seems to support these plurilingual approaches to learning languages (e.g. The Human Connectome Project and ongoing related work on the Language Connectome 2009; or Kovelman et al. 2008, amongst others). Learning a language can also physically change brain structure and adjust perception through the creation of new neural paths. This may relate to both the spontaneous and planned connections established between previously known and new languages.

Finally, the focus on translinguistic conceptualization, that is, the ability to express and connect the same concepts efficiently in different languages (Corcoll and González-Davies 2015) informs the didactic sequences in IPA where verbal, non-verbal, and multimodal model texts guide the learner to create their own texts through meaningful plurilingual tasks and reflective questions, thus favouring student agency. The IPA framework includes two components to create a natural and realistic plurilingual and translanguaging environment (Esteve and González-Davies 2017):

1 A didactic model for plurilingual education that helps teachers inform their practices.

2 A formative intervention model that helps teachers appropriate the didactic model in a meaningful way (building on their agency) through an adjustment of perceptions.

The practical application of this working framework implies the acceptance of both planned and spontaneous plurilingual utterances and tasks around an informed use of L1, TOLC, LIT (literary identity texts), and PBCS (pedagogically based code-switching, Corcoll 2011). Our research process explores how cross-curricular plurilingual connections can be best implemented in foreign language learning through an integrated treatment of all languages, including first and heritage languages, and also in content subjects, for example, in the CLIL mode (Content and Language Integrated Learning).

\section{A case study (2017-2018)}

To illustrate our research on the IPA as it is carried out in schools, I will present a specific case study embedded in our six-year formative research project (2013-2019) carried out in several Spanish regions that addresses the transformation of monolingual practices into plurilingual practices in eight schools. Specifically, as part of this case study, we piloted new descriptor scales for 'plurilingual comprehension' and 'building on plurilingual repertoire' from the 2016 draft version of the extended CEFR illustrative descriptors for Mediation Strategies to explore these three research questions:

1 Can effective learning material be designed to foster the students' plurilingual and pluricultural competence based on the CEFR descriptors?

2 Are the CEFR descriptors useful to foster an IPA to language learning?

3 Are the CEFR descriptors helpful for an IPA syllabus design and assessment? 
These aims were also in line with our global research, namely, to favour the development of plurilingual and intercultural competence by integrating them in the plurilingual tasks; to observe and develop student agency by recording and analyzing the students' perceptions and performance regarding the tasks; and to develop teacher agency by analyzing the teachers' perceptions and performance regarding the tasks and their potential inclusion in the general subject curriculum.

\section{Participants}

The team for this case study comprised six researchers, three of which are also schoolteachers who combine professional and academic projects, thus providing valuable insights grounded on everyday practice. Three schools from differing socio-economic backgrounds and two communities (Barcelona and Sabadell) were involved with students from primary and secondary education.

\section{Instruments for data collection}

We observed the use of descriptors during task performance against a checklist. We also analyzed the recordings of student task performance and informal focus group discussions, and the teachers' comments extracted from feedback questionnaires provided by the Education Policy Division of the Council of Europe. Following our sociocultural approach to research, unpredicted descriptors that had not been contemplated in the CEFR document were added after the analysis.

\section{The task}

The task that was finally agreed upon consisted of a real-life communicative situation in which two or three students collaborate to solve an issue through consensus. Special emphasis was laid on the fact that the situation should be sufficiently rich and well planned for the students to use all their linguistic resources (linguistic repertoire and non-verbal communication). A touristic text in two languages (different from the foreign language(s) they are studying and from the official school languages) was handed out. The subject of the text for primary education was "A Visit to the Barcelona Zoo", whereas the subject for secondary education was "A Day in Paris". Both texts gave information about various events and services (e.g. food), including prices. Students were also given a map of the zoo (primary) or Paris (secondary), respectively. The task was to plan a day at the zoo or in Paris on a very restricted budget.

\section{Implementation}

Each teacher carried out the implementation plan in their schools. Permissions to use and release the material were requested and granted by parents and the schools. Two phases were followed in all cases. In the collaboration phase, the students were asked to undertake the task by explaining their thinking process aloud (in any language(s) that they chose) while they wrote their plan down jointly in English (the target language, in our case). In the exchange and discussion phase they explained to another team the day that they had planned in English. The students were recorded on task and a focus group of student-participants was also recorded at two of the schools (one for primary and one for secondary). This is the text designed for primary education: 


\section{You are going to the zoo and you want to see many animals and do many activities.} You also need to have lunch and a drink. You have ten euros each and a map.

Bienvenus au zoo de Barcelone! Vous voulez voir beaucoup des animaux et vous amuser bien? Alors, il faut s'organiser parce qu'il y a beaucoup de choses à faire. On va visiter les animaux de la ferme. Elle est ouverte de 12.00 à 13.30. Ensuite, on va connaître les pingouins et on va leur donner à manger. Ils sont là de 11 a 13.30. Vous pouvez voire comment les éléphants font du sport le matin (de 10 à 12).

Es ist Zeit, aufhören zu essen. In der Cafeteria können wir ein Sandwich für 5 Euro, ein paar Kartoffeln für 3 Euro und eine Flasche Wasser für 2 Euro kaufen. Wir können auch Eis für 3 Euro bekommen. Wir bekommen die Löwen und Tiger zu sehen, wo sind sie?

\section{Results}

The three research questions could be answered positively, with nuances. The sensitizing activities were effective and presented recurring characteristics. For example, all final performance was carried out in the target language (English), thus contradicting the interference hypothesis. Also, collaborative and distributed learning were clearly crucial for success as they allowed for an active use of previous knowledge and for the creation of a ludic motivational atmosphere. The fact that problem-solving revolved around a real-life situation was highly valued by the students. The reflection sessions were beneficial to fostering student agency through reflective action. In accordance with other projects carried out previously, we observed that, contrary to common belief, proficiency and age did not affect performance regarding plurilingual and pluricultural competence.

These were the CEFR (2016) descriptors that the students finally used when carrying out the tasks:

\section{Plurilingual comprehension}

A2 Can understand short, clearly written messages and instructions by piecing together what he/she understands from the versions in different languages.

A2 Can exploit easily identifiable vocabulary (e.g. international expressions, words with roots common to different languages - like 'bank' or 'music') in order to form a hypothesis as to the meaning of a text.

B1+ Can recognize similarities and contrasts between the way concepts are expressed in different languages, in order to distinguish between identical uses of the same word root and 'false friends'.

B1+ Can exploit his/her knowledge of contrasting grammatical structures and functional expressions of languages in his/her plurilingual repertoire in order to support comprehension.

\section{Exploiting plurilingual repertoire}

A2 Can use words and phrases from different languages in his/her plurilingual repertoire to conduct a simple, practical transaction or information exchange. 


\section{Spoken translation of written text (sight translation)}

A2 Can use simple language to provide an approximate translation of very short texts on familiar and everyday themes that contain the highest frequency vocabulary; despite errors, the translation remains comprehensible.

B1 Can provide an approximate spoken translation of clear, well-structured informational texts on subjects that are familiar or of personal interest, although his/her lexical limitations cause difficulty with formulation at times.

B1+ Can translate straightforward, factual texts that are written in uncomplicated, standard language, although a tendency to adhere to both the structure and the formulations of the source text results in passages that may read awkwardly.

\section{Facilitating collaborative interaction with peers}

B1 Can collaborate in simple, shared tasks and work towards a common goal in a group by asking and answering straightforward questions.

B1+ Can collaborate on a shared task, for example formulating and responding to suggestions, asking whether people agree, and proposing alternative approaches.

These are the unpredicted recorded descriptors added during the analysis. Some could be found in the CEFR document (2016), but had not been included in the original checklist, and others were added from results yielded by previous IPA research projects.

\section{Mediating a text}

- Translation and paraphrasing prevailed during the task

- Breaking down complicated information

- Visually representing information

- $\quad$ Linking to previous knowledge

- Summarizing

\section{IPA descriptors}

- $\quad$ Silent reading previous to task.

- Noticing descriptors (i.e. PL and PC awareness or connecting moments).

- Increased self-confidence voiced for problem-solving.

- Reflective learning: expressions of difficulty, enjoyment, perceptions of progress, and distributed learning. 
As to syllabus design, the descriptors could be integrated ecologically into the customary syllabus for planning, teaching, identifying, and assessing the students' plurilingual competence. Their explicit use favoured a change in mindset, as this transcription from the teachers' feedback indicates (Teacher 3):

External influences have always made them think that they should be thinking in the language of the class and not mixing languages. ... What I found most striking was the fact that they seemed to be pleasantly surprised at their own plurilingual and pluricultural competences, despite the fact that they appear to use them on a daily basis.

All the teachers stated that they would include this kind of task and approach in their syllabus, not just in the English (target language) classroom, but for all the language classes. They found it surprising that descriptors for social and affective skills and strategies, which they deem to be crucial at these educational levels, had not been included explicitly in the CEFR document. Finally, they all agreed that the participation of school principals had been crucial.

\section{Impact on the participants}

Regarding teacher's perceptions, two relevant aspects related to teacher agency helped the teachers progress towards appreciating the potential and benefits of a plurilingual approach:

1 Reflective action: Reflecting on and piloting the descriptors contributed to raising their own and their learners' awareness of the concepts being addressed in those descriptors:

The descriptors contributed to design better activities as the teacher could establish learning aims according to the different descriptors. Therefore, the assessment criteria were very coherent/explicit and, as a result, the way to promote the plurilingual competence became clearer. (Teacher 2)

2 Shifting beliefs: The students' plurilingual competence became gradually self-evident as the task developed and unexpected thoughts and actions surfaced. In one teacher's words:

Students are expected to use English with English-speaking teachers on an everyday basis, so for them it was a novelty to be given space to talk in another language in my presence. Given that not all students have a similar L1 they initially had to negotiate which language they would use to carry out the activity, on occasions this was in English. Initially they were concerned when confronted by languages which they knew little of (French and German), but all found that they were able to identify some words which they recognised as similar to other more familiar languages to build meaning and to help them complete the task. (Teacher 1)

As to the students, they verbalized an increasing self-awareness of their own progress, that is, they evolved from a perceived challenge to enjoyment and success as they gradually became used to connecting the languages they were working with, as exemplified in this exchange (third primary): 
TEACHER 3: I'm not sure what these things are? What do you think? Oh, Eis. What can Eis be? What's it in English? Eis, Eis. . .

3P_LSG (2): Gel ['Ice' in Catalan] ... Ice-cream! [smiles]

Their intercultural competence also made an occasional appearance, as we can see in this excerpt (fourth secondary):

4ESO_SP (6): Champs Elysées is a street like. . . [hesitates] Paseo de Gracia! where all the fancy stores are.

As to the pedagogical framework, an effective implementation of collaborative and distributed learning allowed the students to work fruitfully on the plurilingual mediation skills:

TEACHER 1: Was it useful doing it as a group?

4ESO_SP_Students (all): Yes, yeah, much, much. ... We had ideas and we put them together and we made the plan . . . and maybe someone knew the words, like, in that language, like, and the other one knew other words and when you put it together it makes, like, sense ... so being alone it could be more ... . more difficult and . . . less funny.

Most teachers needed time and gentle guidance to move from the monolingual to the plurilingual approach to language learning. On the other hand, many teachers were appreciative of our explicit intervention because they could finally name and speak frankly about what they had been doing intuitively in their classes with little or no institutional support.

\section{Pedagogic approaches and methods}

The grammar-translation method adopted a transmissionist pedagogic approach, in consonance with the mainstream pedagogical approach in most disciplines, including translator training. In this approach the teacher selects the material and imparts knowledge while the students offer a translation that is only deemed correct if it coincides with that of the teacher, very much like a traditional session for translator trainees where the translation is corrected following the "who'll take the next sentence (WTNS) approach" (Kiraly 2005, p. 110).

On the other hand, although not in theory, but extensively in practice, the communicative approach disallowed the use of translation, despite the overwhelming evidence of its actual use by both teachers and students, albeit mainly for understanding, (decontextualized) testing, or contrastive analysis techniques. In any case, neither its complexity nor interactive potential are present in resource books for teachers or in student textbooks, increasingly with a few exceptions (see further reading).

Conversely, the IPA approach considers that student agency is strengthened by collaborative learning, based on socio-constructivist premises. The students work within didactic sequences designed to help them progress along their Zone of Proximal Development through reflection activities embedded in plurilingual tasks (Esteve and González-Davies 2017). The main aim 
is to provide them with academic and social skills that set the basis for lifelong learning to become, not necessarily native speakers, but competent plurilingual speakers. This process, in turn, aims at the development of their self-concept (identity) as learners. Here, I will outline a specific plurilingual pedagogic approach in line with this new perspective: TOLC

\section{Translation for other learning contexts (TOLC)}

Translation is a key mediation skill whose complexity is not usually dealt with even in (wellintentioned) plurilingual approaches to language learning, where the students are asked simply 'to translate'. This may be (unconsciously) in accordance with the extended belief that bilinguals may engage in 'natural translation' effortlessly. Harris (2017) put forward a cline to gauge the level of translation competence that can be developed in different contexts depending on the aims and context of the speakers:

- Natural translators: people who translate without having had any training. They function through intuition rather than following translation norms and strategies.

- Native translators: people who have acquired translation skills through observation and experience in informal contexts.

- Expert translators: formally trained translators who lack experience in the industry.

- Professional translators: people who translate for a living. They may have been trained in a formal setting and be accredited, or they may be advanced native translators.

This scale is especially useful to situate TOLC in the learning process. If we align natural and native translators with Cummins' BICS stage in language learning, and expert and professional translation with the following stage, CALP, the need for explicit scaffolding instruction to lead the way from one stage to the next is self-evident. This may be provided by TOLC, which we situate between the native and the expert levels. TOLC speakers can be described as language users who can apply natural plurilingual practices in an informed way after acquiring translanguaging skills and strategies in formal contexts

In this case, the use of translation is far from the grammar-translation method. TOLC works with transferrable skills rather than language combinations, thus providing a reliable working frame for this new outlook since it favours activities that go beyond straightforward text translating for a set language combination. Rather, in TOLC, the complexity of translation as a dynamic process of communication is dealt with explicitly: on the one hand, findings in research on the development of translation competence in translator training are taken into account. On the other, activities and projects are designed to include both specific reflection and action around an informed use of translation and translanguaging, while working on communicative interlinguistic and intercultural production, reception, mediation, and interaction (CEFR 2018) (see the preceding descriptors, for instance). Thus, translation here goes far beyond its use to check on-the-spot comprehension or syntactic and lexical points in tests, to become a key translanguaging scaffolding activity to develop plurilingual competence.

In TOLC, an acceptable translation (1) keeps the message and effect of the source text, (2) clearly displays use of translation strategies and appropriate resourcing to solve transfer problems, and (3) keeps to the target community conventions and to the assignment. So, here, translation can be used as a means to introduce, reinforce or revise language and concepts related to a given topic through activities such as oral translation (i.e. interpreting), (guided) sight translation, bilingual readings, the creation of decision grids to justify translation choices, discussion around the translation of poems, songs or humour, and other collaborative tasks, all 
of which can be adapted to the CEFR descriptors at different levels (for more teaching ideas, see Further reading).

Besides, following Jakobson's classification of types of translation (1959/2000) activities need not be reduced to translation between different languages (i.e. interlinguistic translation). They can also be designed for transference between different variants of the same language, for example, between Brazilian or Peninsular Portuguese (i.e. intra-linguistic translation), or to practise multimodal translation (i.e. inter-semiotic translation, from road signs or emojis to text and vice versa). Finally, the tasks help to improve the following three macro-competences (González-Davies 2004, pp. 131, 217), which can be expected from both language learners and translation students:

- Linguistic competence. This includes written and oral knowledge of the source and target languages, as well as an awareness of potential interference between them (e.g. false cognates).

- Encyclopaedic knowledge: This includes knowing about the subject in hand, from specific terminology to conceptual and cultural knowledge.

- Transfer knowledge. Here, specific translation strategies such as domestication or explicitation come into play (see below). It is mainly in the command of these that natural translators can access the expert stage.

All the preceding implies that specific pedagogical scaffolding is needed to bridge the languages. Accordingly, we have developed two main syllabus designs (Esteve and GonzálezDavies 2017; González-Davies 2017):

A Integrating the translation (as TOLC) tasks ecologically in the language learning sessions when required, in coherence with the topics and contents developed there.

B Introducing translation (as TOLC) in Project Work alongside the language learning sessions.

\section{An example for model A: cultural references: domesticate or foreignize?}

Develop your intercultural awareness by choosing between domesticating or foreignizing strategies when dealing with cultural references. That is, in the first case, adapt the text to the target readers' culture and, in the second, keep the source culture's 'foreign' flavour, thus highlighting the differences so that we can learn about the other culture.

Firstly, please think of a tree: i.e. if I say the word 'tree', what image comes to your mind? Now translate the following text in pairs or groups of three and justify your choices. Depending on the translation assignment (see the decision grid), you will choose one solution or another.

TEXT (Mr. Pip, Lloyd Jones, 2006/2008, p. 114 - situated on the Bougainville Island in Papua New Guinea)

"Gist. This word needs explaining. Mr. Watts put it this way. 'If I say tree, I will think English oak, you will think palm-tree. They are both trees. A palm and an oak both successfully describe what a tree is, but they are different trees.'" 
When first faced with a text rich in cultural references, it may be useful to draw a 'decision grid' to write down possible translation strategies and solutions. Suggested reading: Haywood et al. (2009) and González-Davies and Scott-Tennent (2005). Let's apply this to your translation process and the product of Mr. Pip by Lloyd Jones: 'Palm-tree, Oak or Pine-tree?'

Decision grid. Example for the cultural reference 'Palm-tree':

\begin{tabular}{llll}
\hline Challenge & Possible translations & Assignment & Final justified solution \\
\hline Palm-tree & 1 Palm-tree & I am translating a & Pine-tree \\
& 2 Palm-tree, a native tree & children's story to & (domestication) \\
species in Bougainville & be published in & \\
3 A native tree & Spain and have been & \\
4 A pine-tree & commissioned by the & \\
(Mediterranean) & publisher to adapt the & \\
5 An oak-tree & text to the children's & \\
$6(. .)$. & culture. & \\
\hline
\end{tabular}

\section{Sample for model B: curated crowdsourcing}

Try your hand at translating literary texts before the official publications come out and then compare your work with that of the professional translators. You may also compare your translation with those done as literary crowdsourcing, that is, online amateur translations of a popular book carried out typically by fans.

Before starting your translation, read the book and decide (only) on the cultural strategies: e.g., domestication or foreignization. If the book chosen is not the first in the series, you may analyze the strategies and solutions published in the previous books, discuss them and follow them (or not, if you can justify more appropriate translations). To help with the process and achieve an informed outcome, use decision grids. When the published translation comes out, check and modify your text as necessary, or keep your own translation if you think it is more accurate.

\section{Conclusions and future directions}

Due to the cross-disciplinary nature of translation, here I have argued that its study can go beyond its representation as a professional activity. Also, that despite its pervasive presence, it is still generally simplified and related only to the interlinguistic written mode in classrooms.

I have first explored how language teachers and learners have engaged in the use of translation, especially since the end of the 19th century up to the present day, exploring the evolution of related beliefs and practices from academic and pedagogic perspectives. Then, I have suggested why translation should have a place as a natural skill in language learning to cope with our plurilingual contemporary world. I have outlined possible theoretical standpoints and subscribed to a connectionist plurilingual paradigm in opposition to a monolingual stance that compartmentalizes knowledge and languages.

I have also presented a case study where these standpoints have been explored and analyzed. The specific proposal to introduce translation as a key mediation skill is TOLC, which can be aligned with Harris' progressive scale for translator competence levels and with Cummins' classification of language learning skills as a scaffolding framework to help students 
become competent plurilingual speakers as they progress from the natural to the expert translator level.

I have suggested a few tasks and projects to optimize the use of translation as a skill in itself and as a key learning strategy despite efforts to banish it from the language learning process. These tasks have been designed as part of a humanistic and socio-constructivist pedagogical environment that requires plurilingually competent teachers.

To end, a question to be explored further: What happens when we reject natural plurilingual practices that are used extensively outside formal learning contexts? How can this position be justified? Further studies will surely throw light on the potential linguistic and cultural intersections within our complex communication systems and, specifically, on the role of translation to understand and bridge the variations, thus enabling us to communicate more efficiently.

\section{Further reading}

Carreres, A., Noriega-Sánchez, M. and Calduch, C. (2018) Mundos en palabras: Learning Advanced Spanish Through Translation. London and New York: Routledge.

Cummins, J. and Early, M. (2014) Big Ideas for Expanding Minds. Toronto: Pearson Education Canada. Duff, A. (1989/1994) Translation. Oxford: Oxford University Press.

González-Davies, M. (2004) Multiple Voices in the Translation Classroom. Amsterdam and Philadelphia: John Benjamins.

Kerr, P. (2014) Translation and Own-language Activities. Cambridge: Cambridge University Press.

All these books include practical teaching ideas for translation informed by research and observation of best practices.

\section{Related topics}

agency, intercultural citizenship, translator training, primary and secondary education, higher education, translation in schools

\section{Note}

1 This work was supported by the Spanish Ministry of Economy and Competitiveness under Grant Ref. EDU2012-38452, 2012-2015 and Grant Ref. FFI2015-63741-R, 2016-19.

\section{References}

Anderson, J. (2017) Reimagining English language learners from a translingual perspective. ELT Journal. 72(1), pp. 26-37.

Anderson, L. and Krathwohl, D (eds) (2001) Taxonomy for Learning, Teaching, and Assessing. A Revision of Bloom's Taxonomy of Educational Objectives. 2nd ed. New York: Longman.

Bachmann-Medick, D. (2009) The translational turn. Translation Studies. 2(1), pp. 2-16.

Chesterman, A. (1997) Memes of Translation: The Spread of Ideas in Translation Theory. Amsterdam and New York: John Benjamins.

Cook, G. (2010) Translation in Language Teaching: An Argument for Reassessment. Oxford: Oxford University Press.

Cook, V. (2016) Premises of multi-competence, in Cook, V. and Wei, L. (eds) The Cambridge Handbook of Linguistic Multi-competence. Cambridge: Cambridge University Press. pp. 1-22.

Corcoll, C. (2011) 'English spelling is weird': Developing children's language awareness. International Journal of Multilingualism, pp. 1-19. 
Corcoll, C. and González-Davies, M. (2015) Switching codes in the additional language classroom. ELT Journal. 70(1), pp. 67-77.

Council of Europe. (2018) Common European Framework of Reference for Languages: Learning, Teaching, Assessment. Companion volume. With new Descriptors [online]. Strasbourg: Council of Europe Publishing. Available from: www.coe.int/en/web/common-european-framework-referencelanguages/home [Accessed 15 April 2019].

Cummins, J. (1979). Linguistic Interdependence and the Educational Development of Bilingual Children. Review of Educational Research, Spring 1979, 49, pp. 222-251.

Cummins, J. (1984) 'Wanted': A theoretical framework for relating language proficiency to academic achievement among bilingual students, in Rivera, C. (ed) Language Proficiency and Academic Achievement. Clevedon: Multilingual Matters. pp. 2-20.

Cummins, J. (2005). A proposal for action: Strategies for recognizing heritage language competence as a learning resource within the mainstream classroom. The Modern Language Journal, 89, pp. 585-592.

Cummins, J. (2007). Rethinking monolingual instructional strategies in multilingual classrooms. Canadian Journal of Applied Linguistics. 10(2), pp. 221-240.

Cummins, J. (2008) Teaching for transfer: Challenging the two solitudes assumption in bilingual education, in Cummins, J. and Hornberger, N. (eds) Encyclopedia of Language and Education. 2nd ed. New York: Springer Science. pp. 65-77.

Cummins, J. (2018) Teaching minoritized students: Are additive approaches legitimate? Harvard Educational Review. 87(3), pp. 404-426.

Esteve, O. and González-Davies, M. (2017) Estratègies de transferència interlingüística en l'aprenentatge de llengües addicionals: un Enfocament Plurilingüe Integrador, in Pereña, M. (ed) Ensenyar i aprendre llengües en un model educatiu plurilingüe. Barcelona: Horsori. pp. 6-16.

García, O. (2009) Bilingual Education in the 21st Century. A Global Perspective. Chichester, West Sussex, UK: Wiley-Blackwell.

González-Davies, M. (2002). Humanising Translation: Tackling a Secret Practice. Humanising Language Teaching, July, University of Kent: Pilgrims. Retrieved September 2013 from http://www. hltmag.co.uk/jul02/mart2.htm; http://www.hltmag.co.uk/

González-Davies, M. (2012) The role of translation in other learning contexts: Towards acting interculturally, in Borodo, M. and Hubscher-Davidson, S. (eds) Global Trends in Translator and Interpreter Training: Mediation and Culture. London: Continuum. pp. 150-160.

González-Davies, M. (2014) Towards a plurilingual development paradigm. From spontaneous to informed use of translation in additional language learning, in Laviosa, S. (ed) Translation in the Language Classroom: Theory, Research and Practice, Special Issue of The Interpreter and Translator Trainer. 8(1), pp. 8-31.

González-Davies, M. (2017) The use of translation in an integrated plurilingual approach to language learning: Teacher strategies and good practices. Journal of Spanish Language Teaching. 4(2), pp. 124-135.

González-Davies, M. and Scott-Tennent, C. (2005) A problem-solving and student-centred approach to the translation of cultural references. Meta: Translators 'Journal. 50(1), pp. 160-179.

Hall, G. and Cook, G. (2013) Own-language use in ELT: Exploring global practices and attitudes. ELT Research Papers. 13(1), London: British Council.

Harris, B. (2017) Unprofessional translation: A blog-based overview, in Antonini, R., Cirillo, L., Rossato, L. and Torresi, I. (eds) Non-professional Interpreting and Translation: State of the Art and Future of an Emerging Field of Research. Amsterdam: John Benjamins Publishing Company. pp. 29-43.

Hatim, B. and Mason, I. (1990) Discourse and the Translator. London and New York: Routledge.

Haywood, L.M., Thompson, M. and Hervey, S. (2009) Thinking Spanish Translation: A Course in Translation Method. Spanish to English. London and New York: Routledge.

The Human Connectome Project. (2009, ongoing) USA National Institute of Health [online]. Available from: www.humanconnectomeproject.org/ [Accessed 15 April 2019].

Jakobson, R. (1959/2000) On linguistic aspects of translation, in Bower, R.A. (ed) On Translation. New York: Oxford University Press. pp. 232-239. 
Kelly, D. (2005) A Handbook for Translator Trainers. Manchester: St. Jerome Publishing.

Kiraly, D. (2005) Project-based learning: A case for situated translation. Meta: Translator's Journal. 50(4), pp. 1098-1111.

Kovelman, I., Baker, S. and Petitto, L. (2008) Bilingual and monolingual brains compared: A functional magnetic resonance imaging investigation of syntactic processing and a possible "neural signature" of bilingualism. Journal of Cognitive Neuroscience. 20(1), pp. 153-169.

Macaro, E. (2001) Analysing student teachers 'codeswitching in foreign language classrooms: Theories and decision making. Modern Language Journal. 85(4), pp. 531-548.

Meier, G. (2017) The multilingual turn as a critical movement in education: Assumptions, challenges and a need for reflection. Applied Linguistics Review. 8(1), pp. 131-161.

Merriam-Webster Dictionary. (2019) [online]. Available from: www.merriam-webster.com/dictionary/ crowdsourcing [Accessed 15 April 2019].

Pym, A., Malmkjaer, K. and Gutiérrez, M. (2013) Translation and Language Learning. Luxembourg: European Commission.

Richards, J.C. and Rodgers, T.S. (1986/2014) Approaches and Methods in Language Teaching. London and New York: Routledge.

van Ek, J.A. (1975) The Threshold Level. Strasbourg: Council of Europe.

Widdowson, H. (2003) Defining Issues in English Language Teaching. Oxford: Oxford University Press.

Williams, C. (1996) Secondary education: Teaching in the bilingual situation, in Williams, G.L. and Baker, C. (eds) The Language Policy: Taking Stock. Llangefni: CAI.

Wilson, J. and González-Davies, M. (2017) Tackling the plurilingual student/ monolingual classroom phenomenon through Translation. TESOL Quarterly. 51(1), pp. 207-219. 


\section{Index}

Note: Page numbers in bold indicate a table and page numbers in italic indicate a figure.

additive bilingualism 16

agency see teacher agency

AIIC see International Association of Conference

Interpreters (AIIC)

alpha box 333

appropriateness of language use, in context 128

assimilation 33

audiolingual method $175-176$

audiovisual translation (AVT): defined 207;

dubbing and 218-219; future directions in

220-221; "golden years" of 209; historical

perspectives in 208-210; key findings in

210-212; pedagogical approaches with

212-220; research approaches with 210-212;

revoicing and 207-208, 216-220; subtitling

and 208, 213-214, 216-218; translation of 207

Augustyn, Prisca 179

Australian Curriculum 1

AVT see audiovisual translation (AVT)

Bale, Jeff 307

Barcelona Formative Model 419

behaviourism 33

Bellugi, Ursula 342

Benjamin, Walter 193

The Big Translate 118-121

bilingual education: brain function and 161-162;

future directions in 165-166; historical

perspectives in 157-160; history of 156-157;

maintenance model of 160 ; pedagogic

approaches and methods with $162-165$; prohibition of 158-159; research approaches in 160-162; Sheltered English in 160; transitional 16,160 ; translanguaging and $160-163$; US Immersion in 160

bi/multilingualism: anthropology and 14-15; historical perspectives in 12; key findings in 12-15; linguistics and 13-14; mind and 13; pedagogic approaches and 15-20; psychology and 13; research approaches in $12-15$; sociology and 14-15; translation and 19-20
CAL2T see computer-assisted L2 learning and translation (CAL2T)

CBI see Content-Based Instruction (CBI)

CCTT see Certificate in Collaborative Translation Teaching (CCTT)

CDFs see Cognitive Discourse Functions (CDFs)

CEFRL see Common European Framework of Reference for Languages (CEFRL)

Celan, Paul 182

Certificate in Collaborative Translation Teaching (CCTT) 387-388, 394

China 405, 409

Chomsky, Noam 12

citizenship education 48-51, 50

CIUTI see Conférence internationale permanente d'instituts universitaires de traducteurs et interprètes (CIUTI)

CLIL see Content and Language Integrated Learning (CLIL)

code-switching 14, 39-40, 40-41; in preschool education 75 ; and productive translanguaging $137-138$

Cognitive Discourse Functions (CDFs) 135-136 collaborative translanguaging 314-315

collocation 280

colonization 12, 85, 309-311

Common European Framework of Reference for Languages (CEFRL) 48, 53, 58, 358, 417, 437-440

communicative approach 176-177

community translation (CT): assessment criteria 247; autonomy and 253-255; historical perspectives in 246-247; key findings in 247-255, 252; pedagogic approaches and methods with $255-257,256$; peer-reflection in 247-248; research approaches in 247-255, 252; self-reflection and 247-248; social inclusion and 245-246

computer-aided translation (CAT) 264; see also computer-assisted L2 learning and translation; technology 
computer-assisted L2 learning and translation (CAL2T): activity design in 289, 290; corpora for 280-281; defined 278; exploratory learning and 285-287, 285-287; future directions in 292-293; historical perspectives in 279-280; key findings in 280-284; machine translation and 281-284; neural machine translation in 278, 284, 287-289; pedagogic approaches and methods with 284-292, 285-288, 290, 291; research approaches with 280-284; and Web as corpus 284-285; and Web for corpus 285-287, 285-287; see also computer-assisted L2 learning and translation; technology

Conférence internationale permanente d'instituts universitaires de traducteurs et interprètes (CIUTI) 386-388, 392

Consortium for the Training of Translation Teachers (CTTT) 386-387

Consortium for Translation Education Research (CTER) 386, 394

constructivism 33-34

Content and Language Integrated Learning (CLIL) 17, 129-130, 133, 136, 144; Englishmedium instruction vs. 145; see also ContentBased Instruction (CBI)

Content-Based Instruction (CBI): and appropriateness of language use in context 128 ; assumptions in 129; and Cognitive Discourse Functions 135-136; and Content and Language Integrated Learning 129-130; and Englishmedium instruction 134; future directions in 139; historical perspectives in 128-130; key findings with 130-134; message-focus in 128; pedagogic approaches and methods with 134-139, 137-138; research approaches with 130-134; and Systemic Functional Linguistics 135 contrastive method: in sign language education 346

Cook, Guy 178-179

corpora: for computer-assisted L2 learning and translation 280-281

corporal punishment 307-308

Council of Europe 1, 46, 435-436

Covello, Leonard 311

creative reconstruction 419

creative writing: future directions with 200-202; heterolingualism and 194-195; historical perspectives in 190-191; key findings in 191-195; pedagogic methods with 195 , 195-200, 199-200; research approaches with 191-195; workshop model and 196-197 critical multilingual awareness 152 crossing 114 cross-linguistic mediation 56-58, 128

CT see community translation (CT)

CTER see Consortium for Translation Education Research (CTER)
CTTT see Consortium for the Training of Translation Teachers (CTTT)

Cummins' Theory of Interdependence 356-357

data-driven learning (DDL) 279

DDL see data-driven learning (DDL)

deaf, as term 354

Deaf, as term 354

deaf community see sign languages

de l'Épée, Abbé 343-344

developmental bilingual programmes 17,83

Dewey, John 1, 29-32, 35-37

Differentiated Model of Giftedness and Talent

(DMGT) 324

divergent thinking 330-331

diversity: preschool education and 67

DLE see dual language education (DLE)

DMGT see Differentiated Model of Giftedness and Talent (DMGT)

Dostert, Léon 401

double stimulation method 421, $\mathbf{4 2 2}-\mathbf{4 2 3}$

dual language education (DLE) 131

dubbing 218-219

Duff, Alan 182

educational development 109, 120

Educational Interpreters Performance Assessment (EIPA) 371

Education Reform Act 111

EIPA see Educational Interpreters Performance Assessment (EIPA)

EMCI see European Master in Conference Interpreting (EMCI)

EMI see English-medium instruction (EMI)

English-medium instruction (EMI) 144; Content and Language Integrated Learning vs. 145; and Content-Based Instruction 134; and critical multilingual awareness 152; defined 143; future directions in 150-152; historical perspectives in 143-144; key findings with 145-147; pedagogic approaches and methods with 148-150; research approaches with $145-147$

Esselink, Bert 266

essence-oriented thinking 421

ethnic revival 82

European Master in Conference Interpreting (EMCI) 404-406

European Society for Translation Studies (EST) 386

FAPE see free and public education (FAPE)

FOMT see free online machine translation (FOMT)

Foreign Language Only 436

free and public education (FAPE) 368

free online machine translation (FOMT) 281, 283, 287, 291-292; see also computer-assisted L2 
learning and translation; computer-assisted L2 learning and translation (CAL2T); technology functional linguistics 176

g factor 329

Gibbons, Reginald 193

gifted education programmes: acceleration in 330; alpha box in 333; creativity and 330; discovery techniques in 332-333; divergent thinking and 330-331; enrichment in 330; future directions in 335-337; general intelligence and 329; in Germany 326; giftedness in 323-325; higher level thinking skills and 331,333; historical perspectives in 324-327; IQ tests and 327-328; key findings in 327-330; Marland Report and 325; mind maps in 333; multiple intelligences and 327; pedagogic approaches and methods with 330-335; principled eclecticism in 334; problem-based learning and 332 ; projects in 332; research approaches in 327-330; self-learning techniques in 333-334; in Slovakia 326-327; study skills and 331; in United Kingdom 326

globalization 114

González-Davies, Maria 196

Gramling, David 181

grammar-translation method 82, 174-175, 435

Grater, John Baptist 344

Graz Model 135

Heinicke, Samuel 343-344

Herbert, Jean 401, 403

heritage language education: alternatives to, as term 306-307; bi/multilingualism and 17; colonization and 309-311; complexity of 304-305; conscientization and 315-316; critical pedagogies and 315 ; future directions with $316-317$; historical perspectives in 306-312; humanization through 311-312; key findings in 312-313; language brokering and 313-314; pedagogic approaches and methods with 313-316; politicization of 304-305; realities of 303-304; research approaches with 312-313; Spanish in 309-310; as term 306-310; xenophobia and 309-310

heteroglossia 194

heterolingualism 194-195

higher level thinking skills 331,333

Hill, Frederick Maritz 344

House, Juliane 183

Huffmaster, Michael 178, 180-181

human resources: technology and 272-273

hybridity, linguistic 114

IATIS see International Association for Translation and Intercultural Studies (IATIS)

IC see intercultural competence (IC)
ICC see intercultural communicative competence (ICC)

IDEA see Individuals with Disabilities in Education Act (IDEA)

immersion bilingual programmes 83, 131

inclusion 109, 120

independent translanguaging 162

Individualized Education Plan (IEP) 368, 374-378, 375, 376-377

Individuals with Disabilities in Education Act (IDEA) 368, 377

Integrated Plurilingual Approach (IPA) 427, 434, 436-440

intercomprehension 103-104

intercultural citizenship: education for 50; historical perspectives on 46-47; key findings in 47-51, 50; mediation and 52-58; pedagogic approaches and methods with 51-58; research approaches with $47-51, \mathbf{5 0}$

intercultural communicative competence (ICC) 48 intercultural competence (IC) 47; mediation and 48 intercultural speaker $46-47$

interlinguistic translation 102

internalization 33

International Association for Translation and Intercultural Studies (IATIS) 386

International Association of Conference Interpreters (AIIC) 401, 404-405

interpretation: admission requirements for education in 228; assessments 238; classroom teaching and learning of 232-233; community 229, 235; conference 234-235; curricula 228; curriculum models 234; defined 226; diversity and 226-227; early approaches to education in 227-229; educators 228; entrance exams 236; evidence-based approach in 228-229; evolution of training in 226; formal training in, for international settings 227; future directions in 238-239; historical perspectives on 227-229; institutional practices in education for 231-232; key findings in 229-233; learner factors in 230-231; need for 226-227; origins of education in 227; pedagogic approaches and methods with 233-238; pedagogy 228 , 236-237; programmes 234; public service 229; research approaches in 229-233; in sign bilingual education of foreign languages 358-359; student admission for education in 235-236; translation vs. 173; see also sign language interpreting; teacher training, interpreting

inter-semiotic translation 102, 104-105

intersentential code-switching 14 intrasentential code-switching 14 IPA see Integrated Plurilingual Approach (IPA) IQ tests 327-328

Iyengar, Malathi 310-311 
Jakobson, Roman 192

Klima, Edward 342

knowledge: as constructed vs. transmitted 37-38

Kramsch, Claire 178, 180

Landers, Clifford 192

language brokering 313-314

Language Triptych 136

langue 12

Lasagabaster, David 133

learning: as democratic 31; in Dewey $30-32$; as ecological 36-37; as embodied $31-32,36$; as emergent 36; in Piaget 34-35; as process 31; as self-corrective 37; in Vygotsky 32-35

least restricted environment (LRE) 368

Leeman, Jennifer 315-316

linguistic hybridity 114

linguistic monitoring 111-112

literary translation see creative writing

Local Government Act 111

Lorde, Audren 90

LRE see least restricted environment (LRE)

machine translation (MT) 264, 281-284; see also computer-assisted L2 learning and translation; free online machine translation (FOMT); neural machine translation (NMT); statistical machine translation (SMT); technology

Maley, Alan 182

manipulation school 191

manual method: in sign language teaching 343-344

Marland Report 325

McCarthy, Carol 19

mediation: activities 54-56; of communication

53; of concepts 53-54; cross-linguistic 56-58, 128; in education 95; future directions with 447-448; historical perspectives in 435-437; Integrated Plurilingual Approach and 434-435, 437-439; intercultural citizenship and 52-58; intercultural competence and 48; key findings with 437-444; pedagogic approaches and methods with 444-447; research approaches with 437-444; strategies 54-56; teacher agency and 421, 423-426; of text 53;

translation as, and sign language instruction 349-350; translation as, for social justice 58; translation as linguistic 104

Meschonnic, Henri 192

message-focus 128

metalinguistic activities 105

metrolingualism 12

MFLAT see Modern Foreign Language Aptitude Test (MFLAT)

MI see multiple intelligences (MI)

mind maps 333
Mitchell, Tania 316

Modern Foreign Language Aptitude Test (MFLAT) 328

Modern Language Association of North America 2 modern languages: audiolingual method and 175-176; communicative approach and 176-177; functional linguistics and 176; future directions with 186; grammar-translation method and 174-175; historical perspectives on 174-177; multilingual turn and 177; pedagogic approaches and methods with 181-186; research approaches with 177-181; translation of translations in 180-181 monitoring, linguistic 111-112

monolingualism 12

MT see machine translation (MT)

multi-competence 438

multiculturalism: and translators in schools $110-112$

multilingual literacy 105

multilingual turn 1, 127, 177, 194

multiple intelligences (MI) 327

neural machine translation (NMT) 278, 284, 287-289

Nord, Christiane 193

Norton, Bonny 14

Nuremberg trials 401-402

one teacher one language policy $98-100$

one-way immersion 16-17

online conversation and discussion 54-55

oral method: in sign language teaching 344

Orellana, Marjorie Faulstich 313-314

parole 12

Paulsrud, BethAnne 134

pedagogy: bi/multilingualism and 15-20; codeswitching and 39-40, 40; subtitling and 39, 39

Pedagogy of Diversity 65

Piaget, Jean 34-35

plurilingualism 87-89

Pluriliteracies Approach to Teaching for Learning 135

polylingual languaging $12,113-114$

practice turn 12

pragmalinguistic factors 263

pragmatic equivalence 263

pragmatism 30

Pratt, Richard 311

preschool education: acknowledgment of other languages in 73-75; code-switching in 75; diversity and 67; historical perspectives on 65-67; key findings in 67-75; language learning and 66-67; language use in 69-70, 70; non-use of translation in 72-73; other languages in, promoted by teacher $71-72$; 
pedagogic approaches and methods in 76-77; recasting in 71 ; rephrasing in 71 ; research approaches in 67-75; self-esteem and 66; wellbeing and 66

primary bilingual classrooms: historical perspectives in 82-85; key findings in 86-87; pedagogic approaches in 87-90; plurilingualism and 87-88; research approaches in 86-87; translanguaging and 86-88; translation as bridge to separation of languages in $82-84$

principled eclecticism 334

problem-based learning 332

productive translanguaging 136-138, 137

profane illumination $202 \mathrm{n} 2$

Ramler, Siegfried 402

recasting 71

refashioning of traditions 51

reflexive exploration 115-116, 121

Reform Movement 435

Rehabilitation Act of 1973368

relfexivity 51

rephrasing 71

revoicing 207-208, 216-220

Rozan, Jean-François 403

Russell, Debra 371

Salamanca Statement 353

Saussure, Ferdinand de 12

savoir apprendre 46

savoir être 46

savoir faire 47

Scheme for a Complete Orienting Basis of an Action (SCOBA) 421, 424-425, 426-427

Schleiermacher, Friedrich 183

SCOBA see Scheme for a Complete Orienting

Basis of an Action (SCOBA)

self-learning techniques 333-334

separation of languages: translation in $82-84$

Sheltered English 160

sign bilingual education, of foreign languages:

and Cummins' Theory of Interdependence

356-357; foreign sign language in 361-362;

future directions in 362-363; historical perspectives in 354-356; and history of deaf education 353-354; interpretation in 358-359; and issues in deaf education 355-356; key findings in 356; pedagogic approaches and methods in 357-362; research approaches with 356; teachers' use of sign language in 359-361 sign language interpreting: aspects of work in $370-371$; in classroom 368-370, 369; effective language work in 371-372; future directions in 378; historical perspectives in 367-371, 369; and history of deaf education 367; Individualized Education Plan and 368,
374-378, 375, 376-377; interpreter as barrier to education in 372-373; key findings in 371-373; pedagogic approaches and methods with 373-378, 375, 376-377; research approaches in $371-373$

sign languages: audiovisual translation and 208; collective reading activities and 348, 348-349; community interpretation and 229; competing teaching methods in 343-344; content-based approach with 345 ; contrastive methods with 346; future directions in 350-351; historical perspectives on 342-344; history of 342-343; interactional approaches with 345-346; learner factors with 231; manual method in teaching of 343-344; oral method in teaching of 344; pedagogic approaches and methods with 347-350, 348; research approaches and key findings with 344-347; and sign language translation 343; Strategic and Interactive Writing Instruction with 345-346

simultaneity 114

SIWI see Strategic and Interactive Writing Instruction (SIWI)

SketchEngine 280, 285, 287, 287-288

SMT see statistical machine translation (SMT) social inclusion: community translation and 245-246

social justice: translation as mediation for 58 social turn 12 software see technology

Spring, Joel 311

statistical machine translation (SMT) 287

stimulated recall (SR) 372

Strategic and Interactive Writing Instruction (SIWI) 345-346

study skills 331

subtitling 39, 208, 213-214, 216-218

superdiversity approach 112-113

Systemic Functional Linguistics 135

talent: giftedness vs. 323-324

TAP see think aloud protocols (TAP)

TBE see transitional bilingual education (TBE) teacher agency: and Barcelona Formative Model 419; creative reconstruction and 419; double stimulation method and 421, 422-423; future directions with 427-428; historical perspectives on 418-419; key findings with 419-420; mediation and 421; pedagogic approaches and methods with 421-427, 422-426; professional development and 417-418; research approaches in 419-420 teacher training, interpreting: content areas in 410-411; curricula in 408; future directions in 412; historical perspectives in 400-405; key findings in 406-407; pedagogic approaches and methods with 408-409, 410-411; 
research approaches with 406-407; teaching methodology in 408

teacher training, translation: future directions in 395; historical perspectives in 387-389; key findings in 389-393; pedagogic approaches and methods in 393-395; research approaches in 389-393

technology: future directions with 273-274; historical perspectives in 265-267; human resources and 272-273; key findings with 268-269; learning 271-272; localization and 266; needs analysis 269; pedagogic approaches and methods with 269-273; research approaches with 268-269; teaching 271-272; technical issues and 273; see also computerassisted L2 learning and translation (CAL2T)

TEnTs see Translation Environment Tools (TEnTs) think aloud protocols (TAP) 371-372

TOLC see translation in other learning contexts (TOLC)

Toth, Jeanette 134

traditions, refashioning of 51

training see teacher training

transformatory critique 51

transitional bilingual education (TBE) 16, 160; see also bilingual education

translanguaging: bilingual education and 160-161, 163; bilingualism and 12; bi/ multilingualism and 14; collaborative 314-315; Content-Based Instruction and 127, 137; and English-medium instruction 144; heritage language education and 314-315; independent 162 ; intercultural citizenship and $53-54$; origin of term $156-157$; primary bilingual classrooms and $85-88$

translation: bi/multilingual approaches and 19-20; as bridge to separation of languages 82-84; defined 173; historical perspectives on 96-98; interlinguistic 102 ; interpretation vs. 173; inter-semiotic 102, 104-105; key findings in $98-102$; as linguistic mediation 104; as mediation, in sign language instruction 349-350; as mediation for social justice 58; non-use of, in preschool education 72-73; pedagogical affordances of, in bilingual education 95-106; pedagogic approaches and methods with 102-105; research approaches in 98-102; of translations $180-181$; as translingual activity 96; see also community translation $(\mathrm{CT})$
Translation Environment Tools (TEnTs) 264; see also computer-assisted L2 learning and translation; technology

translation in other learning contexts (TOLC) 257, 434-436, 445-446

translation management system (TMS) 264; see also computer-assisted L2 learning and translation; technology

Translation Nation 116-117, 121

Translation Technology 264; see also computer-assisted L2 learning and translation; technology

Translation Tools 264; see also computer-assisted L2 learning and translation; technology

translators, in schools: assimilation and 110-112; case studies 116-120; historical perspectives on 110-113; key findings with 113-114; and linguistic hybridity 114; multiculturalism and 110-112; pedagogic approaches and methods with 115-120; and polylingual languaging 113-114; and reflexive exploration 115-116; research approaches with 113-114; and simultaneity 114; and superdiversity approach $112-113$

translingual practice 12

trawsieithu 156-157; see also translanguaging

TWI see two-way immersion (TWI)

two-way immersion (TWI) 17

Ungerer, Tomi 105

US Immersion 160

Velleman, Antoine 401

Venuti, Lawrence 183, 190

vocabulary lists 173

Vygotsky, Lev S. 29, 32-35, 37-38, 421

WaC see Web as corpus (WaC)

Warner, Chantelle 181

Web as corpus (WaC) 281, 284-287, 285-287

Web for Corpus (WfC) 281, 285-287, 285-287

WfC see Web for Corpus (WfC)

Widdowson, Henry 179-180

Winston, Betsy 371

workshop model 196-197

xenophobia $309-310$

zone of proximal development (ZPD) 34, 38, 115,426 